


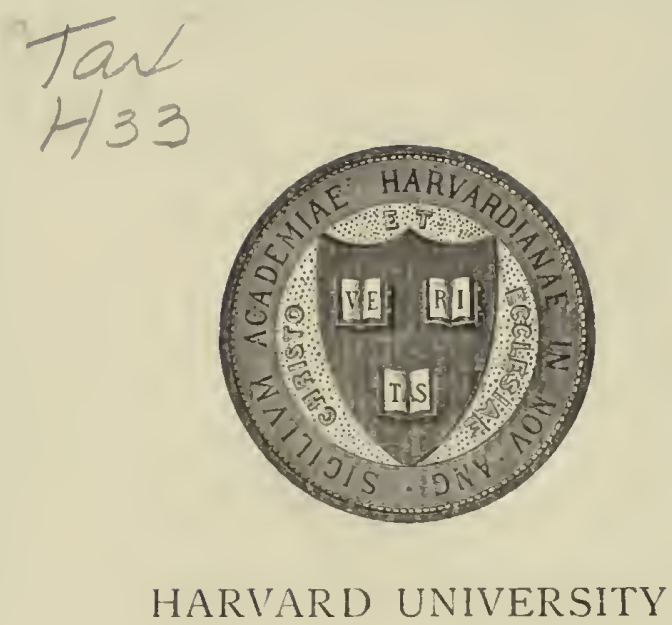

L I B R A R Y

OF TIIF.

\section{GRAY HERIBARIUM}

$$
\begin{aligned}
& \text { Beceived Bougt } \\
& \text { Rebound April 12, } 1955
\end{aligned}
$$



Digitized by the Internet Archive in 2017 with funding from BHL-SIL-FEDLINK 


\title{
$\mathrm{N}$ a c h r i c h t.
}

\begin{abstract}
Wit diesem Hefte erscheinen zugleich einige lose Blätter Text, die mit den vorhergehenden zehn Heften den ersten Band ausmachen. Das dabey befindliche Titelblatt wird gleich hinter das Titelkupfer dieses Bandes gebunden, und zum zweyten Bande wird, so bald sich die Zahl der Kupferplatten bestimmen läfst, ebenfalls ein solches Blatt geliefert werden. Bey dem jetzt erschienenen Hefte konnte ich keinen Text geben, weil es mir, um das Laub ună die Blätter abhandeln zu können, noch an einigen Beyspielen fehlte. Aus eben dieser Ursache habe ich bisher gewöhnlich fast mehr Kupfer als Text geliefert, was aher ins künftige nicht mehr der Fall seyn kann; denn ich habe nicht nur für die noch zu erläuternden Kunstausdrücke schon beyläufig sehr viele Beyspiele abgebildet, sondern es sind auch die, welche noch abgebildet werden müssen, von der Art, dafs sie bey weitem weniger Raum einnehmen, als die, welche schon abgebildet sind. Ich kann daher den Besitzern des Werkes die Versicherung geben, dafs, wenn gleich der Text, den ich noch zu liefern habe, noch mehr als noch ein Mal so viel heträgt, als der, der schon erschienen ist, ich dennoch zur Erläuterung der noch vorkommenden Kunstausdrücke überhaupt nicht halb so viel Kupfertafeln nöthig haben werde, als allein in ersten Bande enthalten sind, und dafs folglich das Ganze nicht so kostspielig werden kann, wie vielleicht mancher, ohne diese meine Bennerkung, fürchten möchte.
\end{abstract}

\section{F. G. Hayne.}

Schönebeck, den I. December 1806. 


\author{
F r. Got t l. H a y $\mathrm{ne}$ \\ T e r m i n i bota n i c i \\ iconibns illustrati, \\ o der: \\ botanische Kunstsprache \\ d n r c b
}

Abbildungen erläutert,

mit

e ine r Vorrede von Willdenow.

11 Hefte mit lateinischcm und deutschem Texte, mit 50 illuminirten Kupfertafeln. Folio, Berlin 1806.

Ladenpreis

16 Thlr. $12 \mathrm{Gr}$.

Pränumerations - Preis 12 Thlr. $20 \mathrm{Gr}$.

Berlin, 1807. Bei Oehmigke dem Jüngern.

Seit dem I6ten Jahrhundert, wo die Kräuterkunde zu einer besondern Wissenschaft erhoben wurde, war man bemüht, das Studium der Botanik zu erleichtern, mehrere grofse Männer, Tournefort, Linné etc. fühlten den Mangel einer guten Terminologie, und sahen es schr deutlich ein, dafs man ohne eine dergleichen keine besondere Fortschritte in dieser Wissenschaft würde machen können. In diesem Werke hat der Verfasser eine gründliche und vollständige Terminologie, auch dazu sehr schöne Kupfer geliefert. Es freut mich dieses der Wahrheit gemïls hier öffentlich sagen zu liönnen; bis Ende December 1807 soll dieses Werk noch um den Prän. Preis geliefert werden.

C. L. Will $\quad$ i enow. 


\title{
TER M I N I B O T A N I C I
}

\author{
I CONIBUS ILLUSTRATI
}

O D E R

\section{BOTANISCHE KUNSTSPRACHE}

\author{
DURCH ABBILDUNGEN ERLAEUTERT
}

$\operatorname{VON}$

\section{FRIEDRICH GOTTLOB HAYNE,}

ASSISTENTE BEY DER KÖNIGL. CHEMISCHEN FABRIK ZU SCHÖNERECK; DER NATURFORSCHENDEN GESELLSCHAFT ZU HALLE, DER PHYSICALISCHEN UND DER PHYTOGPAPHISCHEN GESELLSCHAFT ZU GÖTTINGEN MITGLIEDE.

E R S T E R $\quad$ B A N D

MIT FUNFZIG ILLUMINIRTEN KUPFERTAFELN.

B E R L I N, 18 o 7 .

BEY WILHELM ÖHMIGKE DEM JÜNGERN. 


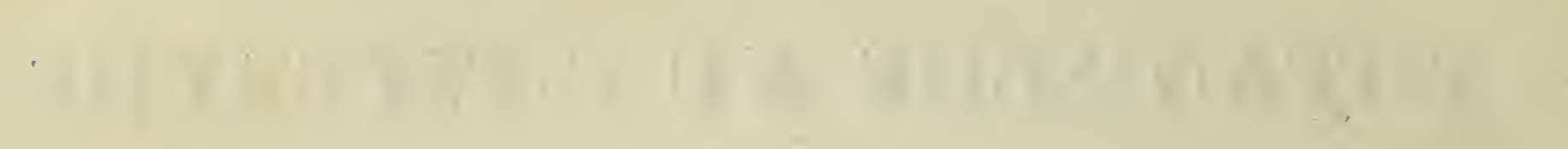



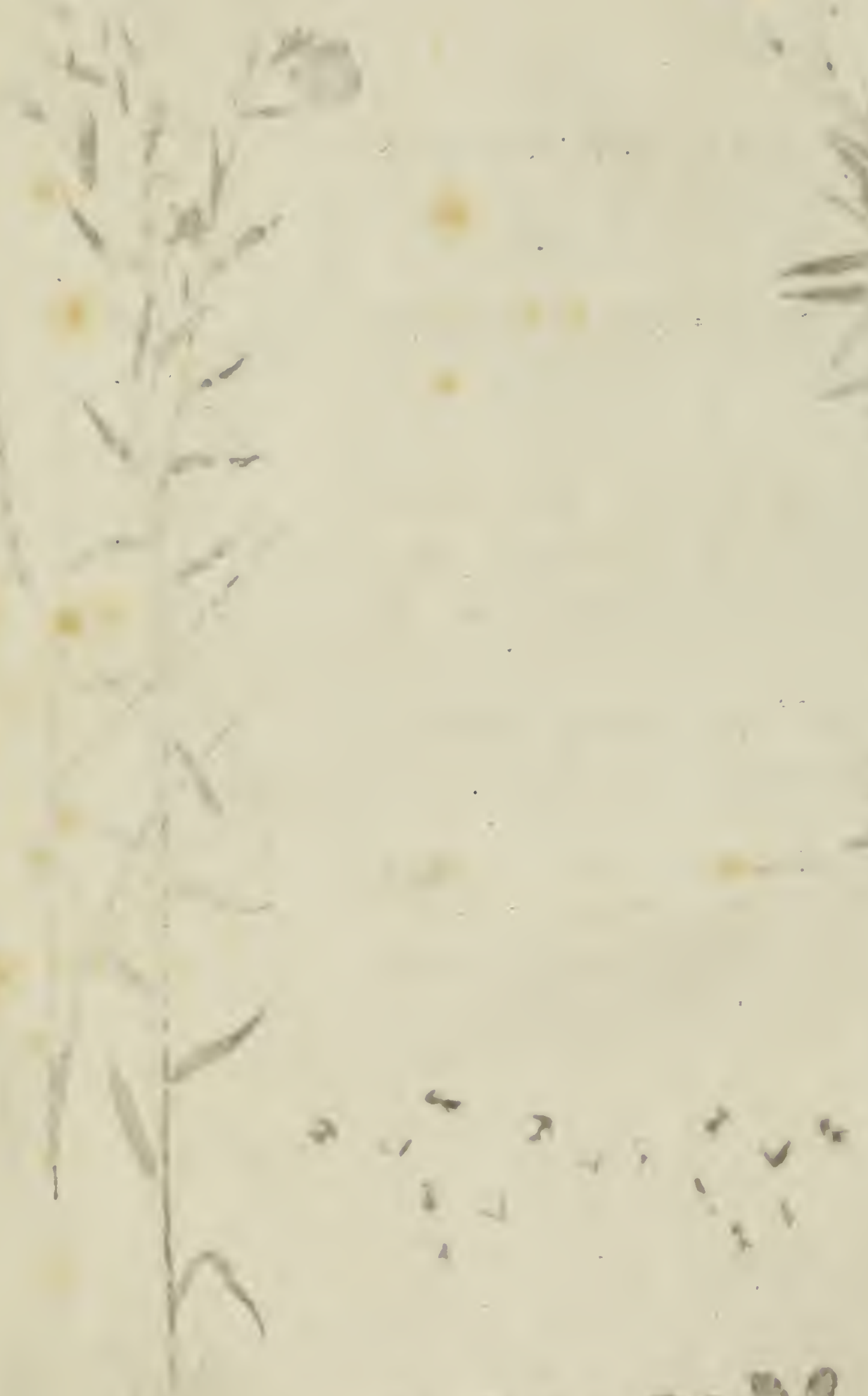

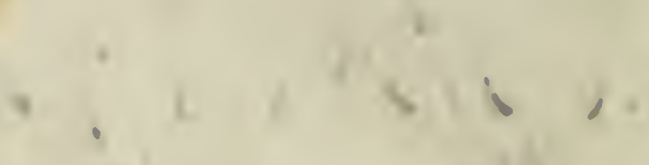

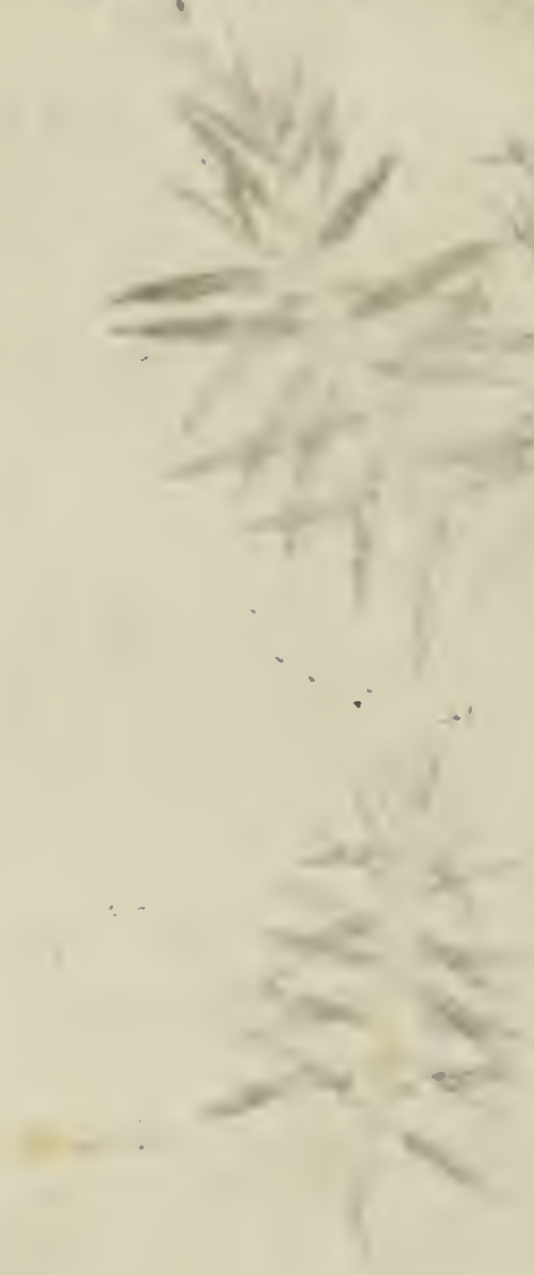




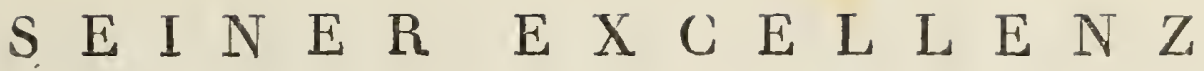

$$
\begin{aligned}
& \text { D E M }
\end{aligned}
$$

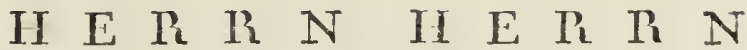

F R E Y II I R N

\title{
CARL AUGUST STRUENSEE VON CARLSBAEH
}

E I D HER I N A U F MA TS CHDORF ETC.

SEINER TÖNIGLICIEN MAJESTÄT VON PREUSSEN GEIIEIMEN ETATS- INRIEGES- FINANZ- UND WIRKLICH DIRIGIRENEM MINISTER UND VICE- PRAESIDENTEN TEY DEAI FüNIGL. GENRRAL - OBERFINANZ- KRIEGES - UND DOMAINEN- DIRECTORIO; CIEF DES GENERAL- TABRIKEN- UND COMIERZIAL-, ACCISE- UND ZOLL-, Wie AUCH DES SAIZ- DEPARTEMEATS UND DER SEEHANDIUNG; COMIMISAMUS bEY DER KÖNIGL. ASSEKURANZ-COMIPAGNIE ETC. 



\section{Hochgebohrner Freyherr,}

\section{Hochgebietender wirklicher geheimer und dirigi- render Herr Staats- Krieges- und Finanz- Minister,}

\section{Hochgechrtester gnädiger Herr.}

Die allgemein bekannte rastlose 'Thätigkeit in Anwendung der Wissenschaften auf Künste und Gewerbe, wodurch Ew. HochfreyherRLiche Excellenz die Fabriken und Manufakturen des ganzen Preufsischen Landes bis zu dem Grade von Vollkommenheit erhoben, in welchem sie sich jetzt befinden und von jedem mit Recht bewundert werden; das Bestreben Ew. HochfreyrerrLiCHeN EXCELlenz junge Künstler und Fabrikanten zu Wissenschaften aufzumuntern, um sie dadurch zur Ausübung ihrer Kunst oder ihres Gewerbes geschickter zu machen; der nicht unbedeutende Einflufs der Gewächskunde auf andere Wissenschaften, besonders aber auf die Technologie; und endlich der Nutzen einer vollständigen botanischen Terminologie bey genauer Bestimmung 
der Gewächse, geben einen unwiderległbaren Beweis, dafs auch dem Technologen die Terminologie der Gewächskunde nicht ganz unwichtig seyn kann; nnd in dieser Hinsicht erdreiste ich mich Hoch DEN ENSELBEN vorliegendes Werk, durch welches ich zur Vervollkommnung dieses Theils der genannten Wissenschıft etwas beyzutragen glaube, in gröfster Unterthänigkeit zuzueignen, und freue mich zugleich den schon lange in meiner Brust verborgen gehaltenen Wunsch in Erfüllung gehen zu sehen, nämlich HochdenenseldeN einen wenn auch nur ganz geringen - Beweis meiner tiefsten Ehrfurcht geben zu können, mit der ich die Ehre habe zu seyn

\section{Ew. Hochfreyherrlichen Excellenz}

ganz unterlhïnigster Diener

F. G. IIayne. 


\section{$\begin{array}{lllllll}V & \mathrm{O} & \mathrm{R} & \boldsymbol{R} & \mathrm{E} & \mathrm{D} & \mathrm{E} .\end{array}$}

Seit dem sechszehnten Jahrhundert, wo die Kräuterkunde durch den Flcifs der damals lebenden Botaniker zu einer besondem Wissenschaft erhoben wurde; seit diesem grofsen Zeitraume war man bemüht, das Studium dieser nützlichen Wissenschaft zu erleichtern. Damals hatte man freylich eine begränztere Splü̈re, man suchte nur die dem Dioscorides bekannt gewesenen Gewächse und solche, von denen andre berühmte Schriftsteller des Alterthums geschriebenen hatten, wieder aufs neue näher zu bestimmen. Es konnte aber nicht fehIen, dafs nuan sich auch in nutzlose Spitzfindigkeiten und Wortklaubereyen einliefs, die öfters mehr Verwirrung als wahre Aufklïrung beförderten; so dafs ntan, wie jener berühmte Dichter sich ausdrückt, $d \in n$ Wald vor Bäumen nicht sah. Bey dem allen aber vernachlälsigte man nicht die einzelnen Theile der Vegetabilien mit besondern Namen zu bezeichnen, nur war zu beklaggen, dafs jeder seiner eigenen Terminologie folcte. Der grofse Reformator der Botanik, Tournefort, der zu früh für die Wissenschaft, nit dem Anfang dieses Jahrhunderts starb, sah das Schwankende der Terminologie ein, und legte den ersten Grundstein zu einer bessern und richtigern. Seine Institutiones rei herbariae enthalten die erste besonders vorgetragene Terminologie, da alle seine Vorgänger, olne besonders die gebrauchten Ausdrücke zu erklären, sich ihrer eigenen bedienten. Mehr aber that hierin der unsterbliche nordische Naturforsoher Linné, dessen systematischer Kopf, um die Mitte dieses Jahrhunderts, uns den Überblick über alles, was die Natur zum Daseyn gerufen hatte, erleichterte, und dem allein wir es verdanken, dafs diesc Wissenschaft zu einer Gröfse und Ausdehnung gediehen ist, die man nur mit Staunen ansehen kann. Er fühlte den Mangel einer gnten Terminologie, nnd sahe sehr wohl ein, dafs wir olne sie, wohl schwerlich sichere und bedentende Fortschritte würden machen können. Aber welcher Sterblicher kanı wohl vorausbestinmen, was in der kommenden Zeit durch die vcreinten Kräfte mehrerer, rastlos für die Wissenschaft arbeitenden, Männer wird entdeckt werden? Eben hierin liegt das Mangyelhafte der Liméschen Terminologie. Unerschöplich ist die Natur in Bildung der Formen, dafs immer bey dor mehr als dreymal gröfsern Anzâhl der Vegotabilien, dic wir, seitdem dieser unvergefsliche Bota- 
niker nicht melır ist, nun kennen, der Mangel einer vollständigen Terminologie bemerkbar werden mufs.

Das helle Licht was der nun leider auch verschiedene achtungswerthe Hedwig, über die zahllose Menge von Farrenkräutern, Moosen, Flechten und Pilzen uns anzündete, zeigte uns Lücken, die ausgefullt werden mufsten, und nothwendig entstand ein neuer vorher fast ganz übersehener Zweig der Terninologie. Wer kann die Gränzen ziehen, wie weit unsre Entdeckungen reichen werden, und wer sagt uns, ob nicht das, was wir jetzt wissen, nach Jahluhunderten, und wohl noch früher, nur der Anfang der Wissenschaft selbst ist? Der fessellose Geist der Naturforscher, der alles prüft und nichts ununtersucht auf Glauben annimt, wird uns sicher in der Zukunft Aussichten gewähren, die wir jetzt nicht entfernt ahnden zu können, glauben. Wir alle, die wir eine Wissenschaft kultiviren, welche dem Menschen in jeder Rücksicht Nutzen verschaffen mufs, dürfen keine Gelegenheit vorbey gehen lassen, diese Wissenschaft so weit unsere Kräfte reichen, der Vollkommenheit, sey es auch nur um ein Getinges, näher zu bringen.

Das trackne Studium der Terminologie, der Grundpfeiler unsers botanischen Wissens, mufs mehr ausgebildet, und vollkommener gemacht werden. Längst schon fehlt es uns an ein Werk, was ohne sich streng an das allein zu binden, was wir schon wissen, diesen Theil der Botanik nach eigenen gemachten Erfahrungen abhandelt. Der Verfasser dieses Werks entspricht hierin meinen Erwartungen; Er bedarf von meiner Seite keiner Empfehlung, da jeder unbefangene Leser den Fleifs und die Sorgfalt mit der Er zu Werke gegangen ist, nicht olne ungerecht gegen Ihn zu seyn, verkennen wird. Kurz, gründlicher und vollständiger hat bis jetzo noch keiner die Terminologie behandelt; so dafs sich die Wissenschaft nicht wenig von ihm versprechen kann. Es freut mich, dieses der Wahrheit gemäfs, hier öffentlich sagen zu können. 


\section{INTRODUCTIO.}

I.

$\mathrm{H}$

nmo, quem natura rationis bencficio, supra animamalia, quae sui conservandi generisque sui propayandi sensu tantum praedita sunt, evexit, alias res non minus necessarias, quae ingenium animumque alant, illumque his dotibus, quibus ceteris animantibus antecellit, dignum efficiant, sentire debet. Nusquam vero major harum rerum copia ipsi offeretur, quam in contemplanda natura; si enim innumerabilem illam rerum diversissimae formae arctissimo vinculo inter se connexarum sibique ipse conjunctarum multitudinem intuetur, sui ipsius intelligentia ei enudabitur, et illa de sapientissimo Creatore in infinitum augetur.

2.

Historia naturalis seu Scientia naturalis, quae inter corpora naturalia discrimen statuere, corumque faciem externam et naturam nos docet, tria nobis eaque maxima in illis discrimina ostendit ideoque tripliciter in universum dividit,

3.

In prima harum divisionem generalium corpora naturalia collocantur genitalibus ad mortem usque persistentibus praedita - Animalia - ; sccunda continentur, quibus plura sunt genitalia, quae vero antequam emoriuntur abjiciunt - Vegetalilia - ; tertia denique complectitur ea, quae genetalibus omnino carent Mincralia -

4.

Corporibus naturalibus ita divisis tria naturae regna, aimale puta, vegetabile et minerale constituuntur;
EINLEITUNG.

I.

Der Mensch, welchen die Natur durch Vorzug an Geisteskrïften über die Thiere erhebt, die blofs mit einem Bestreben zur Selbsterhaltung und Fortpflanzung ihrer Art begabt sind, mufs auch noch andre, nicht minder wesentliche Bedïrfnisse fühleu, die ihm zur Nahrung des Geistes dienen, und ihn dieses Vorzuges würdig machen. Er findet aber nirgend so vielen Uberflufs an Nahrung dieser Art, als bey der Betrachtung der Natur: denn wenn er die unzählige Menge so mannigfaltig gebildeter Wesen durch eine nach allen Richtungen verflechtete Kette mit sich selbst verbunden sicht, so wird bey ihm der Begriff von sich selbst berichtigt, und der ron dem allerweisesten Urheber unendlich erhöht.

2.

Die Naturgeschichte (IIistoria naturalis, Scientia naturalis), welche uns die natürlichen Körper unterscheiden lehret, und uns mit der änfsern Gestalt und den Eigenschaften derselben bekannt macht, zeigt ums an ihnen drey auffallende Verschiedenheiten und bringt sie deshalb in drey Hauptabtheilungen.

\section{3.}

In die erste dieser llauptablheilungen stellt sic dicjenigen Naturkörper, welche mit Zeıgungstleilen begabt sind, die sie bis zum Torle behalten - Thiere-; in der zweyten befuden sich die, welche melwere Zengungstheile haben, die sic aber noch vor ihrem Tode verlieren - Pflanzen - ; mel in der dritten endlich diejenigen, welchon die Zeugungstlıtile mangeln - Mis neralien -

4.

Durch diese Eintheilung werden die drey Reiche der Natur, nïmlich das Thierreich (Regnum animale) das Gewächsreich (Regnum vegetabile) und das 
eaque re ipsa historia naturalis in tres seientias probe inter se distinguendas dilibitur.

5.

Quarum scientiarum ea, cujus beneficio interiorem exterioremque vegetabilium structuram cognoscimus singulas quasque eormm speciss ab omnibus aliis in terrarum orbe notis distinguere docemur, quoque in eorum natura utilitate et salubritate indaganda versatur, Scientia botanica, Pliytologia, Botanologia, Botanice, Botanica appellatur.

6.

Huic scientiae id cum ceteris historiae naturalis partibus commune est, ut in museo addisci non possit, sed utique naturam ipsam observatam velit; indeque variis cultoribus ejus labores eveniunt. Attamen, cum vegetabilia per totam, quam late patet, terram dispersa sint, eamque quasi vestiant, quunque is loci mntandi facultatem natura negarerit: iis multo facilius, quam mineralibus et animalibus, potiri licet; quodque enim pratun, quileque sylva, quaeque vallis, quique mons, imo paludes, lacus, rivi et fluvii opportunam sufficientemque nobis harum rerun observandarum copiam ınanusque, cui, quod sunt, acceptum referunt, commirandae occasioncm offerunt.

$7 \cdot$

Jam plantart aliquam observantes, enm examinantes ullamve ad rem adlibentes, nos oportet, ut certo dicere et affrmare possinus, qualis sit planta nobis objecta; alias enim, nostra de ea sensa cum aliis in conm:nem utilitatem parum communicaremus, nec quisquam experimentis nostris in eam factis repetendis par foret. Ea igitur screntine botanicae pars, per quam omnes vegetalilimm paites variaeque cormu formae nobis innotescrnt, ut secundum praceryta quacham in systenate,

\section{EINLEITUNG.}

Mineralreich (Regnum minerale) festgesetzt; und die Nvanrgeschichte selbst zerfällt dadurch in drey besondere Wissenschaften.

5.

Diejenige von diesen Wissenschaften, welcle uns mit dem innern und äufsern Bau der Gewächse bekannt macht, jede einzelne Gewächsart von allen bekannten des Erdballs unterscheiden lehret, und die Eigenschaften und den Nutzen derselben anszuspähen sucht, heifst die Kräut erkunde, Geväachskunde, Botanik (Scientia botanica, Plytologia, Botanolosiu, Botanice, Botanica.)

6.

Diese Wissenschaft hat es mit den übrigen Theilen der Naturgeschichte gemein, dafs sie sich nicht im Zimmer erlernen lïlst, sondern es schlechterdings fordert. dafs man die Natur selbst beobachtet; und es werden daher ihren Verehrern nicit selten mancherley Mühseligkeiten zu Theil. Jedoch, dn die Gewächse über dem ganzen Erdball verbreitet sind, und gleichsam die $\mathbf{B e}$ kleidung desseiben ausmachen; und da ihnen von der Natur die Fähigkeit, ihren Ort verändern zu können, versagt ist: so künnen wir sie mit weit wenigern Schwierigkeiten in unsern Besitz bringen, als die Mineralien und Thiere; und jede Wiese, jeder Wald, jedes Thal, jeder Berg, ja sellıst Sümpfe, Seen, Bäche und Flïsse geben uns Gelegenheit genug diese Geschöpfe zu beohachten und die Hand zu bewuudern, der sie ihr Daseyn verdanken.

7.

Wenn wir nun aber an einer Pflanze Beobachtumgen machen, Versuche mit ihr anstellen, oder sie zu irgend etwas benutzen: so ist es auch nüthig, d’fs wir mit Gewifsheir bestimmen kōnnen, was es für eine Pfianze wir, die wir vor uns hatten: denn sonst würden wir uns andern nur sehr unvollkommen drüber mitıhilen hörnen, und keinem wärde es möglich seyn, unsre Versıche zu wiederholen. Deslualb ist derjenige Theil der Botumk, welcher uris mit allın Theilen der 


\section{INTRODUTIO.}

quopiam plantam nobis incognitam invenire possinns, gravissima jure habenda est. Nominatur ea botanica lingna seu terminologia; quam tradere atrue extmplis enudare his plagulis propositum est. Cuod tamen, priusquam fiat, consultum milhi est visun, ut repetilioni antevertatur, definitiones quasdam communes a botanicis factas praemittere.

8.

Botanici ad ea, quae in omni vegetatione obvia sunt, quacque statum quendam tempusve alinisod in vita vegetabilium constituunt, saepe vacabula translata adhibent; eoque pertinent quae sequmntur.

I) Germinatio: ubi semen tumescit foliorumque explicandurum initium capit.

2) Frondescentia s. Íernatio: ubi mmidae arborum, fruticum, snffruticumque gemmae folia explieint.

3) Somnzus: si vesperi vel noctis tempore nonnullorum vagetabilium folia complicantur.

4) Defoliatio: si autumni, vel quod idem nliis quibusdam borealibus plantis evenit, veris tempore folia decidunt.

5) Virginitas: id appellatur vegetabilium tempus, quo flores nondum explicati sunt.

6) Anthesis: est tempus illud, quo in regetabilibus flos perfecte explicatus est. Inde illne describentiun voces: flores ante authosin nutantes, vel fores post anthesins erectio
EIN L E I T U N G.

Gewïchse und ihren verscliedenen Bildungen bokannt maclut, dannit wir nach gewissen liegeh in einem System den Nanca ciner uns unbekannter Pflanze auffinden hömnen, als der wichtigste zu betrachten. Er heifst die botanische Spraehe oder 'Terminologie; und diese rorzutragen und durch Beyspieie zu erlïutern, ist der Zweck der vor uns liegenden Blätter. Jedoch eho dies geschehen kann, wird es nüthig seyn, un Wiederholungen zu vermeiden, einige allgemeine Bestimnungen, welche die Dotaniker festgesetzt haben, vorauszusehicken.

$\delta$.

Uin die allgemeinen Erscheinungen der Vegetation, die einen gewissen Zustand, oder Periode in der Lebenszeit des Gewächses ausmnchen, zu bezeichnen, bedienen sich die Botanisten öfters bildlicher Ausdrücke; und dahin gehüren folgende.

I) Das Keimen(Germinatio): wenn der Saane aufschwillt und seine kleinen Elättchen zu entfalten an, fängt.

2) Das Ausschlagen (Frondescentia s. Vernatio): wenn die aufgeschwollencn Knospen der Bäıme, Strüucler und Staudengewächse ihre Blätter entfulterı.

3) Der Schlaf (Sommns): wenn am Abend oder in der Nacht sich die Blätter verschiedener Gewächse zusammenlegen.

4) Das Entblïtern (Defoliotio): wenn im Herbst, oder auch wie bey wenigen andern nürdlichen Pflanzen, im Frühjalur, die Blätter abfallen.

5) Die Jungferschaft (IFirginitns): wird bey den Gewïchsen der Zeitpunkt genannt, wenn ihre Blumenknospen noch unentfaltet sind.

6) Das Offenseyn der Blumen (Anthesis): ist der Zeitpunkt, wo bey den Gewächsen die Blume vollhommen entwickelt ist. Daher sagt man in Beschrcilungen: die Blumen hangen vor dem Offenseyn flores amte anthesin nutantes), oder sie stehen nach dem Offenseyn aufreeht (lores post anthesin erecti.)

$$
\text { A } 2
$$


7) Aestivatio: nominatur mensis, vel illud anni tempus, quo llos perfeetus est.

8) Fructificatio: dicitur, quando floris pollen eum paribus propinquis eommunicatur.

9) Caprificatio: est illa fructificationis plantarun?, ralio, quae non immediate a plantis ipsis efficitur. Tunc enim lloris partibus is situs eave forma est, ut aliud adjumentum e. g. inseetorum simul requiratur.

Io) Viriliae: si flores certo dici vel noctis tempore vel aperiuntur vel clauduntur.

II) Grossificatio: si post anthesin fructus futurus augeri incipit.

12) Maturatio: est tempus, quo fructus matureseunt.

I3) Disseminatio: quando fiuetns permaturus semen dispergit.

\section{9.}

Vegetabilium superficies pro variis eorum partibus variae quoque saepe est structurae. Ad quam varietatem significandam, quae sequuntur stabilita sunt, eaque plantan aliquam deseripturo ad omnes ejus partes adhibentur.

I) nitidus: si ea superficiei eoloratae est laevitas. ut ucis radios reflectat; qualis est foliorum Ilieis Aquifolii et Pruni Lauro - Cerasi.

2) opacus: quod superfieie colorata sua lueem nee reHectente, et priori (nitidus) reeta oppositum est. Exemplo sunt plurimorum regetabiliun folia.
EI Y L I I T N G.

7) Die Zeit der Blïtle (Aestizatio): nennt man den Mronal, oder die Jahreszeit, wena die Bitume in ihrer Toliliommenlacit ist.

8) Die Bega: tunsperiode (Fructificatio): ist der Zeitpunkt bey den Gewïclsen, wenn in der Blume der Blumenstaub den benachbarten Theilen milgetheilt wird.

9) Dic Caprifikation (Caprificatio): nennt man bey den Planzen dicjenigo Art der Begattung, die nicht unmittelbar durch die Pflanzen sellst geschieht. Es haben alsdann die Theile der Blume eine solche Lage oder Bildung, dafs eine andere Beyhülfe, z. B. die der Insekten, ciaru erfordert wird.

10) Das IVachen der Blume (Vigiliae): wenn Blumen zu einer bestimmten Zeit des Tages oder der Nacht sich öffren und schliefsen.

I1) Das Fruchtansetzen (Grossificatio): wenn nach der Blürhe die künftige Frueht sich zu vergröfsern anfïngt.

12) Die Zeit des Reifwerdens (Maturatio): der Zeitpunkt wo dic Früchte reif werden.

13) Das Ausstreuen des Sa amens (Disseminatio): der Zeitpunkt, weun die Frucht ihre völlige Reife erlangt hat, und den Saamen ausstreut.

\section{9.}

Die Oberfläche der Gewächse ist an den verschiedcnen Theilen derselben auch öfters sehr verschieden gebildet. Man hat dalier, un diese Verschiedenheit angeben zu künnen, folgende Beslimmungen festgesetzt, die bey Beschreibungen auf alle Theile eines Gewächses angewendet werden.

1) glänzend (uitidus): wenn die gefurbte Oberfläche so glatt ist, dafs sie die Lichtstrahlen züückwirft; z. B. die Blätrer von Ilex Aquifolium und Prunus Lauro-Cerasus.

2) matt (opacus): wenn die gefärbte OberHläche das Licht nicht zurück wirft. Es wird blos als Gegensatz von dem vorhergehenden gebraucht. Beyspiele geben die Blätter der mehresten Gewächse. 
3) lucvis: cui nec impressiones nec eminentiae, et Ni. 6, $7,20,2 \mathrm{~J}, 26$ ct 27 contrarialtu.

4) glaler: ubi nec pilos, nec selas, nec actuleos lierbaceos videre est. No. 3 ad I9 et 25 aperte contrarintur.

5) punctatus: quod subilia, plenumque impressa, punctula solo visu, nce vero tactu obscrvauda exhibet; qualia sunt folia Thymi vulgaris et Thymi Mastichinae.

6) scaber: ubi solo tactu obscrvabilia punctula emiment. Folia multorum Graninum et Caricis specierum, e. g. Caricis acutae.

7) asper: si punctula tactu observabilia et visu animadrerti possunt; e. g. Pulmonariae olficinalis.

:

3) hispidus: ubi pili brevissimi, fumi occurrunt; e. g. foliornm Myosotis arrensis.

9) lirtns: dicitur, quod pilis longis iisque firmissimis instructum est; e. g. caulis Echii vulgaris.

Io) pilosus: in quo pili longi, solitarii paulum incurvati manifesli; e. g. in Hieracii Pilosellate foliis.

I I) viliosıs: urbi pili longi, molles, stricti, densi constipaii sunt; e. g. caulis Stachydis germanicae.

12) pubcscens: ubi rili brevissimi, subtiles, alli observabilcs sunt; e. g. foliorum Oenotherae mollissimae.

I3) sericens: si pilis vix visibilibus adjacentibus superficies niticle candida est; e. g. Potentillae Anserinae loliortum.

If) lanaius: superficie pilis longis, mollibus, varie curvatis, dense consipatis, perspicue tamen distinguendis, obscssa; qualis est caulis in Stachyde lanata.

15) tomentosus: pilis subtilibus tam arcte intertextis, ut distingui non possint. Tunc plerumque superfcics est colore albo, e. g. in Verbasco Thapso, vel fer-
3) glatt (lacris): wo weder Erhabenheiten, noch Tertiefungen sich finden. Es ist der Gegensatz von Nr. 6, - , 20 21, 26 und 27.

4) unbehaart (glaber): wo weder Haare, noch Borsten, nocl krautarlige Stachel zu sehen sind. Der Gegensalz ron $\mathrm{Nr} .3$ bis if lind 25 .

5) punktirt (puncta!us): wo feinc, gewühnlich vertiefte Punkle, jur dnichs Gesicht, nicht aber durchs Gefïhl zu bemerken sind; z. B. die Dlätter des Thymians, Thymus wulgaris, und des Thymus Mastichiua.

6) scharf (scalier): wo sich kleine durchs Gefiill bemerkbare hervorigende Punkte finden. Die Dlitter vicler Gräser und Seggcnaxten, z. B. Carex acutn.

7) raull (usper): vvenn die durchs Gefüh! bemerkbaren Punkte, auch duxchs Gesicht walırgenommen werden können; z. B. gemeines Lungenkraut Puluonaria officinalis.

8) hackrig (lispidus): wo sehr kurze, stcifc Maare sich zeigen; z. D, die Blïlter des Myosotis arvensis.

9) borstig (hittus): wenn dic Haare lang und selı steif sind; z. B. der Stengel bey Echium vulgare.

Io ha arig (pilosus): wo lange, einzelnc, etwas krumm gelogene Haare rorharden sind; z. B. die Blittter des Hieracimm Pilosella.

I1) zottig (villosus): wo lange, weiche, gerade, diclit stehende Hare sich finden; z. B. der Stengel bey Stacliy's germanica.

I2) weichharig (pubescens): wo sehr kuze, fiinc, weisse Haare sich zeigen; z. B. die Blätter der Ocmothera mollissina.

I3) seidenartig (sericeus): wenn durch kaum sichtbare, dicht anliegende Haare die Flïche ghïnzend weils ist; z. B. die Blätter der I’otentilla Anserinu.

If) wollig (lanatus): wenn die Flichle mit litigen, weichen, verschiedentlich gekrümmten hilaren, die licht stehen, aber dennocí deutlich zu untcrscheiden sind, besetzt ist; z. B. der Stengel bey Stucluys lanrztı.

15) filzig (lomentosis): wenn feine Hare so dicht in einander verwebt sind, dals man sie nicht unterscheiden kann. Gewöhnlich sieht alsdaun die Iläche weifs 


\section{EINLEITUNG.}

rugineo, quo est foliorum Ledi paiustris pagina inferior. Tabulae libri inscriptionem gercntis. Fig. I.

aus, z. B. Wollkraut, Verbascum Thapsus, oder sie ist rostfirben, wie die untere Seite der Blätter beim Porst Ledium palıstre. Titelkupf. f. I.

16) barbatns: pilis fasciculatim positi;; e. g. in Mesembryanthemo barbato.

I7) strigosus: superficie setis jaccntibus, arctc adprcssis, parvis, deorsim incrassatis obsessa; e. g. in Lithosperino officin ali.

13) urens: si superficies pilis parvis obsessa est, sensum doloris urentem infcrentibus; e. g. Urticae.

19) cliaris: margine superficiei cujusdam pilis aequaliter loncis parallelis obsesso; e. g. foliorum varietatis grandiflorae Erigeri uniflori. Tab. 1. fig. 42.

20) papillosus: papillis minoribus carnosis obviis; e. g. in Aloe margaritifera.

21) papulosus: ubi papulae minores cavae adsunt; e. g. in Mescmbry anthemi hispidi foliis.

22) maricatus: mucronibus parvis, brevibus herbaceis; e. g. caulis Asperuginis procumbentis.

23) farinosns: si superficies farina conspersa videtur; e. g. Primulae farinosae.

24) Glutinosus: si superficies materia quadam glutinosa in aqua solubili tecta est; e. g. Primulae glutinosae.

25) visciclns: si superficics materia viscida, in aqua insolubili tecta, et inde vel resinosa vel pinguis est. Plernmque in superficie pili parvi manifesti sunt, quibus hace materia viscida secernitur; exemplo esto, Cerastium viscosum.

26) striatus: striis pluribus in superficie isque subtilibus eminentibus vel depressis occurentibus; e. g. culmi plurimo:tum Graminum.

16) bartig (Larbatus): wenn die Haare büschelförmig beysammen stehen; z. B. Mesembryanthemum barbatnum.

17) striegliclut (strigosus): wenn die Flïche mit liegenden, dicht angeprifsten kleinen Borsten besetzt ist, die nach unten zu dicker sind; 2. B. Lithospermam ofjicinale.

18) brennend (urens): wenn die Flïche mit kleinen Haaren besetzt ist, die eine brennende schmcrzhafte Emplindung verursachen; z. B. die Nessel, Urtica.

19) wimperarig (ciliaris): wonn der Pand eincr Fläche mit gleich langen, parallel laufendeu Haaren be sctzt ist; z. B. die Blätter des Erigeron uniflorum, bey der grofsblumigen Varietät. Tab. I. f. 42.

20) Warzig (papillosus): wenn kleine, fleischige Warzen sich zeigen; z. B. Aloe margaritifera.

2I) blattrig (papnlosins): wo kleine hohle Bläschen sich finden; z. B. Mesembryanthemnm hispidnm.

22) weichstachlich (muricatas): wo kleine, kurze, krautartige Stacheln sind; z. B. der Stengel bey $A s-$ perugo procumbens.

2) mellig (farinosus): wenn die Fläche das Anselın hat, als wïre sie mit Mehl bestreuct; z. B. Prinnla farinosa.

24) klebrig (glutinosus): wenn die Flïche mit ei. ner klebrigen Matcrie bedeckt ist, die sich im Wasser auflösen läfst; z. B. Primula glutinosa.

25) schmierig (viscidns): wenn die Fläche mit einer klcbrigen Materie bedeckt ist, die sich nicht im Wasser auflüsen läfst, und daher harzig oder fettig ist. Gewölnnlich sind auf der Fläche kleine Haare vorhan$\mathrm{dcn}$, durch welche diese klebrigc Materie abgesondert wird; z. B. Cerastium viscosum.

26) gestreift (striatuls): wenn die Flïche mehrere feine, erhabene, oder verticfte Strichc hat; z. B. der Halm bey den mehresten Gräsern. 
I T T R D U T 10.

2-) sulcatus: lis striis magis excavatis; e. g. caulis in multis L'mbellatis.

I0.

Troxime hanc tam diversam vegetabilium formam sunerficiei corum color spectandus; nan licet in pluribus regetabilitus is min ris sit mornenti, accurate tamen copioseque plantam aliquam descripturus et corollae colorem determinet, onortet; ut in vegetabilibus quibusdam, ut in Algis et Fungis, ille vel magni putandus est, quia ad ea accurate determinanda non paulum confert. Colores igitur sequentes distinguuntur, qui in tabula prima, qnain potuit fieri, diligentissine exhibiti sunt.

I) cyanens: saturate coeruleus, quale est coeruleum beroliniense.

2) coerulens: pallide coerulcus, quo colore flores Myosotis scorpioidis.

3) azurezus: color, similis fere praecedenti, sed valde fulgens nti ultramarinum.

4) cnesius: perpallido-coeruleus inque griseum fore transicns.

5) atrovirens: saturatius viridis, in nignum quodammodo transiens.

6) aeruginosts: pallidus coeruleo-viridis.

7) prasinus s. saturate virens: pulchre viridis, ubi nec flavus nec coeruleus emicat.

8) flavo-virens: viridis in flavum quodammodo desinens.

9) glaucus: viridis in griseum potins transiens.

10) anrens: flavus purissimus sine omni admixtione aliena.

II) ocleracens: Havus, qui in brunneum transire vix observatur.
EINLIITU T.

2-) gefurcht (sulcatus): wenn diese Striche tiefer ausgeholt sind; z. B. der Stengel bey vielen Doldengewïchsen.

10.

Aufser dieser so verschicdenen Bildung der Obcrflïche der Gewiichse kommt auch noch die Farbe derselben in Betracht; denn wenn gleich bey den mehresten Gewiichsen nicht viel daranf geachtet wird, so ist es doch nüthig bey genauen Beschreibungen anch die Farbe der Blumenkrone anzugeben; und bey einigen Gewächsen, als bey den Flechten und Pilzen, ist sie sogar von Bedeutung, weil sie zur festen bestimmung derselben nicht wenig beyträgt. Es werden folg nde Hauptfarben unterschieden, die auf der ersten Platue, so genau als es möglich ist, vorgestellet sind.

I) dunkelblau (cyanerus): dunkel wie Berlinerblau.

2) himmelblau (coeruleus): ein helles Blan, wie die Biunien des Vergifsmeinnicht, Myosotis scorpioides.

3) schmaltblau (azurens): beynahe die vorhergehende Farbe, oder selnr brennend wie Ultramarin.

4) blafsblau (caesius): sehr blalsblau und stark ins Graue spielend.

5) stahlgrün (atrovirens): sehr dunkelgrün, etwas ins Schwarze fallend.

6) kupfergrïn (aeruginosus): ein helles Blaugrũn.

7) grasgrün (prasinus s. saturate virens): ein scliönes Grũn, wo weder Gelb noch Blau hervorschimmert.

8) gelbgrün (Aavo-virens): Grün, das etwas ins Gelbe übergelit,

9) graugrün (glaucus): Grün, das stark ins Graue ũbergelıt.

10) goldgelb (aurens): Gelb, was ganz rein ist, und heine fremde Beymischung hat.

II) o chergelb (rcliraceris): Gelb, was kaum merklich ins Braune schimmert. 
12) pallide-favens: flavus in album magis transiens.

ז3) sulplunreus: pallide flavens fulgens, quem colorem flores Hieracii Pilosellae referunt.

I4) vitellinus: pulchre flavus, aliquantum quidem, sed vix manifesto, in rubrum transiens.

15) Serrugineus: brunneus in lnteum magis transiens.

I6) brunnels: brunneus saturatissimus purissimusque.

17) fuscus: brunneus griseum magis fulgens.

18) badins s. hepaticus: brunneus saturatius rubrum coruscans.

I9) antantiacus: flavus rubro commixtus.

20) miniatus s. cinnabarinus: ruber helvolus fulgens.

2I) lateritins: color praecedens, sed languidior inque gilvum transiens.

22) coccineus s. phoeniceus: cinnabarinus, fulgentissimus et vix manifesto in coeruleum transiens.

23) carneus: nixtus albo et rubro.

24) crocens: aurantiacus saturatissimus.

25) punicens: ruber gratissimus, fulgens, ut carmiנuา.

26) sanguinens s. purpureus: praecedente languidior, secl purissimus.

27) rosens: sanguineus perpallidus.

28) atropurpureus: ruber maxime saturatus, ad nisizun magis accedens.

29) violacens: coeruleus rubro commixtus.

3o) lilacinus: color praecedenti haud absimilis, sed multo languilior magisque rubrum lucens.

3i) ater: niger purissimus saturalissimusque.
12) blafsgelb (pallide-flavens): ein Gelb, was stark ins Weilse fällt.

13) schwefelgelb (sulphuretıs): brennend hellgelb wie die Blumen von Hieracinm Pilosella.

14) dottergelb (vitellinus): ein schönes Gelb, das etwas, aber kaum merklich, ins Rothe schimmert.

15) rostfarben (ferruginens): ein Braun, was stark ins Gelbe übergelit.

16) tiefbraun (brunneus): das dunkelste, reinst Braun.

17) gemeinbraun (fuscus): ein Braun, das stark ins Graue schinmert.

18) kastanien- oder leberbraun (badius, hepaticus): ein Braun, das ins Dunkelrothe spielt.

I9) orangegelb (anrantiacus): gelb mit roth gomischt.

2o) zinnoberroth (miniatus s. cinnabarintls): fahles brennendes Roth.

21) ziegelfarben (lateritins): die vorige Farbe, nur matter und ins Gelbe spielend.

22) scharlaclifarben (coccineus, s. pluoenicelis): Zinnoberroth, sehr brennend und kaum merklich ins Blaue spielend.

23) fleischfarben (carnetıs): eine Mischung zwischen weifs und roth.

24) safranfarben (croceus): sehr dunkles Orange.

25) hochroth (punicens): das angenehmste brennende Poth, wie Carmin.

26) blutroth (sanguineus, purpurens): matter als das vorhergehende, aber sehr rein.

27) rosenroth (roseus): ein sehr blasses Blutroth.

28) schwarzroth (atropurpureus): sehr dunkles Foth, das dem Schwarzen sich naht.

29) violet (violaceus): Blau mit Roth vermischt.

30) lilafarben (Iilacinus): die vorige Farbe, aber ungleich matter und mehr ins Rothe spielerd.

3i) rabenschwarz (ater): das allerreinste "und dunkelste Schwarz.

32) $n i-$ 
I N T RODUCTIO.

32) niger: color praecedens, magis vero in griseum transiens.

33) cinerens: saturate griseus.

34) griseus: pallide griseus laetus.

35) canns: magis albus, quam griseus.

36) lividns: saturate griseus in violaceum vergens.

37) lactens s. candidns: splendide albus.

38) albus: languide albus.

39) albidns: squalide albas.

40) lugalinus: pellucidus, vitro infucato similis.

II.

Singulas vegetabilium partes ratione coloris spectantibus nobis apparebit quamque earum suos proprios habere colores, quorum alium alio magis prae se ferat.

Radix plerumque nigro, brunneo, vel albo, interdum flavo, raro rubro, nunquam vero viridi colore est imbuta.

Caulis et folia plerumque viridia, rarins rubra, nonnunquam albo nigroque colore maculata, rarissime l'ava, omnium rarissime coerulea, nec unquam alba aut brunnea, nisi si tomentosa sunt.

Corollae omnibus coloribus, sed raro viridi et rarius nigro imbutae videntur.

Calyx plerumque est viridi, raro alio, nunquam nigro colore.

Stamina plerumque sunt hyalina, alba, veI viridiuscule alba, rarius alius coloris.

Fructus, carnosi aut succosi omnium sunt colorum; capsulae vero sunt plerumque brunneae, virides, vel rubrae, et rarins nigrae.

Semen plerumque nigrum, brunneum vel flavum, rarius alium colorem exhibet.
EINLEITUNG.

32) gemeinscliwarz (niger): was schon nehr ins Grane spielt.

33) a schgrau (cinerens): ein dunkles Grau.

34) perlfarben (grisens): lebhaftes Hellgrau.

35) blafsgrau (canus): was mehr weifs als grau ist.

36) b le yifarben (lividns): Dunkelgrau ins Violette spielend.

37) milchweifs (lacteus s. candidns): blendendes Weils.

38) weifs (albus): mattes Weifs.

39) weifslich (albidus): schnnuziges mattes Weils.

40) durchsichtig (lyalinzss): durchscheinend, wie weifses Glas.

Ir.

Wenn man die eirzelnen Theile der Gewächise in Hinsicht ihrer Farbe betrachtet, so wird man gewalır, dafs jeder derselben einige bestimmte Farben lat, von denen er vorzugsweise eine oder die andere an sich trägt.

Die Wurzel ist gewöhnlich schwarz, braun oder weifs, zuweilen gelb, selten roth, niemals aber grün.

Der Stengel und die Blätter sind gewölnnlich grün, selicner roth, bisweilen weils und schwarz gefleckt, am seltensten gelb, äuljerst selten blau, und weifs oder brann nur alsdann, wenn sie filzig sind.

Die Blumenkronen zeigen sich in allen Farben, selten aber sind sie grün.

Der Kelch ist gewöhnlich grün, selten von andrer Farbe, niemals aber schwarz.

Die Staubfäden sind gewölnnlich durchsiclıtig, weifs oder grünlichweil's, seltener von anderer Farbe.

Die Früchte, welche fleischig oder saltig sincl, kommen von allen Farben vor; die Kapseln aber sind gewöhnlich braun, grĭn oder roth, und nur selten schwarz.

Der Saame ist gewöhnlich schwarz, braun oder gelb, seltener von anderer Fabe. 


\section{EINIEITUNG.}

12.

Vegetabilium colores - si Algas et Fungos excipias, et quibus ipsis id rarius accidit - magnopcre variant, nec ideo ad ea discernenda adliberi possunt; nonnullius tamen ponderis est illa colorum mutatio, quae corollis et fructibus contingit. Plerumque colores in album transeunt. Color ruber et coernleus creberrime nutantur; rarius quidem in flayum, vel ut raber in flarum transeat. Coeruleus in rubrum saepissime degenerat. Quam rem exempla, quae sefquntur, illustralunt:

\section{I) In corollis.}

Color ruber degenerat in album: in Erica, Serpillo, Betonica, Pediculari, Diantho, Agrostemmate, 'T'rifolio, Orchide, Digitali, Carduo, Serratula, Papavere, Fumaria, Geranio et pluribus aliis.

Coeruleus in album: in Campanula, Pulmonaria, Anemone, Aquilegia, Viola, Vicia, Galega, Polygala, Symplyto, Boragine, Hyssopo, Dracocephalo, Scabiosa, Jasione, Centaurea, Cichorio et pl. a.

Flav'us in album: in Meliloto. Agrimonia, Verbasco, Tulipa, Alcea, Centaurea, Chrysanthemo et plo a.

Coeruleus in rubrum: in Aqnilegia, Polygala, Anemone, Centatuca, Pulmonaria e. p. a.

Coeruleus iu favum: in Commelina, Croco et nonnullis aliis.

Ruber in Ravum: in Mirabili, Tulipa, Anthylli et nonnull. al.

Ruler in coeruleum: in Anagallide et nonmull, al.

Albus in rubrum: in Oxalide, Datura, Piso, Bellide e. n. a.

\section{2) In fructibus succulentis.}

Niger in album: in Rubo, Myrtillo, Sambuco.
I2.

Die Farben ändern bey den Gewächsen - Flechten und Pilzc ausgenommen, wo dies seltner der Fall ist - schir ab, und können deshalb nicht als Unterscheidungszeichen bey ihnen angewendet werden; indessen ist doch die Art, wie einige Blumenkronen und Frūchte ihre Farbe verändern, sehr wichtig. Gewöhnlich gehen die Farben ins Weifse über. Die rothe und blaue Farbe pflegt sich am lhäufigsten zu verändèrn; seltener aber sind die Veränderungen in Gelb, oder daf's Poth ins Gelb ïbergelıt; Blau geht selır häufig ins Pothe über. Folgende Beyspiele werden dies erlïutern:

I) Bey den Blumenkronen.

Roth geht ins Weifse über: bey Erica, Serpillum, Betonica, Pedicularis, Dianthus, Agrostemman, Trifolium, Orchis, Digitalis, Carduns, Serralula, Papaver, Fumaria, Geranium u. a. m.

Blau verwandelt sich ins Weifse; bey Campanula, Pulmonaria, Anemone, Aquilegia, Viola, Vicia, Galega, Polygala, Symphytum, Borago, Hyssopus, Dracoceplaalum, Scabiosa, Jasione, Centaurea, Cichorium u. a. m.

Gelb verwandelt sich ins Weifse: bey Melilotus, Agrimonia, Verbascum, Tulipu, Alcea, Centaurea, Chrysanthemum u. a. m.

Bla verwandelt sich ins Rothe: bey Aquilegia, Polygala, Anemone, Centaurea, Pulmonaria u. a. in.

Blan verwandelt sich ins Gelbe: bey Commelina, Crocus i. e. a.

Roth verwandelt sich ins Gelbe: bey Mirabilis Tulipa, Antlyllis u. e. a.

Roth verwandelt sich ins Blaue: bey Anagallis u. e. a.

Weil's verwandelt sich ins Rothe: bey Oxalis, Datura, Pisum, Bellis u. e. a,

2) Bey den saftigen Früchten.

Schwarz verwandelt sich ins Weifse: bey Rubus, Myrtillus, Sambucus. 
Niger iu flavunn: in Solano.

Niger in viridem: in Saubuco.

Ruber in album: in Ribete, Rubo Idaeo.

Ruber in Aavum: in Corno.

Viridis in rubrum: in Rubcte Grossularia.

3) In feminibus.

Albus in favum, flavo-virentem, violaceum, grisenm, fuscnun et nigrum: in Piso et Phaseolo.

Albus in nigrum: in papavere somnifero.

Fuscus in albun: in Vicia Faba.

Fuscus in flavum et nigrume: in Piso Ochro.

Fuscus in nigrum: in Dolicho Lablab.

Niger in album: in Vicia sativa.

13.

In vegetabilibus nonnullis folia in statu naturali nnaculata sunt, quae tamen maculae non sunt perpetuae, sed interdum evanescunt. Sequcntes foliorum maculatorum species distinguuntur.

I) niyrn-maculata: e. g. Ari maculati, Polygoni Hydropiperis, Orchidis maculatae, Hypochaeridis maculatae.

2) allo-maculata: Pulmonariac maculatae, Cyclaminis europaei, Lamii maculati.

3) rulbo-mnculata: Lactucae sativae, Deta ru. brae, Amaranthi tricoloris et nielancliolici.

4) Intco-maculata: Amaranthi tricoloris.
Schwarz verwandelt sich ins Gelbe: bey Solanum.

Scluwarz verwandelt sich ins Grüne: bey Sambucus.

Roth geht ins Weifse über: bey Ribes, Rut bes Idaeils.

Rothverwandelt sichins Gelbe: bey Cornus. Grün verwandelt sich ins Rothe: bey Ribes Grossularia.

3) Bey den Samen.

Weil's verwandelt sich ins Gelbe, Gelbgrüne, Violette, Graue, Braune und Schwarze: bey Pisum und Pluaseolus.

Weil's verwandelt sich ins Schwarze: bey Papaser somniferum.

Braunverwandelt sich ins Weifse: bey $V_{i-}$ cia Faba.

Braun verwandelt $s$ ich ins Gelbe und Schwarze: bey Pisum Ochrus.

Braun verwandelt sich ins Schware: bey Dolichos Lablab.

Schwarz verwandelt sich ins Weifse: bey Vicia sativa.

13.

Bey einigen Gewäclisen sind die Blätter in natürlichen Zustande gefleckt, jedoch sind diese Flecke nicht bestïndig, sondern verschwinden zuweilen. MIan unterscheidet folgende Arten von gefleckten Blättern:

I) schwarzgefleckte (nigro-maculata): z. B. Arum maculatum, Polysonum IIydropiper, Orchis maculata, Hyportacris maculata.

2) weifsgefleckle (ullio-maculata): Pulmonaria maculata, Cyclamen europaeum, Lamium maculatum.

3) rothgefleckte (rubro-maculata): Lactuca sativa, Beta ruba, Anaranthus iricolor und melancholicus.

4) Gelbgefleckte (luteo-maculata): Amaranthus tricolor. 
5) tessellata: Cymbidii borealis Swartz (Cypripodii bulbosi, L.), Satyrii repentis et corollae in Fritillaris.

6) nigro-punctata: Vaccinii Vitis Idaeae.

I千.

Nonnullorum vegetabilium folia autumnus rubro tingit colore, ut Rumicis; alia autem vegetabilia tota rubescunt: Angelica, Fagus, Beta, Amaranthus. Nimius etiam vel calor vel frigus, structura vasoram vitiosa, varia soli et situs ratio efficiunt, ut vegetabilia partim colorcm flavo-virentem, pallide-virentem aut saturate vireniem induant. Simili modo folii vel margo vel discus nonnunquam mutatur. Ejusmodi vegetabilia esse plerumque in statu praeternaturali solent, inde nec botanicum delcciant; hortulani vero, quibus ejusmodi variationes arrident, haec vegetabilin alunt, et iisque angendis operae nomilhil tribuunt. Folia margine flavo ornata: folia anrata; in disco flavo maculata: aureo-variegata; margine albo: argenteo J. albo-marginata; et maculis albis praedita: argenteo-f. albo-variegata dicuntur.

I5.

In vegetabilitus etiam Odor, vel quantum is varict, distingui solet; cum vero hac in re omnia sensu proprio nitantur, cumque in una eademque vegetabilinm specie odor non raro variet: aeque arduum est, ejus variationes accurate indicare, atque haud dubium ad vegetabilia recte definienda $a b$ eo signurn petere difficile est. In nonnullis tamen varietatibus ejus ratio habetur, et hinc variationes, quae sequuntur, distingui solent:

1) fragrans: qualis et Asperulae odoratae, Malvae
EINLEITUNG.

5) würflichtgefleckte (tessellata): Cymbidizur boreale Swartz (Cypripedium bulbosum L.) Satyriun repens-und die Blumenkrone bey Fritillaria.

6) schwarzt üpflicht (nigro-punctata): Taccinium Vitis Idaea.

Í.

Einige Cewïhse bekommen im Herbste rothe Blätter, als Rnmex; und andre werden bisweilen ganz rotl als Angelica, Fagns, Beta, Amarantluts. Zu grolse Hitze oder Kälte, fehlerbafter Bau der Gefäfse, verschiedener Boden und Lage, sind die Ursache wefshalb die Gewächse theils gelbgrïn, hellgrün oder dnnkelgrün werden. Durch ähnliche Zufälle wird bisweilen dcr Rand oder die Mitte des Blatts verändert. Dergleichen Gewächse befinden sich immer in einem widernatūrlichen Zustand, und haben daher für den Botaniker keinen Rieiz; die Gäriner aber, welche gerade an dergleichen Abänderungen Gefallen finden, nelumen sie in Schutz und suchen sie zu vermehren. Man nennt die Blätter, welche einen gelben Rand haben: vergoldete Blätter (Folia anrala); wenn sie in der Mitte gelb gefleckt sind: gelbbunte Blätter (folia anreo-variegala); wenn sie am Rande weifs sind: versilberte Blätter (folia argenteo-f. albo-marginata); und wenn sie weilse Flecke haben: weil's gefleckte Blätter (folic argenteo-s. albo-variegata).

15.

Man pHegt bey den Gewächsen auch den Geruch (Odor), oder die Verschiedenheiten desselben zu unterscheiden; da hier aber alles auf eigne Empfindung beruhet, und da bey einer und eben derselban Gewächsart der Geruch nicht selten Veränderungen unterworfen ist: so lassen sich eben so wenig die feinern Modifikationen desselben bestimmen, als es möglich ist von ilım ein festes Kennzeichen zur Bestimmung der Gewäclsse herzunehinen. Er kommt jedoch bei einigen Abarten in Betracht, und daher pflegt man folgende Verschiedenlieiten zu unterscheiden:

I) angenelı (fragrans): z. T. oemriner Wald- 
mosclatae, Lilii candidi, Resedae odoratae, Rosae centifoliae, Violae odoratae et plurimorum aliorum.

2) aromalicus: Lauri Cinnamomi, Eugeniae caryophyllatac, Myristicae moschatae et pl. al.

3) balsamicus: Vanillae aromaticae, Populi balsamiferae, Trifolii Meiloti ofricinalis, Tijymi vulgaris, Menthate crisjae, Pistaciae Terebintbi et pl. al.

4) acris: Iiutae graveolentis, Teucrii Mari, Cochleariae Armoraciae, Allii sativi et pl, al.

5) narcoticus: Daturae Metel, Croci satlvi et pl. al.

6) foetidrs: Gnaphalii foetidi, Sıapeliae hirsutac et pl. al. $\mathrm{Al}$ hoc sequentes adhuc distinguuntur:

7) cimicinus: Ribetis nigri.

3) lircinns: Hyperici lircini.

i) nanseosus: Olacis zeylanicae.

In accuratiore determinatione regetabilium odoris seçuimur similitudinem alius vegetibilis vel aliortim corporum olentium, et si observemus e. g. odorem vergerabulis alicujus frustantem similen esse Ambrac, Miosclib, Lilii, Resedae, Rosae vel Violae odori: dicimus

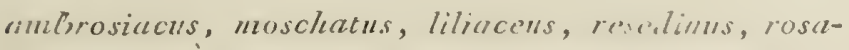
cens ves violacens etc. Simili mudu odur aromaticus, bals unicns, acris, narcoticus et focticlus quorue accuratius determinatur. meister Aspernla odorata, die Bisam-Pappel Malnn moscluata, die weilse Lilie, Lilium caudidmm, die Resede Reseda odorata, die Hose Rnsa centifolia, das Veilchen Viola odorata und mehrere andre.

2) gewürzhaft (uromaticus): Zimmt Laurus Cinnamomum, Nolken Engenia carjophyllata, Muskatennuís Myristica moscleata u. m. a.

3) balsamisch (balsaraicus): Vanille Fanilla aromatica, Balsam-Espe Populıs b.alsamifera, Steinklee Trifolium Melilotus afficiuclis, gemeiner Thymian Thymus vmlgaris, krause Mïnze Menthu crispa, Terpenthin'baum Pistacia Terebinthus, u. m. a.

4) scharf (acris): gemeine Raute Ruta graveolen, Katzenkraut Teucriun Marum, Meerrettig Cochlearia Armoracia, starkriecliender Lauch oder Knoblauch, Allimm sativmm, u, m. a.

5) betäubend (narcoticns): weifser Stechaffel Datara Metel, Safran Crocns suliuns u. m. a.

6) stinkend (foetidıs): stinkendes Ruhrkraut Gnaphalium foetidum, haarige Stanclie Stapelia hirsmta, und mehrere andere. Voll diesem unterscheidet man noch folgende als:

7) wanzig (cimicinns): schwarze Jolıannisbeere, Ribes migrmm.

8) bockig (lircinzs): stinkcndes Hartheu IIpericrme litrcinum.

9) ekel (numseosns): zeylonisches Stinkholz Olax seylanica.

Wenn man den Geruch eines Gervachses noch genauer bestimmen will, so muls man ilın mit dem eines andern Gewächses oder anderer riechbarcr Kürper vergleichen; und findet man alsdann, dafs z. B. der an gen el me Geruch cincs Gewächses dem des Ambers, des Moschus, dor Lilie, der Resede, der Rose oder des Veilchens ännich ist: so sagt man er ist a inberartig (aubrosiacns), moschusartig (mosclutns), lilicnartig (liliaceus), resedenartig (resedimms), rosenartig (rosaceus), oderveilchenartig (violacems) u. s. w. Auf äLnliche Art wird aucl der gewärzhafte, der C 2 
Odor fragrans, acris, narcoticus atque nauscosus cunt potius odoris effcctus, et, si examussim odoris consideremus, heic haud enumerandi essent; attamen melius foret, ob usum commune, horum denominationem ser. vare, effectumque pro cansa assumere, quam omnes omittere, rel seorsim sub effectibus odorum enumerare. Idem valet (\$. 16) de sapore adstringenti, nauscoso atque acri.

16.

Sapor quidem non magis, quam odor ad accuratan vegetabilium determinationem adhibere potest; cum vero in varietatibus nonnullis allegetur, hae ejus variationes, quae notentur, dignae sunt visae.

I) aquosus: qualis est Sempervivi tectorum et plurimorum vegetabilium succulentorum.

2) viscidns: baccarum Callae palustris.

3) dulcis: omnium fructuum dulcium, qui ad sacchari saporem accedunt.

4) salsus: Salicorniae herbaceae.

5) acidus: Rumicis Acetosae et omnium fructuum acidorum.

6) adstringens s. stipticus: Polygoni Bistortae et Tormentillae erectae radicis ut et omnium fructuum immaturorum.

7) nauseosus: radicis Polygalae Senegae et pl, al.

8) amarus: Absinthii vulgaris et pl. al.

9) acris: Sedi acris, Polygoni Hydropiperis, Alii sativi et pl, al. balsamische, der scharfe, der betäubende und der siinkende Geruch näher bestimmt.

Der engenehme, scharfe, betänben Je und ekle Geruch sind eigentlich nur Wirkungen deb Geruchs selbst, und dürften daher, wenn man es genau nelimen wollte, lier keinen Platz finden; da sie aber schon lange gebräuchlich sind, so ist es besser die Wirkung für die Ursache anzurelımen, als sie gänzlich pregzulassen, oder noch besonders als Virkungen aufzufülrcn. Eben so verhät es sich (\$. 16.) mit dem zusammenziehenden, ekeln und scharfen Gesclimack.

16.

Der Geschmak (Sapor) kann zwar eben so wenig als der Geruch zur genauern Bestimmung der Gewäclıse angnwandt werden; da er aber zuweilen bey einigen Abarten angeführt wird, so sind folgende Verschiedenheiten zu merken.

r) wässrig (aquosus): z. B. gemeine Hausivurz Sempervivum tectormm, und mehrere saftige Gewächse.

2) schleimig (viscidus, : die Beeren des gemeinen Schlangenkrauts Calla palustris.

3) sül's (dulcis): alle süfse Frïhte, die dem Geschmacke des Zuckers nahe kommen.

4) salzig (salsus): krautartiges Glasschmalz Salicornia lherbacea.

5) sauer (acidus): gemeiner Ampfer oder SauerAmpfer Rumex Acetosa, und alle saure Früchte.

6) zusammenzieh end (adstringens s. sipticns): die Wurzel des Wisen-Knüterigs oder der Natterwurz Polygonum Pistcria, der gemeinen Turmenille Tormentilla erecta, und alle unreife Früchte.

7) ekel (nanseosns): die IVurzel der virginischen Pelygala oder Senega Pulygala Senega u. m. a.

8) bitter (amarus): gemeiner Wermuth, Artemisia Absinthinm u. m. a.

9) scharf (acris): scharfes Sedum oder Manerpfeffer Sedmm acre, scharfer Knüterig oder Wasserpfeffer Polygonum Hydropiper, starkriechendes Lauch oder Knoblauch Allium saivum. 


\section{N T RODU C T I O.}

10) aromaticus: Lauri Cinnamomi, Eugeniae caryophyllatae, et pl. al.

II) balsamicus: Vanillae aromaticae.

Si saporem alicujus vegetabilis accuratius determinemus, fit hoc simili modo ut in odore, comparatione puta cum vegetabilibus vel aliis corporibus, quorum sapor non ignotus est.

\section{7.}

Inaequalis vegetabilium variorumque eorum partium longitudo nonnunquam rite est indicanda, ad eam. que probe dijudicandam sequentes mensurae adhibentur. (Tab. I. f. 37.)

I) Capillus: diameter capilli, vel pars lineae duodecima.

2) Linea: longitudo albi ad basin unguis digiti medii, vel pars duodecima unciae.

3) Uuğuis: longitudo ungnis digiti medii, rel uncia dinidia.

4) Pollex s. Uncia: longitudo phalangis extremae pollicis, rel pars duodecima pedis.

5) Palmus: diameter quatuor digitorum manus, rel tres unicae.

6) Dodians: quantum spatium extensi pollex et digitus minor complectuntur, vel novem unciac.

7) Spitlama: quantum pollex et digitus index, rel septem unciae.

3) Pes longitudo a cubito ad basin manus usque, vel duodecim unciae, ulna dinidia.

9) Cubitus: longitudo a cubito ad extremitatem digiti medii usque, vel septemdecim unciae.

10) Uina s. Brachium: longitudo totius brachii, veì virti quatuor unciae. ro) gewïrzhaft (aromaticus): Zimmt Laurtls Cinnamomum, Nelken Eungenia caryopluyllata n. n. a.

II) balsamisch (balsanicus): Vanille, Vanilla aromatica.

Wenn der Geschmack eines Gewächises noch genauer bestimmt werden soll, so geschieht dies auf ähnliche Art, wie bei dem Geruche, nemlich durch Vergleichung mit Gewächsen oder andern Kürpern von bekanntem Geschınacke.

17.

Die ungleiche Länge der Gewächse und ihrer verschiedenen Theile erfordert zuweilen eine genaue Bcstimmung, und dazu bedient man sicls folgender Mafse (Tab. I. f. 37.)

I) Ein Haarbreit (Capillus): der Durchmesser eines Haares, oder zwölfte Theil einer Linie.

2) Eine Linie (Linea): die Länge des Weifsen an der Wurzel des Nagels an Mittelfinger, oder der zwölfte Theil eines Zolls.

3). Ein Nagol lang (Unguis): die Länge des Nagels am Mittelfinger oder ein halber Zoll.

4) Ein Zoll (Pollex s. Uncin): die Länge des ersten Gliedes am Daum, oder der zwölfte Theil eines Fulses.

5) Eine Handbreit ( $P_{\text {ullmus }}$ ): der Durchmesser der vier Finger an der Hand oder drey Zoll.

6) Eine Spanne (Dodranls): so weit, als man mir dem Daum und dem kleinen Finger spanuen kann, oder neun Zoll.

7) Eine kleine Spanne (Spilleama): so viel als man mit dem Daum und dem Zeigelinger spannen kann, oder sieben Zoll.

3) Ein Ful's $\left(P_{e s}\right)$ : die Länge von Ellbogen bis an die Handwurzel, oder zwöif Zoll, eine halbe Elle.

9) Ein Vorderarm (Cubitus): die Linge rom Ellbogen bis an die Spitze des Nittelfingers, oder sicbzelın Zoll.

ro) Eine Eille (U'na s. Brachium): die Lünge des ganzen A:uns, oder vier und zwanzig Zoll. 
II) Orgya: longitudo utrinsque brachii extensi, ab altero digito medio ad altertim tisque, vel pedes sex.

I8.

Cum solo, situi, frigori, calori, ariditati et udori magnum sit imperium in vegetationem, ita ut vegetabilium forma exterior (lubitus) his rebus macnopere et mntari possit et mutetur; vegetabilia diligenter descripturum oportet eorum quoque Stationem indicare; et haec d(terminatux; I) Climate, 2) Loco, 3) Solo.

19.

Clime secundum varios poli latitndinis gradus determinatur, in quo tamen determinando ratio habenda est, montium, valium, fluviorum, paludum, sylvarum, marium et soli variabilis, haec enim vim alicpram in clima exserunt. His rite perpensis, vaiiorum climatum sex sequentia facile erunt clistinctione.

1) alpirnnn. In hemisphaera septentrionali in Europa a gradu octogesimo primo ad sexagesimum, inque Asia et America a gradu nouagesimo octaro ad quinquagesimum primum; in hemisphaera australi terras inter gradum quinquagesimum sextun et quinquagesimum sitas complectitur. Comprehendit summatim terras sequentes: Groenlandiam, Islandiam, Spitzbergiam, Novam Zemblam, Lapponiam, Sibiriaun borealem, Kamtsciatkan, Canadam, Terram Ignis vel Tierra del Fuego ab Hispanicis sic dictam, Patagonian, Falklandiae et Petri insulas, Novam Georgiam australem etc. Porro onmes montes alti totius terrae, quorum cacumina supra lineam nivosam geograplicorum sese toliunt ad id pcrinent. Aestas in hoc climate est brevissima, hiems contra acerrima. Plantae in eo crescentes apud nos sub divo proveniunt, hicme vero nive tegendac aliore modo mendac sunt.
II) Eine Klafter $\left(\operatorname{Orgy}^{\prime} \alpha\right)$ : die Länge der beyclen ausgestreckten Arme, von einem MLttelfinger bis zum andern, oder sechs Fufs.

I8.

Da Boden, Lage, Kălte, Hitze, 'Dürre und Nässe einen grofsen Enflufs auf die Viegetation haben, so dals dadurcb die äufsere Gestalt (Habitus) der Gewächse sehr verïndert werden kann; so ist es nüthig bey genaten Beschreibungen auch den Wohnort (Statio) der Gewächse anzuzeigen; und diesen bestimmt man: I) durch das Klima (Clima), 2) durch den Standtort (Locus), 3) church den Boden (Solumn).

Ig.

Das Klima (Clima) wird nach den verschiedenen Graden der Breite bestinmt, jedoch mufs man auch zugleich auf alle Umstände Rücksicht nelmmen, die auf dasselbe einen Einflufs haben, und dahin gehören Berge, Thäler, Flüsse, Sümpfe, Wälder, Meere und der abwechsehnde Boden. Zielnt man diese Umstände mit in Betracht, so lassen sich von den verschiedenen Klimaten folgende sechse sehr gut unterscheiden.

1) gebirgicht (alpinum). Es erstreckt sich auf der nördlichen Halbkugel in Europa vom ein und aclitzigsten bis zum sechszigsten Grade und in Asien und Amerika vom acht und neunzigsten bis zum ein und funfzigsten Grade; auf der südlichen Halblugel begrcift es die Länder in sich, die zwischen den sechs und funfzigsten und funfzigstén Grade liegen. Es enthält überhaupt folgende Länder, als: Grönland, Island, Spitzbergen, Nova, Zembla, Lappland, das nürdliche Sibirien, Kamtschatka, Canada, das Feneıland, Patagonien, die Falklandsinseln, Petersinseln, Nıu-Süd-Georgien, u.s.w. Ferner gchören dazu alle hohen Gebirge der ganzen Erde, deren Gijpel sich über die Schncelinie der Geographen erluben. Der Sommer ist in diesem Klima sehr kurz und der Winter aufsert strenge. Dic in demsellen wachsenden l'flanzen koinmen bey uns im Freyen fort, mëssen aber in Winter mit Sclnce bedeckt, oder auf eine andere 1 rt in Schutz gebracht werden. 
2) germanicunt. Omnes hemisphaerae septentrionalis terrae, quae in Europa inter gradum sexagesinum et quadragesimum sextum, inque $A$ sia et America inter quinquagesimum primum et quadragesimum sextum sitae sunt ad id referuntur; in hemis, haera australi a gradu quinquagesimo usque ad quadragesimum tertinm porrigitur. Terrae quas continet, sunt Anglia, Scotia, Hibernia, pars Galliae borealis, llollandia, Belgium foederatum, Germania tota, Dorussia, Polonia, Lithauania, Selesia, Dania, pars australis Norvegiae et Sueciae, Livonia, pars Russiae australis, Pensylvania, Virginia ete. Aestas et hicms in hoc climate temporis spatio fere sunt aequales et hiemis frigus mediocre. Plantae jus sub coelo nostro omnes proveniunt.

3) italicum. Terras in hemisphaera septentrionali inter rad um quadragesium sextum ct trigesimum quintum, inque australi inter quadragesimum tertium et trigesimum quintum, sitas complectitur, hae sunt: Lusitania, Hispania, pars Galliae australis, Italia, Sardinia, Sicilia, Graecia, insularum graecarum Archipelagus, Persiae, Pars Chinae et Japoniac, Carolina australis, Florida, pars Mexicani et Chilensis regni et. c. In hoc climate est hiems brevior et frigus mitius. Plantae lujus climatis aestate apud nos sub divo hospitantur et liveme frigidario frigus inodo arcente acquiescunt.

4) capense. Ad hoc pertinent Promontorium bonae spei ct montes in Nova Zeelandia, Botany-Bay et Peru. Plantae ex lıoc climate ortae apud nos aestate sub divo permanent, hieme vero aliquanto majorem calorem requirunt, plantis e praecedente climate ad nos allatis.

5) aegrpliacım. Terras in utraque hemisphaera inter gradum trigesiınum quintum et tropicos sitas con-
2) dentsch (germanicum). Auf der nürdlichın Halbkugel gchïren alle die Länder hieher, die in Europa zwischen dem sechszigten und sechs und vierzigsien, und in Asion und Amerika zwischen dem ein und funfziggsten und sechs und vierzigsten Grade liegen; auf der südlichen Halbkugel reicht es rom funfzigsten bis zun drey und vierziggstenGrade. Die Länder, die es in sich fafst, sind England, Sehottland, Irrland, der nördliche Theil von Frankrcieh, Holland, ganz Deutschland, PreuIsen, Polen, Lithauen, Schlesien, Dännemark, der südliche Theil von Norwegen und Schweden, Licfland, der südliche Theil ron Rufsland, Pcnsylvanien, Virginien u. s. w. Sommer und Winter sind in diesem Klima von ziemlich gleicher Dauer, und die Kälte des Winters ist viel erträglicher, als in dem vorhergehenden. Dic Pflanzen desselben kommen bey uns alle in Freyen fort.

3) italiensch (italicnm). Es begreift die auf dcr nördlichen Hälbkugel z:vischen dem sechs und vierzigsten und fünf und dreyfsigsten und auf der südlichen zwischen dem drey und vierzigsten und fünf nnd drejfigsten Grade licgenden Länder in sich, als: Portugal, Spanion, den südlichen Theil von Frankreich, Italien, Sardinien. Sicilien, Griechenland, den Archipelagus der griechischen Inseln, Persien, ein Theil von China, Japan, Süd-Carolina, Florida, ein Theil ron Mexiko, Chili u. s. w. In diesem Klima ist der Winter sehr kurz und die Kïlte unbedentend. Im Sommer stchen bey uns die Pflanzen dieses Klinas im Freyen und im Winter nelmmen sie mit dcm kalten Hause vorlieb, wo nur das Findringen dcs Frostes abgehalten werden darf.

4) kapisch (capense). Hierzu gehört das Vorgebirge der guten Hoffnung und die Gelirge auf NeulSeeland, Botany-Bay und Peru. Die aus diesem Kima herstammenden Pflanzen dauern den Sonmer über bey uns im Frejcn aus, verlangen aber im Winter etwas melır Wärme, als die aus dem vorhergehenden Klima.

5) ïgyptisch (acgjptiactnn). Diescs enthiilt die auf bejden Halbkugeln zwischen dem fünf und dreyfsigsten 
tinet, ut: Syriam, Aeggptum, Arabiam petracam, Californiam, Brasiliam, Novie Hollandıa partem et c. $\mathrm{Hi}$ ems hujus climatis frigore et aestas pluvia destituta est. Plantae ejus in regione nostra non nisi tempastate aestiva calidissina sub divo hospitari possunt, inderue reliquo anni tempore in caldario conserxandae sunt.

6) indicym. Omnes terrae inter aequatorem et

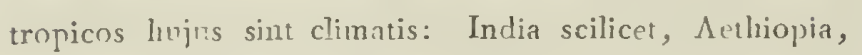
Mexicani regni pars maximn, Indiae occidertalis insulae, Brasilia, omnes insulae a sinu maris persici ad oceanum pacificum usque, pars Novae Hullendiae et c. In hoc con!o dies et noctes omni anni tempore sunt arquales; ct liemis vicem tempestas pluvialis sic dicta obit, aestas contra sine omni pluvia. Plantarum subier hoc coelo natarum in Aegsptum translatarum fiuctus non maturescunt, et apud nos, ipsa tempestate aestiva callidissima, sub divo nec stare licet, et omni anni tempore in caldario fovendae sunt.

In climatibus dividendis et denominandis aliognin ctiam quatuor mundi plagae fundamenti leco uti consuerunt; sed ea re terrae physica indole sua intcr se diversissimae consociantur, et non nisi relatione quadam nominari possunt, cum his semper loci, ubi vcrseris ratio sit habenda. In divisione hic data ex alio in aliud clima transitus reperitur, quod vero pro rerum statu aliter fieri non potest; et ubi, quaeso ccrtos naturae limites repereris?

20.

Locus et situ - pro eo videlicet, quod soli, ventis vel utrisque simul patet, vel minus - et pro soli uatura differt. Ejusque variationes sunt hae:
Grade und den Wendezirkeln liegenden Länder, als; Syrien, Aergypten, das steinigte Arabien, Californien, Brasilien, ein Theil von Neu-Holland u, s. w.. Der Winur ist in diesem Klima olıne Frost und der Sommer ohne Regen. Die PHanzen dieses Klımas künnen bey uns nur in den hellsesten Sommertagren im Freyen stellen, und mïssen daher in der äbrigen Zeit des Jahres in warmen Hanse erhalten werden.

6) indisch (indicum). Alle zwischen dem Aequator und den Wendezirkeln. liegende Länder gehören zu diesem Kliına, als: Indien, Aethiopien, der giöfste Theil von Mexiko, die westindischen Inseln, Brasilien, die ganze Inselgruppe vom persischen Meerbusen bis zum stillen Ocean, ein Tlıeil von Neu-Holiand u. s. w. In diesem Klima sind zu allen Zeiten Tag und Nacht glcich; und die Stelle des Winters vertritt die sogenannte Regenzeit, da hingegen der Sominer ganz ohne Regen ist. Die PHanzen dieses Klimas bringen, wenn sie in das ägyptische versetzt werden, ihre Früchte nicht zur Rieife, und bey uns können sie, selbst in den heifsesten Sommertagen, nicht im Frejen stebn, sondern müssen immer im warmen Hause bleiben.

Man pflegt sonst bey der Eintheilung und Benennung der Klimaten die vier Veltgegenden zum Grunde zu legen, aber dadurch werden Länder in ein Klima zusammengebracht, die ihrer plysischen Beschaffenheit nach sehr yerschieden sind, und die Benennungen kölnen auch nicht anders, als relativ ausfallen, da hier immer der Ort in Betracht kommt, wo inan sich befindet. Bey der hier gegebenen Eiutheilung finden sich zwar Ucbergange von einem Klima zum audern, aber dies kann auch den Umstänlen der Sache nach nicht anders séyn; und wo sind wolll scharfe Grenzlinien in der $\mathrm{Na}$ tur anzutreffen?

20.

Der Standort (Locus): ist theils der Lage nach - nemlich ob er melsr oder weniger der Sonne, den Winden oder beyden z!ngleich ausgesetzt ist - theils aber auch der Bescliaffenheit des Bodens verschieden. Es giebt folgende Verschiedenheitcn: 
I) Mare: boc habet peculiare, ut aquam salsam, aestuum accessu recessuque perpetuo motu constitutam, contineat.

2) Littora: littus maris sabulosum, sale inpraegnatum, ventis perflatum, interdum aqua maris irtiçatum.

3) Fontes: solum, ubi a natura collocati sunt, aqua pura frigida semper humidum servant, multarne propria vegetalilia alunt.

4) Fluvii: aquam puram vehunt, cirsu perpetuo agitatam et adeo profundam, ut eoruin fundus gelı adstringi non possit.

5) Lacus: quorum aqua quieta, pura, adeoque profunda est, ut gelu ad eorum fundum penetrare non possit.

6) Ripae: hieme sub aqua reconditae.

7) Stagna et Fossae: fundus iis Intosns, nec aqua tam profunda, ut gelu fundum attingere non possit.

3) Paludes: humo lutosa, laxa, repletae, acstate maximam partem siccantur, gelu hiemsli jenetrabiles.

9) Uliginosa: his solum est spongiosum, aqqua putrida repletum, aestate siccescens.

10) Cespitosne Paludes: solum earum est lutosum, humo et Sphagno putrido mixtum, tuberibus tectum, aquam lutosam recondens.

II) Inundata: loca hicme sub aqua recondita, aestate siccescentia et imbribus aqquam recipientia.

12) Alpes: omnes montes alti, quorum caenmina
I) das Meer (Mare): es hat das Eigenthünliche, dafs es gesalzenes Wasser enthält, welches durch Ebbe und Fluth in steter Bewegung erhalten wird.

2) der Seestrand (Littora): das sandige, rom Salze dutchdrungene Lfer des Meeres, das ron den Winden durchwehet und zuweilen rom Seewasser befeuclitet wird.

3) Quellen (Fontes): sie erlualten den Boden, wo sie sich finden, durch ein reines, kaltes Wasser, stets feucht, und führen viele ilınen eigenthünliche Gewäclıse.

4) Flüsse (Fluvii): führen ein reines Wasser, das durch ihren Strom in steter Bewegung und von solcher 'Tiefe ist, dal's der Frost nicht bis auf den Dodan dringen kann.

5) Seen (Lacus): ein stehendes, reines Wasser, das von solcher Tiefe ist, dafs der Frost niclit bis auf den Boden dringen kann.

6) Ufer der Flïsse und Seen (Ripae): sind im Winter mit Wasser bedeckt.

7) stchende Wasser und Graben (Stagna ot Fossae): sie haben einen schlammigen Boden und nicht so tiefes Wasser, dal's der Frost nicht den Grund erreiclıen künnte.

8) Sümpfe (Paludes): sind mit einem weichen Schlamme angefüllt, trocknen im Sommer gröl'stentheils aus und werden im Winter vom Froste durchdrungen.

9) Brüche (Uliginosa): haben einen scliwammigen, mit faulem Wasser erfüllten Boden, der in Sommer trocken wird.

10) Torfmoore (Cespisosae Paludes): ein morastiger, aus Dammerde und dem vermoderten Torfmoose gemischter, mit Hïgeln bedeckter Boden, der ein schiammiges Wasser unter sich verbürgt.

II) überschwemmte Örter (Inundata): Gegenden, dic im Winter mit Wasser bedeckt sind, im Somnner austrocknen und rom liegen wieder Wasser erhalten.

12) Alpen (Alpes): alle hohen Gebirge, deren Gipfel sich über die Region der Wolken erlieben, und, 


\section{EINLEITUNG.}

supra nubium regionem evecta, et, si non semper, maximam tamen anni partem, nive tecti.

13) Montes et Rolles: loca elata, pro soli indole magis minusve fertilia.

If) Rupes: loca elata saxosa, terra a Lichenibus et Muscis putridis relicta tecta.

15) Campi: loca sicca, libera, in quibus Musci, prae Graminibus proveniunt.

16) Ericeta: loca sicca, Iibera, arboribus destituta, Erica bulgari vestita.

Simili modo nuncupantur regiones regetabilibus unius generis vel fariliac naturalis obsitae, quae non sub No. 17, 13, 19, 20 et 21 militare possunt; linc dicumur loca alientia aıbores Artoreta, frutices Fruticeta, spinosa vegetabilia Dumeta, salices Saliceta, gramina Graminosa 'et c.

17) Sylvac: Ioca magna, arboribus frondosis et fohis acerosis instructis mixtim vestita, solo variabili.

18) Nemora; loca arboribus tantum frondosis ornata, praeditaque arbusculis et gramine laetiori.

19) Pineta: loca non nisi arboribus foliis acerosis instructis vestita, solo arenoso, arbusculis destituta.

so) Luci: sylvulae mixtae, arboribus truncis altis instructis, abusculis destitutae.

21) Prata: loca depressa, humida, aprica, fertilia, plantis luxuriania.

22) Pascua: differunt a pratis, quod steriliora, sicciora et mägis sunt sabulosa.

23) Agri: solum aratum, stercoratum. wo nicht immer, doch den gröfsten Theil des Jahres, mit Schnec bedeckt sind.

13) Bcrge und Hügcl (Monteśs et Colles): crhabene Gegenden, die nach Beschaffenheit ihres Bodens mehr oder weniger fruchtbar sind.

14) Fels en (Rupes); erhabene, steinichte Gegenden, die blofs mit der von den vermoderten Flechten und Moosen übriggebliebenen Erde bedeckt sind.

15) liclder (Campi): trockne, freye Gegenden, wo mehr Moos als Gras wächst.

I6) Haiden (Ericetr): trockne, freye, baumlose Gegenden, die mit Heidekraut bewachsen sind.

Auf ähnliche Art bezeichnet man anch die Gegenden die mit Gewàchsen aus einer Gattung oder aus einer natürlichen Fanilie bewachsen sind, und nicht zu No. 17, 13. 19, 20 und $2 x$ gerechuet wcrden können; Ocrter mit B.ımen betvachsen heifsen daher Baumplätze (Arboreta), mit Sträuchern Gestrüuche (Fruticeta), mit dorrigen Gewächsen Dornhecken (Dumeta), mit Veiden, Weidenplätze (Saliccta), mit Gràsern Grasplïtze (Graminosa) u. s.w.

17) Wälder (Sylvae): grolse, aus Laub - und Nadellıolze bestehende Gegenden mit abwechselndem Boden.

18) L a ubwälder (Nemora): blofs mit Laubholze bewachsene Gegenden, worin sich Unterholz und hohes Gras findet.

19) Nadelwälder (Pinetr): blofs mit Nadelholze bewachsene Gegenden mit sandigen Boden ohne Unterholz.

20) Haine (Luci): kleine, gemischte Wälder mit hochstämmigen Bäumen olıne Unterholz.

2I) Wiesen (Prata): niedrige, feuchte, der Sonne ausgesetzte, fruchtbare Gegenden, wo die Pllanzen sehr reichlich und schnell in. die Höhe wachsen.

22) Triften (Pascur): untcrscheiden sich von den Wiesen, dadurch, dafs sie trockner, unfruchıtbarer und melır sandig sind.

23) A ecker (Agri): umgepllïgtcr und gediingter Boden. 
24) Arva: agri quieti:

25) Versurae: solum inter agros quictum eosque dissepiens.

26) Cnlta: solum pinģue, sulsactum, stercoratum.

2-) Finnctu.

s0) Ruclerata: ad ea pertinent loca in pagis et juxta cos.

29) Fodinae: fodinae metallicae antiquac.

$2 \mathrm{I}$.

Solum in plantarum incrementum, quae maximam alimenti sui partem ex illo capiunt, maximam vim exe. rit. Illud vero, cum ex pluribus terris putridorumque animalium et vegetabilium reliquiis, quae in eo non semper aequali proportione adsunt, constet, maxime variat, et inde ob vegetabilium culturam, luijus variationes ratio maxime habenda. Nondum quidem a chemicis evictum datum est, unde minscujusque soli mixtio constet; externis tamen claracteribus ejus diversitates a botanicis, oeconomis et hortulanis admissas distinguere in fromtu est, eaeque sunt:

I) Solum alpinum. lliud oritur a putrifaclione foliorum Ericae vulgaris et ${ }^{-} \mathrm{L}$ jcopodii clavati. Nigrum, leve, et, quamvis maxime humectetur, semper solutum, nec unfyuam conglobatur.

2) Solum turfosum. Oritur a purefactione vegetabilium palustrium, praecipue Sphagni palustris. Nigrum est et satis solutum. A solo alpino differt, colherentia suo paulo majore, ab humo, eo, yuod minus facile conglobari se patitur.

3) Solum Lumnosmm f. IIumus. Oritur a perfecta 2f) Brachäcker (Arra): Ackcr, die unbearbcitet und unbebauet liegen blcilsen.

25) Ackerränder (Versurae): das Land, was zwischen den Äckern unbebauct liegen bleibt und dieselben unterscheidet.

26) Gartenland (Cultu): fetter umgegrabncr und gedüngter Boden.

27) Misthaufen (Fimera).

23) Schutthaufen (Ruderata): hierher gehören auch die Gegenden in und bey den Dörfern.

29) Gruben (Fodinae): alte Bergwerke.

$2 \mathrm{r}$.

Der Bodex (Soltum ) hat auf das Wachsthum der Pflanzen, die den grüfsten Theil ihrer Nahrung aus ihm erhalten, sehr grofsen Einflufs Er ist alser, da cr aus melireren Erden und Ueberbleibseln verwester, thierischer und vegetabilischer Substanzen bestehet, die sich nicht immer in gleichen Verlälınissen bey ilım finden, sehr versciecuén, und es ist dalier, besonders wegen der Kulur der Gewïchse, sehr nüthig, nuf diese Vèschiedcnhciten zu achicn. Man hat zwar noch nicl.t durch die Chemie bestimmt, woraus das Gemisch eincs jeclen Bodens besteht; indessen lassen sich doch nach den äufsern Kennzeichen die Verschiedenlıeiten desselben unterscheiden, die von den Botanisten, Ökonomen und Gärtnern angenommen sind, als:

I) Alpenboden (Solmm alpinum). Er entsteht durch das Verfaulen der Blätter des Haidekrauts Éricı vulgaris, und des Lycopodii clavati. Er ist schwarz, leicht und bleibt, wenn er auch noch so stark angcfeuchtet wird, immer locker und ballt sich niennals.

2) Torf-oder Sumplboden (Solum tmrfosmm). Dieser entstcht durch das Yerfaulen der Simpgewächse, besonders des Torfmooses, Splaggnum palnstre. Er ist schwarz und ziemlich locker. Von dem Npenboden unterscheidet er sich durch einen etwas stïrkerm Znsammenhang, und von dem Gartenboden dadurch, dafs er sich nicht so leicht ballen läßst.

3) Gartenboden oder Dammerde (Solnm lum-

$\mathrm{D} 2$ 
ex toto animalium vegerabilinmque putredine. Colore nigro est et facile conglobatu, qua re a solo alpino et turfoso maxime differt.

4) Solum argilacenn. In Statu humido, in quo color ejus magis minusve ex albo in coeruleum vergit, lubricum et molle tactu et firmissime cohaeret, ita ut in forman quolibet effingi possit. Ipso, quo siccatur, tempore in massam firmam durescit.

5) Solum lutosum. Colore luteo, in statu bumido lubricum et asperum contrectanti effertur, formari se patitur et ipso siccationi tempore in massam firman, friabiliorem tamen illa soli arigillacei, induratur. A solo argillaceo praecipue eo differt, quod majorem arenae copiam continet.

6) Solumb calcareum. Pro vario puritalis gradu magis minusve album est. In Statu humido conglobatur, et simul subasperum, nec vero lubricum tangenti apparet. Siccatum, nisi sua sponte resolvatur et diffluat, facillime friabile est.

7) Solum arenosum. Pro puritate sua magis minusque album est, nec aqua humectatum conglobari se patitur, eaque de re et parnm cohaeret. Distinguitur:

a) Arena stabilis, aliis terris praecipue humo commixta ;

b) Arena mobilis, aliis terris destituta, inde colaesione carens et vento dissipanda; et

c) Arena sabulosa, a fluviis ejecta, differt a praecedentibus, quod e granulis majoribus sit composita. mosim f. IIumus). Er entstehet durch die vüllig vollendete Verwesing thierischer und vegetabilischer Subsłanzen. Er ist von schwarzer Farbe und läfst sich sehr leicht ballen, wodurch er von dem Alpen - oder Torfboden anffallend verschieden ist.

4) Thonboden (Solum argillacerm). Im feuchten Zustande, wo seine Farbe aus dem Weifsen mehr oder weniger ins Blaue fällt, ist er schlüpfrig und sanft anzufühlen, und selir stark zusammenlangend. so dals man ihm jede beliebige Form geben kann. Beym Trocknen erhärtet er zu einer festen Masse.

5) Lehmboden (Solum lutosum). Er ist von gelber Farbe, im feuchten Zustande etwas schlüpfrig und scharf anzufühlen, läfst sich formen und ertärtet beym Trocknen zu einer festen Masse, die jedoch zerreiblicher ist, als die des Thonbodens. Von dem Thonboden unterscheidet er sich vorzüglich dadurch, dals er eine weit gröfsere Menge Sand enthält.

6) Kalkboden (Solum calcarenm). Dem verschiedenen Grade der Reinheit nach, ist er mebr oder weniger weifs. Im feuchten Zustande lïfst er sich ballen nnd ist dabey etwas scharf, nicht aber schlüpfrig anzufühlen. Nach dem Trocknen ist er, wenn er nicht von selbst zerfällt, sehr leicht zerreiblich.

7) Sandboden (Solum arenosumz). Er is seiner Reinhleit nach mehr oder weniger weifs, läfst sich durchs Anfeuchten mit Wasser nicht ballen, und bekommt dadurch auch nur einen sehr geringen Zusammenliang. Man unterscheidet:

a) stehenden Sand (Arena stabilis), der mit andem Erden, vorzüglich mit Dammerde gemischt ist;

b) Flugsand (Arenc mobilis), dem keine andre Erden beygemischt sind, weshalb or heinen Zusammenhang hat, und rom Winde umhergetrieben werden kann; und

c) Flulssand (Arena sabulosa), der von den Flüssen ausgeworfen wird, und sich von den vorhergehenden dadurch unterscheidet, dals er aus grübern Körnern besteht. 


\section{N T RODUCTIO.}

8) Solum parasiticum. Huc pertinent prae reliquis arborum trunci, rami ut et folia, quibus alia vegetabilia insident, et e quibus nutrimenti partem capiunt.

22.

Quum vegetabilia hoc illove vitae suae tempore observare necesse sit, variae et indigena et regiones frigidiores calidioresque incolentia colendi viae sunt in-ten, so hat man verschiedene Vorrichtungen getroffen, ventae. Institutum huic consilio respondens, Hortum sowohl die einheinischen Gewächse, als auch die der botanicnm nominant, quaeque is desiderat, ut imitetur kältern und wärmern Erdstriche zu cultiviren. Eine clima (\$. I9.), locum (\$. 20.), solum (\$.21.), haec sunt: Anstalt, die diesem Fintzweck entspricht, heifst ein b oHybermacuia, Aestivaria, Areae, Aggeres, Arbusta, tan ischer Garten (Hortus botanicus); und die Voret Aquaria,

23.

Iybernacula sunt aedificia verso ad melidiem pariete declivi fenestrali instructa, quibusque fornacium welche an der Mittagsseite mit einer einwärtslicgenden canalibus junctarum ope caloris gradus vegetabilibus in Fenstervand versehen sind, und durch öfen, die mit iis servandis aptus est. Plura continens scamna gradatim Canälen in Verbindung stehen, in einer solchen Temassurgentia, in quibus vegetabilia ollis insita collocata peratur erhalten werden können, die den in ilmen aufsunt. Ex vario corum caloris gradu, ex quo nominata zubewalurenden Gewächsen angemessen ist. Sie enthalsunt, distinguuntur:

I) Frigidarium, cujus caloris gradus secundum $R e$ anmnrnm unum ad quinque gradus efficit, vegetabilibus clima alpinnm, italicum, nec non pluribus capense incolentibus hybernaculum praebet. Exemplo sint: Rho- gen und italienschen, so wie auch mehreren des dodendrum ferrugineum, R. hirsutum, R. Chrysan- capischen Klimas zum Winteraufenthalt. Beyspiele thum, R. maximum, porro Olea europaea, Agave solcher Gewächse sind: Rhododendrum ferruginenm, americana, Punica Granatum, Citrus medica, C. Au- R. liirsutnm, $R$. Clırysantlum, R. maximum; ferner rantium; nec non species generis Oxalidis in Capite Olea enropaea, Agave americana, Punica Granabonae spei provenientes etc. ten mehrere, stufenweis sich erhebende Bänke, auf welchen die in Töpfen stehenden Gewächse gestellt sind Nach der verschiedenen Tcmperatur, von welcher sie auch ihre Nahmen erhalten, unterscheidet man folyende:

1) Das kalte $\mathrm{Haus,} \mathrm{oder} \mathrm{Orange-Haus} \mathrm{(Frigida-}$ rinm), dessen Temperatur nach Reaumur ein bis fünf Grade beträgt, dient den Gewächsen des gebirgi- . tun, Citrns medica, C. Aurantium; so wie auch die capischen Arten der Gattung Oxalis und mehrere dergl. 
2) Tepidarizın, cujus calor est graduun quinque

2) Das lauwarme Haus, oder Clashaus (Tepiad novem, et per hiemem plurima climatis capensis ve- darium), liat eine Temperatur von fünf bis neun Graden, getabilia refovet, nec minus multa in climate aegyptiaco und nimmt den Winter über die meliresten Gewächse des nata maximam anni partem alit. Exempli loco hic sunto: capischen Klimas auf, so wie es anch viele aus dem Olea capensis, species capenses genernm Proteae, Bank- ägyptischen Klima den gröfsten Theil des Jahres in siae, Bruniae, Diosmatis, Crassulae, Ericae, Mesembry- sich enthält. Als Beyspiele gehören hierher Olea capenanthemi et Aspalathi; porro Bruceae antidysentericae et sis, die capischen Arten der Gattungen Protea, Bankcomplurium aliarum.

sia, Brunia, Diosma, Crassula, Erica, Mesembryanthemum und Aspalathus; ferner Brucea antidysenterica und mehrere andre.

3) Caldarirm, cujus calor est graduum norem ad

3) Das warme Haus (Caldarium), welches eine Temtredecim, vegetabilibus in climate aegyptiaco natis ma- peratur von neun bis dreyzehn Graden hat, dient den ximam anni partem sedem praebet, et multis ex climate gröfsten Theil des Jahres zur Aufbewahrung der Gewächse indico ad nos allatis perpetto est domicilio. Huc nu- des ägyptischen Klimas, und ist auch der beständige merantur: Convolvulus brasiliensis, Achania Malvaviscus, Aufenthalt vieler Gewächse des indischen Klimas. Sida brasiliensis, porro Heliotropium indicum, Ficus in- Hierher gehören, Convolvulus brasiliensis, Achania dica et plura alia.

Malvaviscus, Sida brasiliensis; ferner Heliotropium indicum, Ficus indica und mehrere andre.

4) Fervidarium continet calorem graduum trede-

4) Das heifse Haus (Éervidarium) wird in einer cim ad septemdecim, in eoque plurima climatis indici Temperatur von dreyzehn bis siebzehn Graden erhalten, vegetabilia perpetuo commorantur. E. g. Saccharum und ist der beständige Aufenthalt der mehresten Gewächse officinarum, Eromclia Ananas, Tamarindus indica, Bixa des indischen Klimas. Beyspiele geben: Saccluarum Orellana et plura.

officinarum, Bromelia Ananas, Tamarindus indica, Bixa Orellana und mehrere.

Hic dictos caloris hybernaculorum gradus de hiemali tantum tempore, quo vegetabilium vegetatio sup. primenda potius, quam promovenda est, intellectos volo.

24

Aestivaria vegetabilia clinatum calidiorum recipiunt, enque sicut hybernacüla fenestris pro temporum ratione, vel aperiendis, vel claudendis instructa sunt. Distinguuntur:

1) Apricarium, cujus paries meridiei oppositus
Die lier angegebenen Grade der Temperatur dieser Winterläuser gelten blofs für die Zeit des Winters, wo das Vegctiren der Gewächse eler unterdrückt, als befördert werden muls.

24.

So mmerhäuser (Aestivaria) sind zum Sommeraufenthalt der Gewächse wärmerer Klimaten bestimmt, und so wie die Winterhäuser, mit Fenstern versehen, die nach Umständen geöfrnet und verschlossen werden können. Man unterscheidet folgende:

I) Das Sonnenhaus (Apricarium), dessen gegen aeque ac tecti pars fenestris constat, in hybernaculorum Mittag stehende Wand, so wie ein Theil des Daches, morem scamna gradatim assurgentia, quibus vegetabılia aus Fenstern besteht, enthält, so vie die Winterhäuser, o:lis insita insistunt, continet, et diebus aestivis calidi- stufenweis sich erhebende Bänke, auf welchen die Georiúus allatá ex climate aegyptiaco vegetabilia accipit, wächse in Töpfen stehen, und dient in den heifsen 
solis radiis aërique libero exponenda simulque ab im- Sommertagen zur Aufnalıme der Gewächse des ägyptíbribus et noctibus frigidioribus tuenda. sclien Klimas, um sie den Sonnenstrahlen und der freyen Luft auszusetzen, und zugleich vor Platzregen und kühlen Nächten schùtzen zu künnen.

2) Solariun est receptaculum humile ex quatuor

2) Das Sonnenbeet, oder Kühlbeet (Solarium) parietibus constructum (vulgo cista dictum), cujus tegu- ist ein niedriger, aus vier Wänden zusammengesetzter mentum meridiem versus declive fenestris constat et in Lehülter, (den man gewöhnlich Kasten nennt), dessen quo vegetabilia humo more solito parata inserantur et gegen Mittag abhängende Decke aus Fenstern bestelıt, aluntur. und in welchem die Gewïchse blofs in Gartenerde, die auf gewöhnliche Art zubereitet ist, gezogen werden.

3) Pulvillum a solario eatenus tantum differt, quod 3) Das Mistbeet (Pulvillum) ist vom Sonnensub humo stratum stercoris equini continet. Efficiendae becte blofs dadurch verschieden, dafs es unter der Erde seminum germinationi inservit. eine Lage von Pferdemist enthält. Man bedient sich seiner um das Keimen der Samen zu befürdern.

4) Vaporarium externa forma utrique jam descripto

4) Das Lohbeet (Vaporariumn) konmt dem Äussimile est, differt autem, quod in fundo stratum sterco- sein nach mit den beyden vorhergehenden überein, unris equini habet, cui cortex coriariorum superstratus est, terscheidet sich aber dadurch, dafs es auf dem Boden in quo vegetabilia ollis insita foventur. Non minus, eine Lage von Pferdemist enthält, worüber sich eine quam pulvillun seminum germinationem ndjuvat, ideo- andere Lage von Lohe befindet, in welcher die Geque eidem est usui ad calidiorum videlicet climatum wächse in Töpfen stehen. Es befördert, so wie das vegetabilia ex seminibus propaganda.

Mistbeet, das Keimen der Samen, und man gebraucht es daher auch in gleicher Absicht, nämlich die Gewächse warmer Klimaten aus Samen zu ziehen.

25.

Arene sunt soli divisiones sub divo quarum forma et magnitudo ab horti delineatione pendent. In minores vulgo diducuntur, Areolae seu Pnlvini dictas. Clima- des Gartens abhïngt. Man bringt sie gewöhnlich wietis germanici vegetabilibus, nec non calidiotum clima- der in kleinere Ablheilungen, und diese nennt man tum plantis annuis, quarum semina aestate nostra ma- $\mathrm{R}$ abatten (Areolae s. Pulvini). Sie sind für die Geturescunt, porro iis regitabilibus quae quidem aestatis wïchse des deutschen Klimas bestimnt, so wie auch tempore apud nos sub divo commorantur, ne vero ne- für die einjährigen Gewäclıse wärmerer Klimaten, die center hiemis tempore in frigidario collocando destinatae in unserm Sommer ihre Samen zur Reife bringen, fersunt. Sequentes distinguuntur: ner auch für solche, die bey uns zwar in Sommer im freyen Lande stehen künnen, im Winter aber ins kalte Haus gebracht werden müssen. Es lassen sich Solgende unterscheiden: 
1) Area annuorum continct vegetatilia, quae endem anno in flores induta fructusque enixa emoriuntur.

2) Area bienniunn vegetabilibus secundo demum anno flores et fructus proferentibus et tum emorientibus dicata est. Quae vegetabilia ut quotannis in flores se induentes videamus, binae sint areae, necesse est, alterno semper anno iisdem speciebus conserendae.

3) Area suffruticum, vegetabilia, quae ad radicem, perennem tamen, omni anno emoriuntur, recipit.

4) Area vernalis pariete ad septentrionem verso vegetabilibus scandentibus et iis vere florentibus destinatur.

5) Area aestivalis vegetabilibus alienigenis, non nisi aestate apud nos sub divo pernoctantibus, hieme autem in frigidario servandis commorandi locum concedit. Horum in numero sunt plures vegetabilium bulbosorum apud extcros natorum species.

6) Area autumnalis vegetabilibus alienigenis quae apud nos non aestate tantum, sed et vere et autumno nuda in solo undique patente vivunt, verum circa hie- nicht nur im Sommer, sondern auch im Frühjahr und mem muscis, foliis dejectis sinilibusqque tegenda sunt, Herbste unbeschuitzt im freyen Lande stehen können, sedem praebet.

26.

Aggeres sunt vel terra soia, vei terra et lapidibus congesti septentrioncm versus declives. Sequentes distinguendi sunt:

1) Agger rupestrium, terra et lapidibus coacervatus vegtabilia rupestria, excipit et sustinet.

2) Agger alpestrium sola terra constat, in eoque vegetabilia alpestria aluntur.
I) Das Sommergewächsbeet (Area annuorum) enthäh diejenigen Gewächse, welche in Einem Jahre Blumen und Früchte bringen, nachher aber absterben.

2) Das zweyjährige Gewächsbeet (Area bienninnn) ist für diejenigcn Gewächse bestimmt, welche erst im zweyten Jahre Blumen und Früchte tragen, und nachher absterben. Um diese Gewächse alle Jahre blühen zu sehen, werden zwey Beete gehalten, die man wechselweise, ein Jahr um das andre, mit eben denselben Arten besäet.

3) Das Staudengewächsbeet (Area suffruticum) nimmt die Gewächse auf, die eine bleibende Wurzel haben, aber alle Jahre bis auf dieselbe absterben.

4) Das Frühlingsbeet (Area vernulis) ist gegen Mitternacht mit einer Wand versehen, und dient zur Cultur der kletternden und der im Frühling blühenden Gewächse.

5) Das Sommerbeet (Area aestivalis) ist für fremde Gewächse bestimmt, die nur im Sommer bey uns im freyen Lande stehen kōnnen, im Winter aber im kalten Hause aufbewahret werden müssen, und wohin vorzüglich mehrere fremde $Z$ wiebelgewächse zu rechnen sind.

6) Das Herbstbet (Area autumnalis) ist zur Aufnahme fremder Gewächse bestimmt, die bey uns gegen den Winter aber mit Moos, Laub und dergleichen bedeckt werden müssen.

26.

Dämme (Aggeres) sind aus Erde, oder aus Erde und Steinen, gemachte Erhöhungen, die gegen Mitternacht abhangen. Es lassen sich folgende unterscheiden:

1) Der Felsengewächsdamm (Agger rupestrium), welcher aus Erde und Steincn besteht, und zur Cultur der Felsengewächse dient.

2) Der Alpengewächsdamm Agger alpestriuım), der blofs von Erde aufgeführt ist, und auf welchen die Alpengewächse cultivirt werden. 
27.

Arbusta sunt arbores et frutices consiti frigoris hiemalis apud nos patientes. Quae sunt:

I) Sylvula: locus arboribus et fruticibus consitus nullo ordine dispositis.

2) Quincunx: locus, in quo arbores lineis rectis rectangulariter se persecantibus justaque distantia consitae sunt.

3) Ambulacrum: via duabus arborum seriebus inclusa.

4) Sepes viva: frutices in lineam simplicem dense dispositi et plerumque soli divisiones finientes.

Hae arborum et fruticum colendorum consitiones vel Arbusta id insuper commodis habent, ut aliis simul vegetabilibus umbrarum amantibus et a vento tutandis locos (\$. 20.) exhibeant.

28.

Aquaria vegetabilia aquatica alunt et sustinent. Sequentia distinguuntur:

1) Aquariun fluviatile: fossa profunda aquae fluentis.

2) Aquarium lacustre: aqua stagnans fundi altioris.

3) Aquarium palustre: solum molle humo lutosa et aqua stagnante repletum, aestate non ex toto exsiccandum.

4) Aquarium uliginosum: solum, quod humo lutosa et aqua putri repletum, aestate exsiccatur.
27.

Gelı̈̈ze (Arbusta) sind Anpflanzungen ron Bäumen oder Sträuchern, welche die Kälte unsers Winters ertragen können. Hierher gelı̈ren:

1) Das Gebüsch (Sylvula): ein Platz, der mit Bäumen und Sträuchern so bepflanzt ist, dafs sich in Hinsicht der Stellung derselben keine Ordnung wahrnehınen lälst.

2) Die Plantage (Quincunx): ein Platz, auf welchem Bäume in rechtwinklich sich durchkreuzenden Linien in bestimmter Entfernung von einander angepflanzt sind.

3) Die Alle e (Ambulacrum): ein Weg oder Gang, der von zwey Reihen Bäumen eingeschlossen ist.

4) Die Hecke (Sepes viva): Sträucher, die dicht in einer einfachen Linie angepHanzt sind, und gewöhnlich zu Umgränzungen des abgetheilten Landes dienen.

Diese zur Cultur der Bäume und Sträucher bestimmten Anpflanzungen oder Gehölze, gewähren noch überdies den Nutzen, dafs sie zugleich Standörter (\$. 20.) für andre Gewächse abgeben, welche den Schatten lieben und vor den IVinden geschürzt seyn wollen.

20.

Wasserbelı̈lter (Aquaria) dienen zur Cultur der Wassergewächse. Es werden folgende unterschieden:

1) Der Canal (Aqutrium fluviatile): ein tiefer Graben mit fliefsendem Wasser.

2) Das Bassin (Aquarium lacustre): stehendes Wasser mit tiefem Grunde.

3) Der Sumpf (Aquarium palustre): weicher mit Schlamm und stehendem IVasser erfüllter Boden, der in Sommer nicht ganz austrocknet.

4) Der Bruclu (Aquarium uliginosum): mit Schlamm und faulem Wasser erfüllter Boden, der im Sommer austrocknet. 
29.

29 .

T'egetabile e pluribus partibus, iisque diversimode $D$ as Gewichs (Vegetabile) bestehet aus mehreren, formatis, quae in tanta specierum vegetabilium copia sub sehr verschieden gebildeten Theilen, die bey einer so diversissima rursus forma obviae sunt, componitur. Om- zahlreichen Menge verschiedener Arten wieder von sehr nes has partes variasque earum formas rite exprinendo mannigfaltiger Form vorkommen. Alle diese Theile und significare, ut singula vegetabilia accurate describere et die verschiedenen Formen derselben mit bestimmten ab omnibus ceteris jam notis distinguere possis, est ma- Ausdrücken zu bezeichnen, um jedes einzelne Gewächs teria, quam tractat, et in qua versatur finisque, quem genau beschreiben und von allen übrigen bekannten unintendit, lingua botanica seu terminologia. terscheiden zu können, ist der Gegenstand und der Zweck der botanischen Sprache oder Terminologie.

30.

30.

Ut omnes vegetabilis alicujus partes cognoscas, na- Ưm alle Theile eines Gewäclıses kennen zu lemen, turam ejus, tam internam, quaın externam spectes, ne- ist es nüthig, sowohl auf die innere, als äufsere Becẹse est; nec tainen structura ejus interna quoad termi- schaffenheit desselben zu sehen; jedoch bedarf in ternologiam, subtilem disquisitionem magnopere desiderat, minologischer Hinsicht die innere Beschaffenheit keiner sed strata diversemode se invicem circumdantia, ex qui- feinen Untersucliung, sondern es ist hinreichend, die bus radix, truncus et rami efficta sunt, distinguere satis verschiedenen, sich einander ungebenden Lagen zu unhabemus. Quae strata, quatenus consilii nostri est, pro- terscheiden, aus welchen die Wurzel, der Stamm und pius intueamur, idque ea serie, qua a parte externa in- die Äste gebildet sind. Wir wollen hier, in so weit es ternam versus sese invicem ambiunt. Vocantur ea, Epi- unser Zweck erfordert, diese Lagen näher betrachten, dermis, Cortex, Liber, Alburnum, Lignum et Medulla. und zwar in der Folge, wie sie sich von aufsen nach innen einander umgeben. Sie heilsen das Oberhäutchen (Epidermis), die Rinde (Cortex), der Bast (Liber), der Splint (Alburnumz), das Holz (Lignum) und das Mark (Medulla).

$3 \mathrm{I}$.

35 .

Epidermis est mənbrana tennis, omnes vegeta- Das Oberhäutchen (Epidermis) ist eine dünne bilis partes, stigmbts excepto obtegens. Truncoram quo- Membran, walche alle Theile des Gewächses — die rundam epidermis fibris transversis nec non pluribus Narbe ausgenommen - bedeckt. Bey einigen Stämmen stratis componitur, e. g. Betulae albae. Vegetabilia ac- besteht das Oberhäutchen aus Querfasern, und ist auch curate descripturus epidermidem, ejus superficiem (S.9.), wohl aus melıreren Lagen zusammengesetzt, wie z. B. et colorem (\$. 10.) describat, oportet. bey Betula alba. Bey genauen Beschreibungen mufs seine Oberlläche (\$. 9.) und Farbe (\$. Io.) angegeben werden. 
32.

Cortex non nisi arboribus et fruticibus proprius
32.

Die Rinde (Cortex), welche sich eigentlich nur et epidermidi subjectus, jam durior, jam minus darus, bey den Bäumen und Sträuchern findet, und unter dem siccus stratisque pluribus compositus est. Invenitur lae- Oberbäutchen liegt, ist unehr oder weniger hart, trokvis in Salice Caprca, rimosus in Acere platanoide, su-ken, und aus mehreren Lagen zusammengesetzt. Man berosus in Ulmo suberosa, variique coloris, maxime findet sie glatt (laevis) bey Salix Caprea, rissig (ritamen fusci, in vegetabilium descriptione secundum $\$$. mosus) bey Acer platonoides, korkartig (sulerosus) 10. pluribus describendi.

bey Ulmus suberosa, und von verschiedener, mehrentheils aber brauner Farbe, die in den Beschreibungen der Gewächse nach §. Io. näher bestinm werden mufs.

In plantis annuis corticis loco Cntis est, e multis vaBei den Sommergewächsen findet sich statt der Rinsis constructa, mollis et succosa. Quae ipsa cutis vascu- de die Haut (Cutis), welche sehr gefälsreich, weich umd losa et suffrutices obtegit, in quibus tamen, sicut arbo- saftig ist. Diese gefïlsreiche Haut ist auch bey den Stauribus et fruticibus accidit, in corticem nonnunquam mu- dengewächsen zugegen, wo sie sich aber zuweilen, so tatur. wie es bey den Bäumen und Sträuchern der Fall ist, in Rinde verwandelt.

33.

Liber non nisi arboribus et fruticibus proprius vasis mollibus succi plenis constat, et a vegetabili quotannis renovatur. Hiemis tempore in bina strata imparia chen Gefälsen, und wird von dem Gewächse alle Jahre diducitur, quorum alterum exterius tenuius est, interiore. erneuert. Zur Zeit des Winters thcilt er sich in zwey Exterins in corticen mutatur, et ex interiore indurato ungleiche Schichten, von denen die äufsere dïnner, als fit alburnum.

In regetabilibus herbaceis, quae liber deficit, caule in transversun dissecto, annulus vasculosus visui sese objicit; isque libri vicem obit.

34 .

Alburnum quoque in solis arboribus adest et fruticibus nec practer ignaun sic dictum molle, immaturum, quidquam alind est, ulterius indurando ligni soliditatem induit.

35.

Lig num sola duritie et densitate ab alburno dif-

33.

Der Bast (Liber), der nur bey den Bäumen und die innere ist. Die äufsere dieser Schichten verwandelt sich in Rinde, und aus der innern entstelıt durch Erhärtnng der Splint.

Bey den krantartigen Gewächsen, welchen der Bast mangelt, zeigt sich, wenn man den Stengel quer durchschneidet, tin Ring von Gefälsen; und dieser vertritt dic Stelle des Bastes.

\section{4.}

Der Splint (Alburnum) findet sich ebenfalls nur bey den Bïumen und Sträuclierı, und ist das sogenannte weiche odcr unreife Holz, was erst durch weitere Erhärtung zu festem Holze wird.

35 .

Das Holz (Iignum) ist blols durch mehrere Härtc fert. Fjus strata in traversum dissecto trunco annulos und Dichtigkeit vom Splinte verschieden. Die Lagen concentricos formant, qui tamen nostro sub coelo in dessclben bilden bey dem Querdurchschnitte des Stanparte septentrioni observa, quam huic contraria, ali- ınes concentrische Ringe, die jedoch in unserm Klima 
quanto sunt angustiores. Anniczbli vocantur, quod eo- an der gegen Mitternacht gckehrten Seite etwas enger, rum numerus quotannis uno augetur; caque re arboris als an der entgegengeselzten sind. Man nennt sie Jahractas indicari potest.

xinge (Anniculi), weil sich ilıre Zahl mit jedem Jahre um Eins vermehrt, und das Alter des Baumes dadurch bestimmt werden kann.

Vegetabilibus herbaceis, quae alburnum cum ligno Bey den krautartigen Gewächsen wo der Splint deficit, est Tela cellulosa jam densior, jam minus den- und das Holz fehlen, ist ein mehr oder weniger dichtes sa, quae est cutis subtilissima, cellulis, vel spatiolis, di- Zellengewebe (Tela celluloșa), eine sehr feine, in versissimae formae sejuncta, ea succi interdum plenissi- äufserst verschieden gestaltete Zellen, oder kleine Räuma, Parenclymma nominatur. In suftruticibus saepius me, abgetheilte Haut, vorhanden, welche zuweilen sehr indurescit, eaque re caulis lignosus evadit.

36. saftig ist, und alsdann Fleisch (Parencly'ma) genannt wirc. Bey den Staudengewächsen erhärtet dieses Zellengewebe öfters, wodurch alsdann der Stengel holzig wird.

\section{6.}

Mednlla est tela cellulosa suae indolis, prove-

Das Mark (Medulla) ist ein Zellengewebe eigner getabilium natura, cellularum, modo angustiorum modo Art, was nach Beschaffenheit der Gewïchse bald eng-, laxiorum, jam sicca, jam succosa niveoque candore, bald weitzellig, bald trocken, bald saftig ist, und sich spongiosaque substantia eminet. In medio trunco, cujus durch sein blendendes Weifs und durch seine schwamquasi axem constituit, invenitur, atque in arboribus et mige Substanz auszeichnet. Es findet sich in der Mitte fruticibus ligno, in vegetabilibus vero herbaceis tela cel- des Stammes, bei dem es gleichsam die Axe ausmacht, lulosa vel parenchymate includitur. In truncis lignosis und wird bey den Bäumen und Sträuchern vom Holze, saepius a ligno, cujus densitas identidem augetur, de- bey den krautartigen Gewächsen hingegen vom Zellenpellitur; et in vegetabilibus caule cavo, ut et in pluri- gewebe, oder vom Fleische, eingeschlossen. In holzigen bus aquaticis, omnino desideratur.

Stämmen wird es öfters durch das immer dichter werdende Holz verdrängt; und bei Gewächsen mit hohlem Stengel, so wie auch bei den mehresten Wassergewächsen, fehlt es gänzlich.

37.

37.

In exploranda vegetabilis alicujus natura externa

Bey Untersuchung der äufsern Beschaffenheit eines observamus, partem ejus alteram terrae vel solo insi- Gewächses wird man gewahr, dafs sich der eine Theil tam, alteram vero aëri libero expositam esse, et utram- desselben in der Erde, oder dem Boden, der andre que tam structura, quam situ differre. Illa Caudex aber in der Luft befindet, und dafs beyde in Hinsicht descendens, haec Candex adscendens salutatur. In ibrer Structur eben so verschieden sind, als in Hinsicht vegetabilibus quibusdam et tertia pars invenitnr, quae ihrer Lage. Jener heifst der niedersieigende Stock secundum structuram suam caudici descendenti, secun- (Candex descendens), dieser der aufsteigende dum situm vero adscendenti, vel vice versa, pro stru- Stock (Caudex adsccudens). Bey einigen Gewächsen ctura sua, adscendenti, et pro sisu, descendenti caudici findet sich noch ein dritter Theil, der seiner Structur annumeranda esset. Cum igitur ratione quadam huic, nach zum niedersteigenden, seiner Lage nach aber zum quadam vero illi conveniat, atque in vegetabilibus, qui- aufsteigenden, oder umgekehrt, seiner Structur ziach 
bus est, digna sit, quae distinguatur Caudicis interme- zum aufsteigenden und seiner Lage nach zum niederdiz nomine insignire eam liceat, steigenden Stocke gerechnet werden mïlste. Da er also in einer Hinsicht mit diesem, in anderer mit jenem übereinkommt, und bey den Gewächsen, wo er zugegen ist, unterschieden zu werden verdient: so will ich ihn mit dem Nalımen Mittelstock (Caudex intermedius) bezeichnen.

39.

Caudex descendens ea vegetabilis pars est,
38.

Der niedersteigende Stock (Caudex descenqua vegetabile lirmatur, eamque alimenti partem, qua dents) ist derjenige Theil des Gewïchses, wodurch dasad se explicandum et sustentandum indiget, a solo acci- selbe Befestigung und den Theil seiner Nahrung erhält, pit. Hae in eo partes, nec tamen omnes, nec eodem den es zur Entwicklung und Erhaltung aus dem Doden simul tempore notantur: Rhizoma, Fibrillae, Radicib- bcdarf. Es lassen sich an ihm folgende Theile, die jelae, Tuber, Bulbus et Soboles. doch nicht alle zu gleicher Zeit zugegen sind, unterscheiden; als: der Wurzelstock (Plizoma), die Wurzelfasern (Fibrillae), die Wurzelzasern (Radiculue), der Knollen ( $T u b e r)$, die Zwiebel (Bullus), und die Wurzelsprosse (Soboles).

39. 39.

Rhizoma est corpus jam magis, jam minus cras- Der Wurzelstock (Rhizóma) ist ein mehrodcr wesum, carnosum variae formae, quod plures annos con- niger dicker, fleischiger Kürper, von verschiedener tinuos unum pluraque Blastemata protrudit. Reperitur Form, der melirere Jahre nach einander Einen oder melsin plantis biennibus et suffruticibus, nec non in ipsis rere Keime (Blastentuta) hervorireibt. Er findet sich fruticibus et arboribus, in quibus lignosum et nunquam bey den zweyjährigen und Staudengewächsen, so wie non medullae ( $($. 36.) expers est. Quale est Dauco Ca- auch bey den Sträuchern und Bäumen, wo er holzig rotae (t. 2. f. I.) Bunio Bulbocastano (t. I.f.44.) Dictam- und jederzeit ohne Mark (6. 36.) ist. So selhen wir ihn no albo (t. I4. f. 4.), Polypodio vulgari (t.2.f.3.), plu- z. B. bey Dancus Carota (t. 2. f. r.), Duninun Bulboribusque aliis.

castanum (t. 1. f. 4千́). Dictamunus albus (t. I千́f. f. f), Polypodium vulgare (t. 2. f. 3.) und mehreren andern.

40. 40.

Filrilla e sunt corpora filiformia, modo magis, modo Die Wurz elf a sern(Fibrillae) sindfadenförnige, mehr minus flexuosa, quaetam in basicaudicis adscendentis, quam oder weniger gebogene Kürper, die sich sowohl an der in caudice intermedio (\$.37.) in rhizomate (\$ 39.), in tubere Basis des aufsteigenden Stockes, als auch an dem Mittel(\$.40.), et in bulbo (\$. 43.) reperies. In plantarum annuarum stocke (\$.37.), dem Wurzelstocke(\$.39.), dem Knollen (\$.42.) plurimis, in graminibus, in quibus candicem descenden- und an der Zwiebel (\$. \{3.) finderı. Beyden mehresten einjälıtem constituunt, caudici adscendenti immediale junctae rigen Gewächsen und bey den Gräsern, wo sie den niedersunt; e. g. in Panico glauco (t. 2. f. ro.). Idem in ve- steigenden Stock ausmachen, stehen sie unmittelbar amit getabilibus quibusdam tuberosis, ut in Panunculo Fica- dem aufsteigenden Stocke in Verbindung; z. B. bey $P_{a t}$ ria (t. 3. f. 10.), in Orchide Morione (t. 3. f. 13), plu- nicum glancun (t. 2. f. 10.;. Dasselbe findet auciı bey 
rimisque hujus generis speciebus obtinet. Caudici inter- einigen knolligen Gewächsen, als bey Ranunculus $F_{i-}$ medio adnatae inseniuntur in Ranunculo bulboso (t.7.f. 2 ) caria (t. 3. f. 10.), bey Orchis Morio (t. 3. f. 13.), und Rhizomati conjunctas videre licet in suffruticibus, e. g.in Bu- den mehresten Arten dieser Gattung Statt. Am Mittelnio Bulbocastano (t. I. f. 4f.), tubere adnexas, in Hemero- stocke finden sie sich bey Ranunculus bulbosus (t. 7. f. 2.) callide flava (t. r. f. 39.), et bulbo nunquam desunt. In ve- Am Wurzelstocke sehen wir sie bey den Staudengewächsen, getabilibus, quibus sunt radices fusiformes (\$. 45. B. 2. k.), z. B. Bunium Bulbocastanum (t. r. f. 44.), am Knollen, bey napiformes (\$. 45. B. 2. 1.) et tuberosae (\$. 45. B. 3.) Hemerocallis flava (t. 1. f. 39.), und bey der Zwiebel omnino interdum desiderantur. Exempla horun vegeta- fehlen sie niemals. Bey den Gewächsen mit spindelförbilium sunto: Daucus Carota (1. 2. f. I.), Pelargonium migen (\$. 45. B. 2. k.), rübenförmigen (\$. 45. B. 2. 1.) barbatum (t. 5. f. II.) et Neottia minor (t. 17. f. 5). und knolligen Wurzeln (\$. 45. B. 3.) vermifst man sie zuweilen gānzlich. Beysp̧iele solcher Gewächse sind: Daucus Carota (t. 2. f. I.), Pelargonium barbatum (t.5. f. II.) und Neottia minor (t. I7. f. 5.).

$4 \mathrm{r}$.

Padicula e sunt corpora subtilia, capillaria, tam
4I.

Die Wurzelfasern (Radiculae) sind feine, haartenera interdum, ut nudis oculis vix subjiciantur. Sunt förmige Körper, die zuweilen so zart vorkommen, dafs organa, quorum beneficio vegetabilia alimenta ex solo sie sich mit blofsen Augen kaum wahrnehmen lassen. exsugunt, ideoque nunquam desunt. In Scirpi acicula- Sie sind eigentlich die Organe, wodurch die Gewächse ris (t. 7. f. 6.), cujus caudicem descendentem formant, ihre Nahrung aus dem Boden hernehmen, und fehlen caudicis adscendentes basi conspiciantur, in Danci Caro- daher niemals. Bey Scirpus aciculuris (t. 7. f. 6.), wo tae (t. 2. f. I.) rhizomate, in Panici glauci (t. 2. f. 10.) sie den niedersteigenden Stock bilden, sieht man sie an fibrillis, et in Spiraeae Filipendulae (t. 3. f. 12.) tuberi- der Basis des aufsteigenden Stockes, bey Daucus Cabus observantur. rota (t. 2. f. I.) am Wurzelstocke, bey Panicum glantcum (t. 2. f. 10.) an den Wurzelfasern, und bey Spiraea Filipendula (t. 3. f. 12.) an den Knollen.

42.

42.

Tuber est corpus crassum, cârnosum forma rari- Der Knollen ( $T u b e r$ ) ist ein dicker, fleischiger um, quod unun pluraque emittens blastemata, nova Körper von verschiedener Forın, der, indem er Einen generis sui corpora - tubera nempe - gignit, et tum oder melırere Keime hervortreibt, neue Körper seiner emoritur. Id vel radiculis adhaeret, ut in Cypero escu- Art - nämlich Knollen - erzengı, und alsdann abstirbt. lento (t. 13. f. 3.), Solano tuberoso (t. 13. f. 3.) et Spi- Er hängt entweder an den Wurzelfasern, wie bey $C_{y-}$ raea Filipendula (t. 3. f. 12.); vel tuberi parenti, ex quo perus esculentus (t. I3. f. 3.), Solanum tuberosum ortum est, insidet, ut in Heliantho tuberoso (t. 16. f. 7.); (t. 13. f. 3.) und Spiraea Filipendula (t. 3. f. 12.); oder vel caudicis adscendentis basi immediate est conjunctun, er sitzt auf dem ältern Knollen, aus dem er entsprang, sicut in Asphodelo luteo (t. 4. f. 3.), Ranunculo Ficaria fest, wie bey Helianthus tuberosus (t. 16. f. 7.); (t. 3. f. In.) et in pluribus Orclidis gencris speciebus. oder ist unmittelbar mit der Basis des aufsteigenden Hic interdum aliqua illi cum rhizomate est similitudo, Stockes verbunden, vie bey Asphodelus luteus (t. 4. eatenus autem differt, quod non toti caudicis adscen- f. 3.), Ranunculus Ficaria (t. 3. f. 10.) und den meluredentis basi conjunctum est. Unum tantummodo blaste- sten Arten der Galling Orclis. Im letztern Falle hat 
ma continens, id vel ex apice superiore evolvit, id quod er zuweilen eine Ähniichkeit mit dem Wurzelstocke, in Orchide est, vel id, dum convertitur, et a planta unterscheidet sich aber dadurch, dafs er nicht unit der ganmatrice solvitur, ex inferiore producit, quod Asphode- zen Basis des aufsteigenden Stockes in Verbindung steht. lus luteus facit. Plura vero blastemata si continent, Wenn er nur Einen Keim enthält, so entwickelt er denhaec in tota ejus superficie progerminant quodammodo felben entweder aus seiner obern Spitze, wie bey Ordistantia, sicut in Solano tuberoso et Heliantho tubcroso clis, oder er bringt ibn, während er sich umwendet viderè est. und von der Mutterpflanze sich trennt, aus der untern hervor, wie bey Aspltodelus luteis. Enthält er aber mehrere Keime, so kommen diese auf seiner ganzen Obcrfläche in gewissen Entfernungen hervor, wie bey Solanum tuberosum und Helianthis tuberosus.

Sequentes tuberis species, quae distinguantur, digFolgende Arten des Knollens verdienen unterschienac sunt: den zu werden:

I) nudum: fibrillis nullis instructum; quale est So-

I) nackt (nudum): wenn er keine Wurzelfasern lani tuberosi (t. 13. f. 3.), Ranunculi Ficariae (t. 3. f. IU.) hat; z. B. Solanum tuberosum (t. I3. f. 3.), Ranuncupluriumque. lis Ficaric (t. 3. f. 10.) und mehrera andre.

2) fibrillatum: fibrillis obsitum; cujusmodi est $\mathrm{He}$ merocallidis flavae (t. 1. f. 39.), Asphodeli lutei (t. 4. f. 3.) et. pl. al.

2) wurzelfaserig (furillatum): wenn er mit Wrurzelfasern besetzt ist; z. B. Hemerocallis Rava (t. I. f. 39.), Asphodelus luteus (t. 4. f 3.) u. m. a.

3) laene: si neque eminentiae sint ipsi neque de-

3) glatt (laeve): wenn er weder Erhabenheiten pressiones; ut in Ranunculo Ficaria (t. 3. f. 10.), Orchi- noch Vertiefungen hat; z. B. Ranunculus Ficariu (t. 3. de Morione (t. 3. f. 13.), Neottia minore (t. 17. f. 5.) et f. 10.), Orchis Morio (t. 3. f. 13.), Neottia minor pl. al.

(t. 17. f. 5) u. a. m.

4) annulatum: in quo anruli vel eminentes vel de-

4) geringelt (annulatum): bey dem sich crlapressi conspiciuntur; quo spectant Iris pumila (t. 6. f.2.) bene, oder vertiefte linge zeigen; z. B. Iris punila et Cyperus esculentus (t. 13. f. 8)

5) subglobosum: quod vel magis vel minus ad globum accedit: quale est tuber Orchidis Morionis (t. 3 . f.' x3.), Saxifragae granulatae (t. 3. f. 20.).

6) oblongum: si diameter longitudinalis transver(t. 6. f. 2.) und Cyperus esculentus (t. 15. f. 3.)

5) kuglicht (suloglobosum): der sich mehr oder weniger der Gestalt der Kugel nähert; z. B. Orcliis Morio (t. 3. f. 13.), Saxifraga granulata (t. 3. f. zo.).

6) länglich (oblongum): wenn der Durchmesser salem superat; hoc in numero sunt Solanum tuberosum der Lïnge gröfier ist, als der Durclimesser der Quecre; (1. I3. f. 3.), Ranunculus Ficaria (t. 3. f. Io.).

7) obliqunm: oblongum et quasi oblique inversum: e. g. in Cypero esculento (t. I3. f. 8.).

8) napiforme: superne ventricosum, inferne autem in apicem longum excurrens; c. g. Hemerocallidis Havae (t. I. f. 39.).

z. B. Solanum tuberosum (t. 13. f. 3.), Ranunculus Ficaria (t. 3. f. 10.).

7) schief (obliqunun): der länglich und gleichsam etwas schief gebogen ist; z. L. (Yperus esculentus (t. I3. f.8.).

8) rübenfürmig (napiforme): wenn er oben bauchig ist, und unten in eine lange Spitze ausläaft; z. B. Hemerocallis fava (t. 1. 5. 39.)

9) elongatum: si longum, cylindraceum fere et in-

9) verlängert (elongalum): wenn er lang, fast $\mathrm{F}_{2}$ 
ferne in apice attenuatum est; ut in Asphodelo luteo walzenförmig und unten spitz zulaufend is:; z. B. As(t. 4. f. 3.).

10) cylindraceum: si cylindri formam refert; sicut Neottiae minoris (t. I\%. f. 5.).

II) sessile: si vel ipsi caudicis, adscendenti basi, pliodelus luteus (t. 4. f. 3).

Io) walzenförınig cylindraceum: wenn er die Gestalt einer Walze hat; z. B. Neottia minor (t. 17. f. 5.). II) sitzend (sessile): wenn er unmittelbar entweder vel tuberi parenti junctum est; tale habent Ranunculus mit der Basis des aufsteigenden Stockes, oder mit dem Ficaria (t. 3. f. I0), Helianthus tuberosus (t. I6. f. 7.).

I2) pendulum: fibrillis si adiaeret, ut in Cypero ältern Knollen verbunden ist; z. B. Ranunculus Ficaria (t. 3. f. 10.), Helianthus tuberosus (t. 16. f. 7.).

12) hangend (pendulum): wenn er an den Wuresculento (t. 13. f. 3.), Solano tuberoso (t. 13. f. 3.) Spi- zelfasern hängt; z. B. Cyperus esculentus (t. 13. f. 8.), raea Filipendula (t. 3. f. 12.).

Solanum tuberosum (t. 13. f. 3.), Spiraea Filipendula (t. 3. f. I2.)

\section{3.}

Bulbus est corpus ex squamis (t. 3. f. II.), vel membra-
43.

Die Zw i e b el (Bulbus) ist ein aus Schuppen(t. 3.f. Ir.), nis concentricis (t. 3. f. 18.), vel ctiam ex substantia so- oder concentrischen Häuten (t. 3. f. 18), oder auch aus lida, carnosa (t. 3. f. 15. I6. et t. 5. f.7.8.) constans, quod einer festen, fleischigen Substanz (t. 3. f. 15. 16. u. 4. 5. f.7.8.) blastema rhizomati insistens involvit, quod unum plures- bestehender Körper, der einen auf einem Wurzelstocke que annos continuos renovare potest et explicare, simul- stehenden Keim einschliefst, welchen er Ein, oder mehque vi gaudet, nova generis sui corpora - bulbos pu- rere Jahre nach einander erneuern und entwickeln kann, ta - procreandi. Bulbi structura non tantum a corpo- und dabey zugleich das Vermögen besitzt, neue Körris, rhizoma et blastema includentis differentia pendet, per seiner Art - nämlich Zwiebeln — zu erzeugen. sed pro vario quoque rhizomatis situ et ipsa variatur. Der Bau der Zwiebel hängt nicht nur von der VerschieRhizoma bulbi basin plerumcque constituit, tumque fi- denheit des.Körpers ab, welcher den Wurzelstock und brillae vel ad marginem superficiei inferioris in circulo den Keim einschliefst; sondern er richtet sich auch nach proveniunt, sicut in Allio sativo (t. 3. f. 17.), vel infer- der verschiedenen Lage des Wurzelstockes. Gewöhnlich ne ad ccntrum ejus in fasciculo apparent, quod in Col- macht der Wurzelstock die Basis der Zwiebel aus, und chico autumnali (t. 3. f. 15.) obtinet. In medio etiam alsdann kommen die Wurzelfasern entweder am Rande bulbo rhizoma invenitur, ubi fibrillis, ut solum pene- seiner untern Fläche in einem Kreise hervor, wie bey trent, corpus rhizoma circumdans perforandun est, id Allium sativum (t. 3. f. 1\%), oder sie zeigen sich unquod in Gladiolo communi (t. 5. f. 7. 8.) et Gladiolo ten am Mittelpunkte desselben in einem Büschel, wie hirsuto (t. 5. f. 5.) videre est. Et maxima rhizomatis bey Colchicum autumnale (1. 3 f. 15.). Ferner findet pars extra bulbum, idque infra eum, posita nonnunquam sich der Wurzelstock in der Mitte der Zwiebel, wo alsest, quod Gladiolus tubatus (t. 5. f. 6.) aperte monstrat. dann die Wurzelfasern, um in den Boden zu gelangen, erst den Körper, welcher ihn umgiebt, durchdringen müssen, wie bey Gladiolis communis (t. 5. f. 7. u. 8.) und Gladiolus hirsulus (t. 5. f. 5). Auch liegt zuweilen der gröfste Theil des Wurzelstockes aufserhalb der Zwiebel, und zwar unter derselben, wie bey Gladiolus tubains (t. 5. f. 6). 
Nonnulli bulbum e corpore solido constructum tuberibus adnumerant, quod quidem aegrius concesserim. Nam inter hujus bulbi speciei et tuberis structuram majus intercedit discrimen, quam ut illum huic conjungere liceret. Nec vero ab aliis bulborum speciebus disjungere fas est; alioque enim bulbi membranis con. centricis constantes ab his, qui ex squamis compositi sunt, distinguendi essent.

44.

Soboles est candicis descendentis productio, latera-
Einige rechnen die aus einem festen Kürper bestehende Z wiebel zu den Knollen, was aber wohl schwerlich zu billigen ist. Die Structur dieser Zwiebelart ist zu auffallend von der des Knollens verschieden, als dafs sie mit ihm vereinigt werden könnte. Ueberdies aber darf sie auch niçt von den übrigen Zwiebelarten ge. trennt werden; denn sonst würden auch die, welche aus concentrischen Häuten bestehen, von denen, die aus Schuppen zusammengesetzt sind, unterschieden werden müssen.

44. Die Wurzelsprosse (Soboles) ist eine seitwärts liter oriens et horizontaliter sub terra prorepens, ex entsteliende, in horizontaler Richtung unter der Erde eaque productione blastemata individuis procreandis ex-fortlaufende Verlängerung des niedersteigenden Stockes, plicantur. Aperte monstrant Aegopodium Pogagraria aus welcher sich Keime zu neuen Individuen entwik(t. ı. f 7. a.), Triticum repens, Carex arenaria et plu-keln. Wir sehen sie bey Aegopndium Pogagraria ra alia. Vegetabilia, quibus sunt soboles, rhizomate (t. Io. f. \%. a.), ferner bey Triticum repens, Carex plerumque destituta, at vero perennia sunt, quod ha- arenaria und mehreren andern. Gewächse, bey welrum sobolium beneficio propagantur.

45. chen sich Wurzelsprossen finden, haben gewöhnlich keinen IVurzelstock, dauern aber mehrere Jahre, weil sie sich durch diese Wurzelsprossen fortptlanzen.

45.

Caudex descendens (\$. 38.), cujus partes (\$.39-4千.) Der niedersteigende Stock (\$. 38.), dessen Theile cognoscimus, in vegetabilium descriptionibus $R a d i x$ di- wir ( $(5.39-44$ ) kennen gelernt haben, wird in den citur. Varias radicis species rite explicaturus, et quoad Beschreibungen der Gewäclıse Wurzel (Radix) gedurationem et quoad structuram observare necesse ha- nannt. Um die verschiedenen Arten der Wurzel richbet; et hae, quae sequuntur, distinguendae sunt.

tig auseinander zu setzen, ist es nüthig, sie sowohl narh ihrer Dauer, als auch nach ihrer Structur zu betrachten; und alsdann lassen sich folgende unterscheiden:

\section{A. Radicum species respectu durationis.}

A. Arten der Wurzel in Rücksicht der Dauer.

I) arınua: quae anno primo, fructu ad maturitatem perducto, emoritur. Fxemplo omnia regetabilia annotina sunt.

2) biennis: quae anno secundo, prolatis a vegetabili floribus et fructibus occidit, quod in omnibus plantis biennibus apparet.

3) perennis: quae plures annos permanct, quod suffruticibus, fruticibus et arboribus contigit.
1) einjährig (annua): die im ersten Jahre, nachdem das Gewächs seine Früchte zur Reife gebracht hat, abstirbt. Beyspiele geben alle einjährige Gewächsc:

2) zweijährig (biennis): die erst im zweyten Jahre, wenn das Gewächs Blumen und Früchte gebracht hat, abstirbt, wie bey allen zweyjullrigen Gewäclssen.

3) ausdauernd (perennis): die viele Jahre bleibt, wie bey den Staudengewächsen, Sträuchern nnd. Büımen. 


\section{B. Radicum species respectu structurae.}

I) fibrillata: si. caudex descendens rhizomate ( $($. 39.) destitutus est, ideoque solis fibrillis $(\zeta .40$.$) constat. Ve-$ getabilia, quibus ea est, omnia sunt annua, exceptis soboliferis, in quibus quotamnis renovatur. Ea est:

a) filiformis: una tantum fibrilla praesente; exemplo est Lepidium alpinum (t. 4. f. 2. b.).

b) fibrosa: quae pluribus fibrillis constat; huc spectat Panicum glaucum (t. 2. f. Io.).

c) capillaris: si fibrillae, e quibus constat, teneriores sunt, vel si solis radiculis ( $\$ .4 \mathrm{I}$.) constare videtur; exemplo est Scirpus aciculäris (t. 7. f. 6.).

d) sobolifera: si soboles ( 5.44 ) agit; qualis in Aegopodio Podagraria (t. 10. f. 7.).

e) caudiciformis : si caudex descendens non omnino in fibrillis dividıtur, sed corpus rhizomati simile format, unum tantummodo annum perdurans; ut in Ocimo minimo (t. I5. f. 2. a.) Mercuriali annua et pl. al.

2) rhizomatoidea: si caudici descendenti rhizoma (§. 39 ) est. Plures ea annos durat et structura admodum variat, atque est:

\section{a. Secundum substantiam.}

a) lignosa: quae ligno solido constat; e. g. arborum fruticumque radices.

b) carnosa: cujus substantia carnosa est; huc spectant Daucus Carota, Apium graveolens et pl. al.

c) cava: cujus rhizomatis pars media cava est; quod Fumaria cava (t. 2. f. 7 et 8.) aperte monstrat.

d) loculosa: si rhizoma longum in se medio ca-
B. Arten der Wurzel in Rücksicht der Structur.

1) f a dig (fibrillata): wenn der niedersteigende Stock keinen Wurzelstock (\$. 39.) hat, und also blofs

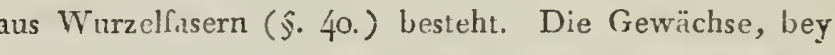
denen sie sich findet, sind jederzeit einjährig, die sprossenden ausgenommen, wo sie alle Jahre erneuert wird. Sie ist:

a) fadenförmig (fliformis): wenn nur eine Wurzelfaser vorhanden ist; z. B. Lepidizım alpinum (t. 4. f. 2. b.).

b) faserig (fibrosa): die aus mehreren Wurzelfasern besteht: z. B. Panicum glaucum (t. 2, f. 10.).

c) haarfaserig (cmpillaris): wenn die Wurzelfasern, woraus sie besteht, sehr feind sind, oder wenn sie blofs aus Wurzclfasern (\$.4I.) zu bestehen scheint; z. B. Scirpus acicularis (t. 7. f. 6.).

d) sprossend (sobolifer $(a)$ : wenn sie Wurzelsprossen (\$. 44.) treibt; z. B. Aegopodium Podagraria (t. 10. f. 7.)

e) stockartig (caudiciformis): wenn der niedersteigende Stock sich nicht völlig in Wurzelfasern zertheilt, sondern einen wurzelstockähnlichen Körper bildet, der aber nur Ein Jahr dauert; z. B. Ocimum minimum (t. I5. f. 2. a.) Mercurialis annua u. a. m.

2) wurzelstockig (rlizomatoidea): wenn der niedersteigende Stock einen Wurzelstock (\$. 39.) hat. Sie dauert mehrere Jahre, und ist ihrer Structur nach sehr verschieden, als :

\section{«. Nach der Substanz.}

a) holzig (lignosa): die aus festem Holze besteht; z. B. die Wurzeln der Bäume und Sträucher.

b) fleischig (carnosa): die aus einer fleischigen Substanz besteht; z. B. Daucus Carota, Apium graveolens u. a. m.

c) hohl (cava): deren Wurzelstock in der Mitte hohl ist; z. B. Fumaria cava (t. 2 f. 7. u. 8.).

d) fächerig (loculosa): wenn ein langer Wur- 
vum habet, secundum longitudinen septis transversis in plures loculos divisum; exempli loco est Cicuta virosa (t. 7. f. 3.).

e) solida: cavo destituta et antedictis duabus contraria.

\section{B. Sectundum figuram.}

f) praemorsa: si rhizoma praemorsum quasi videtur; e. g. in Plantagine majore (ङ. 2. f. 9.).

g) comosa: parte rhizomatis superiore propter ea, quae a siccatis foliis radicalibus remanserunt, pilorum fasciculi quasi faciem referente; exemplo esse possunt Aethusa Meum (t. 6. f. 4.) et plures Uimbellatae.

h) vermicularis: cujus rhizoma vermis more incurvatum est; quod polygonum Bistorta (t. 8. f. 4. a.) aperte ostendit.

i) cylindracea: rhizomate ad cylindri formam accedente; huc in numero est Dictamnus albus (t. 14. f. 4.).

k) fusiformis: cujus rhizoma superne crassum, inferne vero in apicem excurrit. Ea plerumque biennis, perpendicularis et fibrillis destituta est; videantur Daucus Carota (t. 2. f. I.) Pastinaca sativa, et plures Umbellatae.

l) napifornis: si rhizoma superne ventricosum, inferne autem in acumen longum desinit; videatur Pelargonium barbatum (t. 5. f. II.).

m) globosa: rhizomatis forma ad globum propius accedente; adeantur Clajtonia virginiana (t. I. f. 46.) Raphanus sativus var. $\alpha$. (t. 6. f. 3.).

n) bulbiceps: si vegetabili caudex intermedius ( $\$$. 37 et 46.) est, qui ob dilatatam foliorum basin bulbi formam induit et non nisi ex basi sua fibrillas protrudit; exempli loco esse potest Ranunculus bulbosus zelstock in der Mitte eine Höhlung hat, die der Länge nach durch Scheidewände in melırere Fächer abgetheilt ist; z. B. Cicuta virosa (t. 7. f. 3.).

e) fest ( solida): die keine Höhlung hat, als Gegensatzt der beyden vorhergehenden.

B. Nach der Gestalt.

f) abgebissen (praenorsa): wenn der Wurzelstock wie abgebissen aussiclıt; z. B. Plantago major (t. 2. f. 9.).

g) schopfartig (comosa): wenn der obere Theil des Wurzelstockes durch die Überbleibsel der vertrockneten Wurzelblätter das Ansehen erhält, als ob er mit einem Büschel von Haaren besetzt wäre; z. B. Aetlunsa Menn, (t. 6. f. 4.) und mehrere Doldengewächse.

b) wurmförmig (vermicılaris): deren Wurzelstock wie ein Wurm gekrünmt ist; z. B. Polygontum Bistorta (t. 8. f. 4. a.).

i) walzenförmig (cylindracea): wenn sich der Wurzelstock der Figır der Walze nälıer; z. B. Dictamnus albus (t. I千́. f. 4.).

k) spindelförmig ( (nsiformis): deren Wurzelstock oben dick ist, und nach unten spitzig zuläuft. Sie ist fast jederzeit zweyjührig, senkrecht und ohne TVurzelfasem; z. B. Daucis Carota (t. 2. f. r.) $\mathrm{Pa}$ stinasa saiva und mehrere Doldengewïchse.

1) rübenförmig (napifornis): wenn der Wurzelstock oben bauchig ist, und nach unten in eine lange Spitze ausläuft; z. B. Pelargoninm barbatmm (t. 5. f. II.).

m) kugelrund (globosa): wenn die Gestalt des Wurzelstockes der der Kugel nahe kommt; z.B. Claytonia virginiana (t. I. f. 46.) Raphanus sutivias var. a. (t. 6. f. 3.).

n) zwiebelköpfig (bulliceps): wenn das rewächs eincn Mittelistock ( $\$ .37$ u. 46.) hat, der durch die erweiterte Basis der Blätter eine zwichelartige Gestalt bekommt, und blols aus seiner Basis Wurzelfit- 
(t. 7. f. 2.) Avena bulloosa (t. I3. f. I), Phleum nodosum et pl. al.

o) subrotunda: si rhizoma crassum et quodammodo gibbosum est, simul vero jam magis, jam minus ad formam subrotundam accedit; quod Bunium Bulbocastanum (t. I. f. 44.) clare indicat.

p) placentiformis: si rhizoma crassum, rotundum et vehementer depressum est; haec monstrant Cyclamen hederaceum (t. 8. f. r.) Cyclamen europaeum (1. 8. f. 2. a.).

q) nodosa: si rhizoma longum et pluribus prominentiis subrotundis quasi nodosum est; exemplo est Convallaria rnultiflora (t. 4. 5. 6.).

r) geniculata: si rhizoma ex articulis regularibus, inter quos fibrillae proveniunt, constructum est; exempli loco est Gratiola officinalis (t. 4. f. 47.) Hippuris vulgaris et pl. al.

s) squamosa: cujus rhizoma sqamis tectum est; videantur Dentaria bulbifera (t. 4. f. I. c.) Lathraea Squamaria et pl.

t) dentata: in cujus rhizomatis superficie eminentiae dentatae adsunt; exemplo est Ophrys Corallorhiza (t. 3. f. 9.).

\section{$\gamma$. Secundum divisionem.}

u) simplex: rhizomate ramis carente; videantur Convallaria multiflora (t. 4. f. 6.) Reseda Luteola (t. 2. f. 2.).

v) ramosa: ubi rhizoma in ramos dispergitur; ut in Malva rotundifolia (t. 2. f. r2.).

w) multiceps: superiore rhizomatis parte gemmas emittente, e quibus in ramos adscendentes productis, anno futuro caudex adscendens prodit; exempli loco sunt Potentilla alba (t. ro. f. Io, a.), Erigeron uniflorum (t. I. f. 43.), Statice Armeria et pl. al. sern treibt; z. B. Fianunculus lulbosus (t. 7. f. 2.), Avena bulbosa (t. I3. f. r.), Phleum nodosum u. m. a.

o) rundlich (subrotnnda); wenn der Wurzelstock dick und etwas höckerig ist, dabey aber mehr oder weniger einer rundlichen Gestalt sich nähert; z. B. Bnninm Bulbocastannm (t. r. f. 44.).

p) kuclienförmig (placentiformis): wenn der Wurzelstock dick, rund und stark nicdergedrückt ist: z. B. Cyclamen hederacenm (t. 8. f. 1.) Cyclamen europaeum (t. 8. f. 2. a.).

q) knotig (nodosa): wenn der Wurzelstock lang und durch mehrere rundliche Hervorragungen gleichsam knotig ist; z. B. Convallaria multiflora (t. 4. f. 6.).

r) gelenkig (geniculata): wenn der Wurzelstock aus regelmäfsigen Gliedern, zwischen welchen Wurzelfasern liervorkoummen, zusammengesetzt ist; z. B. Gratiola officinalis (t. I. f. 47.), Iippuris vulgaris u. m. a.

s) schuppig (squanosa): deren Wurzelstock mit Schuppen bedecht ist; z. B. Dentaria bulbifera (t. 4. f. 1. c.) Lathraea Squamaria u. m.

t) gezähnt (dentata): deren Wurzelstock auf seiner Oberfläche zahnförmige Erhabsnleiten hat; z. B. Ophry's Corallorhiza (t. 3. f. 9.).

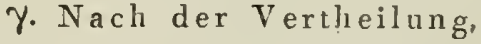

u) einfach (simplex): wenn die Wurzel keine Äste hat; z. B. Convallaria multifora (t. 4. f. 6.) Reseda Lnteola (t. 2. f. 2.).

v) ästig (ramosa): wo sich der Wurzelstock in Äste zertheilt; z. B. Malva rotundifolia (t. 2, t. 12.).

w) vielköpfig (multiceps): wenn der Wurzelstock an seinem obern Theile Knospen treibt, die sich in aufsteigende Äste verlängern, aus welchen im künftigen Jahre der aufsteigende Stock hervortritt; z. B. Potentilla alba (t. Io. f. Io. a.) Erigeron uniAorum (t. I. f, 43.) Statice Armeria u. m. a. 


\section{TERMI NOL O G IA.}

\section{ঠ. Secundum directionem.}

x) perpendicularis: si rhizoma perpendiculariter in terram penetrat; videatur Reseda Luteola (t. I. f. 2.).

y) obliqua: si rhizoma diagonaliter directum inter lineam perpendicularem et horizontalem in terram intrat; ut in Aethusa Mco (t. 6. f. 4.).

2) horizontalis: cujus rlizoma horizontaliter iii terra positum est; quod Polypodium vulgare (t. 2. f. 3.), Convallaria multiflora (t. 4. f. 6.) aperte monstrant.

aa) repens: rhizomate sub terra prorepente et ubique gemmas agente; videatur Rumex Acetosella (t. 2. f. I3.).

\section{Secundum superficiem.}

b) laevis: si rhizomatis superficiei nec prominentiae nec depressiones sunt; exemplo sit Malva rotundifolia (t. 2. f. 12.).

cc) annulata: rhizomatis superficie annulos prominentes vel depressos circum circa habcnte; videatur Polygnnum Bistorta (t. 8. f. 4. a.).

dd) tuberculata: si in rhizomatis superficie plura tubercula apparent; Aethusa Meum (t. 6. f. 4.) ostendit.

ee) paleacea: rhizomatis superficies si squamis paleaceis tecta est; exemplum praebet Polypodium vulgare (t, 2. f. 3.).

ff) cicatrisata: si caudex adscendens emortuus basin suam in superficie rhizomatis relinquit. Talis in Filicibus pluribus atque variae quidem formac apparet; ut in Polypodio vulgari (t. 2. f. 3.), Adianto albicante Plum. fl. t. g6. (t. 6. f. 6.), Danea alata (t. 6. f. 5.).

3) tuberosa: si in caudice descendente tubera (\$.42.) inveniuntur. Fibrillis semper instructa est, haeque vel ip̣sis tuberibus vel caudicis adscendentis basi insident.

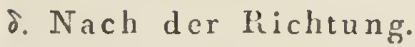

x) senkrecht (perpendicularis): wenn der Wurzelstock senkrecht in die Erde geht; z. B. Reseda Lutenla (t. I. f. 2.).

y) schief (obliqua): wenn der Wurzelstock in diagonaler Richtung zwischen der senkrechten und wagerechten Linie in die Erde geht; z. B. Aethusa Merm (t. 6. f. 4).

z) wagerecht (horizontalis): deren Wurzelstock wagerecht in der Erde liegt; z. B. Polyporlium vulgare (t. 2. f. 3.), Convallaria multiflora (t. 4. f. 6.).

aa) kriechend (repens): wenn der Wurzelstock wagerecht unter der Erde fortgeht und überall Knospen hervortreibt; z. B. Rumnex Acetoselliz (เ.2. f. 13.).

๕. Nach der Oberfläche.

bb) glatt (laevis): wenn die Oberfläche des TVurzelstockes weder Erhabenheiten noch Verliefungen hat, z. B Malva rolundifolia (t. 2. f. 12.).

cc) geringelt (ambulata): wenn die Oberflïche des Wurzelstockes riugs herum erhabene oder vertiefte Pinge hat; z. B. P'olygontm Bistorta (t. 8. f. 4. a.).

dd) hückerig (tuberculata): wenn sich auf der Oberfläche des Wurzelstockes mehrere kleine Höcker zeigen; z. B. Aerhusa Meum (t. 6. f. 4.).

ee) spreuartig (paleacea): wenn die Oberllïche des Wurzelstockes mit spreuartigen Schuppen bedeckt ist; z. B. Polypodium vulgare (t. 2. f. 3).

ff) genarbt (cicatrisata): weun der aufsteigende Stock nach dem Absterben seine Basis auf dem Wurzelstocke sitzen läfst. Sie kommt bey inchreren Farrenkräutern, und zwar von sehr verschiedenem Ansehen vor; wie z. B. bey P'olypodium anlgare (t. 2 . f. 3.), Adiantrum albicans Plum. fil. t. g6. (t. 6. f.6.), Danea alata (t. 6. f. 5.).

3) knollig (uberosa): wenn sich an dem nicdersteigenden Stocke Knollen (\$. 42.) finden. Sie hat jederzeit Wurzelfasern, und diese sitzen entweder auf den 
Knollen selbst, oder an der Basis des aufsteigenden Stockes.

a) granulata: tuberibus granulorum formam habentibus; qualis est radix Saxifragae granulatae (t. 3 . f. 20.).

b) testiculata: si duo tubera oblonga vel subrotunda concreverint; quod in Orchide Morione (t. 3. f. 13.) manifestum est.

c) palmata: si duo tubera oblonga aliquantum compressa, in extremitate divisa adsunt; exempli loco est radix Orchidis maculatae (t. I. f. 38.).

d) digitala: si tuber majus compressum et in digitos quasi divisum est; ut res se habet in Dioscorea alternifolia (t. 7. f. 5.).

e) fasciculata: si plnra tubera oblonga, cylindracea, vel elongata fasciculum componunt; qualem ostendit radix Ranunculi Ficariae (t. 3. f. 10.), Neottiae minoris (t. 17. f. 5.), Asphodeli lutei (t. 4. f. 3.).

f) conglobata: si tubera fibrillis non adhaerent, sed ipsi parenti connexa sunt; quod in Heliantho tuberoso (t. 16. f. 7.) non obscurum est.

g) articulata: si tuber ex tubere oritur, eaque re radix in articulis divisa est; qualis est in Iride pumila (t. 6. f. 2.) pluribusque hujus generis speciebus.

h) moniliformis: si plura tubera subrotunda vel oblonga fillo quasi superstructa sunt; videatur Pelargonium triste (t. 5. f. I2.), Glycine Apios.

4) bulbosa: quae uno pliribusque bulbis (\$. 43.) constans, pro eorum natura vero multum differt, ut:

\section{a. Secundum substantiam.}

a) solida: rhizomate et blastemate solida substan- a) kōrnig (granulata): wenn die Knollen wie kleine Körner gestaltet sind; z. B. Saxifraga granulata (t. 3. f. 20.).

b) hodenförmig (testiculata): wenn zwey längliche, oder rundliche Knollen zusammengewachsen sind; z. B. Orcliis Morio (t. 3. f. 13.).

c) handförmig (palmata): wenn zwey längliche, etwas breitgedrückte, an der Spitze zertheilte Knollen vorhanden sind; $z$. B. Orcliis maculata (t. I. f. 38.).

d) gefingert (digitata): wenn ein starker Knollen breitgedrückt und gleichsam in Finger getheilt ist; z. B. Dioscorea alternifolia (t. 7. f. 5.).

e) büschelförmig (fasciculata): wenn mehrere längliche, walzenförmige oder verlängerte Knollen in einem Büschel zusammenstelın; z. B. Ramuruculus Ficaria (t. 3. f. Io.), Nenttia minor (t. 17. f. 5.), Asphodelus luterus (t. 4. f. 3.).

f) zusammengeballt (conglobata): wenn die Knollen nicht an den Wurzelfasern hangen, sondern mit dem ältern unmittelbar verwachsen sind; z. B. $\mathrm{He}$ liantlus tuberosus (t. I6. f. 7.).

g) gegliedert (articulata): wenn ein Knollen aus dem andern entspringt, und die Wurzel dadurch in Glieder abgetheilt wird; z. B. Iris pumila (t. 6. f. 2.) und mebrere Arten dieser Gattung.

h) rosenkranzförmig (moniliformis): wenn mehrere rundliche, oder längliche Knollen gleichsam wie auf einem Faden aufgereihet sind; z. B. Pelargonium triste (t. 5. f. I2.), Glycine Apios.

4) zwieblig (bulbosa): die aus Einer oder mehreren Zwiebeln (\$. 43.) bestcht, nach Beschaffenheit derselben aber sebr verschieden ist, als:

$$
\text { ж. Nach der Substanz. }
$$

a) fest (solida): wenn der Wurzelstock und der 
tia circumdatis: qualis est Colchici autumnalis (t. 3. . 15 et 16. .).

b) tunicaia: si, quod rhizoma et blastema includit, membranis concentricis constat; quod in radice Allii sativi (t. 3. f. 17 et 19.) et Galanthi nivalis (t. 3 . f. 7 et 8.) patebit.

c) imbricata: si rhizoma et blastema squamis circumdata sunt, se in laterum morem obtegentibus; tali radice gandet Lilium bulbiferum (t. 3. f. II.).

d) nidulans: si bulbus intra substantiam suam nova generis sui corpora, parvos nempe bulbos, generat; hujusmodi radix est Ornithogalo spathaceo (t. 5. f. 14.).

e) rediculata: si rhizoma cum blastemate membranis reticulatis inclusum est; vide radicem Allii Victorialis (t. 5. f. I3.).

f) semireticulata: si solida (a) est, et membrana reticulata tegitur; talis radix est Gladiolo communi (t. 5. א. 7 et 8.).

\section{B. Secundum figuram.}

g) fimbriata: si membrana bulbum ambiens superne in funbriam desinit; hujusmodi radicem praebent, Gladiolus hirsntus (t. 5. f. 5.), Gladiolns communis (t. 5. f. 7), Gladiolus gracilis et pl.

h) depressa: si bulbus rotundus, simul vero ejus latitudo longitndine major est; videatur radix Gladinli communis (t. 5. f. 7.).

i) subgoblosa: bulbo ad globi formam accedente, superne autem plerumque quasi acuminato; exemplo est radix Allii sativi (t. 3. f. 17.).

k) elongata: si bulbus oblongus et longe acuminatus est; talem radicem exhibent Colchicum antumnale (t. 3. f. I5.), Erythronium Dens canis (t. 4. f. 5.), Allium sibiricum (t. 4 f. 4. c.).

1) turbinata: bulbo turbinis formain referente; spectetur radix Ixiae angustae (t. 5. f. r.).
Keim von einer festen Substanz umgeben sind; z. B. Colclicum autnmnale (t. 3. f. Ij und I6.).

b) häıtig (tunicata): jvenn das, was clen Wurzelstock und den Keim einschliefst, aus concentrischen Häuten besteht; z. B. Allium sativuın (t. 3. f. 17 und 18.), Galantluns nivalis (t. 3. f. 7 u. 8.).

c) dachziegelfürmig (imbricata): wenn der Wurzelstock und der Keim von Schuppen umgeben sind, die sich dachziegelförmig decken; z. D. Lilinm bulbiferum (t. 3. f. I I.).

d) nistend (nidulans): wenn die Zwiebel innerhalb ihrer Substanz neue Körper ihrer Art, nämlich kleine Zwiebeln, erzeugt; z. B. Ornitlogalum spathaceum (t. 5. f. 14.).

e) netzförmig (reticulata): wenn der Wurzelstock netst dem Keine von netzfürmigen Häuten eingeschlossen ist; z. B. Allium Victorialis (t. 5. f. 13.).

f) halbnetzförmig (semireticulata): wenn sie fest (a) ist, und von einer netzförmigen Hant bedcckt wird; z. B. Gladiolus commnnis (t. 5. f. 7 u. 8.).

\section{B. Nach der Gestalt.}

g) gefranzt (fimbriata): wenn die Haut, welche die Zwiebel ungiebt, sich oben in eine Franze endigt; z. B. Gladiolns hirsutus (t. 5. f. 5.), Gladiolns communis (t. 5. f. 7.), Gladiolns gracilis n. m.

h) niedergedrückt (depressa): wenn die Zwiebel rund, dabey aber mehr breit als hoch ist; $z$. B. Gladiolus communis (t. 5. f. 7. .).

i) kuglicht (snbglobosa): die sich der Gestalt der Kugel nähert, oben aber gewölınlich etwas zngespitzt ist; z. B. Allium sativum (t. 3. f. 17.).

k) verlängert (elongata): wenn die Zwiebel länglich oder lang zugespitzt ist; z. B. Colclicicun antumnale (t. 3. f. 15.), Erytluronium Dens canis (t. 4. f. 5.), Allium sibiricnm (t. 4. f. 4. c.).

l) kreiselförmig (turbinata): wenn die Zwicbel die Gestalt eines Kreisels hat; z. B. Ixin angustu (t. 5. f. I.)

\section{G 2}


m) campaniformis: si exterior bulbi facies campanae similitudinem refert: inspiciatur radix Gladioli fissifolii (t. 5. f. 3.), Gladioli silenoidis.

n) radiata: si bulbus campaniformis inferne in directione horizontali ita augeatur, ut ea re margo radiatim sulcatus enascatur: talis est radix Ixiae radiatae (t. 5. f. 4.), Ixiae corymbosae, Gladioli ancipitis.

\section{\%. Secnndum situm.}

o) centralis: ubi blastema ex inedio bulbo oritur; exempla suppeditant radices Galanthi nivalis (t. 3 . f. 7 et 8.), Allii sativi (t. 3. f. I7 et r8.), Ixiae angustae (t. 5. f. I.), Ixiae erectae (t. 5. f. ..), Ixiae radiatae (t. 5. f. 4.), Gladioli fissifolii (t. 5. f. 3.), Gladioli hirsuti t. 5. f. 5.), Gladioli communis (t. 5. f. 7 et 8.).

p. lateralis: ubi blastema lateraliter e basi bulbi prorumpit; vide radicem Ixiae virgatae (t. 5. f. Io.).

q) suffulta: si rhizoma longe e bulbo eminet, ejusque quasi pedem constituit; talem radicem habent Gladiolus tubatus (t. 5. f. 6.), Ixia punicea.

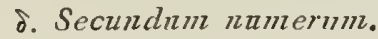

r) solitaria: si radix uno tantum bulbo constat; cujusmodi radice gaudent Colchicum autumnale (t. 3 . f. I5.), Allium sativum (t. 3. f. I7.), Ixia angusta (t, 5 . f. r.), Ixia radiata (t. 5. f. 4.), Gladiolus fissifolius (t. 5. f. 3.), Gladiolus hirsutus (t. 5. f. 5.), Gladiolus communis (t. 5. f. 7.), Ixia virgata (t. 5. f. Io.).

s) duplicata: si bulbus duorum sibi super incumbentium faciem prae se fert; talem se praebet radix Ixiae erectae (t. 5. f. 2.), Gladioli carnei, Allii sphaerocephali. m) glockenfürmig (campaniformis): wenn die äufsere Gestalt der Zwiebel einer Glocke gleiclıt; z. B. Gladiolus fissifolins (t. 5. f. 3.), Gladiolus silenoides.

in) strahlig (radiata): wenn eine glockenförmige Zwiebel sich unten in horizontaler Richtung so crweitert, dafs dadurch ein strahlig-gefurchter Rand gebildet wird; z. B. Ixia radiata (t. 5. f. 4.), Ixia corymbosa, Gladiolns anceps.

r. Nach dem Stande.

o) mittelständig (centralis): wo der Keim aus der Mitte der Zwiebel hervorkommt; z. B. Galanthus nivalis (t. 3. f. 7 u. 8.), Allinm sativnm (t. 3. f. I7 u. 18.), Ixia angusta (t. 5. f. 1.), Ixia erecta (t. 5. f. 2.), Ixia radiata (t. 5. f. 4), Gladiolns fissifolins (t. 5. f. 3.), Gladiolns hirsutns (t. 5. f. 5.), Gladiolns commnnis (t. 5. f. 7 u. 8.).

p) seitwärtsstehend (lateralis): wo der Keim seitwärts aus der Basis der Zwiebel hervorkomunt; z. B. Ixia virgata (t, 5. f. Io,).

q) unterstützt (suffulta): wenn der Wurzelstock aus der Zwiebel weit hervorragt und gleichsam den Fufs derselben ausmacht; z. B. Gladiolns tnbatns (t. 5. f. 6.), Ixia. pnnicea.

\section{$\delta . ~ N a c h$ der Zahl.}

r) einzeln (solitaria): wenn die Wurzel nur aus einer Zwiebel besteht; z. B. Colchicum autumnale (t. 3. f. 15.), Allinm sativnm (t. 3. f. 17.), Ixia angnsta (t. 5. f. 1.), Ixia radiata (t. 5. f. 4.), Gladiolus fissifolins (t. 5. f. 3.), Gladiolus liirsutus (t. 5. f. 5.), Gladiolns commmis (t. 5. f. 7.), Ixia virgata (t. 5. f. 10.).

s) gedoppelt (dnplicata): wenn die Zwiebel das Ansehen hat, als ob zwey über einander ständen; z. B. Ixia erecta (t. 5. ศ. ..), Gladiolas carnens, Allium splıaeroceplıalum. 
i) geminata: si radix ex diobus in basi sna conjunctis bulbis componitur; viteatur radix Erythonii Dentis canis (t. 4. . 5.), Fritillariae pyrenaicae.

u) aggregata: ubi plures ad basin suam cohaerentes bulbi inveniuntur; ut in Allio sibirico (t. 4. f. 4 . c.).

5) notha: si dilatata vel dirisa caudicis adscendentis basis vegetabili firmando inservit, atque ita raclicis vicèn obit. In sulum se densius semper et duius hand penetrat; ideoque non plus quam multae aliae partes ad regetabile nutriendum conferrae videtur. Seqrentes species distingumntur.

a) scitifformis: si caudicis adscenden'is basis in laminam tenuem extendiur; e. g. in Ceramio Filo (t. 17. f. 1. а.) Unbilicaria proboscidea Achar. (t. 16.. . 3.), Lichene florido (t. I 7 . . 6. a.).

b) byssacea: si dilatata caudicis adscendentis basis tenni lanuygine ecctn est, enque re byssi facicm induit. In Fungis obria est; exempio est Agaricus grisens Datsch. (t. I6. f. 5. a.).

c) divisa: si caudicis adscendentis basis in ramns dividinr; exemplo sunt. Yucus digitaias (t. I\% f. .).) Fucus saccharinus et pl. al.

d) papiliosa: si ad regetabile firmandum ia inferiore cjus superficie prolongationes fapilliformes deprehenduntux; quo pertinent Lichen saxatilis, Peltidea syis atica. (1. 33. 5. 3.).

\section{S. 46 .}

Crude $x$ intermedius: qui ob contrariam situs ad structuram rationem caudici nec descendenti nec adscendenti annumerari potest (5.37.), in rubusclam tantum vegetabilibus obvius, vel cormus (\$. † 3 .) infra terram, vel ihizona (\$. 39.) supra terram est. Tarine caudicis interınedii species distingucndae, hae stint:
1) gerweyt (geminata): wenn die Wurzel aus zwey an ihrer Basis verbundnen Zviebuln besteht; z. B. Lirythronium Lens canis (t. 4. 5. 5.), Fritillaria pyrazaice.

u) gchiult (aggregata): wo mehrere an ihrer Basis zusammenlüngende $Z$ wi beln sich frien; z. B. Alitum sibiriculn (t. 4. f. 4. c.).

5) unächt (notlua): wenn die erweiterte oler zertheihte Basis des aufstcirenden Stockins dem Gewäclise zur Befestigung clicnt, und in dieser Lfinsiclıt chie Stclle der Wurzel vertrit. Sie drin ${ }_{y}$ t nicht in den Boden, der jederzcit dichter und härter ist, ais sie silbst; und sie scheint daher nicht mehr zur Ernährung des Gewïchses beyzutragen, als mehrere andre Theile desselben. E; lassen sich fulgend: Arten unterscheiden:

a) sehildförmig (scutiformis): wenn sich die Basis des aufsteigenden Stockes in eine dünne Platte ausdehnt; z. B. Ceraminm Filnm (t. 17. I. ז. a.), Umbilicaric probosculea Achar. (t. 16. f. 3.), Lichen foridies (t. 17. f. 6. a.).

b) byssusartig (byssacea): wenn die erweiterte Basis des aufsteigenilen Siockes nit feiner Wolle bedeckt ist, und dadurcb das Anstien eines Fadenschimnıels (Byssus) erhält. Sie kounmt bey den Piizen vor; z. B. bey Agaricus grisetls Batsch. (t. 16. f.5. a.).

c) zertheilt (alivisa): wenn sich die Basis des aufsteigenden Stockes in Äste vertheilt; z. B. Fucus digitatus (t. 17. f. . .) Fucus saccharinus u. m. a.

d) warzig (papillosa): wenn sich zur Befestigung des Gewächses auf der untern Fläche desselben warzenartige Verlängerungen finden; z. B. Lichen saxatilis, Peltidea sylvalic. (t. 33. ศ. 3 ).

$$
\text { S. } 46 .
$$

DerMittelstock (Caudex intermedius), der wegen des entgegengesetzten Verhaitons seiner Lage zur Structur weder zum niederstcigenden noch zum aufsteigenden Stocke gerechnet werden kann (\$. 3..), fiudet sich nur bey einigen Gewïchsen, und ist entweder ein Stiel (\$. 48.) unter der Erde, oder cin Wuzclstock \$. 39.) 
iiber der Frde. Die verschiedenen Arten' des Mittelstockes, dic untcrschieden zu werdcr verdienen, sind folgende:

I) cormoideus: si infra terram adest, et eadem insi cum caudicis adscendentis cormo figura cst. 'Fum rcperitur:

a) laevis: si ipsi neque eminentiae neque impressiones sunt, et plerumrge in cormum abit. exempli loco est Lilium bulbiferum (t. 3. f. Ir.) et Lathraea Srquamaria (t. 4. f. I.).

b) cicatrisatus: si caudici adscendenti cormus dcest, ubi tum petioli et pedunculi ex caudice intermedio oriuntur et decilcntes basin suan in eo relinquunt; e. g. Cyclamen europaeum (t. 3. f. 2. b.).

2) rlizomatoideus: si supra terram exsistit, liocque in casu caudici descendenti rhizoma nunquam non deest, cujus tum locum supplet. Apparet:

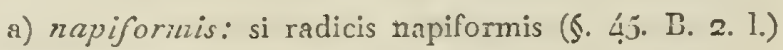
similitudinem refert, et in basi sua in radicem caudiciformem (5. 45. B. I. e.) paulatim transit; exemplo est Brassica oleracea gongylodes (t. 16. f. 2. b).

b) Bulbosus: si bulbi faciem refert, nec in basi sua quidquam praeter fibrillas edit. Tum aliqua ex parte terrae immersus radicom bulbicipitem (5. 45. B. 2. n.) fingit. Vel simplex, ut in Ranunculo bulboso (t. 7 . f. a.) invcritur, vel duplicatus, qualis cst Avenac bulbosae (t. 13. f. I.).

\section{5. $4 \%$.}

Caudex adscendens; vel pars vegetabilis supra terram assurgens ( $(\$ .3-$. $)$, maxime attendi a robis merctur, cum ab eo plerunque solo desumantur charactercs, qui sunt ad tantam vegetabilium copiam distingutentam necessarii. In basi sua magis est minusque simplex, at der Erde befindet, und wie der Stiel des aufsteigcnden Stockes gebildct ist. Man findet ihn alsdann:

a) glatt (laevis); wenn er weder Erhabenheiten noch Verliefungen hat, und gewülnlich in den Stiel übergeht; z. B. Lilium bulbiferum (t. 3. f. I1.) Lathraca Squamaria (t. 4. f. I.).

b) ge narbt (cicatrisatus): wenn dem aufsteigenden Stocke derStiel fehlt, wo alsdann dic Biatt-und Bluınenstiele aus dem Mittelstocke entspringen, und beym Abfallen ihre Basis auf dernselben zurücklassen; z. B. Cyclamen europaeum (t. 8. f. 2. b.).

2) wurzelstockartig (rlizomutniderus): wenn cr sich tiber der Erde befindet, in welchem Falle dem nicdersteigenden Stocke jederzeit der. Wurzelstock fehit, dessen Stelle er alsdann vertritt. Er zeigt sich:

a) rïbenfürmig (napiformis): wenn er einer rübenförmigen Wurzel (\$. 45. B. 2. 1.) gleicht, und an seiner Basis nach und rach in eine stockartige Wurrel (S. 45. B. I. e.) übergeht; z. B. Brassica oleracea gongylodes (t. 16. f. 2. 6.).

b) zwiebelartig (bulbosus): wenn er die Gestalt einer Zwiebel hat, und an sciner Basis blofs Wurzelfasern treıbi. In diesem Falle ist er zum Theil in die Erde versenkt, und bildct dann die zwiebelkoppige Wurzel (\$. 45. B. 2. n.). Man finclct ihn entweder einfach (simplex), wie bey Ranunculus bulbosus (t. 7. f. 2.;, oder gedoppelt (duplicatus), wie bey Avena bulbosa (t. 13. 1. 1.).

$$
\text { ๑. } 47 .
$$

Der aufsteigende Stock (Caudex adscendens), oder der über dem Boden sich befindende Theil des Gewächses (\$. 3-־), verdient unsre grül'ste Aufmerksamkeit, iulem gewühnlich nur von ilın allein die Kennzeichen horgenommin werden, die zur Unterscheidung 
vero quo magis supra solum effertur, co plures explicatur in partes, quae ol variam structuram vel fugicnte oculo discemi plerumque possunt. Vocantur: Cormus, Frous, Folia, Fulcra, Flos, Fructus et Dasis fruciificationis.

\$. 48 .

Cormus caudicis adscendentis pars est ceteras sustinens. Cum vero in magna vegetabilium diversitate familine quaedam natırales sint, quarum cormus proprietate sua insignis et conspicuus est: cormi species ita inter se differentes suis quasque nominibus distinxerunt, quae sunt: Caudex, Truncus, Caulis, Culmus, Scapus, Stipes et Surculus. His annumerantur Sarmentum et Stolo.

Praeterea singulas cormi dividendi partes ex iis, qune inde progignuntur, distinguere annisi sunt, unde lace nata sunt nomina: Rami, Petiolus et Pedunculus. Ex peduncuio ulterits dividcndo $I_{i}$ forescontia exsistit. Postremo Seta muscorum fructum forens huc est numeranda.

Nec vero omne vegctabile cormo est instructum, cum quaedam omnino careant eo, ita ut neque petioli, nec pedunculi appareant. Qune regerabilia acormosa merito dicere licet, eoque Colchicum antumnale pertinct. Quae vero corao destituta sunt, petiolos tamen der so zall'reichen Mienge von Gewächsen erforderlich sind. Fr ist an seincr Basis meir oiler weniger einfacli, verbreitet sich abcr nach und pach, so wie er sich weiter über den Boden erhebt, in mehrere Theile, die sich wegen der Verschiedenheit ilrer Siructur, mehrentheils sclion bey einem flichtigen Blicke ron einander unterscheiden lassen. Sie heil'sen: der S t i l (Cormus), das L a ub (Frons), diẹ Blättcr (Folin), die Stïtzen (Fulcra), die Blume (Flos), die Frucht (Fructus), und die Befruchtungsbasis (Erısis fructificationis).

$$
\text { 5. } 40 .
$$

Der Stiel (Cormus) ist der Tlıeil des aufsteigenden Stockcs, welcher die übrigen Theile trägt. Da es aber bey der grofsen Vcrschiedenheit der Gewächse gewisse natürliche Familien giebt, bey denen der Sliel durch Eigentbïmlichkeit sich auszeichnet: so hat man die in dieser Hinsicht verschicdenen Arten des Stiels durch Lcsondre Namen unterschieden, und diese heifsen: der Stock (Caulex), der Stamm (Truncrs), der Stenyel (Canlis), der $\mathrm{Halm}$ (Culmus), der Schaft (Sccipus), der Strunk (Stipes), und das Stämmchen oder der Mioosstengel (Surculus). Zu diesen sind auch noch zu reclinen die Rauke (Surnicntum) und die Sprosse (Stolo).

Ferner hat man bey der Zertheilung des Sticls die einzelnen Tlieile desseiben ilırem Zwecke nach zu unterscliciden gesucht, und daher entsianden denn noch folgende Jenennungen, als: lie Äste (Rami), dcr Diattstiel (Peiolirs) und der Biumenstiel (Pedunculus). Durch die weitere Zertheilung des Blumenstiels entsteht dic Inflorescens oder der Blütlienstand (Inforscentia). Endlich mufs auch noch hierher die Borste (Seta), welcbe die Fruclit der Moose trägt, gerechnet werden.

Nicht alle Gewächse sind mit einem Stiele verselyen, und zwar fehlt derselbe bey cinigen onzlich, so daßs weder Blatt - noch Blumenstiele sic't zeigen. Man kann diese, wohin z. B. Colchicum cutunnale zu rechnen ist, mit allem rechte stiellos e Gewächse (Ve- 
aut pedunculos protrudunt, e. go. Astragalus execa. pus, vegetabilia subacormosa tantum vocare licet. Plura, e.g. Cyclamen enropaeum, praeter cormum omnia possident, peisoli autem et pedurenli - qui tnmen cormi partes tantum laberi possunt - semper adsunt, caque vegetabiia subcormosa recte dixeris. Denique plurima illorum praeter petiolos et pedunculos 2 qui tamen et ipsi decsse possunt - cormo instructa appa. rent, quane vegctabilia cormosa nominantur.

\section{49.}

Caudex ea comi est species, quae in Palmis et Filicibus quibusdam deprehenditur. Ea re eninet, quod solo in apice germinct, quod plures annos duret, quod ejus superficies nunquam glabra, sed cicatrisata sit. Species, quas olservarunt, hae sunt:

I) annulatus: si frondes decidentes circum caudicem cicatrices annuliformes relinquant; ut in Corypha rotundifolia (t. I I. f. I. a.).

2) squamosus: si frondes, quae decidunt, basin stuam vel potius inferioren sijpitis (\$. 5千.) partem in caudice rilinquant; exemplo est Chamaerops humilis.

3) tessellatus: si frondibus decidentibus quivis stipes depressionem quadratam relinquil; e. g. in Poiypodio arboreo.

4) aculeatus: si pungentes ijosi sunt proinberantiae, quas una cum cortice licet detrahere; exemplo sunt PoIypodium asperum, Cocos aculeata.

5) inermis: in rao gungentes istae prolubrantiae non deprchendiuntur; ut in Polypodio aborco, Corplia rotundifulia (L. I I. f. I. a.).

Palma caulex propric est rỉizoma supra teiram

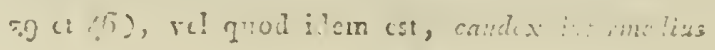

gctabilia acormosa) nennen. Die hingegen, welchen zwar der Stiel fehlt, dabey aber entweder Blattstiele oder Blumenstiele herrortreiben, wie z. E. Astragalus exscapus, kömen nur fast stiellose Gewächse ( V rgerabilix subaccrmosa) genannt werden. Bey mehreren, wic z. B. bey Cyclanen europueum, felslt nur der Stiel, die Blatt- und Blumensticle aber - welche jedoch nur als Theile des Sticls betrachtet werden kön. nen - sind jeủerzeit zugegen, und diese können füglich fast stieltraibende (ie wä chse (Vegetabilia subcormosa) heifsen. Endlich sieht man bey den mehresten Gewäclisen, dals sie aufser den Blatt und Blu. menstielen - die ilınen judoch fchlen können - auch mit einem Stiele $v$ crschen sind, und diese nennt man stieltreibende Gerràclise (Vegerabilia cormosa).

5. 49.

Der Stock (Caudex) ist diejenige Art des Sticls, welche sich bey den Palmen und bey einigen Farrenkräutern findet. Er zeichnet sich dadurch ans, dafs er blols aus der Spitze treibt, viele Jahre dauert, und dals seine Oberfläche niemals glatt, sondern genarbt ist. Die Arten, welche man bemerkt hat, sind folgende:

I) geringelt (annulatus); wenn das Laub beym Abfallen rund um den Stock ringlörmige Narben hinterlälst; z. B. Coryplua rotiundifolia (t. I r. f. r. a.).

2) schuppig (squamosus): wenn das Laub beym Aufallen seine Basis, oder vielmehr den untern Theil des Strunkes ( $($. 5-1. ), auf dem Stocke zurück läfst; z. B. Chamaerops humilis.

3) wiurfelig (icssellatus): wenn berm Abfallen des Laubes jeder Strunk eine viereckige Verticfung hinterlüsts ; z. B. Polypodium arboreum.

4) staclielig (aculeatus): wenn er stechende Hervorragungen hat, die sich mit der Rinde abziehen lassen; z. B. Polypodium asperun, Cocos aculeata.

5) unbewafnet (inermis): bey dem sich keine stecliende Hervorragungen finden; z. D. Polypodium arburcum, Coryplea roindifolia (t. I I. f. I. a.).

Der Stock der Pulme ist eizerntich ein IT arzel-

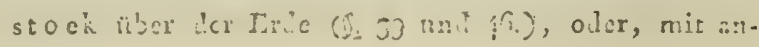


rhizomatoilezs (\$. 45.2.). Blastemaia in apicc posita, utque ca sensim explicantur, frondes inferiores decidunt, ita tamen, ut earum basis, vel potius-inferior cujuslibet stipitis pars in eo remaneat. Irassica olcracea gongylodes lac in re non mediocrom cum Palma similitudinem habet; cjus eniun rlizoma supra tcram quoque exsistens Palmae candici similis fierct, nisi brevior ipsius vita id prohiberet. Nostrum Polypo. dium Filix mas, pluresque Filices aliae rhizoma la. bent a Palmae rhizomate nulla alia re magis difterens, quam situ, quod hic uenuye non supra, scd infra ter. ram est. In regionibus vcro calidioribus sunt quoquc Filices rhizona suum supra terram protrudentes, ut, exi-riorem earum structuram si spectes, Palmis sint simillimae. Palmarum igitur a vegetabilibus phoenoganis ad Fllices trassitus ignorari nequit; et Linnacus, qui idem Palmarum, quod Filicun cormo, nomen recte dixit, minime crrarit, cum et ens Palmarum partes, quas recentiorum botanicorum nonnulli folia 110. minatas volunt, sicut in Filicibus, frondem appellarct,

§. 50 .

Truncus arborum fruticumpre proprius est cormus, ab omnibus aliis speciebus id differt, quod sub ejus epidermide (\$. 3r.) semper cortex (\$. 32.), liber (\$. 33.) et lignum (\$. 3f et 35.) deprehenduntur. Apparet:

1) arborens: si jam in altitudinem quandam s:rpra solam excreverit ramos Cacumen constituentes protrudens.

2) fruticosus: si quam primum solo exierit, ramos protrudit.

Ceterae trunci species alias obviae, de caule (5. 51.) diccutur; inque accurata ejus descriptione naturae cjus interioris ( $\$ .51 .-5^{6}$.) ratio habcbitur. dern Worten gesagt, cin wurzelstockartiger Mittelstock (5. 10. 2\% Die Keime liegen bey ilim oben in ler Spitze, und so wie sich diese allmählig entwickeln, fallt das unterc Laub ab, jedoch so, dals dic Basis desclben, ouer viclmelir der nntere Theil eises jeden Strunkcs, auf ilim zurückbleibt. Brassica oleracer gongyloles hat in dieser IIinsicht niclat geringe Aelınlichkcit mit den Palmen; ilır Wurzelstock, der siclı ebenfalls über der Erde befindet, würde dem Siocke der Palue gleicl werlen, wenn nicht seine zu linze Dauer ilin dies vertinulure. Uuser Polypodium Fiix mas und melirere andere Farrenkriuter liaber cincn Wurzisiock, del sich von dem der Palme durch niclits weiter unterscheidet, als durcl seine Lage, nüm!ich, dals diese nicht ïbcr, sondern uster der Erde ist. In den warmen Elimatou giebt es abcr aucl Tarrenkräuter, die ilıren IVurzclstock ïber die Erde hervortreiben, so dals sie dem àulserı Bauc nac?ı, völ. lig den Palmen gleichen. Es ist dalier der Uebergang, den die Palmen rou den Phocnogamen zu den Farrenkläutern machen, ganz unverkenubạ; und Linne, der selır richtig den Stiel der Palınen und den der Farreuirautcr nit glciclem Namen bezeichnete, irrte gar nicıt, wenn er bey den Palmen auch diejenigen Theile, die einige ncucre Botanisten Blitter nennen wol. len, so wie bey den Tarrenkruatuern La ub (Erons) nannte.

๑. 50 .

Der Stamm (Truncus) ist der den Bäumen und Strüuchern eigene Stiel, welcher sich von allen übrigen Arten dadurch unterschicidet, dafs man unter seinem Oberhäutchen (\$. 3\%) jederz it Rinde (\$. 32.), East (\$. 33.) und Hoiz (\$. 3f und 3j.) findet. Er zeigt sich:

1) baumartig (arborens): wenn er erst in einer gcwissen Hühe ïber dem Boden Äste hervortrcibt, die einen Wipfel (Cacumen) bilden.

2) staucharig (fruticosus): wenn or glcich von nnicn anf Aste treibt.

Die soust noch rorkommenden Arten des Stanmes werle " wie bey dem Siengel (\$.5ı.) bestinım: und bcy genauen Besclureibungen wird aucl auf scine

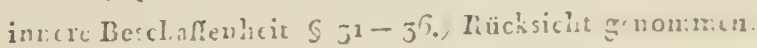




$$
\text { §. } 51 .
$$

Ca ulis est cormus herbaceus - nonnunqram lignosus - folin, flores et frucius fercns, cujus superficies foliis non nimis constipatis - aperte conspici potest. Quae cormi species solis quidem herbis propria, laud tamen raro arionum fruticumque cormus, caulis nomine insignitur. Ilae distinguuntur species:

a. Secundum veretabilium naturam ratione durationis.

I) arborctus: vid. \$. 50. No. $\mathbf{r}$.

2) fruticosus: vid. \$. 50. No. 2 .

3) suffruticosts: cujus inferior pars hiemem tantum sustinet, supcrior vero interit; ut in quibusdam generis Rubi speciebus.

4) herbacens: qui unam tantum aestatem dural; videatur Pulmonaria officinalis.

\section{b. Secundunin subsianticun.}

5) lignosus: qui e solido constat ligno; qualis est arborum fruticum que.

6) fubrosus: qui ex lignosis facile separandis fibris compositus est; ut in plurimis vegetabilibus herbaceis non admodum succulentis.

7) carnosus: carne succulenta constans in cujus sulstantia fibrae lignosae obscrvari nequeunt; excmplo sint Portulaca olcracea, Dentaria bulbifera.

8) inanis: intus laxa medula farctus; ut in lfèiantho tuberoso.

9) lactescens): qui aibo scu flavo lacti simili succo explctus est; videantur Euplıorbia Cyparissias, Clielidoniun majus.

Attamen hoc de toro vegetabili praedicare malunt, ilque tum albo-lactesceas, vel flavo-lactescens dicitur.

\section{6. $5 r$.}

Der Stengel (Caulis) ist ein krautartiger - zuwcilen holziger - Blättor, Biumen und Frǘchte tragender Sticl, dessen Obcrflïche - im Falle die Bfätter nicht zu dicht stehen - frey gesehen werden kann. Figentlich ist diese Sticlart blofs den Krütutern eigen, jedocls wird atech nicht stiten der Silel der Bïune und Sträucher mit dem Nahmen des Stengels belegt. Es werden folgende Arten unterschieden.

a. Nach der Beschaffenheit der Gewächse in Hinsicht ihrer Dauer.

I) baumartig (arborezts): S. \$. 50. No. I.

2) strauchartig (fruticosus): S. S. 50. No, 2 .

3) staudig (suffruticosus): dessen unterer Theil nur den Winter aushält, der obere aber eingchı; z. B. einige Arten der Gattung Rubus.

4) krantartig (herbaceus): der nur Dauer für Einen Sommer hat; z. B. P'ulmonaria oficinalis).

\section{b. Nach der Substanz.}

5) Lolzig (lignosus): der aus festem Holze besteht; wie bey den Däunerı und Stäuchern.

6) fascrig (fibrostls): der aus holzigen, lcicht von einander trennbaren, Fascrn bestcht; so wie bey den mehresten krautartigen Gewächsen, dic nicht schr saftreich sind.

7) fleischig (carnosus): der aus saftigem Fleische bcsteht, und in dessen Substanz keine holzige Fasern walırgenommen werden können; z. B. I'oriulaca oleracea, Dentaria bulbifera.

3) markig (inonis): der innerhalb mit lockerem Miarke (\$.36.) angefüllt ist; z. B. Helianthus tuberoszls.

n) milchend (lacicscens): wenn er nit cinem weifsen oder gelben milcluähnlichen Safte angefüllt ist; z. B. Euphorbia Cyparissias, Chelidoniun majus.

Man gebrauclit jedoch dieses Prädicat lieber von dem ganaen Gewäclise, und sagt alsdann das $G \in$ wächs ist weifs-milchend (albo-lactescens), oder gelb. milchend (Jaro-lactescens). 
TERMI IOLOGIA.

I0) fistulosus: cui intus est carum fistuliforme; exemplo sit Ae goṇodium l'odagraria (t. 10. f. 7. b.).

II) loculosus s. septis transversis interstinctus: est caulis excaratus secundum longitudinem septis transversis in loculos divists; ut in nonnulis Umbelliferis.

12) solidus: qui neçue inanis (No. 8.) neque fistulosus (No. IO.), sed intus ejusdem est soliditatis; e. g. in Dentaria bulbifera (t. 4. f. 1. b.).

\section{c. Secundum firmitaiem.}

13) frmus: quii non nisi majore yi dilaccrari potest; talis est Lini usitatissimi.

I f) debilis: qui facile disrumpitur; exemplo sit Equisetum palustre.

1j) fragilis: qui, quominus frangatur, se inflectinon patitur; invenitur in Chara rulgari, Caulinia frasili, Salice fragili.

16) Rexilis: qui inflecti se patitur, quominus frangatur; exemplo est Chara Hexilis.

17) tenax: qui sacpius inflexus non frangitur; tali gandet Salix vininalis.

18) rigidus: qui, quominus lignosus sit crassusque, se sustinet, et non nisi leviter fractus deflectitur; ut in Dentaria bulbifera et plurimis vegetabilibus herbaceis.

I9) laxus: qui tam exiguae est rigiditatis, ut se vix sustineat, idenque nec lcviter quidem fractus deorsum flecti queat; excmplo est Campanula hederacea, ut etiam vegetabilia omria scandentia.

\section{d. Secundum situm.}

20) natans: cujps superior pars aquae superficiei innatat; videantur Polygonum amphibium * aquaticum, Potamogeton natans.

2I) denersus: qui ex toto sub aquae superficie habi-
10) hohl oder rührig (fistulosus): der innerhalb cine rührenfürmige Hülilung hat; z. B. Aegopodium Podagraria. (t. ro. f. 7. b.).

II) fächerig (loculosis s. septis transversis interstinctus): wenn ein hohler Stengel der Länge nach durch Querscheidewände in Fïcher a bgetheilt ist; z. B. einige Schimpflanzen.

12) fest (solidus): der weder markig (No. 8.) noch hohl (No. Io.), sondern inncrhalb von gleicher Dichtigkeit ist; z. B. Dentarin litlbifera (t. 4. f. I. b.)

c. Nach der Festigkeit.

13) stark (firmus): der nicht mit geringer Kraft zerrissen werden kann; z. B. Linum usitatissimnun.

If) $\mathrm{schwach}$ (delilis): der sich sehr leicht ${ }^{\circ}$ zerreifsen läfst; z. B. Equisetum palusire.

15) zerbrechlich (fragilis): der sich nicht biegen lälst, ohne zu zerbrechen, z. D. Chara vulgaris, Caullinia fragilis, Salix fragilis.

16) biegram (flexilis): der sich ohne zu zerbrechen, bieğen läfst; z. B. Cluara Rexilis.

17) zähe (tenax): der sich, selbst durch öfteres Hinund Herbiegen, nicht leicht zerbrechen lälst; z. B. Salix viminalis.

I3) steif (rigidus): der, olıne holzig oder sonderlich dick zu sejn, sich aufrecht erhith, und sich nicht oline einzuknicken niederbiegen läfst; z. B. Dentaria bulbifera und mehrere krautartige Gewichse.

19) $s c_{1}$ laff (laxns): der so wenig steif ist, dafs er sich haum aufrecht erhïtt, und duher ohne einzuknicken niedtrgebogen werden kann; z. B. Campanula hederacea, so wie auch alle kimmende Gowäclise.

\section{d. Nach der Lage.}

20) schwimmend (natans): dessen oberer Theil auf der Obenflïche dcs Wassers schwimmt; z. B. Pnlygoutun amplubinin a aquaticum Potanogeton natalls.

21) untergetaucht (demersus): der sich gẳzlich 
tat, et pedunculos tantum supra eam aitollit; exempli loco sunt plurimae generis Liricularine species.

22) emersus: qui supra aquae superficiem eninet; ut in Ranunculo polyphyllo (t. 23. א. 3.).

23) parasiticus: qui aliis inhaeret regetabilibus, in quae, ut se nutriat, radices agit; tali gaudent Cuscuta europaea (tabulae libri inscriptionem gerentis figura 5.), Viscum album.

c. Secundum rudicum afixionem et similia.

24) repcus: si caulis una cum ramis procumbit, et tam ille, guam lii non Iongis intervallis radices in terram agunt, quominus ab intervallo ad intervilum arcuatim assurgant; exempli loco est Peplis Portula (t. 13. f. 4.), Lysimachia Nummularia.

25) sarmentosus: si caulis decumbit atque ita longis inter se intervallis, in quibus in arcum assurgit, ridaices in terram agil; exempli loco allegatur Ranunculus reptans (1. Io. f- g. b). Si est ramosus, rectus saepe sine arcu humi procumbit, tum vero ramos sursum a cit; exempli loco sint Lysimachia nemortim (t. 4). f. j.). Chrysosplenium alternifolium, Chrysospleniam oppositifolium.

26) fulcratus: si erectus ex ramis in terram usque agit radices in cormos inuntàndas eumque quasi suffulcientes; exemplo est Rlizopliora Mangle (t. g.) et Ficus indica.

27) radicans: si ad corpus erectum adscendit, et ei adhaesurus in id radices agit; luc pertinent Ficus stimulacea (t. 12. f, 3. a), Hedera I Ielix.

28) scandens: est caulis laxus (No. I9.) ad alia cor, pora se erigens, eaque partium quarundam, quae cirrhi dicuntur, huic rei potissimum destinatarum, ope apprehendens; talem caulcm habet Passiflora coerulea (t. Íf, unter der Oberfläche des Wassers befindet, und nur seine Blumenstiele über diesclbe erhebt; z. B. mehrere Arien der Galuung Uiricilariı.

22) hervorragend (emersus): der sich über die Oberthïche des Wassers erlieut; z. D. Ranunculns polypliyllus (t. 28 . f. 3.).

23) schnarotzend (parasiticus): dor sich auf andern Gewïlisen befindet, in wlche er zu seiner Ernälrung Wurzein schligt; z. B. Cuscut.z europaca (Titelkupfer f. 5), Fiscum albitm.

e. Nach der Anhefturg durch Wurzeln und dergleichen.

af) kriecliend (repers): wenn der Stergel sammt den Ästen niederliegt, und ersterer sowoll n's leizture in nicht weiten Zwischenritmen, Wuzeln in dis Fide triben, ohne sich von einem Zirischenraume zum andern bogenfoumig zu erheben; z. B. Pejlis Poriula (t. I3. f. f), Lysimachia Numinnlaria.

aj) rankend (scrmentosis): wemn der Stengel niederliegt, und nur in weiten Zwischenräumen, wobey er sich in einen Dogen erhebt, Wurzeln in die Erde treibt; z. B. Ranunculis reptans (t. 40. f. 5. b). Wenn er ästig ist, liegt er üflers ganz gerade ohne Bogen auf der Erle, treivt aber alsdinn seine Äste aufrecht; z. B. Ljsimachia nemorimi (t. fo. f. 5.), Chiysosplenium alternifolium, Chrysospleitim oppositifolium.

26) gestïtzt (fulcratus): Wenn er auirecist steht und aus den Zweigen WWurcir bis in die Erde scliligt, die sich in Sliele verwandeln und ihn gleichsan nuterstützen; z. B. Rhizophora Mangle (t. 9.), Ficus indica. 27) wurzelnd (radicuns): wenn er an einem anfrechten Künjer in die Höhe strigt und zu seiner Defestigung Wurzeln in denselben schligt; z. B. Ficus sipulucea (t. I2. J. 3. a), Thedera Helix.

23) Klinumend (scandens): ein schlaffer siongel (ïo. 19.), der an andern Körpern in die Hühe steigt, und sich an ihuen vermiltelst besonders dazu beslimmter Theile, die man Gabeln nenut, fesılhälı; z. B. Passifiora 
(t. If. f. I. a.) et plures hujus generis spicies; item Bryonia alba, Vitis vinifera.

\section{f. Secundum directionem.}

29)3strictus: qui plane rectus est, et omnino perpendiculo convenit; hujusmodi caulem habet Linun usitatissimum (tabulae libri inscriptionem gerentis figura 3.).

3o) erectns: qui non ex toto rectus, paene tamen perpendicularis est; videatur Erigeron uniflorum (t. I. f. $4 \mathrm{r}$.

31) procumbens, prostratus, humifusus: si planus humi jacet; videatur Linnaea borealis (tab. libr, inscript. ger. f. 2.), Veronica prostrata, Hypericum humifusum.

32) adscendens: cujus inferior tantum pars humi jacet, media autem arcuatim ascendit, et superior est erecta; exemplo est Comarum palustre (t. 8. f. 3. a.).

33) declinatus: qui primo erectus, dein obliquus adscendit, tum in arcu terram versus curvatus; huc pertinet Lycium barbarum (t. 10. f. 5.).

34) decumbens: si caulis ad exiguam tantum distantiam usque supra basin suam erectus, tum vero ita deflexus est, ut maxima ejus pars humi jaceat; exemplo est Thymus Serpillum (t. 13. f. 7. a.).

35). cernuzus: cujus pars superior ita est flexa, ut apex horizontem spectet; exempli loco videatur Silene nutans (t. I3. f. 5.).

36) mutans: cujus superior pars ita est flexa, ut apex terram spectet; videatur Fritillaria Meleagris (t. 31.f. 3.a).

37) pendulus: si aliis vegetatilibus rebusque sublimibus insidet, ab iisque dependet; exempli loco videatur Cymbidium pendulum (t. 23. f. 2.).

38) Rexuosus: qui alternatim directione contraria jam "1 jam illuc flexus est, ita, ut plures angulos obtusos sifora coerulea (t. If. f. I. a.) und mehrere Arten dieser Gattung; ferner Bryonia alla, Vitis vinifera.

f. Nach der Richtung.

29) straff (strictus): der vollkommen gerade ist, und völlig senkrecht steht; z. B. Lintun usitatissimnzm (Titelkupfer f. 3.).

3o) a ufrecht (erectus): der nicht vollkonmen gerade ist, aber ziemlich senkrecht steltt; z. B. Erigeron uniflorum (t. 1. f. 4r.).

3r) gestreckt (procumbens, prostratus, lumifusus): wenn er ganz gerade auf der Erde liegt; z. B. Linnaea borealis (Titelkupfer f.2.), Veronica prosirata, Hypericum lunnifusunt.

32) a ufwärts gebogen (adscendens): wenn nur der untere Theil auf der Erde liegt, der mittlere Theil aber in einem Bogen in die Höhe steigt und der obere aufrecht steht, z. B. Comarum palustre (t. 8. f. 3. a.).

33) niedergebogen (declinatus): der anfangs aufrecht, alsdann schief in die Hölhe steigt, und nachher sich in einem Bogen gegen die Erde krümmt; z. B. $L Y$ cinm barbarum (t. 10. f. 5.).

34) niederliegend (decumbens): wenn der Stengel nur bis, zu einer kleinen Entfernung über seiner Pasis aufrecht steht, und alsdann so niedergebogen ist, dals der grölste Theil desselben auf der Erde liegt; z b. Thy'mus Serpillum (t. 13. f. 7. a.).

35) übergebogen (cernuuz): dessen oberer Theil so gekrümmt ist, dafs die Spitze gegen den Horizont zeigt; z. B. Silene nutans (t. I3. f. 5.).

36) überhangend (nutans): dessen oberer Theil so gekrümmt ist, dals die Spitze gegen die Erde zeigt; z. B. Fritillaria Meleagris (1. 31. f. 3. a.).

37) hangend (pendulus): wenn er auf andern Gewächsen, oder erhabenen Gegenständen sich befindet, und von diesen herab hängt; z. B. Cymbidlium pendulum (t. 23. f. 2.).

33) gekniet ( (lexuosus): der abwechselnd nach entgegengesetzter Richtung hin- und hergebogen ist, so 
efformet; ejemplo sunt Peperomia purpurea (t. 24. f. 6. a.), Peperomia alata (t. 2f. f. 4.), Fagara tragodes (t. I4. f. 2. a.).

39) volubilis: caulis laxus, qui circum alia corpora vel vegetabilia spirae in modum volvitur sursum, idque directione duplici:

a) dextrorsum: contra solis motum; ut in Convulvulo arvensi (t. I2. f. r. a.).

b) sinistrorsum: cum solis motu; Exemplo est Polygonum Convolvulus (t, I2. f. 5. a.

\section{g. Secundum divisionem.}

40) simplicissinnus: qui neque in ramos, neque in pedunculos diducitur, indeque non plurcs uno vel flore, vel spica, vel flores tantum sessiles profert; videatur Erigeron uniflorum (t. I. f. 41.).

Linnaeus caulem rult intelligi, qui ramis quidem care?, in pedunculos tamen dividi potest. Hujusmodi vero caulis, si ad vivum rem resecamus, hoc non meretur nomen, cum hoc omnino in sensu strictissimo sumendum sit, ut inter Nir. 40, 41, 42, 43 et 44 certi limites determinari possint.

41) simplex: qui non nisi in pedunculos, nec vero in ramos dividitur; huc pertinet Comarum palustre ( $t$. 8. f. 3.), Silene nutans (t. I3. f. 5.

_Linnaeo est simplicissimus.

42) subramosus: qui umum vel aliquot agit ramos; videatur Campanula rotundifolia (t. 5. f. 9.).

43) ramosus: qui multos ex se edit ramos; quorum tamen perpauci tantum in minores dividuntur ramos; exemplo sit Vaccinium Myrtillus (t. 7 . F. I.).

44) rantosissimns: qui plurimos profert ramos in magnum rursus minorem multitudinem dividendos: ut in Ocimo minimo ( $t, 15 . \mathrm{f}, 2$.). dals er mehrere stumpfe Winkel bildet; z. B. Peperomia purpurea (t. 24. f. 6. a.), Peperomia alata (t. 24. f. 4.), Fagara tragodes (t. I千́f. f. 2. a.)

39) windend (volubilis): ein schlaffer Stengel, der um andre Körper oder Gewächse, spiralförmig sich in die Höhe windet, und zwar nach zweyerley Richtung:

a) rechts (dextrorsum): gegen den Lauf der Sonne; z. B. Convolvulus arvensis (t. 12. f. I. a.).

b) links (sinistrorsum): mit dem Laufe der Sonne; z. B. Polygonum convolvulus (t. 12. f. 5. a.)

\section{g. Nach der Zertheilung.}

40) sehr einfach (simplicissimus): der sich weder in Äste noch in Blumenstiele zertheilt, und daher entweder nicht mehr als eine Blume oder eine $\ddot{A}$ hre; oder überhaupt nur sitzende Blumen trägt; z. B. Erigeron uniflorum (t. I. f. 4r.).

Linne verstelit hierunter einen Stengel, der blols von Aesten frey ist, sich aber in Blumenstiele zerthei. len kann. Ein solcher Stengel verdient aber, wenn man es genau nimmt, dieses Prädicats nicht, welches über dies hier im engsten Sinne genommen werden mufs, um zwischen Nr. 40, 41, 42, 43 und 44 bestimm. te Gränzlinien ziehen zu können.

41) einfach (simplex): der sich blols in Blumenstiele; aber nicht in Äste zertheilt; z. B. Comarum palustre (t. 8. f. 3.), Silene nutans (t. I3. f. 5.).

Nach Linne heifst er sehr einfach (simplicissimus).

42) etwas ästig (subramosus): der. Einen; oder auch wohl einige Äste treibt; z. B. Campanula rotundifolia (t. 5. f. 9.).

43) ästig (ramosus): der viele Äste hervorbringt, von denen jedoch nur wenige sich wieder in kleinere zertheilen dürfen; z. B. Vaccinium Myrtillns (t. 7 . f. I.).

44) vielästig (ramosissimus): der sehr viele Äste hervorbringt; die sich wieder in eine grofse Menge kleinerer Äste zertheilen; z.B. Ocimum minimun (t. Ij.f.2.). 
45) integer: qui dum plures protrudit ramos, ipse non evanescit, sed ad omnium, quos edidit, ramorum apicem excurrit; videatur Solidago Virgaurea (t. 4. . . . .). Rumex Acetosella (t. Ig. f. 3.), Pinus sylvestris.

40) deliqnescens: qui, dum plures in ramos dividitur, et ipse evanescit, nec ideo ad omnium, quos ex se edidit, ramorum apicem pervenit; ut in Valeriana dentata (t. 7. f. 4.), Ledo palustri (tab. libr. inscript. ger. f. 1.).

47) verticillatus: ad caulis apicem plures proveniunt rami, atque ipse caulis redditur longior, ita, ut anno sequenti idem non in ramis modo, sed in caule etiam appareat; tali gaudet Pinus sylvestris.

48) prolifer: si ex caulis apice plures nascuntur rami nec vero caulis ipse longior redditur, ita, ut idem anno sequenti non nisi in ramis, nec vero in caule appareat; talis caulis est Ledo palustri (tab. libr. inscript. ger. f. I.).

49) dichotomus: qui in binas partes, et earum quaevis rursum in totidem, atque ita ad minimos ramos usque dividitur; exempli loco est Valeriana dentata (t. 7 . f. 4. a.), Viscum album.

5o) paniculatus: si caulis in parte sua superiore multos edit ramos, qui rursus in minores, flores potius, quam folio-ferentes ramos didicuntur; ut in Ruınice Acetosella (t. 19. f. 3.)

51) fastigiatus s. corymbosus: si ex caule, varia in altitudine plures, vel simplices vel in ramulos divisi rami, cum caule eadem in altitudine terminati, prodeunt; videatur Carlina vulgaris (t. 2I. f. I.).

52) virgatus: si caulis multos habet ramos, longissimos, tenues, nec multum patulos; huc pertint: caulis Lithospermi officinalis (t. 2I. f: 3.).
45) ganz (integer): der, indem er mebrere Äste hervortreibt, selbst nicht verschivindet, sondern bis zur Spitze des von den Ästen gebildeten Ganzen ausläuft; z. B. Solidago Virganrea (t. 4. f. 7.), Rumex acetosella (t. 19 f. 3.), Pinus sylvestris.

46) verschwindend (deliquescens): der, indem er sich in mehrere Äste zertheilt, selbst verschwindet, und daher die Spize des von den Ästen gebildeten Ganzen nicht erreicht, z. B. I'aleriana dentata (t. 7. f. 4.), Ledum palustre (Titelkupfer f. I.)

47) quirlförmig (verticillatus): wenn an der Spitze des Stengels mehrere Äste entspringen, und der Stengel selbst auch verlängert wird, so dafs man im folgenden Jahre dieselbe Erscheinung nicht nur bey den Ästen, sondern auch bey dem Stengel bemerkt: z. B. Pinus s)lvestris.

43) sprossend (prolifer): wenn an der Spitze des Stengels mehrere Äste entspringen, der Stengel selbst aber sich nicht verlängert, so dafs dieselbe Erscheinung in folgenden Jahre nur bey den Ästen, nicht aber bey dem Stengel Statt findet; z. B. Ledum palustre (Titelkupfer f. 1.).

49) gabelästig (dichotomus): wenn sich der Stengel in zwey Theile, jeder derselben wieder in zwey, und so fort, bis auf die kleinsten Äste, zertheilt; z. B. $\mathrm{Va}$ leriana dentata (t. 7. .. 4. а.), Viscun albun.

5o) rispenartig (paniculatus): wenn der Stengel an seinem obern Theile viele Äste hervortreibt, die sich wieder in kleinere, mehr Blumen als B!ätter tragende, Äste zertheilen; z. B. Rumex _Acetosella (t. 19. f. 3.).

5I) gleichzweigig oder doldentraubenartig (fastigiatus s. corymbosus): wenn aus dem Stengel in verschiedenen Hühen mehrere, entweder einfache, oder in Ästchen zertheilte Äste entspringen, die sich mit dem Stengel in gleicher Höhe endigen; z. B. Carlina zulgaris (t. 21. f. 1.).

52) ruthenförmig (virgatus): wenn der Stengel vicle Äste hat, die selur lang, dünne und richt weitausgebreitet sind; z.B. Litzospermunn officinale(t.2I.f.3.). 
53) brachiatus: si caulis habet ramos oppositos, quorum par quodlibet a pari supra et infra se posito in angulo recto persecatur, ut deorsum spectanti unica tantum omnium ramorum crux appareat; videantur Rhinanthus Crista galli (t. 22. f. 3.), Melampyrum arvense, Melainjyrum sylvaticum, Satureia hortensis, Mercurialis annua.

\section{h. Secundam Figuram.}

54) teres: qui transverse sectus planum orbiculatum refert; huc pertinent caulis Dentariae bulbiferae (t. 4 . f. I. b.), Lupini lutei (t. 29. f. 4. a.), -Myriophylli spicati (t. 29. f. 3. a.).

55) semiteres: cujus latus alterum rotundatum, alterum planum est; ut in Peperomia alata Ruiz (t. 24 f. 4. a.).

56) compressis: qui transverse sectus planum magis minusve ad ellipsin accedens refert; tali gandet Caulinia fragilis (t. 23. f. 3. a.).

57) anceps: si utrumque Iatus angustum canlis coinpressi in acutas excurrit acies; videatur Mesembryanthemum acinaciforme (t. I6. f. I. a.). Persaepe autem caulem teretem intellectum volunt, qui duobus sibi oppositis latexibus membranam habet tenuem angustamque; ut in Hoppea dichotoma (t. 3o. f. 3. a.), Hyperico perforato (t. 13. f. 2. a.).

58) angulatus: si plures ad caulem conspiciuntur anguli; e. go in Vaccinio Myrtillo (t. 7. f. I. a.), Vicia bienni (t. 17. f. 4. a.). Quo nomine Nr. 54. tanquam contrario plerumque ntuntur, vel ubi perpetuitatis defectus caulis figuram accuratius determinandam hand sinit. At vero ubi numerus et figura angulorum laterumque perpetuae sunt: ea diligenter attenduntur, et hae distinguuntur varietates:
53) armförmig (braclivatus): wenn der Stengel gegenüberstehende Äste hat, von denen jedes Par mit dem über und unter ihm stehenden sich rechtwinklig durchkreuzt, so dafs, wenn man von oben herunter sieht, von allen Ästen nur Ein Kreuz gebildet wird; z. B. Rlinanthus Crista galli (t. 22. f. 3.), Melampyrum arvense, Melampyrum sylvaticum, Satureia hortensis, Mercurialis annua.

\section{h. Nach der Gestalt.}

54) rund (teres): dessen Querdurchschnitt einer zirkelrunden Fläche gleicht; z. B. Dentaria bulbifera (t. 4. f. r. b.), Lupinus luteus (t. 29. f. 4. a.), Myriophyllum spicatum (t. 29. f. 3. a.).

55) halbrund (semiteres): der auf der einen Seite rund, aut der andern Hach ist; z. B. Peperomia alata Ruiz (t. 24 . f. 4. a.).

56) zusammengedrüickt (compressus): dessen Querdurchschnitt sich mehr oder weniger der Ellipse nähert; z. B. ('anlinia fragilis (t. 23. f. 3. a.).

57) zweyschneidig (anceps): wenn die beyden schmahlen Seiten eines zusammengedrückten Stengels in scharfe-Kanten auslaufen; z. B. Mesembryanthemum acinaciforme (t. 16. f. I. a.). Sehr oft versteht man aber auch hierunter einen runden stengel, der an zwey gegenüberstehenden Seiten eine dünne, schmalle Haut hat; z. B. Hoppen dichotoma (t. 3o. f. 3. a.), Hypericum perforatum (t. 13. f. 2. a.).

58) eckig (angulatus): wenn sich an dem Stengel mehrere Ecken zeigen; z. B. Vaccinium Myrtillus (t. 7. f. 1. а.), Vicia biennis (t. 17. f. 4. a.). Man bedient sich dieses Prädicats gewöhilich nur als Gegensatz von Nr. 54́, oder man gebraucht es auch da, wo sich wegen Mangel an Beständigkeit die Figur des Stengels nicht genauer bestimmen lälst. Wenn aber Zahl und Gestalt der Ecken und Sriten beständig sind: so achtet man genau darauf und unterscheidet dann noch folgende Verschiedenleiton: 


\section{TERIIINOLOGIA.}

\section{A. Secundum angulos.}

a) obtuse angulatus: si anguli obtusi sunt; ut in Vaccinio Myrtillo (t. 7. f. I. a.), Vicia bienni (t. 17. f. 4. a.).

b) acute angulatus: si anguli acuti sunt; exemplo est Sida triquetra (t. 18. f. 2. a.).

B. Secundum angulos et latera.

a. Lateribus concavis.

c) triangularis: in quo tres apparent anguli cum lateribus concavis; ut in Cacto triangulari.

d) quadrangularis: in quo anguli quatuor cum lateribus concavis notantur; videantur Galium Aparine (t. 13. f. 6. a.), Lamium album, Cactus tetragonus.

e) quinquangularis: e. g. in Spartio scopario, Cacto pentagono. Sic ulterius numeratur, et si angulorum numerus dici non potest: vocatur

\section{$\cdot$ \\ f) multangularis: ut in Euphorbia officinarum.}

\section{B. Lateribus convexis.}

g) obsolete triquetrus: in quo tres anguli cum lateribus convexis conspiciuntur; ita, ut sectio transversalis triangulum sphaericum referat; videatur pars caulis Nerii odori superior (t. 22. f. I. a.),

\section{\% Lateribus planis.}

h) triquetrus: cui tres acuti sunt anguli, latera vero ex toto plano, ita, ut ejus sectio transversalis triangulo rectilineo similis sit; talis est in Sida triquetra (t. 18. f. 2. a.).

i) trigonus: si tres rotundatos habet angulos, et latera prorsus plana apparent. Haec forma magis propria est culmo; videatur Carex tomentosa.
A. Nach den Ecken oder Winkeln.

a) stumpfeckig (obtuse angulatus): wenn dic Ecken stumpf sind; z. B. Vaccinium Myrtillus (t. 7 . f. 1. a.), Vicia biennis (t. 17. f. 4. a.).

b) scharfeckig. (acute angulatus): wenn die Ecken scharf sind; z. B. Sida triquetra (t. 18. f. 2. a.).

B. Nach den Winkeln und Seiten, ж. Mit vertieften Seiten.

c) dreyeckig (triangularis): wo drey Ecken und vertiefte Seiten sich zeigen; z. B. Cactus triangularis.

d) viereckig (quadrangularis): wo man vier Ecken und vertiefte Seiten bemerkt; z. B. Galium Aparine (t. 13. f. 6. a.), Laminm album, Cactus tetragonus.

e) fünfeckig (quinquangularis): z. B. Spartium scoparium, Cactus pentagonus. Man zählt nun so weiter fort, und wenn sich die Zahl der Fcken nicht mehr bestimmt angeben lä[st: so sagt man

f) vieleckig (multangularis): z. B. Euplıorbia officinarum.

\section{ß. Mit erhabenen Seiten.}

g) unvollkommen dreykantig (obsolete triquetrus): wo drey Ecken und erhabene Seiten sich zeigen, so, dafs der Querdurchschnitt einem sphärischen Dreyecke gleicht; z. B. der obere Theil des Stengels bey Nerium odorum (t. 22. f. I. a.).

\section{y. Mit ebenen Seiten.}

it) dreykantig (triquetrus): wenn der Stengel drey scharfe Ecken hat, die Seiten aber ganz eben sind, so, dafs der Durchschnitt desselben einem geradlinigen Dreyecke gleicht; z. B. Sida triquetra (t. 18. f. 2. a.).

i) dreyseitig (trigonus): wenn der Stengel diey abgerundete Ecken hat, und die Seiten ganz eben sich zeigen. Diese Gestalt ist mehr dem Halme eigen;

z. B. Carex comentosa. . 
k) tetragonus: si quatuor sunt anguli et latera plana; exemplo sunt Pelargonium tetragonum (t. 13. f. 3. a.), Nauclea aculeata (t. 29. f. 5. a.).

1) pentagonus: cui quinque anguli et plana sunt latera; e.g. in Lobelia cardinali (t. 22. f. 4. a.). Sic in numerando ulterius progredimus.

m) polygonus: si angulorum numerus non est perpetums.

59) membranaceus: si caulis compressus folii tenuitatem refert; e. g. Cactus Phyllanthus (t. 2 I. f. 2.)

6o) dentatus: cui in superficie dentiformes sunt eminentiae; videatur Stapelia concinna ( $t$, I6. f. 8.)

6r) nodosus: si caulis in plures divisus est articulos, qui ubi compositi esse videntur, quasi nodiformes intumuerunt; exemplo est Peperomia obliqua Ruiz (t. 23 . f. 6.).

62) enodis: cui neque articuli sunt neque nodi, atque ita priori contrarius; exemplo sunt plurima vegetabilia.

63) articulatus: qui ex pluribus constat articulis, iisque locis, ubi ii compositi esse videntur, contractus est; videantur Pelargonium tetragonum (t. I8. f. 3. $\mathrm{a}^{\star}$ ), Cactus moniliformis (t. I3. f. I.).

6f) geniculatus: qui in articulos divisus, atque ubi hi compositi videntur, neque tumefactus nec contractus est, tali gaudent Peperomia purpurea Ruiz (t. 2f.f.6.a.), Hippuris vulgaris.

65) aequalis: est caulis in articulos non divisus, atque ita non duobus modo praecedentibus (N. 63 et 64.), sed nodoso (Nr, 6r.) etiam contrarius. Cujus caulis exemplo plurima suppeditant vegetabilia.

Partes, ex quibus caulium species Nr. 61, 63 et 64 dictae compositae sunt - ut ex allegatis jam definitionibus patet - Articuli vocantur; loca vero, qui- k) vierseitig (tetragonus): wenn er vier Ecken und ebene Sciten hat; z. B. Pelargoniun tetragonum (t. 13. f. 3. а.), Nrinclea aculeata (t. 29. f. 5. а.).

1) fünfeckig (pentagonus): der fünf Ecken und ebene Seiten hat; z. B. Lobelia cardinalis (t,22.f.4.a.). Man zählt nun so weiter fort, bis

m) vieleckig (polygonus): wenn die Zahl der Ecken nicht beständig ist.

59) häutig oder blat tartig (menzbranaceus): wenn der Stengel zusammengedrückt und so dünne wie ein Blatt ist; z. B. Cactus Phyllanthus (t. 21. f. 2.).

60) gezähnt (dentatus): der auf seiner Oberfläche zahnförmige Erhabenheiten hat; z. B. Stapelia concin$n a$ (t. 16. f. 8 .

61) knotig (nodosus): wenn der Stengel in mehrere Glieder abgetheilt ist, die da, wo sie zusammengesetzt zu seyn scheinen, gleichsam knotenförmig aufgetrieben sind; z. B. Peperomia obliqua Ruiz (t. 23. f. 6.).

62) knotenlos (enodis): der weder Glieder noch Knoten hat, und also dem vorbergehenden enfgegen gesetzt ist. Beyspiele geben die mchresten Gewächse.

63) gegliedert (articulatus): der aus mehretn Gliedern besteht, und an den Stellen, wo diese zusammengefüigt zu seyn scheinen, eingezogen ist; z. B. Pelargonium tetragonum (t. 18. f. 3. $\mathrm{a}^{\star}$.), Cactus moniliformis (t. I8. f. I.).

64) gelenkig (geniculatus): der in Glieder abgetheilt, und $\mathrm{da}$, wo diese zusammengesetzt zu seyn scheinen, weder aufgetrieben noch eingezogen ist; z. B. $\mathrm{Pe}$ peromia purpurea Ruiz (t.24. f.6.), Hippnris vulgaris.

65) gleich (aequalis): ein Stengel, der nicht in Glieder abgetheilt, und daher nicht nur den beyden vorhergehenden ( Nr. 63 und 6q.), sondern auch dem knotigen (Nr. 6r.) entgegengesetzt ist. Beyspiele von diesem Stengel geben die mehresten Gewächse.

Die Theile, aus welchen die Stengelarten Nr. 61, 63 und 64 zusammengesetzt sind, heirsen - wie auch sclion aus den gegebenen Definitionen erhellet - Glie. 
bus hi articuli conferti esse videntur, Genicula, et in No. 6r. Nodi etiam dicuntur.

\section{i. Secundum superficiem.}

66) rimosis: si aucta caulis extensione ejus cortex, quod ulterius extendi nequit, tenues agit rimas fissurasve; adeatur Acer platanoides.

67) suberosus: qui cortice molli elastico tectus est; videatur Acer campestre, Quercus Suber.

Reliquae caules huc pertinentes species secundum \$. 9 , ubi de superficie iu universum tractatum est, definiuntur.

\section{k. Secundum vestitum.}

68) nudus:' 'qui vestitu omnino destitutus, et foliis, et squamis iisque similibus caret; ut in Cuscuta europaea (tabula libri inscriptionem gerentis figura 5). Sed hoc nomine etiam pro eo, quod Nris 70 ad 73 oppositum est, utuntur.

69) aplıyllıs: qui foliis caret. Folioso (No. 72.) est contrarius.

70) squamosus: qui folia non fert, eorum autem loco squamis foliis similibus aut carnosis tectus est; videantur Monotropa Hypopithys (t. 20. f. J. a.), Lathraea Squamaria.

71) frondosıs: qui nulla fert folia, sed quiddam his simile, quod frondcm vocant; videatur Equisetum arvense (t. I5. f. 3. b.).

72) foliosus: qui - quod plerumque est - fert folia.

73) alatrus: caulis foliis instructus ad cujus latera expansiones membranaceae decurrunt; videantur Carduus arabicus (t. 18. f. 4. a.), Latbyrus tingitanus (t. 22. f. 2. a.), Scrophularia aquatica. der (Articuli); die Stellen hingegen, wo diese Glieder zusammengefügt zu seyn scheinen, werden Gelenke (Genicula), und bey Nr. 6r. auch Knoten (Nodi) genannt.

\section{i. Nach der Oberfläche.}

66) rissig (rimostis): wenn bey zunehmender Ausdehnung des Stengels die Rinde desselben, wegen Mangel an Dehnbarkeit, dünne Risse oder Spalten bekommt; z. B. Acer platanoides.

67) korkartig (tuberosus): wenn er mit einer weichen, elastischen Rinde bedeckt ist; z. B. Acer campestre, Quercus Suber.

Die übrigen Arten des Stengels, die hierher gehören, werden nach $\$ .9$. , wo im allgemeinen von der Oberfliche gehandelt worden ist, bestimmt.

\section{k. Nach der Bekleidung.}

68) nackt (ııนdıs): der gar keine Bekleidung, weder Blätter, Schuppen, noch etwas diesen ähnliches hat; z. B. Cuscuta europaea (Titelkupfer f. 5.). Man bedient sich aber auch dieses Praedicats als Gegensatz, von Nr. 70 bis 73 .

6g) blattlos (apliyllīs): der keine Blätter hat. Er ist dem beblätterten (N. 72.) entgegen gestellt.

7o) schuppig (spucamosis): der keine Blätter trägt, statt dieser aber mit blattartigen, oder fleischigen Schuppen bedeckt ist; z. B. Monotropa Hypopitlys (t. 20. f. I. a.), Lathraea Squamaria.

7r) belaubt (froudosis): der keine Blätter, sondern etwas diesen ähnliches, was man Laub nennt, trägt; z. B. Equisetnm arvense (t. I5. f. 3. b.).

72) beblättert (foliosis): der - so wie es gewöhnlich der Fall ist - Blätter trägt.

73) geflügelt (alatus): ein mit Blättern versehener Stengel, an dessen Seiten häutige Ausbreitungen lierunter laufen; z. B. Carduus arabicus (t. I8. f. 4. а.), Lathyrus tingitanus (t. 22. f. 2. a.), Scrophularict. aquatica. 
74) perfoliatus: si caulis media fere folia transit; exemplo est Bupleurum rotundifolium (t. 16. f. 4. a.).

75) stipulatus: si caulis eo loco quo folia, vel petioli exsistunt, minoribus insuper foliis stipulae dictis praeditus est; huc spectant Orobus niger (t. I9. f. 5. a.), Vicia biennis (t. 17. f. 4. a. b.), Lathyrus tingitanus (t. 22. f. 2.), Astragalus glycyphyllus (t. I7. f. 2. a.).

76) exstipulatus: qui his foliolis stipulisve destitutus est; videantur Erigeron uniflorum (t. 1. f. 4r.), Silene nutans (t. 13. f. 5.).

77) bulbifer: qui tubera vel bulbos in ramorum foliorumve angulis fert; exemplo sunt Dentaria bulbifera (t. 4. f. I. b.).

78) aculeatus: si caulis pungentibus eminentiis cum cortice detrahendis instructus est; videatur Rosa canina (t. 3i, f. 4. a.).

79) spinosus: si cauli pungentes sunt eminentiae ex ligno oriundae, nec ideo cum cortice detraliendae; huc spectat Genista anglica (t. 26. f. I.).

80) inermis: pungentibus eminentiis destitutus. Binis modo memoratis oppositus est; ejusque exempla plurima exhibent vegetabilia.

\section{l. Secuudum forum fructuumqne feracitatem.}

81) Rorifer: si flores sese explicaverunt.

82) fructifer: si maturos habet fructus.

83) fertilis s. fructificans: qui fructibus ferendis destinatus est et aptus; videatur Equisetum arvense (t. 15. f. 3. а.).

84) sterilis: qui tantum frondem aut folia, nec vero flores fert nec fructus; videatur Equisetum arvense (t. 15. f. 3. b.).
74) durchwachsen (perfoliatus): wenn der Stengel fast mitten durch die Bläıter geht; z. B. Bupleurum rotundifolium (t. 16. f. 4. a.).

75) afterblättrig (stipulutus): wenn der Stengel in der Gegend wo die Blätter oder Blattstiele entspringen, nôch mit kleinern Blättern, die man Afterbiätter nennt, begabt ist ; z. B. Orobus niger (t. 19.f. 5. a.), Vicia biennis (t. 17. f. 4. a. b.) Lathyrus tingilanus (t. 22. f. 2), Astragalus glycypluyllns-(t. 17. f. 2. a.).

76) afterblätterlos (exstipulatus): dem diese kleinen Blätter oder Afterblätter fehlen; z. B. Erigeron uniflorum (t. I. f. 4r.), Silene nutans (t. I3. f. 5.).

77) knollen- oder zwiebeltragend (bullifer): der Knollen oder Zwiebeln in den Winkeln der Zweige oder Blätter trägt; z. B. Dentaria bulbifera (t. 4 . f. r. b.), Lilium Gulbiferuuu.

78) stachelig (aculeatus): wenn der Stengel mit stechenden Hervorragungen begabt ist, die sich mit der Rinde àbzieken lassen; z. B. Rosa canina (t. 3r. f. 4. а.).

79) dornig (spinosus): wenn der Stengel stechende Hervorragungen hat, die aus dem Holze entspringen, und sich daher nicht mit der Rincle abziehen lassen; $z$. B. Genista anglica (t. 26. f. I.).

80) unbewaffnet (inermis): der keine stechende Hervorragungen hat. $\mathrm{E}_{\mathbf{r}}$ ist den beyden vorhergehenden entgegengesetzt; und Beyspiele von ihm geben die mehresten Gewächse.

1. Nach dem Blüthen- und Fruchttragen.

8I) blühend (Alorifer): wenn seine Blumen sich entfaltet haben.

82) fruchttragend (fructifer): wenn er reife Friichte hat.

83) fruchtbar (fertilis s. fructificans): der dazu bestimnıt oder fähig isi, Früchte zu tragen; z. B. Equisetum arvense (t. 15. f. 3. a.).

84) unfruclutbar (sterilis): der blofs Laub oder Blätter, aber keine Blumen und Früchte trägt; z. B. Equisetum arvense (t. 15. f. 3. b.).

85) uni-
85) ein- 


\section{TERIVI NOLOGIA.}

85) $u m i$ - bt-s. triflorus: pro eo, quod unum, duos tresve fert flores. Uniflorum exhibet Erigeron uniflor um (t. I. f. 4r.).

86) paucifinrus: cui pauci tantum sunt flores secundum numerum nondum perpetui; huc pertinent Comarum palustre (t. 8. f. 3.), Ranunculus polyphyllus (t. 28 . f. 3.).

87) multiflorus: qui multos fert flores; exemplo est Ranunculis polyanthemos.

In describendis vegetabilibus si caulis occurrit, cui nec hoc nec illud attributum omnino congruit: utimur voce sub dicentes - si e. g. caulis quidem teres videtur, nec tamen ex toto talis est - : caulis subteres; vel - si magis differt - : caulis tertiufculus,

Vegetabilia caule destituta, quorum structura exterior jam indicat, si cormus ipsis foret, eum caulem futurum, Plantae acaules vocantur; quae vero caule instructa sunt, Plantae caulescentes dicuntur.

\section{§. 52.}

Culmus est cormus herbaceus, fistulofus - raro inanis, - nodis plerumque in articulos divisus, cujus superficies a parte foliorum inferiore arcte adjacente tecta est, ideoque liberi conspici non potest. In Graminibus et Calmariis adest. In his tamen enodis, saepiusque in parte tantum inferiore foliis'involutus apparet. Culmi species maximam partem aeque, ac caulis determinari possunt, eae igitur lic dicendae sunt, quae culmo, quam cauli magis propriae sunt, vel quae ob exempla iis adjuncta eum exhibent usum; ut tironi rationem culmi clarius ob oculos ponant. Sunt sequentes:
85) ein-zwey-oder dreyblumig (uni- bi. s. rifiorl): je nachdem er eine, zwey oder drey Blumen trägt. Einblumig sehen wir ihn z. B. bey Erigeron uniflorim (t. I. f. 41.).

86) armblumig (panciflorns): der nur wenige Blumen hat, die der Zahl nach nicht beständig sind; z. B. Comarum polustre (t. 8. f. 3.), Ramunculus polyphyllus (t. 28. f. 3.).

87) vielblumig (multiflorns): der viele Blumen trïgt; z. B. Ranunculus polyanthenios.

Wenn einem beym Beschreiben der Gewächse ein Stengel vorkommt, zu dem eines oder das andre von den hier aufgeführten Prädicaten nicht ganz passen will: so bedient man sich des Wörtchens fast (sub) und sagt alsdenn - wenn z. B. der Stengel zwar rund zu seyn scheint, aber nicht vollkommen es ist - : ein fast runder Stengel (caulis subteres); oder man sagt auch: - wean er noch nehr abweicht - ein et. Was runder oder rundlicher Stengel (caulis te. retiusculus).

Gewächse, denen der Stiel fehlt, und deren äufserer Bau es zeiğt, dafs, wenn sie einen Stiel bätten, derselbe ein Stengel seyn würde, heifsen stengel. lose Pflanzen (Plantae acaules); die hingegen, wel. che mit einem Stengel begabt sind, werden stengeltreibende. P $£ I$ anzen (Plantae caulescentes) genannt.

\section{§. 52.}

Der Halm (Culmus) ist ein krautartiger, hohler selten markiger, - gewöhnlich durch Knoten in Glieder abgetheilter Stiel, dessen Oberfläche von dem untern, dicht anliegenden Theile der Blätter bedeckt ist, und daher nicht frey gesehen werden kann. Er findet sich bey den Gräsern und grasartigen Gewïchsen. Bey den letztern aber sehen wir ihn ohne Knoten, und öfters auch nur an seinem untern Theile von den Blättern eingehüllt. Die Arten des Halmes lassen sich grölstentheils wie die des Siengels bestimmen, und es diirfen also hier nur diejenigen aufgeführt werden, die entweder mehr dem Halme, als dem Stengel eigen sind, oder 
I) simplex: qui ramis caret; ut in Melica nutante (tabul. libri inscript. gerent. f. 4.), Lolio perenni (t. I2. f. 2.) et Bromo molli (t. 12. f. 4.) videre est, id quod in Graminibus plerisque et Calmariis obtinet.

2) ramosus: qui ramos protrudit; videatur Rottboellia incurvata (t. 25. f. I.).

3) frondosus: qui in multos dividitur ramos, qui apice in expansiones foliis similes transeunt. Et vel ipse est fructifer, vel juxta culmum fructiferum apparet, vel utrumque simul obtinet; ut in Restione trifloro (t. 25 . f. 5. a.).

4) obliquzus: qui oblique directus adscendit, ita ut situs ejus lineam horizontalem inter et perpendicularem incidat, uti tamen ad illam, quam ad hanc proprius accedat; exemplo est Poa annua.

5) infractus s. geniculatus: qui in parte inferiore in morem genu Hectitur; ut in Fottboellia incurvata (t. 25 . f. I. a.).

6) "nodosus: qui nodis in articulatos divisus est; quod in omnibus paene Graminibus usu venit.

7) enodis: qui nodis caret, ideoque totum quoddam haud interruptum constituit, ut in Calmariis videre licet; e. g. in Scirpo campestri (t. 25. f. 4. a.), Scirpo setaceo (t. 23. f. 4. a.), Scirpo capillari ( 6.26 . f. 7.); porro in gencrum Junci, Caricis, Typhae et ceterorum speciebus.

8) filiformis: qui est teres, enodis neque crassus; rideantur Scirpus campestris (t. 25. f. 4. a.), Juncus filiformis.

9) setaceus: si filiformis est, et a basi versus apicem sensim gracilescit; tali gaudet Scirpus setaceus, ( $t .23$. f. 4. a.).

10) capillaris: si culmus filiformis capilli tenuitatem die, vermöge der dabey angeführten Beyfpiele, dazu dienen können, dem Anfänger den Begriff vom Halme melır anschaulich zu machen. Es sind folgende:

I) einfach (simplex): der keine Äste hat; z. B. Melica nutans (Titelkupfer f. 4.), Lolinm perenne (t. 12. f. 2.), Bromus mollis (t. 12. f. 4.), und wie überhaupt die mehresten Gräser und grasartigen Gewächse.

2) ästig (ramostus): der Äste hervortreibt; z. B. Rottboellia incurvata (t. 25. f. 1.).

3) belaubt (frondofius): der sich in viele Äeste zertheilt, die an der Spitze in blattartige Ausbreitungen übergehn. Er ist entweder selbst fruchttragend, oder er zeigt sich neben dem fruchttragenden Halme, oder es finden auch beyde Fälle zugleich Statt; wie z. B. bey Restio triflorus (t. 25. f. 5. a.).

4) schief (obliquzts): der in schiefer Richtung in die Höhe steigt, so dafs seine Lage zwischen der wagerechten und senkrechten Linie fält, wobey er sich jedoch mehr der erstern als der letztern nähern darf; z. B. Poa annua.

5) eingeknickt (infracius s. geniculatus): der an seinem untern Theile knieförmig gebogen ist; z. B. Rottboellia incurvata (t. 25. f. 1. a.).

6) knotig (nodofils): der durch Knoten in Glieder abgetheilt ist; wie z. B. fast bey allen Gräsern.

7) knotenlos (enodis): der keine Knoten hat, und dalıer ein ununterbrochnes Ganzes ausmacht, wie bey den grasartigen Gewächsen; z. B. Scirpus campestris (t. 25. f. 4. a.), Scirpus setaceus (t. 23. f. 4. a.), Scirpus capillaris (t. 26. f. 7.); ferner die Arten der Gattungen Juncus, Carex, Typha u. m. a.

8) fadenförmig (filiformis): der rund, knotenlos und nicht sehr dick ist; z. B. Scirpus campestris (t. 25 . f. 4. a.), Juncus filiformis.

9) borstenfürinig (setaceus): wenn er fadenförmig ist, und ron der Basis nach der Spitze zu sich allm.ïllig verdünt; z. B. Scirpus setacens (t. 23. f. 4. a.). 10) hąarförınig (capillaris): wenn ein fadenförmi- 
fere adaequans eundem in tota longitudine diametrum servat; ut in Scirpo capillari (t. 26. f. 7.) manifestum est.

II) vaginatus: qui a parte foliorum inferiore vagina nominata circumdatur, id quod in omnibus Graminibus, nec non pluribus Calmariis, e. g. in Lolio perenni (t. 12. f. 2.), Bromo molli (t. 12. f. 4.) Carice Hava vel Oederi (t. 36. f. 3. a.), conspicuum est.

12) nudus; qui non ab inferiore foliorum parte, vel vaginis circumdatus, interdum tamen inferius in basi a vagina brevi tectus est; exempli loco sunt Scirpus setaceus (t. 23. f. 4. a.), Scirpus campestris (t. 25. f. 4. a.).

\section{§. 53 .}

Scapus est cormus herbaceus non folia sed tantum Hores et fructus ferens. Non in Liliis solum, quiLus maxime proprius, sed in aliis etiam vegetabilibus reperitur; in his tamen floribus pluribus praeditus sit, rel si unum tantummodo fert florem, cum eo non ipse per se, sed pedunculi interventu conjunctus sit, oportet. Species scapi obviae eo plerumque modo, quo caulis species distinguuntur, ideoque eae, quae scapo, quam cauli magis propriae sunt, allegandae videntur:

1) filiformis: qui longus est, teres et tenuis; videalur Draba verna (t. 25. f. 2. 6.).

2) cylindricus: si est teres, crassus et superius et inferius eundem habet diametrum; exenplo sit Haemanthus tigrinus (t. 3o. f. 3. a.).

3) attenuatus: qui apicem versus tenuior evadit; ut in Ornithogalo comoso (t. 34. f. 4. c.).

4) incrassatus: qui apicem versus sensim suclus crassescit; videatur Ornithogalum spathaceum (t. 27. f.4. b.). ber Halm fast so dünne wie ein Haar, und durchaus von gleichem Durchmesser ist; z. B. Scirpus capillaris. (t. 26. f. 7.).

II) gescheidet (vaginatus): der von dem untern Theile der Blätter, den man die Scheide nennt, umgeben wird, wie bey allen Gräsern und auch bey mehreren grasartigen Gewächsen; z. B. Lolium perenne ( $\mathrm{t}$. 12. f. 2.), Bromus mollis (t. 12. f. 4.), Carex flava oder Oederi (t. 36. f. 3. a.)

12) nackt (nudus): der nicht von dem untern Theile der Blätter oder den Scheiden umgeben ist, jedoch zuweilen ganz unten an seiner Basis von einer kurzen Scheide bedeckt wird; z. B. Scirpus setaceus (t. 23. f. 4. a.), Scirpus campestris (t. 25. f. 4. a.).

\section{§. 53.}

Der Schaft (Scapus) ist ein krautartiger Stiel, der keine Blätter, sondern blofs Blumen und Früchte trägt. Er findet sich nicht nur bey den Lilien, denen er vorzüglich eigen ist, sondern auch bey andern Fewächsen; jedoch mufs er bey letztern entweder mit mehreren Blumen begabt seyn, oder, wenn er nur Eine Blume trägt, nicht unmittelbar, sondern vermittelst eines Blumenstiels mit dieser in Verbindung stelm. Die vorkommenden Arten des Schaftes werden mehrentheils so wie die des Stengels unterschieden, und es verdienen daher nur noch folgende, die mehr dem Schafte als dem Stengel eigen sind, angeführt zu werden, als;

I) fadenförmig (fiiformis): der lang, rund und dïnne ist; z. B. Draba verna (t. 25. f. 2. b.).

2) wal z enförmig (cylindricus): wenn er rund, dick, und oben und unten von gleichem Durchmesser ist; $z$. B: IIaenanthus triginus (t. 30. א. 8. a.).

3) verdünnt (attermatus): der gegen die Spitze dünner wird; z. B. Ornitlogalum comofum (t.34.f.4.c.).

4) verdickt (incrassatus): der siclı gegen die Spitze nach und nach erweitert, und also dicker wird; z. B. Ormithogalum spalhacemm (t. 27. f. 4. b.).

K 2 
5) vaginatu's: si in basi vagina circumdatus est; tali - gaudet Galanthus nivalis (t. 3. f. 4. 5.).

6) polystaclyyus: si in quosdam ramos, quorum quilibet plures fert flores, dividitur; exempli loco sunt Anthericum flexifolium (t. 3o. f. 6.), Lxia polystachya.

Linnaeus dicit in Drosera : scapis radicatis, et in $\mathrm{O}_{s}$ munda: scapis caulinis, sed neutrum scapo recte attribuitur; illud enim abundat, et hoc notioni de scapo contrariatur,

Cum scapus species cormi sit, pedunculus vero pars ejus (\$. 48.) 1antum haberi possit; apparet hunc illi quidem esse subjectum, nec vero eodem, quo ille lo. co haberi posse; atque utrumque, ubi alter in alterum non transit - ut in Liliis - sed tantummodo transire videtur, probe esse distinguendum. At vero scapus uniflorus et pedunculus radicalis nullo modo disingui possunt, nisi statuas, partem, quae adest, tum denique scapum dicí posse, si flos non per se, sed pedunculi ope ei conjunctus est; sed pedunculum radicalem tum recte vocari, si a caudice $\nabla e l$ descendente $v e l$ in. termedio ad florem usque totum quoddam continuum constituit. Secundum hanc regulam - quae vero ex causis jam dictis in Liliis non obtinet - Oxalis Acetosella scapum possidet; Cyclamen europaeum contra pedunculum radicalem. Leontodon Taraxacum, Bellis perennis, Hieratium Pilosella et plura hujusmodi sca. pum habent, quia plures ferunt flores. Receptaculum commune pro pedunculo composito, qui nec expandi. tur nec dividitur, sed arcte densus remànèt, in iis ha. bendum est.
5) 'gescheidet (vaginotus): wenn er an der Basis mit einer Scheide ungeten ist; z. B, Gulanthus nivalis (t. 3. f. 4. 5.).

6) vielährig (polystachyus): wenn er sich in einige Äste zertheilt, von denen jeder mehrere Blumen trägt; z. B. Aniluericum Alexifolium (t. 3o. f. 6.), Ixia polystachya.

Linne sagt bey Drosera: scapis radicatis, und bey Osmunda: scapis caulinis; aber beyde Pràdicate können nicht wohl dem Schafte beygelegt werden; denn das erstere ist überflüssig, und das letztere dem Begriffe rom Schafte widersprechend.

$\mathrm{D}_{a}$ der Schaft eine Art des Stiels ist, der Blumenstiel aber nur als ein Theil desselben (\$. 48.) betrachtet werden kann: so folget hieraus, dafs letzterer dem erstern zwar untergeordnet, aber nicht gleichgeordnet werden datf; und dafs beyde, da wo sie nicht wirk- lich in einander übergehn - wie bey den Lilien sondern nur in einander überzugehen sclieinen, wohl unterschieden werden mulssen. Der einblumige Schafi (Scapus uniflorus) und der wurzelständige Blumenstiel (Pedunculus ralicalis) lassen sich aber gar nicht unterscheiden, wenn man nicht festsetzt, dals der vorhandene Theil nur alsdann $S c h a f t$ lheirsen kann, wenn die Blume nicht unmitelbar, sondern vermittelst eines Blunıenstiels mit ihm verbunden ist, wnrzelständiger Blumenotiel hingezen, wenn er von dem niedersteigenden Stocke, oder vom Mitıelstocke bis zur Blume ein ununterbrochnes Ganzes ausmaclit. Nach dieser Regel - die aber, aus den sçhon angeführten Gründen, bey den Lilien niclıt angewendet werden kann - hat Oxalis Actosella einen $\mathrm{Sch}$ a t, Cyclamen europaeum hingegen cinen w urzel. ständigen Blumenstiel. Leontodon Taraxaeum, Bellis perennis, Hieratium Pilosella und mehrere der. gleiclien haben einen Schaft, weil sie mehrere Blumen tragen. Den gemeinschaftlichen $B$ fruchtungsboden muls man bey ihnen als einen zusammengesetzten Blumen. stiel betrachten, der sich nicht ausbreitet oder zertheilt, sondern zusammengedrängt bleibt. 
TENMI:NOLOGIA.

Tegetabilia cormo destituta, cctcroģian rero ratione sulcturac externac crum is convenientia, quorum core Jius est scrpus, dicuntur vegetabilia exscapa; ea con1ra, quae scapo predita sunt, regetabilia scaj igrera nomirantur.

\section{S. ว่.}

Sripes cst cormus Palmis, Filicibus et Fungis proprius, lrac re insignis, quod in folis simili cxpansione quam foliorum loco fert, in unum quasi confluit. Palmarum Filicumque stipiti calem fere structura est; Fungorum vero stipcs ab co natura externa aeque, as interna admolum differt, ita nt, quem scparatim spectemus, dignus sit. Stipitis specics sunt:

\section{a. In Palnis et Filicibus.}

I) tcres: vid. \$. 5r. Nr. 54.; Corypha rotundifulia (t. II. f. I.), Adlantum albicans (t. 6. f. 6.) monsirant.

2) compressus: vid. S.5I. Nr. 56.; Clamaerops hunilis (t. I I. 1. 3.) indicat.

3) canaliculatus: qui in altero latcrc secundum longitudinem sulcum profundun habct; exemplo est Danea alata (t. 6. 6. 5.).

4) palcacers: in cujus superficie squanae admodum tencrae, siccae, paleaceac conspicimtur; cxcmpli loco sit Darallia pedata (t. $=6$. .5 . а.), Polypodium Filix mas.

5) squamostz: qui squamis membranaccis tfclus cst; videatur Asplenium squamosum (t. 29. ศ. 2. a.).

6) alatns: in cujus duobus lateribus oppositis expansiones membranaceae decurrunt; ut in Danea alata (เ.. 2g. f. I. a.).

7) mulus: qui neque expansiones menubranaceas, neque squamas paleaceas vel membranaceas habet, atque
TER II I OLOG $1 \mathrm{E}$.

Gewäclısc, cie keinen S:iel haben, übrigens abcr in Rüclisicht desaussern Dares mit čenen übcreinkommen, deren Stic! cin Schaft ist, licifsen scla ftlose Ge. waclise, (I'regetabilia exscapa); die liugrgen, welche mit eincm Schafte bczalt sind, werden schaftrei. bende Gew ächse (I egelabilia fapigera) Eenannt.

\section{S. j.j.}

Der Strnnk (Stipes) ist der dỏn Filmen, Furrenkräutern und Pilzen eigene Sticl, der sich dadurch auszeichmet, dals or mit eincr blatiartigen Ausbrcitung, die cl slatt der Blitter trïgt, gleiclisam in Eíns zusammen Hiofst. Der Strunk der Palnen und der der Farrenkrïuter sind ziemlich übereinstimmend gebildet; der Sirunk der Pilze hingegen wicht ron diesen, sowobl seincr innem als ïulsern Tescliaffenheit nach, sehr ab, so dafs er besoncters bctrachtet zu werden verdicnt. Dic Arten des Strunkics sind:

a. Dey den Palmen und Farrenkräutern.

1) rlind (leres): S. S. 5r. Ni. 5f.; z. B. Coryplea roumalifolia (t. II. I. I). Adiantum albicans (t. 6. I. 6.)

2) zusammengedrückt (compiessus): ' S. S. 5 r. Nr. 56.; z. B. Chamaerops humilis (t. I I. r. 3).

3) rinnenförmig (canalicu!alus): der auf einer Site der Länge nach cine ticfe Furclıe hat; z. B. Danea alata (1.6. 5. j.).

4) spreuartig (palencous): der auf seiner Oberfliche sely zarte, trockne, spreuarige Schuppen liat: z. B. Davallia pedatu (t. 26. 1.5. a.), Polypodium $\mathrm{Fi}_{\text {- }}$ lix mas.

5) schuppig (squamosus): der mit Mäutigen Schuppen bedeckt ist; z. B. Asplenium souamosum (t. 29 . f. 2. a.).

6) geflïgclt (alaius): weun bey ilun an zwey gegcnïiberstclıcnden Seiten hiutise Atusbrcitungen lıcrunter laufen; z. B. Danea alala (1. 29. f. I. a.).

7) nackt (nudus): der weder häulige Ausbreitungen, noch spreuartige oder hïutige Schuppon hat, und also 
ita tribus modo memoratis contrarius est; adeatur Corypha rotundifolia (t. II. f. I.), Polypodium vulşare

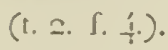

8) nodostz: vid. S. 5r. Nr. 6r; exempli loco sint Darea alita (t. 20. f. I. a.), Danea nodosa.

(1) emodis: vid. \$.5!. Nr.62.; inspiciatur Polypodinm vit? (t. 2. f. 4.).

Io) aculeatus: vid. \$. 5r. Nr. -8.; exemplo est $\Lambda$ diantum aculeatum (เ. 2-. . . 6.).

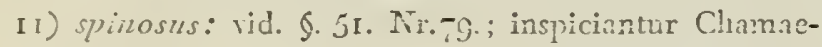
rops humilis (t. I I. f. 3.), Cycas circinalis (1. I I. f. 2.).

I2) inermis: vill. \$.5 . Nir. 80.; invenitur in Corypha rotundifolia (t. II. f. I.), Polypolio vil gari (t.2. f. 4.).

\section{b. Iit Filngis.}

I) carnosus: qui pro substanita porosus ei lumore repletus est; videatur Eolcâus borirus.

2) coriccetts: qui siccis constat fibris; ut in Boleto perenni.

3) fistulostı: vid. S. 5 r. Nr. IO; Agaricus ceracens Sowerby (t. 20. f. 3. $a^{*}$ ).

4) solidus: çni caro destitutus est; videatur $\Lambda$ garicus croceus Soberby (t. 20. f. 2. $a^{*}$.).

5) sinplex: qualis plemuque apparet, rui nempe ramis destitutus est; exempli loco sint Agaricus procerus (t. 6. f. I. a.), Agaricus ceraceus (t. 20. f. 3. a.), Agaricus croceus (t. 20. f. 2. a.), Agaricus peronatus (t. 20. f. 6. a.) et pl. al.

6) ramosus: qui in ramos divichitur; exemplo est Boletus (t. =3. f. ..).

7) cylinaricus: vid. 5. 53. Nr.2.; invenitur in Agarico piperato (t. 33. f. Io. a.).

8) ventricosus: cujus pars media, inferiore et simeriore, crassior est; inspiciatur Agaricus cepaestipes Sowerby (t. 20. f. g. a.). den drey vorhergehenden entgegengesetzt ist; z. B. Coyophat rotundifolia (1. I I. f. I.), Polypodium unlgare (1. 2. f. 4. - .).

S) knotig (nodosus): S. S.5r. Ni. 6r.; z. D. Danea aírta (t. 29. I. I. a.j, Danca nodosa.

(1) knotenlos (enodis): S. S. 5r. Nr. 62.; z. D. Polypodinm mlgare (t. 2 f. 4.).

Io) st a chelig (aculcatus): S. S. 5r. Nr. - ?.; z. E. Adiantum aculeatum (t. 27. f. 6.).

I I) dornig (spinosus): S. S. 5I. Nr. 79.; z. B. Cluamacrops lutumilis (t. II. f. 3), Cycas circincalis (t. II. 5. 2.).

I2) unbewaffnet (inermis): S. \$.5r. Nr. 80.; z. B. Corypha rotundifolia (t. II. f. I.), Polypodinn sulgare (t. 2. f. f.).

\section{b. Bey den Pilzen.}

I) fleischig (carnosus): der, seiner Substanz nach, porös und mit Feuchtigkeit erfüllt ist; z. B. Boletus bovinus.

2) lederartig (coriaceus): der aus trocknen Fasern bestcht; z. B. Boletus perennis.

3) hohl oder rührig (fistulosus): S. \$. 5I. Nr. Io.; z. D. Agaricus ceraceus Sowerby (1.20. f. 3. a*.).

4) fest (solidus): der keine Höllung hat; z. B. $A g a-$ ricus croceus Sowerlyy (t. 20. S. 2. a*.). •

5) einfach (simplex): wie er gewöhnlich bemerkt wird, nünlich ohne Aesic; z. B. Agaricus procerus (t. 6. f. I. a.), Agaricus ceraceus (t. 20. f. 3. а.), Agaricus croceus (t. zo. א. 2. a.), Agaricus peronatus, (t. 20. গ. 6. a.) u. m. a.

6) äsıig (ramosus): der sich in Aeste zertheilt; z. B. Boletus ramosus (t. 23. f. - . .).

7) walzenfürmig (cylindricus): S. \$. 33. Nr. 2; z. B. Agaricus pipratus (t. 33. f. 10. a.).

8) bauchig (witricosus): wenn der mittere Theil dicker, als der untere un 1 obere ist; z. B. Agaricus cepraestipes Sowerly (t. 2. f. g. a.). 
9) Iuberosis s. Zulinosizs: cujus basis arles o t di'alata, ut ea tuberi vel bulbo similıs sit; e. g. in 1 saico jrocero (t. G. f. 1. a.).

10) tortus: si stipitis fibrae rectace non sunt, sed in modum spirae tor quentur; inspiciatur Agaricus $S_{p}$ hinx Datsch (t. 33. f. G. a.).

I I) lacunosus: cujus superficiei permuliac sunt depressioncs; vileatur Helvella sulcata (t. 20. ᄃ. ૬. a.).

12) peronaius: cujus pars inferior luterogenia quasi substantia obducta apparet; inspiciatur Agaricus peronatus (1. 20. f. 6. a.).

13) squamosus: qui squamis adjacentibus tectus est; e. §. in Agarico squamoso l'ers. (t. 35. f. 3. a.).

If) squarrosus; qui squamas liabet patentes apiribus subreflexis; videatur Agaricus croceus Sowerby (t. 20. f. 2. a.).

15) mudus: in cujus superficie neque scpuanac, neque aliud quoddam integumentum conspicitur, indeque et tribus praegressis et sequenti oppositus est; exempli loco sint Agaricus ceraceus Sowerby (t. 20. ศ.3. a.), Agaricus castaneus Bolt. (1. 20. f. 8. a.).

I6) armuleztis: qui menibrana anmuli formam reférenie cincius est; ut in Agarico procero (t. G. ᄃ. I. ab.), Agricus cepacstipes Sowerby (t. 20. א. 9. ab) ).

17) exannulutus: qui membrana lmjusmodi annuli formam referente caret; inspiciantur Agaricus craceus Suwerby (t. 20. โ. 3. a.), Agaricus crocels Sowerby (t. 20. 1. 2. a.), Agaricus peronatus (1.20. א.G. a.) et pl.al.

Eae stipitis specics, quae secundum directionem ct superficiem distingui forte possunt, co, quo caulis species ( $\$$. 5r. f ct i) modo determinan:ur.

Ir Palmis et Filicibus quibusdam stipes ex caudice (5. 49.) nasciur, nec ob id cormus, sed non nisi pars ex diviso cormo orta apparct. Cum vero Palmarum
9) knoilis oder zwicbelartig (tulerosis s. butlos.l): W(1n ex an scincr I?: is so siark erweitert ist, dal's dicschlo fast cinen Ino?en odce ciner Zwiebel

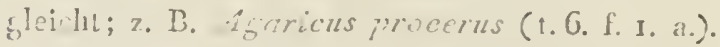

10) godrehel (iortus): vis an die Fasern des Sirunkes nicht gerade fortlaufen, sondern spiralfürmig sich win-

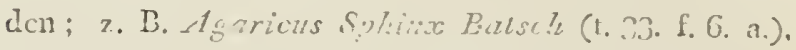

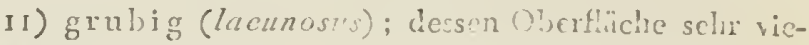
le Tertiefungen hat; z. D. Ilelbelius suicain (t.20. . 7. a.). I2) gestiefelt (perouatis): desscn micrer Theil gleichsam wie mit einer fremden S.rbstanz umgeben erscieint; z. B. Agaricus peroratus (t. 20. f. 6. a.).

13) schuppig (squanosus): der mit anlicgenden Scluuppon bedeckt ist; z. I. Ljaricus squamosus Pers. (1. 35. 1. 3. a.).

I ئ) sparig (sq:uarosizs): der abwïtssteliende, an den Spizen zurïcligebogene Schuppen hat; z. L. Agarirus crnorus Surwerly (t. 20. א. 2. a.).

15) nackt (nuths): ly don sich wodnr Scluppen, nocls eise andcre Dedeckung aus der Oberltïcise finden, und weshalb er also sowoll den drey vorhergehenden als auch dem folgenden entrgengesetzt ist; z. B. Agaricus ceracews Sowerby (t. 20. โ. 3. a.), Agaricus castancus Bolt. (t. 20. א. 3. а.).

16) geringe/t (aımalatus): der mit einer ringförmigen Haut umgeben ist; z. B. Agaricus procerus (t. 6. f. r. ab.), Agaricus cmanclsipes Sowerby (1.20. 1. 9. ab). I.) ungeringelt (cxamulatus): der keine dergleichen ringfürmige Haut hat; z. D. Agaricus ceracens Sowerly (t.20. S.3. а.), Agaricits riocens Sowerby (t. 20. 1. 2. а.), Agaricus peroulltis (t. zo. א. G. а.).

Diejenigen Arten des Sirunlics, die sich etwa noch naclı der Richtung und OberAiche usterscheilen las. scn, werden so wic bey dem Siengel ( $\$ .5$ r. f und i) bcstimmt.

Bey den Palmen und einiren Farrenkräutern entspringt der Strunk aus dem Stocke (\$. 49.) und er- clieint daher nicht als Stiel, sondern nur als cindurch Zertheilung des Stielscntstandener Theil. Da aber der I. 2 
Tilicumque nonnullarum caldex nil, nisi rtiroma s:1pra terram elatum, seu eaudex intermadius rhizomatoidens ( $\$$. 49. observatio) sit, sipes vero - qui in. super in Filicibus plurimis, quarum rlizoma infra terram latet, per se ex radice prodit - caudici adscendenti adnumcrandus sit: linc manifestum est, stipitem his ipsis in regetabilibus, in quibus ex caudice nascilur, quadan ratione non nisi pro aliqua cormi parte, alia autem majore cum jure ipso pro cormo posse liaberi.

In Fungis stipes saepius desideratur, iisque tum Fungi exstipitati rocantur; at vero stipite instructi Funge i stipitati nominantur.

\section{§. 53.}

Surculus est Muscomen comms, in qro hoc peculiare animaurertim, guod arcte folis obsitus sil, ct ea plerumque sine peiclo ferat. Hae distingumfur species :

I) simplex: qui in ramos hand diuncitur, in Folytricho communi (t. IO. f. I. a.) perspicuun est.

2) ramosts: qui in ramos sese cxplicat; exempla sunt Hypnum lutesccus (t. 10. f. G.), Hypnum proliferum (t. 2.̣. f. 5.), Hypnum parietinum (1. 2-1. . 8. 8.).

3) rogus: si est ramosus, ramique rariores nulloque ordine positi sunt; in Hypno Iutescente (t. IO. f. 6.) manifestum cst.

4) pimatus: si in duobns contra se positis surculi lateribus rami ita collocali sunt, ut uni omnes plano incubent; videatur Hypnum filicinum (t. 24. f. 7.).

5) Gipinnatus s. duplicato-pinuatus: si in duobus oppositis surculi lateribus plures prodeunt rami, uni in-
Stock der Palmen und cinigex Farrenliäuter eigentlich nur cin über der Erde sich befindender Wurzelstock, oder cin wurzelstockartiger Mittclstock (\$. 49. An. merkung) ist, der Strunk hingegen - der überilies bey den mclisten Farrenkrüutern, deren Wuraelstock unter der Erde licgt, unmittelbar aus dcr Murzel hervorkommt - zmm aufsteigenden Stocke gercelinet werden muls: so ergiebt siclı lieraus, dals man den Strunk, selbst bey denen Gewaclisen, wo er aus dem Stocke entspringt, in einer Hinsicht nur als einen Theil des Stiels, in anderer aber mit meluerem Reclue als den Stiel selbst betrachten kamn.

Bei den Pilzen felht öfters der ctrunk, und dann nenut man sie struuklose Pilze (Fungi exstipirati); wenn sic aber mit einem Strunke verselren sind, so heifsen sie strunktreibendePilze (Fungi stipitati).

§. 55.

Das Stiimmchen odor der Moosstengel (Surculus) ist der Siiel der Moose, an dem man das Eigenthümliche bemerkt, dal's er sehr dicht mit Blättern besetzt ist, und dieselben gewöhnlich obne Blattstiele trägt. Man unterscheidet folgende Arten des Stämmchens:

I) einfach ( $\operatorname{simplex)}$ : das sich nicht in Aeste zertheilt; z. B. Polytrichum commune (t. IO. f. I. a).

2) istig (ramosus): das sich in Aeste verbreitet; z. B. Hypunum lutesceus (t. Iо. f. 6.), Iypumm proliferum (t. 24. f. 5), Hypumm parietimum (t. 24. f. 8).

3) zerstreut ( $\operatorname{ag}$ gls $)$ : wenn es ästig ist, und die Aeste etwas weitlüufig und ohne Ordnung gestellt sind; z. B. Iypuzuz lutescens (t. I0. f. 6).

4) geriedext (pimuatus): wenn an zwei gegenüberstelienden Seiten des Strimmchens die Aeste so gestellt sind, dafs sie alle in einer Fläche liegen; z. B. $H_{y} p-$ unun filicinum (t. 2f. f. .).

5) doppelt gefiedert (bipinnatus s. duplicatopiunatris): wenn an zwey gegeniberstehenden Seiten des Stämmchens mehrere $\Lambda$ este hervorkommen, dic in 
cubantes plano, quorum quilibet surculi pinnati similitudinom $r \in$ fert; adeatur Hypnum parietinum (t. 2;. f. o.).

(6) tripimatus s. triplicato-pinnatus: si plures rami in duobus adversum se positis surculi lateribus uni incubantes plano inveniuntur, quormm quisque surculi duilicato-pinnati formam cxhibet; ut in Hypno prolifero (t. 2-. f. . 5.).

7) prolifer: si ex veteriore novi sese erolvunt; cxempli loco sit Hypnum p:oliferum (t. 24́. f. 5.).

8) dendroides s. fasciculatus: si crectus et in partc inferiore simplex est, ad apicem rero fasciculatim in plures diducitur ramos, ut ca re minoris arbusculac faciem nanciscatur; videatur Neckera dendroides ( $\mathrm{r}$ ro. f. 8.).

9) erectus: vid. \$.5r. Nr. 3o.; excmplo sint Polytrichum commune (t. Io. f. r. a.), Neckera dendroides (t. 10. f. 8.).

10) procumbens: vid. \$. 51. Nr.3r; inspiciatur Hypnum parictinum (t. 2-4. โ. 3).

II) depressus: cujus pars inferior terrae incubat, superior vero in directione diagonnli suberectus attollitur, ita ut depressus csse vidcatur; in Hypno lutescente (r. ro. f.6.) videre licet.

I2) repens: qui decumbit, radiccs in terram agit, ramos vero magis uninusque ercctos attollit; in Hypno velutino (t. Io. f. f́) apparet.

I3) intricatus: si plures surculi procumbentes seu repentes cespitem fingunt et sibi invicem quasi intricati sunt; Hypnum intricatum inclicát.

If) Auitans: qui horizontaliter dircctas secundum totam longitudinem in aqua fluitat, et cujus basis non alte infra aquae styerficiem inhaeret; videatur Fontinalis antipyretica. ciner Füche liegen und ron dencn jeder einem gefiederten Stämmchen gieicht; z. B. IIypnnm parietinnm (1. $2-i .5 .8)$.

6) dreyfach gefiedcrt (iripinnatus s. triplicatopiunatus): wenn melurcre Aeste an zwcy gegenübcrstehenden Sciten des Stämmchens in einer Fläche liegend sich finden, ron denen jedcr eincm doppelt geficderten Stümmclsen ïlnnlich ist; z. D. Ihymum prolifernm (t. 24. โ. 5 ).

7) sprossend (prolifer): wenn aus dem ïltern sich

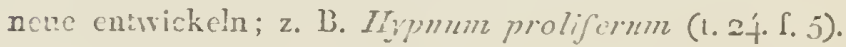

8) b a umïlnnlich oder bîtschelfürınig (dendroides s. fasciculatus): wena es aufrecht und an seinem untern Theile cinfach ist, gegen die Spitze aber sich büschelfürmig in melırere Aeste zerilıcilt, so dafs es ditdurcls das Ansehen eincs kleincn B.̈̈mmchens belomm; z. B. Iicckera dondroides (t. I O. f. 3).

9) aufreclit (erectus): S. S.jo. Mr.3o.; z. B. Polytrichun commune (t. IO. Г. I. a), Nechera dendroides (t. 10. f. 8).

I0) gestreckt (procumbens): S. 51. Nr. 3r.; z. D. H.pnum parietinzm (t. 24. ศ. 8).

II) nicdergcdrückt (depressus): wenn es mit seinenu untern Theile auf der Erdc liegr, mit dom obcrn aber sich in diagonaler Richtung etwas aufrecht crhebt, so dafs es scheint als ob es niedergedruickt wïre; z. B. IIJpnzm lutescens (t. Io. ᄃ. (6).

12) kriechend (repens): das niederlięt, Wurzeln in die Erde treibt, seine Aeste abor melrr oder weniger aufrecht erhebt; z. B. Hypunum ('clutinum (t. Io. ᄃ. 千).

13) verwebt (intricatus): wonn melirere gestreckte oder kriechende Stïmmelien cinen Finsen bilden tind untor einander gleiclsain verwebt sind; z. D. Ir, yettuz intricatum?

If) schwimmend (Anitans); das in honizontaicr Richtung einer źanzen Lïnçe nach im Wasscr schwimmt und mit sciner ganzen Basis nicht tic $\int$ unter der Wasscrfläche befestigt ist; z. B. Fontinalis antipyreticz. 


$$
\text { TERMINOLOGIA. }
$$

Mrusci surculo dcsituti, quod in nonnullis gincris Flasci specicbus obrinct, csurcillati rocantur, qui rero surculo instrnci sum, strulati dicuntur. Illos quiden acastes, los rablescontes plermmque vocant; lace vero nunina minis sumt apta, cum is tantum vegetalilibus applicari possint, quorum cormus cs: culalis.

\section{ร. 56.}

Sarmentum est cormus filiformis, uudus, decumbens, ex radice juxta erectum cormum proveniens, qui apicc, ubi blastema continet, radices in terram agit, novumque evolvit individum, ex quo sursus unus pluresque sui generis cormi - sarmenta pula - protruduntur. Samentum in is tantum vegetabilibus plerumque reperitur, quorum cormus ercctus scapts cst, ut in Fragaria vesca (t.27. f.5. a.), Saxifragn samentosa ct pl. al. Proprie autem ct in subacormosis et snbcormosis vegetabilibus ( $\hat{y}$. 430. Obscrv) sarmentum adest, in quibus tamen caulem id habere constierunt. Excmpla praebent Ranumculus reptans (t. 10. f. . b.) ct Potentilla reptans.

Vegetabilia, quae sarmentorum ope propasantnr, Plantae samentiferae, vel lationi in scnsu Fégerbilia sarmentifera appellantur.

\section{5. $5:$}

Srolo est cormus folia ferens, decumbens, ex radice juxta cormum erectum nascens, et in lintere inferiole, quo terram tangit, radices, apice antem folia tantum, interclum flores etinm protundens. In is
TERMI IOLOG 1 F.

TTenn bey den Moosen das Stummchen felult, wie z. L3. bey cinigen Arten der Gallung Füscum, so nennt man sic stammelrenlose Rio ose (Tinsci csurculati); dic lingezen, bcy denen das Stimmcisen zngegen ist,

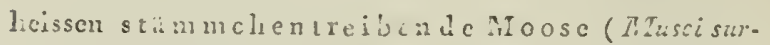
(ulati). Gewölnilich nennt man zwar cic erstern stengncllose (acaules) und dic lctzterin stengeltrei. b cude (caulescontes); aber dicse Ausclücke sind weniger prassend, da sie sicl wur bey solchen Gerwithsen gebruclien lassen, deren Sticl cin Stenerel ist.

\section{S. 56 .}

Dic Ranke (Sarmentum) ist ein aus der Wurzel neben cincm aufrechten Stiele hervorkommender, fadenförmiger, nackter, niederliegender Stiel, der an der Spitze, wo cr einen Keim cnthäl, Wurzeln in die Erde schlägl, und ein neues Individuum entwickelt, aus welchom wieder ein oder mehrerc Stiele sciner Art - nämlich Ranken - hervorgetrieben worden. Die Ranke findet sich gewölnnlich nur bey solchen frewäclısen, deren aufrechter Stiel ein Schaft ist, wie bey Fragaria yesca (t. 27. f. 5. a.), Saxifraga sarmentosa u. m. a. Eigenulich findei sie sich aber auch bey den fast stiellosen und fast sieltrcibenden Gewälısen (\$. 43. Anmerlumg), wo man aber grewolmt ist, sie für einen siengel zu balten. Jiysyicle geben Iunnmculus reptans (t. 1o. f. 9. b.) und Potensilia repians.

Gewachse, die sich durclı Panken fortphanzen, werden ranlentreibende pilanzen (Flantae sarnentiferac), oder, im weitern Sinne rankentrcibende Gew i clise (ergetabilia sarmentifera) genannt.

S. 57.

Die Sprosse (Stolo) ist cin aus der Wurzel neben einem aufrechten Stiele hervorkommender, blättcrtragender, niederliegender Stiel, der auf seiner untern Scite, wo er den Boden berïhrt, Wurzeln schiligt, aus 
plemunque vegetabilibus, quibus cormus erectus juxta cum proveniens vel caulis vel scapus est, reperitur. Illa in

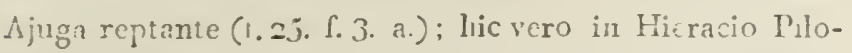
sclin, PLisricio dubio et IIierncio Auricula conspicitur.

Tegetabilia stolonibus praelita Prantae stcloniferae, Iatiore vero significatione I'getabilia stóonifora nomi. nantur.

\section{§. 53 .}

Rami surt partes ex cormi divisione orientes, quae secundum structuram ipsi cormo siniles sunt, et phura folia floresque ferunt. Rami ulterius si dividuntur, partesque inde nascentes iis ipsis similes sunt: hac partes Ramuli vocantur. Ex rinmorum numero lii sunt notandi :

1) simplices: in ramulos sese non dispergentes; videntur Carlina rulgaris (i.2r.f. I).

2) raunsi: qui in ramulos diducuntur; ut in Ocimo minimo (t. 15. f. 2.).

3) alterni: si ramus alius alio altior, ita tamen, ut inter binos hujus lateris unus tantum in opposito latcre inveniatur; excmjllo est Ficus stipulacea (t. 12. f. 3.).

4) oppositi: si rami ita sunt collocati, ut bini eadcm altitudine, in duobus tamen opnositis cormi lateribus adsint; in Rhinantho Crista galii (1. 22. f. 3.) perspicunn est.

5) distichi: si rami alterni vel oppositi in duobus oppositis cormi lateribus collocati, sinulque ita directi sunt, ut omnes uni plano incubent; vidcatur Ficrs st.pulacea (t. I2. f. 3.).

6) sparsi: si rami ita positi sunt, ut nullus obser- der Spitze aber nar Blättor und z'wweilen auch Blumen hervortribt. Sie finlet sich gewïhnlich nur bei solchen Gowächsen, wo der nchon ihr herrorkommende aufrechte sicl entweder ein šingul oder cin Schnft ist. Im ersten Falle selien wir sie bey Ajuga rev'ans (t. 25 . f. 3. a) und im zweiten bey Iticraciun P'ilosella, Iricraciun dubium und Itieraciun Antricula.

Gewächse, welche mit Sproffen begabt sind, heifsen sprossentreibende Pfianzen (Plantae stolonio f(rae), in weiterer Beleutung abcr sprossentreibende Gewächse (I'egetajilia stolonifira).

६. . 3.

Die Aeste (Rami) sind die drich Zertheilung des Stiels entstelicnden Theile, weiche ihrer Structur nach, mit dem Stiele selbst Aehnliclikct haben und melirere Blätter und Biumen tragen. Vicn sich die Aeste noch weiter zertheilen, und die dadurch entstehenden Thcie ihnen selbst ähnlich sind: so werden diese Theile $\Lambda$ estchen (Razizuli) genannt. Fon den Aesten werden fulgende unterschieden:

I) e infache (siuplices): die sich nicht in Aestchen zertheilen; z. B. Carliua vulgaris (t. 2r. f. I.).

2) ïstige (เauzosi): die sich in Aestchen zertheilen; 7. B. Ocimnun minimum (t. 15. f. 2).

3) abwechselnde (alierii): wenn cin Ast immer höher als der andere steht, jecloch so, dits zwischen zweyen auf dieser Seite, nur Einer auf der entgegengesetzten sich findet; z. B. Ficus stipulacea (t. I2. f.3).

4) gegenüberstehende (oppositi): wenn die Aeste so gestellt sind, dafs immer zwey und zwey in glcicher Hühe, aber auf zwey entgngengesetzten Seiten des Stiels stehen; z. B. Rluinanthus Crista galii (t.22. (.3).

5) zweyreilsige (distir/ii); wrum die Acsto abwec?selnd oder gargenüberstehend, auf zwey cnigrbenis stzten Seiten des strels gestclli sind, und zugheich cine solche Richtung hasen, dấs sie alie in Einer Iläche liegen; z. B. Ficus stipulacea (t. 12. f. 3).

G) zerstreute (sparsi): wenn sich in Irinsicht ihr. ${ }^{*}$ 
vari possit ordo; Lithospcrmum officinale (t. 2t. ศ. 3.) indicat.

7) remeti: si longe inter se a'jsunt; ut in Duplcuro rotundifolio (t. IU. f. t.).

8) conferti: si adeo sunt densi, ut cormum cx toto fere obtegant; exemplo est Cornus mascula.

9) erecti: qui, eaule etiam decumbente, modice ad perpendiculum direeti sunt; exemplum praebet Thymus Serpillum (t. 13. S. 7. L.).

I0) coarctati: (qui ad cormum flexi sunt; ut in Populo dilataia.

II) patentes: si rami ita sunt directi; ut ii cum cormo superne angulum quadraginta circiter quinque graduum forment; exemplo sunt Bupleurum rotundifolium (t. I6. f. 4), Vaceinium Myrtillus (t. 7. .. I).

I2) diffusi: si rami ita sunt directi, ut angulus ab is cum cormo superne effictus medium fere inter gradus quadraginta quinque et honaginta efficiat; vidcatur Nigella arvensis (t. 33.. . 3.).

13) divergentes: qui cum cormo angulum rectum formant; exempli loco est Hiprocratea volubilis (:t. Í́. ก. 3. a.).

If) divaricati: qui superne cum como angulum obtusum, inferne autem acutum formant; videatur Pinus Abies.

I5) cleflexi; qui in areus forma dependent; tales sunt Pini Laricis, Sphagni palnstris (t. IJ. I. I.).

16) reflexi s. pendnli: si ad perpendiculum direcii dependent; ut in Salice baluylonica, Betula alba pendula.

7) retroflexi: si ita sunt horsum vorsum flexi, ut ralione directionis nullus ordo observari jpossit; videantur Solanum Duleamara, Amaranthus retroliexus.
Sicllung keine Ordnung warnehmen lälst; z, B. Lithospernnmu officinale (t. 2r. f. 3.).

7) weitläufigstehende (remoli): wenn sie woit entfernt ron einander stchen, z. D. Eupleurum rotundifoli-

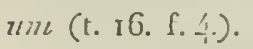

8) diehtstchende (conferti): wenn sie so dicht beisammon stchen, dals sie don Stiel fast ganz beclecken; z. B. Cormus masczila.

9) a ufrechte (erccti): die, wenn der Stiel auch niederliegt, zicuhich senkrecht stelien; z. B. Thymuns Scrpillum (t. 33. f. . . b.).

10) gedrïngte (coarctati): wenn sie gegen den Sticl gebogen sind; z. B. Populns dilatata.

Ii) abstelıende (patentes): wenn die Aeste so gerichtet sind, clal's sie mit dem stiele olsen einen IVinkel von ungefelır fünf und vierzig Graden bilden; z. B. Buplcurum rotundifolinm (t. IG. S. 4.), Taccininu Miyrtillus (t. 7. . I.).

I2) weitschweifig (diffrusi): wenn die Aeste eine solche Riclitung haben, dal's der Winkel, den sie oben mit don Sticle bilden, ungefehr clas Mittel zwischen einem ron fünf und vierzig und einem von neunzig Graden hiilt; z. B. Nigella arvensis (t. 38. א. 3).

13) a usgebreitete (divergentes): wenn sie mit dem Stiele einen rechten Winkel bilden; z. B. Irippocratea solnbilis (t. 14. א. 3. a.).

If) ausgesperte (divaricati): Wenn sie mit dem Sticle obes1 einen stumpfen, unten aber einen spitzen Winkel bilden; z. B. Pinns Abies.

15) herabgelogene (deflexi): wenn sie in einem Bogen herabhingen; z. D. Pinus Larix, Splagnzum paInstre (1. 15. 5. 1).

IG) herabluangende (reflexi s. penduli):' wenn sie in scnkieclnter Richntng herunterhangen; z. B. SoTix babjlonica, Bctula alba pendula.

I7) hin-und hergebogene (retrofexi): wenn sie so hin und wieder gebogen sind, dulfs man in Ilinsicht ilrer Fichtung keine Ordnung bemerkon kann; z. D. Solanum Dulcamara, Anuarantlus retrofexus. 
TERMIXOLOGIA.'

18) virgari: si perlongi sunt ac tenues; exemplo est Salix viminalis, Betula alba.

19) verrucosi: quorum superficiei plures subrotundae, nec raro rimosae sunt emincntiae; exemplum praebet Malpighia tuberculata (t. 35. f. 6. a.), Eronymus verrucosus.

so) spinosi: si rami pungentibus, ex ligno oriundis eminentiis instructi, ex apice auicın gemmam protrudunt; exemplo est Genista anglica (t. 26 . f. I.).

21) spinescentes: ipsa ramorum apex si in hujussoodi eminentian pungentem excurrit; exempla praebent Prunus spinosa (t. 36. f. 4. a.) Mespilus Pyracantha (t. 36. f. 3. a. *).

22) aculeati: si ramis pungentes, ex cortice nascentes sunt eminentiae; exemplo est Berberis vulgaris (t. 3j. f. 2.).

23) armati: communis trium, quae praecedunt specierum (Nr. 20, 21 et 22) t(rminus, quo non nisi sequenti contrariun islicare volentes utuntur.

24) inernes; si rami pungentibus eminentiis sunt destimi, et oppositi quatuor speciebus ( $\mathrm{Nr}, 20,2 \mathrm{r}, 22$ et 23), quae praccedunt.

25) ranentacei: si srfuamis scariosis, ramcntis similibus, obsessi sunt; ut in Erica ramentacea (t. 47 . f. 4.).

26) lepidoti: quorum superficies minimis, nudo oculo vix conspicuis sfruamis est obsita; exempli loco est Elaeagnus angustifulia.

27) alepidoti: quorum superficies lis ipsis squamis caret, ideoque sfecici jam memoratae olpositi sunt; exemplo sunt plurima vegetablia.

28) cicatrisati: in quorum superficic foliis decidentibus cicatrices relinquunt; videatur Limpetrum nigrum (1. 31. f. I.).
18) ruthenförınige (virgati): wenn sie sehr lang und dünne sind; z. B. Salix viminalis, Detula alba.

19) warzige (verrucosi): deren Oberfläche melirere rundliche, niclit selten rissige, Erhabenlıeiten hat. z. B. Malpighia tuberculata (t. 35. f. 6. a.), Evonymuls verrucnsils.

20) dornige (spinosi): wenn die Äste mit stechenden, alas lem Holze entspringenden Hervorragungen begabt sind, an der Spitze aber eine Knospe hervortreiben; z. B. Genista anglica (t. 26. f. I.)

21 ) dornartige (spinescentes): wenn sich selbst die Spitze der Äste in eine dergleichen stechende Hervorragung endigt; z. B. Prunus spinosa (t. 36. f. 4. a.), Mespilus Pyracantha (t. 36. f. 8. a. *)

22) stachlige (aculeati): wenn die Äste mit stechenden, aus der Rinde entspringenden Hervorragungen begabt sind; z. B. Berberis vulgaris (t. 3j. f. 2.)

23) bewaffnete (armati): ist der allgemeine Ausdruck für die drey vorhergehenden Arten (Nr. 20, 21 und 22), der nur als Gegensatz des folgenden gebrauclit wird.

24) unbewaffnete (inermes): wenn die Äste keine stechencle Hervorragungen liaben, als Gegensatz der vier vorhergehenden Artell (Nr. 20, 2r, 22, und 23).

25) a usschlagscluppige (ramentacei): wenn sie nit trocknen Schuppen, die den Ausschlagschuppen gleichen, besetzı sind; z.B. Erica ramentacea (t. -47.f.4).

26) geschilderte (lepidoti): deren Oberfläche mit sebr kleinen, dem unbewaffneten Ange kanm sichtbaren Schupyen bedeckt ist; z. B. Elaeagnus angustisolia.

27) ungeschild erte (alepidoti): die auf iher Oberflïche keine dergleichen Schuppen haben, und daher der vorhergrhenden Art entgegengesetzt sind; z. B. dienen lirr die mohiesten Gewirhse.

28) genalbe (cicatrisati): auf deren Oberfäche durch das Abrallen der Blätter Narben zurückbleiben; z. B. Einpetrum nigrum (t. 31. f. I.). 
Secundum figuram rami aeque cormi species ( $\$$. 51 - 53) determinantur. Eorum superficies ex f. 9. pari. ter, ac color ex f. 10. nonnunquam describitur.

\section{59 .}

Petiolus est pars ex cormi ramorumve divisione oriens, qui, si structuram respicis, a cormo aut ramis plerumque differt, nec unquam ultra unum fert folium. Quodsi folium, quod fert, non simplex, sed ex pluribus minoribus compositum: Petiolus communis vocatur, quod Astragalus glycjphyllos (t. 17. f. 2. b.) et Cassia marylandica (t. 28. f. I. a. *) aperte indicant. Folia minora saepe non per se, sed per minores petiolos cum communi conjuncta sunt, id quod Cassia marylandica (t. 20. f. 1. b.) ostendit; quos tum Petiolos parlinles vocant. Petioli species sunt:

I) teres: vid. 6. 51. Nr. 54; exemplo esto Cjclamen europaeum (t. 8. f. 2.), Cyclamen hederaceum (t. 3. f. I.).

2) seiniteres: vid. \$. 5 I. Nr. 55.; exemplum praebet Alisma Planıago ( 136. f. 7 . a.).

3) compressus: vid. S. 5r. Nr. 56.; exemplum exhibet Populus tremula (t. 3o. f. 5 a.), Populus nigra (t. 32. f. 6. a.).

4) triquetrus: vid. S. 5I. Nr. 58. B. h.; exempli loco est, Sagittaria sagittifolia (t. 36. f. 9. a.).

5) canaliculatus: si in latere superiore secundum longitudinem altus ipsi impressus est sulcus; exemplum adfert Tussilago Petasites (t. 27. f. 2, a.).

6) inflatus s. ampullaceus: si ventricosus et intus cavus est; exemplum exhibet Trupa natans (t. 23. f. 4 . a.)
Nach der Figur werden die Aeste so wie die Ar. ten des Stiels $\left(\$ .5^{1}-53\right)$ bestimmt. Ihre Obeinaclie wird nach 5. 9. so wie aucl zuweilen ihre Farbe nach \$. 10. beschricben.

Der Wiukel, welchen ein $\Delta$ st mit dem Stiele, von dem er anslauft, nach oben macht, wird die Astachsel (Ala) genaunt.

\section{59.}

Der Blattstiel (Petiolus) ist ein durch Zertheilung des Stiels oder der Aeste entstehender Theil, welcher in Hinsicht der Structur gewöhnlich von dem Stiele oder den Aesten sich unterscheidet, und jederzeit nicht mehr, als Ein Blatt trägt. Ist ein Blatt, was von ihm getragen wird, nicht einfach, sondern aus mehreren kleinen Blättern zusammengesetzt: so heifst er ein allgemeiner Blattstiel (Petiolus comnunis), wie bey Astragalus glycypliyllos (t. 17. f. 2. b.) und Cassia marylandica (t. 28. f. I. a. *). Öfters sind dicse kleinen Blätter nicht unmittelbar, sondern durch kleinere Blattstiele mit dem allgemeinen verbunden, wie bey Cassin marylandica (t. 28. f. I. b.); und dann werden diese besondere Blattstiele (Petioli partiale's) genannt. Die Arten des Blattstiels sind.

I) rund (teres): S. §. 5I. Nr. 5j; z. B. Cycla men europaeum (.. 8. f. 2.), Cyclanen hederaceun (t. 8. f. I.).

2) halbrund (semiteres): S. §. 51. Nr. 55; z. B. Alisura Plantago (t. 36. f. 7. a.).

3) z us a in mengedrü ckt (compressus): S. \$. 5 r. Nir. 56.; z. B. Populus trennala (t. 30. f. 5. a.), Populus nigre (t. 32. f. 6. a.).

4) dreykantig (triquetrus): S. S. 5 I. Nr. 58. B. 1.; z. B. Sagittaria sngittifolia (t. 36. f. 9. a.).

5) rinnenfürmig (canaliculatus): wenn er auf der obern Seite der länge uach eine tiefe Furche hat; z. B. Tussilago Petasites (t. 27. f. 2. a.).

6) aufgeblasen (inflatus s. ampullaceits): wenn er bauchig und innerhalb hohl ist; z. B. Trapa natans (t. 28 . א. f. a.). 
7) auriculatus: si in utroque latere folio similis est expansio, nec cum ejus basi nerque cum folio cohaerens; videatur Coreopsis auriculata (t. 4 f. f. I.).

8) alatus: si illa folio similis expansio à petioli basi usque ad folum porrigitur; ut in Citro Aurantio (t. 26. f. 2. a.).

9) stipulatus: si in caule stipulato (\$. 5 r. Nr. 75.) folia minora, quae stip lae vocant, cum inferiore petioli parte concreverint; in Potentilla alba (t. 10. f. Io. d.) conspicuum est.

10) exstipulatus: stipulis non connatus, qui priori oppositus est.

I1) uzudus: qui nec folio simili expansione praedi1us, nec stipulis connatus, et $\mathrm{Nr} .7,8$ et 9 tanquam contrarius est.

I2) expausus: si petiolus sursum dilatatur, et sensim in folium transit; excmpli loco est Ajuga reptans (t. 25. f. 3. a. b.), Berberis vulgaris (t. 35. f. 2.). Vulgo dicunt: foíinun in petiolun decurrens.

13) vaginatus: qui in basi sicut folium dilatatus est, eoque cormum sive ramos amplectitur; inspiciatur Conarum palustre ( $t .3$. f. 3. b.) Angelica sylvestris et plures Umbellatae.

If) Slenclulosits: una pluribusve glandulis insuructus; exempli loco sunt Cassia marylandica (t. =0. f. I. a.), Prumus Padus, Salix pentandra.

15) eglandulosus: glandulis destitutus, et priori oppositıs.

I6) brevissimus: qui tantum observalilis, et ex sua cum folii longitudine comparatus exigui est momenti; ut in Empetro nigro.

17) brevis: qui quidem evidentissimus est, nec ta-
7) geohrt (auriculatus): wenn er an beyden Seiten eine blattartige Ausdehnung hat, die weder mit seiner Basis, noch mit dem Blatte zusammenhïnght; z. B. Coreopsis auriculata (t. 44. f. I.).

8) geflägelt (alatrus): wenn jene blattartige Ausdehnung sich von der Basis des Blattsticls bis zum Blatte erstreckt; z. B. Citrus Aurantium (t. 26. f. 2. a.).

9) afterblittrig (stipulatus): wenn bey einem afterblättrigen Stengel ( $(5$ r. Nr. 75.) die kleinen Blätter, welche man Afterblätter nennt, mit dem untern Theile des Blattsiiels verwachsen sind; z. B. Potentilla alba (t. Io. f. Io. d.).

ro) afterblätterlos (exsipulatus): der nicht mit den Afterblättern verwachsen ist, als Gegensatz des vorhergehenden.

I ) nackt (nudus): der weder mit ciner blattartigen Ausdelnung begabt, noch mit den Afterblättern verwachsen ist, als Gegensatz von Nr. 7, 8 und 9 .

I2) ausgebreitet (expausus): wenn der Blattstiel nach oben sich erweitert, und allmählig in das Blatt übergeht; z. B. Ajuga reptaus (t. 25. f. 3. a. b.), Berberis valgaris (t. 35. f. 2.). Gewöhnlich sagt man auch dafür: das Blatt verläuft sich in den Blattstiel (Folinun in petiolun decurrens).

13) scheidenartig (vaginatus): der an seiner Basis sich blattartig erweitcrt, und mit dieser den Stiel oder die Aeste umfafst; 7., B. Coinarnun palnstre (t. 3. f. 3. b.), Angelica sylvestris und mehrere Doldengewïchse.

I4) drüsig (glandulosus): der mit einer od r r melireren Drüsen begabt ist; z. B. Cassia marylandica (t. 28. ᄃ. I. a), Pinunus Padus, Salix peutandia.

r5) drüsenlos (eglaudulosus): der keine Drüsen hat, als Gegensatz des vorhergehenden.

rG) sehr kurz (brevissimus): der nur eben bemerkbar, und seiner Länge nach gegen die des Blattes verglichen, sehr unbedeutend ist; z. B. Empetrmun nigriutu.

17) kurz (brevis): der sich sehr deutlich bemer$\mathrm{MI} 2$ 


\section{TERMINOLOGIE.}

mon quartam folii longiludinis partem exsuperet; exemflum pracbet Quereus pedunculata (t. 20. f. 4.).

13) longus: qui quartam quidem folii longitudinis partem excedit, nunquam vero totam folii longitudinem superat; videatur folia in Lysimacliae nemorum caule sarmentoso (t. 40. 5. 5. a.).

19) longissimus: qui folio ipso est longior; e. g. Potentilla alba (t. 1o. f. Io. b.), Cyleamen europaeum (t. 8. f. 2.).

Praeter attributa hic memorata in describendo petiolo eorum, quae in cormi speciebus $(\$ .51-53$. allegata sunt, plura licet adjicere. Superficies secundum §. g. deterninatur.

\section{§. 60 .}

Pedunculus cst pars ex cormo ramorumve aut divisione aut continuatione oriens, quae secundum structuram à cormo ramisve saepius differt, atque ipsa vel nnum ve' plures fert flores. Hic dividitur, e. g. in Pelargonio tetragono (t. 13. f. 3), et tum pars inferior nondun divisa (c.) Pedunculus communnis dicitur, partes vero singulas ex divisione natas (d.) Pedunculos partiales s. Pedicellos vocant. At pedunculi ulterius dividendi partes ipsi flori junctas Pedicellos nominant. Peduneuli speeies sunt, quae secquuntur:

I) persistens: qui fructu ipso diutius persistit; videatur Citrus Medica.

2) d'eciduns: qui cum fruetu decidit; e. g. Pyrus Malus.

3) scapiformis: si ex erecto aut procumbente caule seu stipite oritur, simulque Seapi facien refert, quod ken lïlst, jedoeh nur höehstens so lang seyn darf, als der vierte Theil der Blattlänge; z. B. Quercus pedizlculata (t. 20. f. 4.).

I8) lang (lougus): der lïnger ist, als der vierte Theil der Blanlänge, niemals aber die ganze Länge des Biattes ïbertrift; z. B. sehe man die Blïtter am rankenden Stengel der Lj'simachia nemorum (t. 40. f. 5. a.). 19) sehr lang (longissimus): der linger ist, als das Blatt; z. B. Potentilla alba (t. 10. f. 10. b.), Cyclamen enropaeum (t, 8, f, 2.).

Aufser den hier bemerkten Prädicaten lassen sich bey der Bestimmung des Blattstiels noch melurere von denen anwenden, die bey den Arten des Stiels ( $\$ .5^{1-}$ 53) angeführt worden sind. Die Oberfiache wird nach S. 9. bestimmt.

$$
\text { §. } 60 .
$$

Der Blumenstiel (Pedunculus) ist ein durch Zertheilung oder Fortsetzung des Stiels oder der Aeste entstehender Theil, wescher sich der Structur nach üfters von dem Stiele oder den Aesten unterscheidet, und unınittelbar eine oder mehrere Blumen trägt. Im letztern Falle zertheilt er sich, wie z. B. bey P'elargonium tetragonum (t. I8. f. 3.), und dann heifst der untere, noch unzertheilte Theil (c.) allgemeiner Blumenstiel (Ped:mnculus communis), die durch die Zertheilung entstehenden einzelnen Theile (d.) hingegen werden besondre Blumenstiele (Pedunculi partiales) oder Blumenstielchen (Pcdicelli) genannt. Bey der weitern Zertheilung des Blumenstiels nennt man aber nur diejenigen Theile Blumensticlchen, die mit der Blume selbst in Verbindung stehen. Die Arten des Blumenstiels sind folgende:

I) bleibend (persistens): wenn er länger stehen bleibt als die Frucht; z. B. Citrus Medica.

2) abfallend (decidnus): der mit der Fruelut abfillt; z. B. Pyrus Malus.

3) schaftartig (scapiformis): wenn er aus einem gestreekten oder kriechenden Stengel olier aus 
in reǵetabilibus nonnullis aquatieis et Filieibus obtinet; e. g. Utricularia intcrmedia (t. 26. f. 6. c.), Calla palustris, Osmunda hirta (t. 26. f. 3. b.).

4) radicalis: e radiee si exiens integrum quoddam eontinuum constituit, nec plures uno fert flores; exemplum est Cyclamen europacuin (t. 8. f. 2.). Videatur observatio ad $\S .53$.

5) caulinus: qui, quod plerumque fit, ex eaulo seu ramis prodit.

6) petiolaris: ex petiolo qui nascitur; videatur Thesium ebracteatum (t. 26. f. 4. b.).

7) foliaris: folio qui insistit. In Ruseo Hypoglosso (t. 4I. f. 6) parti superiori, in Rusco Hypophyllo inferiori, in Xyloplıylla arbuseula (t. 28. f. 5.) margini, et in Polyeardia madagasearensi (t. 45. f. 4.) apici folii insistit.

8) axillaris: si ab axilla - angnlo, quem folium et cormus vel rami formant - prodit; exempli loco sunt Astragalus glycyphyllos (t. 17. f. 2. d.), Orobus niger (t. Ig. f. 5. c.), Malpighia A (juifolia (t. 32 , f. I. b.) Lysimachia nemorum (t. 4o. f. 5. e.).

9) alaris: qui alae ( 5.53 . observ.) insistit; videatur Hoppea dichotoma (t. 30. f. 3. b.), Chironia inaperta, Alsine medis, Silene conoidea, Gypsophila muralis.

10) lateralis: qui infra turiones teneras, ex prioris anni ramulis jam defoliatis prodit. Non nisi arboribus et fruticibus reperitur; exempli loco videatur ErytroxyIon Coea (t. 3o. f. 4. c.), Mispighia tuberenlata (t. 35. f. 6. ᄂ.), Dapline Mezereum.

I1) oppositifortus: pedunculis axillae non insisten- einem Strunke entspringt, und dabey das Arsehen eines Schaftes hat, wie bey einigen Wassergewäclısen und Farrenkrüutern; z. B. Utricularia intermedia (t. 26. f. 6. c.), Calla palustris, Osmunda hirta (t. 26. f.3. b.).

4) wurzelstïndig (radicalis): wenn er aus der Wurzel entspringt, ein ununterbrochnes Ganzes ausmacht, und nicht mehr als Eine Blume trägt, z. B. Cyclamen europaeum (t. 8. f. 2.). Man sehe die Anmerkung zu 5.53.

5) stengelständig (caulinus): der, wie es gewölnnlich der Fall ist, aus dem Stengel oder den Aesten hervorkommt.

6) blattstielständig (petiolaris): der aus dem Blatisticle entspringt; z. B. Thesinun ebracteatum ( $\mathrm{t}$. 26. f. 4. b.).

7) blattständig (foliaris): der anf dem Blatte steht. Bey Ruscus Hypoglossum (t. -jir. f. 6.) stcht er auf der obern Seite, bey Ruscus IIjpoplyjllun anf der untern, bey Xylopliylla arbuscula (t. 28. f. 5.) am Rande, und bey Polycardia madasascarensis (t. 45. f. 4.) an der Spitze des Blattes.

3) blattachselständig (axillaris): wenn er aus der Blattachsel - dem Winkel, der von dem Blatte und dem Stiele oder den Aesten gebildet wird - hervorkomint; z. B. Astragalus glycypliyllos (t. 17. f. 2. d.), Orobuls niger (t. I9. f. 5. c.), Mulpighia Aquifolia (t. 32. f. I. b.), Lysimaclia nemorum (t. 40. f. 5. c.).

9) astachselständig (alaris): wenn er in der Astaclisel (S. 53. Anmerkung) stelıt; z. B. Hoppea dichotoma (t. 3o. f. 3. b.), Chironia inaperla, Alsine media, Silene conoidea, Gy $G_{3}$ soplita muralis.

10) seitenstïndig (lateralis): wenn er unter den jungen Trieben, an den vorjährigen, schon entblitterten Aestchen hervorkommt. Man findet ilın daher nur bey den Bäumen und Stränehen; z. B. bey Erytroxylon Coca (t. ₹o. f. 4. c.), Meulpiglia tuberculatı (t. 35. ศ. 6. b.), Dapline Mezereum.

II) gegenüberstehend (oppositiflorus): wenn 
tibus, simul autem ita positis, ut alter alteri recta oppositus sit; inspiciatur Cornus mascula (t. 3j. f. I, a.).

12) oppositifolins: ex alio cormi latere folio oppositus; ut in Phytolacca decandra (t. 3ł. f. 5. b.).

13) laterifolius: folio ad latus positus; e. g. Anchusa officinalis.

I4) extrafoliaceurs: arcte sub folio prodiens; invenitur in Uvularia amplexifolia ( 1.32. f. 5. b.).

15) suprafoliacens: qui supra folium protruditur; tali gaudet Menispermum canadense ( . 45. f. 3. b.).

I6) intrafoliacenss s. vagus: qui intra folia ita prodit, ut modo supra folia, modo infra ea appareat; quo pertinent Solanum nigrum (t. 28. f. 2.) et plures hujus generis species.

17) terminalis: qui cormi seu ramorum apici insistit; videatur Ligustrum vulgare (t. I9. f. 2.).

18) lracteatns: si bracteis - foliis flori prope junctis, quneque a cormi ramorumve foliis practer minorem magnitudinem etiam figura nec non raro colore differunt - obsitus est; e. g. Malpighia Aquifolia (t. 32. f. I. b.), Silene nutans (t. 13. f. 5. d.).

19) ebracteatus: bracteis destitutus; vidcatur Lycium barbarum (t. Io. f. 5. c.).

20) squamosus: pluribus exignis foliolis, squamis similibus, interdum siccis, obsitus; inspiciatur Aster ericoides (t. 40. f. 6.), Catananche coerulea.

21) nudus: qui et bracteis et foliolis squamis simi- die Blumenstiele nicht in den Blattachseln stehen, dabey aber eine solche Stellung haben, dafs einer dem andern gerade gegenüber sich befindet; z. B. Cornus mascila (t. 35. f. I. a.).

12) dem Blatte gegenüber stehend (oppositifolius): wenn er auf der andern Seite des Siicls dem Dlatte gegenüber sich befindet; Playtolacca decandra (t. 34. f. 5. b.).

13) neben dem Blatte stehend (laterifolius): wenn er dem Blatte zur Seite gestellt ist; z. B. Anclutsa officinalis.

14) unter dem Blatte stehend (extrafoliacens): wenn er dicht unter dem Blatte hervorkommt; z, B. Unularia amplexifolia (t. 32. f. 5. b.)

15) über dem Blatte stehend (snprafoliacens): der über dem Blatte entspringt; z. B. Menispermum canadense (t. 45. f. 3. b.).

16) zwischen den Blättern stebend (intrafoliacenss s. vagus): der so zwischen den Blättern hervorkommt, dafs man ihn bald über, bald unter denselben gewahr wird, z. B. Solanum nigrum (t. 28, f, s.) und mehrere Arten dieser Gattung.

17) gipfelständig (terminalis): der an der Spitze des Stiels oder der Aeste steht; z. B. Lignstrun vulgare (t. 19. f. 2.).

18) nebenblättrig (bracteatrus): wenn er mit Nebenblättern - Blätter die nahe bey der Blume stehen, und die sich von denen des Stiels oder der Aeste aufser ihrer mindern Grölse auch durch Gestâlt, so wie auch nicht selten durch Farbe unterscheiden - besetzt ist; Malpighiu Aquifolia (t. 32. f. I. b.), Silcne mutans (t. 13. f. 5. d.).

19) nebenblätterlos (ebractcatns): der keine Nebenblätter hat; z. B. Lycinm Zarbarum (t. го. f. 5. c.). 20) schuppig (squamosns): der mit mehreren kleinen, schuppenartigen, zuweilen trocknen B'ätchen besetzt ist; z. B. Aster erivoides (t. fo. f. 6.), Catananche coernlea.

21) nackt (nudus): der weder Nebenblïtter, noch 
libus caret; e. g. Lycium barbarum (t. ro. f. 5. c.), Cyclamen europaeum (t. 8. f, 2.). Est duobus praecedentibus (Nr. I9 et 20), contrarius.

22) uniflorus: qui unum tantum fert florem; ut in Galantlıo nivali (t. 3. f. 2.), Lycio barbaro (t. Io. f. 5. c.).

23) liflorus: qui binos fert flores; videatur Linnaea borealis (tab. libri inscriptionem ger, f. 2.).

2-i) triflorus: et sic porro.

25) multiflorus: qui plures fert flores, horumque numerus non est perpetuus; exemplo esto Hippocratea volubilis (t. I千́f. 3.).

26) simplex: in ramos non divisus, ideoque tribus, qui sequuntur ( $\mathrm{Nr}, 27,28$ et 29.), oppositus est; exempli loco inspiciatur Galanthus nivalis (t. 3. f. 2.), Lycium barbarum (t. IO. f. 5. c.).

27) dichotomus: si pedunculus ip binos ramos, atque horum uterque in binos, et sic porro, rursus dividitur; videatur Yeperomia obliqua $\operatorname{Puiz}($ t. 23. f, 6 ).

28) tricluotomus: qui antecedentis more in ternos dividitur ramos, lıorumque quivis in ternos, et sic porro, rursus dividitur; c. g. Galium scabrum (t. 45. f. I.b.).

29) ramostıs: qui nullum illozum ordinum (Nr. 27 et 23.) observans in ramos dividitur.

Secundum directionem ac figuram pedunculus sicut cormi species ( $\$ .51-53$ ) deterninatur; attamen quoad illam notandum est, prout vegetabile vel floret, vel fructus fert, aliam atque aliam apparere. Ita praebet e. g. C.yclamen europaeum (t. S. f. s.) tempore florcscentiae pedunculum (d.) erectum, cum contra fructus ferens (e.) spiralis appareat; et in Lysimaclia nemorum (r. fo. f. 5.) peinuculus ercctus fore (c.) illius Metanorphosis schuppenarlige Blättchen hat; z. B. Lycium barbarum (t. 10. f. 5. c.), Cyclamen europaeum (t. 8. f. 2.). Er ist den beyden vorhergehenden (Nr, Ig und 20) entgegengesetzt.

22) e inblumig (uniflorus): der nur Eine Blume trägt; z. B. Galanthus nivalis (t. 3. f. 2.), Lycium Zarbarum (t. Io. f. 5. c.).

23) zweyblumig ( (iflorus): der zwey Blumen trägt; z. B. Limnaea borealis (Titelkupfer f. 2.) $P e$ largonium tetragonum (t. I8. f. 3.).

24) dreyblumig (triflorus): u. s, w.

25) vielblumig (multiflorus): wenn er mehrere Blumen trägt, und die Zahl derselben nicht beständig ist; z. B. Hippocratea volubitis (t. I f. f. 3.).

26) einfach (simplex): der sich nicht in Aeste zertheilt, und daher den drey folgenden (Nr. 27, 28 und 29) entgegengesetzt ist; z. B. Galantluzs niz'alıs (t. 3. f. 2.), Lycium barbarum (t. Io. f. 5. c.).

27) gezweytheilt oder gabelästig (dichotomus): wenn sich der Blumenstiel in zwey Aeste, jeder derselben wieder in zwey, und so fort zertheilt; z. B. Peperomia obliqua Ruiz (t. 23. f. 6.).

23) gedreytheilt, jeder derselben wieder in drey und so wciter fort; z. B. Galium scabrum (t. 45. f. 1. b.).

29) ästig (ramosiss): wenn er sich obne eine von jenen Ordnungen (27 und 28.) zu befolgen in Aeste zcrtheilt.

Nach der Richtung und Gestalt wird der Blumenstiel so wie die Arten des Stiels $(\$ .51-53)$ bestimmt; jedoch ist in Rücksiclit der erstern zu bemerken, dafs sie, je nachdem das Gewàclı im blühenden oder fruclittragenden Zustande sich befindet, sehr verschieden sich zeigt. So ist z. B. bey Cyclamen europaeum (t.8. f.2.) wallrend des Blühens der Blumenstiel (d.) a ufrecht (erectus), da er hingegen im fruchttragenden Zustande (e.) s clrraubenförmig (spiralis) erscheint; und bey $L y$. simachia nemorum (40. f. 5.) wird der f.rst aufreclite Blnmensticl (c.) wahrend derselben Metamorphose 
tempore in circinatum mutatur. Vice rersa in speciebus germanicis generis Droserae scapus ( $\$$. 5j.) ante anthesin circinatim convolutus sensim evolvi viletur, ita, ut in fructifero statu plane erectus appareat. Spiralis autem pedunculus, quem Vallisueria spiralis exhibet, et ante anthesin, et post eam non musatur. - Pedunculi superficies secundum $\$$. 9. determinatur.

§. $6 r$.

Inflorescentia, qua varia florum dispositio significatur, pedunculi divisione et partium inde oriundarum, diversitate, tam quoad situm, quam quoad proportionem inter se, maxime nititur, partim vcro in varia florum, seu potius fructuum ipsorum, coacervatione tantum sita est. Variae inflorescentiae species, quae ex earum figura aptis insignire nominibus studuerunt, sunt: Verticillus, Capitulum, Glomerulus, Fasciculus, Spicula, Spica, Racemus, Corjmbus, Uinbella, Cyina, FlabelInm, Panicula, Thyrsus, Anthurus, Spadix, Amentumn et Sortus.

\section{62.}

Verticillus pluribus circum caulcur in forma annuli collocatis, eique vcl per se, vel simplicium ramosorumve pedunculorum beneficio junctis floribus constat. Apparet:

I) sessilis: Horibus sine pedunculis, atque ita per se cauli junctis; exempla praebent Mentba arvensis, Myriophyllum spicatum (t. 29. f. 3. c. d.). scknecker.förmig (circinatus!. Umgekehrt sielit man bey den deutsclen Arten der Gattuag Drosera den vor dem Blühen sc'ıneckenförmig aufrerollien Schaft (\$. 53.) nach und nach sich aus einander winden, so, dafs er in fruchutragenden Zustande röllig aufrecht sich zeigt. Da. gegen ist und bleiùt der scl!raubenförmige Blumenstiel der I'allisneria spiralis, suwohl vor, als auch nach dem Bïihen, unverändert. - die Oberfache des Blumenstiels wird nach \$. 9 . bestimmt.

§. $6 r$.

Der Blïihenstand oder die Inflorescenz ( Inforescentia), womit man die mannigfaltige Stellung der Blumen bezeichnet, gründet sich gröfstentheils auf die Zertheilung des Blumenstiels und auf die Vcrschiedcnheit der dadurch entstehenden Theile in Rücksicht ihrer Lage und ihres Verhältnisses gegen einander, theils aber auch nur blols auf die verschiedene Zusanmenhïufung der Blumen, oder vielmehr der Frïcite, selbst. Die verschiedenen Arten des Blüthenstandes, weiche man ihrer Gestalt nach mit passenden Namen zu bezeichnen gesucht hat, heirsen: der Quirl (Verticillns), der Kopf (Capitulum), der Knauel (Glomerulus), der Büschel (Fascicnlns), das A ehrchen (Spicula), die Aehre (Spica), die Traube (Racemus), die Doldentraube (Corymbrts), die Dolde (Umbella), die Afterdolde (Cyma), der Fechel (Flabellum), die Rispe (Panicula), der Straufs (T/ijrsus), der Schweif (Anthnrus), der Kolbcn (Spadix), das Kätzchen (Amentan), und das Häufcheit (Sorns).

\section{62.}

Dor Quirl (Terticillns): bestehct aus mehrercn Blumen, die ringfürmig um den Stengel stehon, und mit demselben entweder unmitte'bar, oder vermittelst einfachcr oder ästigcr Blumenstiele verbunden sind. Er zeigt sich:

I) sitzend (sessilis): wenn die Blumen olne Blumcnstiele, also unmittelbar, mit dem Stengel verbunden sind; z. B. Mentha arvonsis, Myrioply liam spicatum (t. 23. f. 3. c. d.). 
2) pedunculatus: floribus brevium pedunculorum ope cauli insidentibus; e. g. Dracocephalum thymiflorum (t. 3o. f. r. b.)

3) capitatus: si floribus ita refertus est, ut hemisphaeram referat; videaur I'hlomis tuberosa (t. 32. f. 7. a.). Clinopodium vulgare (t. 31. f. 5. b.)

4) dimidiatns: si florcs dimidium tantum caulis peripheriae cingunt; e. g. Melissa officinalis (t. 33. f. 7. c.).

5) integer: floribus, quod plerumque $f_{i t}$, caulem totum ambicntibus; ta'en refert Lupinus luteus (r. 29 . f. 4. c.), Staclyys syluatica (t. In. f. 4. b.), Clinopodium vulgare (t. 3t. f. 5. b.), Phlomis tuberosa (t. 32. f. 7. a.)

6) confertus: ubi verticillus verticillo arcte superimposiius; inspiciatur Nepeta Cataria (t. 43. f. 3.).

7) distans: pluribus verticillis longis intervallis sibi superimpositis; exemplo est Stacliys sylvatica (t. Ig. f. 4. b.).

8) Soliosns; cujus basi folia insident; e. g. Staclyys sylvatica (t. Ig. f. 4. H.), Dracocephalum thymillorum (t. 30. f. I. b.), Pllomis tuberosa (t. 32. f. 7. a.), Melissn officinalis ( 1.33. f. 7. c.), Clinopodinm vulgare (t. 3r. \{. 5. b.).

9) apllyyllus: cujus basis foliis caret; ut in Lupino luteo (t. 29. ᄃ. 4. c.).

10) bracteatus: si in ejus basi vel ctiam inter flores exigua sunt folia, quae practcr minorem suam magnitudincm figura etiam aut colore a foliis cormi ranorumve differant; videatur Plılonvis tuberosa (t.32. f. -. a.)

17) ebracteatus: in qio folia, bracteae dicta, non arimadvertuntur; ut in $\Lambda$ juga reptante ( $t, 25$. f. 3. f.).
2) gestielt (pedunculatns): wenn die Blumen vermittelst kurzer Blumenstielchen auf dem Stengel befes. tigt sind; z. B. Dracocephalum thymiflorum (t. 30. f. I. b.).

3) kopfförmig (capitatus), wenn er so voll von Blumen ist, dafs er einer Halbkugel gleicht; Phlomis tuberosa (t. 32. f. 7. a.), Clinopodium vulgare (t. 3:. f. 5. b.).

4) halb (dimidiatns): wenn die Blumen den Stengel nur bis z.ır Hälfte seines Unk reises umgeben; z. B. Melissa officinalis (t. 33. f. 7. c.).

5) ganz (integer): wenn die Blumen, wie es gcwöhnlich der Fall ist, den Stcngcl ganz umgeben; z. B. Lupinns luteus (t. 2.3. f. 4. c.), Staclys sylvatica. (t. Ig. f. 4. b.) Clinopodium vilgarc (t. 31. f. 5. b.), I'hlomis tuberosa (t. 32. f. 7. a.).

6) gedrängt (confertus): wenn cin Quirl diclit über dem andern steht; z, B. Nepeta Cataria (t. 43. f. 3.).

7) entfernt (distans): wern mehrere Quirle in weiten Zwischcnräumen über einancler stehen; z. B. Stacliys sylvatica (t. Ig. f. 4. b.).

3) beblättert (foliosns): wenn an seiner Easis sich Blätter befinden; z. B. Stachy's sylvalica (t. 19. f. 4. b.), Dracoceplualum thijmiflorum (t. 3o. f. I. b.), Pluomis tuberosa (t. 32. f. 7. a.), Melissa officinalis (t. 33. f. 7. c.) Clinopodinm vulgarc (t. 3t. f. 5. b.).

9) Llattlos (aplyyllus): wenn er keine Blätter an seiner Dasis hat; z. D. Lupinus luteus (t. 29 . f. 4. c.).

10) nebenblättrig (brarieatus): wenn sich an seincr Basis oder auch zwischen den Blumen kleine Blïtter finden, die sich aufser ihrer geringern Grülse auch durch Gestalt oder Farbe ron denen an dem Stiele oder den Acsten stehenden unterscheiden; z. B. Phlomis tubcrosa (t. 32. f. 7. a.).

II) nebenblätterlos (cbracteatus): an dem man keine dergleichen klcine Blätter, die man Ncbenblätter nonnt, bemerkt; z, B. Ajuga reptans (t. 25 . f. ว. f). 
12) nuths: cui nec folia nec bractcac sunt; cxempli loco est Myriophyllum spicatum (t. 29. f. 3. c. d.).

13) sexflorirs: ex floribus sex si est compositus; excmplum praebet Stachys sylvatica (t. 19. f. 4. b.).

If) octoflorns: octo flores si continet; c. g. Sideritis candicans.

15) decemflorus: si decem flores in verticillo sunt; videatur Stachys heraclea. Sic ulterius numerantur usque ad

16) multiforus: multos flores si continet, quorum tamen numerus non est perpetuts; exempli loco vidleatur Stachys germanica.

\section{§. 63.}

Capitulmm est plurium florum coacerratio communi pedunculo vel per se vel brevium pedicellorum ope arcte insidentium, ut constipatum quoddam totum, qüod ad figuram subrotundam magis minusve accedit, effingant. Reperitur:

1) globosum s. splunericum: si perfecte globosum est; refert Nauclea aculeata (t. 29. f. 5. c, d.). Mimosa caracasana Jacq. (t. 35. f. 5. b.).

2) subglobosmm s. snbrotndnm: si non ex toto est globosum, ut latitudinis diametrum longitudinis diameter superet; videatur Trifolium pratense (r. 23. f. I.). Poterium Sanguisorba (t. 40. f. 8.).

3) hemisphaericum: hemisphaeram si refert; inspiciatur Statice Armeria (t. 40. f. I.).

4) conicum: si à basi ad apicem sensim angustatur, ut ad coni figuram accedat; e. g. Trifolium rubens (t. 45. f. 8.), Trifolium montanum.
12) nackt (mulns): bey dem weder Blätter noch Nebenblätter sich finden; z. B. Myriophlllnm spicatnm (t. 29. f. 3. c, d.).

13) sechsblumig (serforns): wenn er aus sechs Blumen zusammengesetzt ist; z. B. Stachy's sylvatica (L. 19. f. 4. b.).

14) achtblumig (octoforts): wenn er acht Blumen enthält: z. D. Sideritis candicans.

15) zehnblumig (dccemflorns): wenn zehn Blumen im Quirl stehen; z. B. Stacly's heraclea. So zählt man weiter, bis

16) vielblumig (milliflorns): wenn er nämlich viele Blumen enthält, deren Zahl aber nicht beständig ist; z. D. Stachy's germanica.

\section{S. 63.}

Der $\mathrm{Kop}$ f (Capitnltm ) ist eine Zusammenhïufung von mehreren Blumen, die auf einem gemeinsclıafllichen Blumenstiele entweder unmittelbar, oder vermittelst kurzer Blumenstielchen so dicht zusammen gestellt sind, dafs sie ein zusammengedrängtes Ganzes bilden, was mehr oder weniger einer rundlichen Gestalt sich nähert. Man findet ilın:

I) kugelrund oder kugelförmig globosnm s. splaaericmn): wenn er eine vollkommen kugelfürmige Gestalt hat; z. B. Nanclea acnlcata (t. 29. f. 5. c. d.) Mimosa caracasana Jacq. (t. 35. f. 5. b.).

2) rundlich (smbglobosmm s. snbrotmnlum): wenn er nicht vollkommen kugelfürmig ist, so dafs der Durchmesser der Länge, den der Breite übertrift; z. B. Trifolinn pratense (t. 23. f. I.), Poterimm Sanguisorba (t. 40. f. 8.).

3) halbkugelförmig (Lemisphaericmm): wenn er einer Halbkugel gleicht; z. B. Statice Armeria (t. 40. f. I.).

4) kegelförmig (conicum): wenn er sich von der Basis nach der Spitze allmählig verengt, so dafs er der Figur des Kegels nahe kommt; z. B. Tiffolinm rnlons (t. 45. f. 8.), Trifolinm montanum. 
5) radictunz: si capituli giobosi s, sphraerici (Ni. I.) pedunculus communis ad corpus extenditur g'ósosum, quod flowes ad omnes plagas directos radiorun instar sine pediccllis fert; excmpli loco inspiciatur Eudicia globosa, Nauclea aculcata (t. 29. f. 5. c, d.).

6) sparicatunn: si peduncultus communis capituli conici (Nr. 4.), subrotundi (Nr. ..) seu globosi (Nr. r.) ad corpus oblongum extenditur floresque fert sine pedicellis; e. g. Dipsacus fullonum (t. fí f. S.), Poterium Sanguisorba (t. fo. f. 8.).

7) umbellaium: flores si sunt pedicellati omnesque pclicclli uno ex puncto ad apicem pedunculi communis nascuntur; videatur Trifolium repens (1. 30. f. 7. b), Trifulium ligbridum.

8) spicatum: florcs si breviter pedicellati sunt et pedicclli varia in allitudine circa pedunculum communem adstant; exemplo est Trifolium rubens (t. 45. f. 8.), Trifulium pratense (t. 23. f. r.).

9) vesticns: si partem caulis superiorcm ita ambit, ut ipsi rami superiores, cum foliis in hasi sua ab eo circumvelcutur; excmpla praebent $\Lambda$ stragalus compactus (t. 43. ᄃ. 5.), Astragalus longifolius, Astragalus aurens.

10) conzosumz: supra cujus apiccin foliorum fasciculus observatur; inspiciatur Bromelia Ananas.

II) foliosunt: si in basi sina foliis cst restitum; e. g. Trifolium pratense (t. 23. f. I.).

12) involucratum: quod in basi sua is cincmun est foliis, quac a cormi ramorumve fuliis non minore soliin liagnitudine, sed figura etian, substantia vel colore differunt, alque ita composila sunt, ut totum constitu-

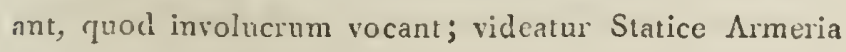
(เ. โо. T. I.).
5) strablig'(radiatum): wenn sich bey einem kugelrunden Kopfe (Nr. r.) der gemeinschaftliche Blumensticl zu einem kugeiförmigen erweitert, welcher die, gleichsam wie Stralilen nach allen Richtungen ausgebreiteten Blumen ohne Blımenstielchen trägt; z. B. Budleia globosa, Nanclea aculeata (t. 29. f. 5. c, d.)

6) kolbenartig (spadicatum): wenn der gemeinschaftliche Blumansticl eines kegeiförmigen (N.r. 4.) rundlichen (Nr. 2.) oder kugelrunden Kopfes (Nr. I.) zu einem länglichon Körper sich erweitert, und die Blumcn ohne Blumenstielchen träg!; z. B. Dipsacıs fullomun (1. 41. . .8), Poterinu Sangrisorba (1. \{. Г. 8.)

7) doldig (umbellatum): wenn dic Blunen gestieit sind, und alle Blumenstielchen aus eineml'uncte an der Spitze des gemeinschaftlichen Blumenstiels entspringen; z. B. Trifoliun repens (t. 3o. f. 7. b.), Trifolium hy bridum.

8) ährenartig (spicatum): wenn die Blumen kurz gestielt sind, und die Blumenstielchen in verschiedener Höhe um den gemeinschaftlichen Dlumenstiel stehen; z. B. Trifolinm raliens (t. 4.J. f. 8.), Trifolium pratense (t. 23. f. I.).

9) bekleidend (vestiens): wenn er den obern Theil des Stengels dergestalt ungiebt, difs selbst die obern Aeste und Blätter an ilırer Basis von ihm um. hüllt werden; z. B. Astragains compactus (t. 43. f. 5.), Astragalus longifolius, Astragalus aurens.

ro) schopfig (comosum): ïber dessen Spitze man eincn Büschcl von Blüttcrn gewahr wird; z. D. Bromelia Ananas.

II) beblättert (foliosum): wenn or an seine: Basis mit Bläitern umgcben ist; z. B. Trifolium prateruse (t. 23. f. r.).

12) getuullt (involucratumz): der an sciner Basis mit solchen Blättern umgeben ist, die von denen am Stiele oder den Aesten sich findenden nicht blofs durch geringere Gröise, sondern auch durch Gcstalt, Substanz oder Fabe sich unterscheiden, und dnbey so zusnmmen gestellt sind, dafs sie cin Ganzes bilden, welches man cinc Hülle nemut; z. B. Stalice Arıneria (t. fo. f. I.). 
33) nuclum: in quo nec fulia, ncc lis simile quiddam observatur, ideoque tribus praecedentibus (Nr. 10 II et 12.) opponitur; exemplum pracbet Potcrium Sanguisorba (t.' 40. f. 0.).

14) solitarium: si in apice cormi vel in qualibet axilla unum tantum capitulum adest; exempli loco sunt Nanclcil aculcata (t. 29. f. 5. c. d.), Trifolium repens (t. 30. f. 7. b.).

15) conjugatum: si bina semperi capitula consistunt; e. g. Anthyllis Vulneraria (t. 37. f. 6. b.), 'Trifolium rubens (t. 45. f. 8.).

Capituli situs, locum puta, ubi existit, ut in pedunculo (\$. 6o. Nr. 4 - 17.) detcrminatur. Pl=rumqre est terminale vol axillate, raro autem laterale vel oppo. sirifolium.

\section{5if.}

Glomerulus est coacervatio flosculorum parum speciosorum, quae in capituli forma apparet et. a capitulo (§. 63.)non nisi minore magnitudine differt. Feperitur:

1) axillaris: vid. §.60. Nr. 8; e. g. Amaranthus albus (t. 24. f. 1. a.).

2) lateralis: vid. §. 6o. Nr. ıo; e. g. Boelımeria ramillora (t. 31. f. 2. a.).

3) verticillatus: qui cormum in forma annuli complectitur; ut in Parietaria officinali (t. 39. f. I. b.).

Glomeruli figura eo, quo capituli modo $(9.63 . \mathrm{Nr}$. 3 - 4.) determinatur.

\section{§. 65 .}

Fascictulus est plurium florum longortum pedicellis brevibus non ex nno puncto nascentibus satis tamen crecte atque arctissime inter se insistentium coacervatio, il., ut cxteriorum inferiorumve florum apices altiores siat, gnam punctum, ex quo interiornm superiorumve
13) nackt (nudum): an dem man weder Blätter roch etwas diesen älınliches bemerkt, und dahor dea drey vorhergehenden ( 10 . I I und I2.) enigegengesetzt ist; z. D. Poterimm Sanguisorba (t. 40. f. 8.).

If́) einzeln (solitarium): wenn an der Spizc des Stiels cder in jeder Blattaclisel nur ein Kopf stelit; z. B. Nauclea aculeata (t. 20. f. 5. c. d.), Trifulium repens (t. 30. f. -. b.).

15) ge paart (congujatum): wenn immer zwey" Iöple beysammen stehen; Anthyllis Vulneraria (t.3-. f. 6. L.), Trifolium rubens (t. 45. f. 8.).

Die Lage des Kopfes, nämlich der Ort, wo er entspringt, wird so wie bey dem Blumenstiele ( $\$$. fo. Nr. 4-17) bestimmt. Gewöhnlich ist er gipfelständig (rrminale) oder blattachselständig (axillare), scltcucr aber sieht man ihn seitenständig (lateralc) odcr dem $B$ latte gegenüber (oppositifolium).

\section{6 千́.}

Der Knauel (Glomerulus) ist eine Zusammenhäufung von kleinen, unansehnlichen Blumen, die sich in Gestalt eines kleinen Kopfes zeigt, und vom Kople (§. 63.) selbst nur durch mindere Gröfse sich unterscheidet. Er findet sich:

1) blattachselständig (axillaris): S. §. 60. Nr. 8.; z. B. Amaranthus albus (t. 24. f. I. a.).

2) seitenständig (lateralis): S. \$. 60. Nr. Io.; z. B. Boeluneria ramiflora (t. 3r. f. 2. a.).

3) quirlförmig (verticillatıs): wenn er den Stiel ringförmig umgiebt; z. B. Parietaria officinalis (t. 3r. f. 1. b.).

Die Gestalt des Knauels wird auf ähnliche Art, wie die des Fopfes ( $\delta .6 \overrightarrow{3}$. Nr. $1-4$. ) bestimint.

\section{65.}

Der Büschel (Fasciculus) ist eine Zusammenhäufung von mehreren langen Blumen, die auf kurzen, niclıt aus einem Puncte entspringenden Blumensticlchen selur gedrïngt in zicmlich aufrechter Richtung nelicn einander stehen, so, dals die Spitzen der äufsern oder 
florum pedicelli oriuntur. Fasciculus capitulo ( $\$ .03$ ) quodammodo similis est, at vero hac re differt, quod in eo pedicelli in basi sua sunt, in capitulo contra magis minusie ad centrum accedunt. Apparet:

I) pauciflorus: paucos tantum flores contincns; e. g. Dianthus Armeria (t. 33. f. 3. a.), Diarthus carulusianorum.

2) multiflorus: ex multis floribus si compositum est; Spermacoce rubra Jacq., Dianthus barbatis, I. chnis calcedonica.

Quod reliquum est in denominando fasciculo plura in capitulo ( $\$ .63$.) dicta nomina adhiberi possunt, qua a Nr. 11. ad 15. perinent. Si situm spectes fasciculus plerumque est termina? is, rarius t:xillaris

\section{§. 66 .}

Spicula vel uno vel pluribus graminibus lisque similibus propriis constat floribus, hi communi pedicello alius super alium arcte insistunt, seque tegularum instar tegunt. Plures spiculae in graminibus fingunt spicam (\$. 63.), paniculam (\$. 73.$)$, vel flabellum (\$. 72.) prout collocatae sunt. In vegetabilibus gramineis e. g. in generibus: Cyperus, Scirpus, Juncus etc. non solum idem obtinet, sed in his etiam in forma corymbi (\$. 69.) rel umbellae ( $\left(7^{\circ}\right.$.) junctas saepe videmus. - Pedicellus, qui in spicula flores fert, "Rhachis dicitur; exempli loco videaim Lromus secalinus (t. 37. 5. 9. d.). - Invenitur Spicula: untern Blumen hölıer liegcn, als der Punct, aurs witchem die Blumenstielchen der innern oder obern Blumen entspringen. Der Büschel hat einige Achnlichkcit mit dem Kopfe (\$. 63.), er unterscheisiot sich aber dadurch, dafs man auch bey ilmm die Blumenstielchen an der Basis findet, da sie hingegen beym Kople mehr oder weniger dem Mittelpuncte nahe liegen. Man findet ilın:

I) armblumig (pauciflorus): wenn er nur wenige Blumen enthält; z. D. Dianthus Arneria (t. 33. f. 3. a.), Dianthus carthusianorum.

2) vielblumig (multiflorus): wenn er aus vielen Blumen zusammengesetzt ist; z. B. Spermacoce rubra Jacq., Dianthus barbatus, Ljclunis calcedonica.

Uebrigens lassen sich bey der Destimmung des Bäschels melirere von den bcym Kopfe (\$.63.) angeführten Prädicaten anwenden, wolin die von Nr. 11 bis 15 gehören. Der Lage nach ist der Büschel gewöbnlich gipfelförmig (tcrminalis), seltner blattachsel. ständig (axillaris).

§. 66 .

Das Aehrchen (Spicula) besteht entweder aus einer oder aus mehreren, den Gräsern and grasühnlichen Gewächsen eignen Blumen, die im letztern Falle auf einem gemeinschaftlichen Blumenstielchen sehr gedrängt über einander stehen, und nach Art der Dachziegel sich decken. Mehrere Aehrchen bilden bey den Gräsern eine Aehre (\$. 67.), Traube (\$. 63.), Rispe (§. 73.) oder einen Fechel (\$. 72.), je nachdem sie zusammengestellt sind. Bey den grasähnlichen Gewächsen, z. B. bey den Gattungen: Cyperus, Scirpus, Juncus u. s. w. findet nicht nur dasselbe Statt, sondern man sielıt sie bey diesen auch öfters in Gestalı einer Doldentraube ( $\$ .60$.) oder Dolde (\$. ๆ०.) beysammen stehen. - Das Biumenstielchron, was bey dem Aelirchen die Blumen trägt, wird die $\mathrm{S}_{\text {pindel }}$ (Rhachis) genannt; als Deyspiel sehe man Bromus secalinus (t. 3.. f. 9. d.). - Man findet das Aetrchen: 
I) linearis: si oblonga, valde elongata figura est, et laterum arcus minus tantum sunt curvati, ita, ut lineas rectas parallelasque fere forment; videatur Festuca fluitans (t. 46 f. 3.).

2) lanceolata: si est oblonga, et diameter longitndinalis plus quam triplo superat transversalem; ut in Bromo tectorum (t. 30. f. 1.).

3) oblonga: si oblonga est figura, et longitudinis cliameter plns quam duplo, minus vero quam triplo snperat transversalem; inspiciatur Lolium perenne (t. 12. f. 2. d.).

4) ovata: sie est oblonga fignra, cujus basis majorem efficit arcum, quam apex, qui ntrorpue ]atere sensim concurrente formatur; exempli loco sunt Briza media (t. 37. f. 2.), Bromus mollis (t. 12. f. 4. c.).

5) cordata: si oblonga, et in basi exsecta est; e.g. Driza maxima (t. 45. f. 7.).

Oblonga hic dicitur (No, 1-5) in genere quaequae figura, quae e duobus circuli segrmentis, chordis sibi appositis, componitur.

6) triangularis: si triangulum describit, cujus alterum latus basin constituit; exemplum praebet Briza virens (t. 45. f. G.).

7) disticha: si spiculae flores in duabus seriebus sibi oppositi, atque ita directi sunt, ut omnes uni plano incumbant, quod in C5pero pluribusque graminum generibus obtinet; exempli loco videntur Cyperus longus (t. 45. f. 2.), Lolium perenne (t. I2. f. 2. d.) Bromus mollis (t. 12. f. 4. c.), Briza maxima (t. 45. f. 7.), Briza virens (t. 45. f. 6.).

8) teres: si transwersalis spiculae sectio rotunda est; e. g. Restio triflorus ( $t .25$. f: $_{\text {5. c. c.) }}$.

9) miflora: si spicula unum tantun florem con-
I) linicnfórmig (linearis): wenn es von lïnglicher, stark verlängerter Gestalt ist, und die Bogen der Seiten nur wenig gekrümmt sind, so, dals sie fast gerade und gleichlaufende Linien bilden; z. B. Festuca fuitans (t. 구. f. 3).

2) lanzettförmig (lanceolatr): wenn es länglich ist, und der Durchmesser der Lïnge den der Breite mehr als dreymal übertrifit; z. B. Eromus tectornm (t. 33. f. I.).

3) liinglich (oblonga): wenn es eine längliche Ges:alt hat, und der Durchmesser der Länge den der Breite mehr als zweynahl, weniger aber als dreymahl übertriftt; z. B. Lolium perenne (t. 12. f. 2. d.).

4) eyrund (ovata): wenn es eine längliche $\mathrm{Ge}$ stalt hat, bey welcher die Basis einen gröfsern Bogen beschreibet, als die Spitze, die durch ein allmähliges Zusammenlaufen der Seiten gebildet wird; z. D. Driza media (t. 3.-. f. 2.), Bromis mollis (t. 12. f. 4. c.).

5) herzförmig (cordata): wenn es lïnglich ist, und an der Basis einen Ansschnitt hat; z. B. Briza maxima (t. 45. f. .7.).

Länglich heifst hier (Nr. 1-5.) im allgemeinen jede Figur, die ans zwey, mit ihren Sehnen gegen einander gekehrten Kreisabschnitten zusammengesetzt ist.

6) dreyeckig (triangularis): wenn es ein Dreyeck beschrcibt, von welchem die eine Seite die Basis ausmacht; z. B. Lriza virens (t. 45. f. G.).

7) zweyreihig (disticha): werm die Blumen des Achrchens in zwvey Reihen gegen einander über stchen, und so gerichtet sind, dafs sie alle in eine Fläche liegen, wie bey der Gattung Cyperıs und bey mehreren Gattungen der Gräser; z. B. C)perils longus (t. 45. f. 2.), Lolinm perente (t. I2. f. 2. d.), Hronus mollis (t. I2. f. 4. c.), Briza maxima (t. 45. f. 7.), Briza virens (t. 45. f. 6.).

8) stielrund (teres): wenn der Queerdurchschnitt des Aehrchens rund ist; z. B. Restio triflorils (t. 25. . . 5. c.).

9) einblumig (mifora); wenn das Aehrchen 
tinet; exemplum pracbet Agrostis hispida (t. 45. f. 5. a.) nur eine Bluıne enthält, z. B. Agrostis liispida (t. 4j. et omnes hujus generis species.

f. 5. a.) und alle Arten dieser Gattung.

Io) biflora: ex duobus floribus composita; ut in

10) zweyblumig (biflora): das aus zwey BluAira aquatica (t. 37. f. 5. b.) et omnibus generis Airae speciebus.

II) triflora: si ex tribus floribus constat; videatur Avena fatua. Sic porro numerant, dum florum numerus inconstans appareat, tum dicitur.

I2) multifora: exempla praebent Bromus mollis (t. 12. f. 4. c.), Bromus tectorum (1. 38. f. I.), Dromus secalinus (t. 37. f. 9. a.), Lolium perenne (t. I2. f. 2. d.). men zusammengesetzt ist; z. B. Aira aquatica (t. 37. f. 5. b,) und alle Arten der Gattung Aira.

II) dreyblumig (triflora): wern es aus drey Blumen bestcht; z. B. Averu fatua. So zühlt man weiter fort, bis dal's die Zahl der Blumen nicht mehr beständig sich zeigt, alsdann sagt man

I2) vielblumig (multiflora); wie z. B. bey Bromus mollis (t. 12. f. 4. c.), Bromus tectornum (t. 38. f. I.) Bromuls secalinus (t. 37. f. 9. a.), Lolinm perenne (t. 12, f, 2. d.).

\section{§. 67.}

Spica pluribus consiat fioribus vel spiculis (\$. 66.) pedunculo longo communi vel per se, rel pediceliorum brevium ope junctis. Hoc si est, pedicclli minus longi sint, quam ipsi flores, et hi si exiniae sunt longitudinis, id quod Spigelia marylandica (t. 4‥ f. 5.) ostendit: pedicelii ad diametrum transversalem calycis (vel, hic si deest, transversalem partis inferioris corollae diametrum) ne accedant. - Pedunculus communis spicae aeque ac spiculae Rlzachis rocatur. - Spica apparet:

1) glomerata: si glomeruli (\$. 64.) more ex floribus parvis inconspicuis est composita.

IIujus spicae si non figutam modo, sed compositionem etiam intuearis: propriam inflorenscentiae speciem constituit a Link atque 11liger Antharus nominatam, quam paulo inferius ( $($. $7 j$ ) diligentius spectabimus.

2) verticillata: spica e verticillis ( $\$, 62$. ) si com-

\section{§. 67.}

Die Aehre (Spica) besteht aus mehreren Blumen oder Aehrchen ( $($.66.), die mit einem langen gemeinschaftlichen Blumenstiel, entweder unmittelbar, oder vermittelst kurzer Blumenstielchen, verbunden sind. Im letztern Falle dürfen die Blumenstielchen nicht völlig so lang seyn, als die Blumen selbst; und wenn diese von beträchtlicher Länge sind, wie z. B. bey Spigelia marylandica (t. 4f. f. 5.): so dürfen die Blumenstielchen den Queerdurclunesser des Kelches (oder, wenn dieser fehlt, der Quecrdurchmesser des untern Theils der Blilmenkrone) nicht völlig erreichen. - Der gemeinschaftliche Blumenstiel der Aehre wird, so wie bey den Aehr. chen, die śpindel (R/tachis) genannt. - Die Aehre zeigt sich:

1) geknauelt (glonerata): wenn sie nach Art des Knauels (\$. 64.) aus kleinen unanselinlichen Blumen zusammengesetzt ist.

Wenn man bey dieser Aehre niclıt blols auf die Gcstalt, sondern auch auf die Zushmmensetzing sicht: so maclut sie eine eigne Art des Blüthenstandes aus, die voll Link und Illiger der Scluweif (Anthurus) genannt wird, und den wir weiterhin (f. 75.) genauer betracliten wollen.

2) quirlfürmig (vcrticillata): wenn die Aehre 
posita est pari inter se intervallo distantibus; videatur Mgriophyllum spicatum (t. 29. f. 3. c. d.).

3) interrupta: si spatia floribus destituta passim labet, vel partim tantum ex verticillis est composita non aequo inter se intervallo distantibus; exemplum exhibet Lavandula Spica (t. 30. f. 2.).

4) continua: in qua locus nullus floribus destitutus videtur. Praecedenti opposita.

5) imbricata: si spicae flores tegularmm more sibi incumbunt; exempla praebent plurimae gencris Caricis species.

6) disticha: si flores vel spiculae in duabus seriebus oppositis collocati, simulqne ita direcli sunt, nt omnes uni plano incumban; videatur Lolium perenne (1. 12. f. 2. d.).

7) tetrasticha: si flores quaterna serie recta ita sunt collocati, ut spica transversim dissecta quadrangularem referat figuram; e. g. Melampyrun cristatum, Lavandula Stoechas (t. 37. f. 7.).

8) hexusticha: Horibus sena serie ita collocatis, ut spica transversin dissecta sexangularem referat figuram; exemplo est Hordeum hexastichon.

9) astictar: si quond flores collocatos non idem, qui in praecedentibus ( Nr. 6, 7 et 3.), ordo est conspicums. His itaque tribus contrariatur.

10) tmilateralis: si pedunculus communis non nisi unum latus, idque vix ad mediam peripheriae floribus est obsitus; e. g. Nardus stricta, Spigelia marylandica (t. 4 f. 5.), Elzloltzia cristata (t. 30. f. 6. b.).

Ir) completa: si pedunculus communis floribus

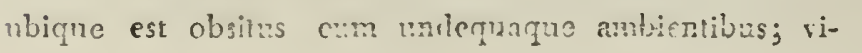

aus Quirlen (క. G2.) zusammengesetzt ist, die in regelmilisigen Enifernungen ron einander stehen; z, D. $M y$ riophyllum spicatinm (t. 29. f. 3. c. d.).

3) unterbrochen (interrupt (1): wonn sie hin und wiedor blumenlose Zwischenräume hat, oder nur zum Theil aus Quirlen zusammengesetzt ist, di nicht in regelmäfsigen Ertfernungen von cinauder stehen; z. D. Laveandula Spica (t. 30 f. 2.).

4) u keine blumenlose Stelle gcwalı wird. Als Gegensatz der vorhergelienden.

5) dachriegelfürmig (imbricata): wenn die Blumen der Aehre nach Art der Dachzi gel über einander liegen; z. B. die meliresten Arten der Gattung Carex.

6) zweyreihig (aisticlua): wenn die Blumen oder Aehrchen in zwey cntgegengesetzten lieihen gestellt sind und zmgleich eine solche Tiilntung haben, dafs sie alle in eine Fliiche liegcn; z. B. Lolium perenne (t. 12. f. 2. d.).

7) vierreilig (tetrasticlıa): wenn die Blumen in vicr geraden Reilten stehen, so, dâfs die Aehre im Queerdurchsclinitte eine viereckige Figur zeig! ; z. B. Melampyrum cristatum, Lavandula Stoechas (t. 37. f. 7.).

8) sechsreihig (hexasticha): wenn die Biumen in sechs lieiluen stehen, so, dafs der Durchschnilt der Aelure einem Sechseck gleicht; z. D. IIurdeum hexasticlion.

9) unreihig (asticha): wenn man in Ruicksicht der Stellung der Blumen keine solche Ordnung, wie bey den drey vorhergehenden ( $\mathrm{Nr}, 6,7$ und 3.), bemerkt. Sie ist allen drey"en entgegengesetzt.

Io) einseitig (unilateralis): wenn der gemeinschaftliche Bhmenstiel nur an einer Scite, und zwar kaum bis zur Hälfte seines Unkreises mit Blumen besetzt ist; z. B. Nordus stricia, Spigelia marylandica (t. 4f. f. 5.), Elzholizia crisiata (t. 33. f. 6. b.).

II) vollstïndig (completa): wenn der gemeinscinfliche Blumonsticl äberall mit Dismon besetzt isi. 
deatur exempli loco Veronica spicata, Agrimonia Eupatoria, Phleum pratense, Lagurns ovatus (t. 38. f. 4.), Polygonum Bistorta (t. 43. f. 4.), Carex sylvatica (t. 41. f. 5. b. et c.), Equisetum arvense (t. 15. f. 3. a.). Priori contraria non nisi hac ratione distinguitur.

12) secunda: si pedunculus communis ubique fere, vel saltim usque ad duo opposita latera, vestitus est floribus, qui omnes ad unam plagnm vermani; c. g. S.ttyrium repens (t. fo. f. f. b.), (Hiadiolus communis.

13) vaga: cujus flores haud ad unarn, sed ad omnes plagas vertuntur. Priori opposita est, eique explicandae exempla inserviunt Nro. Ir. allegata.

If) spiralis: floribus commmi pedunculo linea curva ita circumpositis ut totnm spicae similitudinem referat; insp̧iciatur Ophrys spiralis (t. f2. f. g.).

1.5) linearis: vid. §. 66. Nr. I.; exempli loco sunt Rottboeilia incurvata (t. 25. f. I. b.), Lolium perenne (t. I2. f. 2. d).

I6) cylindrica: cylindri formam si cxhibet; rel, quod idem ist, si omnibus sectionibus transversalıbus iicien contingunt circuli; e. g. Phleum pratense (t. f-. f. I.).

17) ovata, rectius oviformis: ad ori figuram si accedit, ut sectiones transversales circuli, mediae longitudinalcs vero ovatain figuram (\$. 65. Nr. 4.) offerant; exempla pracbent Lagurus ovatus (1. 33. f. 4.) Plaalaris canariensis.

18) ventricosa: si oblongam effingit figurnm, Trae media latior ad utramque exiremitatem sensim angustatus, ita, ut sectiones transversales circuli promant, mediae longitudinalcs autcm figuran exlibcant, die denselben ron allen Scicen umgeben; z. B. Vero. nica spicata, Agrimonia Eupatoria, Plleum pratense, Lagurus ovatus (1. 33. 6. 4.), Polygorbum Bistorta (t. 43 f. 4.), Carex sylvatica (t. 4I. f. 5. b. und c.), Equisetum arvense (t. 15. f. 3. a.). Sie ist der vorhergehenden entgegengesetzt und wird auch nur in dieser Püicksicht unterschieden.

12) einseitswendig (secunda); wenn der gcmeinschaftliche Blumensiel fast überall, oder doch wenigstens bis zu zwey entgegengesetzten Seiten mit Blumen besetzt ist, die alle nach einer Seite sich wenden; z. B. Satyrium repens (t. 49. f. 4. b.), Gladiolus commnunis.

13) allseitswendig $(\operatorname{vgg} \alpha)$ : dercn Blumen nicht nach einer Scite sich wenden, sondern nach allen Seiten gerichtet sind. Sie maclıt den Gegensatz der vorhergthenden aus; und zu ihrer Erlïuterung dienen dieselben Beyspiele, die bei Nr. Ir. angefïhrt sind.

I4́) schraubenförmig (spiralis): wenn die Blumen in einer krummen Linie um den gemeinsclaftlichen Blumesıstiel stehen, so, dafs das Ganze Aelnnlichkcit mit einer Schraube hat; z. B. Ophirys spiralis (t. $4=$ f. 9.).

1.5) linienfürmig (linearis): S. §. 66. Nr. I.; z. B. Rottboellia incurviatu (t. 2J. f. I. b.), Lolium perenne (1. 12. f. 2. d.).

I6) Walzenförmig (cylindrica): wenn sie die Gestalt einer Walze hat; oder, was gleich viel ist, wenn alle Queerdurchschnitue gleiche Kreise geben; z. B. Plleum pratense (t. 47. f. I.)

17) eyförmig (ovata, besser oviformis): wenn sie sich dex Figur des Eyes nähert, so dafs die Queerdurchschnitte Kreise, die mittleren Längendurchischniue aber cine eyrunde Figur (§. 66. Nr. 4.) gtben; z. B. Iagurus ovatus (1. 33. f. 4.), I'lualaris canariensis.

13) bauchig (ventricosa): wenn sie eine lïngliche Fïgur bildct, die in der Mitte crweitert ist, und gegen beyde Enden sich allmällig verengt, so, dafs die Queerdurchschnitte Kreise geben, die mittleren Längen- 
in medio longe latiorem, quam in utraque extremitate; inspiciatur P'olygonum Distorta (t. 43. f. 4.)

19) foliusa: quae inter flores habet folia. - Quod nomen raro quidem adjicere aussim; Linnaens tamen in diagnosi Caricis arenariae adhibet, verum hujus vegetabilis spica non nisi bracteata (Nr. 2I.) est.

20) apliylla: cui nulla inter flores sunt folia. Priori opposita est.

2r) Eracteata: cui inter flores sunt bracteae; exempli loco esto Cynosurus cristatus, Melampyrum cristatum, Lavandula Stoechas (t. 37. f. ..). Si spica unilateralis ( $N_{r}, r_{0}$.) est, tum bracteae in latere averso apparent; ut in Elzholtzia cristata (t. 38. f. 6. b.).

22) ebractcata: quae bracteis destituta, ideoque praecedenti opposita est; e.g. Spigelia marylandica ( $t$. 44. f. 5.).

23) comosa: cujus apex folia vel bracteas fert fasciculum referentes; e. g. Lavandula Stoechas (t. 37. f. 7.), Lavandula viridis.

24) nuda: cujus aper nec folia habet nec bracteas, atque ob id priori opposita est; ut in Lavandula Spica (t. 30. f. 2.).

25) composita: si pedunculus communis varia in altitudine in proprios dividitur pedunculos, quorum quivis spicam format, ita, ut totum ex spicis simplicibus sit compositum; videatur Carex intermedia Good. (t. 39. f. 5. a.).

26) decomposita: si peduncalus communis varia in altitudine proprios fert pedunculos in ramos sese divid'ntes, quorum quilibet spicam fingit, ita, ut totun ux spicis compositis constructum sit; exemplo est Curex paniculata (t. 3y. f. 2.). durchschnitte aber eine Figur, die in der Mitte betrïchtlich breiter, als an den beyden Linden ist; z. B. Polrgonum Bistorta (t. 43. f. 4.).

19) beblittert (foliosa): wenn sie zwischen den L'umen Dlätter h hat. - Dieses Prädicat mügte wohi nur selten angewendet werden können; L i n n é gebrancht es zwar in der Diagnose bey Carex arenarir, aber die Aehre dieses Gewächses ist nux nebenblättrig (Nr. 2I.). -

20) blätterlos (aplollla): die keine Blätter zwischen den Blumen hat. Sie ist der vorhergehenden entgegengesetzt.

21) nebenblättrig (bracteata): die zwischen den Blumen Nebenblitter hat; z. B. Cynosurtes cristatus, Melamprum cristatum, Luvandula Stoechus (t. 3\%. f. ..). Wenn die Aelire einseitig (Nr. ro.) ist, dann finden sich die Tebenblütter auf der Rückseite, wie bei der Elzloolzia cristata (t. 38. f. 6. b.)

22) nebenblätterlos (ebracteata): die keine Nebenblätter hat, als Gegensatz der vorhergehenden; z. B. Spigelia marylandica (t. 44. f. 5.).

23) schopfig (comosa): die an der Spitze Blätter oder Nebenblätter, in Gestalt eines Buischels, trägt; z. B. Lavandula Stoechas (t. 37. f. 7.)', Lavandula ziridis.

2-j) nackt (nuda): die keine Blätter oder Nebenblitter an der Spitze hat, und daher den vorhergehenden entgegengesetzt ist; z. B. Lavandula Spica (t. 3o. f. 2.).

25) zusammengesetzt (composita): wenn der gemeinschaftliche Blumenstiel in verschieden in besondre Blumenstiele zertheilt, ron denen jeder eine Aehre bildet, so, dafs das Ganze aus einfachen Aehren zusammengesetzt ist; z. B. Carex intermedia Goosl. (t. 3.. f. 5. a.).

26) doppelt - zusammengesetzt (decomposita): wenn der gemeinschaftiche Blumenstiel in verschiedener Höhe besondre Blumenstiele trägt, die sich in Aeste zerheilen, von denen jeder eine Aelıre bildet, so, dafs das Ganze aus zusammengesetzten Aehren zusammengesetzt ist; z. E. Carex paniculata (t. 39. f. 8 
27) stipradecomposita: si pedunculus comm:mis varia :n altiludine proprios fert, pedunculos, qui in ramos atrue hi denuo partin in ramulos dividitur, quorum quisque spicam ostendit, ita, ut totum ex spicis decompositis constructum sit; exempli loco est Spiraea Aruncus.

23) panicnlata: duae praecedentes ( $\mathrm{Nr} .26 \mathrm{et} 27$. ) saepentumero vocantur.

29) ranosa: est commune quatuor praccedentium (Nr. 2j-28.) nomen, si mimirum alia denominatione opas non est.

30) simplex: cujus peduncalus communis in proprios non dividiur; e. g. Lolium perenne (t. 12. f. 2. d.), Tiottboellia incurvata (t. 25. f. I. b.). Quinque praecedentibus (Nr. 25-29) contrariatur.

31) conjugata: si binae in basi sua spica sunt junctae; e. g. Andropogon distachyon (t. 4o. f. 3.).

32) fascicnlata: si plures spicae arcte conjunctae quasi fasciculam formant; videatur Chloris radiata ( $t$. 40. f. 2.).

33) digitata: ubi plures spicae in culmi (\$. 52.) apice binis oppositis in lateribus collocatae, atque ita directae sunt, ut omnes in uni plano incumbant; e. $g$. Andropogon Ischaemum (t. 4r. \&. z.), Panicum sanguinale, Panicum Crus galli.

Hae spicarum collocatio secundum $\mathrm{Link}$ afque $11 \mathrm{l}$ ger propriam inforescentiae speciem constituit, quae nominc Flabelli (S.72.) magis nobis innotescet.

34) nmbellata: si plures spicae in morem umbellae ( $\$$. ?o., ad quam rectius referantur,) ex eodem puncto oriuntur; inspiciatur Cyperus longus (t. 45. f. 2.).

Tam hoc, quam tribus praecedentibus terminis plcrumque non nisi in plurali numero utuutur.
27) vielfach - zusammengesetzt (stipradecorzposita): wenn der gemeinschaftiche Blumenstiel in ver schiedener Hülıe besondere Blumenjtiele trigt, die sic!ı in Aeste und diese wieder zum Theil in Aestchen zertheilen, von denen jedes eine $\Lambda$ chre billet, so, dilis das Ganze aus doppelt - zusammengesetzten Athren zusammengesetzt ist; z. B. Spiraen Aruncus.

28) rispenartig (paniculata); so werden üfters die beyden vorhergehenden (No. 20 und 2?) genannt.

29) ästig (ramosa): ist die allgemeine Benennung der vier vorhergehenden $\left(\mathrm{Nr}_{0}=5-28\right)$, ivcnn nünlicis keine genauere Bestimmung nöthig ist.

30) einfach (simplex): deren gemeinschaftlicher Blumenstiel sich nicht in besondere Blumensticle zertheilt; z. B. Lolium perenne (t. 12. f. 2.d.), Rottboellis incurvata (t. 25. f. r. b.). Sie ist den fünf vorluergehenden (Nr. 25-29.) entgegengesetzt.

3r) gepaart (eonjugata): wenn zwey Aehren an ihrer Basis verbunden sind; z. B. Andropogon distaclayon (t. 40. f. 3.).

32) büschelförmig.(fasciculąa): werm mehrere Aehren dicht beysammen stehen und gleichsanz einen Büschel bilden; z. B. Chloris radiata (t. fo. f. 2.).

33) gefingert (digitata): wenn mehrere Aehrers an der Spitze eines Halms (\$. 5z.) an zwey entgegengesetzten Seiten stehen, und dabey so gerichtet sind, dafs sie alle in einer Fläche liegen; z. B. Andropogon Isclaaomnm (t. f́r. ᄃ. 2.), I’anicum sangninale, Panicum Cirns galli.

Diese Stcllung der Acliren macht nach Link and Illigger eine eigne Ast des Blüıhenstandes aus, lie wir ( $(5.72$.$) unter den Nahmen des Fechels (Ftabel-$ lum) nalier kennen leinen werden.

3i) doldenartig (umbcllata): wenn mehrorc Aelıren, nach Art der Dolde ( $\$$. Zo., zu der sie auch mit mehrerm Rechte gereclunet wird,) aus einem Puncte entspringen; z. B. Cyperus longns (t. 45. f. 2.).

Sowolil dieser, als auch die drcy vorlergeirenten Iurstausdrücke werden gewühnlich nur in der Mebrlicit gcbraucht. 
35) solitaria: si non dno pluresve conjunguntur. Contrariatur Nris 3 r, 32, 33 et 34.

Situs spicae aeque ac pedunculi (\$. 6o. Nr. 4-17.) indicatur, et quoad firmitatem ac direetionem iidem Termini illi adjiciuntur, qui in racemo ( $\$ .68, \mathrm{Nr} .18-25$. occurrunt.

§. 68 .

Racemus pluribus constat floribus vel syiculis ( $\$$. 60.) longi communi pedunculo insistentibus eique pedicellorum eandem fere longitudinem habentium beneficio conjunctis. Ne vcro pedicelii floribus ijsis sint breviores, nisi si his eximia sit longitudo, quod Lobelia cardinalis (t. 22. f. 4.) ostendit: idque tuin fit, si illorum longitudo dianetrum transversalem calycis (vel, si lic deficit, transversalem partis inferioris corollae diametrum) aequat. Racemns quidem et spica floribus pedicellatis ( $\$ .67$. ) in sese transeunt, sed ex longitudine pedicellorum hic dicta facile possunt distingui. - Connmunis racemi sicut spiculae et spicae pedunculus $R / \iota a$ cleis vocatur. - Racemus deprehenditur;

1) unilateralis: vid. §. 67. Nr. 10.

2) completus: vid. §. 67. Nr. Ir.; e. g. Phytolacca decandra (t. 34. f. 5. b.), Cakile maritima (t. 17. f. 3.).

3) secundlus: vid. §. 67. Nr. 12.; e. g. Lobelia cardinalis (t. 22. f. 4.), Convallaria majnlis (t. 37. f. 4.), Orobus niger (t. 19. f. 5. c.).

4) vagus: vid. \$. 67. Nr. I3.; e. g. Phytolacea decandra (t. 34. f. 5. b.), Calkile maritima (t. 17. f. 3.).
35) einzeln (solitaria): wenn nicht zwey oder melirere beysammen stehen. Der Gegensatz ron Nr. 3 r, 32,33 und 34 .

Die Lage der Aehre wird so wie die des Blumen. stiels ( $\$ 60, \mathrm{Nr}, 4-17$.$) bestimmt, und in Hinsicht$ der Festigkeit und liichtung lassen sich bey ihr diescl. ben Kunstansdrücke antwenden, die bey der Traube ( $\$$. 68. Nr. 18 -25.) vorkommen.

\section{68 .}

Die Tranbe (Tacemus) besteht aus mclireren Blamen ode: A hrchen ( $\$ .66$. ), die auf enen langen gemeinschaftlichen Biumenstiel befestigt, und mit dinsclben vermittelst ziemlich langer Binmenstielclien verbunden sind. Die Elumenstielchen dürfen aber nicht kürzor scyn als die Blumen selbst, es wäre denn, daifs lu:ztcre eine betrïthtliche Länge hätten, wie z. D. bej der Lobelia cardinalis (t. 22. $\mathrm{f}, 4$ ): dann ist es hinreichend, wenn die Lïnge der erstern dom Queerdurchmesser des Kelches (oder, wonn dieser fthlt, dem des untern Theils der Elumenkrone) glcich kommt. Die Traube und die Achre mit gestielten Blumen (\$. 67.) gehen zwar in einander über, aber sie lassen sich durch die hier bestimmte Lïnge der Bhmenstielchen sehr leicht untericheitlen. - Der gcmeinschaftliche Blumenstiel der Traube heifst, so wie bey dem Achrchen und der Achre, die Spindel (H/hachis). - Man findet die Tranbe:

I) einseitig (unilateralis): S. \$. 67. Nr. 10.

2) vollständig (completus): S. \$. 67. Nr. II.; z. B. Pleytolacca decandra (t. 34. f. 5. b.), Cahile maritima (t. 17. f. 3.).

3) einseitswendig ( $\operatorname{secundus):~\$ .~\$ .~67.~Nr.~I2.;~}$ z. B. Lobelia carlinalis (t. 22. f. 4), Convallaria majalis (t. 37. f. 4.), Orobus nigger (t. I9. f. 5. c.).

4) allseitswendig (vagus): S. \$. 67. Nr. 13.; z. B. Plytolacca decandra (t. 3ł. f. 5. b.), Cakile marituma (t. 17. f. 3 ). 
27) supradecomposita: si pedunculus communis varia in altitndine partiales fert pedunculos, qui in ramos atque hi denuo partim in ramulos dividitur, quorum quisque spicam ostendit, ita, ut totum ex spicis decompositis constructum sit; exempli loco cst Spiritea Aruncus.

23) paniculata: duae praecedentes ( $\mathrm{Nr}, 26$ et 27.) saepenumero vocantur.

29) ramosa: est comınune quatnor praecedentium (Nr. 2j-28) nomen, si nimirum alia denominatione opus non est.

3o) simplex: cujus pedunculus communis in partiales 110 n dividitur; e. g. Loliun perenne (t. 12. f. 2. d.). Iiottbocllia incurvata (t. 25. f. I. b.). Quinque praecedentibus (Nr. 25-29) contrariatur.

3r) conjugata: si binae in basi sua spicae sunt junctae; e. g. Andropogon distachyon (t. 40. f. 3.)

32) fasciculata: si plures spicae arcte conjunctae quasi fasciculam formant; videatur Chloris radiata ( 1.40. f. 2.).

33) digitata: ubi plures spicae in culmi (\$. 52.) apice binis oppositis in lateribus collocatae, atruue ita directae sunt, ut oinnes un plano incubent; e. g. Androprogon lschaemum ( t. fr. f. 2.), Panicum sanguinale, Panicnm filiforme.

Hae spicarum collocatio secundum Link atque Illiger propriam inforescentiae speciem constiluil, quae nomine Flabelli (\$.72.) magis nobis innoiescet.

34) umbellata: ubi plures spicae in morem umbel-

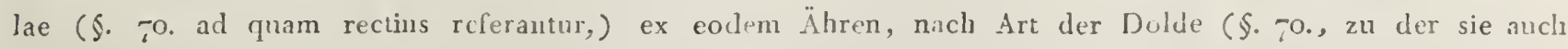
puncto oriuntur; inspiciatur Cyperus longus (t. 4.5. f. 2.) mit mehrem Rechte gerechnet wird, ) aus einem Puncte

Tam hoc, quam tribus praecedentibus terninis plerunque son nisi in plurali numero uluntur.
27) vielfach-zusammengesetzt (supradecomposita): wenn der allgemeine oder gemeinschaftliche B'umenstiel in verschiedener Höhe besondere Blumenstiele trïgt, die sich in Äste und diese wieder zum Theil so, dafs das Ganze aus doppelt-zusammengesetzten Ähren zusammengesetzt ist; z. B. Spiraea Aruncus.

28) rispenarig (paniculata); so werden öfters die beyden vorhergehenden ( No. 26 und 27) gennnnt.

29) ästig (ramosa): ist die allgemeine Benennung keine genauere Bestimmung nölhig ist.

30) einfach (simplex): deren gemeinschafslicher oder allgemeiner Blumenstiel siclı nicht in besondere Blumensticle zerheilt; z. B. Lolium perenne (t. 12. f. 2. d.), Rottboellia incurvatu (t. 25. f. 1. b.) Sie ist den fïnf vorluergehenden ( $\mathrm{Nr} .25-29$.$) entgegengesetzt.$

3i) gepart (conjugata): wenn zwey Ähren an ihrer Basis verbunden sind; z. B. Andropogon distacliyon (t. fo. f. 3.).

32) büschelfürmig (fasciculata): wenn mehrere Ähren dicht beysammen stehen und gleichsam einen Büschel bilden; z. B. Cluloris radiata (t. fo. f. 2.)

33) gefingert (digitata): wenn mehrere Ähren an der Spitze eires Halms ( $\$$. 52.) an zwey entgegengesetzten Seiten stchen, und dabey so gerichtet sind, dafs sie alle in einer Fläche liegen; z. B. Andropogon Ischaemum (t. 41. f. 2.), Panicum sangninale, Panicum filiforme.

Diese Stellung der Aehren macht nach Link und Illigger eine eigne Art des Blüthenstandes aus, die wir (\$. 72.) unter dem Nahmen des Fächels (Flas bellum) naher lennen lernen werden.

34) doldenartig (umbellata); wenn melurere entspring'n; z. B. ('yperus longus (1. †.5. f. 2.).

Suwohl dicser, als auch die drey vorhergehenden Kunstansarizche werden gewülnlich nur in der Richr. heir gebraucht. in $\ddot{A}$ stchen zertleilen, von denen jedes eine Älıre bildet, der vier vorhergehenden (No. 25 - 28), wenn nämlich 
35) solitaria: si non duo pluresve conjunguntur. 35) einzeln (solitaria): wenn nicht zwey oder Contrariatur Nris 3r, 32, 33 et 34. mehrere beysaminen stehen. Der Gegensitz von Nr.3r, 32,33 und $3 i$.

36) hermaphlirodita: si florum ejus quilibet tam

36) zwitterblumig (hermaphrodita): wenn jede mascıla, quam feminea genitalia continet; vel, si ex Ho- ihrer Blumen sowohl männliche, als auch weiblıche Geribus hermaphroditis est compusita; videatur Phleum schlechtstheile enthält; oder, wenn sie aus Zwitterblupratense (t. 4і. f. 1.), Lagurus ovatus (t. 38. f. 4.), Ca- men zusammengeselzt ist; z B. Phlenm prateruse (t. 47. rex hermaphrodita.

f. 1.), Lagurus ovatus (t. 38. f. 4.), Carex hermaplerodita.

37) mascula: cujus flores non nisi mascula genita-

37) männlich (mascula): deren Blumen nur lia habent; vel, quae non nisi e masculis genitalibus est männliche Geschlechıstheile enthalten; oder, die blufs composita; exempli loco videatur Carex Oederi (t. 36. aus männlichen Blumen zusammengesetzt ist; z. B. Caf. 3. c.) Carex sylvatica (t. 4r. f. 5. b.). rex Oederi (t. 36. f. 3. c.), Curex sylvatica (t. $4 \mathrm{I}$. f. 5. b.)

38) feminea: cujus Hores non nisi feminea genita-

38) weiblich (feminea); wenn ihre Blumen nur lia continent; vel, si ex solis floribus fenineis constat; weibliche Geschlechtsheile enthahten; oder, wenn sie exempla praebent Carex Oederi (t. 36. f. 3. b.j, Carex blols aus weibliclen Blumen besteht; z. B. Curex Oesylvatica (t. 41. f. 5. c.).

39) androgyna: quae flores masculos et femineos simul continet. 'Tam est vel

a) superne mascula: si flores masculi in apice, feminei in basi adsunt; e. g. Carex capitata (t. 36 . f. 2.); vel

¿) superne feminea; cui in apice feminei in basi vero masculi sunt flores; e. g. Carex ovalis (t. 50. f.Io).

Situs spicae aeque ac pedunculi ( $($. $60 . N$. N. 4 - 17.) indicatur, et quoad firmilatem ac directionem iidem Termini illi adjiciuntur, qui in racemo ( $\$ .68$. Nr.19-26.) occurrunt.

deri (1. 36. f. 3. b.). Carex sylrarica (t. 4t. f. 5. c.).

39) männlichweiblich (androgyzu): wenn sie männliche und weibliche Blumen zugleıch entlıält. Sie ist alsdann entweder

a) oben männlich (superue mascula): wenn sich die unānnlichen Blumen an der Spitze, die weiblichen an der Basis hefinden, z. B. Carex capitata (t. 36. f. 2.); oder

b) oben weiblich (superne feminea): wenn sie an der Spitze weibliche, an der Basis aber männliche Blumen hat; z. B. Carex ovalis (t. 50. f. 10).

Die Lage der Athre wird so wie die des Blumen. stiels (\$. 60. Nr. 4- 17.) bestimmt, und in Hinsichat der Fesligkeit und Richtung lassen sich bey ihr diesel. ben Kinnstausdrücke anwenden, die bey der Traube ( $($. 68. Nr. 19 - 26.) vorkommen.

5. 68.

5. 68.

Racemus pluribus constat floribus vel spiculis ( $\$$. Die Traube (Racemus) besteht aus mehreren Blu66.) longo communi pedunculo insistentibus eoque pe- men oder $\bar{A} h r c h e n(\$ 66)$, die auf einem langen alldicellorum eandem fere longitudinem habentium bene- gemeinen Blumenstiel befestigt, und mit demselben verlicio conjunctis. Ne vero pedicelli floribus ipsis sint mittelst ziemlich langer Blumensticlchen verbunden sind. breviores, nisi si his eximia sit longitudo, quod Lobelia Die Blunenstitlchen düıfen aber nicht kürzer sejn, als 
cardinalis (t. 22. f. Ł.) ostendit: idque tum fit, si illo- die Blumen selbst, es wäre denn, dafs letztere eine berum longitudo dianctrum transversalem calycis (vcl, si trächtiche Länge hätten, wie z. P. bey der Loleliı hic deficit, transvcrsalem partis inferioris corollae dia-cardinalis (t. 22. f. 4.): dann ist es hinreichend, wenn ınctrum) aequat. Racemus quiden ct spica floribus pe- die Länge der erstern dcm Queerdurchinesser dcs Keldicellatis (\$. 67.) in sese transeunt, sed ex longitudine ches (oder, wenn dieser felht, dem des untern Theils pedicellorum lic dicta facile possunt distingui. - Com- der Blumenkrone) gleich kommt. Die Traube und die munis racemi sicut spiculae et spicae pedunculus $R /$ a - Ähre mit gestielten Blumen (\$. 67.) gehcn zwar in eincliis vocatur. - Racemus deprehenditur: ander ïber, aber sie lassen sich durch die hier bestimmte Länge der Blumenstielchen sehr leicht unterschciden. Der gemeinschaftliche Blumenstiel der Traube heifst, so wie bey dem Ährchon und dor Ähre, die Spindel (R/lachis). - Man findet die Traube:

1) unilateralis: vid. \$. 67. Nr. 10.

2) completus: vid. S. 67. Nr. Ir.; e. g. Phytolacca decandra (t. 3ł. f. 5. b.), Cakile maritima (t. 17. f. 3.).

3) secundus: vid. §. 67?. Nr. ז2.; e. g. Lobelia cardinalis (t. 22. f. 4.). Convallaria majalis (t. $3 \%$ f. 4.), Orobus niger (1. 19. f. 5. c.)

4) ragres: vid. §. 67. Nr. 13.; e. g. Phytolacca decandra (t. 3 . f. 5. b.), Cakile maritima (t. 17. f. 3.).

5) corymbosus: si et pedunculus communis ct pedicclli superiorcs non nisi cum florent ita jroducuntur, ut racemi apex corymbi (\$. 69.) faciem referat. Reperitur in fluribus vegetabilibus classis Linnaei decimae verlängern, so, dals die Spitze der Traube das Ansequintae; ut in Draba verna (t. 25. f. 2.), Cakile ma- hen einer Doldentraube (\$.6j.) hat. Sie findet sich ritima (t. 17. f. 3.).

6) verticillatus: si pedicelli ex communi pedunculo in morem verticillorum (\$. 6. 2.) proveniunt; exempli loco videatur Sagittaria sagitufolia (t. 36. f. 9. c.), (-nitis Hottonia palustris.

7) umbellatus: si pedunculus communis varia in altitudine partiales protrudit pedunculos, quilibet simpli- Blumenstiel in verschiedener Hühe besondere Blumen-
1) einseitig (unilateralis): S. §. 67. Nr. เо.

2) vollstïndig (completus): S. \$. 6\%. Nr. Ir.; maritima (t. 17. ศ. 3.).

3) einseitswendig oder einwendig (secundus): S. \$. 67. Nr. 12; z. B. Lobelia cardinalis (t. 22. f. 4) ), Convallaria majalis (t. 37. f. 4.), Orobus miger (t. I9. f. 5. c.).

4) allseitswendig oder vielwendig (vaguls): S. \$. 67. Nr. 13.; z. B. Pluytolacca decandra (t. 3ł́. 5. b.), Cakile maritima (t. 17. f. 3.).

5) doldentrabenartig (corymbosus): wenn sich sowoh] der allgemeine Blumenstiel, als auch die obern Blumenstielchen nur erst während des Blühens bcy den mehresten Gewächsen der funfzehnten Linncschen Classe; z. B. Draba verna (t. 25. f. 2.), Caliile maritima (t. 17. f. 3.)

6) quirlfürmig (serticillatus): wenn die Blumenstielchen aus dem allgcmeinen Blumenstiel nach Art der Quirle ( $\left.\begin{array}{l}5 \\ \text { 62.) }\end{array}\right)$ hervorkommen; z. B. Sagittaria sagittifolia (t. 36. f. 9. c.), Ifottonia palustris.

7) doldig (unbellatus): wenn der allgemcinc $\mathrm{P}=$ z. B. Phytolacea decandra (t. 34. f. 5. b.), Calile 
cem fert umbellam (\$. 7o. Nr.); e. g. Aralia racemosa stiele treibt, von denen jeder eine einfache Dolde ( $\$$. (t. 38. f. 5.), Ceanothus americanus. 70. Nr.) trïgt ; z. B. Aralia racemosa (t. 38. א. 5.) Ceanothus anericanns.

8) compositus: si pedunculus communis varia in

8) zusammengesetzt (compositus): wenn der altitudine in partiales dividitur pedunculos, quorum quivis allgemeine Blumenstiel in verschiedener Höhe sich in racemun format; videatur Veratrum nigrum (t. 40. f.7.) besondre Blumenstiele zertleilt, von denen jeder eine Spiraea laevigata.

Traube bildet; z B. Veratrun nigrun (\$. 4\%. ᄃ. 7.), Spiraea laevigata.

9) decompositus: si pedunculus communis varia in

9) doppelt-zusammengesetzt (decomposirus): altitudine partiales fert pedunculos, qui in ramos quo- wenn der allgemeine Blumenstiel in verschıedener Hölıe rum quilibet format racemum, se se dividunt; inspicia- besondere Blumenstiele trägı, die sich in Äste zertheitur Spiraea salicifolia.

len, von denen jeder eine Traube bildet; z. B. Spiraea salicifolia.

10) supradecompositus): ubi pedunculus commu-

I0) drey - oder vielfach - zusammengeset $z \mathrm{t}$ nis varia in alitudine partiales gerit pedunculos, qui in (supra decompositus): wenn der allgemeine Blumenramos, et hi partim in ramulos, quorum quilibet fingit stiel in verschiedener Höhe besondre Blumenstiele trägt, racemun, rursus diducuntur; exemplum praebet Vera- die sich in Äste, und diese zum Theil wieder in Ästchen trum album. zertheilen, von denen jedes eine Traube bildet; z. B. Veratrum albnu.

I1) simplex: cujus pedunculus communis in partia-

II) einfach (simplex): deren allgemeiner Blnmenles non dividitur; e. g. Convallaria majalis (t. 37. f. 4.), stiel sich nicht in besondere Blumenstiele zertheilt; z.B. Berberis vulgaris (t. 35. f. 2. c.), Phytolacca decandra Convallaria maialis (t. 37. f. 4.), Berberis vulgaris (t. 34. f. 5. b.), Cakile maritima (t. 17. f. 3.). Quatuor praecedentibus (Nr. $7-10)$ contrarius est.

(t. 35. f. 2. c.), Plurtolacca decandra (t. 34. f. 5. b.), Cakile maritima (t. 17. f. 3). Sie ist den vier vorhergehenden (Nr. 7 - 10.) entgegengesetzt.

I2) conjngatus: si duo racemi arcte consistunt, vel 12) gepaart (conjugatus): wenn zwey Traubei ex eodem Iruncto communi enascuntur; c. g. Staphylea dicht beysammen stehen, oder aus einem gemeinschaftpinnata (t. 4r. f. 9. b.) Actaea spicata (t. 50. ศ. 7.).

lichen Puncte entspringen, z. B. Staplyylea pinnata ( $t$. 41. f. 9. b.), Actaea spicata (t. 50. f. 7.).

I3) solitarius: si racemi bini pluresque non arcte 13) einzeln (solitarins): wenn die Trauben nicht sunt conjuricti, sed separati apparent; exemplo sunt zu zwey oder mehreren dicht beysamımen stehen, sonBerberis vulgaris (t. 35. f. 2. c.), Phytolacca decandra dern von einander abgesondert sich zeigen; z. B. Ber(t. 34. f. 5. b.) et pl. al. Praecedenti oppositus est.

beris vnlgaris (t. 35. f. 2. c.), Phytolacca decandra (t. 3 f. 5. b.) u. m. a. Sie steht im Gegensatze mit der vorhergelienden.

I/) foliosus s. foliatus: ubi folia inter flores ad14́) beblātlert (foliosus s. foliatus): wenn zwisunt; ut in Thesio elıracteato (t. 26. f. 4.), Lobelia car- schen den Blumen sich Blätter finden; z. B. Thesium dinali (t. 22, f. 4.) eluracteatun (t. 26. f. 4.), Lobelia cardinalis (t. 22 . f. 4.). 
I5) aphllhis: qui inter Hores folia non habet, at1.5) blattlos (apliyllus): die zwischen den Blumen que ita priori contrarius est; inspiciatur Convalleria ma- kcine Blätter hat, und also der vorhergehenden entgejalis (37. 1. 4), Phytolacca decandra (t. 34. f. 5. b.), g ngesetzt ist; z. B. Convallaria majalis (t. 37. f. 4.), Berberis vulgaris (t. 35. f. 2. c.).

Pluytolacea decandra (t. 34. f. 5. b), Berberis vulgaris (t. 35. f. 2. c.).

16) bracteatus: qui bracteas habet; e. g. Con16) nebenblärtrig (bracteatus): die Nebenblätvallaria majalis (t. 37. f. f.), Phytolacca decandra (t. 34. ter hat; z. B. Convall.zria majalis (t. 37. f. 4.), Phyf. 5. b.).

rolacca decandra (34́. f. 5. b.).

17) ebracteaths: bracteis carens; ideoque priori

17) nebenblätterlos (ebracteatus): ohne Neoppnsitus; e. g. Thesiun ebracteatun (t. 26. f. ł.), Sta- benblätter, der vorhergehenden entgegengesetzt; z. B. phylea pinnata (t. 4r. f. 9. b.).

Thesinm ebracteatum (t. 26. f.4.), Staply lea pinnata (t. 41. f. 9. b.)

I8) nudus: qui et foliis et bracteis caret, idleoque

18) nackt (nudns: die weder Blätter noch NebenNris If́ et I6 oppositus est; videatur Staphylea pinnata blätter lıat, und daher Nr. Íf. und I6 entgegengesetzt (t. 4r. f. 9. b.).

ist; z. B. Staplyylea pinnata (t. 4r. f. g. b.)

19) laxus: qui facile inflectitur; exemplo est Arabis thaliana.

19) schlaft (luxus): die sich sehr leicht biegen lälst; z. B. Arubis thaliana.

20) rigidus: qui non facile inflectitur; e. g. Aesculus Hippocastanum.

20) steif (rigidus): dre sich nicht leicht biegen lärst; z. B. Aesculus Hippocastanum.

21) strichus: qui plane rectus, atque ex toto est perpendicularis; rideatur Uinitlogalum pyrenaicum.

22) erectus: qui, quanquam non plane rectns, satis

21) straf (strictus); die vollkommen gerade ist, und völlig senkrecht steht; z. B. Ornithogalum pyrenaicunn.

22) a ufrecht (erectn/s): die, wenn sie auch nicht volltamen perpendicularis est; exemplum präbet Aesculus kommen gerade ist, doch ziemlich senkrecht steht: AesHippocastanum, Sagittaria sagıttifolia (t. 36. f 9.).

culus Hippocastanum, Sagittaria sagittifolia (t.36. f. . .)

23) cernuthls: si superior racemi pars ita est curva-

23) ̈̈bergebogen (cernuus): wenn der obere ta, ut apex horizontem versus spectet; e. g. Arabis nu- Theil der Traube so gekrummt ist, dafs die Spitze getans, Convallaria majalis (t. 37 . f. 4.).

gen den Horizont zeigt; z. B. Arabis nutans, Convallaria majalis (t. 37. f. 4.).

24) nuttans: si superior racemi pars ita est curvata, 24) überhangend (nutans): wenn der obere ut apex terram spectet; exemplo est Monotropa $\mathrm{Hy}_{y}$ - Theil der Traube so grkrümmt ist, dafs die Spitze gopopithys (t. 20. f. 1. b.).

gen die Erde zcigt; z.B. Monotropa Hypopithys (t. 20. f. 1. b.).

25) deflexus: si in arcus forma dependit; exempli loco videatur Berberis vulgaris (t. 35. f. 2. c.).

25) herabgebogen (deflexus): wenn sie in einem Bogen herabhängt; z. B. Berberis vulgaris (t. 3j. f. 2. c.).

26) reflexus s. pendnhlus: si ad perpendiculum di26) herabhangend (reflexus s. pendulus): wenn rectus dependet; e. g. Staphylea pinnata (t. 41. f. g b.). sie in senkrechter Richtung gerade herabhängt; z. B. Stapluylea pinnata (t. 41. f. g. b.). 
Racemi situs aeque ac pedunculi ( $\$ .60 . \mathrm{Nr}, 4-17$. determinatur,

\section{§. 69.}

Corjunbus oritur, ex communi pedunculo si plures partiales - simplices vel ramosi - diversa in altitudine enascuntur omnesque aequali fere altitudine ita terminantur, ut flores superficiem magis minusque planam forment. Apparet:

I) siunplex: pedunculis partialibus in ramos haud dirisis, sed simplicibus; exemplo est Ledum palustre (tabulae libri inscriptionis figura 1.), Dentaria bulbifera ( $t$. 4. f. r. a.), Spiraea opulifolia.

2) rainosis: partiales pedunculi in ramos si dividuntur; exemplum exhibet Tanacetum vulgare, Achillea Millefolium, Achillea nobilis (t. 34. f. 2. b.).

3) coucpositus: si pedunculus communis in ranıos ita dividitur, ut plures nascantur corymbi quoddam quidem totum costituentes, attamen, cum in aequali altitudine terminentur, facile possunt distingui; exemplo est Sorbus Aucuparia (t. 38. f. 7. b.).

4) bipartitus: pedunculo communi duos aequales in ramos ita diviso, ut duo corjmbi, unum tantumnodo tolum constituentes, eandem in altitudine excurrentes, indeque hand faciles distinctu, oriantur; e. g. Mespilus Pyracantha (t. 36. f. 8. b.).

5) dichotomns: si pedunculus communis dichotomus ( $\$ .60$. Nr. 27. ) est, et minimi ejus ramuli in unam desinunt planiciem; e. g. Corymbium glabrum (t. 50 . f. 3.).

6) prolifer: si in corymbo ramoso (Nr. 2.) vel composito (Nr.3.) quidam e pedunculis partialibus longiores ceteris evadunt, partialesque ferunt Corymbos; exemplum praebet Spiraea Ulmaria (t. 43. f. 2.).
Die Lage der Traube bestimmt man so wie die des Blumenstiels (\$. 6o. Nr. $4-17$.).

§. 69 .

Die Doldentraube (Corjmbus) entsteht, wenn auf einem allgemeinen Blumenstirle mehrere besondre - einfache oder ästige - in verschiedener Höhe entspringen und sich alle in ziemlich gleicher Höhe endigen, so dafs die Blumen eine mehr oder weniger ebene Oberfläche bilden. Sie erscheint:

1) einfach (simplex): wenn die besonderen Blumenstiele sich nicht in Äste zertheilen, sondern sehr einfach sind; z. B. Leduuz palustre (Titelkupfer f. 1.), Dentaria bulbifera (t. 4. f. 1. a.), Spiraea opulifolia.

2) ästig (ramosizs): wenn sich die besondern Blumensticle in Äste zertheilen; z. B. Tanacetum vulgare, Aclillea millefolium, Aclitlea unbilis (t. 34́. f. 2. b.).

3) zusammengesetzt (compositus): wenn der allgemeine Blumenstiel sich so in Äste zerthellt, dals mehrere Doldentrauben entstehen, die zwar zusammen ein Ganzes bilden, sich aber dennoch, da sie nicht in gleicher Höhe sich endigen, unterscheiden lassen; z. B. Sorbus Ancuparia (t. 38. f. 7. b.).

4) zweytheilig (bipariius): wenn sich der allgemeine B:umenstiel in zwey gleiche Äste zertheilt, so, dals zwey Doldentrauben entstehen, die nur ein Ganzes bilden, in gleicher Höhe sich endigen, und daher nicht leıcht unterschieden werden können; z. B. Mespilus Pyracantlua (t. 36. f 8. b.).

5) gezweytheilt oder gabelästig (dichotomus): wenn der gemoinschaftliche Blumenstiel gezweitheilt (\$.6o. Nr. 27) ist, und die kleinsten Ästchen desselben in eine Fläche sich endigen; z.B. Corymbium glabrum (t. 50.f. 3.).

6) sprossend (prolifer): wenn bey einer ästigen (Nr. 2.) oder zusamniengesetzten (Nr. 3.) Doldentraube einige der besondern Blumenstiele sich stïrker als die übrigen verlängern und besondre Doldentrauben tragen; z. B. Spiraen Ulmaria (t. 43. f. 2.) 


\section{TERMINOLOGIA.}

7) confertzs: pedunculis partialibus directionis ope arcte satis sibi ita accuban'ibus, ut vacuum inter se spatium relinquant; e.g. Achrllea nobrlis (t. 3j. f. 2, b.).

8) rarus: pedunculis partialibus directionis suae ope inter se ita discıdentibus, ut inter flores multa loca non obsita remaneant; e.g. Dentaria bulbifera (t. 4. f. I. a.).

Pro situ corymbus plerumque est terminalis et axil. laris, rarius vero lateralis. Secundum divectionem non nisi erevtus inventus est, licct et perclulus occurrat,

\section{70.}

Umbella oritur, ex $\mathrm{u} \cdot \mathrm{o}$ puncto communi si tres pluresque pedunculi partıales enascuntur, in diversis plagis vergentes, atque ita eorum axes longitudinales non in uno, sed in diversis planis sunt collocati. Partiales pedunculi umbellae (t. 4I. f. 4. c. et d.), tam universalis (Nr. 4.), quam partialis (Nr. 5.) Rezdii vocantur. Umbella apparet:

1) simplex: radii si sunt simplices, ut singulos quisque flores tantum ferat; exemplo est Spiraea hypericifolia (t. 36. f. 5. b.), Ornithogalum spathaceum (t. $2 \%$. f. 4. d.).

2) composita: si quisque umbellae radius floris loco simplicem fert umbellain; e. g Bupleurum rotundifolium (t. 16. f. 4.), Carum Carvi (t. 19. f. 3.), Sison trägt; z B. Bupleurum rotundifolium (t. I6. f.4.), CaAnomum (t. 36. f. 10. a. et b.), Cachrys Libanotis (t. 41. rum Carvi (t. rg. f.3.), Sisnm Amomum (t. 36. f. ro. a f. 4.), Caucalis Antbriscus (t. 43. f. 6.).

3) prolifera: plurimi umbellae radii si sunt simplices, eorum vern alius simplıcem floris loco umbellam fert; videatur Asclepias Vincetoxicum (t. 42. f. 3. b.).
TER MIINOLOG I E.

7) dicht (confertus): wenn die besonderm Blumenstiele vermöge ihrer Richtung ziemlich dicht neben einander liegen, so, dals die Blumen keinen leeren Platz zwischen sich lassen; z. B. Aclibllea nobilis (t. 34. f. 2. b.).

3) lose (rarus): wenn sich die besondern Blumenstiele vermöge ihrer Riclitung von einander entfernen, so, dal's zwischen den Blumen viele Plätze unbesetzt bleiben; z. B. Dentaria bullifera (t. 4. f. 1. а.).

Der Lage nach ist die Doldentraube gewöhnlich gipfelständig (terminalis) und blattachselständig (axillaris), seltener aber seitenständi Richtung nach hat man sie nur a ufecht (erectus) bemerkt, ol, sie gleich auch lıangend (pcrilulus) vorkom. men kann.

\section{§. 70 .}

Die Dolde (Umbella) entsteht, wenn aus einem gemeinschaftlichen Puncte drey oder mehrere besondre Blumenstiele entspringen, die sich nach verschiedenen Richtungen verbreiten, und daher mit ihren Längsachsen nicht in Einer, sondern in verschiedenen Ebnen liegen. Die besondern Blumenstiele der Dolde (t. 41.f.4.c. und d.) sowohl der allgemeinen (Nr. 4.) als auch der besondern (Nr. 5.) werden Strahlen (Radii) genannt. Die Dolde zeigt sich:

I) e infacls (simplex): wenn die Strahlen einfach sind, so dals jeder nur Eine Blume trägt; z. B. Spiraen hjperinifolia (t.36 f.5. b.), Ornithogalum spathaceum (t. 27 . f. 4. d.).

2) zusammengesetzt (composita): wenn jeder Strahl der Dolde statt der Blume eine einfache Dolde und b.), Cachry's Libanotis (t.41. f. 4.), Caucalis Anthriscus (t. 43. f. 6.).

3) sprossend (prolifera): wenn die meliresten Strahlen der Dolde einfach sind, einer oder der andre aber statt der Blume eine einfache Dolde trägt; z. B. Asclepias Vincotnxicum (t. 42. 5. 3. b.). 

diis formattr umbellas simpiices ferentibus (t. Ig.f. 3. e.). $\mathrm{Ab}$ ea distinguitur.

5) partialis seu Unbellula: quaevis umbella simplex, quae a compositae radiis geratur (t. Ig. f. 3. f.).

6) tricadiata: secund!m Linnaeum trifida: quae ex tribus tantum radiis constat; e. g. umbella universalis in Denanthe fistulosa (t. 39. f. G. b.).

7) quadriradiata: secundum Linnaenm quadrificla: si quatuor umbella radios habet; exemplum quarundam umbellarum universalium exhibet Sison Amomum (t. 36. f. ro. a.).

8) quinqueradiata, secundum $L i n n$ a enm (quinquefida): si umbella ex radiis quinque constat; exemplum superioribus umbellarum universalium praebet Sison Amomum (t. 36. f. 10, b.) Ita numerantes pergunt usque ad

9) multiradiata: secundum Linnaeum multifida: si ex pluribus radiis, quorum numerus certo dici nequit, constat; e. g. Daucus Carota (t. 5I. f. I.) Angelica sylvestris, Heracleum Sphondylium.

Quatuor praecedentes denominaticnes (Nr. 6 - 9.) non nisi ad umbellam universalem determinandam adhibentur; nam in partiali vel simplici determinaturus in eadem ratione potius dicit: umbella est triflora, qualriflora, quinqueflora et sic porro multiflora.

Io) conferta: multis ex radiis si constat ita directis, ut satis arcte sibi adjaceant, vacuumque inter flores spatium non maneat; e. g. Daucus Carota (t. 5I. f. I.) Asclepias syriaca.

I1) rara: umbellae radiis nec numerosis, et ita direc-
4) universalis: in unbella composita (Nr. 2.) a ra-

4) allgemein (universalis): sie wird bey der zusammongesetzien Dolde (Nr. a.) von den Strahlen gebiluet, welche die einfachen Dolden tragen (t. 19. f. 3. e.). Von ihr unterscheidet man die

5) bcsondere (partialis): oder das Döldchen (Umbellula): jede einfache Dolde, die von den Stral1len der zusammengesetzten getragen wird (t. I9, 5. 3. f.).

6) dreystrablig (triradiata), nach Linne dreyspaltig (trifida): wenn die Dolde nur aus drey Strahlen besteht; z. B. die allgemeine Dolde bey Oenanthe fistulosa (t. 3j. f. 6. b.).

7) vierstrallig (quadriradiata), nach Linné vierspaltig (quadrifila): wenn die Dolde vier Sirahlen hat; z. B. einige der allgemeinen Dolden bey Sison Amomum (t. 36. f. го. а.).

8) fünfstrahlig (quizqqueradiata), naclı Linné fünfspaltig (quinquefida): wenn die Dolde aus fünf Strahlen besleht; z. B. die obern der allgemeinen Dolden bey Sison Amonumm (1. 36. f. Io. b.). So zählt man weiter fort, bis

9) vielstrahlig (multiradiata), nach Linné vielspaltig (multifida); wenn sie aus mehreren Strahlen besteht, deren Zahl sich nicht bestimınt angeben läfst; z. B. Daucus Carota (t. 5r. f. 1.), Angelica sylvestris, Heracleum Spluondylium.

Die vier vorhergelienden Prädicate (Nr. 6 - 9.) werden nur zur Bestimmung der allyemcincn Dolde ge. braucht; denu wenn man in dieser hücksicht die besondere oder die einfache bestimmen will: so sagt man lieber: sie ist drey-, vicr-, fünf-n, s. w. viclblu. mig (tri-, quadri-, quinque - etc. mulriflora).

ro) dicht (conferta): wenn sie aus vielen Strahlen besteht, die so gerichtet sinu, dafs sie zimlich dicht neben einander liegen, so dafs zwischen den Blumen kein leerer Platz bleibt; z. B. Daucus Carota (t. 51. f. I.) Asclepias syriaca.

11) lose (rara): wenn die Strahlen der Dolde tis, ut remoti inter se sint, atque ita multa inter flores in- nicht sehr zahlrcich, und so gerichtet sind, dafs sie enttervalla inaneant; exemplo est Carum Carvi (t. 19. f. 3.). fernt von einander liegen, so dafs zwischen den Blumen 
viele Zwischenrïume bleiben; z. B. Carum Carvi (t. 19. f. 3.).

12) depanperata: quae ex paucis tantum radis constat; videatur Sison Amomum (t. 36. f. 10. a. et b.). w

12) concava: si umbellae superficies a floribus effecta concava est; exemplun praebet Daucus Carota (t. 5r. f. I.), Chaeropliyllum bulbosum.

Íf) plana: si superficies a floribus facta nec concava est nec convexa; e. g. Caucalis Anthriscus (t. 43. f. 6.).

15) convexa: si superficies a floribus formata superficici sphaericae partem dimidio globo minorem men gebildete Oberfläche einem Theil von einer Kuaequat; videatur Oenanthe fistulosa (t. 39. f. 6. b.), gelläche gleicht, der weniger als die Hälfte der Kugugel Carum Carvi (t. 19, f. 3.),

16) hemisplunerlca: si superficies a floribus eiffecta hemisphatrae formam refert; exemplo est Cachrys Libanotis (t. 4í f. 4.).

17) pednuculata: umbeliae radii ex pedunculo communi si enascuntur; videatur exempli loco Buplen- der Dolde aus einem gemeinschaftlichen Blumenstiel rum rotundifolium (t. 16. f. 4.) is Carum Carvi (1. 19. entspringen; z. B. Buplentum rotundifolinn (t. 16. f. f. 3.), Sison Amomum (t. 36. f. 10.), Oenanthe fistu- 4.), Carnm Carvi (t. 19. f. 3.), Sisonz Anomnn (t. 36. losa (t. 39. f. 6. b.), Asclepias Vincetoxicum (t. 42. f. f. 10), Oenanlhe fistulosa (t. 39. f. 6. b.), Asclepias 3.), Ornithogalum spathaceum (t. 27. f. 4. d.).

18) sessilis: si umbella pedunculo communi est destituta; exempli loco est Spiraea hypericifolia (t. 36 . f. 5. b.

Quoad situm umbella est plerumque terminalis vel axillaris, rarius oppositifolia.

In umbellae compositae superficie a floribus effecta partem median ad maruinem usque fere porrectam a parte juxta marginem ambiente distinguunt, illum Discum, hanc vero Radium appellantes, quam tamen Limbum vocare liceret, unde nec nomen cum pedunculis umbellae partialibus confunderetur.
12) arm (depauperata): wenn die Dolde nur aus f. ro a. u. b.).

13) vertieft (concava): ivenn die von den Blumen gebildete Oberläche der Dolde vertieft ist; z. B. Dancus Carnia (t.51.f.1.), Chaeropluyllum bulbosum.

If́) eben (plana): wenn die von den Blumen gebildete Oberläche weder vertieft noch erhaben ist; z. B. Caucalis Antluriscus (t. 43. f. 6.).

15) erhaben (convexa): wenn die von den Blubetrïgt; z. B. Oenanthe fistulosa (t. 39. f. 6. b.), Carun Carvi (t. 19. f. 3.).

16) halbkugelförmig (Lemispluaerica): wenn die von den Bitumen gebildete OberHäche der einer Halbkugel gleichı; z. B. Caclirys Libanotis (t. 4r. f. 4.). 17) gestielt (pedunculata): wenn die Strahlen Vincctoxicun (1.42. f.3.), Ornithogalum spathacenm (t. 27 . f. f. d.).

18) sitzend (sessilis): wenn der Dolde der gemeinschaftliche Blumenstiel fehlt; z. B. Spiraea liypericifolia (t. 36. f. 5. b,).

Der Lage nach ist die Dolde gewöhnlich gipfelständig (terminalis), oder blattachselständig (axillaris), seltner dem blatte gegenüberstehend (oppositifolia).

Bey der zusammengesetzten Dolde unterscheidet man an der von den Blumen gebildeten Obertäche den mittleren, fast bis zum Rande sich erstreckenden Theil von dem langst dem Rande sich herumziehenden, und nennt den erstern die $S$ cheibe oder das Mittelfeld (Discus), den letztcrn hingegen den Strahl (Radius), 


\section{S. $7 \mathrm{r}$.}

Cyma pedunculis partialibus constat tribus pluri- den man jedoch richiger den $S$ a a $m$ (Limbus) nennen köunie, wodurch auch das Gleichnalımige mit den besoudern Blumenstielen der Dolde vermieden würde.

\section{71 .}

Die Afterdolde (Cyma) bestehet aus drey oder busque ramosis ex uno puncto oriundis it in diversas nethreren besondern ästigen Blumenstielen, die aus eiplagas ila vergentibus, ut totum prımóobtutu umbel'ae nem Puncte entspringen und sich nach verschiedenen compositae faciem referat, ab hac vero eo differat. quod Ruchungen verbreiten, so, dafs das Ganze beym ersten partiales ejus pedunculi non in umbellulas, sed nullo Blick das Ansehen einer zusammengesetzten Dolde hat, ordine in ramos dividuntur. Reperitur: sich von dieser aber daturch unterscheilet, dafs ihre besondern Blumenstiele, sich ni.ht in Düllchen, sondern, oline bestimmte Ordnung, in Äste zertheilen. Man fintlet sie

I) Eripartita: si tres tantum partiales ei sunt peI) dreytheilig (tripartita): wenn sie nur drey dunculi; exemplum praebet Sambucus Ebulus (1. 38. besondre Blumenstuele hat; z. B. Sambucus Ebulns (t. f. 2.). 38. f. 2.).

2) quadripartita: ex quatuor partialibus constans pelunculis; e. g. Cornus sanguinea.

3) quinquepartita: ex quinque pedunculis partia-

2) viertheilig (quadripartita): die aus vier besondern Biumenstielen besteht; z. B. Cornus sanguiner.

3) fünfılıeilig (quinquepartita): die aus fünf libus composita; exemplo est Sambucus nigra (t. 32. f. besondern Blumenstielen zusammen gesetzt ist; z. B. 2.). Ita ulterius numeratur, usque ad

4) multipartita: si pedunculorum partialium nuSambucus nigra (t. 32. f. 2.). So zïhit man weiter, bis 4) vieltheilig (multipartita): wenn die Zahl merus accrescens non est perpetuus; exemplum exhibet der besondeın Blumenstiple höher steigt und dabey Viburnum Opulus (t. 32. f. 4.).

5) umbellifera: si pedunculorum partialium rami unbeständig ist; z. B. Vilurnum Opulus (t. 32. f. f́).

5) doldentragend (umbellifera): wenn die ferunt umbellas simplices; videatur Astrantia major (t. Äste der besondern Blumenstiele einfaclue Dolden tra5. f. 2.).

Ceterum in determinanda cyma plura nomina in umbella (\$.70. Nr, 10-18.) explicata adhiberi possunt.

Plures generis Euphorbiae specics cyma sunt instructae, quae vero umbella vocatur, licet nec simplici nec compositae possit adnumerari.

\section{gen; z. B. Astrantia major (t. 50. f. 2.).}

Uebrigens lassen sich bey der Bestimmung der Afterdolde melirere von den Pradicaten anwenden, die wir bey der Dolde ( $\$$. 70. Nr. Io. - 18.) erläutert haben.

Melirere Arten der Gattung Euphorbia haben eine Afterdolde, die aber Dolde genannt wird, ob sie gleich weder zur einfachen noch zur zusammengesetzten ge. rechnet werden kann.

\section{\$. 72.}

Flabellum oritur, si pedunculıs communis delique-

Der Fächel (Flabellums) entstcht wenn der gescens ( . 5t. Nr. 46.) est, atque in du.sbus oppositis la- meinschaftliche B'umenstiel verschwindend ( $\$$. 5r. Nr. teibus in tres pluresque pedunculos pantiales dividitur 46.) ist, und sich an zwey entgegengusetzten Seiten in 
ita directos, ut axibus suis longitudinalibus uni plano incubent. Flabellum deprehenditur:

I) spicatum: cujus pedunculi partiales per se floribus sunt conjuncti; e. g. Andropogen Ischaemum (t. f́. f. 2.), Panicum sanguinale, Panicum fliforme.

2) racemosum: cujus pedunculi partiales bresium pedicellorum beneficio floribus conjuncti sunt; exempli loco est Veratrum viricle, ubi inflorescentia pluribus constat flabellis, quorum in icone (t. fo. f. 9.) unum tantumuodo exhibetur.

Pro situ nabellum plerumque est vel terminale, vel axillare. Quoad diresionem maximam partem horizontale, rains verticale apparet.

๒. 73.

Panicula oritur, si ex communi pedunculo longo

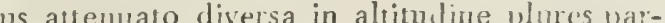
tiales pedunculi vel singulatim vel fasciculitim prose- meinon Blnmenstiele in verschedener Hühe mehrere niunt, et deliquescentes ( $\$$ 5r. Nr. 46 ), magis nimusve b sordre Blumenstiele einzeln oder bïsclielweis hersorin ratros dividuntur ita elongatos, ut nata incle inflo- konmen und, indem sie verschwinden ( $\$$. 51. Nr. 46.), rescentia formam oblongam nanciscatur. Panicula ap- sich mehr oder weniger in Äste zertheilen, die sich pai et :

I) simplex: si pedunculi partiales ipsi in pedicellos (\$. 6o.) dividuntur; videatur Bromns mollis (t. 12. f. 4.).

2) romos $a$ : si pedunculi partiales in ramos et hi in pedicellos dividuntur; e. g. Aira aquatica (t. 37. f. B 5.), Agrostis hispida (t. 45. f. 5.).

3) ranosissina: si pedunenlorum partialinm rami in ramulos et hi in pedicellos druiucuntur; ut in Poa pratuisi. drey oder nehrere besondre Blumenstiele zertheilt, die so gerichtet sind, dafs sie alle mit iluren Längsachsen in einer Fläche liegen. Man findet den Fächel :

1) ïhrig (spicatum): dessen besondre Blumenstiele unmittelbar mit den Blumen verbunden sind; $z$, B. Andropogon Ischaemnm (1. 41. f. 2.) Panicum samguinale, Panicum filiforme.

2) traubig (racemosum): dessen besondre Blumenstiele vermittelst kurzer Blumenstielchen unit den IHumen in Verbindung stehen; z. B. Veratrum viride, wo der Blüthensıand aus mehreren Fächeln zusammen gesetzt ist, von denen lier aber die 1 bbildung ( $t$. 40. f. g.) nur Einen darstellt.

Der Lage nach ist der Fächel gewöhnlich gipfelständig (terminale) oder b l a t t a c hs e l s t ä ndig (axillure). In Rücksicht der Pichtung möchte er wohl grölstenheils nur wagerecht (horizontale), seltner

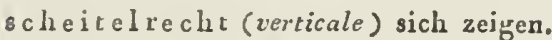

§. 73.

Die Rispe (Prnicula) entsteht, wenn aus einem dergestalt verlängern, dafs der dadurch gebildete Blüthenstand eine längliche Gestalt bekommt. Die Rispe zeigt sich:

I) einfach (simplex): wenn die besonderr Blumenstiele unmittelbar in Blumunstielchen (\$. 6o.) sich zertheilen; 2. B. Lromns mollis (t. 12. f. 4.).

2) ästig (ramosa): wenn sich die besonlem Blumenstiele in $\ddot{A}$ ste, und diese in Bumerstielchen zerthenlen; z. B. Aira aquatica (t. 37 f. 5.), Agrostis hispiala (t. fj. f. 5 ).

3) vielïstig (ramosissima): wenn sich die Äste der besondern Blumenstiele in Ästchon, und diese in Blumensticlchen zertheilen; z. B. Poa pratersis. 
4) coarctata: cujus pedunculi partiales ad communem flexi sunt; videatur Bromus mollis (t. 12. f. 4.).

5) patens: cujus pedunculi partiales ita sunt directi, ut cum communi superne angulum circiter quadraginta quinque graduum effingant; exempli loco est Alisma Plantago (t. 36. f. 7.).

6) patcntissima seu diffusa: pednnculi partiales si ita sunt directi, ut cum commmni superne angulum forment recto ninorem, vero graduum quadraginta quinque angulo majorem; exempli loco videatur Uniola paniculata (t. 47. f. 6.).

7) verticillata: si pedunculi partiales ex commmni in morem verticillorum ( $\$$.62.) proveniunt; exemplum praebet Alisma Plantago (t. 36. f. 7. c.).

8) fasciculata: si ex communi pedunculo partiales, modo in hoc, modo illo in latere, aequali distantia fasciculatim proveniunt, ut in plurimis graminibus obtinet; e. g. in Bromo tectorum (t. 38. f. r.).

9) Aabellata: si in specie praecedente (Nr. 8) -singuli partialium pedunculorum fasciculi in morem Habel-

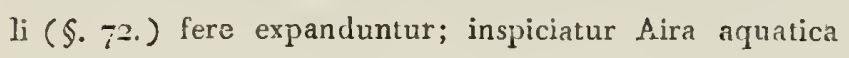
(1. 37. f. 5. a.).

10) sccunda: si circumcirca communem pedunculum vel ad plura ejus latera pedunculi partiales proveniunt, et omnes ad idem latus vergentes; e. g. Silene nutans (t. I3. f. 5.), Bromus tectorum (t. 38. f. I.).

II) vaga: cujus pedunculi partiales non ad unum, sed onnia latera versus vertuntur. Praecedenti opponitur; exempla praebent Bromus mollis (t. 12. f. 4. c.), Eriza media (t. 37. f. 2.), Alisma Plantago (t. 36. f. 7.).
4) gedrängt oder zusammengezogen (coarctata): deren besondre Blumenstiele gegen den allgemeinen gebogen sind; z. B. Bromus mollis (1. 12. 5. 4).

5) a bstehend oder ausgebreitet (patens): deren besondre B lumensticle so gerichtet sind, dafs sie mit dem allgemeinen nach oben zu einen Winkel von ungefähr fünf und vierzig Graden bilden; z. B. Alisma Plantago (36. f. 7.).

6) weit a us gebreitet (patentissima) oder weitschweifig (diffusa): wenn die besondern Blumenstiele eine solche Richtung haben, dafs sie mit dem allgemeinen nach oben zu einen Winkel bilden, der kleiner als ein rechter, aber gröfser als einer von fünf und vierzig Graden ist; z. B. Uniola paniculaia (t. 47. f. 6.).

7) quirlförmig (verticillata): wenn die besondern Blumenstiele ans dem allgem('inen nach Art der Quiıle (\$. 62.) hervorkommen; z. B. Alisma Plantago (t. 36. f. 7. c.).

8) bündelartig (fasciculata): wenn aus dem allgemeinen Blumenstiele in regelmäfsigen Enffernungen, bald auf dieser bald auf jener Seite, die besondern Blumensiiele bündelweis hervorkommen, wie bey den mehresten Gräsern z. B. Bromus tectorum ( 38 . f. I.).

9) fächelartig (Aabellata): wenn sich bey der vorlicrgehenden Art (Nr. 8.) die einzelnen Bündel der besondern Blumenstiele fast nach Art eines Fächels (5. 72.) verbreiten; z. B. Aira aquatica (t. 37. f. 5. a.). I0) einseitswendig oder einwendig (secun$d a)$ : wenn rings um den allgemeinen Blumenstiel oder an mehreren Seiten desseiben die besondern Blumen. stiele hervorkommen, und sich alle nach Einer Seite wenden; z. B. Silene nutans (t. I3. f. 5.), Bromus tectorum (t. 38. f. I.).

II) allseitswendig oder vielwendig (vaga): deren besondre Blımenstiele sich nicht nach Einer, sondern nach allen Sriten hinwenden. Sie macht den Gegensatz der vorherge henden aus; und z. B. dienen Bro- 
I2) erecta: vid. \$. 68. Nr. 2 r.; e. g. Bromus mollis (1. 12. f. 4. c.), Alisma Plantago (t. 36. f. 7.).

13) cernna: vid. \$. 68. Nr. 22.; e. g. Melica nutans (tabulae libri inscriptionis figura 4.), Silene nutans (t. 13. f. 5.).

14) mutaus: vid. S. 68. Nr. 23 ; e. g. Bromus tectorum (t. 38. f. r.).

Pro situ panicula maximam partem est terminalis, rarius axillaris.

\section{S. 74 .}

Thyrsus est inflorescentia vel racemosa vel paniculata floribus conslipatis. Praeter flores constipatos et hoc ipsius proprium observatur, communem ejus pe- men. Aulser dem Gedrängıstehen der Blumen beinerkt dunculum, si racemi (\$. 63.) faciem refert, semper esse man an ihm auch noch das Eigenthïmliche, dafs, wenn crassissimum; et si ut panicula (\$. 73.) apparet, ejus er als Traube (\$. 68.) erscheint, sein allgemeiner Blupartiales pedunculos esse breviores, quam in hac. In- menstiel jederzeit sehr dick ist; und dafs, wenn er als venitur thyrsus:

1) racemosus: peduncnlis partialibus in ramos haud divisi; videtur Tussilago Petasites (t. 27. f. 1.), Tussilago hybrida (t. 37. f. 3.).

2) paniculatus: si pedunculi partiales in ramos dividuntur; exemplun praebet Ligustrum vulgare (1. I9. f. 2. b.), Lysimachia thyrsiflora.

3) corymbosus seu fastigiatus: si partialium pedunculorum inferiores superioribus sunt longiores, ut omnes fere in eadem altitudine terminentur; exemplo est Tussilago spuria (t. 28. f. 6.).

Ceternm in thyrso etiam figura, nt in capitulo ( $\left.\$ .6_{3}.\right)$, in spicula (o 66.) el in spica (\$.67.) determinalur. Sccundum directionem hyrsus semper est erectus, et pro situ terminulis vel axillaris. mus mollis, (t. 12. 5. 4. c), Briza media (t. 37. f. 2.), Alisma Plantago (t. 36. 5. 7.).

12) aufrecht (erecta): S. §. 68. Nr. 2I.; z. B. Bromus mollis (t. 12. f. 4. c.), Alisma Plantago (t. 36. f. 7 ).

I3) übergebogen (ceruua): S. §. 68. Nr. 22.; z. B. Melica nutans ('Titelkupfer f. 4.), Silene nutants (t. I3. f. 5.).

14) ũ berhangend (nutans): S. 6. 68. Nr. 23.z. B. Bromus tectormm (t. 38. f. I.).

Der Lage nach ist die Rispe grörstentheils gipfelständig (terminalis) seltener blattachselstandig (axillaris).

\section{§. $7 \dot{4}$.}

Der Strauls (Thyrsus) ist ein trauben- oder risRispe ( $\$ \cdot 73$ ) vorkoinmt, die besondern Blumenstiele kürzer sind, als bey dieser. Man findet den Straufs:

I) traubenartig (racemosns): wenn die besondern Blumenstiele sich nicht in Äste zertheilen; Trussilago Petasites (1. 27. I. I.), Tussilago hybrida (t. 37. 5. 3.).

2) rispenartig (paniculatus): wenn sich die besondern Blumenstiele in Äste zeriheilen; z. B. Ligustrum vulgare ( $\mathrm{t}$. I9. f. 2. b.), Iysimachia thyrsiflora.

3) doldentraubenartig oder gleichzweigig (corymbostus s. fastigiatus): wenn die untern der besondern Blumenstiele länger sind, als die obern, so, dafs sie sich fast alle in gleicher Höhe endigen; z. B. Tussilago spuria (t. 28. f. 6.).

Lebrigens wird bey dem Stranfse auch noch die Figur, so wie bey dem Kopfe (\$. 63.), dem Aehrchen (\$. 66.) und der Aehre ( $\left.\$ . C_{7}\right)$, bestinmt. Der Richtung nach ist der Straufs jederzeit a ufrecht (erectus), 


\section{§. 75 .}

Anthurus est paniculata, ex parvis floribus indecoris, arcte constipatis composita inflorescentia, cujns partiales pedunculi adeo sunt breves, ut prae floribus conspici nequeant. Deprehenditur:

I) simplex: non ex minoribns anthuris compositns; exemplum exhibet Amaranthus parisiensis Schkuhr (t. 47. . . 8. c).

2) compositus: ex pluribus simplicibus anthuris constructus; inspiciatur Amaranthus Havus (t. 45. f. 9.).

3) decompositus: ex compositis anthuris qui constans; videatur exempli loco Amaranthus caudatus.

4) supradecompositus qui - si non ex toto, at maximum tamen parten - ex decompositis anthuris constat; e. g. Amaranthus paniculatus.

5) interruptus: cui plura sunt intervalla floribus destituta; exemplo est Amaranthus lividus (t. f2. f. 7.).

6) continuls: in quo loci floribus destiluti non observantur; exemplum praebet Amaranthus parisiensis (t. 47. f. 8. c.).

Secundum situm anthurrs est terminalis vel axillaris; quoad firmitatem ac directionem aeque ac racemus (ฐ. 60. Nr. I9 - 26.) determinatur.

\section{\$. $7^{6}$.}

Spadix est spicata floribus sessilibus, in aetate teneriore plerumque vel bracteis vel Spatha circumsessa inflorescentia, cujus pedunculus flores rarius tantum in apice gerit. In Palınis atque in vegetabilibus generi Ari affinibus deprehenditur. In illis plerunque est ramosus, in his vero semper simplex. Apparet: und der Lage nacl gipfelständig (terminalis) oder blattachselstandig (axillaris).

\section{S. $7{ }^{7} 5$.}

Der Schweif (Anthurus) ist ein rispenartiger, ans kleinen, unanschnlichen gedrängt stehenden, Blumen zusammengesetzter Biïhenstand, dessen besondre Blumenstiele und Blumenstielchen so kurz sind, dafs man sie vor den Blumen nicht sehen kann. Man findet ilus:

I) einfach (simplex): wenn er nicht aus kleinen Schweffen zusammen gesetzt ist; z. B. Amaranthus parisiensis Sclulinlur (t. 47. f. 8. c.).

2) zusammengesetzt (compositus): der aus mehreren einfachen Schweifen zusammen gesetzt ist; z. B. Amarantlus favis (t. 45. f. 9.).

3) dopipelt - zusammengesetzt (decompositus): der ans zusamm ngesetzten Schweifen bestelut; $z$. B. Amaranthus candatns.

4) drey - oder vielfach - zusammengesetzt (supradecompositus): wenn er - wo niclıt gänzlich, doch gröfsteutheils - aus doppoltzusammengesetzion Schweifen besteht; z. B. Amaranthus paniculatus.

5) unterbrochen (ioferruptus): wenn er mehrere blumenlose Zwischenräume hat; z. B. Amaranthus lividus (t. f2. f. 7.).

6) ununterbrochen (continutus): an dem man keine blumenlose Stclle gewahr wird; z. B. Amaranthus parisiensis (t. 47. f. 8. c.).

Der Lage naclı ist der Schweif gipfelständig (terminales) oder blattachselstandig (axillaris) und in Rücksicht der Festigkeit und Richtung bestimmt man ilhn wie die Traube (\$. 60, Nr. $99-26$.$) .$

\section{§. 76 .}

Der Kolben (Spadix) ist ein ährenartiger Plüthenstand mit sitzenden Blımen, der im jün erı Zustande gewölinlich von Nobenblättern oder son einer Bliuficnscheide umschlossen wird, und dessen Blomenstiel nur selten an der Sịitze Blumen trägt. Er findet sich bey den Palmen und boj den mit der Gattung Arum ver- 
wandten Gewächsen. Bey den erstern ist er gewöhnlich ästig, bey den letztern aber jederzeit einfach. Er erscheint :

I) simplex: si pedunculus communis in ramos non

I) einfach (simplex): wenn der allgemeine Bludidivitur; e. g. Acurus Calamus (t. 39. I. 3.), Calla pa- menstiel sich niclit in Äste zertheilt; z. B. Acorns Calustris (t. 36. f. 6. b.), Arum maculatum (t. 39. f. 8 . lamus (t. 39. f. 3.), Calla palustris (t. 36. f. 6. b.), b. c. d.), Arum Dracontium (t. 39. f. 4. d.), Zostera Armm macnlatum (t. 39. f. 8. b. c. d.), Arnm Dramarina (t. 5I. f. 2. b.). contilnn (t. 3j. f. 4. d.) Zostera marina (t. 5I. f. 2. b.).

2) ramosus: cujus pedunculus communis in ramos 2) ïstig (ramosus): dessen allgemeiner Blumensinplices dividitur; videatur Borassus pinnatufrons Jacq. stiel sich in einfache Äste zertheilt; z. B. Borassns (t. 52. Г. 2.). pinnatifrons Jacq. (t. 52. ศ. 2.).

3) ramosissimns: si pellunculus communis in ra3) vielästig (ramosissimns): wenn der allgemos, et hi in ramulos rursus diducuntur; exemplum meine Blumenstiel sich in Äste, und diese sich wieder praebet Coryplia rotundifulia (t. II. f. I.).

in Ästchen zertheilen, z. B. Corypha rotundifolia ( $t$. I1. .. I.).

4) spicatus: qui spicac (\$. 6-.) simplici vel ramo4) ährenartig (spicatus): der einer einfachen sae est similis; inspiciatur $\Lambda$ corus Calamus (t. 3 • t. 3.), oder zusanmengesetzten Älure (\$. 67.) gleicht; z. B. Calla palustris (t. 36. f. 6. b.), Borassus pinuat:frons Acorms Calumns (t. 39. f. 3.), Calla palnstris (t. 36. (t. 52. f. 2.).

f. 6. b.), Borassus pinnalifrons (t. 52. f. 2.).

5) amentacens: si amenti (\$. 7\%:) faciem refert;

5) kätzchenartig (amentacens): wern er das exemplum exhibet Borassus Hiabelliformis (1.52. f. I. b). Ansthen eines Käizchens (\$. 77.) 1at; z. B. Borassus fabelliformis (t. 52. f. 1. b.).

6) clavatns: si est teres, ejnsque inverior tantum 6) keulenförmig (clavatns): wenn er stielrunl pars flores fert, sursum dilatatur, atque in apice rursus ist, nur an seincm untern Theile Blamen trägt, nach ita attenuatur et rotundatur, ut clavae formam cilribe- oben zu sich erweitert und an der Spitze sich wieder at; videatur Arum naculatim (t. 39. א. 8. L. c. d.). rerengt und abrundet, so, dafs er das Anschen einer Keule hat; z. B. Alum maculatum (1. 3g.f. 8. b. c. d.).

7) cylindricus: si ad cylindri figuram accedit; ut 7) walzenförmig (cylindricus): wenn er der in Calla palustri (t. 36. f. 6. b.), Borassus Habellıformis Figur der Walze nahe kommt; z. B. Calla palnstris (t. 52. f. I. b.).

(t. 36. f. 6. b.), Lorassus fabelliformis (t. 52. 1. I. b.).

8) conicus: qui teres est et apicem versus sensim

8) kegelförmig (coniczus): wenn er stielrund ita attenuatur, ut ad coni figuram accedat; e. g. Acorus und dick ist, und nach der Spitze zu sich allmählig Calamus (t. 3y. 5. 3.). verengt, so, dafs er der Figur des Kegels nahe kommt; z. B. Acorus Calanus (t. 39 ケ. 3.).

9) snbulatus: qui coni longi acute acuminati for9) prriemförmig (subulatus): der die Gestalt mam cum basi parva exhibet; vel, si teres, tenuis est eines langen, scharf zugespitzten Kegels mit kleiner ct lonģissimus, et susum sensim attenuatus acute acu- Grundflïche bat; oder, wenn cr stielrund, dïnne und 
minatur; exemplo est'Arum Dracontium (t. 39. f. sehr lang ist, und rach oben zu sich allmällig verengt 4. (1.). und scharf zuspitzt; z. B. Arum Dracoutium (t. 39. f. 4. d.).

10) linearis: si est longus, angustus et compres-

10) linienförmig (linearis): wenn er lang, sus, et bini margires ejus laterales ubique a basi ad schmal und zusammengedrïckt ist, und seine beyden apicem usque aequali distantia absunt; videatur Zostera Scitenränder in allen Puncten, von der Basis bis zur marina (t. 5 r. f. 2. b.)

Spitze, gleich wreit entfernt von einander sind; z. B,

1I) tectus: qui in tota sua superficie floribus est Zostera marina (t. 5r. f. 2. b.).

obsitus; exemplum exhibet Calla palustris (t. 36. f. 6. b. Acorus Calamus (t. 39. f. 3.).

II) bedeckt (tecills): der auf seiner ganzen Oberfläche mit Blumen besctzt ist; z. B. Calla palustris (t. 36. f. 6. b.) Acorus Calamus (t. 39. f. 3.).

\section{S. 77 .}

Anneutum est inflorescentia spicata a spica $\$ .67$. eo differens, quod pedunculus ejus commnnis pro floribus completis seu spiculis ( $\$$. 66.) squamas fert, quae essentiales tantum floris partes continent. Pedunculus communis amenti ut in spicula, in spica atque racemo Rhacliis vocatur. Amentum deprehenditur:

1) globosum: si globi similitudinem refert; videatur Platanus occidentalis (t. 20. f. 5. b. c.).

2) ovatun, rectius ovifornte: quod ovi figuram ita exlibet, ut sectiones transversales circuli, mediae vero longitudinales figuram ovatam ( $\$$. 66. No. 4.) exhibeant; exempli loco est Salix caprea mas (t. 24. f. 3.).

3) oblongum: si sectiones transversae circuli, mediae contra sectiones longitudinales figuram referunt oblongam, cujus diameter longitudinis plus quam duplo, minus vero quam triplo, superat latitudinis diametrum; exemplum praebet Salix caprea femina (t. 24. f. 2.).

4) cylindricum: si cylindri figuram ita exhibet, ut sectiones transversae aequales sistant circuli; exemplo est Populus tremula mas (t. 36 . f. I. b.).

\section{77.}

Das Kätzchen (Amentum) ist ein ährenartiger Blüthenstand, der sich von der Ähre (\$. 67.) dadurch unterscheidet, dals sein allgemeiner Blumenstiel statt der vollständigen Blumen oder Ährchen ( $\$$. 66.), Schuppen trïgt, die nur die wesentlichen Theile der Blumen enthalten. Der allgemeine Blumenstiel des Kätzchens heifst, so wie bey dem Ährchen, der Ähre und der Traube, die Spindel (Rlıachis). - Das Kälzchen erscheint:

1) kugelförmig (globosum.): wenn es einer Kugel gleicht; z. B. Platanus occidentalis (t. 20. f. 5. b. c.).

2) eyrund (ovatum) besser eylürmig (oviforme): wenn es einem Eje älnhlich ist, so, dal's die Queerdurchschnitte Kreise, die Längsdurchschnitte aber eine eyrunde Figur (\$. 66. Nr. 4.) geben; z. B. Salix caprea mas (t. 24. f. 3.).

3) länglich (oblonga): wenn die Queerdurchschnitte Kreise, die mittleren Längsdurchschnitte hingegen eine längliche Figur geben, deren Durchmesser der Länge den der Breile mehr als zweymal, weniger aber als dreymal übertrifft; z. B. Salix caprea femina (t. 24. f. 2.)

4) walzenförmig (cylindricum): wenn es einer Walze gleicht, so, dafs alle Queerdurchschnitte gleiche Kreise geben; z. B. Populus tremula mas (t. 36. ᄃ. I. b.). 
5) attenuatum: si amentum cylindricum apicem versus sensim attenuatur; exemplum est salix vitellina fenina (t. 41. f. I. a.).

6) conicum: quod ad coni fguram accedit; exemplo est salix triandra mas (t. 4r. f. 3. b.).

7) gracile: si diameter pro amenti longitudine admodum est parvus; exemplum praebet Salix vitellina fe$\operatorname{mina}$ (t. 4r. f. I. a.), Quercus pendiculata (t. 20. f. 4. b.).

8) interruptum: cui plura sunt intervalla lloribus seu squamis destituta; videatur Quercus pedunculata (t. 2o. f. 4. b.).

9) continaum: in quo intervalla floribus seu squamis destituta non observantur; videatur Salix vitellina femina (t. 4I. f. r. a.), sicut omnes Salicum species et plurima vegetabilia amentacea.

Io) confertum: Horibus seu squamis tam arcte consistentibus, ut rhachin videre non liceat; exemplum esto Populus tremula mas (t. 36. f. I. b.) et Salix caprea (t. 24. f. 2. et 3.).

11) rarım: floribus seu squamis inter se distantibus, ut rhachin clarissime videre liceat; videatur Salix hastata (t. 37. f. 8. c.).

12) multiflorum: quod multis floribus seu squamis constat; e. g. Salix caprea (t. 24. f. 2. et 3.), Populus tremula mas (t. 36. f. I. b.) et pl. al.

13) pauciforum: quod paucis tantum floribus seu squamis constat; videatur Salix retusa (t. 39. f. 7. b.).

I4) hermapliroditum: si squamarum amenti quaclibet tam mascula quam feminea genitalia continet; e. g. Salix hermaphroditica.

15) mascullum: cujus squamae non nisi mascula ge-
5) verdünnt (attenuatum): wenn ein walzenförmiges Kätzchen gegen die Spitze allmählig dïnner wircl; z. B. Saiix vitellina femina (t. 4r. f. r. a.)

6) kegelfürmig (eonicum): das der Figur des Fiegals nahe kommt; z. B. Salix triandra nas (t. $4 \mathrm{I}$ f. 3. b.)

7) schlank (gracile): wenn der Durchmesser in Rücksicht der Länge des Kälzchens sehr klein ist; z. B. Salix vitellina femina (t. 4x. I. 1. a.), () nercus pediuculata (t. 20. f. 4. b.)

8) unterbrochen (intcruptum): wemn es mehrere blumen - oder schuppenlose Zwischenrïume hat; z. B. Quercus pedinnculata (t. 20. f. 4. b.)

9) ununterbrochen (continunu): an dem man keine blumen - oder schuppenlose Zwischenräume bemerkt; z. B. Salix vitellina fenina (t. 41. f. 1. a.) so wie alle Weidenarten und mehrere käizchentragende Gewächse

Io) dicht (confertumu): wenn die Blumen oder Schuppen so dicht stehen, dafs man die Spindel nicht sthen kann; z. B. Populus tremula mas (t. 36. f. 1. b.) und Salix caprea (t. 24. f. \& und 3.)

II) los e (rarum): wenn die Blumen oder Schurpen so weit von einander abstehen, dafs man die Spindel sehr deutlich sehen kann; z. B. Salix hastatr (t. 37. f. 5. c.)

12) vielblumig (multiflorum ): das aus vielen Blumen oder Schuppen besteht; z. B. Salix caprea (t. 24. f. 2 und 3.), Populus tremula mas (t. 36. f. I. b.) u. m. a.

13) armblumig (paucifortum): das nur aus wenigen Blumen oder Schuppen besteht; z. B. Salix retusa (t. 39. f. 7. b.)

14) zwitterblumig (hernapliroditum ): wenn jede der Scluppen des Käizchens sowoll männliche als aucis weibliche Zeugungstleile enthïlt; z. B. Salix hermaphrodicica

15) mäninlich (masculnunu): dessen Schuppen nur $\mathrm{R}$ 
nitalia continent; videantur Salix caprea mas (t. 24 . f. 3. b. c.) Populus tremula mas (t. 36. f. 1. b. d. f.).

16) femineuz: : si ejus squamae non nisi feminea genitalia continent; inspiciatur Salix caprea femina ( $t$. 24. f. 2. b. c.).

17) androgyuzun: quod flores (seu squamas) masculos et femineos simul continet;

18) pedunculatum: si amenti rhachis non ad basin usque floribus seu squamis est obsessa; videatur Salix reticulata (t. 50. f. 9. a.) Salix tıiandra mas (t. 4r. f. 3. b.).

19) sessile: cujus rhachis ad basin usque floribus seu squamis est obsita; e. g. Myrica Gale (t. 47. f. 12).

Quoad situm amertum semper est terminale, si una cum foliis eadem ex gemma prorenit; tum enim apicem terminatum teneri ramuli semper constituit, quo cum eodem tempore explica. tur. Interdum autem hic ramulus est bresissimus, id quod Salix triandra mas (t. 41. f. 3.) ostendit, tumque id laterale esse videtur, quod quidem est, si ex Fropria gemma - non simul folia proferente - erumpit. Tum plura fere amenta apparent, vel alterna, id quod Salix caprea (t. 24. f. 2. et 3.) et Myrica Gale (t. 47. 1. 12.) monstrant, vel opposita, qualia Salix mo. nandra fenina ( 1.47 . f. 2.) exhibet. - Amenti directio aeque ac in ramis ( 5.58 . Nr. $11-16$ ) indicatur; dicendum tamen est, loc respectu non semper esse perpetuum. Ita Salix monandra femina (t. 47. f. 2.) inennte forescentiae tempore areuatim incurvatum exlibet, apice ad ramum voggcnte (a), vel quod ilcm est, incurvatum; censim autem in contrarium ita dirigitur, ut in fine Ioresccritiae temporis apcx ejus a ramo sit aversus (b), ubi rechrvalum rocant, männliche Zeugungshlieile enthalten; z. B. Salix caprea mas (t. 24́. f. 3. b. c.) Populus tremula mas (t. 36. f. I. b. d. f.)

16) weiblich (fenineum): wenn die Schuppen desselben nur weibliche Zeugungstheile enthalten; z. B. Salix caprea femina (t. 24. f. 2. b. c.)

17) männlichweiblich (audrogyuım): wenn es männliche und weibliche Blumen (oder Schuppen) zugleich enthält

18) gestielt (pedunculatum): wenn die Spindel des $\mathrm{Kätzchens} \mathrm{nicht} \mathrm{bis} \mathrm{an} \mathrm{die} \mathrm{Basis} \mathrm{mit} \mathrm{Blumen} \mathrm{oder}$ Schuppen besetzt ist; z. B. Salix reticulata (t. 50. f. 9. a.), Salix triandra mas (t. 4r. f. 3. a.)

19) sitzend (sessile): dessen Spindel bis an die Basis mit Blumen oder Schuppen besetzt ist; z. B. Myrica Gale (t. 47. f. I2.)

In Riacksicht der Lage ist das Kaizchen jederzeit giplelständig (terminale), wenn es mit den Blättern aus einer und eben derselben Lnospe herrorbricht; denn es macht alsdanu immer die Endspitze des jungen $Z$ weiges aus, mit dem es sich zu gleicher Zeit entfaltete. Zuweilen aber ist dieser Zweig sehr kurz, wie bci Salix triandra mas (t. 41. f. 3.) und alsdann scheint es seitenständig (laterale) zu seyn, was es aber nur ist, wenn es aus eirer eignen Knospe - die nicht zugleich Blätter bringt herrorkommt. Es erscheinen alsdann gewöhn. lich inehrere Kätzchen, die entweder wechselweisstehend (alterna), wie bey Salix caprea (1. 2f. f. 2 uud 5) und Myrica Gale (t. 47. f. 12.), oder gegenüberstehend (opposita), wie bei Salix monandra femina (t. 47. F. 2.) sind. Die Richtung des Kätzchens wird so wie bei den Aesten ( 5.58 . Nr. II - 16) bestimmt; je. doch ist hierbei zu bemenken, dafs es in dieser Rückıicht nicht immer besiändig ist. SJ sieht man es bei Salix monandra femina (t. 47. f. 12.) im Anfange der Blübezeit in einem Bogen gekıümat, mit der Spiıze nach dem $Z$ weige zei- 


\section{TE R MI NOLOGIA.}

\section{78 .}

Sorns non nisi Filicibus proprius est horum vegetabilium coacervatio, quae varia forma et situ in pagina eorum frondis aversa observatur. Apparet:

1) indusiatus: si membrana tenui indusium dicta tectus est; e. g. Adiantum reniforme (t. 42. f. 2. c.), Adiantum pedatum (t. 49. f. 6. b.), Blechnum occidentale (t. 48. f. 3. a.) et plurimae Filices.

2) nudns: indusio destitutus; videatur Polypodium vulgare (t. 2. f. 5.).

3) subrotnndns: si ejus figura magis minusve ad vinculum accedit; exempla praebent Polypodium vulgare (t. 2. f. 5.).

4) innatns: si ad lunae figuram in quadrante primo vel ultimo magis minusve accedit; e. g. Lonchitis aurita (t. 46. f. 12.).

5) linearis: si est longus et angustus, et bini margines ejus laterales ubique aequali distantia absunt; exempla exhibent Asplenium squamosum (t. 29. f. 2. b.) Pteris tricuspidata (t. 48. f. 5.), Pteris furcata (t. 5t. f. 9.), Blechnum occidentale (t. 43. f. 3. a.).

6) inordinalus: si fructus eum construentes nullo ordine sunt coacervati; ut in pluribus Filicibus; videantur Adiantum pedatum (t. 49. f. 6. b.), Blechnum occidentale (t. 48. f. 3. a.) et Filices plurimac.
TERMINOLOGIE.

gend (a), oder, was gleich viel ist eingekrümmt (incurvatum); nach und nach aber nimmt es dic entgegengesetzie Richtung an, so, dals es am Ende der Blühezeit mit der Spitze vom $Z$ weigo abgekehrt (b) ist, wo es dann $z a$ rü ckgekrü $\mathrm{mmt}$ (recurvatum)-genannt wird.

9. 78.

Das Häufchen (Sorus), welches sich nur bey den Farnkrïutern findet, ist eine Zusammenhäufung der Frïchte dieser Gewächse, die man von verschiedener Gestalt und Lage auf der Rückseite ihres Laubes bemerkt. Es erscheint:

I) verschlejert (indusiatus): wenn es von einer dünnen Haut, die man das schleyerchen nennt, bedeckt ist; z. D. Adiantum reniforme (t. 42. f. 2. c.), Adianinn pedatnn (t. 40. f. 6. b.), Blechnun occidentale (t. 45. f. 3. a.) und die mehresten Farrnkräuter.

2) nackt (nuchus): dem das Schleyerchen febit; z. B. Polypodiun vulgare (t. 2. f. 5.)

3) rundlich (subrotundus): wenn seine Gestalt sich mehr oder weniger dem Kreise nähert; z. B. Polypodium vulgare (t. 2. f. 5.)

4) mondförmig (lunatus): wenn es der Gestalt des Mondes im ersten oder leizten Viertel mehr oder weniger nahe kommt; z. B. Lonclititis antita (t. 46. f. 12.)

5) linienförmig (linearis): wenn es lang und schınal ist, und seine beiden Scitenrinder in allen Punkten gleich weit entfernt von einander bleiben; z. B. Asplenium squanosum (t. 29. f. 2. b.), Preris tricuspidata (t. 48. f. 5.), Pteris furcata (t.51.f. g.), Bleclunum occidentale (t. 48. f. 3. a.)

6) ungeordnet (inordinatus): wenn die Früctte, woraus es besteht, obne Ordnung znsammengehäuft sind; wie bey den mehresten Farrnkilutern; z. B. Adiantum pedatrun (t. 43. f. 6. b.) Blechituin occi$\mathrm{R} 2$ 
7) bifariam ordinatus: si fructus sori in duas lineas parallelas sunt dispositi; e. g. Angiopteris evecta (t. 53. f. 8. a.), sicut omnes lujus et Danaeae generis species.

8) interruptus: si sorus linearis longus pluribus spatiis intermissus, vel ex soris pluribus brevioribus compositus est; exempli loco Woodwardia radicans (t. 50. f. 6.).

9) continuus: sorus linearis longus, cui intervalla non sunt; exemplum exhibent Pteris tricuspidata (t. 48. f. 5.), Pteris furcata (t. 5I. f. 9.), Blechnum occidentale (t. 48. f. 3.).

10) longitudinalis: sorus linearis ad lineam rectam a basi frondis, vel foliolorum ejus, ad apicem usque excurrens; exempli loco Dlcchnum occidentale (t. 48. f. 3.).

II) trausversus: sorus linearis a frondis, vel foliolorum ejus, nervo primario ad marginem excurrens; exemplo est Aspleniun squamosum (t. 29. f. 2. b.).

12) marginalis: sorus linearis longus juxta marginem ambiens, id quod Pteris tricuspidata (t. 48. f. 5.) et Pteris furcata (t. 51. f. 9.) monstrant; vel Sori plures, qui juxta marginem in unam lineam sunt dispositi ut in Polysticho montano Rot/ (t. 55. f. 1.) et Angiopteride evecta (t. 53. f. 8.).

13) ziniseriales: si Sori plures formant lineam, quae alteri in eodem frondis foliolo non est parallela ; e. $g$. Polysticlumm montauum Rot/ (t. 5j. f. I.), Angiopteris evecta (t. 53. f. 8.).

1') Liseriales: si sori plures in duas lincas parallelas sunt dispositi; e g. Polypodium vulgare (t. 2. โ. 5.). dentale (t. 48. f. 3. a.) und die mehresten Farrnkräuter.

7) zweyzeilig - geordnet (bifariam ordinatus): wenn die Früchte des Häufchens in zwey parallelen Linien stehen; z. B. Angiopteris evecta (t. 53. f. 8. a.), so wie alle Arten dieser Gattung und der Gattung Damaea

8) wnterbrochen (interruptus): wenn ein langes linienförmiges Häufchen oft durch Zivischenräume getrennt, oder aus mehreren kürzern zusammengesetzt ist; z. B. Woodwardia radicaus (t. 5o. f. 6.)

9) ununterbrochen (continuts): ein langes linienförmiges Häufchen, das keine Unterbrechungen hat; z. D. Pteris tricuspidata (t. 43. f. 5.), Pteris furcata (t. 51. f. 9.), Bleclinum occidentale (t. 4.8 . f. 3.)

so) längslaufend (longitudinalis): ein linienförmiges Häufchen, welches in gerader Linie von der Basis cles Laubes, oder der Blättchen desselben, Lis zur Spitze ausläuft; z. B. Blechnum occidentale (t. \{3. א. 3.)

I I) qu eerlaufend ( transversus): ein linienförmiges Häufchen, welches von der Hauptrippe des Laubes, oder der Blättchen desselben, nach dem Piande ausläuft; z. B. Asplenium squamosum (t. 29. f. 2. b.)

12) r andständig (marginalis): ein langes linienfürniges Häufchen, welches längs dem Rande sich hinzieht, z. B. Pteris tricuspidata (t. 48. f. 5.) und Ptcris furcata (t. 51. f. 9.); oder melurere Häufchen, die lïngs dem Rande in eine Reihe gestellt sind; z. B. Polysticlum montanum Roth. (t. 55. f. I.), Angiopceris evecia (t. 53. f. 8.)

13) einreihig (uniseriales): wenn mehrere Häufchen eine Linie bilden, die der andern auf eben demselben Blïtchen des Laubes nicht parallel ist; 2. B. Polystichum monkanum Roth. (t. 55. f. I.), Angiopteris evecta (t. 53 f. 3.)

ŕf) 2 weyleilig (biseriales): wenn mehrere Häufchen in zwey parallellaufende Linien gestellt șind; z. D. Polypodium vulgare (t. 2. f. 5.) 
15) catenati : si sori duo longi lineares saepius se ita intersecant, ut catenae figuram fere exhibeant; videatur Hemionitis lanceolata (t. 48. f. 7.).

16) reticulati: si sori plures lineares variis angulis sese ita intersecant, ut rete quasi forment; exempli loco est Hemionitis palmata (t. 55. f. 2.).

\section{£. 79.}

Seta est cormus tenuis, simplex, filiformis, in Muscorum frondosorum et Jungermanniarum flore, post foecundationem excrescens et horum regetabilium fructus ferens. Pedunculo quodammodo est similis, cum, aeque ac hic, fructus ferat; at vero hac re differt, quod flores non tulit. Setae species sunt:

1) solitaria: si non duo pluresve conjunguntur; exempli causa Hypnum velutinum ( $t$. 10. f. 4. b.), Hypnum lutescens (t. Io. f. 6.), Neckera dendroides (t. Io. f. 8.) et pl. al.

2) aggregata: si plures setae arcte conjunctae sunt; videatur Bryum cuspidatum (t. 42. f. I. 6.).

3) terminalis: vid. 9.60. Nr. 17; e. g. Polytrichum commune (t. 10. f. I. b.), Bryum cuspidatuin (t. 42. f. r. b.).

4) axillaris: vid. \$. 6o. Nr. 8; e. g. Hypnum velutinum (t. 10. f. 4. b.), Hypnum lutescens (t. 10. f. G.) et pl. al.

5) lateralis: si seta primum est terminalis, ob surculi (\$.55.) innovationem vero ad basin junioris lateraliter collocatur; exempli loco est Bryum palustre ( $t$. 56. f. 4.). (Observatio infera videatur.)

6) basilaris: si e basi surculi ( $\$$. 55.) nascitur; exemplum pracbet Bryum annotinum (t. 56. f. 2.).
15) kettenfürmig (caterzati): wenn zwey lange linienförunige Häufchen sich öfter durchkremzen, so, dal's sie fast die Gestalt einer Kette annehmen; z. B. Ifemionitis lanceolata (t. 48. f. 6.)

16) netzförmig (reticulati): wenn mehrere linienförmige Ḧ̈ufchen unter verschiedenen Winkeln sich durchkreuzen, so, dals sie gleichsam ein Netz bilden; z. B. Inemionitis palmata (t. 55. f. 2.)

\section{79 .}

Die Borste (Seta) ist ein dünner, einfacher, fadenförmiger Stiel, der in der Blume der Laubmoose und Jungermannien nach geschehener Befruchtung hervorwächst und die Früchte dieser Gewächse trägt. Sie hat einigo Aehnlichkeit mit dem Blumenstiele (\$. 6o.), indem sie, eben so, wie dieser, Frïchte trägt; sie unterscheidet sich aber dadurch, dafs sie keine Blumen getragen hat. Die Arten der Borste sind:

1) einzeln (solitaria): wenn nicht zwey oder mehrere beysammen stehen: z. B. $I_{y}$ pnum velutinum (t. 10. f. 4. b.), Hypnum lutescens (t. 10. f. 6.), Aieckera dendroides (t. Io. f. 3.) u. m. a.

2) gehäuft (aggregata): wenn mehrere Borsten dicht beysammen stehen; z. B. Bryum cuspiclatum (t. 42. f. 1. b.)

3) gipfelständig (terminalis): S. 6.60. Nr.17.; z. B. Polytrichum commune (t. 10. f. I. b.) Bryum cuspidatu:n (t. 42. f. I. b.)

4) blattachselstïndig (axillaris): S. 5. 60. Nr. 3 ; 2. D. II ypum velutinum (t. 10. f. 4. b.), Iypnum lulescens (t. 10. f. 6.) u. m. a.

5) seitenstïndig (lateralis): wenn die Borste anfangs gipfelständig ist, durch die Erneuerung des Stämmclıens ( $(55$. ) aber seitıärts an die Basis des jüngern zu stehen kommt; z. B. Bryum palustre (t. 56. f. 4.). (Man sehe unten die Anmerkung.)

6) grundstăndig (basilaris): wenn sie sus der Basis des Stämmchens ( $\$$. 55.) bervorkommt; z. B. Bryum annotinum (t, 56. f. 2.) 
7) Alexuosa: vid. §. 5r. Nr. 38; e. g. Dicranum Alexuosum (t. 50. f. r.).

8) siricta: vid. 5. 5r. Nr. 29 ; e. g. HJpnum lutescens (t. Io. f. 6.) et pl. al.

9) incurva: si arcuatim ita est curvata, ut apex basin spectet; videatur Funaria hygrometrica (t. 53. f. 9.).

Io) erecta: vid. §. 51. Nr. 30; e. g. Hypnum velutinum (t. 10. f. 4. b.) et pl. al.

II) tortilis: si una extremitas, dum altera quiescit, circum axem suam se convertit, idque directione duplici:

a) dextrorsum: contra solis motum; e. g. Encalypta lanceolata (t. 56. f. I. a.);

b) sinistrorsum: cum solis motu; e. g. Didymodun rigidulum (t. 56. f. 3. a.).

12) exasperata: cujus superficies punctulis eminentibus, solo armato oculo observabilibus, est obsita; exemplum praebet Hypnum rutabulum (t. 42. f. 6.).

13) laevis: cui punctula hujusmodi non sunt, ut in Muscis frondosis plurimis.

In nonnullis vegetabilibus - praecipue in Muscis frondosis - cormus ex apice forifero post antbesin ramos juniores protendit, quod cor. mi Innovatio seu Prolificatio vocatur. In Bromelia et Pino (t. 53. f. 5.) novus cormus seu ra. mus ex apice pedunculi communis, in Polytricho (t. 56. f. 5.) e floris medio ipsius excrescit; in Ledo palustri (Tab. libri inscriptionis f. 1.) et Eryo palustri (t. $5^{6}$. f. 4.) plures ramos $i: a$ si. mul evolvuntur, ut peracta innovatione in illo pedunculus in hosum ramorum medio, in hoc contra seta juxta eos obervetur.
7) gekniet (Rexuosa): S. 5. 51. Nr. 38.; 2. B. Dicranum flexuosum (t. 50. f. r.)

3) straff (stricta): S. গ. 5r. Nr. 29.; z. B. $H_{y p-}$ nuin lutescens (t. 10. f. 6.) u. m. a.

9) eingekrümmt (incurva): wenn sie so in einem Bogen gekrümmt ist, dafs die Spitze gegen die Basis zeigt; z. B. Funaria lygromelrica (t. 53. f. 9.)

10) a ufrecht (erecta): S. \$. 5I. Nr. 30.; z. B. Hypnun velutinum (t. 10. f. 4. b.) u. m. a.

11) gedreht (tortilis): wenn sich das eine Ende, wälrend dafs das andere ruhet, um seine Achse drehet, und zwar nach zweyerley Richtung:

a) rechts (dextrosum): gegen den Lauf der Sonne; z. B. Encalypta lanceolata (t. 56. f. I. a.); b) links (sinistrorsum): mit dem Laufe der Sonne; z. B. Didymodon rigidulum (t. 56. f. 3. a.) 12) $\mathrm{rauh}$ (exasperata): deren Oberfläche mit kleinen erhabenen Puncten, die nur mit bewaffnctem Gesicht wahrgenommen werden können, besetzt ist; z. B. Irypum rutabulum (t. 42. f. 6.)

13) glatt (laevis): die dergleichen Puncte nicht hat wie bey den mehresten Laubmoosen.

Bey einigen Gewäclısen - vorzüglich bey den Laubmoosen - treibt der Siiel aus der blumen. tragenden Spitze nach dem Blühen junge $Z$ weige hervor, welches die Erneuerung oder das Sprossen (Innovatio s. Prolificatio) des Stiels genannt wird. Bei Bromelia und Pinus (t. 53 . f. 5.) kommt der neue Stiel oder $Z$ weig aus der Spitze des gemeinschaftlicisen Blumenstiels, boy Polytrichum (t. 56. f. 5.) aus dem Mittelpuncte der Blume selbst; bey Ledum palustre (Titclkupfer f. 1.) und Bryum palustre (t. 56. f. 4.) werden mehrere $Z$ weige zugleich entwickelt, so, dars naclı vollendeter Erneuerung bey jenem der Blumenstiel in der Mitte dieser $Z$ weige, bey diesem hingegen die Borste zur Seite derselben b cmerkt wird. 
\$. 80.

Plyllinum est caudicis adscrnlentis (\$ 47.) extcnsin diversissime formata, vel simplex occurrens vel partiLus phrrihus aeyualibus constructn, quae inter omnes fere ceteras vegotabilis partes praecipue discemitur. Istius quae dignoscuntur species sunt: Thallis, irons ac Folin. Hue etism pertinent partes foliorum constructionem imitantes vel quidem ab illis dependentes. Sunt quse dicuntur: Stipulae, Auricula, Ramentum, T"aginn, Ligula, Oclerea, Gemma, Ascidimn, Eractcae, Goma, Involucrum, Spatha ac Indusium.

\section{ร. ชิ โ.}

Thallius est phyllinum (\$. 80.), cormi (\$. 40 ) simul tenens locum, ei, ad vegetabile propazandum, propagula ferens ant thalamos, aut ambos simul, nisi totum solis ex illis est constructum. Thallus non nisi in Liclicribus, a:tamen vero tum secundum substantiam, tum figuram et directionem cjus admodum varius invenitur. Apparet:

A. Secundur substantinam.

I) gelatinosus: qui est mollis, elasticus et diaphanus; e. g. omnes species generis Collematis 11 of $\mathrm{m}$.

2) cornens: praccedenti similis, attamen aliquanto durior, minus diaphanus atque intus plerumque albus; exemplo sunt omnes generis Corniculiriac Achar. species.

3) coriacens: si instar membranae videtur ac tenuis, tenax, opacus; c. g. Parinelia pulmonacea, Parmelia scrobiculata, Peltiden canina.
§. 80.

Die Belaubung ( $P / h$ llintum) ist eine schr versclieden gubildete Ausduthung des aufsteigenden Stoclies (S. fi.), die entwedrr einfach oder aus mulueren, meistens gle:ciantign 'Theilen zusaumengesetzt sich z.cigt, und gewölnlich untex allen übrigen Theilen des Gewächses am meisten in die Augen fäilt. Man unterscheidet folgrude Arten, als: das La ub (Thallus), den Wedel (Frons) und die Blätter (Folia). Auch gehören noch diejenigen Theile hierher, welche ähnliche Bildung mit den Piäitern haben, oder von denselben abbangen, und diese sind: die Afterbliitter (Stiptolae), das Öhrchen (Anricula), die Ausschlagsschuppe (Ramentum), die Blattscheide (Iagina), das Blauhüutchen (Lignla), die Tute (Ochren), die Knospe (Gemma), der Śchlauch (Ascidinm), die Siebenblätter (Bractecie), der Schopf (Coma), die Hülle (Involucrum), die Blumenscheide (Spatha) und Lias $S$ chleyerchen (Indusium).

\section{\$. $8 \mathrm{r}$.}

Das Laub (Thalizts) ist eine Dchaubung (S. 80.) dic zugleich die Stelle des Stiels (\$. 40.) vertrit und, zur Fortyflanzung des Gewiichses, Staulfortsiizze oder Fruchtlager oder auch beyde zugleich trägt, wenn sie niclit ganz aus crsteren zusammengestzt ist. Man fincet das Laub nur Ley den Flechien, dennoch iber, sowoll der Substanz, als auch der Gestalt und Richtung nach, schr verschieden. Es zeigt sich:

A. Nach der Substanz.

I) gुallertariig (gela:inosus): das woich, elastisch und durchscheinend ist; z. B. alle Arten der Gattung Cullema IIoffm.

2) hornartig (corne:ts): dem vorhergehenden a!nlich, jedoch etwas häıter, wenizer durchicheinend und inwendig gewölınlich weils; z. B. alle Arten der Gatung Cornicularin Achar.

3) lederartig (coriacens): das hautatig, dirr: zähe und undurchsichtig sich zeigt; z. L. P'armelics pn!monacea. Parmelia scrobicnlata, Peltidea caninc 
4) membranaceus: qui priore (No. 3.) minus est tenuis, parum tenax et subdiaphanus; exemplo sunt Peltidea resupinata, Cetraria glanca, Parmelia tilincea.

5) sublignosus: qui est fibrosus, solidus ac ligni fere soliditatis; exemplum adfert Usnea mielaxanilıa.

6) tartarells: si duris constat granulis, quae inter se congrua arcteçue conjuncta vix discernuntur, et solidum exhibent massam tartaro adsimilem; e. g. Parmelia tartarea, Parmelia ventosa.

B. Secundum figuram.

7) crustacens: qui, ubi occurrit, tanquam crusta oblucit corpora. Distinguitur:

\section{«. Plano toto.}

2) firinosus: si consistit subtilissimo pulvere, cnjus granula ita arcie sunt conjuncta, ut vix distingui, attamen abstergi queani; e. go. L'rceoluria contorta furinosa Flürl.

b) pulverulentns: praecedenti similis, granula minus habet subtilia eaque leviter collaerentia, quo fit, ut facile sint distinctu et abstersu; exemplum praebet Lepraria leipluaema, Lepraria incalıc.

c) grannzlosus: qui rotundis, duris, pltine distinguendis consistit granis haud facile abstersu; $u$ in Lecialea uliginosu, Parnelia vilellina.

d) leprosus: squamulis non plane distinguendis, inaeqaalibus arcte inter se conjunctis, quibus tegnen efficitur soìdum; sic ut praebet Lecidea punctazta, si in arborum cortice occurrit.

e) rigosus: cu;us superficies parras, oblongas,
4) hautartig (membranaceas): das dünner als das vorherigehende ( io. 3.), wenig zähe und etwas durchscbeinend ist; z. B. Peltidea resupinata, Ceirarir glauca, Parmelis tiliacea.

5) fast hoizig (sublignosus): das faserig, dicht und fast ron der Festigkeit des Holzes ist; 2. D. Usnea melaxantha.

6) weinsteinartig (iortareuss): das aus harlen, gleichfü:mig und sehr dicht zusammen verbundenen Kürnchen besiedt, die katın zu unterscheiden sizd, und eine feste, dem Weinstein äbnliche Masse bilden; z. B. Parifielia tartarea, Purnetia verztosa.

\section{B. Nach der Gestait.}

7) rindenartig (cristacelis): wenn es die Kürper, auf denen es cokkomint, nach Art eirer hinde bedocht. MIan unierscheidet es:

\section{ж. Fach cler ganzin Fläche.}

a) mehlartig (farinorus): wenn es aus selir zartem Staube besteht, dessen Körnchen sehr diclit verbunden sind, so, dafs sie kaum unterschicden werden können, sich aber dennoch abwischen lassen; z. B. Urceolariu contorta farinosa Flürl.

b) staubartig (pulverulentus): deın vouhergehenden ähnlich, die Körnchen aber sind nicht ganz so fein und hangen nur locker zusammen, so, daf's sie sich leicht untersclseiden und abwischen lassen, z. B. Lepraria leiplacema, Lepraria incana.

c) Kürnig (uranulosus): das aus deutlich zu unterscheidesiden, rund n, harten Körnern bestełt, die sich nicit leicht abwischen lassen; z. B. Lecidea uriginosu, Parmelia vitellina.

d) schorfartig (ieproszus): das aus nicht deutlich zu unterscheiúenden, ungleich gestalteten kleinen Schiippchen besteht, die dicht zusammen hangen und eine féste Decke bilden; z. B. Lecidea punctatu, wenn sie auf Batuminde vorkommt.

e) runzlig (rugosti:) dessen Ober Häche kleine, 
irregulares, passim vagantes habet prominentias; ut demonstrat Farioliriu fuginen.

f) ae.ruabilis: superficies thalli crusticei ubi iniquitatibus aut caret, aut, quas tamen ostendit parvas, ut in thallo leproso (d.) et rugoso (e.), nimirum in totam superficien congruenter habet dispersas; exempij loco est Parmelia vitclina (t. 62. 1. 2.), Lecidea confluchs.

g) inueguabilis: si in superficie thalli crustacei reperiuntu i.uquitates vel prominentiae haud congruenter d:spertitac; exemplum exhibet Lecide: sanguinaria (t. 64. f. g.).

h) rimostz: ubi thallus leprosus (d.) vel tartareus (No. 6.) dirumpit, ita, nt complures, plerumque se decussatim secantes observentur rimae, superficiem vero nihilominus planam seu aequam subsistere necesse est; videantur Variolaria orbicitlata (t. 66. f. 4.), Parmelia thallina (t. 57. f.5. b.).

i) continnus: thallus leprosus (d.) vel tartareus (No. 6.) si rimis non divisus, seu cohaesio ejus non est interrupta. Exempla praebent omnes Liclienes in praecedente (h.) citati, si adhuc sunt in statu juvenili.

k) areolatus: si thallus tartareus (No. G.) ex parvis, editis, sibi quodammodo adjacentibus consistit areolis; exemplum pracbet Urccolaria ocellata (t. 58. f. 12.).

1) verrucosns: si thallus crustaceus obsitus est prominentiis plus minusve verrucis similibus; exemplo est Thelntrema pertusum (t. 6j. ᄃ. I.).

\section{B. Ambitu vel peripheris.}

m) effusibs: si thalli peripheria terminis neque insignibus neque certis est praedita; excmplum fert Urceolaria Hoffmanni. längliche, unregelmälsige, verworren laufende Er. habenheiten hat; z. D. Variolaria faginea.

1) gleichflächig (requabilis): wenn die Oberfläche des rizdigen Laubes cntweder olne Unebenheiten ist, oder, wenn aucls kleine bemerkt werden, wie beym scliorlartigen (d.) und runzligen (e.) Laube, diese doch gluichfürmig über des ganzen Oberlläche veriheilt sind; z. B. Parmelia vitellina (t. 62. f. 2.) Lecidea confluens.

g) ungleichflächig (inaequabilis): wenn sich auf der Oberfläche des rindenartigen Laubes Unebenheiten oder Hervorragungen finden, die nicht sleichförmig vertheili sind; z. B. Lecidea sanguinaria (t. 6-́. S. .).

l) rissig (rimostzs): wern das scliorf-(d.) oder weinsteinartige Laub (No. 6.) zerspringt, so, dafs man mehrere, gewöhnlich sich darchkreuzende, Risse bemerkt, wobey jeduch die Oberfläclie noch chen bleiben mufs; z. B. Tariolarin orbiculala (1. 65. f. 4.), Parmelia thailina (1. 5- . f. 5. b)

i) zus ammenhaltend (continizus): wenn das schorf-(d.) oder weinsteinartige Laub (No.6.) nicht durch Risse getrennt, oder in seinem Zusammenllange unterbrochen ist. Beyspiele geben die bey dem vorliergehenden (h.) angeführten Flechten in jugendlichen Zustande.

k) gefeldert (areolatus): wann das weinsteina:tige Laub (No. G.) aus kleinen erhabenen, etwas zusammenstolsenden Feldern besteht; z. B. Urceolirvia ocellata (t. 58. f. 12.).

1) warzicht (verrucosus): wenn das rindenartige Laub mit Elhabenheiten besetzt ist, die melr oder weniger den Warzen ähn?ich sind; z. B. Thelotrema periusium (t. 65. f. I.).

\section{B. Niach dem Uinfange.}

m) unbestimmt (rffnszls): wenn der Limfang des Laubes keine ausgezeichnule und bestimmle Gränze hat; z. B. Urceolariı Iloffmanni. 
n) determinatus: si thalli peripheria insigniter certoque indicatur. Tunc apparet:

r) dendriticus: si peripheriae tenues, plerumque ramosis inesse libras obscratur; exempli loco sunt Parmelia dendritica (¿. 65. א. 2.), Lèpraria leipluaema (t. 66. f. 10.).

2) limitatus: si complurimum individuorum limites se invicem attingunt, quo pulla inter eas linea venit in conspectum; insuiciatur l'armelia thallina (t. 5\%. f. 5. a.).

o) unicolor: thalli margo si disco est concolor. Sequenti opponitur; exemplum praebet f'ariolaria $\operatorname{lacieu}($ t. 60. f. 7.).

p) zonains: sí thalii peripheriam versus stria (seu fascia) alius coloris discum includit; a g. Fariolaria orbiculata (t. 66 f. 4.).

7) mniformis: thalli margo atque illius discus si cjustemmodi sunt formati. Oppositus est binis insequentibus; cxempiu cst Parmelia zitellina (1. 6. . . 2.).

r) rfiguratus: Sarinosi (๕.), pulverulenti (b) vel granulosi (c.) thalli granula si peripheriam versus in parras transeunt extensiones foliaceas; quod monstrat Lecanora leiclıolyta (t. 59. .. 3.).

s) crusinceo-folinceus: si totus thallus ex parvis, conjunctis, crustam efficientibus consistit foliolis, in peripheria magis ginam in disco conspicuis; videatur Parmelia lentigera (t. 57. f. 2.).

8) foliacens: si membranaceus ( Wo. 4.) aut coniaceus (No. 3.) est, rel, etsi quidem quoad substantiam ab is differa!, attamen talis apparet quoad figuram. In quilus distinguitur:

a) lobatus: thallus foliaceus si tantummodo ad n) bestimm: (determinatus): winn der Um. fang des Laubes ausgezeichnet und bestimmt begr ïnzt ist. Er zeigt sich alsdann:

I) dcndritisch (dendriticus): wenn an dem Urularge feine, gewölnaich ïstige, Fasern wahrgenommen werden; z. B. Parmelia dendritica (1. 6j. f. 2.), Lepraria leiphaema (t. 66. f. 10.). 2) durchgränzı (limiiclias): wenn die Begräuzungen mehrezer Individuen sich berühren, wo dann zwisclien ilınen eine dunkle Linie bemerkt wird; z.B. P'armelia thallina (t.57-f.5. a.).

o) einfarbig (unicolor): wenn der Fand des Laubes ron gleicher Farbe mit dem Mittelfelde isi. Fs maclut den Gegensatz von dem fo!genden aus; z. B. Vuriolaria iaciea (t. 66 f. 7.).

P) gezont (zonatus): wenn gegen den Umfang des Laubes ein anders gefärbter Streif (oder Binde) das Mittelfeld einschliefst; z. B. Varioiaria orbiculata (t. 66. f. 4.).

q) einfürmig (uniformis): wenn der Rand des Laubes von gleicher Bildung mit dem Mitteifelde Uesselben ist. Ls ist der Gegensatz der beyden folgenden und z. B. diene Parmelia vitellina (1. 62. f. 2.).

r) verziert (efigurains): wenn die Kürnchen des mehlartigen (a.), staubartigen (b.) oder körnigen (c.) Laubes am Umfange in kleine blattartige Ausdehnungen übergelın; z. B. Lecanora teichol) ta (t. 59. f. 8.).

s) rindenartig-blattrig (crustaceo-foliacrus): wenn das ganze Laub aus kleinen, zusainmexhangenden, eine Rinde bildenden Blättchen besieht, die am Umfange deutlicher sind als am Nittelfelde; z. B. Parmelia lentigera (t. 57. f. 2.).

3) blattartig (foliacens): wenn es haut-(No.4.) oder lederarlig (No.3.) ist, oder wenn es auch der Substanz nach, von diesen abweicht, doch der Gestalt nach sich so zeigt. Man unterscheidet bey diesem:

a) lappin (lobatus:) wenn das blattartige Laub 
TE R M I N O L O E I A.

dimidiun usque excisuris (\$. 8f. No. 16.) in plures divisus est partes, inier se distantes et in utroque latere lintis plerumque arcuatis finitas; inspiciatur l'armeliu scrobiculatu (t. 57. f. 8 ).

b) laciniaius: si nullo ordine certo excisuris mulium recessis in plures dispertitus est partes angustas, quae et ipsae simili modo sunt excisae, et in utroque margine laterali a lineis fere paralielis finitae; id quod ostendit Parmelia pruntastri (1. 62. f. 14.).

c) intricalis: si thalli foliola in morem laterum seu imbricum se deinceps obtegunt; exemplum adfert Parinelia conspersa (t. 33. f. II.).

d) inflatlis: qui membranaceus (No. 4.) atque intus cavus exstat; e.g. Parmelia p/ly) sodes (t. 66. f. 9.).

e) scrobiculatus: cujus superiori paginae multiudo levium impressionum est, qui offerunt ficiem ac si essent impressi corpore brsi rotundato; videatur P'armelia scrobiculata (t. 57. f. 8.).

f) lachunsus: cujus superiori paginze sunt numcrosae et profundhe impressiones, quae offerunt faciem, ac si essent impressae corpore basi planu; inspiciantur I'arinelia pulmonacen (t. 55. f. 11.), I'urmelic fraxinea (t. 33. f. 4. a.).

g) pilstulatus: pagina inferior ubi multas habct cavitates, pustularum alte fornicatarum figura, pagina superiori eminentes; exemplum exhibet Lecidea pustulaca (t. 65. f. I4.).

li) nutulicatus: thallus si inferioris paginae medio tantum radice scutata (\$. 45. B. No. 5. a.) superfixus est corpori, cui increscit; e. g. Gyropllora proboscidea (t. 16. f. 3.) et omnes species generis Umbilicariae Hoff $m$.

9) filcuntertosus: si longum, subtile, ubique fere
TLR MINOLO G I E. 115

nur bis zur Hälfte durch Ausschnitte (\$. 8f. No.ı6.) in mebrere Theile abgetheilt ist, die von einander abstehen, und zu beyclen Seiten gewöhnlich durch Bogenlinien begränzt sind; z. B. Parmelia serobiculata (t. 57 . f. 8 ).

b) zipflig (lucinintus): wenn es ohne bostimmie Ordnung in mehrere schmale Theile abgetheilt ist, die wieder auf ähnliche Art ausgeschnitten und an beyden Seitentindern von fast gleichlaufenden Linien begränzt sind; z. B. Parmelic prinasiri (1. 62. f. 14.).

c) dachziegelartig (imbricatus): wenn sich die Blättchen des Laubes nach Art der Dachziegel decken; z. B. Parnuelia conspersa (t. 33. f. Ir.).

d) aufgeblasen (inflatus): das hautarigg (No. 4.) und innerhalb bohl ist; z. E. Farmelin physodes (1. 66. f. 9.).

e) flachgrubig (scrobiculatus): auf dessen obere Fläche viele schwache Vertiefungen sind, clie das Anselyen haben, als ob sie mit einem an der Grundfläche zugerundeten Körper eingedrūckt wären; z. B. Parmelia scrobiculata (t. 57. f. 8.).

f) grubig (lacunosus): auf dessen obere Fläche viele starke Verticlungen sich finden, die das Ansehen haben, als ob sie mit einem an der Grundfläche ebenen Körper eingedrückt wären; z. B. Parmelia pulmonacea (t. 55. f. II.), Parmelia fraxinea (t. 33. f. 4. a.).

g) hocliblatrig (pnstulatus): wenn die untere Fläche viele Hölungen hat, die auf der obern Fläche in Gesialt von hochgewölbten Blattern hervortreten; z. B. Lecidera pustulata (t. 65. f. 14.).

h) nabelartig (umbilicatus): wenn das Laub auf seiner untern Fläclıe nur in der Mitte durch eine schildfürmige Wurzel (\$. 45. B. No.5. a.) auf dern Körper befestigt ist, auf dem es wächst; z. B. $G y$ rophora proloscidea (t. 16. f. 3.) und alle Arten der Gattung Uimbilicaria IIoff $m$.

9) fadenartig (filantentosiss): wenn es als ein 
eadem crassitudine est corpus, vel simplex vel in ramos divisum. Disting:nitur:

a) articulatus: cujus cortex rimis annulatis in articulos quasi est divisus; exemplo est Farmelia divaricata Ach. Meth. (t. 46 . f. 5.).

b) continuus: cujus cortex ammulatis rimis haud interruptus est, inspiciatur J'armelia sarmentosa Ach. Meth. (t. 46. f. I).

c) implexus: rami dum thalli filamentosi se acutangulate intersecant nec non tangunt; videatur Cornicularia lanata (t. 65. f. 12).

10) friticulosis: qui filamentosis (No. 9.), erectus (No. 12.) ramosusque invcnitur; e. g. Usnea florida (t. 17. f. 6.), Cornicnlaris spadicea (t. 57. f. 4.).

II) caespritosns: thallus foliaceus (No. 8.) aut filainentosus (No. 9.) si acervatim ex una tademque radice scutaia ( $\$ .45$ B. No. 5. a.) provenit, ad omnes plagas directus et caespitem quasi refert; e. g. T'nrmelia pollinaria, Comicularia lanata (t. 65. f. I2.), Cornicularia tristis.

\section{Directione.}

12) erectus: si thallus foliaceus vel filamentosus ita sursum est directus, ut ad lineam perpendicularem plus minusve accedat; ut in Usnea florida (t. 17. f. 6.), Cornicularia spadicea (t. 57. f. 4.).

13) pendulns: thallus filamentosus si ita deorsum est directum, ut lineam perpendicularem plus minusve aequat; exemplo sunt Parmelia divaricata (t. 46. f. 5.), Parmelia sarmentosa (t. 46. f. I.).

14) aulscendens: si inferior thalli pars, in quo deprehenditur, incubat corpori, unde superiori in parte arcuatim transit in directionem erectam; exemplum praebet Peltidea polydactyla (t. 58. f. 9.). Cornicularia tristis.

15) decmmlens: thallus filamentosus si nec multum supra basin defiectitur, ita, ut nisi totus, maxima tamen langer, feiner Körper, der fast iiberall gleicl dick ist, entweder einfach oder in Äste zertheilt sich zeigt. Man unterscheidet:

a) gegliedert (articulatus): bey dem die Pinde durch ringfürmige Risse gleichsam in Glicder abgetheilt ist, z. B. Parmetia divaricate Ach. Meile. (t. 46. f. 5.).

b) fortlauferd (continutus): dessen rinde niclut durch ringförmige Risse zerheilt ist, z. B. Parmeliz sarmentosa Ach. Micth. (t. 46. I. I.).

c) verflochten (implexus): wenn sich die Äste des fadenartigen Laubes in spitzigen Winkeln durchlkreuzen und berühren; z. B. Cornicularia larazica (t. Gj. f. 12.).

10) strauchartig (fruticulosa): das faderförmig (No. 9.), aufrecht (No. 12.) und ästig ist; 2. B. Usnea Aorida (t. 17. f. 6.) Comicularia spadicea (t. 57. f. 4.).

II) rasenartig (cuespitosus): wenn das blattartige (No. 8.) oder fadenartige (No. 9.) Laub geluätht aus E:ner schildförmigen Wurzel (\$. 45. B. Noo. 5. a.) hervorkommt, sich nach allen Richtungen verbreitet und gleichsam einen Rasen darstellt; z. B. Parmelia pollinaria, Cornicnlaria lanata (1.65. f. 12.), Corincularia tristis. C. Nach der Richtung.

12) a ufrecht (erectirs): wenn sich das blatt - oder fadenarige Laub so nach oben kehrt, dafs es sich der senkred liten Linie melu oder weniger nähert; z. B. Usnea florida (t. 17. f. 6.), Cormicularia spadicea (1.5-. .. 4.).

13) lhangend (pendulus): wenn das fadencürmige Laub so nach unten gekehrt ist, dafs es sich der senkrechten Linie mehr oder weniger nühert; z. B. Parmelia divaricata (t. 46. f. 5.), Parnelia sarmentosa (t. 46. f. I.).

14) a ufwärtsgebogen (adscendens): wenn der untere Theil des Laubes, auf deın Körper liegt, auf dem es vorkommt, und dann an dem obern Theile durch einen Bogen in die aufrechte lichtung übergcht; z. B. Peltidea polydactyla (t.59. f.9.), Cornicularia tristis.

15) niederliegend (decumbens): wenn das fadenartige Laub nicht weit über der Basis sich nieder- 
T E R II I N $N$ O L

ex parte incubet corpori, ubi reperitur; e. g. Cornicu. laria pubescens, Corniculuria lanata (t.65. f. 12).

16) depressus: thallus foliaceus si plus minusve orbiculatim expanditur, cujus foliola radios directione sua accedunt; videatur Purmeíic conspersa (t. 33. f. II.).

Acharius tiullum filamentosnm, ut propriam phy!lini speciem, Lorulum nominavit, id quod deprecaruur eo consilio, tt ne in scientiac detrimentum termini augeantur frusira.

\section{82.}

Irons cst Phyllinum ( $\$$. 30.$)$ semper fere e cormo (\$. 43.) ortum, vegetabilis propagandi non nisi raro ferens propagines, plerumque semina aut fructus, his tamen sacpezumero destitutum exstat. Frons cormo carens non aisi in Hamallophyllis, nonnullis Hepaticis atque in goncribus, Ulva, Riccia et Tremella nominatis, videtur. In genere Mcircluanlicue fert propagines easque cyatho comprchensas; in Algis semina plerumque infra ejus supcrficicm, aut supra eam'dispersa fructibus coninentur; in Filicibus plerumque pagina ejus dorsali observantur fructus in soros ( $\$$. 70.) dispositi, etsi in pluribus quoque is destituta npjaret; in Palmis denique sempor sine fructus reperitur, attamen in this co differt a foliis ( $\$ .83$ ), ut semper e caudicis ( $\$ .49$ ) apice evolvatur et partes ejus singulares - pinnae aut Soliola - aeque ac in Filicibus, cum stipite (\$. 5t.) quasi conlluant. Quam igitur in singula quoque familiarnm naturalium hic dictarum eminet proprietste: digna est quae, praesertim hac sola tamen ratione, in earum quavisuna separatim contempletur. Deprchenditur :
T E R MI I N N

117

beugt, so, dafs es, wo nicht ganz, doch grüfstentheils, auf $\mathrm{dcm}$ Körper liegt, auf dcm es sich zeiğt; z. B. Cornicularia pubescens, Cormicularia lunaia (t. 6j. f. 12.).

16) niedergedrückı (depressus): Wenn das blattartige Laub sich mehr oder weniger krcisförmig ausbreitet und die Blïttchen desselben sich, ihrer Richtung nach, den Tadien nïhern; z. B. Parnelia conspersa (t. 33. f. II.).

Acliarius laat das fadenartige Laub, als eine eigne Art der Belaubung, Lorulun geuannt, was abcr nicht angenommen werden liann, weil man dadurch zum Naclitheile der Wissensclaft die Kunstausdrüç̌e ohne Noth vermelien wïrde.

§. 02.

Der Wedel (Trons) ist eine Deluubung (\$. So.) die fast immer aus einem Stiele ( $\$$. 48.) entspringt, zur Fortpflanzung des Gewächses nur selten Fortsätze, gewöhnlich aber Samen oder Fï̈chte trïgt, of jecloch auch olne diese erscheint. Stiellos sitht man ihn nnr bey den Platumoosen, einigen Lebermoosen und bey den Gatiungen Ulva, Riccia und Tremella. Bey der Gattung Marclianiia trägt er Fortsätze, die in einem Becher entlalten sind; bey den Tangen liegen die Samen gcwöhnlich unter stiner Obertliche oder auf derselben zerstreut in Früchten cnllalten; bey den Farmkráutern bcmerkt man gew ühn'ich auf seiner Rückseite Früchı in Häufchen $(\oint \cdot 78$ ) zusammengestellt, ob er gleich auch bey mehreren ohre dieselben sich zeigt; bey den Palmen endlich findet man ihn stets obne Früchte, jedoch unterscheidet er sich by diesen dadurch von den Blättern ( $\$ .83$.$) , dafs er sich jederzeit aus dor Spiize eines$ Stockes ( $\$$. 49.) entwickelt, und dal's seine einzelnen Theile - die Fiedern oder biättchen - so wie bey den Farrnkräulern mit dem Strunke (\$. 5ł.) gleichsam zusammenfliefsen. Da er bey jeder der hier genannten natürlichen Familitn durch Eigenthümlichkeit sich auszciclinet: so verdicnt er auch, jedoch vorzïglich nur in dieser fiucksicht, bey jeder derselben besonders betrach:el.zu werden. Man findet, ilın: 
A. In Hamallophyllis et Hepaticis.

I) thalloidea: cormo destituta; inspiciantur Jungermannia epiplyylla (t. 46. f. Io. a.), Riccia glaisa (1. 67. ศ. 13.), Riccia crystallina (1. 67. f. 12.).

2) stellata: si plus minusve est orbicularis et partes ejus singulares e centro radiatim excurrunt ad peripheriam; exempla praebent Riccia glauca (t. 67. f. 13.), Riccia crystallina (t. 67. f. 12.).

3) imbricata: si in fronde stellata partes ejus singulares in morem laterum seu imbricum se obtegunt; ut ostendit Riecia crystallina (t. 67. f. 12).

4) Lipinnatifida: frons si ex utroque latere excisuris (ร. 8f. No. เ6.) dividitur in plures partes, quae perpendiculariter fere insistunt mediae longitudinali lineae, atque ipsae simili modo sunt exsectae; exemplum fut Jungermannia mullifida (t. 62. $\int$. 5. a.).

\section{B. In $A I_{g}$ is.}

a. Secundum figuram.

I) capillaris: corpus quam maxime subtile, Ionfinm, saepe diverse flexum, rel solitarie vel acerratim, ant simplex aut ramose apparet; exẹmp'a praebent Conferva difinsa (t. 46. f. 9.), Conferva Lullosa (1. 56. 1. 10.), Confurier casppilosa (r. 56. f. r r.).

2) fiifornis: corpus sultile, longum, ejusclem cunc:ibus fere partibus crassitudinis occurrit, vel solitarie vel accrvation, ant simpliciter aut ramuse; videaniur Ceraminm Filun (t. 17. f. r. b.), Fucus Fascioln (t. 46. F. 3.).

3) Inimlosa: plus minusve cylindrica et cava; e. g. Conferva intestinulis (t. 56. f. 7. a. et b.), Ceramium u. lullostin (1. 46. f. 6.), Conferva compressa (t. 55. f. 4.).

4) articu!ata: qui in articulos divisa, atrque ubi hi inter se conjuncti videntur, est constricta; exemplo sunt Conferva ericctornm (t. 46. f. 3. a. et b.), Conferva compressa (t. 55. f. 4.).

\section{A. Bey den Plattmoosen und Lebermoosen.}

1) laubartig (thalloidea): dem der Stiel fehlt; z. B. Tungermannia epiplyylla (t. 46. f. 10. a.), Riccia glanca (t. 6-. f. 13.), Riccia orystallina (t. 67. f. 12).

2) sternförmig (stellata): wenn er mehr oder weniger kreisrund ist und die einzelnen Theile rom Mitelpunkte wie Strahlen nach dem Umfang hin auslaufen; 7. B. Riccia glauca (t. 67. f. 13.), Ricciiz $\mathrm{cry}^{\prime}$ stallina (t. 67. f. 12.).

3) dachziegelartig (imbricata): wenn beym sternförmigen Wedel die einzelnen Theile desselben nach Art der Dachziegel sich decken; z. B. Riccia crj- $^{-}$ stallina (t. 67. F. I2.).

4) doppolt-fiederspaltig (bipinnatifida): wenn der Wedel von beyden Seiten durch Ausschnitte (S. Óf. Ni. I6.) in mebrere Theile abgetheilt ist, die ziemlich senkreclit auf der mittlern Lüngslinie stehen und wieder auf äbliche Art ansgeschniten sind; z. B. Jungermannia multifida (t. 62. f. 5. а.).

$$
\begin{aligned}
& \text { B. B ey den } \mathrm{T} \text { angen. } \\
& \text { «. IVach der Gestult. }
\end{aligned}
$$

I) haafförmig (capillaris): der als ein äufserst feiner, langer, oft verschicden gebogener Körper, einzeln oder gehüuft, einfach oder ästig sich zeigt: z. B. Conferva difinsa (t. 46. f. 9.), Conferva lullosa (i. 56. f. 10), Conferva caespitosa (t. 55. f. Ir.).

2) fadenförmig (fliformis): der als ein feiner, langer, fast überall gleich dicker Körper, einzein ode! Ge!säuft, einfach oder ästig sich zeigt; z. B. Ceramitun Filum (t. 17. f. r. b.), Fucus Fasciola (t. 46. f. 3.).

3) röhrenartig (tubnlosa): der mehr oder weniger walzenförmig und hohl ist; z. B. Conferva intestinutis (t. 56. f. 7. a. u. b.), Ceraminun inbulosum (t. 45 . f. 6.), Conferva compressa (t. 55. f. 4.).

4) gegliedert (articnlata): der in Glieder abgetheilt und $\mathrm{da}$, wo diese zusammengefügt zu seyn scheinen, zusammengezogen ist; z. B. Conferva ericetorinu (t. 46. f. 3. a. u. b.) Conferva compressa (t. 55. f. 4.). 
5) geniculata: quae in articulos divisa, atque ubi hi videntur inter se conjuncti, neque constricta est neq!ue tumefacta; exemplum praebet Ceramium Filum (t. I7. f. I. b.).

6) nodosa: divisa in articulos, qui, ubi videntur compositi, nodiformes quasi intumuerunt; inspiciatur Conferva fluviatilis (t. 57. f. 9.).

7) continuc: in articulos haud divisa, ergo nec interrupta, atque igitur tribus prsecedentibus (No.4.5. et 6.) opposita; e. g. Conferva bullosa (t. 56. f. ro.), Conferva caespitosa (1. 56. f. Ir.), Conferva inlestinalis (i. 56. f. 7. a. et b.).

8) istlmis interceptr: si tubulosa (No. 3.), continua (No. 7.) et saepius constricta est, ita tamen, ut ejus cavitas non intermittatur; exempli loco est Conferva intestinalis in ejus perfectae evolutionis statu (t.56.f.7.b.).

9) aequalis: tubulosa, reque vero constricta neque in articulos partita, arque ita non praecedenti (Nr. 8.) solum, sed articulatae (No. 4), geniculatae (No. 5) ac nodosae (No. 6.) etiam contrariatur; exemplnm praebet Conferva intestinalis in juvenili ejus statu (t. 56. f. 7. a.).

10) teres: cujus sectiones transversaies plana aequant onbicularia; exemplum exhibet Ceramium Frlum (t. 17. f. I. b.).

II) compressa: cujus sectiones transversales plus minusve imitantur ellipsin; sicut monstrat Fucus Fasciola (เ. 46. f. 3.).

12) plana: crassitudo ejus si, ad latitudinem longitudinemque relata, adeo parvi est momenti, ut rei minime sit habcaca ratio; exemplum praebet Ulva plantaginea (t. 56. f. 9.).

\section{ß. Secundume divisionem.}

13) simplex: in ramos haud diducta; exemplo. est Ceramium Filum (t. 17. f. I. b.).
5) gelenkig (geniculata): der in Glieder abgetheilt, und da, wo diese zusammengefügt zu sejn scheinen, weder zusammengezogen noch aufgetrieben ist; $z$. B. Ceramium Filum (t. 1-. f. I. b.).

6) knotig (nodosa): der in Glieder abgetheilt ist, die da, wo sie zusammengesetzt zu seyn scheinen, gleichsam knotenförmig aufgetrieben sind; z. B. Conferva Aluviatilis (t. 57. f. 9.).

7) fortlaufend (continna): der nicht in Glieder abgetheiit, also nicht unterbrochen, und daher den drey vorhergelienden (No. 4. 5. v. 6) entgegengesetzt ist; z, B. Conferva bullosa (t. 56. f. Io.), Conferva caespitosa (t. 56. f. II.), Conferva intestinalis (t. 56. f. 7 . a. b.).

8) mit Verengungen (isttumis intercepta): wenn er röhrenartig (No. 3.), fortlaufend (No. 7.) und öfter zusammengezogen ist; jedoch so, dafs seine Höllung nicht unterbrochen wird; z. B. Conferva intestina!is im vollkommen entwickelten Zustande (t. 56. f. - ?. b.).

9) gleich (aequalis): der röhrenartig, aber veder zusammengezogen noch in Glieder abgetheilt, und daher nicht nur dem vorhergehenden (No. 8.), sondern auch dem gegliederten (No. 4.), gelerkigen (NTo. 5.) und knotigen (No. 6.) entgegengesetzt ist; z. B. Contferva intestinalis im jugrndlichen Zustande (t. 56. f. 7.a.).

ro) sticlrnnd (tcres:) dessen Querdurchschnitte kreisrunden Flächen gleichen; z. B. Cercumiumn Filum (t. I7. f. I. b.).

II) zusammengedrü ckt (compressi): dessen Querdurchschnitte mehr oder weniger der Ellinse ähnlich sind; 2. B. Fucres Fasciola (t. 46. f. 3.).

12) flach (plana): wenn seine Dicke gegen die Breite und Länge so unbedentend ist, dal's sie gar nicht in Betracht kommt; z. B. Ulva plantaginea (t.56. f. 9.).

\section{ß. Nach der Zertheilung.}

13) einfach (simplex): der sich nicht in Äste zertheill; z. B. Ceramium Filum (t. 17. f. I. b.). 
I4) ramosa: quae in ramos dividitur; e. g. Conferva Anviatilis (t. 57. f. 9.).

15) ramosissima: multos protrudens ramos, qui denuo dividuntur in minores; inspiciatur Conferva diffrusa (t. 46. f. g. a.).

16) dicliotonna: civisa in duas partes, quarum utraque denuo bipartitur, et sic porro ad minimos fit ramos; videatur Fucus Fasciola (t. 46. f. 3.).

17) anastomosans: ramosae vel ramosissimae frondis capillaris vel filiformis rami si inter se iterum conjunguntur, ita, ut totum aequat rete; exemplo est $I_{y^{\prime}}$ drodiction majus (t. 56. f.6.).

$\%$ Secundum acervationem.

18) solitaria: si una tantum frons ex una radice scutata (\$. 45. B. No. 5. a.) protruditur; ut nonnunquam in Ceranio Filo (t. 17. f. I. b.).

I9) Sasciculata: si permultae frondes capillares ex una radice scutata proveniunt, et in fasciculi forma sunt coarctatae; exemplum exhibet Conferva compacta (t. 55. f. 17.).

20) caespitosa: ubi plures frondes capillares eadem ex radice prodeuntes ad omnes plagas verstis in caespitis forma sunt diffusae; ut in Conferva caespitosa (t. 56. f. I1.), Conferva bullosa (t. 56. f. 10.).

21) contexta: permultae capillares aut filiformes eadem e radice protrusae frondes, quae in caespitis forma dilatatae se variis angulis intersecant; videatur ConzServa bullosa (t. 56. f. 10.).

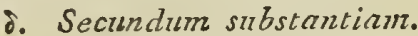

22) herbacea: plus minusve carnosa et cui substantia herbaceorum vegetabilium est; e. g. plurimae generis Confervae species.

23) membranacea: tenuis, tenax et parum diaphana; ut in plurimis generis Ulvae speciebus.
I彷) ästig (ranıosa): der sich in Äste zertheilt; z. B. Conferva Aluviatilis (t. 57. f. 9.).

I5) vielästig (ramoosissima): der viele Äste hervortreibt, die sich wieder in kleinere zertheilen; z. B. Conferva diffusa (t. 46. f. g. a.).

16) gezweytheilt (dichotona): der sich in zwey Theile, jeder derselben wieder in zwey, und so fort, bis auf die kleinsten Äste zertheilt; z. B. Fucus Fascio$\operatorname{la}$ (t. 46. f. 3.).

17) aderästig (anastomosans): wenn die Āste eines ästigen oder vielästigen baar-oder fadenförmigen Wedels sich wieder verbinden, so, dafs das Ganze einem Netze gleicht; z. B. Hydrodiction majus (t. 56. f. 6.).

\%. Nach der Alllüufung.

18) einzeln (snlitaria): wenn nur ein Wedel aus der schildförmigen Wurzel ( $($. 45. B. No. 5. a.) hervorgetrieben wird; wie z. B. bisweilen bey Ceramium Filum (t. 17. f. I. b.).

19) bũschelförmig (fasciculata): wenn sehr viele haarförmige Wedel aus Einer schildförmigen Wurzel hervorkommen, und in Gestalt eines Büschels zusammengedrängt sind; z. B. Conferva compacta (t. 55. f. 17.).

20) rasenartig (caespitosa): wenn mehrere haarförmige Wedel, die aus einer Wurzel hervorkommen, nach allen Sciten in Gestalt eines Rasens ausgebreitet sind; z. B. Conferva caespitosa (t. 56. f. II.), Conferva bullosa (t. 56. f. 10.).

2I) verwebt (contexta): wenn sehr viele haaroder fadenförmige, aus Einer Wurzel hervorgetriebene Wedel sich in Gestalt eines Rasens ausbreiten und in verschieden€n Winkeln sich durchkreuzen und berülren; z. B. Conferva bullosa (t. 56. f. 10.).

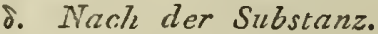

22) krautartig (herbacea): der mehr oder weniger Hleischig, von der Substanz krautartiger Gewächse ist; z. B. die mehrsten Arten der Gattungen Conferva.

23) hautartig (membranacea): wenn er dünn, zähe und wenig durchscheinend ist; z. B. die mehrsten Arten der Gattung Ulva. 
T E R II I N

24) cartilaginea: dura, tenax ac simul diaphana apparens; exemplo est Fucus cartilagineus.

25) gelatinoso - cartilaginea: inter praecedentem (No. 24.) et sequentem (No. 26.) tenens medium; sic in omnibus generum Rivulariae et Batrachospermi speciebus apparet.

26) gelatinosa: mollis elasticus ac diaphanus exstat; gqualis in omnibus generis Tremellae speciebus reperitur.

Singulae partes et capillaris (Nr. 1.) et filiformis (No. 2.) frondis, sit articulata (No.4.), geniculata (No. 5.), nodosa (No.6.) sive continua (No.7.), simplex (No. 33.) vel ramosa (No.14), dicuntur Fila, illae contra frondis tubulosae (No. 3.) Tubuli nominantur. Loco termini Fila et quidem Filamenta dici solet, haec vero minus apta est denominatio, quae istas jam significat partes antheras ferentes.

In fronde articulata, geniculata et nodosa perinde atque iu caulis speciebus ejusdem nominis (\$. 51. No. 61.63 et 6 \%.) distinguuntur $A r$. ticuli, Genicula et Nodi (vid. observ. J.51. post No. 68.). In siccando hae partes multum mutari solent, quam ob causam non in vivido solım, sed in sicco etiam earum statu sunt observan. dae. Articuli, qui in statu vivido sunt teretos, siccando constringuntur, ita, ut tunc vel collapsi, vel corrugati, vel ut plerumque fit compressi, vcl saepe adeo alternatim contracti, ut in Corfer. va diffusa (t. 46. f. 9 b.) venit in conspectum. Genicula, quae siccata plcrumque contracta in. veniuutur, in statu vivido aut pellucila aut obscura videntur, pro utraque earum latitudinis varietate, ex qua modo annularia modo oblonga apparent.
24) knorplig (cartilaginea): der hart, zähe und dabey durchscheinend sich zcigt; z. B. Fucus cartilasineus.

25) gallertartig - knorplig (gelatinoso - cartilaginea): der zwischen dem vorhergehenden (No. 24́.) und dem folgenden (No. 26.) steht; z. B. alle Arten der Gattung Rivularia und Batrachospermum.

26) gallertartig (gelatinosa): der weich, clastisch und durchscheinend ist; z. B. alle Arten der Gattung Tremell $\%$.

Die einzcinen Theile des haarförmigen (No. r.) und fadenfürmigen (No. 2.) Wcdels, er mag num gegliedert (No. 4.), gelenkir (No. 5.), knotir (No. 6.) oder fortlanfend (No. 7.), einfach (No. 13.) oder ästig (No. 14.) seyn, heifsen $F a$ àden (Fila), die des röhrenartigen (No. 3.) hingegen Röhrchen (Tubuli). Statt Fila plegt man zwar aucl Filamenta zu sagen, aber diese Benennung ist nicht so gut, da man damit schon die Theile bezcichnet, welche die Staubbeutel tragen.

Bey dem gegliederten, gelenligen und knotigen WVedel werden auf gleiche Art, wie bey den eben so benannten Stengelarten ( $\$ .51 . N_{0} .61$. 6j. und 64.), Glieder (Articuli), Gelentie (Genicula) und Knoten (Nodi) unterschieden (m. 8. die Aumerkung I. 51. nach No. 65.). Beym Trocknen phegen sich diese Theile sehr zı verandern, wefshalb man sic nicht nur im leben. den, sondern auch im trocknen Zustande beobachten mufs. Die Glieder, welche im lebenden Zustande stielrund (teretes) sind, ziehcu sich bcym Trocknen zusammen, so, dals man sie alsdann zusammengefallen (collapsi) oder zusammengerunzelt (corrugati) oder, wie meistens, zusammengedrückt (compressi), ja oft auch wecliselsweis-zusammengezogen (alternatim contracti), wie bey der Conferva difusa (t. 46. f. 9. b.), sieltt. Die Gelenke, welche mau nach dem Troclinen gewöhnlich zusammengezogen (contracta) fin$\mathrm{T} 2$ 
Color in Algis siccando pariter haud raro inutatus, in utroque statu determinatur secundum 5. 20.

\section{In Filicibus.}

«. Secundum figuram.

1) reniformis: si subrotunda et in basi est excisura vel sinu (\$. 34. N. 16. I7.) praedita, cujus anguli laterales sunt rotundati; ut ostendit $\mathscr{A}$ diantum reniforme (r. 42. f. 2. b.).

2) cordata: subrotunda vel oblonga ( $\$ .66$. observ. post No. 5 ), in apicem excurrens et in basi excisura vel sinu instructa, cujus anguli laterales sunt rotundati; exemplum praebet Oplioglossum reiiculatum (t. 55. f. Io.).

3) ovata: cui oblonga est fignra ( $\$$. 66. observat. post No. 5.), ubi basis arcum describit apice, lateribus sensim concurrentibus formato, majorem; inspiciatur Oplioglossum vulgatum (t. 43. f. I. a.).

4) lanceolata: que oblonga ( $\$$. 66. observat. post Nio. 5.) est, ac cujus diameter longitudinis plus quam triplo illum latitudinis superat; videatur Grammitis elongatae frons sterilis (t. 62. f. 4. a.).

5) lincaris; si oblongae (\$. 66. observ. post No. 5.). muitum elongatae est figurae, arcubus lateralibus non nisi parum curvatis, quibus rectse fere ac parallelae exhibentur linese; ut monstrat Grammitis linearis (t. 62. f. 6.).

6) tricuspidata: apex frondis si duabus excisuris in tres partes est divisus; inspiciatur Pteris tricuspidata (t. 48. f. 5.).

7) daedalea: frondis apex si multum est dilatatus, det, zeigen sich im lebenden Zustande entwe. der durclisclieinend (pellucida) oder un. durchsichtig (obscura), so wie sie, naclı Ver. schiedenheit ihrer Breite, bald ringförmig (annularia), bald länglich (oblonga) erscheinen.

Die Farbe, welche bey den Tangen durch das Trocknen ebenfalls nicht selten verăndert wird, bestimme man in beyden Zuständen nach 5.10.

\section{Bey den Farrnkräutern.}

«. Nach der Gestalt.

I) nierenförmig (reniformis): wenn er rundlich ist und an der Basis einen Ausschnitt oder eine Bucht (\$. 84. No. 16. 17.) hat, deren Seitenwinkel zugerundet sind; z. B. Adiantum reniforme (t. 42. f. 2. b.).

2) herzförmig (cordata): wenn er rundlich oder länglich ( $\$$. 66. die Anmerk. nach No. 5.) ist, in eine Spitze ausläuft und an der Basis einen Ausschnitt oder eine Bucht hat, deren Seitenwinkel zugerundet sind; z. B. Oplioglossum reticulatum (t. 55. f. Io.).

3) eyrund (ovata): wenn er er eine längliche Gestalt ( $\$$. 66. die Anmerk. nach No. 5.) hat, bey welcher die Easis einen grölsern Bogen beschreibt, als die Spitze, die durch ein allmähliges Zusammenlanfen der Seiten gebildet wird; z. B. Ophioglossum vulgatum (t.48.f. r. a.).

4) lanzettförmig (lanceolata): wenn er länglich ( $\$$.66. die Anmerk. nach No. 5.) ist, und der Durch- messer der Länge den der Breite mehr als dreymahl übertrifft; z. B. der unfruchtbare Wedel von Grammitis elongata (t, 62. f. 4. a.).

5) linienförmig (linenris): wern er von läng?icher ( $\$$. 66. die Anmerk. nach No. 5.), stark verlängerter Gestalt ist, und die Bogen der Seiten nur wenig gekrümmt sind, so, dafs sie fast gerade und gleichlaufende Linien Lilden; z. B. Grammitis linearis (t. 62. f. 6.).

6) dreyspitzig (tricuspidata): wenn die Spitze des Wedels durch zwey Ausschnitte in drey Theile zertheilt ist; z. B. Pteris tricuspidata (t. 48. f. 5.).

7) verworren (daedalea): wenn die Spitze des 
incisuris diductus, simulque crispus; e. g. Scolopendrinm officinarmm $\delta$. daedalenm (t. 63. f. Io.).

8) diclıotoma: si frons in duas partes est divisa, quarum utraque iterum bipartitur et sic continue; exemplum exhibet Taenites furcata (t. 51. f. 9.).

9) pinnatifida: frons si ab utroque latere excisuris ad costam mediam non pertinentibus, in plures dividitur partes, costae satis perpendiculariter insistentes; inspiciatur Polypodium vulgare (t. 2. f. 5.).

10) conflnente pinnata: quae inferne est pinnata (No. II.), ad supernum autem versus in pinnatifidam (No. 9.) transit; exemplo est Polypoditum tenzuifolinm (t. 48. f. 2.).

II) pinnata: stipite (\$. 54.) duobus lateribus oppositis foliola ferente, quae omnia uni plano incubant; videantur Bleclunum occidentale (t. 48. f. 3.), Anemia Tiria (t. 26. f. 3. a.).

12) pimato-pinnatifida: ubi foliola pinnatae frondis (No. I1.) sunt pinnatifida (No. 9.); e. g. Woodwardia radicans (t. 50. f. 6.). - Frons bipinnatifida Filld. - .

13) bipinnata s. duplicato-pinnata: ubi stipes (\$. 54.) in duobus sibi oppositis lateribus frondes fert pinnatas (No. I I.); inspiciatur Lspidium fragile (t. 55. f. I5.).

14) tripinnata s. triplicato-pinnata: stipes (\$. 54.) ubi in duobus sibi oppositis lateribus frondes fert bipinnatas (No. 13.); videatur Polypodium effusum (t. 63. f. 14.).

15) quadripinnata s. quadruplicato-pinnata: cujus stipes (\$. 54.) in duobus sibi oppositis lateribus frondes fert tripinnatas (Nr. 14.); exempli loco est Adianıum polypluyllum.

16) digitato-pinnata, si in stipitis ( $\$ .54$.$) apico$ plures ex eodem puncto prodeunt frondes pinnatae
Wedels stark erweitert, durch Finsclınitte zertheilt und dabey kraus ist; z. B. Scolopendrium oficinarum :. daeduleum (t. 63. F. Iо.).

8) gezweytheilt (dichotoma): wenn sich der Wedel in zwey Theile, jeder derselben wieder in zwey und so fort zertheilt; z. B. Taenites furcata (t.5 r. f.9.).

9) fiederspaltig (pinnatifida): wenn der Wedel von beyden Seiten durch Ausschnitte, welche die Mittelrippe nicht völlig erreichen in mehrere Theile abgetheilt ist, die ziemlich senkrecht auf derselben stehen; z. B. Polypodium vulgare (t. 2. f. 5.).

Io) zusammenfliefsend-gefiedert (confluente pinnata): der unten gefiedert (No. II.) ist, nach oben zu aber nach und nach in den fiederspaltigen (No. 9.) übergeht; z. B. Polypodium tenuifolium (t. 48, 1. 2.).

I I) gefiedert (pinnata): wenn der Strunk (\$. 5ł.) an zwey entgegengesetzten Seiten Blätıchen trägt, die alle in einer Fläche liegen; z. B. Blechnum occidentale (t. 48. f. 3.), Anemia liria (t. 26. f. 3. a.).

12) gefiedert-fiederspaltig (pinnato-pinnati$f(a)$ : wenn die Blättchen des gefiederten Wedels (No. II.) fiederspaltig (No. 9.) sind; z. B. IVoodwardia radicans (t. 50. f. 6.). - Frons bipinnatifida Willd. - .

I3) doppelt-gefiedert (bipinnata s. duplicatopinnata): wenn der Strunk ( $(.54$ ) an zwey entgegengesetzten Seiten gefiederte Wedel (No. I I.) trägt; z. B. Aspidium fragile (t. 55. f. 15.).

14) dreyfach-gefiedert (tripinnata s. triplicato-pimata): wenn der Strunk (\$. 54́.) an z.wey entgegengesetzten Seiten doppelt-gefiederte Wedel (No. I3.) trägt; z. B. Polypodium effusum (t. 63. f. I4.).

15) vierfach-gefiedert quadripinnala s. quadruplicato-pinnata): wenn der Strunk (\$.5千.) an zwey entgegengesetzten Seiten dreyfach-gefiederte Wedel (No. Íf) trïgt; z. B. Adiantum Polyplıyllunn.

16) gefingert-gefiedert (rligituto-pinnata): wenn an der Spize des Strunkes ( $\$$. 5ł.) mchre gefie- 
(No. I1.), quas uni plano incubant; videatur Adientum radiatum (t. 46. f. II.).

17) pedato-pinnata: ubi stipes (6.54) in duos patentissimos ramos diducitur, et frondes pinnatae (No.Ir.) in apice, sicut in interiori cujusvis rami latere, sunt collocatae; e. g. Adiantum pedatum (t. 49. f. 6.).

18) pinnato-binata: foliola frondis pinnatae (No. Ir.) ubi bina deinceps in eorum basi sunt inter se conjuncta; cui exemplum adfert frons fructificans Acrostici trifoliati (t. 53. f. 2.).

19) pinnato-ternata: foliola frondis pinnatae (No. I 1.) si terna deinceps in eorum basi inter se conjuncta sunt; excmplo est Acrostici trifoliati frons sterilis (t. 53. f. 1.).

\section{ค. Secundum relationem ad alias partes.}

20) sterilis: haud ferens fructus; videantur Acrosticum trifoliatm (t. 53. f. I.), Grammitis elongata (t. 62. f. 4. a.).

21) fructificans: quae ad fructus ferendum est destinata vel ad id idonea; e. g. Acrosticum trifoliatum (t. 53. f. 2.), Grammitis elongata (t. 62. f. 4. b.).

22) radicans: deflexa ad terram, ubi ex ejus apice radices agit; inspiciatur Asplenium rlıizoplugllun (t. 49. f. 8.).

Frondis species, in Filicibus praeterea occurrentes, reliquae omnes possunt determinari ex iis, quae in foliis ( $(5.83$.$) sunt distinctae.$

\section{In $\mathrm{P}$ a $\mathrm{lm}$ is.}

I) Aabelliformis: si in stipitis (\$.54.) apice aut plura longa orbicula:im fere dilatata exstant foliola, quo exhibetur frons; aut haec si orbiculat fere, radiatim

\section{T E R MI I N O L O C I I.}

derte Wedel (No. Ir.) aus Einem Punkte hervorgehen und in Einer Fläche liegen; z. B. Adiantum radiatum (t. 46. f. II.).

17) gefulst-gefiedert (pedato-pinnata): wena der Strunk ( $(5.5$.) in zwey weit von einander abstehende Äste getheilt ist, und an der Spitze, so wie an der innern Seite eines jeden Astes gefiederte Wedel (No. Ir.) stehen; z. B. Adiantum pedaltum (t. 49. f. 6.).

18) gefiedert - zweyzählig (pinnato-binata): wenn die Blättchen des gefiederten Wedels (No. II.) zu zwey und zwey an ihrer Basis verbunden sind; z. B. der fruchtbare Wedel von Acrosticum trifoliatiun (t. 53. f. 2.).

19) gefiedert-dreyzählig (pinnato ternata): wenn die Blättchen des gefiederten Wedels (No. II.) zu drey und drey an ihrer Basis verbunden sind; z. E. der unfruchtbare Wedel von Acrosticism trifoliatum (t. 53. f. I.).

в. Nach den Ve Thültnifs zu andern Theilen.

20) unfruchtbar (sterilis): der keine Früchte bringt; z. B. Acrosticun trifoliatum (t. 53. f. 2.), Grantmitis elongata (t. 62. f. 4. a.).

21) fruchtbar (fructificans): der dazu bestimmt oder fähig ist, Früchte zu tragen; z. B. Acrosticnm trifoliatmm (t. 53. f. 2.), Gramnitis elongata (t. 62. f. 4 . b.).

22) wurzelnd (radicans): wenn er sich zur Erde niederbengt und in dieselbe aus seiner Spitze Wurzeln schlägt; z. B. Asplenium rluizopluyllum (t. 49. f. 8.).

Alle übrigen, bey den Fannkrüutern noch vorkommenden Arten des Wedels lassen sich nach denen, die bey den Blättern ( 5.85 .) unterschieden sind, bestimmen.

\section{Bey den Palmen.}

1) făchelförmig (Aabelliformis): wenn an der Spitze des Strunkes ( $\$ .54$ ) entweder melirere lange Bläıttchen fast kreisförmig ausgebreitet stehen, und so 
TE I II 1 N O L O G I A.

plicata atque incisa videtur; e. g. Borassus fabelliformis, Cluamaerops lumilis (t. Ir. f. 3.), Coryplta rosundifolia (t. II. f. I. b.).

2) peltata: si stipitis ( 6.54 ) apex cum inferiori pagina frondis plus minuste orbiculatae est conjünctus, atque ubi hujus incisurae non altius descendunt, quam ut circa stipitis apicem frons resistat indivisa; exemplum praebet Coryplia rotundifolia (t. II. f. I. b.).

3) pinnata: vid. C. No. II.; exemplum exhibet Cicas circinalis (t. Ir. f. 2.).

4) bipinnata s. duplicato-pinnata: vid.C. No. 13.; e. g. Caryota urens.

\section{83.}

Folia constituunt Phyllinum (\$.80.) ubi semper cormus ( $($.48.) potest distingui, nunquam autem nec propagines, nec semina nec fructus inveniuntur, nisi si flores ferunt, quod fit in generibus Phylluntlii, Xylophyllae, Rusci et Polycardiae. Illa in Jungermanniis, AIuscis, Stachyopteridibus ac, Palmis exceptis, phanerogamis omnibus inveniuntur. Quo ex omnibus eorum diversitatibus satus definiantur, illa exposituri sumus hic eo ordine, qui in vegetabilium descriptione est observandus, atque igitur secundum locum, vibi enascuntur, eorum relationem ad alia corpora, dispositionem, affixionem, directionem, substantiam, interiorem structuram, durationem ac denique figuram. Postrema hac ratione id est respiciendum, utrum planum an corpus offerant, et si illud est, utrum simplicia an composita reperiantur folia, quorum singulum quodque est examinandum secundum ejus circumscriptionem, basin, apicem, marginem, nec non secundum utramque ejus paginam.
A. Secundum locum, ubi enascuntur vel reperiuntur.

r) seminale: quod ante ejus evolutionem alterum
T E R M I N O L L O C 1 I E.

den Wedel bilden; oder wenn derselbe fast kreisrund, strahliggefaltet und eingeschnitten ist; z. B. Borassus fabelliformis, Chamaerops lumilis (t. II. f. 3.), Coryplua rotundifolia (t. II. f. I. b.).

2) schildförmig (peltata): wenn die Spitze des Strunkes (\$. 5千.) mit der Unterseite des mellr oder weniger kreisförmigen Wedels verbunden ist, und die Einschnitte des letztern nur so tief sind, dafs noch ringsum die Spitze des Strunkes der Wedel unzertheilt bleibt; z. B. Coryplaa rotundifolia (t. I1. f. I. b.).

3) gefiedert (pinnata): m. s. C. No. Ir.; z. B. Cicas circinalis (t. II. f. 2.).

4) doppelt-gefiedert (lipinnata s. duplicatopinnata): m. s. C. No. 13.; z. B. Caryota urens.

6. 83.

Die Blätter (Folia) machen eine Belaubung (\$. 80.) aus, bey der jederzeit der Stiel (\$. $\$$ ४ 3 .) unterschieden werden kann, niemahls aber Fortsïtze, Samen oder Frïchte gefunden werden, es sey denn, dafs sie Blumen tragen, wie bey den Gattungen Pluyllanthus, Xylophijlln, Ruscus und Polycordia. Sie finden sich bey den Jungermannien, den Moosen, den Ährenfarrn und bey allen Phanerogamen, wenn man die Palmen ausnimmt. Um sie nach allen ihren Verschiedenheiten näher zu bestimmen, wollen wir sie hier in der Ordnung aufführen, wie sie bey der Besclireibung der Gewächse betrachtet werden müssen, als nach dem Orte, wo sie entspringen, nach ihrem Verhältnifs zu andern Gegenständen, nach der Stellung der Anheftung, der Richtung, der Substanz, der innern Structur, der Dauer und der Gestalt. In letztrer Rücksicht mufs man darauf achten, ob sie a!s Fläche oder als Körper vorkommen, und ob sie, als Fläche betrachtet, einfach oder zusammengeseizt sich zeigen, wo dann wieder jedes einzelne Blatt nach dem Umrisse, der Basis, der Spitze, dem Rande und den beyden Flăchen betrachtet werden mufs.

A. Nach dem Orte, wo sie entspringen oder sich befinden.

I) Samenblatt (seminale): das vor seiner Ent- 
constituit seminis dimidium. Plerumque figura prae caeteris foliis insignitur, et, quoniam prius quam haec decidit, in paucis tantum vegetabilibus videtur; exemplo sunt bina folia inferiora Polygoni Fagopyri(ı.6o.f.4.a.).

2) radicale: excrescens e radice, vel e caudice intermedio cormoideo ( $(.46$. No. I.); inspiciantur Ajnga reptans (t. 25. f. 3. b.), Gnaphalirum dioicum (r. 62. f. 16. a.), Pinguicula vulgaris (1. 6r. f. 6. a.), Cyclamen europaeum-(t. 8. f. 2. c.).

3) cauliunem: cauli ( $(5.5 \mathrm{I}$ ) insistens; exempli loco sunt Ajuga reptans (t. 25. f. 3. c.), Silene nutans (t. 13. f. 5. b.).

4) culmeum: in culmo ( $\$ .52$.$) apparens; videan-$ tur Rottbellia incurvata (t. 25. f. I. a.), Carex Drymeja (t. 4r. f. 5. a.).

5) rameum: quodvis folium in ramis ( 6.58 .) versans; e. g. Thymus Serpillum (t. I3. א. 7. b.).

6) alare: alae ( $\$ .58$. observat.) adstans; exemplum praebet Rhinanthus Crista galli (t. 22. f. 3. a.).

7) Alorale: prope flores occurrens; exemplum exhibent Ajuga reptans (t. 25. f. 3. d.), Silene untans (t. 13. f. 5. c.).

B. Secundum relationcm ad alia corpora.

8) scanclens: folium - plerumque compositum cujus petiolus alind corpus circumrolvit; e. g. Clematis Viticella, Clematis Vitalba, Clematis glauca (t. 6r. f. 4.).

9) radicans: vid. \$. 82. C. No. 22 . Frondi magis est proprium quam foliis.

I0) demersum: quod in vegetabilibus aquaticis subter aquae superficiem invenitur; exemplo est Ranunctlus polypliyllus (t. 20. f. 3. a.). wicklung die eine Hälfte des Samens ausmachte. Es zeichnet sich gewöhnlich durch seine Gestalt von den übrigen Blättern aus, und, da es früher als dicse abfällt, so sieht man es nur bey wenigen Gewäclısen; z. B. die beyden untern Blätter bey Polygonum Fagopyrun (t. 6o. f. 4. a.).

2) wurzelständig (radicale): wenn es aus der Wurzel oder aus dem stielartigen Mittelstocke ( $\$ .46$. No. I.) entspringt; 2. B. Ajuga reptans (t. 25. f. 3. b.), Gnaphalium dioicum (1. 62. f. 16. a.), Pinguicula vulgaris (t. 6r. f. 6. a.), Ciclanen europaeum (t. 8. f. 2. c.).

3) stengelständig (caulinum): das am Stengel (§. 5r.) steht; z. B. Linga reptans (t. 25. f. 3. c.), Silene nutans (1. 33. 5. 5. b).

4) halmständig (culmeum): das am Halme (\$.52.) sich zeigt; z. B. Rottbellic incurvata (t. 25. f. I. a.), Carex Drymeja (t. 41. f. 5. a.).

5) astständig (rameum): jedes Blatt, das an den Ästen (6. 58.) sich befindet; z. B. Thymus Serpillum (t. 13. f. 7. b.).

6) astachselständig (alare): das an der Astachsel ( $($. 53. die Anmerk.) steht; z. B. Rluinanthus Crista galli (t. 22. f. 3. a.).

7) blüthenständig (Alorale): das nahe bey den Blumen sich befindet; z. B. Ajuga reptans (t.25.f.3.d.), Silene nuiclus (t. I3. f. 5. c.).

\section{B. Nach dem Verbältnifs zu andern Körpern.}

8) kletternd (scanclens): ein - gewöhnlich zusammengesetztes - Blatt, an welchem sich der Blattstiel um einen andern Körper windet; z. B. Clematis Viticella, Clentatis Vitalba, Clematis glauca (t. 6r. f. 4.).

9) wurzelnd (radicans): m. s. 9. 8r. C. No. 22. Es ist mehr dem Wcdel, als den Blättern eigen.

I0) untergetaucht (demersum): das bey den Wassergewächsen unter der Oberfläcbe des Vassers sich befindet; z. B. Ranunculus polyply.llus (t. 23. f. 3. a.). 


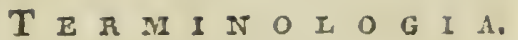

II) natans: quod aquae superficiei innatat; ut in Ranunculo polyplizllo (t. 28. f. 3. b.).

12) ennersum: super aquae superficiem exstans; exemplum praebet Ranunculus polypluzllus (t.28. f.3.c.).

\section{Secundum dispositionem.}

13) alcerna: sicut in ramis $\$ .58$. No. 3.; exemplum praebet Erigeron uniflorım (t. I. f. fo-43).

If) opposita: ut in ramis 6.58. No. 4.; inspiciantur Rlinanthus Crisia galli (t. 22. f. 3. a.), Thymus Serpillum (t. 13. f. 7. b.), Silene nutans (t. 13. f. 5. b.).

15) terna: ubi tria ejusdem altitudinis caulem circumstant folia; videatur Nerium odorum (t. 22. f. I. b.).

16) quaterna: ubi quatuor folia ita sunt disposita; exemplo est Galium palusire (t. 6o. f. I4. a.). Simili modo occurrunt.

17) quina: e.g. Myrioplıyllum spicatum(t.29.f.3.b.).

18) sena: e. g. Galium Aparine (t. I3. f. 6. a.). Ita numerantes continuunt: septena, octona, novena etc.

I9) verticillata: ubi folia caulem circumstant plura, quorum numerus non semper idem est; inspiciatur Hippuris vulgaris (t. 6ł. f. 15. ค.). Loco ejus dicitur etiam stellata, praecipue, si pro denominatione praecedentium (No. 16., 17. et I8.) communi adhibitur.

20) spircearic: si folia in spirae morem circum caulem sunt disposita; e. g. Pandanus utilis, Pandaruts humilis.

21) disticha: sicut in ramis \$. 58. No. 5.; e. g. Cupressus disticha (t. 59. f. I.).

22) decussata: ubi folia alterna (No. 13.) aut opposita (No. If) cauli seriebus quatuor longitudiralibus ita insistunt, ut deorsum conspecta unam constituant

$$
T E R M I N O \text { I }
$$

J) schwimmend (natans): wenn es auf der Oberfläche des Wassers schwimmt; z. B. Ranuncrulus polypliyllis (t. 28. f. 3. b.).

12) aufgetaucht (entersus): das über der Oberfläche des Wassers sich befindet; z. B. Ranzinculus polypliyllus (t. 28. f. 3. c.).

C. Nach der Stellung.

13) wechselsweisstehende (alterna): wie bey den Ästen §. 58. No. 3.; z. B. diene hier Erigeron uıiforum (t. I. f. $40-43$ ).

14) gegenüberstehende (opposita): wie bey den Ästen 5. 58. No. 4.; z. B. seine man Rluizaizthus Crista ğalli (t. 22. 1. 3. a.), Thzmuzıs Serpillum (t. I3. f. 7. b.), Silene nutans (t. 13. f. 5. b.).

i5) dreyfache (terna): wenn drey Blätter in glei- • cher Höhe rings um den Stengel stehen; z. B. Nerium odorum (t. 22. f. 1. b.).

16) vierfache (quaterna): wenn vier Blätter so ges:ellt sind; z. B. Galium palustre (t. 6o. f. I4́. a.). Auf ähnliche Art giebt es:

I7) fünffache (quinn): z. B. Myriopluyllum spi- : catum (t. 29. f. 3. b.).

13) sechsfache (sena): Galium Aparine (t. I3. f. 6. a.). So zählt man weiter: siebenfache (septenca), achtfache (octona), neunfache (nozena) u. s. wr.

I3) quirlständige (verticillata): wenn mehrere Blïter rings um den Stengel stclien, deren Zahl niclat beständig ist; z. B. Ifippuris vulgaris (t. 6f. f. I5. a.). Man sagt dafür auch sternförmige (stelluta), besonders, wenn man es als allgemeine Renennung der vorhergehenden (No. 16, 17, u. 18.) gebraucht.

20) schraubenständige (spiracaria): Wenn die Blätter nach Art einer Schraube um den Stengel gestellt sird. z. B. Pandanus ruilis, Pandanus humilis.

21) zweyreihige (disticha): wie bey den Ästen 6.58. No.5.; z. B. sehe man Cupressus disticluz (เ.59. f. 1.). 22) kreuzweisstehende (decussatu): wenn die Blïtter wechselsweis-(No. I3.) oder gegenäberstehend (No. If.) in vier Reihen der Länge nach am Stengel sich 
crucem; exemplo sunt Phlox paniculata (t. 52. f. 6.), Euploorbia Lathyris.

23) sparsa: sicut in ramis §. 58. No. 6.; inspiciatur Lithospermum officinale (t. 2I. f. 3.).

2-f) remota: ut in ramis §. 53. No. 7.; videatur Comarum palustre (t. 8. f. 3.)

5) conferta: in modum ramorum $\oint .58$. No. 8.; exempla praebent Eupluoruia Cyparissias, Polytriclutm commune (t. 10. f. I. a.) ac omres Musci.

26) imbricata: si conferta (No. 25.) sunt, et in morem laterum seu imbricum se inter se obtegunt; e. g. Aretia helvetica (t. 18. f. 5. a.), sedim acre (t. 57. f. 7.a.). Adhuc distinguuntur:

a) Lifariam imbricata: si ita sunt disposita, ut juxta caulem duas tantum efficiant series.

b) trifariam imbricata: ubi tres exhibent series; e. g. Apicra viscosa Willd. (t. 6o. f. 7.).

c) quadrifariam imbricata: in quatuor series disposita; videatur Strutiola ciliata Andress (t. 5千. f. 6.). Quoad numerum porro indicantur: guinguefariam inbricata, sexfiriam imbricata etc.

27) fasciculata: plura folia si eodem ex loco enascuntur; e. g. Lycium Larbarum (t. IO. f. 5. b.) Pinus Larix.

23) disparia: Lolia opposita (No. r4.), ubi inter se differunt magnitudine; videantur Atropa Belladonna (t. 58. f. 5.), MTelastoma Majeta.

29) Leteromorplia: opposita (No. 14.) aut terna No. I5.) si figura inter se differunt folia; exemplo sunt Melastoma lieterophylla, Lasiopetalum triphyllum (trb. !ibri inscript. 2. f. If́). befinden, so, dafs wenn man von oben herab sieht, alle Blätter nur ein Kreuz bilden; z. B. Phlox paniculata (t. 52. f. 6.), Euphorlia Lathyris.

23) zerstreute (sparsa): wie bey den Āsten $\oint .59$. No. 6.; z. B. Lithospermum officinale (t. 21. f. 3.).

2f) weitläuftigstehende (remota): wie bey den Ästen 6.58. No. 7.; z. B. Comarum palustre (t. 8. f. 3).

25) dichtstehende (conferta): wie bey den $\ddot{\Lambda}$ sten §. 53. No. 8.; z. B. Eupluorlia Cyparissias, Polytrichum commune (t. ro. f. r. a.) und alle Moose.

26) dachziegelartige (imbricata): wenn sie diclit stehen (No. 25.) und nach Art der Dacliziegel über einander liegen; z. B. Aretia luelvetica (t. 13. f. 5. a.) Sedtum acre (t. 57. f. 7. a.). Man unterscheidet hier noch: a) zweyzeilig-dachziegelartig (bifariam imbricata): wenn sie so gestellt sind, dals sie längs dem Stengel nur zwey Reihen bilden.

b) dreyzeilig - dachziegelartig (trifariam imbricata): wenn sie in drey Reihen stehen; z. B. Apicra viscosa ITilld. (t. 6o. f. 7.).

c) vierzeilig - dachziegelartig (quadrifaricm imbricata): die in vier Peilien gestellt sind; z. B. Strutiola ciliata $A n d r e$ ws (t. 54. f. 6.). Der Zahl nach bestimmt man weiter: fünfzeiligdachziegclartig (quinquefariam imbricata), sechszeilig-dachziegelartig (sexfariam imbricata) u. s. w.

27) büschelständige (fascicnlata): wenn mehrere Blätter aus einer Stelle entspringen; z. B. Lycium barburum (t. 10. f. 5. b.), Pinus Larix.

28) verschiedengeparte (disparia): wenn gegenüberstehende Plätter (No. 14.) ungleich an Grölse sind; z. B. Alropa Bellaclonna (t. 58. f. 5.), Melastoma Majeta.

29) verschiedengestaltete (heteromorpha): wenn gegenüberstehende (No. If.) oder dreyfache Blätter (No. 15.) von ungleicher Gestalt sind; z. B. Melastoma heteropluylla, Lasiopetalum triplyyllum (Titelkupfer 2. f. Í́. 
TE I III I $\mathbb{N}$ O

\section{Secundum affixionem.}

30) petiolatum: si petioli ( $(9.59$.$) beneficio folium$ cauli aut ramis est conjunctum. Distinguuntur:

a) palaceum: si petiolus folii margini est issertus; exempla ferunt Quercuis pednnculata (t. 20. f. 4. d.) Tilia enropaea (t. 32. f. 3. a.), Sida triguetra (t. 18. f. 2. b.).

b) peltatum: si petiolus inferiori folii paginae - plerumque in medio - est insertus; exempla praebent Pelargonium tetragonum (t. I8. f. 3. b.), Hydrocotyle vulgaris (t. 54. f. I2.), Tropaeolum majus (t. 55. f. 14.).

3r) sessile: petiolo destitutum cauli aut ramis conjunctum est; inspiciatur Carlina vnlgaris (t. 2r. f. I.), Lithospermun officinalc (t. 21. f. 3.), Rhinanlhus Crista galli (t. 22. f. 3. a.).

32) solutumn: carnosum, plerumque plus minusve cylindricum, est folium, non sua basi, sed supra erm altero in Fatere, cauli aut ramis leviter tantummodo conjunctum; exempli loco est Sedumu reflexum (t. 59.f. Ir.a.).

33) circunncissum: carnosum crassumque folium, cujus basis quasi in uno tantum puncto, medio plus minusve propinquanti, conjuncta est cauli vel ramis; id quod ostendit Sednome acre (t. 57. f. 7. b. c.).

34) circumnatum: carnosum crassumque folium, cujus basis tota cauli ant ramis est conjuncta, ut plerumque occurrit. Idque duobus praecedentibus (No.32. et 33.) contreriatur; exemplo sunt Sedum album, $S e$ dum villosum, Mescmbrianthemmn aequilaterum (t. Co. f. I1.), Mesembrianthemum lunatum (t. 6o. f. 8.), Cacalia Ficoides (t. 6o. f. 5.), Cacalia repens (t. 59. f. 10.).

35) decurrens: si in altero vel in utroque folii sessilis (No. 3r.) latere infra ejus basin folii substantia ad-

\section{Nach der Anlieftung.}

3o) gestielt (petiolntum): wenn das Blati vermittelst eines Blattstiels (\$. 53.) mit dem Stengel oder den $\Lambda$ sten verbunden ist. Man unterscheidet:

a) randstielig (palaceum): wenn der Blattstiel dem Rande des Blattes eingefïgt ist; z. B. Quercus pedunculata (t. 20. f. 4. d.), Tilia ellropaea (t. 32. f. 3. a.), Sidce triquetra (t. 10 f.f. 2.b.).

b) schildförmig (peltatum): wenn der Blactsticl der Unterseite des Blattes - gewöhnlich in der Mitte - eingefïgt ist; z. B. Pelargonium tem tragonum (t. 18. f. 3. b.), Iyylrocotyle vulgaris (t. 54. f. 12.), Tropacolum majus (t. 55. f. If.).

31) sitzend (sessile): das ohne Biattstiel mit dem Siengel oder den Ästen verbunden ist; z. B. Carlina zizlgaris (t. 21. f. I.), Lithospermum afficinale (t. 2 I. f. 3.), Rhinanthrts Crista galli (t. 22. f. 3. а.).

32) gelüst (solutum): ein fleischiges, gewöhnlich mehr oder weniger walzenförmiges, Blatt, das nicht an seiner Grundfläche, sondern über derselben an ciner Scite nur locker mit dem Stengel oder den Ästen verbunden ist; z. B. Sedum reflexum (t. 59. f. II. a.).

33) ringsumschnitten (circunncissum): ein fleischiges, dickes Blatt, dessen Grundfläche gleichsan nur in einem Punkte, welcher der Mitte mehr oder weniger nahe ist, mit dem Stengel oder den Ästen in Verbinclung steht; z. B. Sedum acre (t. 57. f. 7. b. c.).

34) ringsumwachsen (circunnatnm): ein fleischiges, dickes Blatt, dessen ganze Grundilläche mit dem Stengel oder den Ästen verbunden ist, so wie es gowöhnlich rorkommt. Es ist der Gegensatz ron den beyden vorhergehenden (No. 32. u. 33.); z. B. dienen hier Sedum albnm, Sea'nm villosum, Mesembrianthemnm aequilaterum (t. Go. I. II.), Mesembrianthemnn lnnatum (t. 6o. f. 8.), Cacalia Ficoides (t. 6o. f. 5.), Cacalia repeis (t. 59 . f. ro.).

35) herablaufend (decurrens): wenn sich dio Blatlsubstanz an einer oder an beiden Seiten eines sitzen- 
buc in caule continuatur, atque igitur quasi decurrit; exemplum exhibet Carduus arabicus (t. 18. f. 4.).

36) vaginans: folium sese dilatans in basi, infra Guam continuatur, ac cormum, cui adhaeret, circumcludit tanquam vagina; e. g. folia inferiora Veratri nigri (t. 40. f. 7. a.), et Neoticue repentis (Satyrii repentis I. t. 40. f. 4. a.).

37) equitans: ensiforme (No. 235.) aut lineare (No. 82.) folium, ad basin versus in margine interiori profundissimo arcteçue compresso canali praeditum, quocum, in morem vaginae, caulem aut folii ex adverso superantis ac similiter formati basin complectitur; e. g. Ixia pumila (t. 54. f. 8.), Iris arenaria (tab. libr. inscript. ger. 2. f. 16.).

38) amplexicanle: sessile (No. 31.), plerumque cordaiur (No. IOr.), est folium suo basi caulem e duobus lateribus circumdans; exempli loco est. Uvularia amplexifolia (t. 32. f. 5. a.).

39) coadunatum: foliorum oppositorum (No. I4) petioli si in sua basi tanquam confluant; videatur $\mathrm{Lo}_{\mathrm{O}}$ nicera inericlyinenum (t. 57. f. 3. a.).

40) connatum: folia opposita (N. 14.) ubi ipsa in eorum basi confluunt; inspiciatur silene nutans (t. 13. f. 5. b.).

41) perfoliatrm: nisi folium marginis ope junctum est cauli, sed ab hoc in disco penetratur; exemplum exhibet Bupleurum rotundifolinm (t. I6. .. 4.).

42) connato-perfoliatum: folium perfoliatum (No. 4r.) duobus connatis (No. 40.) formatum; exemplum praebet Lonicera Caprifoliun (t. 57. f. I. a.).

43) distinctum: ubi in folis oppositis (No. 14.) neyue in is ipsis, neque, dummodo petiolata sint, in "orum peliolis, ullıs obscrvatur nexus. Contrariatur den Blattes (No. 3r.) noch unter der Basis desselben am Stengel fortsetzt, und daher gleichsam herabläuft; z. B. Cardutus arabicus (t. I8. f. 4.).

36) scheidenartig (vaginans): ein an der Basis sich erweiterndes Blatt, welches unter derselben sich fortsetzt und den Stiel, an welchem es sich findet, ringsum wie eine Scheide einschliefst; z. B. die untern Blätter bey Veratrum nigrum (t. 40. f. 7. я.) und Neottia re."ens (Satyrim repens L. t. 40. f. 4. a.).

3-) reitend (equitans): ein schwerdt-(No. 235.) oder linienfürmiges Blatt (No. 82.), welches gegen die Dasis am innern Rande eine sehr tiefe, dicht zusammengedrückte Rinne hat und mit dieser nach Art einer Scheide den Stengel oder die Basis des an der entgegengesetzten Seite über ihm stehenden, ähnlich gebildeten Blattes umfalst; z. B. Ixia pumila (t. 54. f. 8.), Iris arenaria (Titelkupfer 2. f. I6.).

38) umfassend (amplexicaule): ein sitzendes (No.3r.), gewöhnlich herzförmiges Blait (No. ror.), welches mit seiner Basis den Stengel an zwey Seiten umgiebt; z. B. Uvalaria amplexifolia (t. 32. f. 5. a.).

39) verbunden (coadnnatum): wenn die Blattstiele gegenüberstehender Blätter (No. If) an ihrer Basis gleichsam zusammenfliefsen; z. B. Lonicera Periclymenum (t. 5\%. f. 3. а.).

40) verwachsen (comnatm): wenn gesenüberstehende Blätter (No. 14.) selbst an ihrer Basis zusaminenfliefsen; z. B. Silene mutans (t. 13. f. 5. b.).

41) durchivachsen (perfoliatnm): wenn das Blatt nicht durch den Rand mit dem Stengel in Verbindung steht, sondern im Mittelfelde ron diesem durchdrun. gen wird; z. D. Dupleurum rotundifolium (t. IG. f. 4.).

42) verwachsen-durchwa chsen (comato-perfoliatum): wenn das durchwachsene Blatt (No. 4r.) aus zwey verwachsenen (No. 40.) gebildet ist; z. B. Lonicera Caprifolinm (t. 57. f. 1. a.).

43) ges ondert (distinctumz): wenn bey gegenüberstehenden Blättern (No. If.) weder an ihnen selbst, noch an ihren Blattstielen, im Falle sie gestielt sind, eine Ver- 
No. 39., 40. et 42.; excmpla ferunt plurima foliis oppositis vegetabilia.

44) adpressum: quod apice ejus sursum diverso, cauli est parallelum; exempli loco est Gnaphalizm dioicum (t. 62. f. 16. b.).

E. Secundum directionem.

45) erectzon: apice sursum verso, linea accedens perpendiculari, ubi, dum caulinum (No. 3.) sit, alia potest esse caulis directio; videantur Ornithogalnm spathaceum (t. 27. f. 4. a.), Convallaria Polygonatnm (t. 61. f. g.).

46) patens: si ita est directum, ut superne cum caule efficit angulum circiter quadraginta quinque graduum; exemplo est Ligustrum vulgare (t. 1g. f. 2. a.).

47) divergens: si cum caule angulum format rectum; e. g. Phlox paniculata (t. 52. f. 6.).

48) divaricatun: quod superne cum caule nngulum obtusum, inferne autem acutum format; ut folia floralia Pllomidis tuberosae (t. 32. f. 7.) et folia inferiora Hyperici perforati (t. 13. f. 2. b.).

49) reflexim: si apice deorsum est directum et cauli fere parallelum; e. g. folia inferiora Agattosmzatis acnuninati (t. 66. ᄃ. I1.).

50) prostratum: folium radicale (No.2.) terram incubans; excmplum praebet Pinguicula vn! garis (t. 61 . f. 6 . a.).

51) incurvatum: quod sursum est curvatum; inspiciatur Mesembrianthemum Innatnm (t. 6o. f. 8.), Iris arenaria (tab. libri inscript. 2. f. 16.).

52) recurvatnin: quod deorsum est curvatum; videatur Aster reflexus Andrews (tab. libr. inscript. ger. 2. f. 13.). bindung $z u$ bemerken ist. Es ist der Gegensatz von No. 39., 40. u. 40. und Beyspiele geben die mehresten Gewāchse mit gegenüberstehenden Blättern.

44) a ngedrückt (adpresszum): das mit der Spitze aufwärtsgekehrt und mit dem Stengel gleichlaufend ist; z. B. Gnaptualiun dioicum (t. 62. f. 16. b.).

E. Nach der Richtung.

45) a ufrecht (erectum): das sich, die Spitze nach oben gekehrt, der senkrechten Linie nähert, wobey der Stengel, wenn es stengelständig (No. 3.) ist, eine andro Richtung haben kann z. B. Ornithogaluin spathacenm (t. 27. f. 4. a.), Convallaria Polygonatum (t. 6r. f. g.).

46) abwärtsstehend (patens): wenn es eine solche Richtung hat, dafs es mit dem Stengel nach oben zu einen Winkel von ungefähr fünf und vierzig Gred bildet; z. B. Lignstrum vnlgare (t. 19. f. 2. a.).

47) ausgebreitet (divergens): wenn es mit dem Stengel einen rechten Winkel bildet; z. B. Phlox paniculata (t. 52. f. 6.).

48) ausgespreitet oder ausgesperrt (divaricatumu): das mit dem Stengel oben einen stumpfen, unten aber einen spitzen Winkel bildet; z. B. die blüthenständigen Blītter der Pĭlonis tuberosa (t. 32. f. 7.) und die untern Blätter des Hypericum perforatum (t. 13. f. 2. b.).

49) zurïckgeschlagen (reflexum): wenn es init der Spitze nach unten gekehrt und mit dem Stengel fast gleichlaufend ist; z. B. die untern Blätter bey $A g a$ tisosnue acnininatunn (t. 66. f. I r.).

50) gestreckt (prostratunt): ein wurzelständiges Blatt (No. 2.), welches auf der Erde liegt; z. B. Finguicula vulgaris (t. 6r. f. 6. a.).

51) einwärtsgekrümmt (incurvatum): wenn es nach oben gekrümmt ist; z. B. Mesembrianthemum lunatnm (t. 6o. f. 8.), Iris arenaria (Titelkupf. 2. f. 16.).

52) zurückgekrümmt (recurvatum): wenn es nach unten gekrünnt ist; z. B. Aster reflexus Andrews (Titelkupfer 2. f. 13.). 
53) dependens: ubi perpendiculari directione apex terram spectat; inspiciantur folia inferiora Cacaliae $\mathrm{cy}^{-}$ lindricae (t. 6o. f. 6.).

5f) sechizdnme: plura folis si in pluribus caulis lateribus proveniunt, omnia vero ad unam plagam vergunt; videantur Convallaria Polygonatum (t. 6I. f. 9.). In Muscis dicitur secundum Mobr et Weber homomallum, secundum Hedwig et Schwägrichen contra heteromallum; e. g. Dicraumu heteromallum (t.6j.f. 8.).

55) vagum: si folia haud ad unam, sed ad omnes plagas, ut plerumque, vertuntur. Praccedenti est oppositum; exempla praebent plurima vegetabilia.

56) adversum: cujus superior pagina caulem versus est directa; e. g. Lactuca virosa (t. 58. f. 7.) et plurima vegetabilia.

57) aversum: cujus margo caulem versus est directus; ut in Lactuca Scariola (t. 58. f. 8.).

58) obliquım: si ita vertitur, ut inferiori parte adrersum (No. 56.) superiori contra aversum (No. 57.) apparet; exemplo est Melalencr styplicloides (1.6o. f. 9.).

Angulus, quem folium vel petiolus cum caulle efficit, Axills nominatur.

F. Secundurn substantiam.

59) izembranaceum: folium planum, tenue, diaphanum et parum tenax; exemplum praestant Leontodon Taraxacum, Louicera Periclymentm et plurima vegetabilia.

60) coriaceun: membranaceo simile, sed aliquanto cst crassius et tenacius; e. g. Citrus Aurantium, Laum rus Campliora.

61) carizostnul : suculente fibrosoque consistens contextu; reperitur in Generibus, quae dicuntur Crassula, Sedum, Sempervivum, Mesembrianthemum et pl. a.
53) herabhangend (dependens): wenn in senkrechter. Richtung die Spitze der Erde zugekehrt ist: z. B. die untern Blătter der Cacalia cylindrica (t. 6o. f.6.).

54) einseitswendig (secundnm): wenn mehrere Blätter an mehreren Seiten des Stengels hervorkommen, sich aber alle nach einer Seite wenden; z. B. Convallarium Polygonainm (t. 6r. f. 9.). Bey den MIoosen heifst es nach Mohr und Weber homomalliom, nach Hedwig und Schwägrichen hingegen heteromallum ; z. B. Dicranum heteromallium (t. 65. f. 8.).

55) allseitswendig (vagum): wenn die Blätter nicht nach einer, sondern nach allen Seiten, wie es gewöhnlich geschieht, sich wenden. Es ist der Gegensatz des vorhergehencien; Bejspiele geben àie meisten $\mathrm{Ge}$ wächse.

56) zugewandt (adversum): das mit der-obery Fläche dem Stengel zugekehrt ist; z. B. Lactuca virosa (:. 58. f. 7.) und die mehresten Gewächse.

57) $a b g e w a n d t$ (aversum): das mit dem Mando dem Stengel zugekehrt ist; z. B. Lactuca Scariola (t. 58. f. 8.).

58) schiefgewandt (obliquum): wenn es so gedrehet ist, dafs es am untern Theile zugewandt (No. 56.), am obern hingegen abgewandt (No. 57.) sich zeigt; z. B. Melaleuca styplueloides (t. 60. f. 9.).

Der Winkel, welchen das Blatt oder der Blattstiel mit dem Stengel macht, wird die Blattachsel (-4xilla) genannt.

F. Nach der Substanz.

59) hautartig (membranaceum): ein flaches, dünnes Blatt, das curchscheinend und wenig zähe ist; z. B. Leontodon Taraxacum, Lonicera Periclymenum und die mehresten Gewächse.

60) lederartig (coriaceum): dem hautartigen ähnlich, aber etwas dicker und zäher; z. B. Citrus $A_{u l-}$ rantium, Laurus Camploora.

61) Heischig (carnosum): wenn es aus einem saftigen, fasrigen Gewebe besteht; z. B. die Gattungen Carssula, Sedun, Sempervivunu, Mescmbriantluenum u. m. a. 


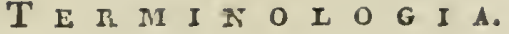

G. Secundum interiorem structuram.

62) fistulosum: folii longi, plus minusve teretis, si totius longitudo cava est, unde imitatur tubulum seu fistulam; exemplum exhibet Allithn sibirict'm (t.4.f.4.b.).

63) bifistulosum: longum est folium, cui tubulosae seu fistulosae cavitates insunt dure parallelae; exemplum praebet Lobelia Dortmanna (t. 53. f. 7. a.).

64) loculosum: folium fistulosum (No. 62.) septis transversis in loculos divisum; videatur Juncus sylvaticuls (t. 64. f. 8. a.).

65) inane: raro contextu velluloso est repletum; e. g. Scirpus lacustris.

66) solidum: neque cavitatibus constructum, neque raro contextu celluloso repletum. Hoc termino non nisi quatuor illis praecedentibus (No.62., 63., 64. et 65.) contrario utantur.

H. Secundum durationem.

67) sempervirens: quod ultra annum viget; exemplo sunt Buxus sempervirens, Hedera Helix, Vaccinium Vitis idaea.

68) annotinum: per unam modo aestatem vigens, e. g. Vaccinium Mjrtillus.

6g) persistens: ita dicitur folium semina!e (No. I.), ubi remanet usque dum flores evolvuntur; e. g. Polygonum Fagopyriun (t. 6o. f. 4. a.).

70) decidunım: folium seminale (No. I.), quod, ante quam flores evolvuntur, decidit; ut in plurimis vegetabilibus.

I. Secundum figuram.

a. Dum planum offerunt.

I. Folia simplicia.

a. Secundum circumscriptionem.

7i) orbiculatzın: circuli figuram si aeqnat, rel quidem ei propius accedit; inspiciantur Hydrocotyle vulgaris (t. 54. f. 12.), IJrola media (1. 55. f. 13.).
G. Nach der innern Structur.

62) röhrig (fistulosum): wenn ein langes, mehr oder weniger stielrundes Blatt seiner ganzen Länge nach hohl ist, und daher Ähnlichkeit mit ciner Rühre hat; z. B. Allium sibiricum (t. 4. f. 4. b.).

63) d oppelröhrig (bifistulosum): cin langes Blatt in welchem sich zwey röhrenförmige, gleichlaufende Höhlungen finden; z. B. Lobelia Dortmanna (t. 53.f. -. a.).

64) fächrig (loculosum): ein röhrichtes Blatt (No. 62.), welches durch Queerscheidewände in Fächer abgetheilt ist; z. B. Junculs sylvaticzls (t. 64. f. 8. a.).

65) markig (inane): welches mit einem lockern, zelligen Gewebe ausgefüllt ist; z. B. Scirpus lacustris.

66) fest (solidumn): welches weder Höhlungen hat, noch mit lockrem zelligem Gewebe ausgefüllt ist. Man bedient sich dieses Ausdruckes nur als Gegensatz der vier vorhcrgehenden (No. 62., 63., 64. v. 65.).

H. Nach der Dauer.

67) immergrün (sempervirens): das länger als ein Jahr dauert; z. B. Buxus sempervirens, Hedera Helix, Vaccinium Vitis idaea.

68) jährig (annotinum): welches nur einen Sommer danert; z. B. Vaccinium Myrtillus.

69) bleibend (persistens): so nennt man das Samenblatt (No. I.), wenn es so lange bleibt, bis dafs sich die Blumen entwickeln; z. B. Polygonum Pagopyrum (t. 6o. f. 4. a.).

70) a b fallend (decidutum): das Samenblatt (No. I.), welches vor dem Entwickeln der Blume abfällt; z. B. die meisten Gewächse.

I. Nach der Gestalt.

a. Als Fläche betrachtet.

r. Einfache Blätter.

$\alpha$. Nach dem Umfange.

71) kreisrund (orbiculatum): wenn es der Figur des Kreises gleicht, oder doch wenigstens dieser schr nahe kommt; z. B. Hydrocotyle vulgaris (1. 54. f. 12.), Pyrola media (t. 55. f. 13.). 
72) snbrotmndum: praecedenti simile, a circuli figura vero magis discedens; e. g. Salix reticulata (t. 50. f. g. b.), Populus tremula (t. 3o. f. 5. b.), Tropaeolum majns (t. 55. f. I4.).

73) ovatum: vid. S. 82. C. No. 3.; exempla referunt Peperomia purpurea (t. 24. f. 6. b.), Neottia repens, Salyrimm repens L. t. 40. f, 4. a.), Phytolacca decandra (t. 3ł. f. 5. c.).

7í) subdimidiato-ovatum: praecedentis formae, eo autem diversum, quod a costa media in duas partes inaequales est divisum; exemplum exhibet Dracontivm pertusium (t. 63. f. 9.).

75) ellipticum: si oblongum ( $\$$. 66 . observ. post No. 5.) est, ubi basis atque apex aequalibus segmentis circuli finiuntur, quorum chordae altera alteri sunt adversae; id quod ostendit Alisma natans (1. 59. f. 2.), Potagometon natans.

76) ovale: praecedenti simile, eo autem ab illo diversum, quod basis et apex non finiuntur arcubus, sed angulis marginum amborum lateralium concursu effectis; id quod monstrat Lonicera Periclymenum (1. 57. f. 3. a.), Porlaliria bifora (t. 66. f. 12.).

77) oblongrm: si oblongum ( 5.66 . observ. post No. 5.) est, et longitudinis diameter plus quam duplo neque verum multo plus quam triplo illum latitudinis superat; exemplum fert Turraea virens (1.23. f. 5. a.), Limosella aqnatica (t. 63. f. 1.).

78) subdinidiato-oblongtun: praecedentis formae, eo autem diversum, quod a costa media duas in partes inaequales dividitur; e. g, Peperomia obliqua (t.23. f.6.).

79) parabolicunn: folium ovatum (No. 73.) in ejus medio aliquantum contracta, ita, ut linea arcuata, qua in utroque latere finitur, tribus composita sit arcubus, quorum alter in basi atque apice extrorsum, alter in me-
72) rundlich (subrotundum): dem vorhergehenden ähnlich, aber mehr von der Kreisform abweichend; z. B. Salix reticulata (t. 50. f. 9. b.), Populns tremula (t. 3o. f. 5. b.), Tropaeolum majus (1. 55. f. I4.).

73) eyrund (ovatum): m. s. S. 82. C. No. 3.; z. B. Peperomia purpurea (t. 24. f. 6. b.), Neottia repens (Satyrium repens L. t. 40. f. 4. a.), Plbytolacca decandra (t. 3f. f. 5. c.).

74) schief-eyrund (subdimidiato-ovatum): von der Gestalt des vorbergelienden, aber dadurch verschieden, dafs es durch die Mittelrippe in zwey ungleiche Theile abgetheilt ist; z. B. Dracontium perinsum (t. 63. f. 9.).

75) elliptisch (ellipticum): wenn es länglich (\$. 66. die Ammerk. nach No. 5.) ist, und die Basis und Spitze von gleichen Kreisabschnitten begränzt werden, die mit ihren Sehnen einander zugekehrt sind; z. P. Alisma natans (1. 5g. f. 2.), Potagoneton natans.

76) oval (ovale): dem vorhergehenden ähnlicl, aber dadurch verschied $\mathrm{n}$, dafs die $\mathrm{B}$ asis und die Spitze nicht von Bogen, sondern von Winkeln begrănzt werden, die durch das Zusammenlaufen der beyden Seitenränder enistelien; z. B. Lonicera Periclymenznn (t. 57. f. 3. a.), Podaliria biflora (t. 66. f. I2.).

77) länglich (oblongumu): wenn es länglich ( $\$ .66$. die Anmeık. nach No.5.) ist, und der Durchmesser der Länge den der Dreite mehr als zweymahl, nicht viel mehr aber als dreymahl übertrifft; z. B. Turraea virens (1. 23. f. 5. a.), Limosella aquatica (t. 63. f. 1.).

- 78) schief-länglich (subdimidiato-oblongum): von der Gestalt des vorhergehenden, aber dadurch verschieden, dafs es durcl die Mittelrippe in zwey ungleiche Theile abgetheilt wird; z. B. Peperomia obliqna (t. 23. f, 6.).

79) parabolisch (parabolicum): ein eyrundes Blatt (No. 73.), welches in der Mitte etwas zusammengezogen ist, so, dals die Bogenlinie, die es an jeder Seite begrănzt, aus drey Logen zusammengesetzt ist, von 
dio introrsum spectet; inspiciatur Eucalyptus longifolia Willi., sed folia ejus inferiora sola (t. 5j. f. 7.).

80) spathulatum: oblongum (No. 77.) basi angustum folium, in utioque latere vel rectis lineis finitum vel arcubus introrsum directis, quibus sensim ad apicem versus dilatatur ibique rotundatur; exempla offerunt replis Portula (t. I3. f. 4.) et Silene nutans, inferiorum ejus foliorum respectu (t. 13. f. 5. a.).

81) länceglainm: vid. 9. 82. C. No. 4.; e. g. Iignstrum vulgare (t. Ig. f. 2. a), Lithospermum officinale (t. 21. f. 3.).

32) lineare: vid. \$. 82. C. No. 5.; exemplum exhibet Thesiun ebracieatum (1. 26. 1. 4. a.), Aster ericoides (t. 40. f. 6.).

83) falcatum: folium angustum, quod finitur per duos sibi eadem directione incubantes arcus inaequales, quorum extremitates in basi et apice coeunt; inspiciatur Xylopliylla Atbuscula (t. 28. f. 5.).

8f) angulatum: ubi e folii peripheria obtusati aut acutati prodeunt anguli (\$. 84. No. I5.), qui lineis rectis vel curvis possunt finiri; e. g. Menispermum canadense (t. 45 f. 3 . a.). Secundum numerum ac diversitatem angulorum et laterum distinguntur:

a) triangulare: si tribus lateribus est inclusum, a, ut eorum unum conficiat besin; videatur Smilax aspera (t. 37. f. I.).

b) cuneiforme: ubi tribus conclusum est lateribus, ita, ut angulorum unus, plerumque apparens ceteribus minor, efficiat basin; exemplo est $A d e$ nanihos cuneata Billard. (t. 53. f. 6.).

c) guadrangulare: quatuor lateribus inclusum. Ubi distingumtur:

I) rlıombeum: lateribus aequalibus, angulis denen sich die an der Basis und an der Spitze nach aufsen, der in der Mitte aber nach innen kehrt; z. B. Encalyptns longifolia Ifilld., aber nur die untern Blätter desselben (t. 55. f. 7.).

Co) spat elförmig (spathalatım): ein längliches (No. .7.), an der Basis schmales Blatt, welches an beyden Seiten entweder durch gerade Linien oder durch einwärtsgekehrte Bogen begränzt ist, sich durch diese allmählig nach dor Spitze hin erweitert uud alsdann zurundet; z. B. Peplis Portula (t. 13. f. 4.) und die untern Blätter der Silene nutans (1. 13. f. 5. a.).

81) lanzettförmig (lanceolatum): m. s. 6. 82. C. No. 4.; z. B. Ligustrum vnlgare (t. 19. f. 2. a.), Litíospermum officinale (t. 21. f. 3.).

82) linienförmig (lineare): m. s. \$. 82. C. No.5.; z. 13. Thesinm ebracteatnm (t. 26. f. 4. a.), Aster ericoicles (t. 40. f. 6.).

83) sich elförmig (falcatum): ein schmales Elatt, welches von zwey ungleichen, in gleicher Richtung liegenden, an der Basis und Spitze mit ibren Enden sicl berihrenden Bogen begränzt wird; z. B. Xylopirylı Arbuscula (t. 23. f. 5.).

Sí) eckig (angnlutum): wenn aus dem Umfange des Blattes stumpfe oder spitzige Winkel ( $(.84$. No. 13.) hervortreten, die durch gerade oder krumme Linien begränzt seyn können; z. D. Menispermum canadénse (t. 4j. f. 3. a.). Nach der Zahl und der Verschiedenheit der Winkel und Seiten unterscheidet man:

a) dreyeckig (triangalare): wenn es ron drey Seiten eirgeschlossen ist, so, dals eine Seite die Easis ausmacht; z. B. Smilax aspera (t. 37. f. r.).

b) beilfürmig (cuneiforme): wenn cs von drey Seiten eingeschlossen ist, so, dafs ein Winkel, der gewöhnlich kleincr, als die übrigen sich zeigt, die Basis ansmacht; z. B. Adenanthos cuncata Billard. (r. 53. f. 6).

c) viereckig (quadrangulare): von vier Seiten cingeschlossen. Hier unterscheidet man:

I) rautenförmig (rhombenm); wenn dic $\mathrm{X}$ 
autem duobus obtusis, duobus acutis, quorum hi, alter basin, alter apicen efficiunt; inspiciatur Hibiscus rlıomúifolius (t. 55. f. 6.).

2) Thomboideum: ubi quatuor latera et anguli inter se omnia sunt aequalia, vel latera baseos angulum conficientia si oppositis sunt majora; exemplum praebent foliola Medicaginis obscurae (t. 67. f. I.).

3) deltoideum: latera quae baseos angulum conficiunt, ubi bina binis oppositis sunt multo minora, unde angulus in basi illum apicis tanto superat; id quod probat Betula alba (t. 5r. f. 4.).

4) trapeziforme: ubi vel duo tantum latera sunt aequalia, duo inaequalia, vel omnia inter se differunt, utique vero angulorum unus semper efficit basin. Quae invenitur forma in foliolis frondis Filicum saepius quam in aliorum vegetabilium foliis; videatur Adiantum trapeziforme (t. 62. f. 7.).

d) quinquangulare: si quinque lateribus est inclusum, aut quinque anguli e peripheria procedunt.

e) septangulare: ubi septem e peripheria procedunt anguli; e. g. Malva rotundifolia (t. 66. f. 3.).

f) multangulare: si pluribus includitur lateribus, quorum numerus haud amplins est constans, quo quidem sensu et angulatım dicere licet.

85) integrum: folium, cui non sunt fissurae, excisurae vel sinus (6. 84. No. 15., 16., 17.) in discum usque intrantes; exempla exhibent Peperomia obliqua (t.23. f.6.), Popuins nigra (t. 32.f.6.b.), Verea crenata (t. 6o. f. 2.), Thirincia hirta (t. 58. f. 6.), Tussilago Petasites (t. 27. f. 2. b.).
TERMI N O L O G I E.

Seiten gleich, zwey Winkel aber stumpf und zwey spitz sind, so, dafs die letztern die Basis und die Spitze ansmachen; z. B. Hiliscris rliombifolius (t. 55. f. 6.).

2) rautenälnlich (rhomboideum): wenn alle vier Seiten und Winkel gleich, oder die den Winkel der Basis bildenden Seiten gröfser sind als die gegenüberstehenten; z. B. die Blättchen der Medicago olscura (1. 67 f. r.).

3) deltaähnlich (deltoideum): wenn die beyden Seiten, welche den Winkel der Basis bilden, viel kleiner sind, als die beyden gegenüberstehenden, wefshalb denn auch der Winkel an der Brsis viel gröfser als der an der Spitze ist; z. B. Betulez alba (t. 5t. f. 4.).

4) trapezenförmig (trapeziforme): wenn entweder nur zwey Seiten gleich und zwey ungleich, oder alle Seiten ungleich sind, wobey aber immer ein Winkel die Basis ausmacht. Man findet diese Form mehr bey den Blättchen des Wedels der Farrnkräuter, als bey den Blättern andrer Gewächse; z. B. Adiantuın trapeziforme (t. 62. f. 7.).

d) fünfeckig (quinquangulare): wenn es von fünf Seiten eingeschlossen ist; oder wenn fünf Winkel oder Ecken aus dem Umfang hervortreten.

e) siebeneckig (septangulare): wenn sieben Winkel oder Ecken aus dem Umfang hervortreten; z. B. Malva rotundifolia (t. 66. f. 3.).

f) vieleckig (multangulare): wenn es von mehreren Seiten eingeschlossen wird und die Zahl derselben nicht mehr beständig ist, wofür man dann aber auch eckig (angulatumu) sagen kann. 35) ganz (integrum)! wenn das Blatt keine bis in das Mittelfeld reichende Spalten, Ausschnitte oder Buchten (6. 84. No. 15., 16., 17.) hat; z. B. diene Peperomia obliqua (t. 23. f. 6.), Populus nigra (t. 32. f. 6. b.), Verea crenata (t. 6o. f. 2.), Thrincia liirta (t. 58. f. 6.), Tussilago Petasites (t. 2\% f. 2. b.). 
TE R MI I N O L O G I A.

85) lobatım: folium subrotundum, excisuris (\$. 34́. INo. 16.), ad dimidium tantummodo intrantibus in plures partes vel lobos, eosque inter se distantes et in utroque latere plerumque lineis arcuatis finitos, est divisum. Quarum prirtium numero distingmuntur:

a) bilobum: una tantum excisura in duas partes divisum; e. g. Passiflora lumata (t. 5I. f. 5.).

b) trilobum: duabus excisuris in tres partes divisum; exemplo est Passiflora suberosa(t. 52. f. 3.).

c) quinquelobum: quatuor excisuris in quinque partes diductum; exempla praebent Acer platanoides (t. 5o. f. 3.), I'elargonium tetragomum (t. 18. f. 3. b.).

d) septemlobum: excisuris sex in septem partes divisum; inspiciatur Henchera americana (t. $4=$. f. 5.). Sic impar loborum numerus progreditur.

87) bicrurium: folium ubi excisura longe ultra dimidium in duas patentissimas divisum est partes in utroque latere rectis et parallelis lineis finitas; exemplum exhibet Passiflora perfoliata (t. 5r. f. 3.).

38) palnututun: folium subrotundum excisuris ultra medium, ad basin usque fere, in quinque, septem vel novem divisum est partes, quae inter se adeo distant, ut quasi in morem digitorum dilatentur; videatur $I^{\prime} a s-$ siflora coerulea (t. 14. f. 1. b.), Jatropha napaenefolia (t. 66. f. 1.).

89) perlatificlum: palmato simile, eo autem ab illo diversum, quod excisurae laterales non adeo intrant, quo quidem et folii pedati (No. 216.) figuram quodanmodo participat; excmplum exhibet Saxifraga geranoides (t. 5ะ. f. 4.).

90) partitum: folium excisuris ad basin usque fere
TE I I I I $\mathbb{N}$ O

157

86) lappig (lobatum): ein rundliches Blatt, das durch Ausschnitte (\$. 84. No. 16.), die nur bis zur Hälfte reichen, in mehrere Theile oder Lappen zertheilt ist, dic von einander abstelien und an beyden Seiten gewöhnlich durch Bogenlinien begränzt sind. Nach der Zall dieser Theile unterscheidet man:

a) zweylappig (bilobum ): wenn es nur durch einen Ausschnitt in zwey Theile zertheilt ist; z. B. Passifura lunata (t. 5r. f. 5.).

b) dreylappig (trilobum): das durch zwey Ausschnitte in drey Theile zertheilt ist; z. B. Pas. siftora suberosa (t. 52. f. 3.).

c) fünflappig (quinquelobumu) : das durcl vier Ausschnitte in fünf Theile abgetheilt ist; z. B. Acer platanoides (t. 50. f. 8.), Pelargonium tetragouun (t. 18. f. 3. b.).

d) siebenlappig (septemlobum): durch sechs Ausschnitte in sieben Theile zertheilt; z. B. Hetlchera anuericana (t. 42. f. 5.). Und so steigt es durch die ungleichen Zahlen weiter.

87) zweyschenklig (bicrurium): wenn ein Blati durch einen Ausschnitt weit über die Hälfte in zwey weit von einander abstehende Theile zertheilt ist, die an beyden Seiten durch gerade und gleichlaufende $\mathrm{Li}$ nien begränzt sind; z. B. Passiflora perfoliata (t. 51.f.3.).

38) handförmig (palnzatum) : ein rundliches Blatt, weiches durch Ausschnitte, die über die Mitte, fast bis zur Basis reichen, in fünf, sieben oder neun Theile zertheilt ist, die so von einander abstelsen, dafs sie gleichsam wie die Finger der Hand sich ausbreiten; z. B. Passiflora coerulea (t. 14. f. 1. b.), Jatroplua napacaefolia (t. 66. f. 1.).

89) fufsspaltig (pedatifidum): den luandförmigen ähnlich, aber dadurch verschieden, dafs die Seitenausschnitte nicht so tief eindringen, wodurch es denn auch mit dem gefulsten Blatte (No. 216.) einige Ähnlichkeit bekommt; z. B. Saxifraga geranoides (t. 52. f. 4.). go) getheilt (partitum): ein durch Ausschnitte $x_{2}$ 
in plures partes divisum. Secundum numerum harum partium distinguuntur:

a) bipartitum: una excisura in duas partes divisum.

- b) tripartitum: duabus excisuris in tres partes divisum; e g. Hibiscus Trionntn (t. 57. f. 6), Coreopsis auriculata (t. 4 4. f. r.).

c) quinquepartitum: quatuor excisuris in quinque partes diductum; exemplo est Hibiscus hereroply.llus (t. 65. f. 6). Ita numerantes continuant usque ad

d) mnltipartilum: ubi folium in multas partes ad basin usque fere est divisum.

91) dichotomum: si folium in duas discedit partes, quarum utraque ita denıo bipartitur, id quod eodem ordine continuatur; exemplo illustrat Ceratoplayllum demersum (t. 5r. f. Ir.).

92) laciniatum: vid. 5. 81. No. 8. b. Liclienum thallo magis quam aliorum vegetabilium foliis est proprium.

93) pinnalifidum: ubi folium incisuris ad costam mediam fere intrantibus, in plures partes sive lacineas est divisum, quae admodum perpendiculariter costae insistunt; exemplum exhibent superiora folia Scabiosae arversis (t. 59. f. 3.).

94) runcinatmm: folitm pinnatifidum (No. 93), cujus autem partes sive lacineae sunt acutae et basi adversap; vileantur Leontodnn Turaxacum (t. 51. f. 8.), Mntisia retrorsa Cav. (1. 5i. f. 13.), Lactuca Sca. riola (t. 53. f. 8 ).

95) squarroso-lociniatum: folium pinnatifidum (No. 93.), cujns autem partes sive laciniae non eodem plano incubant, sed omnes plagas versus diriguntair; cxeil pluin praebet Cardunts arabicus (t. 18. f. 4. b.).

96) panduraeforme: foltum oblongum, medio in
TE R MI I N O L O O G I A.

fast bis auf die Basis in melirere Theile zertheiltes Blatt. Nach der Zahl dieser Theile unterscheidet man:

a) zweytheilig (bipartitum): wenn es durch einen Ausschnitt in zwey Theile zertheilt ist.

b) dreytheilig (iripartitum): wenn es durch zwey Ausschnitte in drey Theile abgetheilt ist; $z$. B. Hibiscus Trionum (t. 57. f. 6.), Coreopsis auriculata (t. 4 4. f. I.).

c) fünftheilig (quinqueparlitumu): durch vier Ausschnitte in fünf Theile zertheilt;-z. B. Hibiscus heterophyllius (t. 66. f. 6.). So zählt man fort, bis:

d) vieltheilig (multipartitum): wenn es in viele Theile fast bis auf die $\mathrm{B}$ asis zertheilt ist.

91) gezweytheilt (dichotomum): wenn sich ein Blatt in zwey Theile zertheilt, jeder dieser Theile wieder in zwey und so weiter fort in dieser Ordnung; $z$. B. Ceratopluyllum demersum (t. 5r. f. I I.).

92) gezipfelt (laciniatum): m. s. S. 8r. No. 8. b. Es ist melır dem Laube der Flechten, als den Blättern archrer Gewächse eigen.

93) fiederspaltig (pinnatifdum): wenn das Blatt durch Ausschnitte, die fast bis auf die Mintelrippe gehan, in mehrere Theile oder Zipfel abgetheilt ist, die ziemlich senkrecht auf derselben stehen; z. B. die obern Blätter der Scabiosa arvensis (t. 59. f. 3.).

94) schrotsāgenartig (runcinalum): ein fiederspaliges Blatt (No.93), dessen Theile oder Zipfel aber spitzig und nach der Basis hin gerichtet sind; z. B. Leontodon Taraxacum (t. 51. f. 3.), Mnitisia retrorsa Cax. (t 5i. f. 13.), Lactuca Scariola (t. 53. f. 8).

9.5) sparrig-gezipfelt (squarroso-laciniatum): ein fiederspaitiges Blatt (No. 93.), dessen Theile oder Z p fel abur nicht in einer Ebene liegen, sondern nach allen hichungen hinstehen; z. B. Cardutus arabicus (t. 18. f. f. b) ).

96) geigenförmiğ (panduraeforme): ein läng- 
utroque latere excisuram ostendit arcuatam vel sinum (\$.84. No. 17.); e. g. Euphorbia cyathopliora (t.34.f.3.).

97) sinuatum: folium oblongum, in utroque latere excisuris arcuatis, sive talibus, quorum angulus introccdens rotundalur, in plures partes seu lacinias divisum; exemplum praebet Qnercus pedunculata (t. 20. f. 4. d.).

98) lyratum: folium pinnatifidum (No. 93.) aut sinuatum (No.97.); cujus extrema quidem lacinia est maxima. Atque igitur distinguuntur:

a) pinnatifido-lyratum: e. g. folia caulina inferiora Valerianae dioicae (t. 60. f. 10.).

b) sinuato-lyrato: e. g. Zacintla verrucosa (t. 51. f. 7.).

\section{ß. Secundum basin.}

99) Iunatum: folium potius latum quam longum, qund finitur duobus inaequalibus, eadem directione sibi incubantibus arcubus, quorum extremitates utroque latere coeuntibus, ila, nt basis sinum, apex arcum prominemtem tfficiat. Invenitur quidem non nisi in foliolis frondis Filicum; exemplum praebet Adiantum lumulatum (t. 59. f. 7 ).

100) reniforme: folium subrotundum in basi habens excisuram vel sinum ( 9.84 . No. 16. et 17.$)$, cujus anguli laterales sunt rotundat; exemplum exhibet $A s a-$ rum europaenm (t. 42. f. 8. a.), Cyclanen europacum (t. 8. f. 2. c.).

101) cordatum: folium subrotundum vel oblongum, in apice excurrens, basi instructum excisura vel sinu, cujus anguli laterales sunt rotundati; e. g. Silla iriquetra (t. 13. f 2. b.), Stachy's syluatica (t. 19. f. f. a.), Unul.ria anıplexifolia (t. 3ิ. f. 5. a.), Sycios anguíata (r. 3f́. f. 1. a.).

102) subdinidiuto-cordatun: praecedenti simile, liches Blatt, welches in der Mitte an beyden Seiten einen bogenfürmigen Ausschnitt oder eine Bucht ( $९$. 84. No. I7.) hat; z. B. Eut leorlia cratlophlıora (t. 34. f. 3.).

97) gebuchtet ( $\operatorname{sinuatum):~ein~längliches~Platt,~}$ welches an beyden Sciten durch Bogenförmige Ansschnit. te, oder solche, deren einwïrtsgchenter Winkel sich zurundet, in mehrere Theile oder Zipfel abgetleilt ist; z. B. Quercus peumuculata (t. 20. f. 4. d.).

98) leyerförmig (lyratum): ein fiederspaltiges (No. 93) oder gebuchtetes Blatt (No. 97.), dessen äusscrster Zipfel aber sebr grols ist. Man unterscheidet daher auch:

a) fiederspaltig-leyerförmig (pinnatificlol)ratum): z. B. die untern stengelständigen Blïtter der Valeriana dioica (t. 6o. f. 10.) und

b) gebuchtet - leyerförmig (sinuato-lyratum ): z. B. Zacintlu veriucosa (t. 5t. f. 7.).

\section{ß. Nach der Basis.}

99) mondfürmig (lunatum): ein mehr breites als langes Blatt, welches von zwey ungleichen, in gleicher Riclutung liegenden, an beyden Seiten mit ibren Enden sich berührenden Bogen begränzt wird, so, dal's die Basis eine Bucht, die Spitze ein hervortretender Bogen ist. Man findet es wohl nur bey den Blättchen des Wedels der Farrnkräuter; z. B. Adiantum lunulatum (t. 5y. f. 7.).

roo) nierenförmig (reniforme): ein rundliches Blatt, welches an der Basis einen Ausschnitt oder eine Bucht (\$. 84 No. 16. u. 17.) hat, dessen Seitenwinkel zugerundet sind; z. B. Asarum europaeum (เ. f2. f. 8. a.), Cyclanen europaeun (t. 8. f 2. c.).

IOI) herzförmig (cordatum): ein rundliches oder längliches Blatt, welches in eine Spize aus!äuft, und an der Basis einen Ausschnitt oder eine Bucht hat, deren Seitenwinkel zugerundet sind; z. B. Sida trique'ra (t. 18. f. 2. b.), Stachys sylvalica (t. Ig f. 4 в.), Uvnlaria antexifolia (t. 32. f. 5. a.), Sycios angulata (t. 34. f. 1. ฉ.).

I(2) schief - herzförmig (subdimidiato-corda- 
eo vero ab illo diversum, quod costa media in duas divisum est partes inaequales; exempla praebent Tilia europaea (โ. 32. f. 3. a.), Begonia actminata (t. 60. 1. 1.), Ficns stipulacea (t. 12. f. 3.)

103) lanceatun: folium plus minusve lineare (No. 82.) basi vel truncatum vel cordatum. Quae quidem figura non tam in foliis, quam in pinnis aut foliolis frondis Filicum occurrere videtur; exemplo sunt Pteris spiculata (t. 6千. f. 6.), Pteris atropurpurea.

101) spiculatzin: folium cordatum (No. IOr.), cui. vero anguli sinus laterales sunt acutati; inspiciantur Salvia glutiuosa (t. 64. f. 5.), Polygonum Convolvulus (t. 12. f. 5.).

105) sagittatum: folium oblongum, cujus basis ostendit excisuram acutatis angulis lateralibus, qui duos efficiunt lobos vel lacinias (\$. 8千. No. 18. 19.) deorsum spectantes; exempla praebent Sagittaria sagittifolia (t. 36. f. g. b.), Convolvulus arvensis (t. 12. f. I. b.).

106) hastatum: praecedenti simile, lobi autem in basi sunt patentissimi, ita, ut costae mediae perpendiculariter insistant; e. g. Cacralic sucveolerus (t. 53. f. 4.), numex Acetosella (t. 19. f. 3. a.).

107) anriculatum: si folio in utroque latere baseos est lobus, qui ratione magnitudinis folii ipsius habita, parvus nodo invenitur; exemplum fert Crambe hispanica (t. 64. f. ro.), aeque ac foliola seu pinnae Blechni anstralis (1. 62. f. 15.). Praecedenti admodum est affine ac saepe non nisi eo diversum, quod baseos lobi sunt minores minusque acuti, vel costae mediae haud perpendiculariter iissistunt.

103) ptcrygoidcum: folium oblongum, quod non media basi, sed altero ejus latere cauli adnectitur. In $(u m)$ : dem vorhergehenden ähnlich, aber dadurch verschieden, dafs es durch die Mittelrippe in zwey ungleiche Theile abgetheilt ist; z. B. Tilia europaea (t. 32. f. 3. a.), Begonia acuminata (t. 6o. f. I.), Ficus stipulacea (1. 12. f. 3.).

103) speerfürmig (lanceatum): ein mehr oder weniger linienförmiges Blatt (No. 82.), welches an der Basis entweder abgestutzt oder herzförmig ist. Diese , Gestalt scheint sich nicht sowohl bey den Biäitern, als vielmehr bey den Fiedern oder Blättchen des Wedels der Farrnkräuter zu finden; z. B. Pteris spiculata (t. 64. f. 6.), Pteris atropurpurea.

roł́) piekenförmig (spiculatum): ein herzförmiges Blatt (No. 1or.), bey dem aber die Seitenwinkel der Bucht spitzig sind; z. B. Salvia glutinosa (t. 64. f. 5.), Polygonum Convolvulus (t. 12. f. 5.).

105) pfeilförmig (sagittatum): ein längliches Blatt, welches an der Basis einen Ausschnitt mit spitzigen Seitenwinkeln hat, die zwey nach unten gerichtete Lappen oder Zipfel (\$. 34. No. 18. 19.) bilden; z. B. Sagittaria sagittifolia (t. 36. f. 9. b.), Convolvulus arvelusis (t. 12. f. I. b.).

106) spielsförmig (hastatum): dem vorhergehenden ähnlich, aber die Lappen an der Basis sind sehr weit ausgebreitet, so, dafs sie senkrecht auf der Mittelrippe stehen; z. B. Cacalia suaveolens (t. 58. f. 4), Ilum ex sicetosella (t. 19. f. 3. a.).

10-) geohri (atriculatum): wenn das Blatt an der Basis anf jeder Seite einen Lappen hat, der in Riücksicht der Gröfse des Blattes selbst nur klein ist; z. B. Crambe hispanica (t. 6ł. f. 10), so wle auch die Blättchen oder Fiedern des Bleclunum australe (t. 62. f. 15.). Es ist mit dem vorhergehenden sehr verwandt und oft nur dadurch verschieden, dal's die Lappen der Basis kleiner und nicht so spitzig sind̉ oder auch nicht senkrecht auf der Nittelrippe stehen.

108) flïgelartig (pterygoidenm): ein längliches Blatt, welches uicht in der Mitte der Basis, sondern an 
TE $\mathrm{R}$ II I

Mluscis tantum invenitur; e. g. Anictanginm bulbosum Schwägr. (t. 65. f. 10. a.).

109) inaegnale: nbi alteram folii latus basi magis est elongatum; e. g. Ulmus effusa (t. 6r. f. 2. a.) et folia radicalia Betonicae officinalis (t. 55. f. 9.).

I IO) aequale: ubi basis, ut solet, in utrorpue laiere est aequalis; id quod probant plurimorum vegetabilium folia.

$\%$ Secundum ipicem.

III) cciltum: folii apex in angulum desinit acutatum; e. g. Phlomis tuberosa (t. 32. f. ..).

112) acuminatum: ubi margines laterales apicem versus adeo mutant directionem, ut, antequam coeunt, directionem parallelam quasi affectent, unde apex magis procedat. Quod longitudinem apicis procedentis variam refert, distinguitur: brevissime-, breve-, longeac longissime-acuminatum; e. g. Veratrum nigrum (t. 40. f. 7. a.), Turraea virens (t. 23. f. 5. a.), Tilia enropaea (t. 32. f. 3. a.), Populus nigra (t. 32. f. 6. b.), Celtis occidentalis (t. 51. f. 6.), Ficus religiosa (t. 64. f. 7.).

I13) cuspidatum: apex, ubi angulum efficit maxime exiguum, ita, ut setaceus desinat; exempla praebent Boelımeria ramiflora (t. 3I. f. 2. b.), Acer platanoides (t. 50. f. 8.).

IIf) obtusum: apex ubi in angulum desinit rotundatum vel obtusatum; e. g. Ficus stipulacea (t. I2. f. 3.), Hypericum perforatnm (t. 13. f. 12. b.).

II5) cirrhosum: cui in apice est filiformis, simplex aut ramosa elongatio volubilis, quae nominatur cirrhus; inspiciatur Mutisia retrorsa (t. 51. f. 13.), Gloriosa superba.
TE R II I NO IO G I K. 141.

der einen Seite derselben mit dem Stengel verbunden ist. Es findet sich nur bey den Minosen; z. B. bey Anictangium bulbosum Schwägr. (t. 6j. f. ro. a.).

103) ungleich (inacquale): wenn die eine Seite des Blattes an der Easis mehr verlängert ist; z. B. Ulmus effusa (t. 6r. f. 2. a.) und die wurzelstindigen Blätter der Betonica officinalis (t. 55. f. 9.).

n10) gleich (aequale): wern die Basis, wie gewühnlich, an beyden Seiten gleich ist; wie bey den B'ïttern der mehresten Gewächse.

$$
\% \text { Nach der Spitze. }
$$

III) spitzig (ucutumu): wenn die Spitze des Blattes sich in einen spitzigen Winkel endigt; z. B. Phlomis tuberosa (t. 32. f. 7.).

I12) zugespitzt (acuminctum): wenn dic Seitenränder gegen die Spitze ibre Püchtung dergestait verïndern, dals, ehe sie sich berïhren, sie der parallelen Richtung sich gleichsam zu nähcrn streben, wodurch alsdann die Spitze mehr hervortritt. Beziehungsweise unterscheidet man auch nach der verschiedenen Länge der hervortretenden Spıtze: sehr kurz-(brevissime-), kurz-(breve-), lang-(longe-) und sehr lang-z ngespitzt (longissime acuminatum); z. B. Feratrum nigrun (t. 40. f. 7. a.), Turraea virens (t. 23. f. 5. а.), Tilia europaea (t. 32. f. 3. a.), Populus nigra (1. 32. f. 6. b.), Celtis occidentalis (t. 5r. f. 6.), Ficus religiosa (t. 64. f. 7.).

I13) feinspitzig (cuspidatum): wenn die Spitze einen sthr kleinen Winkel macht, so, dafs er borstenförmig sich endigt; z. B. Boeluneria ramiflora (t. 3I. f. 2. b.), Acer platanoides (t. 50. f. 3.).

IIf́) stumpf (obtusum): wenn die Spitze sich in einen zugerundeten oder gestumpften Winkel endigt; z. B. Ficus stipulacea (t. I2. f. 3.), Hypericinu perforatum (t. 13 f. 2. b).

II5) wickelrankig (cirrhosum): wenn es an der Spitze eine fadenförmige, einfache oder äsıge, sich wındende Verlängerung hat, die man W:ckelranke nennt; z. B. Mutisia retrorsa (t. 51. f. 13.j, Gloriosa supcrla. 
$1+2$

T E R R N I I N

II6) spinescals: $u^{1} \mathrm{i}$ apex desinit in prominentiam pungentem, quae nominatur spina; Conclitum aciculare, Irucca filamentosa (t. 64. f. 14.).

I1-) mucronatum: si in folii obtusi apice invenitur aculeus brevis, setaceus, herbaceus; videatur Bupleurum fruticosum (t. 63. f. 6.).

I18) apiculatum: si in Muscis ex apice foliorum nervus excedit et colore viridi, fuscescente vel purpurascente apparet; videatur Gymnostomum minutulum (t. 65. f. II. b.).

I I9) piliferum: praecedenti simile, sed nervus excedens est colore albo. In Muscis tantummodo invenitur, et quidem apparet tum pilo simplici, ut in Grinzmia sudetica (t. 6o. f. 3. a.), tum ramoso, sicut Bryun macrocarpum (t. 6o. f. 12. a. b.) bene monstrat.

120) seliferum: praecedenti simile, sed prominentia piliformis est rigidior; exemplum praẹet Lycopodium clavatum (t. 62. f. 9. a.).

I2I) arachnoideum: Colia si ante explicationem sunt obducta materia viscida tenaci, quae sub explicatione extendifur in fila subtilia, peracta explicatione in foliorum apicibus praecipue observata; inspiciatur Sempervivim arachnoideum (t. 66. f. 8.).

122) rotundaitum: ubi arcus latitudinem folii ipsins contines!s, dorso averso terminat apicem; e. g. Corea alba (t. 63. f. 3.), Peplis Poriula (t. I3. f. 4.).

123) praemorstmz: si apex in lineam transversalem repandam vel deniiformi-f!exuosam desinit; exemplo est Pravoria prueliorsa (t. 52. f. 5.).

I24) truncatnm: si linea transversali recta - quae quidem in costa medis intcrdum efficit angulum obtu-

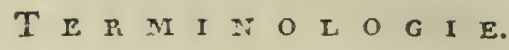

116) dornspitzig (spinescens): wenn sich die Spitze in eine stchende Hervorragung, die man Dorn nennt, endigt; z. B. Conclium aciculare, Fucca flamentosa (t. 64. f. I-\{.).

117) stachelspitzig (mucronatum): wonn sich an der Spitze eines stumpfen Blattes ein borstenförmiger, krautartiger, kurzer Stachel befindet; z. B. Bupleurum fruticosum (t. 63. f. 6.).

II8) spitzentragend (apicnlatum): wenn bey den Moosen aus der Spitze der Blätter der Nerve hervortritt und grün, bräunlich oder röthlich erscheint; $\mathbf{z}$. B. Gymnostomum minutulum (t. 65. f. I1. b.).

IIg) ha artragend (piliferum): dem vorhergehenden äbnlich, aber der hervortretende Nerve ist von weisser Farbe. Es findet sich nur bey den Moosen und zwar zeigt es sich sowohl mit einem einfachon $\mathrm{Haar}$, wie bey Grimmia sudetica (t. 6o. f. 3. a.), als auch mit einem ästigen, wie bey Bryum macrocarpum (t. 60. f. 12, a. b.).

120) borstentragend (setiferum): es ist dem haartragenden ähnlich, aber die haarförnige Hervorragung ist steifer; z. B. Lycopodium clavatum (t. 62. f. 9. a.).

12I) spinnwebig (arachnoideum): wenn die Blätter vor der Entwicklung mit einer schmierigen, zähen Materie bedcckt sind, die sich während der Entwicklung zn fẹisen Fäden zielut, welche nach vollendeter Entwicklung vorzïglich an den Spitzen der Blâtter bemerkt werden; z. B. Sempervizum arachnoicteum (t. 66. f. 8.).

I22) zugerundet (rotundatum): wenn die Spitze durch einen mit dem lï̈cken rach aufsen gekehrten Bogen, von der Breite des Blattes, begränzt wird; z. B. Corea alba (t. 63. f. 3.), Peplis Portula (t. I3. f. 4.).

123) a b gebissen (praemorsum): wenn die Spitze in einer gebogten oder zahnfürmig gebognen Queerlinie sich endigt; z. B. Pavonia praemorsa (t. 52. f. 5.).

r24) abgestutzt (truncatrm): wenn die Spitze durch eine gerade Queerlinie - die jedoch an der Mit- 
sum introrsum vel excisuram - terminatur apex; vidcatur Liriodendron tulipifera (t. 49. f. I.).

125) retusum: folium majus minusve rotundatum (No. 120.), cujus apex sinu levi terminatur; exemplum exhibet Salix reticulata (t. 50. f. g. b.).

126) enzarginatnm: ubi apex parvam labet exisuram et anguli laterales sunt rotundati; inspiciatur Trrrraea virens (t. 23. f. 5. a.), Bruxus bulearica (t.61.f.7.).

127) excisum: ubi apicis excisura est major, quam in praecedente, et anguli laterales sunt acntati vel obtusati; exempla praebent Larrea cmneifolin Cavan. (t. 5I. f. 12.), Amarantlus Blitum (1. 62. f. 3.).

12(i) Iridentatzmm: apex folii si duabus excisuris vel sinibus diducitur in tres dentes; ut in Cortesica cuneifolia (t. 5ł́. f. I3.).

r29) Aabelliforme: vid. §. 82. D. No. I. Haec forma frondi Palmarum potius, quam aliorum vegetabilium foliis est propria.

I30) daedaleum: vid. 6. 82. C. No. 7. Quae forma haud dubie non.nisi in Filicibus fronde deprehenditur.

131) fisstm: folium si incisuris vel fissuris (\$. 8千. No. 14,15 ), ab apice utra mediam usque intrantibus divisum est in lacinias (\$. 84. No. 19.). Quarum numero destinguuntur:

a) bifidum: si una incisura vel fissura folium in duas lacinias s. lobos dividit; e. g. Salisburia adiantoides (t. 66. f. 5.).

b) trifidmm: si duae incisurae vel totidem fissurae folium in tres lacinias dividunt; exemplum ad- telrippe zuweilen einen einwärtsgekelirten stumpfen Winkel oder Ausschnitt bildet - begränzt wird; z. B. Liriodendron tulipifera (t. 4). F. I.).

125) zurückgedrückt (retusum): ein mehr oder weniger zngerundetes Blatt (No. 122) dessen Spitze durch eine flache Bucht ( $\$$ 84. No. 17.) begränzt ist; z. B. Sulix reticulata (t. 50. f. 9. b.).

I:6) ausgerandet (emarginalnun): wenn die Spitze einen kleinen Ausschnitt (\$.3ł. No. I6.) hat und die seitwirtsstehenden Winkel zugerundet sind; z. B. Turraea virens (t. 23. f. 5. a.), Buxus balearica (เ. 61. f. 7.).

127) a usgeschnitten (excisum): wenn die Spitze einen göfseren Ausschnitt hat, als bey dem vorhergehenden, und die seitwärtsstehenden Winkel spitzig oder siumpf sind; z. B. Larrea crneifolia Cavan. (1. 5r. f. 12.), Amaranthus Blitum (t. 62. f. 3).

I28) dreyzähnig (tridentatuin): wenn die Spitze des Blattes durch zwey Ausschnitte oder Bucliten in drey Z̈̈hne zertheilt ist; z. B. Cortesia cuneifolia (t. 54 f. 13.).

129) fächelförmig (Aabelliforme): m. s. \$. 82. D. No. I. Diese Form ist melır dem Wedel der Palmen, als den Blättern andrer Gewïchse eigen.

I30) verworren (daedaleum): m. s. 5. 82. C. No. 7. Man sielıt diese Form wolll nur bey dem Wedel der Farrnkräuter.

I3I) gespalten ( isstum): wenn das Blatt durch Einsclinitte oder Spalten ( $\$ .84$. No. If́., 15.), die von der Spitze bis ïber die Mitte gehen, in Zıpel ( $\$$. 84. No. 19.) zertheilt ist. Der Zahl der Zipfel nach werden untersclieden:

a) zweyspaltig (bifidnm): wenn Ein Einschnitt oder Eine Spalte das Blatt in zwey Zipfel oder Lappen theilt; z. B. Salisburia adiantoides (t. 66. f. 5.).

b) dreyspaltig (trifidum): wenn zwey Einsclinitte oder Spalten das Blatt in drey Zipfel thei- 
ferunt folia inferiora Athanasiae annuae (t. 50. f. I.). Numerantes ita pergunt usque ad

c) multifidum: ubi multi incisurae rel fissurae, quorum numerus non est perpetuus, diducunt folium in lacinias.

$\delta$. Secundum marginem.

132) integerrimum: si folii margo nec incisuras, nec excisuras ostendit, neque sinus (\$.8f.No.If.16.I7.); exempla praebent Peperomia obliqua (t. 23. f. 6.), Passiflora lunata (t. 51. f. 5.), Passiflora coerulea (t. 14. f. I. b.), Quercils pedunculata (t. 20. f. 4. d.), Sagittaria sagittifolia (t. 36. f. 9. b.) et Scabiosae arvensis folia superiora (t. 59. f. 3.).

133) fimbriatum: margo ubi incisuris per multis divisus est in parvas lacinias angustas. Cujusmodi folium nihi quidem nondum occurrit, interea nunc jam licet hoc loco proferre corollam IValdschuidine nyuphoidis (t. 6j. f. 3.) et petala tria inferiora in Tropaeolo.

I34) crenatum: margo ubi excisuris acutatis divisus est in angulos rotundatos, margini perpendiculariter insistentes; e. g. Balsamita vulgaris (t. 6j. f. 5.). Anguli marginis si sunt admocum parvi, ut in Crassuia spattulata (t. 62. f. I.), dicitur crenulatum, sicut contrarie grosse crenatum nominatur, ubi anguli per masni apparent, cujusmodi sunt folia radicalia Betonicae officinalis (t. 55. f. 9.).

135) obinse crenalzun: ita et nominatu $\vec{i}$ folium praecedens, (No. I34.) quo indicetur sequentis (No. 136.) contrarium.

136) acute crenatmm: si in folio crenato (No. I34.) anguli rotundati in apice gerunt angulum parrum acutatum; e. g. folia radicalia Calthae palustris (t. 59. f. I2.). len; z. B. die untern Blätter der Atlanasia annna (t. 53. f. I.). Man zählt nun so weiter fort, bis

c) viclspaltig (multifdum): wenn viele Einschnitte oder Spalten, die der Zahl nach nicht beständig sind, das Blatt in Zipfel zertheilen.

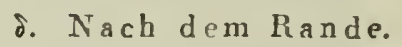

132) ganzrändig (inlę̧errinumn): wenn der Pand des Blattes weder Einsclinitte noch Ausschnitte noch Buchten (\$.84. No. I4. I6. 17.) hat; z. B. dienen Peperomia obliqua (t. 23. f. 6.), Passiflora Inuata (t. 51.f. 5.), Passifora coerulea (t. I4́. f. I. b.), Quercus pedunculata (t. 20. f. 4. d.), Sagittaria sagittifolia (t. 36. f. 9. b.) und die obern Blätter der Scabiosa arvensis (t. 59. f. 3.).

133) gefranzt (fmbriatunu): wenn der Rand durch selır viele Einschnitte in kleine, schmale Zipfel zertheilt ist. Ein dergleichen Blatt kenne ich zwar noch nicht, indessen kann ich hier vor?äufig die Blumenkrone der Waldschmidtia nymplioicles (t. 65. f. 3.) nnd die drey untern Kronenblätter bey Tropaeoluin anführen.

I34) gekerbt (crenatum): wenn der Rand durch spitzige Ausschnitte in zugerundete Winkel zertheilt ist, die auf den Piande senkreclit stehen; z. D. die wurzelständigen Blätter der Balsamita vulgaris (†. 65. f. 5.). Sind die Winkel des Randes sehr klein, wie bey C'rassula spathulata (t. 62. f. I.), so heilst es fein-gekerbt (crenulatum), so wie man es hingegen grobgekerbt (grosse crenatum) nennt, wenn sich die IVinkel sebr grofs zeigen, wie bey den wurzelsıändigen Blättern der Deionica oficinalis (t. 55. f. 9.).

135) stumpf-gekerbt (obtuse crenatumi): so wird auch das vorhergehende Blatt (No. I34.) genannt, wenn man den Gegensatz des folgenden (No. 36.) damit bezeichnen will.

136) spitzig-gekerbt (acute crenatum): wenn bey einem gekerbten Blatte (No. 134) die zugerundeten Winkel an der Spitze einen kleinen spitzigen Winkel tragen; z. B. die wurzelständiggen Blätter der $\mathrm{Cal}$ tha palustris (t. 5g. f. 12.). 
137) serrato-crenatum: ubi excisurac sunt acutatae, anguli rotundati, dum hi non perpendicrtariter insistunt margini, sed ad folii apicem versus spectánt; exemplum praebet Ageratum conyzoides (t. 63. f. 2.).

138) duplicato - crenatum: si anguli folii crenati (No. I3f.) ipsi denuo sunt crenati; exemplo est Verea crenata (t. 6o. א. 2.).

139) serratum: margine excisuris acutatis in angulos acutatos diducto, qui ad folii apicem vertuntur; e. g. Stachys sylvatica (t. 19. f. 4. а.), Populus nigra (t. 32. f. 6. b.). Simili modo, ut in folio crenato (No. 134.), hic quoque distinguuntur serrulatum, e. g. Barosma scrratum (r. 63. f. 8.), et grosse serratum, ut in $H_{n-}$ inulo Lupulo (1. 59. 1. 5.).

I40) retrorso-serratum : ubi marginis excisurae et anguli sunt acutati, quorum li vero ad folii b.ısin spectant; videatur Veronica scutellata (1. 6: f. 8.).

I fi) crenato-serratum: excisurae et anguli marginis si aculati et lineis rectis finiti sunt, ac margini perpendiculariter insistunt; exemplum exhibet Pelargoniun Earringtonii (t. 65. f. 13.).

I f́) duplicato-serratum: ubi anguli folii scrrati (No. 133.) ipsi denuo sunt serrati; inspiciantur Betula alba (t. 51. f. 4.), Ulnums effusa (1.61. f. 2. а.).

143) dentatunz: ubi margo excisuris obtusatis seu rotundatis - paris sinibus - dividitur in angulos acntatos, in folii maigini perpendiculariter insistentes; videantur Thrincic hirta (1. 58. f. 6.), Trapa natans (t. 28. f. 4. b.). Non minus quam in folio crenato (No. I3f.) et hic distinguitur denticulatzm e. g. Cyci.zmen curopaeum (t. 3. f. 2. c.) a termino grosse
13-) sä gुำartig-gekerbt (se-rato-crenatumI). wenn die Ausschnitte spitzig und die Winlel zugerundet sind, letztre aber nicht senkrecht auf dem Rande stehen, sondern nach der Spitze des Rlattes hingerichtet sind; z. B. Ageralum conyzoides (†. 63. f. 2.).

138) doppelt - gekerbt (duplicato - crenatumu): wenn die Winkel eines gekerbten Blattes (No. 13ł..) selbst wieder geherbt sind; z. B. Terea crenata (t. 6o. f. 2.).

139) sägenartig (serratiun): wenn der Rand durch spitzige Ausschnitte in spitzige Winkel zertheilt ist, die nach der Spizze des Blaltes hin gerichtet sind; z. B. Staclu's sylvaticn (t. I9. 1. 4. a.), Populus nigra (t. 32. f. 6. b.). Auf ähnliche Art, wic bey dem gekerbten Blatte (No. 134.), unterscheidet man auch hier feinsägenartig (serrulatum), z. B. Barosma serratum (t. 63. f. 8.), und grob-sägen artis (grosse serratum), wie bey Hunuulus Lupulus (t. 59. f. g.).

I fo) rii ckwärts-sägenartig (retrorso-serratzzm): wenn die Ausschnitte und Winkel des Randes spitzig, letztre aber nach der Basis des Blattes bin gerichtet sind; z. B. Veronica scuiellata (t. 62. f. 8.).

I f́r) gekerbt - sägenartig (crenalo-serratum): wenn die Ausschnitte und IVinkel des Randes spiizig und geradlinig sind, und senkrecht auf dem Rande stelıcn; z. D. Pelargoniun Paringionii (t. 65. f. 13.).

I42) dòppelt-sägenartig (dvplicato-scrrainm): wenn die Winkel eines sägenartigen Blattes (No. I39.) selbst wieder sägenartig sind; z. B. Detula alba (t. jl. f. 4.), Ulinus effusa (t. 6r. 1. 2. а.).

143) gezähnt (dentcutum): wenn der Rand durch gestumpite oder zugerundeie Ausschnitte - kleine Buchten - in spitzige Winkel zertheilt ist, die senkrecht auf dem Rande des Blattes stehen; 2. B. Thrincia livira (t. 53. f. 6.), Trapa natans (t. 28. f. 4. b.). Eben so, wie bey dem gekerbten Blatte (No. I3 f́) unterscheidet man auch licr fein-gezähnt (denticulatunu), z. B. 
dentatum, ut in foliis radicalibus Hieracii paludosi (t. 64. f. 4.).

14㣙 serrato-dentalum: ubi excisurae sunt obtusatae seu rotundatae, anguli acutati. quornm hi ad folii apicem spectant; videatur Silplizum therebinthinaceum (1. 63. f. 15.).

If5) duplicato-dentatum: anguli folii dentati (No. 143.) ubi ipsi denuo sunt dentati; ut bene monstrant Tussilago Petasiles (t. 27. f. 2. b.), Begonia actuminata (t. 6o. f. 1.).

Íf6) erosum: praecedenti (No. I 45 .) simile, atque eo tantum differens, quod majores excisurae angulique minus sunt regulares, exemplum adfert Salvia nilutica (t. 53. f. 6.).

I ́f ) repandum: folii margo ubi ita est excisus, ut anguli ac sinus rotundati inter se alternant sibi succedant; vel si idem finitur arcubus alternatim modo extrantibus modo intrantibus; inspiciatur Ficus religiosa. (t. 6t. f. 7.).

148) unclulatum: ubi ab aequa planitie folii eo discedit margo, quod per vices angulis rotundatis modo adscendit modo descendit; e. g. ATicotiana fruticosa (t. 63. f. 12.).

Ił́9) crispum: margo undulatus folii si denuo angulis parvis rotundatis vel ipsis angulis acutatis modo adscendit modo descendit; ut in Malva crispa (t. 62. f. II.).

150) involutum: ubi folii margo ad paginam superiorem est reflexus, ac plus minusve involutus; videantur Pinguicula wulgaris (t. 6ı. f. 6. a.), Barbula rigida (t. 63. f. 15. a.).

I51) revolutum: ubi folii margo ad paginam inferiorem est reflexus, ac plus minusve est involutus; e. g. Ledum palnstre (tab. Jibri inscript. 1. £. I.), Banlisia marginata (t. 5i. f. If́.).
Cyclamen europaeum (t. 8 f. 2. c.), von grob-gezähnt (grosse dentatum), z. B. die wurzelständigen Blätter des $I I$ eracium paludosum 't. 64́. f. 4.).

I4ł) sägenartig-gezähnt (serrato-dentatum): wenn die Aụss hnitte gestumpft oder zugerundet, die Winkel spitzig, letztre aber nach der Spize des Blattes hin gerichtet sind; z. B. Silplium thurebinthinaceum (t. 63. f. 15.).

145) doppelt - gezähnt (duplicato-dentatum): wenn die Winkel eines gezähnten Blattes (No. I $\mathfrak{q}^{2}$ ) selbst wieder gezähnt sind; z. B. Tussilngo Petasites (1. 27. f. 2. b.), Begonia actminata (1. 60. f. I.).

1 i 6 ) a usgenagt (erosunz): dem vorhergehenden (No. 145 .) ähnlich, und nur dadurch verscbieden, dals die grölsern Ausschnitte und Winkel nicht so regelmäfsig sind; z. B. Salvia nilotica (t. 55 f. 16.).

147) ausgeschweifı (repaudumi): wenn der Pand des Blattes so ausgeschnitten ist, dal's zugerundete Winkel und Buchten mit einander abwechseln; oder wenn derselbe durch wechselsweis aus - und einwärtsgek=hrte Dogen begränzt ist; z. B. Ficus religiosa (1. 6\%. f. 7.).

148) wellenförmig (undulatum): wenn von der geraden Ebene des Plattes der Rand dadurch abweicht, dafs er abwechselnd in zugerundeten Wirkeln auf-und absteigt; z. B. Nicutiana fruticosa (1.63. f. 12.).

149) kraus (crispum): wenn der wellenförmige Rand des Blattes wieder in kleinern zugerundeten oder auch spitzigen Winkeln auf-und absteigt; z. B. Malva crispa (1. 62. f. 11.).

150) eingerollt (involutum): wenn der Rand des Blattes nach der obern Fläche umgebogen und mehr oder weniger eingerollt ist; z. B. Pinguicula vulgaris (t. 6r. f. 6. a.), Burbula rigida (t. 65. f. 15. a).

151) zugerückgerollt (revolubtum): wenn der Rand des Blattes nach der uniern Fläche umgebogen und mehr oder weniger eingerollt ist; z. B. Ledum palustre (Titelkupfer I. f. I,). Bankisia marginata (i. 51. f. 1千.). 
T E R II I N O L O G I A.

I52) cartilagineum: folium si margine tumido, duro, paulo diaphano - plerumque plus minusve Havo est circumductum; exemplo est Ilex nqnifolinm (t. 55. f. 3.).

153) filiferum: ubi folii margo in partes dissolvilur atque in forma filorum plus minusve subtilium remanct pendens; exemplum praebet Incca fllamentosa (t. 64. f. 1千́.).

154) spinosnm: margo ubi eminentiis pungentibus est obsitus; videatur Cardnns arabicns (t. 18. f. 4. 6.), Malpighice Aquifolia (t. 32. f. I. a.).

E. Secundum utramque paginam.

I55) aculeatum: si pagina superior aut inferior, vel utraque, eminentiis pungentrbus est obsita; exemplum exlibet Solannm aculeatissimnm (t. 6.f. f. 2.).

156) concavum: si paginae superiori cavitas inest; inspiciantur IIydrocotyle vulgaris (t. 54. f. 12.), Drosera rotundifolia.

I57) convexnm: ubi pagina inferior cavitate, superior autem fornicatione est instructa; e. g. folia superiora Correae albae (t. 65. f. 3.), aeque ac nonnunquam in Pyrola media (t. 55. f. 13 ).

153) cuculalum: si ad folii basin versus margines laterales superiori paginae ita sunt Hexae, ut cavitatem efficiant; exemplo est Eriospermum lannginosmm (t. 5千. f. 7.).

159) canalicn'atnin: folium longum, angustum, cujus pagina superior in medio toto longitudinali lacunam ostendit; ut Sparganium ramosnm (t. 61. f. 8.).

I6o) plicainm: si folium a planitie aequa eo discedit, quod angulis acutatis per vices sursurn deorsumque flectıtur, unde plicae exseruntur. In hoc possunt distingui :

a) longitudinalicer plicatum: ubi plicae a basi ad apicem versus excurrunt; exemplum exhibet Veratrmm nigrum (t. fo. 1. 7. a.).
$\begin{array}{llllllllllll}T & E & \text { P } & M & I & N & 0 & L & O & G & I & E\end{array}$ 147

I52) knorplig (cartilaginenm): wenn das Blatt mit einem aufgetriebenen, harten, etwas durchscheinenden - gewühnlich mehr oder weniger gelben - Rande eingefafst ist; z. B. Ilex Aqnifolmm (t. 55. f. 3.).

153) fadentragend (filifernm): wenn der Rand des Blattes theilweise sich ablöst und in Gestalt melır oder weniger feiner Fäden hangen bleibt; z. B. Y Y flamentosa (t. 64. f. I4).

15f) dornig (spinosum): wenn der Rand mit stechenden Hervorragungen besetzt ist; z. B. Cardnns arabicns (t. I8. f. 4. b.), Malpigluia Aquifolia (t. 32. f. I. a.).

๕. Nach den beyden Flächen.

I55) stachlig (aculeatum): wenn die obere oder untere Fläche, oder auch beyde, mit stechenden Hervorragungen besetzt sind; z. B. Solannm aculeatissinnm (t. 6千. f. 2.).

156) ausgeböhlt (concavmm): wenn die obere Fläche eine Höhlung hat; z. B. Hydrocoiyle vulgaris (t. 54. f. 12.), Drosera roinndifolia.

157) gewölbt (convexnm): wenn die untere Fläche eine Höhlung, die obere Fläche eine Wölbung hat; z. B. die obern Blätter der Correa alba (t. 63. f 3.), so wie auch zuweilen bey Pyrola media (t. 55. f. I3).

158) kappenfürmig (cnculıtmm): winn ggegen die Basis des Blattes die Seitenränder nach der obern Fläche zu so gebogen sind, daf's sie eine Höhlung bilden; z. B. Eriospermm lanuginosum (t. 54. f. 7.).

159) rinnenformig (canalicula $n \mathrm{~m}$ ): pin langes, schrnales Blatt, welches auf der obern Fläche in der Mitte seiner ganzen Länge nach eine Vertiefung hat; z. B. Sparganium ramosum (t. 61. f. 8.).

160) gefaltet (plicatumu): wenn das Blatt von der geraden Ebene dadurch abweicht, dafs es sich in spitzigen Winkeln abwecliselnd auf - und niederbeugt und dadurch Falten bildet. H er lassen sich unterscheiden:

a) längsfaltig (longitndinaluer plucaimm): wenn die Falten von der Basis rach der Sultzo auslaulen; z. B. Veratrmm nigrmm (t. 4́o. f. 7. d.). 
b) transverse plicatum: plicae si a cosia media ad marginem usque protendunt; videantar folia juniora Carpini Betuli (t. 4t. f. 7.).

c) radiatim plicatum: si folium est subrotundum ac plicae, ubi illud cauli aut petiolo jungitur, ex eodem proceciunt puncto, unde in omnes directiones ad marginem usque dilatantur; exemplum exhibet Alchemilla vulgaris (t. 43. f. r. b.).

16i) undatum: folium si angnlis rotundatis, alternatin sursum deorsumque flexis, a planitie aequa discedit; e. g. Begonia acuminata (1. 6o. f. I.), Ilex aquifolitum (t. 55. f. 3.), Draconitur. fertusum (t. 63. f. g.).

162) bullatum: si inferiori paginae sunt cavitates, sureriori fornicationes vesicaeformes; inspiciantur Primula cortusoides (t. 5f́. ศ. Ir.), Ocymum Basilicum $\delta$. bullatum.

163) lacunosum : ubi superiori paginae sunt cavitates, quae instar fornicationun ex inferiori pagina procedunt. Quae quidem declinatio a planitie recta in foliis minus crebro quam in thallo-(\$. 8I. No. 3. e. f.) videtur occurrere.

164) rugosmm: si in pagina superiore folii planum inter venas aliquantum procedit, ita, ut hae quasi videantur immersae; exempla offerunt Althaea ficifolia (t. 50. f. 4.), Salvia nilotica (t. 55. f. 16.).

165) carinatum: in pagina inferiore folii oblongi, lanceolati vel linearis, si costa media - aut, hac absente, pars folii illum tenens locum - procedit sicut navis carina; inspiciantur Lactnca virosa (1. 53. f. 7.), Lactucn Scariola (t. 58. f. 8.), Aloe carinata (t. 54. f. 2.), Sparganinu ramosum (t. 6r. f. 3.)

166) lineatnn: si vasa subtilia a basi ad apicem densu ac parallela inter se excurrunt atque in superficie b) querfaltig (iransverse plicatum): wenn die Falten von der Mittelrippe nach dem Rande hin sich erstrecken; z. B. die jungen Blätter bey Carpinus Betulus (t. 41. . . 7.).

c) strahlenfaltig (radiatim plicatum): wenn das Blatt rundlich ist, die Falten da, wo es mit dem Stengel oder dem Blattstiele in Verbindung steht, aus einem Punkte hervorgehen und sich nach allen Richtungen bis zum Rande hin verbreiten; z. B. Alchemilla vulgaris (t. 43. f. I. b.).

161) wogicht (zundatum): wenn das Blatt von der geraden Ebene durch abwechselnd sich auf - und niederbeugende, zugerundete Winkel abweicht; z. B. Begoniur acuminata (t. 6o. f. I.) Ilex aquifolium (t. 55. f. 3.), Dracontium pertusum (t. 63. f. 9.).

162) blasicht (bullatum): wenn die untere Fläche Höhlungen, die Oberseite blasenartige Wölbungen hat; z. B. Primnla cortusoides (t. 54. f. II.), Ocymum Basilicum i. bullatum.

r63) grubig (lacunosum): wenn die obere Fläche Höhlingen hat, die als Wölbungen auf der Unterseite herwortreten. Diese Abweichung von der geraden Fuene scheint aber nicht so hiufig bey den Piluttern, als bey dem Laube (\$.8r. No. 8. e. f.) gefunden zu werden.

I6ł) runzlig (rugosum.): wenn auf der obern Fläche die Fläche des Blaties zwischen den Adern etwas hervortritt, so, dafs diese gleichsam eingesenkt zu seyn scheinen; z. B. Alliaea ficifolia (t. 50. f. 4.), Salvia nilutica (1. 5j. f. 16.).

I55) kielförmig (carinatum): wenn bey einem länglici: ב, lanzett - oder linienförmigen Blatte auf der untern Fläche die Mittelrippe - oder, wenn diese fehlt, der an ihrer Stelle vorhandene Theil des Blattes - wie der Kiel eines Schiffes hervortritt; z. B. Lactuca virosa (t. 58. f. 7.), Lactuca Scariola (t. 58. f. 3.), Aloe carinata (t. 5f. f. 2.) Sparganium ramosum (t. 61. f. 8.).

166) gestrichelt (lineatum): wenn feine Gefilfse dicht und parallel von der Basis nach der Spitze laufen 


\section{T E}

inearum modo apparent; exemplum adfert Melaleuca styplueloides (t. 6o. T. 9.).

167) nervosim: ubi vasormm fasciculi crassiores haud deducti in ramos, a basi folii ad apicem usque excurrunt; videantur Peperomia alata (t. 24. f. 4. b.), Neottia repens (t. 4o. f. 4. a.), Veratrum nigrmm (t. 4o. f. 7. a.), Comvallaria Poljgonatmm (t. 6r. f. 9.), Plantago lanceolata (1.63. f. I1. t. 64. f. 12.).

160) requaliter nervosmm: si vasorum fasciculi longitudinales fjusdem crassitudinis sunt omnes; e. g. Plantogo lanceolnta (t. 63. f. I 1. t. 6i. f. r2.).

169) innequaliter nervosmm: ubi ex his vasorum fasciculis nonnulli sunt crassiores; e. g. Convallarice Polygonatum (t. 6r. f. 9.).

170) mninervinm: in quo unum modo vas longitudinale seu nervus medio invenitur, uti est in Muscis. Tunc vel ad apicem usque excurrit, ut in Grmnostomo prorepente (t. 65. f. 7. a.), vel ante evanescit, quam ad illum pervenit; id quod ostendit Necherı filiformis (เ. 65. f. 9. a.).

171) trinervimn: tribus vasorum fasciculis a basi ad apicem usque excurrentibus; e. g. folia primordialia Plantaginis lanccolatae (t. 63. f. II.).

172) quinquenervinm: ribi vasorum fasciculi quinque a basi ad apicem usque procedentes apparent; videantur folia serius provenientia Plantaginis lanceolatae (1. 6í. f. 12 ).

173) septemnervinm: cui septem sunt vasorum fasciculi longitudinales; inspiciatur Plantngo major \% rosea.

17f́) triplinervinn: si supra basin e costa media utroque laiere oritur vasorum fasciculus ad ajicem versus excurrons; exemplum fert Laurus Camplsora (เ. 55. f. 8.).

175) quintuplinervinm: ubi supra basin $€$ costa media utroque latere duo oriuntur vasorum fasciculi ad und auf der Oberflïche sich als Linien zeigen; z. B. Melalenca stypheloides (เ. 6o. f. 9.).

167) nervig (nervosmm): wenn stärkere Gefülsbündel, die sich nicht in $\ddot{A}$ ste zertheilen, von der Basis des Blattes bis zur Spitze auslaufen, z. B. Peperomia alata (t. 24. f. 4. b.), Neottia repens (t. 40. f. 4. a.), Veratrum migrmm (t. 40. f. 7. a.), Convallaria Polygonatnm (t.6r.f. 9.), Plantago lanceolata (t. 63. f. II. t. $6 \frac{1}{4}$. ก. 12.).

168) glei hnervig (aequaliter nervosum): wenn die längslaufenden Gefäfsbündel alle von gleicher Dicke sind; z. B. Plautngo lanccolata (t.63. f. 11.t. 64.f. 12.).

169) ungleichnervig (inaequaliter nervosum): wenn unter diesen Gefäl'sbïndeln einige dicker sind; Convallaria Polygonatum (t. 6r. f. 9.).

170) einnervig (mninervium): bey den nur ein Längsgefäl's oder Nerve in der Mitte sich befindet, wie bey den Moosen. Er läuft dann entweder bis zur Spitze

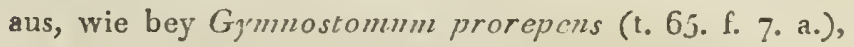
oder er verschwindet, che er dieselbe erreicht, wic bey Necheru filiformis (t. 6j. f. 9. a.).

171) dreynervig (irinervinuz): wenn drey Gefälsbiindel von der Basis bis zur Spitze laufen; z. B. die erstern Eiätler der Plantago lanceolata (t. 63. ᄃ. I I.).

$\left.\mathbf{y}_{1}-2\right)$ fünfnernig (quinquenervium) : bey dem man fünf von der Basis bis zur Spitze laufende Gefäfsbündel bemerkt; z. B. die später hervorkommenden Blätter der Plantago lanceolata (t. 6ł. f. 12.).

173) siebennervig (septeinnervium): bey dem sieben längslaufende Gefälśbïndel vorhanden sind; z. B. Plantajo major \% rosea.

174) dreyfachnervig (triplinervium): wenn über der Basis aus der Mittelrippe auf beyden Seiten ein Gefïlsbündel entspringt, der nach der Spitze hin ausläuft; z. B. Lamrus Campliora (t. 55. f. 8.).

175) fünffachnervig (quintuplinervium): wenn über der Dasis zwey Gefïlsbïndel aus der Mittelrippe 
apicem excurrentes; exemplo sunto Pyrola media (t. 55 . f. I3.), Melasioma scabrosnm (t. 6r. f. I.).

176) septuplinervium: ubi supra basin ex utroque costae mediae latere tres oriuntur vasorum fasciculi ad apicem excurrentes.

177) cosiamm: vasorum fasciculi e costa media crientes, dum, in ramos haud diducti, ad folii marginem usque excurrunt paralleli atque arctissimi; exemplo est Hellenia Allugluas (t. 64. f. 13.).

178) venosum: ubi e costa media longis intervallis oriuntur vasorum fasciculi in ramos diducti, e. g. Plllox paniculata (t. 52. f. 6), Liriodendrou tulipifera (t. 49. f. I.), Turrea virens (t. 23. f. 5.).

179) reticulato-venosun: vasorum fasciculi e costa media orientes, ubi, non minus ac eorum rami, eadem fere sunt crassitudine, atque, in ramos divisi, rursum conjunguntur, ita, ut rete quasi efficiant; inspiciatur Chelidominm majns (tab. libri inscript. 2. f. I5.).

I80) nervoso-venosum: ubi vasorum fasciculi, ut in folio nervoso (No. I67.) fit, e basi proveniunt, sed in ramos dividuntur; e. g. Paris quadrifolia (t. 55. f. 12.), Tropaeolnm majus (t. 55. f. I4.).

181) obtecto-venoszm: si supra vasomm fasciculos e costa media provenientes alii e basi orientes transeunt; exempla praebent Alysina Plantago (t.36. f.7.b.), Erylroxylon Caca (t. 3o. f. 4. b.).

I82) costato-venosum: ubi e costa media oriuntur crassi vasorum fasciculi, ad folii marginem recti ac paralleli, sed non conferti, excurrentes, quod primo adspectu videntur simplices, at vero in subtilissimos ramos ipsosque ramosos diducti ad morem retis subtilis inter se conjunguntur; exemplo sunto Ulmus effusa (t.6r. f. 2. a.), Alnus glainosa.

\section{T E $\mathbf{R}$ II I N}

auf jeder Seite entspringen und nach der Spitze zu auslanfen; z. B. Pyrola media (t. 55. f. I3.), Melastama scubrosum (t. 6r. f. I.).

I,6) si ebenf a ch nervig (septuplinervium): wenn über der Basis auf jeder Seite der Mittelrippe dreygefäfsbündel entspringen und nach der Spitze auslaufen.

I77) rippig (costatum): wenn aus der Mitelrippe Gefäfsbündel entspringen, die ohne sich in Äste zu zertheilen parallel und sehr dicht bis zum Rande des Blattes auslaufen; z. B. Hellenia Allughas (t. 64. f. 13.).

I73) aderig (venosum): wenn aus der Mutelrippe in weiten Zivischenräumen GtfäCsbïndel entspringen die sich in Äste zertheilen; z. B. Plulox paniculata (t. 52. f. 6.), Liriodendron mlipifera (t. 49. f. 1.), Turrea virens (t. 23. f. 5.).

179) netzförmig-geadert (reticulato-vcnosnm): wenn die aus der Mittelrippe entspringtnden Gelärsbündel, so wie die Äste derselben von zi(mlich gleicher Dicke sind und sich so in Äste zerthrilen und wieder verbinden, dafs sie gleichsam ein Netz bilden; z. B. Chelidouium majus (Titelkupfer 2. f. I5).

180) nervig-geadert (nervoso-venosinm): wenn die Gefärsbündel wie bey einem nervigen Blatte (No. I67.) aus der Basis kommen, sich aber in Aste zertheilen; z. B. Paris quadrifolia (t. 55. f. 12.), Tropaeolnm majus (t. 55. f. 14.).

I81) bedeckt-geadert (obtecto-venosum): wenn über die aus der Mittelrippe kommenden Gefälsbündel andre einfache, aus $\mathrm{d}$ r Basis entspringende weglaufen; z. B. Alysma Plantago (t. 36. f. 7. b.), Erytroxylon $\operatorname{Coca}($ t. 3o. f. 4. b).

182) rippig-geadert costato-venosum): wenn aus der Mittelrippe dicke Gefälsbïndel entspringen, die gerade und parallel, aber nicht dicht neben einander, nach dem Rande des Blattes auslaufen, und beyn ersten Elick einfach zu seyn scheinen, sich aber dennoch in sehr feine Äste zertheilen, die wieder ästig sind, und nach Art rines feinen Nelzes sich verbinden; z. B. Clinus effisa (t.6ı. f. 2, a.), Alnus glutinosa. 


$$
\text { T E I. MI I N }
$$

183) cancellatum: ubi vasorum fasciculi, cancellorum forma, in ramos abeunt, stque membrana sunt induti, idque ita, ut inter ipsos vacua remaneant spatia, dum et superior et inferior folii pagina caret membrena; inspiciatur Hydrogeton fenesiralis Persoon. (t. 6r. f. 5.).

134) enervium: folium, cui, praeter costam mediam, vasorum fasciculi, a basi ad apicem excurrentes, quos rocant nervos, sunt nulli; exemplo sunt Plilox paniculata (t. 52. f. 6.), Liriorlendron tulipifera (t. -49. f. I.), Tirren wirens (1. 23. f. 5.). In Muscis hoc termino indicatur folium nervo medio quoque destitutum; ut in Barbula rigida (t. 6j. f. rj. a.).

185) avenimn: ubi vasorum fasciculi e costa media orientes ramosi, venae dicti, $110 n$ apparent; exempla ferunt Laurzs Campliora (i. 5j. f. 3.), Comvallaria Polygonatum (t. 6r. f. 9.), Neottia repens (t. 4o. f. f. a.).

186) perlusum: si inter vasorum fasciculos unus pluresve reperiuntur loci, ubi deest membrana et superior et inferior, ita, ut primo adspectu folium fortuito percussum videatur; exemplum exbibet Dracontinm periusium (t. 63. f. 9.).

137) pellucide punctatum: si puncta pellucida in folio observantur; e. g. Ilypericum perforatum et plares generis Mesembrianthemi species.

IC8) nnicolor: si tota folii superficies uno codemque - plerumque viridi - est colore. Sequenti tentum opponitur; exemplo sunt plurimorum veggetabilium folia,

133) zonatum: stria (seu fascia) magis minusve lata, margini parallelis, si in folii subiotundi disco est alius coloris; e. g. Pelargoniun zonule (t. G6. f. 2.).
133) gegittert (cancellatum): wenn die Gefäsbïndel in Gestalt eines Gitters sich verästen, mit eincr Haut umkleidet sind, und zwar so, dafs zwischen ihnen leere $\mathrm{R}$ vime hleiben, da sowohl der obern als untern Fläche des Blattes die Haut fehlt; z. B. Iy drogeton $\int_{e-}$ nestralis Pers. (t. 6r. f. 5.).

184) nervenlos (enervium): ein Blatt, welches aufser der Mittelrippe keine von der Basis zur' $S_{p}$ itze auslaufenden Gefirsbiindel, dic inan Nerven nemut, hat; z. B. Phlox panioulatn (t. 52. f. 6), Liriodendion thlipifera (t. 49. f. r.), Furrea virens (i. 23. f. j) Bey den Monsen bedeutet dieser Ausdruck ein Blatt, welchen auch die Mitelrippe fehlt; z. B. Parúula rigich. (t. 65. 1. 15. a.).

185) a derlos (nveuituiz): bey dem man keine aus dur Mittelrippe entopringende ästige Gefilsbündel, die man Adern nenint, gewalur wird; z. B. Laurus Campliora (t.5j. f. 8.), Convallaria Polygonatum(t.6r.f.9.), Neottia repens (t. fo. f. 4. a.).

186) durchstofsen (pertusum): wenn sich zwischen den Gefürbündeln eine oder mehrere Stellen finden, wo sowohl dio obere als untere Blatthaut fehlt, so, dafs es beym ersten Blick das Anselıen hat, als wäro das Blatt zufällig durchstofsen; z. B. Dracontiunz pertusum (t. 63. f. 0.).

187) durchscheinend - punktirt (pellucide purzctatum): wenn an dem Blatie durchscheinende Punkte bomerkt werden; z. B. IIjpericum perforainm und viele Arten der Gittung Mesembrianthemum.

188) einfarbig (unicolor): wenn die ganze OberHïche des Blattes von einer und derselben - gewöhnlich von grüner - Farbe ist. Es ist nur der Geyensilz des folgenden; z. B. dienen die Blïtter der mehresten Gewächse.

189) gezont (zonatum): wenn sich im Mittelf ulde eines rundlichen B'dites ein mehr oder weniger breiter, mit $d \in m$ Fande glichlaufend,r, Stre if (oder Bun les) von anderes Fariefindet; z. B. I'eliegonium zonule (1. C6.f.2). 
152

T E R II I N O L

Igo) concolor: ubi folii pagina superior et inferior aequales sunt colore. Seqnenti contrariatur; exempla praebent plurimorum vegetabilium folia.

191) discolor: pagina inferior si est alius coloris, quam superior; e. g. Tradescantic discolor, Peperomia purpurea (1. 2.i. f. 6. L.), Cornus alua.

2. Folia composita.

a. In petioli apice composita.

192) binatum s. gcminatnm: ubi in petioli apice duo collocata sunt foliola (\$. 8ł́. No. 23.); e. g. Drosera binata Billard. (t. 54. f. 9.), Zygoplyyllum Fabago.

193) bigeminatum s. bigeminum: petiolus si in duas diducitur partes, quarum utraque in apice duo gerit foliola; exemplum praebet Inga meilifera (t. 4. f. 千. ).

194) trigeninatum s. tergeminum: petiolus ubi in duas dividitur partes, in utroque divisionis laiere unam foliolum atque in utrinsque partis apice duo ferens foliola; videatur Inga lergeintina (t. 5'. f. 3.).

195) ternatzm: ubi in petioli apice tria inveniuntur folia; exempla exhibent Fragaria elatior (t. 27. f. 5. b.), Trifolium repens (t. 3o. f. 7 . a.).

Ic6) biternatunu s. duplicuio-tematumn: petiolus si in tres dividitur partes, glanrum guaccpue in apice tria fert foliola; exemplo est Atragene aipina (t. $4 \mathrm{~J}$. . 4.).

19-) bicomposito-1eritalmm: a praecedenti (No. ic6.) eo tantummodo difierens, quod non absolute pro numero ita est regulare; e. g. Acgopodium Podagraric (t. 59. f. 13.).

\section{T E I M I N O L}

19o) gleichfarbig (concolor): wenn die obere und untere Fläclie des Blattes von gleicher Farbe sind. Es ist dem folgenden entgegensetzt; Deyspiele geben die mehresten Gewächse.

IgI) ungleichfarbig (discolor): wenn die untere Fiäche des Blattes von andrer Farbe als die obere ist; z. B. Tradescantia discolor, Peperomia pulpurea (t. 24. f. 6. L.), Cormits alba.

2. Zusammengesetzte Blïtter.

a. An der Spitze des Blattstiels zusammengesetzte.

192) z weyzählig (binatum s. geminatum): wenn an der Spitze des Blattstiels zwey Blăttchen , S. 8ł No. 23.) stehen; z. B. Drosera binnata Billard. (t. 54. f. 9.), Z'gophyllum Fabago.

193) doppelt - zweyzählig (bigeminatum s. bi(c)ininunz): wern der Blattstiel sich in zwey Theile theilt and jeder dieser Theile an der Spitze zwey Blättchen trägt; z. B. Inga mellifera (1. 4千. f. 4.).

19f) dreyfach-zweyzäblig (trigeminatnuns. (ergeminumz): wcun der Blattstiel sich in zwey Theile theilt, an beyden Seiten der Theilung ein Blättchen und an der Spitze eines jeden Theils zwey Elättchen trïgt; z. B. Inga tergemina (t. 5ł́. f. 3.).

Ig5) dreyzählig (lernatum): wenn an der Spitze des Blattstiels drey Blättchen sich befinden; z. B. Fragarin elatior (t. 27. f. 5. b.), Trifolium repens (1. 30. f. 7 . a.).

r96) doppelt-dreyzählig (biternatum s. duplicato-ternatum): wenn sich der Blattstiel in drey Theile theilt und jeçer dieser Theile an der Spitze drey Blättchen trägt; z. B. Atragene alpina (t. 49. f. 4.).

19:) doppelt - zusammengesetzt-dreyzāhlig (bicomposito-ternatum): von dem vorhergehenden (No. ig6.) nur dadurch verschieden, dafs es nicht wollkommer der Zahl nach so reg lüllsig ist; z. B. Aegopodium Podagraria (1. 59. f. 33... 
198) triternatum s. triplicaio-ternatum: cujus petiolus in tres dividitur partes, quarum quaeque tripartitur ipsa, singulae autem.in apice tria ferunt foliola; inspiciatur Seriana triternata Jacq. (t. 5.f. f. 5.).

199) tricomposito-ternatum: a praecedente (No. I93.) eo tantummodo differens, quod pro numero non absoluts est ita regulare; ut folia inferiora caulina Actaere spicatae.

200) multicomposito - ternatum: a praecedente (No. I99.) eo tantummodo diffurens, quod petiolus saepius adhuc tripartitur; exempla praebent folia radicalia Peucedani oflcinalis et Actaeae spicatae.

201) quadrinctumt: ubi in petioli apice quatuor reperiuntur foliola, e. g. Hedysartun tetraplyclinm (t. 5 f. f. ro. a ).

202) qrinatum: foliolorum quinque in petioli ap:ce ostendens; exemplo est Potcntilla alba (t. 10. f. Io. b).

203) bicomposito-quinatzem: ubi petiolus in apice ex uno eodemque puncto in quinque dividitur partes, quarum ruael.bct fere in ejus apice quinque fert folia; ut bene monstrat Cussonir spicata (t. 59. f. 5).

zoł́) septena:nun: ubi foliolorum in petioli apice deprehenduntur septem; exemplo est Bombax pentan$\operatorname{dra}($ t. 6千. f. I.).

20.j) novenatum: cui in petioli apice foliolorum sunt novem; id quod praebent inferiora foliola caulina Canuabis sativae (t. 59. f. 4.). Sic numeris imparibus ulterius progreditur, usque dum folia admodum aggregartur, tunc vero dicitur:
190) dreyfach-dreyzählig (triternatum s. triplicato-tcrnatumz): wenn der Blattstiel sich in drey Theile theilt und jeder derselben wieler in drey, von denen dann jeder an der Spitze drey Blïttchen trïgt; z. B. Scriana triternata Jacq. (t. 54́. f. 5.).

I99) dreyfach - zusammengesetzt - dreyzählig (tricomposito - ternatum): von dem vorhergelienden (No. 198.) darlurch verschicden, dals es der Zahl nach nicht vollkommen so regelmälsig ist; z. B. die untern stenģelständigen Blätter der Acbaea spicata.

200) vielfach-zusammengesetzt-dreytheilig (mnlicomposito-ternatum): von dem vorhergehenden (Yo. 193.) nur dadurch verschieden, dafs sich der Blattstiel noch üfter in drey Theile zertheilt; z. B. die wurzelständigen Blätter des Peucedanum officinale und der Actaea spicata.

201) vierzählig (quadrinatum): wenn sich an der Spitze des Blattstiels vier Blättchen befinden; z. B. Iiedysarum tetraphyllnm (r. 5f́. f. IO. a.). •

202) füinfzählig (quinałum): wenn fünf Blättchen an der Spitze des Llattstiels bemerkt werden; z. B. Po. tentilla alba (t. Io. f. Iо. b.).

203) doppelt-zusammengesetzt - fünfzählig (bicomposito-guinatum): wenn sich der Blattsticl an der Spitze aus eirnom Punkte in fünf Theile zerheilt und fast jeder derstlben an der Spizze fünf Blättchen trügt; z. B. Cussonia s,icuta (t. 59. f. 5.).

20f́) siebenzählig (septenatim): wenn sich sieben Blättchen an der Spitze des Plattsticls finden; z. B. Bombax pentandra (t. 6'f. f. 1.).

205) neunzählig (norenutzum): wenn neun Blättchen an der Spize des Diatustiels vorhanden sind; z. B. die untern stengeiständigen Blätter bey Cannabis sativa (t. 5j. f. 4.). So sieigt dies durch die ungleichen Zahlen noch wciter, bis dafs sich die Blättchen sehr Läufcn, und denn sagt man: 
205) umliellatzum: ubi foliolorum adeo sunt multa, ut inter ipsa sibi incubent, atque circa petioli apicem nmbellae forma expandantur; id quod ostendit Aralia Sciodaphylla (t. 61. f 3.).

207) digitalun: est communis No. 192., r.5., sor., 202., 204., 205. et 206. praecedentium denomiratio; et vero saepe nonnisi folium quinatum (No. 202.) aut septenatum (No. 204.) ita indicatur.

\section{B. In petioli lateribus composita.}

208) conjugatum: si in petioli laterum oppositorum utroque foliolum unum est dispositum; ita ostendit Laityrus tingitanus (t. 22. f. 2. i.). Cum binato (No. rg2.) non confundatur, quum notius ad sequentem (No. soy.) pertineat, a quo non differt nisi eo, quod ulira duo non habet folia.

209) pirnatum: petiolus ubi duobus lateribus oppositis est obsitus foliolis uni plano omnes incubantibus. In hoc vero et accuratius saepe distinguuntur:

a) paripinnatum: si folium pinnatum in apice duobus terminatur foliolis; ut in Cassia marilandica (t. 28. f. I. b.).

b) imparipinnatun: ubi in folii pinnati apice deprehenditur singultim rel impar foliolum; e. g. Asiragatus glycypliyllos (t. 17. f. 2. b.), Sorbus aucuparia (t. 38. f. 7. a.).

c) bi-, tri-, quadri-etc. multijuge pirnatum: folium pinnatum si e tot foliolorum paribus (Jugis 5. 8 t. No. 23.) . est compositum, quam terminis modo dictis indicatur.

\section{T E R II I N}

206) doldenartig (unbellatum): wo der Blăttchen so viele sind, dafs sie über einander liegen und um die Spitze des Blattstiels in Gestalt eines Schirms sich ausbreiten; z. B. Aralia Sciodaplyylla (t. 61. f. 3.).

207) gefingert (digitatum): dies ist der allgemeine Ausdruck für No. 192., 19.j., 201., 202., 204. 205. und 206. der vorhergehenden; (ff aber wird auch nur allein das fünf-( $\mathrm{N} \cap .202$ ) oder siebenzählige Blatt (No. sof) damit bezeichnet.

\section{B. An den Seiten des Blattstiels zusam. mengesetzte.}

203) gepant (coningatum): wenn an jeder der beyden enigegengesetzten Seiten des Blattstiels Eın Blăttchen steht; z. B. Lathyrus tingitanus (i. 22. $\mathrm{f}$ 2. i.). Es darf nicht mit dem zwejzähligen (No. 1 2 ) verwechselt werden, da es ebe zum folgenden (No. 20 ) ) gehört, von dem es sich nur dadurch unterscheidet, dais es nicht melir als zwey Blätichen hat.

209) gefiedert (pinnatum): wenn der Blattstiel an zwey entgegengesetzten Seiten mit Blättchen besetzt ist, die alle in Einer Fläcbe liegen. Bey diesem werden aber oft noch gensuer unterschieden:

a) pa arweis-gefiedert (paripinnatum): wenn ein gefiedertes Blatt an der Spitze mit zwey Blättchen sich endig:; z. B. Cassia marilandica (t. 28 . f. 1. b.).

b) u n par-gefiedert (imparipinnatum): wenn bey einem gefiederten Blatte an der Spitze nur ein einzelnes oder unpaares Blättclsen sich findet; z. B. Astragalius glycypliyllos (t. 17. f. 2. b.), Sorbus aucuparia (t. 38. f. 7. a.).

c) zwey-, drey-, vier- u. s. w. vielpariggefiedert (bi-, tri-, quadri-etc. multijuge pinnatum): wenn das gefiederte Blatt aus so viel Paar Blättchen (Blättchenpaar $§ .84$. No. 28.) zusammengesetzt ist, wie de bier genannten Ausdrücke bezeichnen. 


\section{T E R M I A}

d) Jýrato-pinnatum: folii imparipinnati (b.) foliolum apici additum ubi ceteris est multo majus; exemplum adfert Aniluyllis vulneraria (t. 37. f. 6. a.).

e) cirrlunse pinnatunz: folii pinnati petiolus si in apice filitormem hithet elongationem simplicem aut ramosam, eamque volubilern, unde vocatur cirrhus; exemplo est Vicia biennis (t. I7. f. 千. c.).

f) opposite pinnatum: folii pinnati foliola ubi bina inter se sunt ofposita; videnntur Astragatus glycrplayllos (t. 17. f 2. b.), Cassic marilandica (t. 28. f. I. b.), Surbus ancuparia (t. 38. f. 7. a.).

g) alternatim-pinnatum: folii pinnati foliola ubi alternatim utroque latere petioli sunt disposita; exemplum praebet Vicia biennis (t. I\%. f. 4. c.).

b) interrupte pinnatum: ubi in folio pinnato vicissim inveniuntur foliola modo minora; inspicia-tur Agrimonia Eupatoria (1. 42. f. 4.).

i) decursive pinnacum: ubi in folio pinnato foliolorum quodcunque infra ejus basin adusque proxime subsidens continuat substantiam folii; e. g. Melianthus nzajor (t. 5g. f. 6.).

k) alato-pinnatum: folii pinnati petiolus si in utroque latere instructus est foliorum substantia, foholis non conjuncta; inspiciantur Weinmannica trichosporma Cav. (t. 5f. f. I.), Bignonia fulua Cav. (เ. 53. f. 4.).

1) crescente pinnatun: si folii pinnati foliola d) leyerartig-gefiedert (lyrato-pinna!nm): wenn bey einem unpaar-geficderten Blatte (b.) das an der Spitze stehende Blättclien viel grö́rer ist, als die übrigen; z. B. Anthyllis vulucraria (t. 37. f. 6. a.).

e) wickelrankig-gefiedert (cirrlose pirnatum): wenn der Blattstiel des gefiederten Blattes an der Spitze eine fadenförmige, einfache oder ästige, Verlängerung hat, die sich windet und daher Wickelranke heifst; z. B. Vicin bieanis (t. 17 . f. 4. c).

f) gegengefiedert (opposite pilnatum): wenn die Blätthen des gefiederten Blatles paarwe:s einander gegenüberstehen; z. B. Asir igalus glychphyplos (t. 17. f. 2. b.), Cassia marilendica (t. 28 . f. 1. b), Sorbus aucuparia (1. 38. f. 7. a.).

g) wechselnd-gefiedert (alternatim pinnatum): wenn bey den gefiederten Blatte die Blättchen abwechselnd an beyden Seiten des Blattstiels stehen; z. B. Vicia biennis (t. 17. f. 4. c.).

h) unterbrochen gefiedert (interrupte pinnatnm): wenn bey dem gefiederten Blatte weclıselweis gröfsere und kleinere Blättchen sich finden; z. B. Agrimonia Eupatoria (t. 42. f. 4).

i) herablaufend-geliedert (decursive pin. nat (m) : wenn bey dem gefiederten Blatte ein $10-$ des Bättclien noch unter seiner Basis bis zu dt-m nächst unter thrn stehenden die Biattsubstanz fortsetzt; z. B. Melianthus major (t. 5.1. 1. 6.).

k) geflügelt-gefiedert (alaro pinnatmm): wenn der Blattstiel des gefiederten Blattes an beydin Seiten mit Blattsubtanz begabr ist, die nicht mit den Bï̈ttchen in Verbindung st.h ; 7. B. W int mannia rrichesperma Can.(t. 5+. f. 1) Bighnnicu fulva Cav. (t. 53. 1. . .).

1) zunchmend-gafiedert (crascante yinn- 
ad apicern ejus sensim evadunt majora; e. g. Poientilla Auscrina, Poterinm Sanguisorba (t. 60. f. ז3.).

m) decrescente pinnatnm: folii pinnati foliola ubi ad apicem ejus sensim evadunt minora; exemplum adfert Astragalus glycypligllos (t. I7. f. 2. b.).

n) articnlate pinnatum: ubi folii pinnati petiolus sirgulis articulis, foliola saepo aequantibus, est compositus; exemplum praebet Fagara tragodes (t. If́. f. 2. b.).

o) verticillate pinnatum: folii pinnati foliola ubi sunt opposita, binis, ternis, quaternis pluribusque ex uno eodemque puncto exortis ac petiolum, sicut folia verticillata (No. rg.) faciunt, circumdantibus; videatur Astragalus dasypliyllus (i. 49. f. 7.).

210) Lipinnatum s. dnplicato-pinnatum: ubi petiolus duobus lateribus oppositis pinnata (No. 209) fert foliola uni plano incubantia; exemplum exhibet Acacia caracasana (t. 35. f. 5. a.j.

ari) licomposito-pinnatnlll: praecedenti (No. 210.) simile, eo verum ab illo differens, quod ad apicem versus in folium simpliciter pinnatum (No. 209.) transit; e. g. Dancus Carota (t. 19. f. I. a. b.).

212) tripinnatunn s. triplicato-pinnatnm: petiolus ubi duobus lateribus oppositis foliola fert bipinnata (No. 210.), uni plano incubantia. Nisi primordialia folia radicalia Sii latifolii vocare ita licet: aliud exemplum vix investigaretur.
TE R II I N O L O G I E.

tum): wenn die Blittchen des gefiederten Blattes gegen die Spize desselben allnaillig gröfser werden; z. L. Potentilla Anserina, Poterinm Sanguisorba (t. Go. S. I3.).

m) abnehmend-gefiedert (derrescente pinnatum): wenn die Blätchen des gefiederien Blattes gegen die Spıtze desselben allmählig kleiner werden; z. B. Astragalus glycyphyllos (t. 17 . f. 2. b.).

n) gliederartig-gefiedert (articulate pinnatum): wenn der Blattstiel des gefiederten Dlattes aus einzelnen Gliedern, die oft den Blättchen gleichen, zusammengesetzt ist; z. B. Fagara tragocles (t. 14. f. 2. b.).

o) quirlartig-gefiedert (verticillate pinna$t r(m)$ : wenn bey dem gefiederten Blatte die Blättchen einander gegenüberstehen, immer zwey, drey, vier oder mehrere aus einem l'unkte entspringen urd clen Blattstiel wie quirlständige Blätter (No. Ig) umgeben; z. B. Astragalus dasyphyllus (t. 49.f.7.).

210) doppelt - gefiedert (bipinnatum s. dnplicato-pinuatum): wenn der Blattstiel an zwey entgegengesetzten Seiten gefiederte (No. 209.) Dlättchen trägt, die in Einer Fläche liegen; z. B. Acacia caracasana (t. 35. f. 5. a.).

2(1) doppeltzusammengesetzt-gefiedert (bicomposito-pinnatnm): dem vorigen (No. zro.) ähnlich, aber dadurch verschieden, dal's es nach der Spitze lin allmäblich in ein einfach-gefiedertes Blatt (No. 20g.) übergeht; z. D. Dancus Carota (t. 19. f. I. a. b.).

212) dreyfach-gefiedert (tripinnatum s. triplicato-pinnatum): wenn der Blaltstiel an zwey entgegengesetzten Seiten doppelt-gefiederte (No. 2ro.) Blättchen trägt. Wenn man niclit die erstern Wurzelblätter des Sizzm laiffolinm so nernen will: so müchte man schiverlich ein andres Beyspicl auffinúen. 
T E R II I N

213) tricomposito-pinualun : praecedenti (No.212.) simile, ad apicem versus autem minus compositum; id quod monstrat Tordylizm Anthriscus (t. 6j. f. 6.).

214) innlicontposito-pinnatum: praccedenti (No. 213.) simile, at vero magis compositum, ita, ut foliola in basi collocala ad minimum tricomposito-pinnata sun!; ut folia radicalia Conii maculasi.

$$
\text { \%. Mixtim composita. }
$$

215) superstructum: si unum folium vel plura in alius apice insistunt; ut folia primordialia Acıciae gुlnucescentis (t. 6i. f. 11.).

216) pedatum: petiolus ubi in duas partes vel todidem ramos diducitur, non nisi in apice atque interiori latere foliola gerentes, quorum quidem vel unum sarpe in petioli divisione est collocatum; videantur Helleborus niger, Arum Dracontinn (t. 39. f. 4. b.).

217) binato-pinnatum: ubi e petioli apice duo nascuntur foliola pinnata (No. 209.); exemplum praebet Inga circinalis (t. 5f. f. 4.).

213) ternato-pinnatum: ubi e petioli apice tria procedunt foliola pinnata (No. 20g.); ut in IIoffmannseggia trifoliata (t. 4 f́. f. 6.).

219) qualrinato-pimatum: si e p’etioli apice quatuor proveniunt foliola pinnata (No. 209.); id quod ostendit Mimosa pudica (t. ,8. r. 4.).

220) pimato-binatum: petiolus ubi duobus lateribus sibi oppositis foliola fert binata (No. ryz); exemplum adfert lnga foetidn (1. f́. f. 3.) Folium superius solum ad verum delineatum).

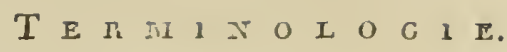

157

2r3) dreyfaclizusammengesetzt-gefiedert (tricomposito - pinuatum): dem vorhergehenden (No. 212) ähnlich, aber nach der Spitze hin weniger zısammengesetzt; z. B. Tordylimin Anthriscus (t 6j. f. 6.).

2I f́) vielfaclizusammengesetzt - gefiedart (multicomposito - pinnatnm): dem vorhergehenden (No. 213.) inlich, jedoch noch mehr zusammengesetzt, so, dafs die an der Basis stehenden Blïtichen wenigstens dreyfachzusammengesetzt-gefiedert sind; z. B. die wurzelständigen Blätter des Conimm macılatum.

$\%$ Gcmischt zusammengesetzt.

215) übersetzt (superstructum): wenn ein Elatt oder inehrere auf die Spitze des andern stelien; z B. die erstern Bläiter der Acacia glaurescens (1.64. I. 11.).

216) gefu[st (pedatmm): wenn der Platstiel sirls in zwey Thcile oder Äste theilt, die nur an der Spitzc und der Innenseite Blïtchen tragen, wobey jedloch oít auch eins in der Theilung des Blattstiels steht; z. B. Hellelorus niger, Arum Dracontium (t. 39. f. 4. b.).

2I7) zweyzählig-gefieder (Linato-pinnalu:n): wenn aus der Spitze des Blattstiels zwey gefieclerte (No. 209.) Blätıchen entspringen; z. B. Inga circinczlis (1. 54. f. 4.).

218) dreyzälllig-gefiedert (ternato-pimnaimm): wenn sus der Spitze des Blattstiels drey gefiederte (No. zog.) Blättchen hervorgehen; z. B. Halfmamnseggia trifoliata (t. 44. f. 6.).

=I ) vierzählig-gefiedert (quadrimato-pimn$(t u m)$ : wenn vier gefiederte (No. 209 ) Bläuclıcn ans der Spitze des Blattstiels hervorkommen; z.-D. Mimosa pradica (t. 48 f. 4.).

220) gefiedert-zweyzählig (pinnuto - binarum): wenn der Blattstiel an zweý entgegengrsetzten S:-iten zweyzïhlige (No. 192) Blättchen trïgt; z, B. Inga foeticla (t. 4f. f. 3. Nur das obere Biatt ist richtig gezeiclinct). 


\section{b. Dum corpus offerunt.}

221) capillare: quod subtilissimum, longum ac saepe diverse est flexum; e. g. Scirpus capillaris (t. 26. f. 7.$)$.

222) setacerm: quod subtile, longum atque acutum est; exemplo sunt Asparagus cfficinalis (t. 58. f. II ), Scirpus acicularis (t. 58. f. 10.).

223) acerosum: folium longum, plus minusve subtile est rigdum ac plerumque hiemen persistens; e. g. omnes generis Pini species. Videantur Pinus sjlvestris (t. 53. f. 5), Pinns Alies (tab. Libri inscript. 2. f. 9.).

224) suỏnlatunt: si formam longi, scute acuminati coni, baseos parvae, ostenilit; exempli loco sunt Seclum rejexnm (t. 59 f. I1.), Allium sibiricum (t. 4. f. 4. b.).

225) filiforme: haud admodum subtile, plus minusve teres, longum ac omnino fere eadem crassitndine; cxempla praebent Orlifluogalum spathaceum (t. 27. f. 4. a.), Juncus sjivalicus (t. 6j. f. 8.).

226) te:es: folium plus minusve lorgum et plas minusve crassum, cujus sectiones transversales circulos aequant, vel quidem accedunt eos; id quod monstrant .Juncus sylvaticus (t. 64. f. 3.), Seduin reflexum (1.50. f. II.), Alliwn sibiricum (t. 4. f. 4. b.), Ormillogralum "petlace:mu (t. 27. f. 4. a.), Cacalia cylindrica (1. 60 . f. 6. а.). Hac denominatione srepenumero non nisi contrariam rolii plani (No. 236), triquetri (No. 237.), tetragoni (No. 24́r.) cic. indicatur, ubi seclioncs transversales a circulo forma milio possunt discedere.

227) cylinciricun: fulium longum, cujus sectiones transverse'es exhibent circulos ejusdem magnitudinis, vel quidem inter se fire acquales; sive quod cylindri formae nisi prorsus respondeat, sane accedit; e. g. Cacalia cylindrica (t. 60. f. 6. a.).
T E I I

\section{b. Als Körper betrachtet.}

221) h a arförmig (capillare): das schr fein, lang und oft verschieden gebogen ist; z. B. Scirpus capillaris (t. 26. f. 7 ).

222) borstenförmig (setnceitm): das fein, lang und spitzig ist; z. B. Asparagus officinalis (t. 53. f. I1.), Scirpus acicularis (t. 58. f. 10).

223) nadelaxtig (acernsum): ein mehr oder weniger feines, langes Elatt, weiches steif ist und gewöhnlich ïber Winter ausdauert; z. B. alle Arten der Gattung Pinus. Hier sthe man Pinus sylvestris (t. 53. f. 5.) und Pims Abies (Titelknpler 2. f. 9.).

2-7) pfriemförunig (silbrlutum!): wenn es die Gestalt eires langen, scharf zugeszpitzten K̈gels mit kleiner Grundfäche hat; z. B. Se.lan iffexum (เ. 5j]. f. 11.), Allinu sibiricun (t. 4. f. 4. b.).

22j) fad enförmig (fliforme): das nicht selır fein, melir oder weniger stielrund, lang und fast durchaus gieich dick ist; z. B. Orniclıogalum siuktlace:Im (t. 27. f. 4. a.), Juncus sylvaticus (t. 6 j. f. 8 ).

226) stielrund (teres): ein mehr oder weniger langes und mehr oder weniger dickes Blatt, dessen Queerdurchschnitte den Kreisen gleichen, oder doch wenigstens denselben nahe kommen; z. D. Junca syluaticus (t. 64. f. 8.), Sedum reflexim (t. 59. f. Ir.), Allinm sibiricmm (t. 4. f. 4. b.), Ornithogalnm spathaccrun (1. -7. f. 4. a.), Cacalia cylindrica (ı. Co. f. 6. a.). Oft bezeichnet man durch diesen Ausdruck nur den Gegensatz von einem Hachen (No. 236.), dreykantigen (No. 237.), vierseitigen (No. 2fir) u. s. w. Blatte, wo dann die Queerdurchschniue betı̈̈chlich ron der Gestait des Kreises abweichen köinen.

22-) walzenförmig (cylindricum): ein langes Blatt, dessen Queerdurchschnitte Kreise von givicher oder doch zicmlich gl:icher Grülse geben; oder das der Figur der Wralze, wenn es derselben rticht völlig entspricht, selir nabe kommt; z. B. Cacalia cylindrica (t. 6o. f. 6. a.). 
T E R M I N O L

220) semicylindricum : folium longum, cujus sectiones transversales ostendunt liemicyclos ejusdem magniudinis, vel quidem inter se fere sequales;- exempli loco est Meinbrianthemnn uoctiflornm (t. 63. f. 13. а.).

20.) compressum: ubi plana duo lateralia magis se mutio approximant, quam pagira superior atque inferior; exemplum adfert Cacalia Ficoides (t. 6o. f. 5. a.).

230) impressum: ubi pagina superior est excavata; videatur Cacalia repens (1. 59. f. 10. a.), Aloe carinata (t.5ł.f. 2.). - A Linn a o depressizn vocatur -

231) depresso-truncatum: si in folio, planum apicis loco deprchenditur, ita, ut vileatur, ac si hoc esset clfectum depressionc in illam facta; inspiciatur Aloe reinsa (t. 6q. f. 3).

232) gibunm: ubi in folio, cujus Iongitudo haud multum longitudinem superat, cum superior tum inferior pagina est convexa; ut bene monsirat Mesembriantlentum eclinatnin (t. 63. f. 5).

233) lingniforme: folium longum, vel planiusculum, vel leviter biconvexum, vel etiam impressum (No. 230.), apice plus minusve rotundatum. Vidcatur sloe obscrira (1.63. f. 7.), Aloe carinata (1. 54. .. 2 ).

33-1) anceps: ubi folium longum in utraque pagina Jus nuinusve convexum margines ostendit laterales ( $\$ .34$. No. 8. c.) in acies ( $\$ .34$. No. 32.) acutas excurrentes; exemplum pracbet Aloe olscrura (t. 63. f. . .)

33j) ensiforme: folium longum, valde compressum - vel planum aversum (No. 5\%.), - quod a crassiore basi ad apicem versus, et, per to:am cjus longitudinem a medio ad acies - vel margines laterales - versus atienuatur, in apicem acutum excurrens ac plus minusve incurvatum (No. 51.); exemplum exlibet fris arenaria (tab. libri inscript, 2. f. IG.).

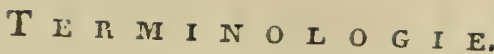

228) I alb walz enförmig (semicylindricum): ein langes Blatt, dessen Queerdurchschnitte Halbkreise von gleicher oder doch ziemlich gleicher $\mathrm{Gr} u ̈$ fse geben; z, B. Mesemlrianthemnm noctiflorum (t. 63. f. 13. a.).

229) zusammengedrückt (compressum): vvenn die beyden Sitenflächen einander mehr genäbert sind, als die obcre und untere Fläche; z. B. Cacalic Ficoides (r. 6o. f. 5. a.).

230) eingedrückt (impressunz): wenn die obere Fläcile ausgelıöhlt ist; z. B. Cacalia repens (․ 50.f. 10. a.), Aloe carinata (s. 54́. f. 2.). - Linné nennt es niedergedrückt (depressum) - .

231) niedergedrïckt - abgestutzt (depresso(runcaitun): wenn bey dem Platte da, wo die Spitze seyn soil, eine Fläche sich findet, so, dafs es scheint, als wïre diese durch einen Druck auf jene entstanden; z. B. Aloe reiusa (t. 6íf. f. 3.).

232) buckelig (gibbum): wenn bey einem Blatte, dessen $L " n g e$ die Bicite nicht viel übertriff, sowohl die obere als auch die untere Flïche gewölbt is!; z. B. Mcseinbrianthenzm echiralnm (t. 63. 5. 5).

233) zungenförmig (lingizifornze): ein langes, cntweder ziemlich Haches oder schwach doppelt-gewölbtes, oder auch eingedrïcktes (No. 230) Blatt mit mehr oder weniger zugerundeter Spitze; z. B. Aloe obscura (t. 63. f. 7.), Aloe carinata (t. 54. f. 2.).

233) zweyschncidig (anceps): wenn bey einem langen, auf beyden Flächen melır oder weniger gewülbten Blatte die Seitenrinder ( $\$ .3$. No. 3. c.) in scharfe Fanten ( $\$ .84$. No. 32.) auslaufen; z. B. Aloe obscurc (1. 63. f. 7.).

235) schwertförmig (ensiforme): ein langes, stark zusammengedrücktes - oder flaches, abgewandtes (No. $j_{i}$ ) - Blatt, das von dur dickern Lasis gegen die Spize und seiner ganzen Länge nach, von der Mitte gegen die Kanten - oder Seitenränder - dünner wird, in eine scharfe Spitze auslïuft und mehr oder weniger einwärtsgekrümmt (No. 51.) ist; z. D. Iris arenaria (Titelkupfer 2 . f. I6.). 
160

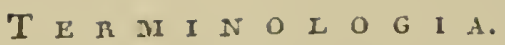

336) planum: ubi cum superior tum infer:or folii pagina planitiem seu aequum planum, nisi omnino, propemodo quidem aequat; videantur Verea crenata (t. 60 f. 2.), Sedun Telephum. Hac denommatione saepenumero non nisi contrarium folii triquetri (No.237.), tetragoni (No. 2qr.) aut teretis (No.2:6) indicatur, ubi utraque pagina a planitie seu aequo plano mudio possunt discedere.

237) triquetrum: folium Inngum, tribus planis lateralibus ( $5.8+$. No. 31.) inclusum. Idque est vel

a) aequilaterum: ubi sectio transversalis $r$ fficit triangnlum aequilatcrum, sicut in Mesembrianthemo aequilatero (t. 6o. f. II.), vel

b) inaequilaterum: ubi sectio transwersalis ostendit triangulum inaequilaterum, ut in .hesembrianthemo aurantio (t. 65. f. 4. a.).

238) acinaciforme: folium triquetrum, cujus planum angustius laterale, ut pagina stperior, introrsuni, acies inferior contra extrorsum directum describit arcum; videantur Mesembrianthemum acinaciforme, Mesembrianthemum lacerum (i. 16. f. I. b.).

239) dolabriforme: folium in basi teres fere, ceterum autem compressum, in apice cınarginato ad inferiorem aciem mulio ac rotunde dilatatum, in superiore contra est obtusum; exemplum exhibct Mesembrigizthemum clolabriforme (1. 5.j. f. 14.).

2'o) delioides: foln:in triqnetrum, bicre, breviter ornminatum, in cujus aciebus monnull cons iciontur an-
TE $\mathbb{R}$ II I N O L O G I E.

236) flacb (planum): wenn sowohl die obere als untere Fläche des Blattes einer Ebene, wo nicht ganz, doch ziemlich, gleich kommi; z. B. Verea cienata (t. 6o. f. 2). Of bezeichnet man durch diesen Ausdruck nur den Gegensaiz von einem dreykantigen (No. 2.-.), vierseirigen (No. 2fi.) oder stielrunden (No. 226.) Blatte, und dann kōnnen die beyclen Seitın beträchthıh ron einer eben Fläche abıreichen.

2.37) dreykantig (iriquerrum): ein langes Blatt, welches durch drey Seitenflichen (\$. 84. No. 3r.) begränzt ist. Es ist entweder

a) gleichscitig (aequilaterum): wenn der Queerdurchschinitt rin gleichseituges Dreyeck giebt, wie bey Mesembrianthemum aequilaterum (t. 60 . f. II.), oder

b) ungleichseitig (inaequilaterum): wenn der Queerdurchschnitt ein ungleichseitiges Dreyeck darstellt, wie bey Mesembrianthemum aurantium (t. 65. f. 4. a.).

230) säbelförmig (acinaciforme): ein dreykantiges Blatt, bey welchem die schmalere Scitenfläche, als obere Fläche, einen Bogen nach innen, die untere Kante hingegen, einen nach aufsen beschreilt; z. B. Mesembrianthemun acinaciforme, Mesembrianthemum lacerum (t. I6. f. 1. b.).

239) hobelförmig (dolabriforine): ein an der Basis fast stielrundes, übrigens aber zusammengedrïcktes Blatt, welches an der ausgerandeten Spitze nach der untern Kante stark und rund erweitert, an der obern hinzegen stumpf ist; z.,B. Mesembrianthemiun dolaEriforme (เ. 54. f. I千́f).

2fo) deltartig (delioides): ein dreykantiges, kurzes, kurz-zugespitzies Blatt, an dessen Kanten man 
TE $E$ R II I N

guli acnati; inspiciatur Mesembrianthemum deltoides (t. 53. .. 3.).

2i1) iciraģonum: folium longum quatuor planis lateralibus inclusum; exemplo est Pinus Abies (tab. libri isscript. 2. f. 9.).

2:) quadricanaliculatmm: folium longum, quatuor planis laieraibus angustis inclusum, in quo, acierum loco, guatuor reperitintur cavitates profundas, a Basi ad apicem rersus excurrentes, itn, ut sectio transversalis crucem offerat; e. g. Ixia cruciaia (t. 35 . f. 4. d.). - A Willdenow quadricarinatum vocatur - .

243) mamnillare: complura folia crassa, brevia, in apice convexa ubi arcte conjuncta sunt collecta; c. g. nonnullae Eupleorliae africanae, nec non Siaje'ia mammilaris (t. 16. f. 6.) - A IVilldenow vcrracosim vocatur - .

24千́f) uncinatum: foliun - plerunque - triquetrum, cujus apex est reflexus; exemplim pricbet Niesembriantleemum uncinatum (

Tcrminorum luc edictorum nisi quis ad folium eo designandun totus conrenit: dicunt particulan sub auhibentes - si e. S. folium indicandum folio cordato quidem accclir, neque tamen ex toto responder; subcordatum. Simili modo usurpantur roces: subsagittatum, suboratum, sublineare ctc. - . Iraud raro folium designandum ct duorum icrminorum compositione accuratius putcst indicari, in quo vero est dicendun, illum, cui plurimum respondct, posipoui, quam ob causam ovaro - oblongum ab oblongoovato, lanccolato-lineare a lineari-lanceolato etc. satis dignoscantur nccesse est. - Si folium, cıjus figura est indicanda, cum quodam tcruino constituto non nisi differt co, quod apaci est
TE $\mathrm{R}$ II I $N$ O

16)

ciatge spizige Winkel oder Ecken bemerkt; z. D. Mesembriantlemum delloides (t. 53. f. 3.).

=f́) vierseitig (Le:tragonum): ein langes Bla!t, welches durch vier Seitenflächen beģrïnzt ist; z. B. $P_{l-}$ nus Abies (Titelkupfer 2. f. ..).

242) vierrinnig (quadricanalicnlatum): ein langes, von vier schmalen Seitenflïchen begrïnztes Blatt, bey weichem sich statt der Kanten vier tiefe Höhlungen finden, die ron der Basis bis zur Spitze auslauf:n, so, dafs der Quecrdurchsclinitt ein Kreuz bildet; z. B. Ixia cruciata (t. 35. f. 4. d.). - TVilldenow nennt es vierfach kielförmig (quadricarinatum) - .

243) zitzenförmig (nammillare): wenn mehrere dicke, kurze, an der Spitze gewölbte Blïtter dickt beysammen siehen; z. B. einige africanische Euphorbien, so wie auch Stapelia mammillaris (t. 16. f. G.) - Willdenow nennt es warzenförmig (verrucosim) -

=\{-4) hakenfürmig (uncinatmm): ein - gewöhnlich - dreykantiges Blatt, dessen Sṇitze zurückgesdılagen ist; z. B. Mesembrianthemum "incina!m? (t. 55. S.5..

Weun ciner vou den hicr aufgeführten Küustausdrïcken uicht ganz zu dem Blatte, wclchcs damit bezciclenct werder: soll, passen will: so bedicut man sich des TFörtcheus fast (sub), mud siggt alsdaun - wenn z. B. das zu Lestimmcudo Blatt dem- Ierzfurmigen blatte sich ndhert, aber doch nicht volliomuncu demselben entspricht: - fast lierzförmig (subcordatum). Auf ähnliche Art gebraucht man die Ausdriiclic: fast pfeilförmigg (subsagittatum), fast eyrund (subovatum), fast linienförmig (sublinearc) u. s. w. - Oft lafst sich aucls das zu bestimmende Blatt durch Zusammonsétzung zweycr Kunstausdrïiclic fुcuauer bezeiclnen, wohey aber zu bemerken ist, hal; दcrjenige, dcm es am moi-

1 a 2 
T E I MI I N O L O G I A.

figura, qualis conveniat basi: iermino ceterum congruenti praeponitur $o b$, proiude audinniur obcordatum, oboratum.

\section{84 .}

In foliis describendis, sicut haud raro et in aliis vegetabilium partibus, formatione illis similibus, nonnulli obveniunt termini, nobís scparatim exponendi atqque exactius definiendi. Sunt sequentes:

\section{A. In foliis pIanum offerentibus.}

$$
\text { «. In simplicibus. }
$$

I) Peripheria: linea, que folium, quod planum offert, ambit atque ejus figuram constituit.

2) Basis: folii extremitas, ubi est cauli insertum.

3) Apex: extremitas libera, basi opposita.

4) Superficies: spatium a peripheria conclusum.

5) Pagina superior: coelum spectans pagina. Lo. co ejus in descriptionibus solis supra solet adbiberi.
TE $\mathrm{R}$ II I N O L O G I E.

sten eutspricht, zuletzt gesctzt wird, wefshall man denn die Ausdruiche eyrund-länglicl (ovato-oblongum) und litnglich-eyrund (ob. longo-ovatum), lanzett-linienförmig (lanceolato-lineare, und linien - lanzet tförmig (lincari-lanceolatum) u. s. w. wolll unterscheiden muls. - Weicht das der Form nach zu be. stimmende Blatt von einem der festgesetzten Kunstausdrücke nur dadurch $a b$, dals es an der Spitze so gestaltet ist, wie es an der Basıs seyn sollte: so setzt man dem übrigens passenden Kunstausdrucke umgekelirt (ob) vor, als u m. gekelırt - Iıerzförmig (obcordatum), umgekehrteyrund (obovatum).

\section{S. 84 .}

Bey den Blättern, so wie nicht selten auch bei andern Theilen der Gewächse die ähnliche Bildung mit ihnen haben, kommen noch einige Kunstausdrücke vor, die wir hier noch auffütren und genauer bestimmen nıüssen. Es sind folgende:

A. Bey den Blättern die als Fläche betrachtet werden.

$$
\text { a. Bey den einfacluen. }
$$

I) der Umfang (Periplteria): die Linie, welche das Blatt, als Fläche betrachtet, umgränzt und die Figur desselben bestimmt.

2) die Basis (Basis): das Ende des Blattes womit es dem Stengel einver'eibt ist.

3) die Spitze (Apex): das der Basis entgegengesctzte, freystehende Ende.

4) die Oberfläche (Suiperficies): der vom Umfange eingeschlofsne Riaun.

5) die obere Fläche (Pagina superior): die dem Himmel zugekehrte Fläche. Bey den Beschreibungen pllegt man dafür blofs oberhalb (supra) zu gebrauchen. 
T E R II I N O L O

6) Pagina inferior: ad terram spectans pagina. In descriptionibus plerumque subtus dicitur.

7) Disculs: pars plani media, ad peripheriam usque fere porrecta.

8) Margo: plani pars juxta peripheriam ambiens, quae discum includit. Distinguuntur:
a) Margo basalis,
b) Margo apicalis et
c) Margo lateralis.

9) Nervi: vasorum fasciculi a folii basi ad illius apicem usque excurrentes neque in ramos diducti. Fasciculus vasorum obtinens medium vocatur Nervns medius sive Nervus primarins; in folio costato (No. 177.) vero nec non in venoso (No. 17 - 8 .) Costa media dicitur. In carinati (No. 165.) prgina inferiore format folii partem, quae nominatur Carina. Nervus prinarius si provenit in Muscorum foliis: apparet vel excedens, ut in folio apiculato (No. I18.) et pilifero No. (I19.), vel excurrens, vel etiam evanescens sen evanichns, sicut in folio uninervio (No. 170.).

10) Costae: vasorum fasciculi a nervo medio seu costa media ad folii marginem usque paralleliter excurrentes, neque in ramos diducti.

I1) Venae: vasorum fasciculi a costa media ad folii marginem excurrentes in ramos divisi.
TE I M I N O L O G 1 E. 163

6) die untere Fläche (Pagina inferior): die der Erde zugewandte Fläche. Bei den Beschreibungen sagt man gewühnlich unterhalb (subtus).

7) das Mittelfeld (Discrus): der mittlere Theil der Fläche, der sich fast bis zum Umfange erstreckt.

8) der Thand (Margo): der am Umfange sich herumziehende Theil der Fläche, welcher das Mittelfeld einsch!iefst. Hier unterscheidet man noch:
a) Grundrand (Murgo basulus),
b) Endrand (Murgo apicalis) und
c) Seitenrand (Margo lateralis).

9) die Nerven (Nervi): Gefälsbundel, die von der Basis des Blattes bis zur Spitze dessel'ben auslaufen, ohne sich in 1 ste zu zertheilen. Der mittlere dieser Gefâlsbündel heilst der Mittelnerve (Nervus met!izts) oder Hauptnerve (Nervus primarizs); ist das B'alt aber gerippt. (No. 17.) oder geadert ( $\mathrm{N} n$. 178), so nenut man ihn Mittelrippe (Costa media). Bey dem kielförmigen (No. I65.) bildet sie auf der untern Flïche den Theil des Blattes, welcher der Kiel (Carina) genannt wird. Wenn der Hauptnerve bey den Blittern der Moose vorkommt: so erscheint er eriweder hervortretend (excedens), wie bey dem spitzentragenden (No. I 18.) und haartragenden (No. Irg.) Dlatte, oder auslaufend (excurrens), oder auch verscinwindend (evainescens sen evaniclus) wie bey dem cinnervigen Blatte (No. I - O.).

I0) die Rippen (Costac): Gefülsbündel, die von dem Mittelnerven oder der Mittelrippe parallel nach dem Frande des Blattes auslaufen ohne sich in Äste z!1 zertheilen.

11) die Adern (Venae): Gefäfsbündel, die von der Mittelrippe nach dem Rande des Blautes auslaufen und sich in $\ddot{A}$ ste zerthellen. 
- C.

12) Lalera: spatia inter costam mediam et margines latcrales.

13.) Angulus: pars folii e peripleria progrediens illa, quae a duabus lincis rectis vel curvis, vel alıcra recta altera curva est inciusa. Diciur:

a) acutatus: si in punctum, desinit;

b) obtusatus: si a linea arcuata terminatur.

A mathenaticis quidem acutus er obtusus usurpatur, illuc autem alio sensu atque luc adhibentur.

14) Incisura: incisura linearis, quae non nisi folii marginem dirimit.

15) Fissura: incisura linearis, quae ad folii medium aut basin usque intrat.

16) Excistıra: angulus acutatus folium intrans, qui tanquam triangulo exsecto videtur effectus.

17) Sinus: angulus obtusatus folium intrans, qui tanquanı exsecto triangulo, cujus apex est roiundatus, videtur ortus.

18) Lobus: pars sinibus, excisuris aut fissuris orta, eademque lata nec non lineis arcuatis finita.

19) Lacinia: rars sinibus, excisuris aut fissuris effecta, eaque angusta nec non lincis rectis fere finita.
12) Die Seiten (Latera): die Riume zwischen der Mittelrippe und den bejaden Scitenüindern.

13) der Winkel oder die Ecke (Ángulns): der aus dem Unfange des Blattes beraustretende Theil, der von zwey geraden, oder von (iner geraden und einer krummen, oder auch von zwey krummen Linien einçeschlossen ist. Er heilst:

a) spitzig (acutatus): wenn er sich in einem Punkte scliliefst;

b) gestumpft (obtusatus): wenn er von einer Bogenlinie begränzt wird.

In der Mathematik sagt man zwar spitz und stumpf aber man bezeichnet dort anch etwas anderes dadurch, als man hier dartunter versteht.

I4) der Einschnitt (Incistura): ein linienförmiger Einschnitt, welcher nur den Rand des Blattes zertheilt.

15) dic Spalte (Fissura): ein linienförmiger Einschnitt, welcher bis in die Mitte oder bis auf die Basis des Blattes eindringt.

16) der Ausschnitt (Excisura): ein in das Blatt eindringender spitziger Winkel, der gleichsam durch Herausschneiden cines Drejecks entstanden zu seyn scheint.

17) die Bucht (Sinus): ein in das Blatt cindringender gestumpfter Winkel, der gleichsam durch Herausschneiden eines Dreyecks, dessen Spitze zugerundet ist, entstanden zu seyn scheint.

18) der Lappen (Lobrus): rin durch Buchten, Ausschnitte oder Spalten enistandener Theil, der breit und durch Bogenlinien begränzt ist.

19) der Zipfel (Laciniu): ein durch Dishten, Ausschnitte oder Spalien entstandezer Theil, der, schraal und durch fast gerade Linien begrinzt ist. 
T E R MI I R

20) Dentatura: angulus acutatus in folii margine parvis sinbbis effectus.

21) Serratura: angulus acutatus in folii margine parvis excisuris reddıtus.

22) Crenalura: angulus obtusatus vel rotundatus, in margine folii parvis excisuris exhibitus.

\section{In compositis.}

23) Foliolum: foliorum composiorum quodvis parvum Solium simplex itá dicitur; at plerumque eo non subintelligitur nisi folium parvum qrodcunque in foliis apice petioli compositis (No. 192-20\%.) nec non in folio pedato (Na. ar6.) apparet, non minus quam quodlibet parvum folium simplex in folio tripinnato (No. 212.) eodem nomine indicatur.

24) Pinna: quodvis parvum simplex folii pinnati (No. 209.) folium, vel quodlibet folii bipinnati (No. 210.) folium pinnatum, vel quidem quodque folii tripinnati (No. 212.) folium bipinnatum.

25) Pinnula: quodvis parvum folium simplex folii bipinnar (No. 2Io.), vel quodlibet folium pinnatun folii tripirnati (No. 212.).

26) Pinna impar s. terminalis, vel foliolum impar s. terminale: quod in folio imparipinnato (No. 20g. b.) est petiuli apici additum.

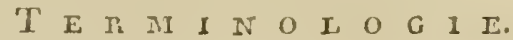

$16_{5}$

20) der Zahn (Dsntatura): ein spitziger Winkel, der am Rande des Binttes durch kleine Buchten entsteht. 21) der Sägezahn (Serratura): ein spitziger Winkel, der am Rande des Blattes durch kleine Ausschnitte lervorgebracht wird.

22) der Krebzahn (Crenatura): ein gestumpiter oder zugerundeter Winkel, der am Rande des Blattes durch kleine Ausschnitte gebildet wird.

\section{B. Bey den zusammengesetzten.}

23) das Blättcluen (Foliolum): heifst ju:!es kleine einfache Blatt bey den zusammengesptzten Blättern; gewöhnlich aber versteht man nur darun:ar jedes kleine Blatt, welches sich bey den an der Spitze des Bla:tstiel zusammengesetzten Blättern (No. r 92- - 207.) und bey dem gefufsten Blatte (No. 216.) findet, so wie denn auch jedes kleine, einfache Blatt bey dem dreyfachgefiederten Blatte (No. 212.) mit diesem Nahmen bezeichnct wird.

24) die Fieder (Pinna): jedes kleine einfache Blatt eines gefiederten Blattes (No. zoj.), oder jede's gefiederte Blatt eincs doppelt-gefiederten Blattes (Nio. zroj, oder auch jedes doppelt-gefiederte Blatt eines dityfachgefiederten Blattes (No. 2iz.).

25) Das Fiederchen (Pimula): jedes k?eine rinfache Dlatt eines doppelt-gefinderten Biattrs (No. 210.), o ler jedes gefiederie Blatt eines drejlach-gefiederten Blattes (No. 2iz.).

26) die unpare oder gipfelständige Fieder (Pinna impor s. terminalis), oder das un pare od'r gipfelständige Blättchen (Folıolum imporr soterminale): das bey einsm unpaar-gefiederten Blatte (No. zoy. b.) an der Spitze des Blatisticls stehende Binttclen. 
166

T E R MI I

2-) Pinna laveralis s. folioinm lalerale: quodvis in folio pinnato folium petioli laicri additum.

28) Jugrum: quaevis duae folii pinnati pinnae laterales scu foliola lateralia (No. 27.) vel propemodo vel plane opposita.

In speciebus generum Irgae, Mimosae, Schronkiae, Desmanthi et Acaciae foliis bipinnatis adluc inveniuntur termini proprii a $\mathrm{Linnaeo}$ adlibiti, nempe Pinna partialis pro $p_{\text {inna, et }}$ - Finna propria pro Pinnula, quos quiden communibus permulare fas esset.

Adhuc dicendum est, secundum Linna e $11 \mathrm{~m}$ in generibus supra memuratis folium pinnatum quingruejugum esse folium pimatum, quinque paribus pinnarum consistens, atque quod luic scusui omnino repugnat illum in folio bipinnato usurpare vocem pinnis partialiuss quinquejugis, propriis multijugis, qua quidenx intelligi rult, quinque pinurum paria foliolum bipin. natum, sicut unulta pinnularum paria quamque illius pinnam conficere.

B. In foliis corpus offerentibus.

-3) Planum liasala: Tlinnum, quo folium cauli est inscrtum.

20) P!rmtum apical.: planum basali plano oppositum. Non nisi in paucis foliis exstat, atque ideo in illo $a_{j} \cdot$ e. p plerumque videitr.

31) Pl wa latanalis: plana inter planum basalem et apicalem.

32) Aciss: ancu'i a planis cocurtibus confecti.
-7) die seitenständige Fieder ('Pinza lateralis) oder das seitenstiindige Blätichen (Foliolum laterale): jedes bey einem gefiederten Blatte an der Seite des Blattstieis stehonde B!äitchen.

23) das Blatichenpar (Jugum): jede zwey beywahe oder vollkommen gegenüberstehende seitenständige Fiedern oder Blättchen (No. 27.) eines gefiedcrten Blattes.

Bey den Arten der Gattungen Inga, MTimosa, Sihrankia, Desmanthus und Acacix mit doppeltgefiederten Blättern finden sich noch die ron Lin né gebraucliten besondern Kunstauserrücke, nümlich Pinna partialis für Pinna, und Pinna propria für Pinnula, die aber füglich mit den allgemeinen vertauschit werden liömten.

Ferner ist noch zu benerken, dafs bey deil eben genanuten Gattungen nach $L i$ n u é ein Folium pinnatum quinguejugum ein aus fünf $\mathbf{P a x}$ Fiedern besteliendes geficdertes Blatt ist, und dals er ganz diesem Bę̧riffe zurrider, bey den doppelt - gefiederten Dlatte sich c'es Anslruchs: rinnis particlilus quinquejugis, propriis multijusis, bedicut, worunter er nimlich verstelit, difs fünf Paar Fiedern das doppelt gefiederte Dlatt und viele Paar Fiederclen jeche Fieder L'esselbea billen.

B. Bey den Blăttern die als Körper betrachtet werden.

29) die Grundfliiche (Planzım Gasale) : die Fläche, womit das Blatt dem Stengel einverlcibt ist. Wenn diese Fliiche nur von likeiner Ausdehnung ist, so heifst sie blofs Basis (Pasis).

3o) die Endfläclse (Plemm aycrie): die der Grunalläche entgegengese:zte Fläche. Nur bey wenigen Blättern ist diesc vorbanden, und daher sieht max gcwöhrich bey denselben dic Spitzo ( $A_{p}$ ') ;.

31) die Seiterflächen (fllana l:erizliz): die Fuächen zwischen der Grund- und Endilizhe.

32) die Kanten (Acies): die von den zusammenstołsenden Flïlen gebildeten Tinkel. 
S. 85.

Stipulae sunt partes foliis structura similes, juxta foliorum basin positae et plerumque $a b$ eis figura ac minori magnitudine tantum differentes. Apparent :

I) solitariae: si unica tantum stipula ad cujusvis folii vel petioli basin occurrit; e. g. Ruscus Hypoglos$\sin$ (t. 41. f, 6.).

2) Geminae: duae ad basin cujusvis folii vel potooli positae, ubi et semper sunt

3) oppositae: e. g. Astragalus glycyplyyllos (t. 17. f. 2. a.), Vicia biennis (t. 17. f. 4. b.), Orobus niger (t. rg. f. 5. a.), Latluyrus tingetantus (t. 22. f. 2.).

4) laterifoliae: solitariae (Nr. I.) seu oppositae (Nr. 3.) si folio ad latus sunt positae. Eis explicandis inserviunt exempla praecedentium ( $\mathrm{Nr}$. 3.).

5) extrafoliaceas: arcte sub folio prodientes; videatur Russus IIypoglossnm (t. 41. f. 6.).

6) suprafoliaceae: quae supra folium protruduntur.

7) oppositifoline: ex alio caulis vel rami latere folio oppositae; ut in Coronilla coronata et partim in Astragalo arenario.

8) axillares: axillae ( $\$$. 83. observ. post $\mathrm{Nr}$. 58.) insertae; exemplum praebent Sambucus nircu, SainJuculs Ebulus et generum Mori ac Ficus species.

9) potiolares: petioli basi supra insidentes; ut in Rubo nemoroso et fiubo corylifolio.

I0) pedicellatae: pedicelli officio loco, ubi apparent, affixae sunt: vidcatur Vicia liennis (t. 17. f. 4. b.)
S. 55 .

Die Afterblitter (Stipulae) sind Theile, welche der Structur nach Aelınlicbkeit mit den Blättern haben, in der Gegend der Basis der Blätter stehen und von diesen gewülnnlicb nur durch Gestalt und mindere Grölse verschieden sich zeigen. Sie erscheinen

I) einzeln (solicariaz): wenn an der Basis eines jeden Blattes oder Blattstiels nur ein Afterblatt vorkount; z. B. Ruscus Hypoglossum (t. 4I. f. 6.).

2) gepart (geminac): wenn zwey an der Basis eines jeden Blattes oder Blattstiels stehen, wo sie jederzeit auch

3) gegenüberstehcnd (oppositae) sind; z. B. Astragalus glycyplyyllos (t. 17. f. 2. a.), Vicia bientnis (t. 17. f. 4. b.), Orobus niger (t. 19. f. 5. a.), Lathyrus lingetanus (t. 22. f. 2.).

4) blattseitsständig (laterifolize): wenn sie einzeln (Nr. 1.) oder gegenüberstehend (Nr. 3.), den Blatte zur Seite gestell sind. Zu ihrer Erlïuterung dienen die Beyspiele der vorhergehenden (Nr. 3.).

5) blattunterständig (extrafoliaceae): die dicht unter dem Blatte hervorkommen; z. B. Ruscus Hypogiossum (t. 4r. f. 6.).

6) blattüberständig (suprafoliaceae): die über dem Blatte entspringen.

7) blattgegenständig (oppositifoliae): wenn sie auf der andern Seite des Stengels oder der Aeste dem Blatte gegenüber stehen; z. B. Coronilla cororata und zum Theil auch Astragalus arenarius.

S) blattachsclständig (axillares): die der Blattachsel (S. 8ł. Anmerk. nach Nir. 58.) eingefügt sind; z. B. Sambucus nigra, Sambucus Iibulus und die Arten der Gattungen Morus inhd Ficus.

9) LIattstielständig (petiolarcs): die oberbalb der Basis des Blattstiels eingefügt sind; z. B. Rubus nentorosus und Rubus corylifolius.

10) gestielt (podiccllntre): die an dem Orte, wo sie sich zeigen, vermittelst eines Stielchens befestigt sind; z. B. Vicia biennis (t. 17. f. 4. b.).

B b 
II) sessiles: si pedicello destitutae sunt insertae; exemplo inserviant vegetabilia plurima stipulis instructa.

12) connatce: geminae $\left(\mathrm{Nr}, 2_{*}\right)$, si in caule oppositae marginibus lateralibus inter se conjunctae sunt; e. g. Agrimonia Eupatoria (t. 42. 1. f. a.), Alchemilla vulgaris (t. 43. f. 1. a)

15) aduatae: geminae (Nr. 2.), laterifoliae (Nr. 4.), si longitudinaliter petiolo sunt conjunctae; exemplo sunt Potentilla alba (t. 10. f. 1o. d.), Rosa canina (t. 5I. f. 4.) et omnes horum generum species.

14) sphacilatae: si macula brunnea sunt notatac; ut in Vicia sativa.

I5) spinatae; quae spinas (S. 100.) aequant; inspiciatur Robinia Pseudo Acacia.

16) caducae: quae, dum folia explicantur, decidunt; exemplum exhibet Corrlus Avellana.

17) deciduae: quae post foliorum evolutionem, attemen ante eorum casuin, decidunt; e. g. Alnus glutirosa.

rS) persistentes: si cum foliis decidunt vel post eorum casum remanent; exemplo inserviunt plura vegetabilia, praecipue Papilionaceae.

Stipulae in nonnullis foliis compositis basi foliolorum rel pinnarum occurrentes Stipellae nominantur; e. $g$. Phaseolis multiforus (t. 6; - f. 5. a).

Quod reliquum est in determinandis stipulis iidem in foliis (\$. 83. D. E. I. I.) dicti termini adbibentur.

In nonnullarum Iungermanniae specierum foliis distichis instructa:um pagina inferiori Stipulae occurrunt rel simplici ordine, e. g. in Iungermnnnia tamariscifolia et Iungermannia magellanica Lamark (t. 69 . f. 3. a. b.), vel triplici, ut in Iungermannia placyphylla r. Thuie (t. 6g. f. 2. a. b.),
Ir) sitzend (sessiles): wenn sie obne Stielchen eingefügt sind; z. B. dienen die mehresten Gewächse, die mit Afterblättern versehen sind.

12) verwachsen (connatae): wenn sie gepaart (Nir. 2.), am Stengel gegenüberstehend und an den Seitenrändern unter sich verbunden sind; z. B. Agrimonia Eupatoria (t. 42. f. 4. a.), Alcluemilla vulgaris (t. 43. f. I. a.).

13) angewachsen (adnatae): wenn gepaarte (Nr. 2.), blattseitsständige (Nr. 4.) Afterblätter der Länge nach mit dem Blattstiel verbunden sind; z. B. Potentilla alla (t. 40. f. Io. d.), Rosa canina (t. 3 I. f. 4.) und alle Arten dieser Gattungen.

I4) brandig (spluacilatae): wenn sie mit einem braumen Fleck bezeichnet sind; z. B. Jiciu sativa.

15) dornartig (spinntae): welche den Dornen (S. I0o.) gleichon; z. B. Robinia Psendo-Acacia.

16) hinfällig (caducae): die, wälırend die Blätter sich entfalten, abfallen; z. B. Corylus Avellana.

17) abfallend (deciduae): die nach dem Entwickeln der Blätter, aber doch vor dem Abfallen derselben, verschwinden; z. B. Alnus glutinosa.

18) bleibend (persistentes): wenn sie mit den Blättern abfallen oder nach deren Verschwinden noch bleiben; z B. dienen melırere Gewäclıse, vorzüglich die mit Schmetterlingsblumen.

Die Afterblätte:, welche bey einigen zusammengesetzten Blättern an der Basis der Blättchen oder Fiedern sich finden, werden Afterblätıchen (Stipellae) genannt; z. B. Phaseolus multiforus (t. 67. f. 5. a.)

Uebrigen werden zur Bestimmung der Afterblätter eben dieselben Kunstausdrücke angewendet, die bey den Błättern (\$. S3. D. E. F. I.) angezeigt sind.

Bei einigen Jungermanniesarten, welche zwejzeilige Blütter haben, bommen auf des untern Pläche die Afterblätter entweder in einfachen Reiben vor, wie bey der Iungermannia tamariscifolia und Inngermannia magellanice Lamark (t. 6g. f. 3. a. b.), oder in dreyfacher, wie'bey des Jungermannia platyphylla \%. Thuia (t. 6g. f. a a. b.). 
TERMINOLOGIA.

Horum vegetabilium Stipulae ab Ehrhart atque Wieber et MIokr Amphigastria vocantur.

\section{86 .}

Auricula est folium parvum, varie formatum in Iungermanniarum foliis distichis praeditarum axillis (6. 83. observ. post Nr. 53.) vel foliorum basi salitarie occurrens, ut in Iungermannia tamariscifolia et Iun. germannia magellanica Lamark (t. 6g. f. 3. a. c.).

Auriculae species aeque ac foliorum (5. 83. D. E. F. I.) determinantur.

\section{S. 87 .}

Ramertum est folium parvum, membranaceum, magis minusve tenue, plerumque brunneum, post frondescentiam (\$. 8. Nr. 2.) mox deciduum, multiplex npparens in arborum fruticumque junioribus turionibus, qui ante evolutionem ab eo in gemma ( $(5 \cdot 9 x)$ aggregatim - plerumque imbricatim - involvuntur. Exempli loco sit (uercus pedunculata (t. 20. f. 4. a.), Fagus sylvaticn (t. 69. f. It a.), Pinns sylvestris (t. 67. f. 4.).

\section{85.}

Vagina est foliacea pars circumcludens caulem, (\$. 51.), scapum (\$. 53.), praecipue vero culmum (\$. 52.) et plerumque petioli tenens locum. Invenitur:

1) foliifera: in morem petioli suffultiens folium; ut in omnibus Graminibus; e. g. in Melica nutante (tab. libri inscript. ger. vol. I. fig. 4.), Lolio perenni (t. I2. f. 2.), Bromo molli (t. 12. f. 4).

2) aphylla: si folio est destituta; videantur Galanthus nivalis (t. 3. f. 5.), Arum Dracontium (t. 39. f. 4. a.) et vagina infimae Scirpi setacei (t. 23. f. 4.).
Die Afterbläıter dieser Gewïchse werden von Ehpbart und von Weber und Nohs Amiphigastria genannt.

\section{§. $£ 6$.}

Das Öhrchen (Auricula) ist ein kleines, versclieden gebildetes Blatt, welches bey den Jungermannien mit zweizeiligen Blättern in der Blattachsel (5. 8.3. Anmerk. nach Nr. 58.) oder an der Basis der Blătter vorkommt, wie bey Iungermannia tamariscifolia und Inngermannia magellanica Lamark (t. 69. f. 3. a. c.

Die Arten des Öhrchens werden wie die der Blätter (\$. 83. D, E, F. I.) bestimmr.

$$
\text { S. } 87 \text {. }
$$

Die Ausschlagsschuppe (Ramentulm) ist ein kleines, häutiges, mehr oder weniger feines, gewühnlich braunes, nach dem Ausschlagen (\$. 8. Nr. 2) bald abfallendes Blatt, welches bey den Bäumen und Sträuchern vielfach an den jungen Trieben sich zeigt, die es vor der Entwicklung in der Knospe ( $\left(.9^{\mathrm{I}}\right.$.) angehăuft - meistens dachziegelartig - einhüllt. Als Beyspiel stehe hier Quercus pedunculata (t. 20. f. 4. a.), Fagus sylvatica (t. 68. f. 11. a.), Pinus sylvestris (t. 67. f. 4.)

\section{88.}

Die Scheide (Vagina) ist ein blattartiger Theil, welcher den Stengel ( $(5$ I.), den Schaft (\$. 53), vorzüglich aber den Halm (\$. 52.) umschliefst und gewöhnlich die Stelle des Blattstiels vertrit. Man findet sie

r) blattragend (fuliifera): die als Blattstiel das Blatt unterstützt, wie bey allen Gräsern; z. B. Melica nutans (Titelkupfer Bd.I. f. 4.), Lolium perenne (t. I 2. f. 2.) Bromus noollis (t. 12. f. 4.).

2) blattlos (apliylla): wenn ibr, das Blatt fehlt: z. B. Galanthus nivalis (t.3. f. 5.), Arum Dracontium (t. 59. f. 4. a.) und die untersten Scheiden bey dem Scirpus setaceus (t. 23. f. 4.).

$\mathrm{B} \mathrm{b} 2$ 
5) truncata : si est aphylla et onmia sui marginis apicalis puncta uni plano incubant. Apparet vel

a) horizontaliter truncata: margine horizontali, e.g. in Equiseto arvensi (t. 15. f. 3. c.), vel

B) oblique truncata: margine obliquo, ut in Galantho nizali (t. 3. f. 5.); porro

\%) integra: absque incisuris, fissuris vel excisuris, e. g. in Galantho nivali (t. 3. f. 5.), vel

i) dentata: excisuris divisa in angulos acutatos ut Equisetum arvense (t. 15. f. 3. c.) bene mon. strat.

Vagina membranacea in pluribus generis Pini speciebus foilorum fasciculos basi circumcludens secunduin Decandolle Vaginclla appellatur.

S. 89.

Ligula est vaginae (\$. 83.) membrana interna, exstans nbi vagina transit in folium, et plerumque membranulae tenuis pellucidae instar - raro cartilaginea vel e pilis composita - apparens. Graminibus tan. tum est propria. Reperitur:

I) integra: quae incisuris, fissuris vel excisuris non est divisa; e g. Poa pratensis.

2) bifid: : fissura aut excisura ad dimidium tantum in duas lacinias divisa; ut in Festuca varia, Festuca zaxa.

3) bipartita: fissura vel excisura ad basin usque in duas lacinias divisa; videatur Arundo arenaria.

4) lacera: si excisuris et lateribus et apice in plures lacinias irregulariter est divisa; inspiciatur Miliumn efusum, Phleum pratense.
3) abgestutzt (truncata): wenn sie blattlos ist und alle Punkte ihres Endrandes'in einer Ebene liegen. Sie erscheint entweder

a) wagerecht abgestutzt (horizontaliter (runcata): mit wagerechtem Rande, wie bey Equisetum arvense (t. 15. f. 3. c.), oder

B) schief abgestutzt (obligne truncata): mit schiefen Rande, wie bey Galantlus nivalis (t. 3. f. 5.); ferner

\%) ganz (integra): ohne Einschnitte, Spalten oder Aussclinitte, wie bey Galanthus nivalis (t. 8. f. 5.), oder

d) gezähnt (dentata): durch Ausschnitte in spitzige Winkel getheilt, wie bei Equisetum arvense (t. 55. f. 3. c.).

Die häutige Scheide, welche die Blätterbüschel bei melreren Arten der Gattung Pinus an der Easis umschliefst, heifst nach Decandolle das Blattscheidchen (Vaginella).

S. 89 .

Das Blatthäutchen (Ligula) ist die innere Haut der Scheide (\$. SS.), die da hervortrit, wo die Schide in das Blatt, und gewöhnlich als ein zartes, durchscheinendes Häutchen - selten knorpelartig oder aus Huaren bestehend - sich zeigt. Es ist nur den Gräsern eigen. Man findet es:

1) ganz (integra): das nicht durch Einschnitte, Spalten oder Auschnitte zertheilt ist; z. B. Poa pratensis.

2) zweyspaltig (bifila): das durch eine Spalte oder einen Ausschnitt nur bis zur Hälfte in zwey Ziplel zertheilt ist; z. B. Festuca varia, Festuca lax $r$.

3) zweytheilig (Uipartita): das durch eine Spalte oder einen Ausschnitt bis an die Basis in zwey Zipfel getheilt ist; z. B. Arundo arenaria.

4) zerschlitzt (lacera): wenn es sowohl an den Seiten, als auch an der Spitze, unregelmäfsig durch Aussclinitte in mehrere Zipfel zertheilt ist; z. B. Miliım effusum, Pluleum pratenșe. 
5) truncata: apex si linea transversali recta terminatur; exemplo sit Por serotina.

6) obtusa: vid. S. \$3. Nr. I1 1.; exempla sunto Poa praiensis, Pua aqualica, diopecurus pratensis.

7) acistu: vid. \$. 83. Nr. III.; e. g. Avena planiculmis, Avenu versicolor.

8) acuminata: vid. S. 83 . Nr. I12.; exemplum praebet Melica uniflora.

9) biaurita: si - ut plenumque - est brevissima (Nr. 15.) et utroque latere baseos in auriculae forma procedit e vagina; e. g. Festuca ovina (t. 67. f. 2 . et 3. b.)

10) decurrens: ubi est brevissima (Nr. 13.) vel pilosa (Nr. 12.) et si utroque latere vaginae continuatur; exempla sunt Calamagrostis minima, Panicum gluncum.

I) carti'aginea: si est tumida, solida, tenax et brevissima (Nr. 13.); e. g. Bromus giganteus.

12) pilosa: quae e pilorum parallelorum serie constans; inspiciantur Arundo Pluragmites, Melicu coerulea, Punicum glaucum.

13) Zrevissima: cujus longitudo latitudinis octavam partem non superat; ut in Stipa pennata, Festuca pratensi.

14) brevis: cujus longitudo octavam latitudinis partem excedit, nec dimidiam latitudinem superat; exemplum praebet Lagurus ovatus.

15) longa: si dimidio latiudinis est longior, neque totam latitudinem et dimidiam superat; videatur Alopecurus agrestis.

16) longissima: cujus longitudo totam latitudinem et dimidiam superat; e. g. Poa trivialis, Sira flexuosa, Agrostis Spica venti. Hacc ligulae species - nec non praecedens (Nr. 15.), si accedit ad baac - ple. rumque elongata appellatur.
5) abgestutzt (truncata): wenn die Spitze durch eine gerade Querlinie begränzt wird; z. B. Pon serotina.

6) stumpf (olitusa): m. s. S. S3. Nr. II 4.; z. B. Poa pratensis, Poa aquatica, Alopecurus prateusis.

7) spitzig (acuta): m. s. \$. 83. Nr. III.; z. B. Avena planiculmis, Avena versicolor.

8) zugespitzt (acuminata): M. s. \$. 55. Nr. I12.; z. B. Melica uniflora.

9) zweyohrig (bianrica): wenn es - wie gewöhnlich - selır kurz (Nr. I3.) ist, und an beyden Seiten der Basis in Gestalt eines Oehrchens aus der Scheide hervortrit; z. B. Festuca ovina (t. 67. f. 2. u. 3. b.).

10) herablaufend (decurrens): wenn es selur kurz (Nr. 13.) oder haarig (Nr. 12.) ist, und an beyden Rändern der Scheide sich fortsetzt; z. B. Calamagrostis minima, Panicum glancum.

11) knorplig (cartilaginea): wenn es aufgetrieben, fest, zälıe und sehr kurz (Nr, 13.) ist; z. B. Bromus giganterıs.

12) ha arig (pilosa): welches aus cirer Reihe gleichlaufender Haare besteht; z. B. Arundo Phrogmites, Melica coerulea, Panicum glaucum.

13) selır kurz (brevissima): dessen Långe nicht über den achten Theil der Breite beträgt; z. B. Stipa pennata, Festuca pratensis.

14) kurz (brevis) : dessen Länge melir als den achten Theil der Breite beträgt, nicht aber die Hälfte der Breite übertrift; z. B. Lagurus ovatus.

I5) lang (longa): wenn es länger ist als die Hälfte der Breite, diese aber nicht über tin und ein halbes Nal übertrifft; z. B. Alopecurus agrestis.

16) sehr lang (longissima): dessen Länge die Breite mehr als ein und ein lialbes Mal übertrift; z. B. Poo irivialis, Aira flexnosa. Diese Art des Blatthäutcheus - und auch die vorhergebende (Nr. 15.), wenn sie sich dieser nähert - wird gewölnnlich verlängert (elongatu) genannt. 


\section{S. 90.}

Oclurea est foliacea vel membranacea pars in generibus Polygoni et Rumicis supra foliorum basin excedens et caulem cingens, in pluribus generis Cyperi speciebus contra pedunculos pedicellosque basi includens. Reperitur:

I) foliifera: margo apicalis si in folium - plerumque lineare vel subulatum - terminatur. In nonnullis generis Cyperi sdeciebus tantum occurrit.

2) apluylla: si, ut plurimum provenit, ejus margo epicalis non extenditur in folium; e. g. Cyperus longuls (t. 45. f. 2. a.).

3) truncata: vid. S. 83. Nr. 3. Conspicitur:

a) horizontaliter truncata: vid. S. S8. Nr. 3. ж.; exemplum praebet Cyperus longus (t. 45. f. 2. a.)

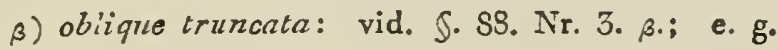
Polygonum Bistorta (t. 8. f. 4. b.), Cyperus Monti.

y) integra: vid. S. S8. N. 3. g.; exemplum exhibet Polygonum Bistorta (t. 8. f. 4. b.), Cyperns longus (t. 45. f. 2. a.)

8) lacera: pluribus fissuris in angustas lacinias divisa; ut in Polygono aviculari (t. 67. f. 7. a.).

Ochreae parvae pedunculos proprios vel pedicellos circumcludentes Ochreslae bractenceae aptius nominantur.

S. 9r.

Gemina est rudimentum ad vegetabilis ramum vel totum caudicen adscendentem (\$. 47.), prout in trunci (5. 50.) ramis vel in radice adest. Climatum frigidorum arboribur fruticibusque tantum et suffruticibus est propria. Vera nominatur, si Tegmento e Squamis ficto circumcluditur; sproria contra, si illo
S. 90.

Die Tute (Ochrea) ist ein blattartiger oder bäutiger Theil, welcher bey den Gattungen Polygonum und Rumex über die Basis der Blätter hervortrit und den Stengel umgiebt, bey mehreren Arten der Gattung Cypertıs hingegen die Blumenstiele und Blumenstielchen an der Basis umschliefst. Man findet sie:

I) blatttragend (foliifera): wenn sich ihr Endrand in ein - gewölnnlich linien- oder pfriemförmiges - Blatt endigt. Sie kommt nur bey einigen Arten der Gattung Cyperus vor.

2) blattlos (aphyłlla): wenn, wie sie gewöhnlich vorkommt, ihr Endrand sich nicht in ein Blatt ausdehnt; z. B. Cyperus longus (t. 45. f. 2. a.).

3) abgestutzt (truncata): m. s. S. 83. Nr. 3. Sie erscheint:

a) wagerecht abgestutzt (horizontaliter truncata): m. s. S. 88. Nr. 3. a.; z. B. Cyperus longus (t. 45. f. 2, a.).

$\beta$ ) schief abgestutzt (oblique truncata): $\mathrm{m}$. 8. S. 8S. Nr. 3. B.; z. B. Polygonum Bistorta (t. S. f. 4. b.), Cyperus Monti.

y) ganz (integra): m. s. S. 88. N. 3. y.; z. B. Polygonum Bistorta (t. S. f. 4. b.), Cyperus longus (t. 45. f. 2. a.).

j) zerschlitzt (lacera): durch mehrere Spalten in schmale Zipfel zertheilt; z. B. Polygonum aviculare (t. 67. f. 7. a.).

Die kleinen Tuten, welche die besondern Blumen. stiele oder Blumenstielchen umschliefsen, werden pas- ender nebenblattartige Tutchen (Ochreolae bracteaceae) genannt.

\section{S. 9 T.}

Die Knospe (Gemma) ist der Entwurf zu einem Zweige oder zum ganzen aufsteigenden Stocke (S. 47.) des Gewächses, je nachdem sie an den $\ddot{A}$ sten des Stammes ( $\$$. 50.) oder an der Wurzel erscheint. Sie ist nur den Bäumen und Sträuchern kalter Himmelsstriche und den Stauden eigen. Sie heilst 
destituta. Praeterea sequentes species distingu- echt (vera), wenn sie von einer aus Schuppen untur.

(Squamae) gebildeten Decke (Tegunentum) umschlossen ist; unecht (spuria) lingegen, wenn ihr diese fehlt. Aufser diesen unterscheidet man noch folgende Arten :

«. Nach den Theilen, die sich aus der

$$
\text { Knospe entwickeln. }
$$

«. Secundum partes se e gemma evolventes.

I) fuliifera: e. g. omnes gemmae in genere Alni et gemma terminalis (Nr. II.) in Pruno domestica, Amygdalo Persica et pl. al.

2) Rorifera: et quidem :

a) hermaphrodita: e. g. gemmarum lateralium (Nr. 10.) superiores in Daphne Mezereo, Amygdalo Persica et pl. al.

b) mascula: e. g. gemmae laterales superiores in Salicis viminalis mare et pl. al.

c) Jeminea: e. g. gemmarum lateralium superiores in Sulicis viminalis feminu,

3) foliifera et florifera: et quidem ratione Horum:

a) hermaphrodita: e. g. Staphylea pinnata, $P y$ rus Malus et $\mathrm{pl}$ al.

b) mascrula: e g. in genere Pini, Salicis triandrae mare et pl. al.

c) feminea: e. g. in generibus Coryli, Carpini, Betulae, siquidem in Salicis triandrae femtino et pl. al.

\section{Secundum tegmentum.}

4) valiata: tegmenti squamae exteriores si interioribus sunt longiores. Hic distinguuntur:

a) univalvis : tegmenti extima squama - Valvnla dicta - si totam gemmam includit, ut in generis Salicis speciebus; e. g. Salix triardra mas (t. 4T. f. 3. a.).

b) bivalvis: si dice squamse sunt extimae, et

1) blätterbringend (foliifero): z. B. alle Knospen bey der Gattung Alnzss und die gipfelständige (Nr. II.) bei Prunus dumestica, Amjgdalus Per. sica u. m. a.

2) blumenbringend (florivera), und zwar:

a) zwitterlich (hermaplurodita): die obern seitenständigen Knospen (Nr. Io.) bey Daplune Mczereum, Amygdalus Persica u. m. a.

b) männlich (mascula): die obern seitenständigen Knospen bey Salix viminalis mas u. m. a.

c) weiblich (feminea): die obern seitenstïndigen Knospen bey Salix viminalis femina u. m. a.

3) blätter - und blumenbringend (foliifera et florifera), und zwar in Rücksicht der Blumen:

a) zwitterlich (htrmaphrodita) bey Staphylea pinnata u. m. a.

b) männlich (mascula) bey der Gattung Pinus, Salix triandra mas u. m. a.

c) weiblich (feminea) bey den Gattungen $C_{o}$ rylus, Carpinus, Retula, so wie auch bey Salix triandra femina u. m. a.

$$
\text { B. Nach der Decke. }
$$

4) klappig (valiata): wenn die äussern Schuppen der Decke länger sind als die innern. Man unterscheidet hier:

a) einklappig (univalvis): wenn die äusserste Schuppe der Decke, welche Klappe (Valvula) heifst, die ganze Knospe einscliliefst; wie bey den Arten der Gattung Salix; z. B. Salix triandra mas (t. 4I. f. 3. a.)

b) zweiklappig (bivalvis): wenn zwey Schup- 
gemma hac de re valvulis duabus est tecta; exempla exhibent Stapliylea pinnata(t. 67. f. 12. a.), Acer persyluanicum.

5) imbricata: extimae tegmenti squamae si interioribus ita sunt breviores, ut in morem laterum seu im-

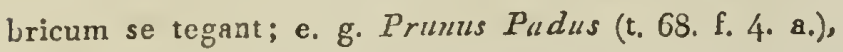
Pruntus domestica (t. 68. f. 7. a.), Ulmi suberosae gemma folifera (t. $G_{7}$. f. S. b.). Adhuc distinguuntur :

a) bifariam imbricata: si squamae duas series formant; exemplo sit Ulmi suberosae gemma forifera (t. 67. f. 8. a.).

b) quadrifariam imbricala: squamae si in quatuor series sunt dispositae; exemplum praebet $S_{y}$ ringa wulgaris (t. 6S. f. 2. a.).

\section{y. Secundum nexum cunn ramis.}

6) pedicellata: gemma si pedicelli beneficio ramo est inserta ; exemplo sint Alnus glutinosa (t. 68. f. 6. a), Cornus alba (t. 68. f. 5. a.).

7) sessilis: quae ipsa cum ramo est connexa; e.g. plurimae arbores fruticesque gemmis instructae.

S) immersa: quae in cortice incubat, ita tamen, ut conspiciatur; e. g. Ptelea trifoliata (t. 67. f. ro. u. 1 I. a.).

9) recondita: quae phyllulae (\$. 103.) immersa et ita est tecta, ut conspici nequeat; exemplum praebet Philadelplus coronarius (t. 68. f.. 14. 15. 16. c., 17. a).

\section{d. Securdum dispositionem.}

10) laterales: quae in rami lateribus adsunt (t. 68 . f. 2. 4. 5.6. a.), ubi adtuc distinguantur:
I I I II I O L O G I E.

pen die äussersten sind, und die Knospe daher von zwei Klappen bedeckt wird; z. B. Staplyylea pirtnata (t. G7. f. I2. a.), Acer pensyluanicum.

5) ziegeldachartig (imbricata): wenn die äussern Schuppen der Decke kürzer sind als die innern, so, dals sie nach Art der Dachziegel sich decken; z. B. Prunus Padus (t. 68. f. 4. a.), Prunus domestica (t. 68. f. 7. a.), die blitterbringende Knospe der Ulintis suberosa (t. 67. f. 8. b.). Man unterscheidet hier noch :

a) zweyzeilig - ziegeldachartig (bifariam imbricata): wenn die Schuppen zwey licihen bil. den; z. B. die blumenbringende Knospe der Uimus suberosa (t. 67. f. 8. a.).

b) vierzeilig - ziegeldachartig (quadrifariam imbricata): wenn die Schuppen in vier Reihen gestellt sind; z. B. Syringa vulgaris (t. 68 . f. 2. a.).

r. Nach çer Verbindung mit den Asten.

6) gestielt (pedicellata): wenn die Knospe vermittelst eines Stielchens dern Aste eingefügt ist; z. B. Alnus glutinosa (t. 68. f. 6. a.), Cornus alba (t. 68. f. 5. a.).

7) sitzend (sessilis): die unnittelbar mit dem Aste verbunden ist; z. B. die meisten Bäume und Sträucher, welche Knospen haben.

8) versenkt (immersa): die in der Finde liegt, jedoch so, dafs man sie sehen kann; z. B. Ptelea trifoliata (t. 67. f. 10. u. II. a.).

9) verborgen (recundita): die in die Phatmarbe (S. I 0 j.) eingesenkt und bedeckt ist, so, dafs man sie nicht sehen kann; z. B. Plitladelpluzs coronarius (t. 63. f. 14. 15. 16. c., 17. a.).

\section{Nach der Stellung.}

I0) seitenständig (Interales): die an den Seiten des Astes steben (t. 68. f. 2. 4. 5. 6. a.), wo man noch unterscbeidet : 
a) inferiores et

b) superiores. Porro:

c) alternae: ut in ramis $\$ .58 . \mathrm{Nr} .3$.; inspiciantur Prunus Padus (t. 68. f. 4. a.), Prunus domestica (t. 68. f. 7. a.).

d) oppositae: sicut in ramis $\$ .58$. Nr. 4.; videantur Syringa vulgaris (t. 63. f. 2.), Philadelpluzs coronarius (t. 68, f. 14. 16, c. 17. a.).

e) ternae: ut in foliis $\$ . \mathrm{S} 3 . \mathrm{Nr}, 15$. ; exempli lo. co est Bignonia Catalpa.

I) cerminalis: quae rami apici insistit (t. 68. f. 2. 4. 5. 6. $\mathrm{a}^{*}$ ).

\section{ع. Secundum numerum.}

12) solitaria: si ad quamvis phyllulam (\$. 10j.) una tantum gemma reperitur, ut in plurimis arboribus fruricibusque gemmis instructis; exempli loco sunt Prunus domestica (t. 68. f. 7. a.), Syringa vulgaris (t. 68. f. 2. a.).

13) aggregata: plures gemmae, si supra quamvis phyllulam (\$. 103.) insistunt; e. g. geminae laterales (Nr. Io.) Pruni Armeniscae et terminales (Nr. II.) Quercus pedinculatue (t. 68. f. 19. a.*).

Ratione directionis ac figurae gemma sicut folia (\$. 83. E. et 1.) et superficiei secundum §. g. determinatur. Color, qui in gemma valde est perpetuus, itidem est describendus. Jam adbuc pbylloplocium gemmae pliyilulam (\$. 103.) ac gibbum (\$. 102.) observantes et rationem superficiei ac coloris ramul rum habentes: nobis describuntur diagnoses, quibus arbores fruticesque hieme distingui possunt.

Arborum, fruticum suffruticumque gemmae si vere intumescunt, hoc dicitur Foliatio; foliorun hucusque in gemma latentium, nondum explicatorum complicatio vocalur Pliylloplocium. Ejus species ex gemmae trsanversali sectione cognoscendae sunt sequentes: a) untere (inferiores) und

b) obere (superiores). Ferner:

c) wechselsweisstehende (alternae): wie bey den Ästen, S. 58. Nr. 3.; z. B. Prunus Padus (t, 68. f. 4. a.), Prunus domestica (t. 63. f. 7. а.).

d) gegen überstehende (oppositae): wie bey den Ästen, \$. 58. Nr. 4.; z. B. Syringa vulgaris (t. 68. f. 2. a.), Pliladelpluts coronarius (t. 68. f. 14. 16. c. 17: a.).

e) dreifache (ternae): wie bey den Blättern §. SS. Nr. 15.; z. B. Bignonia Catalpa.

I1) gi pfelständige (terminalis): die auf der Spitze des Astes sich befindet; (t. 68. f. 2. 4. 5. 6. a*).

8. Nach der Zahl.

12) einzeln (solitaria): wenn bey jeder Blattnarbe (\$. 103.) nur eine Knospe sich findet, wie bey den meisten Bäumen und Sträuchern, welche mit Knospen versehen sind; z. B. Prunus domestica (t. 68. f. 7. a.), Syringa vulgaris (t. 68. f. 2. a.).

13) gehäuft (aggregata): wenn mehrere Knospen über jeder Blattnarbe (S. 103.) stehen; z. B. die seitenstïndigen (Nr. Io.) Knospen bey J'runus Armeniaca und die gipfelstāndigen (Nr. II.) bey (uercus peduuculata (t. 6S. f. 19. a."

Der Richtung und der Gestalt nach bestimme man die Knospe wie die Blätter (\$. 63. E. und 1.) und in Rücksiclıt der Oberlache nach §. 9. Die Farbe, welche bey der Knospe sehr beatändig ist, mufs ebenfalls beschricben werden. Ziehe man dann norb das Blattgefïge der Knospe, die Blatuarbe (\$. 103.) und den Buckel (s. r02.) hinzu, und sieht dabey mit auf die Oberfïcbe und Farbe der Ästchen, so lassen sich Diagnoseu entwerfeu, durch welche man Däume und Strïu. cher im Winter unterscheiden kann.

Venn die Knospen der Bäume, Sträucher und Stauden im Früljahre anscliwellen, und die Blätter hervorzutreiben anfangen, so nennt man dies das Ausschlagen (Foliatio); die Zusammenfügung der bis dahin in der Knospe liegenden, noch unentfalteten Blätter, C c 
I) complanatum: gemmae folia recta,-parallela, magis uninusve plana si eorum planities inter se acclinant; exemplum exhibet Amaryllis formosissima (t. 68. f. I. a. b.).

2) reclinatun: si gemmae folia ita sunt complicata, ut cujusvis folii pars superior inferiori incubet; e. g. Aoonitum ueonoutaunum (t. 68. f. I8. a. b.).

3) complicatum: si unum foliorum quodvis interiorem paginam versus ad costam mediam - vel, si plures costae seu nervi adsunt, ad quemvis eorum - in longitudinem se complicat, vel tamen se complicare nititur. Hic distinguuntur:

a) conduplicatum: folii cujusvis duo dimilia si in longitudinem ad costam mediam ita se complicant, ut paginis interioribus se contingant: videatur Pranus Padus (t. 68. f. a. b.).

b) interplicatum: duo cujusvis folii dinidia si in longitudinem ad costam mediam ita se complicant, ut duorum adversum directorum foliorum quodvis dimiditim alterum alteri folio imponat; exemplum praebet Cornits alba (t. 68. f. 5. a. b.).

c) equitans: folia magis minusve adversum directa si duobus dimidiis in longitudinem ad costam mediam ita se complicare nituntur, ut interior exterioris Solii pagina exteriorem folii interioris contingat. Distinguuntur:

a) Zifariam equitans: si folia in duabus seriebus genmae incubant; e. g. Hemerocallis fulva (t. 68. f. 8. a. b.), generis Iridis species.

B) trifariam equitans: si folia tres exhibent se- heifst das Blattgefüge (Pliglloplocium). Die Arten desselben, die man erkennt, wenn man die aufgeschwollene Knospe queer durchschneidet, sind folgende:

I) geflächt (complanatum): wenn die geraden, gleichlaufenden, mehr oder weniger ebenen Blätter der Knospe ihre Flächen an einander legen; z. B. Amaryllis formosissima (t. 68. f. 1. a. b.).

2) zurückgelehnt (reclinatım): wenn die Blätter der Knospe so zusammengelegt sind, dals der obere Theil eines jeden Blattes auf dem untern Theile liegt; z. B. Aconitum neomontanum (t. 68. f. 18. a. b.).

3) zusammenliegend (complicatnm): wenn jedes der Blätter nach der innern Fläche an der Mittelrippe - oder, wenn mehrere Rippen oder Nerven vorhanden sind, an jeder derselben, - der Länge nach sich zusammen legt oder wenigstens zusammen zu legen sich strebt. Hier unterscheidet man:

a) dop peltliegend (conduplicatum): wenn die beyden Hälften eines jeden Blattes längs der Mittelrippe sicl zusammen legen, so, dafs sie sich mit den innern Flächen berühren; z. B. Prunuls Padus (t. 68. f. 4 . a b ).

b) $\mathrm{z}$ wischenliegend (interplicatum): wenn die beyden Hälften eines jeden Blattes sich längs der Mittelrippe so zusammenlegen, dafs jedes zweyer sich entgegengerichteter Blätter die eine Hälfte in das andere legt; z. B. Cornus alba (t. 68. f. 5. a. b.).

c) reitend (equitans): wenn die mebr oder weniger sich entgegen gerichteten Blätter mit beyden Hälften sich lïngs der Mittelrippe zusammen zu legen streben, so, dafs die innere Fläche des äufsern Blattes die äufsere des innern berührt. Man unterscheidet:

o.), zweizeilig-reitend (bifariam equitans): wenn die Blitter in der Knospe in zwey Reihen liegen; z. D. Hemerocallis fulva (t. 68. f. S. a. b.), die Aiten der Gatiung Iris.

B) dreyzeilig-reitend (trifariam equi- 
ries; exemplum praebet Carex caespitosa (t 68 . f. 3. a. b.).

r) quadrifariam equitans: folia si in quatuor series sunt disposita; ut in Syringa vulgari (t. 68 . f. z. a. b ).

d) plicatum: folia si pluribus costis aut nervis sunt instructa et ad horum quemvis in longitudinem complicata. Distiuguuntur:

a) opposite plicatum: ubi folia bina opposita gemmae incubantia, post evolutionem etiam boc modo apparent; videatur Cornus alba (t. 68. f. 5. a. b.)

B) sparse plicatum: folia si sparse incubant gemnae, post evolutionem vero plerumque alterna conspiciuntur; tali phylloplocio gaudet Alnus glutinosa (t. 68. f. 6. a. b.).

4) volutatum : si folia ab altero margine laterali alterum versus magis minusve sunt voluta. Hic distinguuntur:

a) convolutum: marginum lateralium alter axis tenens locuin a toto lolio paginam interiorem versus circamvolvitur; vel, foliorum costa media insigniens alterum folii dimidium paginam interiorem versus se involvit et ab altero directione contraria circumflectitur; exempli loco sunt Convallaria majalis (t. 68. f. 12, a. b), Prmnus doinestica (t. 6S. f. 7. a. b.), Prunus Armeniaca.

b) involutum: si margines foliorum laterales paginam interiorem versus sunt volutati, ubi sicut in phylloplocio plicato (3. d. ๔. $\beta$.) simili modo distinguuntur:

a) opposito involutum: ut in Fvonymo europaeo (t. 68. f, 9. a. b). tans): wenn die Blätter in drey Reihen liegen;

z. B. Carex caespitosa (t. 68. f. 5 a. b.)

y) vierzeilig-reitend. (qnadrifariam equitans): wenn die Blätter in vier Reihen liegen; z. B. Syringa vulgaris (t. 69. f, 2. a. b.).

d) gefaltet (plicatım): wenn die Blätter mehrere Rippen oder Nerven haben und an jeder derselben der Länge nach zusammen gelegt sind. Man unterscheidet :

a) gegenüberstehend-gefaltet (opposite plicatum): wenn die Bläter in der Knospe paarweis gegenüber liegen, und auch nach der Entwickelung so erscheinen; z. B. Cornus alba (t. 68. f. 5. a. b.).

B) zerstreut-gefaltet (sparse plicatum): wenn die Blätter in der Knospe zerstreut liegen, nach ihrer Entwickelung aber gewölınlich wech. selsweisstehend sich zeigen; z. B. Fagus sylvati:a, Alnus glutinosa (t. 68. f. 6. a. b.).

4) gerollt (volutatum): wenn die Blätter melır oder weniger von einem Seitenrande nach dem andern gerollt sind. Hier unterscheidet man:

a) zusammengerollt (convolutum): wenn einer der Seitenränder als Achse dient, um welche das ganze Blatt nach der innern Fläche sich aufrollt; oder, wenn die Mittelrippe der Blätter sich auszeichnet, die eine Hälfte des Blattes sich nach der innern Fläche aufrollt, und die andere sich um diese, in entgegengesetzter Richtung herumschlägt; z. B. Convallaria majalis (t. 63. f. 12. a. b.), Prunus domestica (t. 68. f. 7. a. b.), Prunus Armeniaca.

b) eingerollt (involutum): wenn die Seitenränder der Blätter nach der innern Fläche gerollt sind, wo man auf gleiche Art wie bey dem gefalteten Blatigefüge (3. d, $\alpha \cdot \beta$.) unterscheidet:

a) gegenüberstehend-eingeroht (opposite-involutum); 2. B. Evonymus europaeus (t.68. f. 9. a. b.)

C c 2 
B) sparse involutum: e. g. Populus dilstata

(t. 68. f. 10. a. b.).

c) revolutum: margines foliorum laterales si paginam exteriorem versus sunt volutati. Itidem ut antea (b. a $\beta$.) simili modo distiguuntur:

a) opposite revolutum: exemplum praebet Rosmarinus officinalis (t. 68. f. 13. a. b.)

3) sparse revolutum : exemplum exhibet Andromeda rosmarinifolia (t. 68. f. 20. a. b.).

5) circinatum: Frons, ut solis in Filicibus, si pagina dorsali ab apice deorsum est volutata, e. g. Folypodiuin vulgare (t. 2. f. 6.)

Juxta depictas gemmarum sectiones transversales (t. 69.) etiam a Linnaco delineatas figuras ideales ad. jeci, quae, ut insigniant, non sunt coloratae.

\section{S. $9^{2}$.}

Ascidium est pars foliacea, cava, operculo instructa, plerumque aquam continens. Invenitur:

1) cirrlato-pedicellatum: quod cirrho (S. 99.) folii cirrhosi (\$. 83. Nr. 115.) est insertum, ut in omnibus generis Nepenthis speciebus hucusque detectis; exemplo inserviat Nepenthes destillatoria (t. 69, f. 10).

2.) sessile: quod absque cirrho ulloque pedicello vegetabilis parti, ubi occurrit, est insertum, ut in omnibus generis Sarraceniae speciebus; videatur Sarracenia purpurea (t. 67. f. 14\%).

\section{S. 93.}

Bracteae sunt folia prope flores positae ab ejusdem vegetabilis veris foliis forma et saepe etiam colore ac
B) zerstreut - eingerollt (sparse-involutum); z. B. Populus dilatata (t. 68. f. 10. a. b.) c) zurückgerollt (revolutum): wenn die Seitenränder der Blätter nach der äufsern Fläche gerollt sind. Man unterscheidet hier ebenfalls auf gleiche Art wie vorher (b. $\alpha_{0} \beta_{0}$ ):

a) gegenüberstelıend-zurückgerollt (opposite revoluthm); z. B. Rosmarinus officinalis (t. 6y. f. 13. a. b.)

ß) zerstreut-zu rückgerollt (sparse revolu(um); z. B. Andromeda rosmarinifolia (t. 69 . f. 20. a. b.).

5) schneckenförmig (circinatum): wenn, wie nur allein bey den Farrnkräutern, der Wedel auf der Rückfläche von der Spitze abwärts gerollt ist; z. B. Polypodium vulgare (t. 2, f. 6.).

Neben den abgebildeten Queerdurchschnitten der Knospen (t. 68.) habe ich auch die von Linné entworfenen idealen Figuren hiazugefügt, die der Auszeichnung wegen unilluminirt geblieben sind.

$$
\text { S. } 9^{2} \text {. }
$$

Der Schlauch (Ascidium) ist ein blattartiger hohler, mit einem Deckel versehener Theil, der gewöhnlich Wasser enthält. Man findet ihn:

1) wickelrankig-gestielt (cirrlato-pedicella. ( $九$ ) : wenn er der Wickelranke (S. 99.) eines wickelrankigen Blattes ( $($. 83. Nr. I15.) eingefügt ist, wie bey allen bis jetzt entdeckten Arten der Gattung $N e$ penthes; z. B. diene hier Nepenthes destillatoria (t. 69 . f. Io.).

2) sitzend (sessile): wenn er obne Winkelranke oder irgend einen Stiel dem Theile des Gewächses, auf dem er vorkommt, eingefügt ist, wie bey allen Arten der Gattung Sarracenia; man sehe z. B. Sarracenia purpurea (t. 67. f. 14.).

$$
\text { S. } 93 .
$$

Die Nebenblätter (Bracteae) sind Blätter, welche nahe bey den Blumen stehen, und von den eigent. 
minori magnitudine differunt; e. g. Tilia ( $t .32$. f. 3. b.), Rhinanthus Christa galli (t, 22. f. 3. b.). Si pedunculus est divisus, eae tantum Bractere dicuntur, quas pedunculo communi (\$. 6o.) insistunt, ut in Silene nutante (t. 13. f. 5. c.), eae contra, quae in pedunculis partialibus seu pedicellis ( $($. 6o.) proveniunt, Bracteolae appellantur (t. 13. f.5. d.). Bracteae secundum durationem sunt:

1) caducae: ante floris explicationem vel sub eadem decidentes.

2) deciduae: ante fructus maturationem delabentes.

3) persistentes: ad fructus maturationem usque remanentes.

Ceterum bracteae sicut folia (\$. 83. C. D. E. J.) determinantur; attamen ratione figurae bractea ascidifformis. vel galeata in generibus Ascii, Ruyschiae et Marcgraviae occurrens digna est, quae memoretur. Conspicitur pedicellata in Ascio violaceo (t. 67. f. 15.), sessilis in Ruyscha Surubea.

\section{S. 94 .}

Coma est foliorum vel bractearum (S. 95.) supra Hores congestarum complexus. Apparet:

I) foliata: e foliis composita; e. g. Bromelis Ananas, Eucomis punctata, Fricillaria imperialis (t. 67. f. Iว.).

2) bracteate: e bracteis constans; exemplum exbibet Lavandula Stoecleas (t. 37. f. 7.).

S. 95 .

Involucrum est bractearum (S. 93.) sub floribus yer- lichen Blättern desselben Gewächses durch Gestalt und oft auch durch Farbe und geringere Gröfse vẹschieden sich zeigen; z. B. Tiliı (t. 32. f.3. b.) Rinanthns Clzrista galli (t. 22. f. 3. b.). Wenn der Dlumenstiel sich zertheilt, so heifsen die nur Nebenblätter (Bracteae), welche auf dem allgemeinen Blumenstiel (s. 60.) sichen, wie bey Silene nutans (t. 13. f. 5. c.), die hingegen, welche an den besondern Blumenstielen oder den Blumenstielchen (\$. 6o.) vorkommen, werden $\mathrm{Ne}$ benblät tchen (Bracteolae) genannt (t. 13. f. 5. d.). Der Dauer nach sind die Afterblätter:

1) hinfällig (caducae): die vor oder während der Entfaltung der Blume abfallen.

2) abfallend (deciduae): die vor der Reife der Frucht verschwinden.

3) bleibend (persistentes): die bis zur Reife der Frucht bleiben.

Übrigens bestimmt man diø Nebenblätter wie die Blätter (§. 83. C. D. E. J.); jedoch verdient der Ge. stalt nach noch das schlauchförmige oder helmförmige Nebenblatt (Bractea ascidiiformis vel ga. leata), welches sich bey den Gattungen Ascium, Ruyschia und Maregravia findet, bemerkt zu werden. Es zeigt sich gestielt (petiolata) bei Asciun violaceum (t. 67. f. I5.), sitzend (sessilis) hingegen bey Ruyschia Surubea.

$$
\text { ๑. } 9 \text { f. }
$$

Der Schopf (Coma) ist eine Vereinigung von Blättern oder Nebenblitttern ( $(9.9$.$) , die über den$ Blumen büschelständig zusammengestellt sind. Man sicht ihn:

I) blättrig (foliata): wenn er aus Blättern zusammengesetzt ist; z. B. Bromelia Ananas, Eucomis punctata, Fritillaria imperialis (t. 67. f. 13.).

2) nebenblättrig (Uracteata): wenn er aus Nebenblättern besteht; z. B. Lavandula Sroeclass (t. 3\%. f. 7. .).

S. 95.

Die Hülle (Involucrum) ist cine Vereinigung von 
ticillatim congestarum complexus. Vnuın florem vel plures ante eorum evolutionem includit, quamvis post eandem nonnunquam flori longe distat, ut in generis Pulsatillae speciebus (t. 47. f. ro. a.), ubi tum Pedunculus conspicitur involucratus. Involucri partes Foliola nominantur. Involucri species, quae distinguuntur, sunt sequentes:

I) viniversale: quod in Umbelliferis umbellae universali ( $\$ .7 . \mathrm{Nr} .4$ ) est subjectum; e. g. Caclirys Libanotis (t. 4r. f. 4. a.), vel cymae suppositum; e. g. Astrantia major (t. 5o. f. 2. a.).

2) partiale vel Involucellum: quod in Umbelliferis sub umbella partiali (S. 70. Nr. 5.) est positum; e. g. Caclury's Libanotis (t. 4r. f. 4. b.) Bupleurum rotundifolium (t. 16. f. 4. b.), Astrantia major (t. 50. f. 2. b.).

3) commune: in aliis vegetabilibus, quam Umbelliferis occurrens plures tlores cirigit.

4) proprium: unum florem tantum cingens.

Hic et praecedens terminus (Nr. 3. et 4.) vero ut oppositi tantum adhiberi possunt; praeterea semper Involucrune tantum dicitur, ut in Armeria vulgaris (t. $4^{0}$. f. I.), Pulsatilla prateneis (t. 47. f. 10. a.).

5) vaginale: quod basi in vaginam pedunculum includentem est productum; ut in Armeria vulgari (t. 40. f. I.).

6) integrum: si, ut plurimum, florem vel inflorescentiam undique cingit; exempla exhibent Caclirys Libanotis (t. 4r. f. 4. a. b.), Buplererum rotundifolium (t. 16. f. 4. b.), Astrantia major (t. 50. f. 2. a. b.).

7) dimidiatnm: floren vel inflorescentiam partim tantum cingens; exempnli loco est Aethusa Cynapium (t. 69. f. 5. a.).
Nebenblättern ( 5.93.$)$, die unter den Blamen quiriständig zusammen gestellt sind. Sie schliefst eine oder mehrere Blumen vor der Entwickelung derselben ein, wenn sie gleich zuweilen nach derselben weit von der Blume entfernt ist, wie bey den Arten der Gattung Pulsatilla (t. 47. f. 10. a.), wo alsdann der Blumeastiel gehüllt (involncratus) erscheint. Die Theile der Hülle werden Blättchen (Foliola) genannt. Man unterscheidet folgende Arten der Hülle:

1) allgemeine (universale): die bey den Doldengewächsen unter der allgemeinen Dolde (\$. 70. Nr. 4.) stebt; z. B. Caclirgs Libanotis (t. 4r. f. 4. a), oder unter einer Afterdolde; z. B. Astrantia major (t. 50. f. 2. A.).

2) besondre (partiale), oder das Hüllchen ( $1 n$ volucellum ): die bey den Doldengewächsen unter der besondern Dolde ( $(5.70 . \mathrm{Nr}$. 5.) gestellt ist; z. B. Caclarys Libanotis (t. 41. f. 4. b.); Bupleurum rotundifolivm (t. 16. f. 4. b.), Astrantia major (t. 50. f. 2. b.).

3) gemeinschaftliche (commune): wenn sie bey andern Gewächsen als den doldentragenden vorkommt, und mehrere Blumen uıngieltt.

4) eigne (proprium): die nur eine Blume umgiebt. Dieser und der vorhergehende Kunstausdruck (Nr. 3. u. 4.) können aber nur als Gegensätze ang'wendet werden; sonst sagt man stets nur Hülle, wie 2.6 . bey Armeria vulgaris (t. 40. f. I.), Pulsatilla p'atensis (t. 47. f. 10. a.).

5) scheidenartige (vaginale): die an der Basis in eine den Blumenstiel einschliefsende, Schicide verlingert ist; z. B. Armeria vulgaris) t. (0. f. :.).

6) ganze (integrum): wenn sie, wie es gewöbnlich der Fall ist, die Blume oder den Blüthenstand ganz umgiebt; z. B. Caclurys Libanotis (t. 4I. f. 4. a. b.), Bupleurum rotundifolium (t. I6. f. 4. b.), Astrantia major (t. 5o. f. s. a. b.).

7) halbe (dimidiatum): wenn sie dic Blume oder den Blüthenstand nur ztun Theil ungiebt; z. B. die besondre Hülle bey Aetlusa Cynapium (t. 69. f. 5. a). 
8) monopliyllum: uno ex folio tantum constans; e. g. involucrum universale in Astrantia majori (t. 50. f. 2. a.).

9) di-, tri-, tetra-, penta- etc. phytum: si e duobus, tribus, quatuor vel quinque foliis est compositum.

10) polyplyyllum: e multis foliis constans; ut involucrum partiale in Astrantia majori (t. 50. f. 2. b.).

Involucri directio atque ejus foliolorum forma aeque ac folia (§. 83. E. J.) determinantur.

\section{S. $9^{6}$.}

Spatha est pars foliacea aut membranacea, unum vel plures nudos vel incompletos vel etiam completos includens flores, qui post eorum evolutionem plerumque magis minusve ab illa distant. Occurit tantum in nonocotyledonibus, attamen Graminibus et eorum affinibus exceptis. Species definiendae sunt sequentes:

1) Tuniversalis: si ante florum vel spadicum ( $(\cdot 76$. evolutionem plures eorum includit, quorum pedunculus nonnunquam ad ejus divisiones spathis partialibus (Nr. 2.) est instructus, ut in pluribus Palmis; e. g. in Borasso flabelliformi (t. 52. f. 1. a.:)

2) partialis: quaeque vagina, quae ab universali (Nr. 1.) includitur, vel ad pedunculi aut spadicis (\$. 7 .). divisiones invenitur; e. g. in Musa paradisiaca.

3) univalvis: una tantum fissura longiludinaliter dehiscens (ut in Aro maculalo (t. 39. f. \&. a.), Calla palustri (t. 36. f. 6. a.), Gaiantho nivali (t. 3. f. 3.).

4) bivalvis: si ab apice ad basin versus in duas partes dividitur; exempla pracbent Stratiotes aloides (t. 4 \%. f. I1. a.), Ixia cruciata (t. 35. 4.).
8) e inblättrige (monoplyyllum): die nur aus einem Blatte besteht; 2. B. die allgemeine Hülle bey Astrantia major (t. 5c. f. 2. a.).

9) zwey-, drei-, vier-, fünf-u. s. w. blättrige (di-, tri-, tetra-, penta- - plyyllum): wenn sie aus zwey, drey, vier oder fünf Blättern zusammengesetzt ist.

10) vielblättrige (polypluyllum): die aus vielen Blättern besteht; z. B. die besondere Hülle bey AstranLis major (t. 5o. f. 2. b.).

Die Richtung der Hülle und die Gestalt ihrer Blättchen werden wie die Dlätter (s. 83. E. J.) bestimmt.

5. 96 .

Die Blumenscheide (Spatha) ist ein blattartiger oder häutiger Theil, welcher eine oder mehrere nackte, oder unvollständige, oder auch vollständige Blumen einschliefst, die nach ihrer Entwickelung gewöhnlich mebr oder weniger entfernt von ihm sind. Sie kommt nur bey den Monocotyledonen vor, jedoch noch mit Ansnahme der Gräser und ihrer Verwandten. Die Arten, welche man unterscheidet, sind folgende:

1) allgemeine (universalis): wenn sie vor der Entwickelung der Blumen oder Kolben $\left(\mathcal{S} \cdot 7^{6}\right.$. ) mehrere derselben einschliefst, deren Blumenstiel an seinen Zertheilungen zuweilen noch mit besondern Blumenscheiden (Nr. 2.) versehen ist, wie bey mehreren Palmen; 2. B. Borassus flabelliformis (t. 52. f. r. a.).

2) besondere (partialis): jede Blumenscheide, die von der allgemeinen (Nr. I.) eingeschlossen wird, oder die sich an den Zertheilungen des Rlumenstiels oder Kolbens (\$. 76.) findet; 2. B. Musa paradisiuca.

3) einklappige (univalvis): wenn sie nur durch eine Spalte der Länge nach aufspringt; z. B. Arum maculatum (t. 39. f. 8. a.), Calla palustris (t. 36. f. 6. a.), Galantlus nivalis (t. 3. f. 3.).

4) $z$ weyklappige (bivalvis): wenn sie sich von der Spitze bis an die Basis in zwey Theile theilt; z. $D$. Stratiotes aloides (t. 47. f. II. a.), Ixia cruciata (t. 35. f. 4.). 
5) simplex: si una tantum adest, ut in plurimis vegetabilibus spatha instructis.

6) duplex: si duae adsunt, quarum altera alteram includit; e. g. in Croco maesiaco. Hic distinguuntur:

a) exterior et

b) interior.

7) integra: quae flores ante eorum evolutionem circumcludit, ut plurimae spathae; e. g. exterior in Croco maesiaco.

8) dimidiata: quae dimidium tantum florum lateraliter cingit; e. g. spatha interior Croci maesiaci.

9) unifora: e qua unus tantum flos provenit; exemplo sunto Galanthus nivalis (t. 3. f. 3.), Stratiotes aloides (t. 47. f. II. a.) Narcissıs poëlicus.

Io) liflora: e qua duo flores evolvuntur; e. g. Narcissils biflorils. Ita numerantes pergunt usque ad sequentem.

I) multiflora: e qua plures flores proveniunt; ut in Narcissu Tazetta.

12) marcescens: quae sub anthesi vel ante eam marcescit; videatur Narcissus poëticus.

I3) persistens: ad fructus maturationem usque virens; ut in Ixia cruciata (t. 35. f. 4.) et Ornithogalo spathaceo (t. 27. f. 4. c.).

\section{S. 97}

Indusiun est membrana magis minusque tenuis Filicum sorum ( 1 . 7 S.) obtegens aut includens et capsula. rum maturatione plernmque dehiscens. Invenitur:

I) planum : planitiem rectam magis minusve aequans capsulas obtegit; conspiciatur filccluntım occidentale (1. 48. f. 3. а.), Aspidinu aculeranu (t. 67. f. 6. а.).
5) einfache (simplex): wenn nur eino vorbanden ist, wie bey den mehrsten mit Blumenscheiden verse. henen Gewächsen.

G) doppelte (duplex): wenn zwey zugegen sind, von denen die eine die andere einschliefst; z. B. Crocus maesiacus. Hier unterscheidet man:

a) die äu fsere (exterior) und

b) die in nere (interior).

7) ganze (integra): welche die Blumen vor ihrer Entwickelung ringsherum einschliefst, wie die meisten Blumenscheiden; z. B. die äufsere bey dem Crocıs maesiacus.

8) halbe (dimidiata): welche die Blumen nur zur Hälfte seitwärts umgiebt; z. B. die innere Blumenscheide des Crocus maesiacus.

9) einblumige (unifora): aus der nur eine Plume hervorkommt; z. B. Galanthus nivalis (t. 3. f. 3.), Stratiotes aloides (t. 47. f. II. a.), Norcisins poëtichls.

ro) zweyblumige (biflora): aus der sich zwey Blumen entwickeln; z. B. Narcissus biflorus. So zählt man weiter fort, bis

II) vielblumige (mulliflora): nus welcher melrere Blumen hervorkommen; 2. B. Nurcissis Tazetia.

12) welkende (marcescens): die wäbrend des Blühens oder vor demselben welkt; z. B. Narcissıs poëticus.

13) bleibende (peisistens): die bis zur Reife der Frucht grün bleibt; z. B. Ornit/ıogulnım spathaceum (t. 27. f. 4. c.).

\section{S. 97.}

Das Schleyerchen (Inclusiumi) ist eine mehr

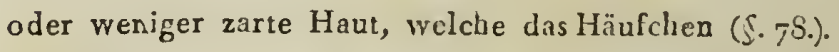
der Farrnkräuter bedeckt oder einschlielst, und beym Reifwerden der Kapseln gewölnlich aufspringt. Man findet es:

I) flach (planum): das mehr oder weniger einer geraden Ebene gleicht und die Kapseln bedeckt; z. B. Elechnum occidentale (t. 43 f. 3. a.); Aspidium aculeatum (t. 67. f. f. a.). 


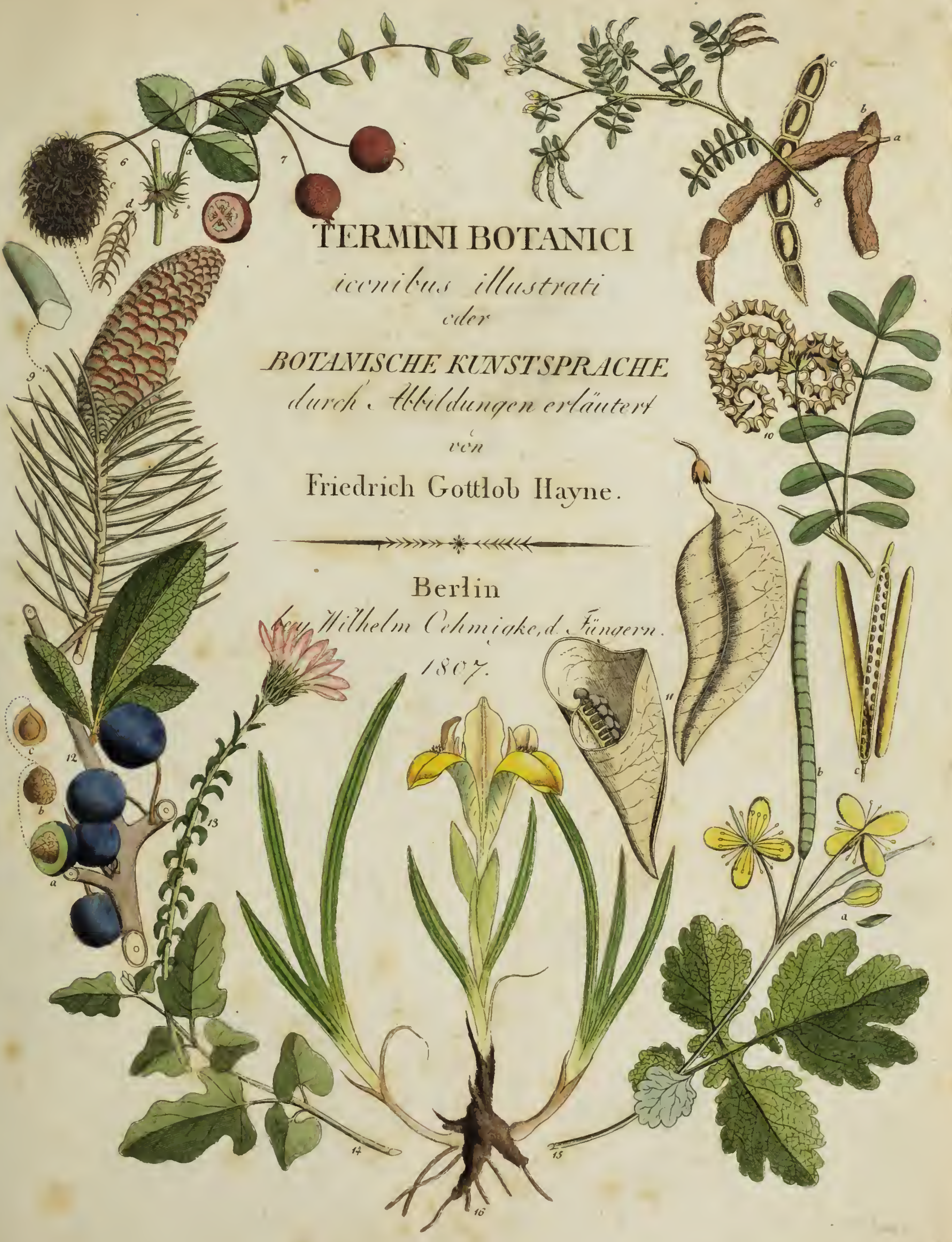





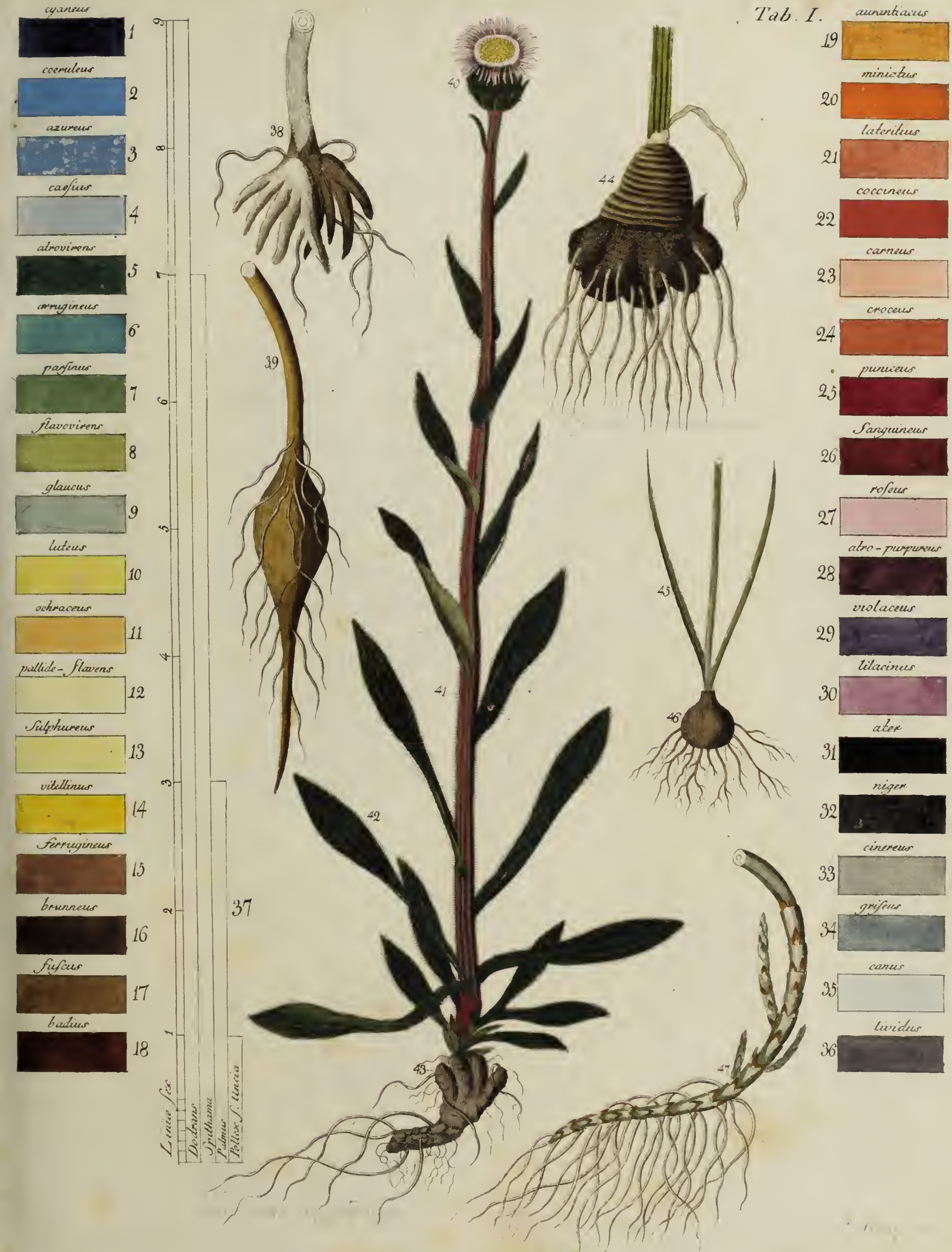





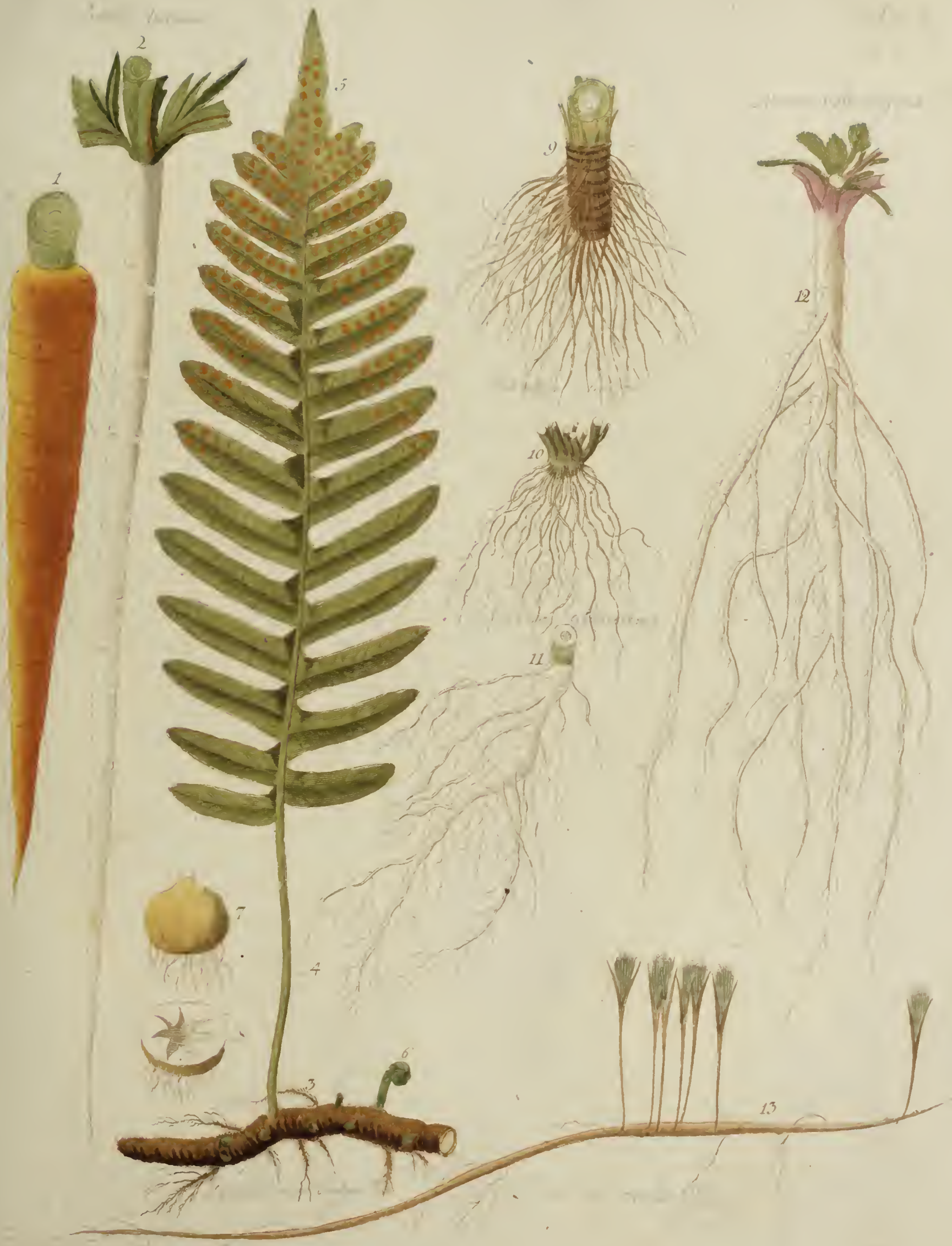




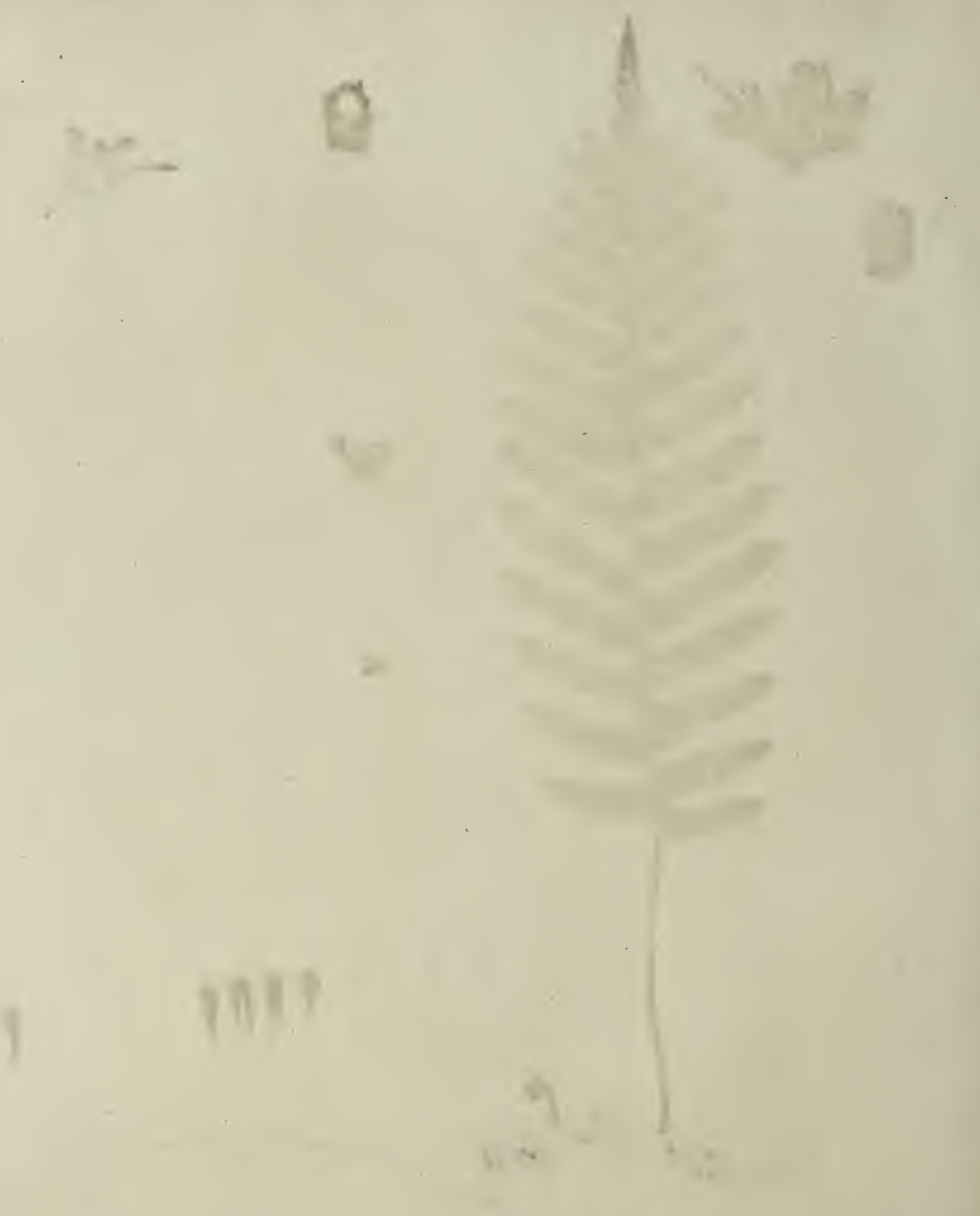




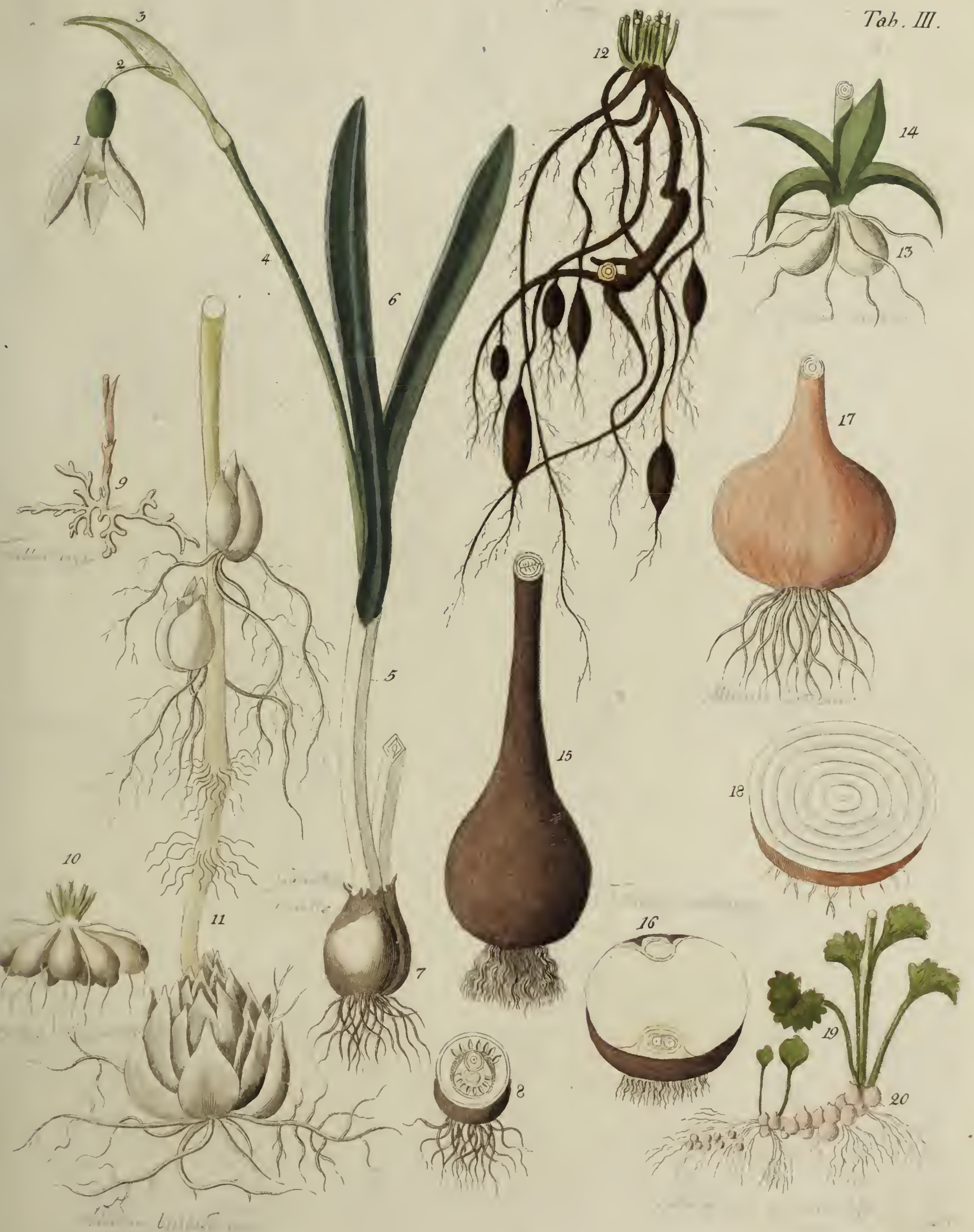



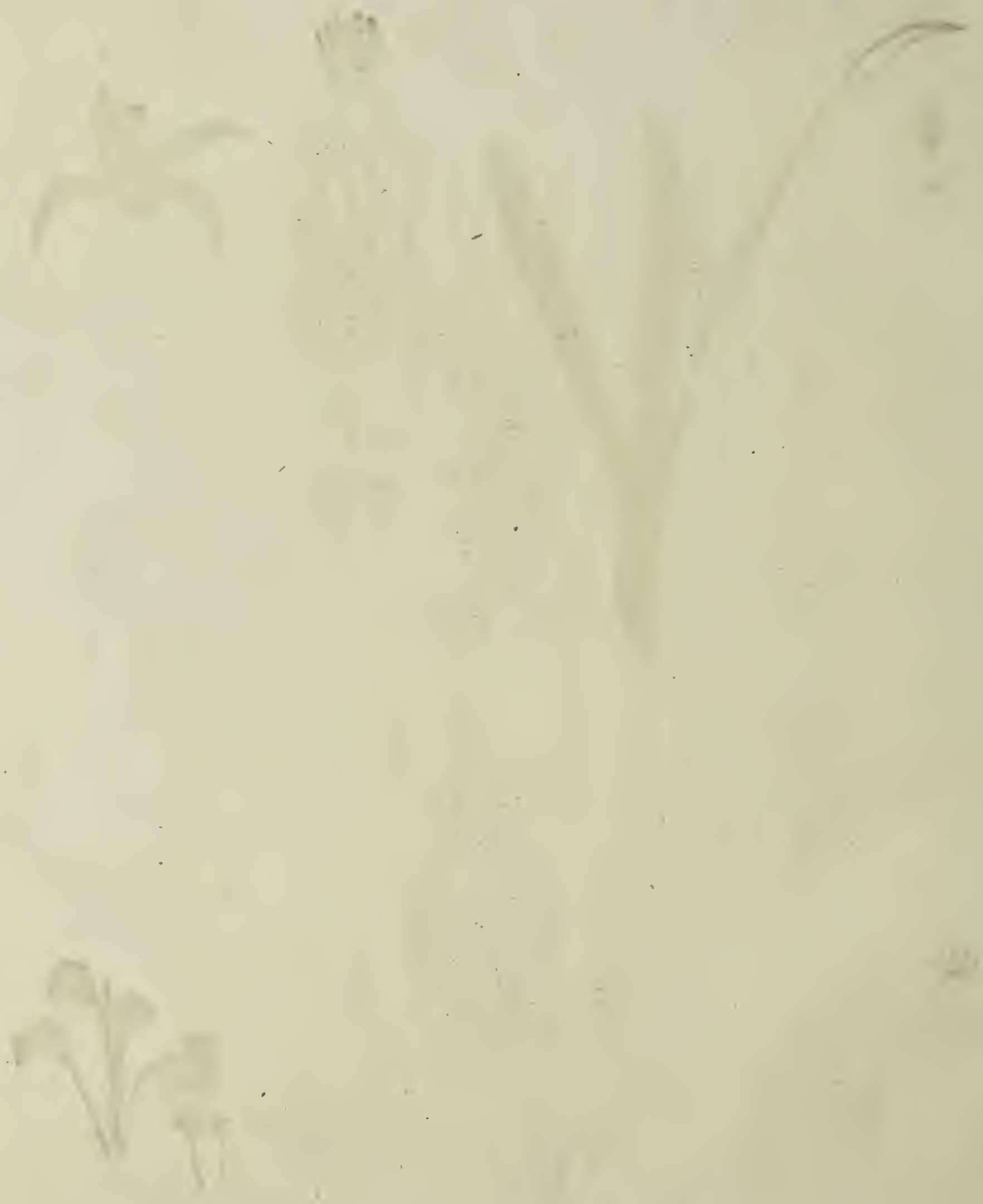


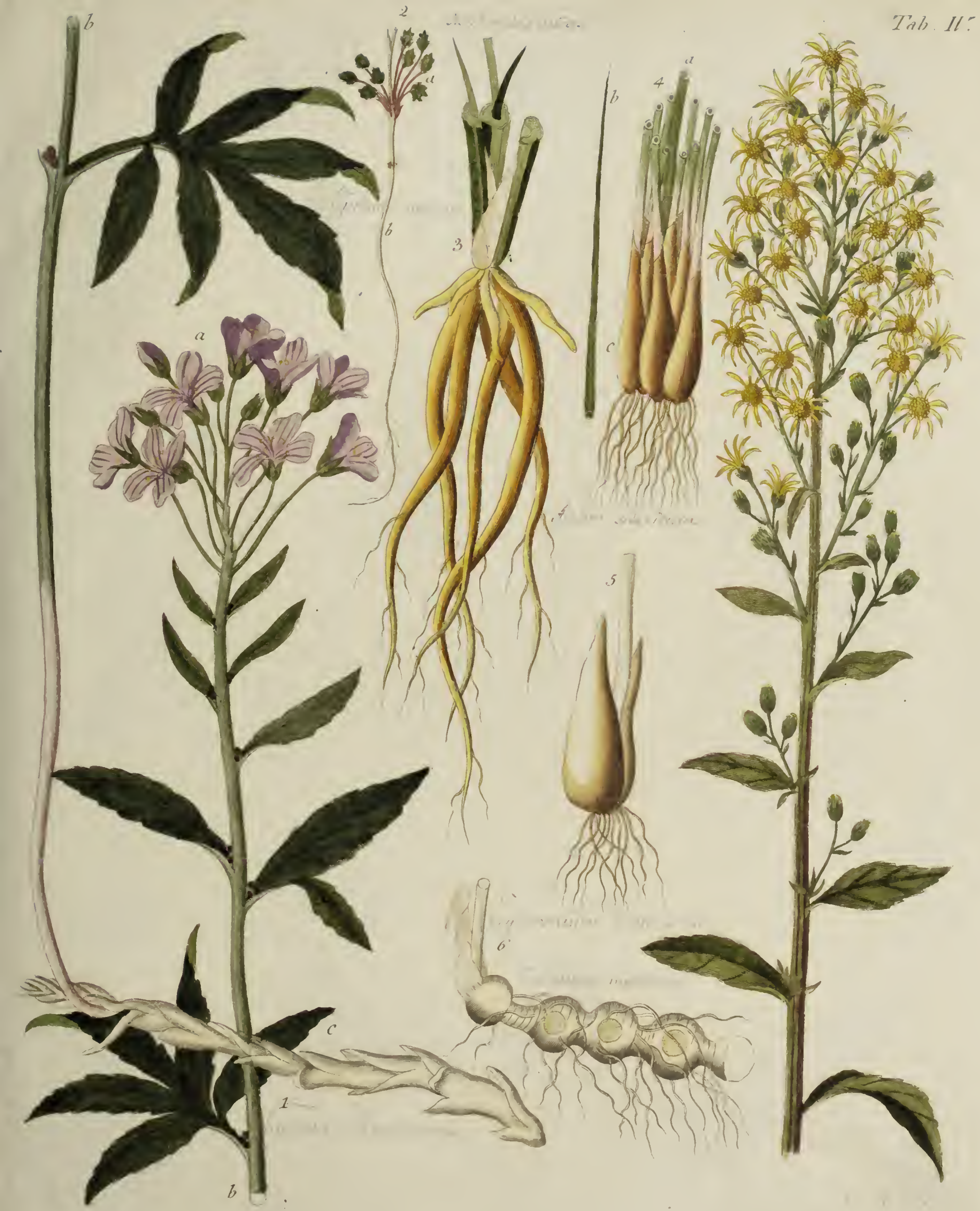





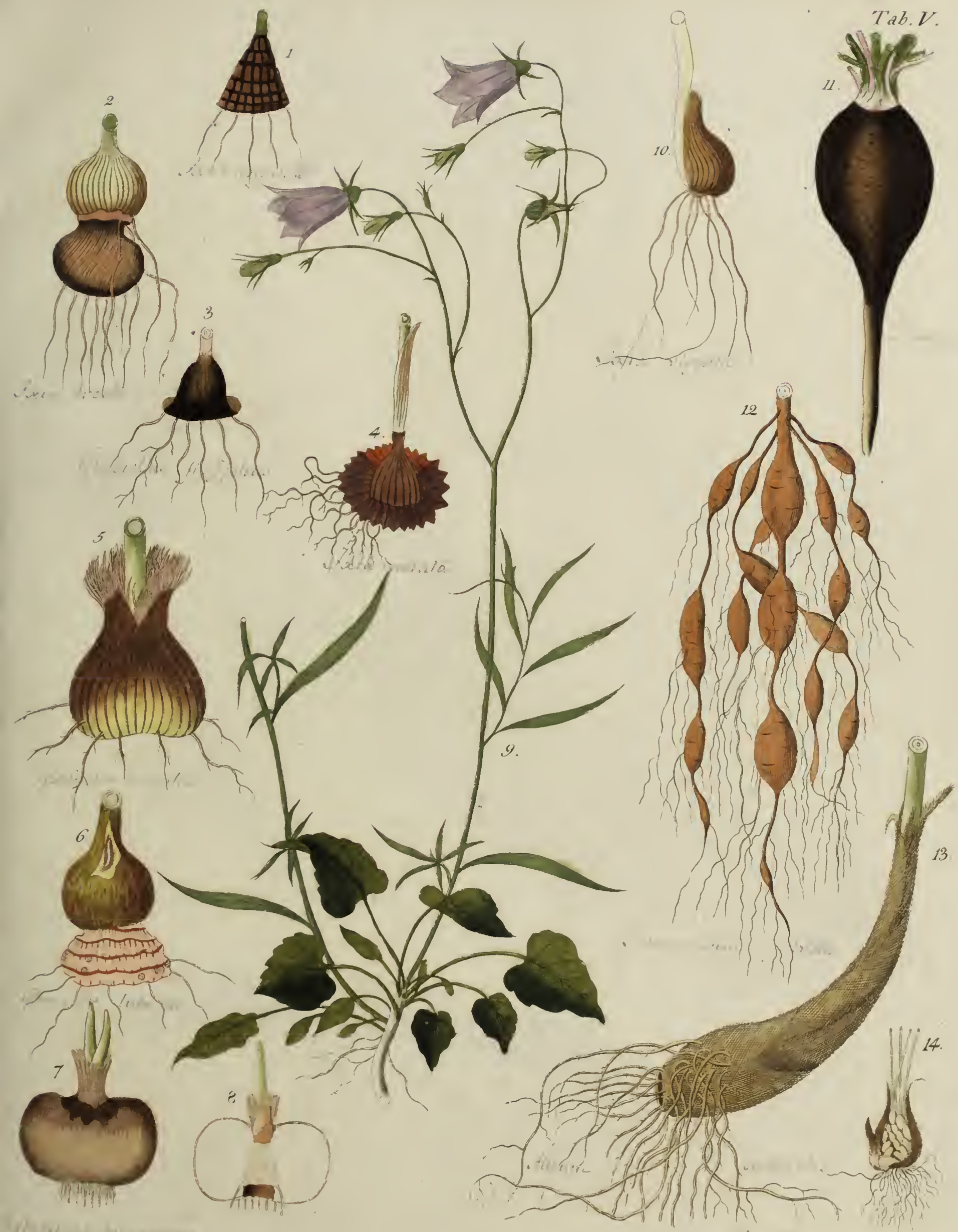





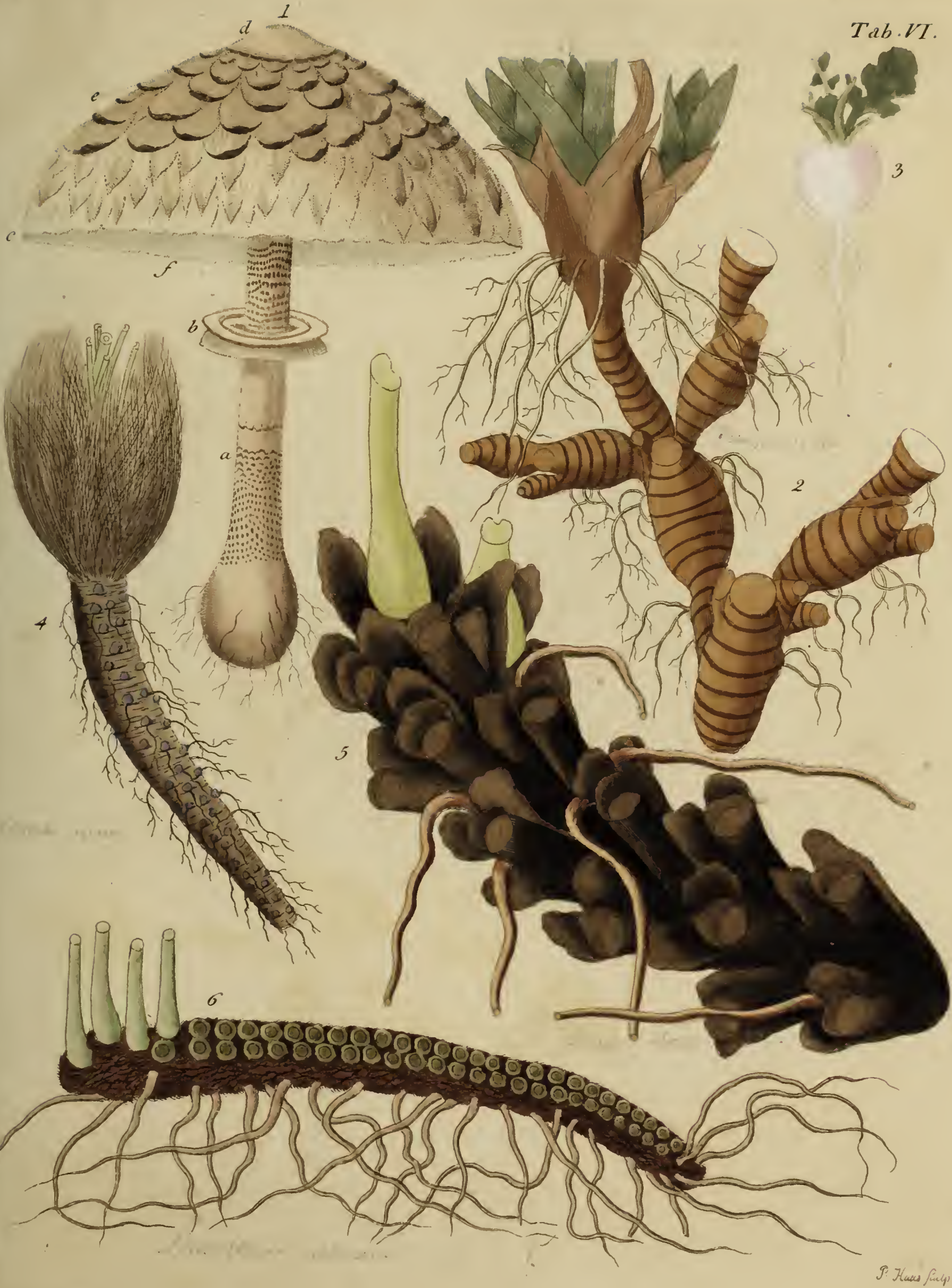




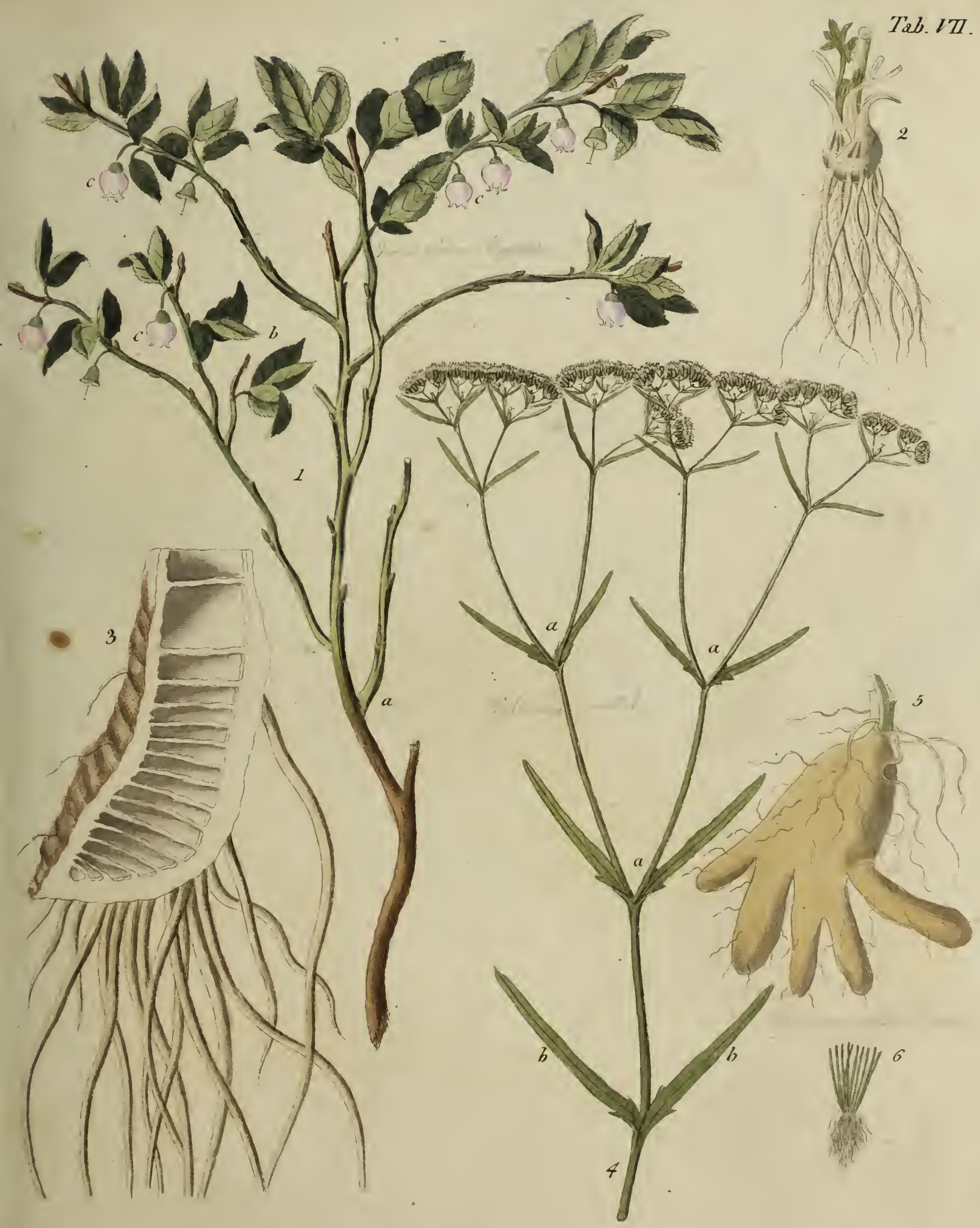




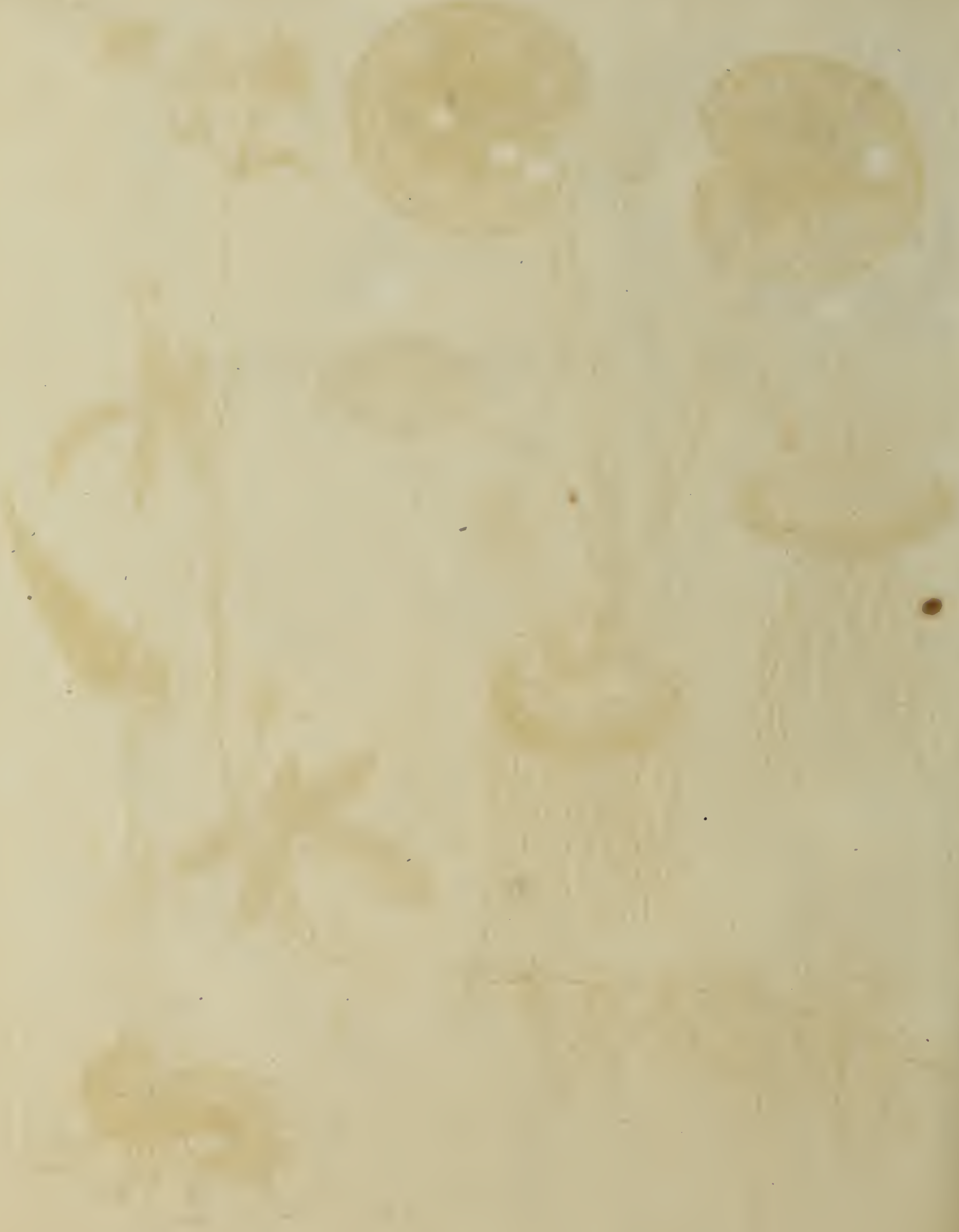




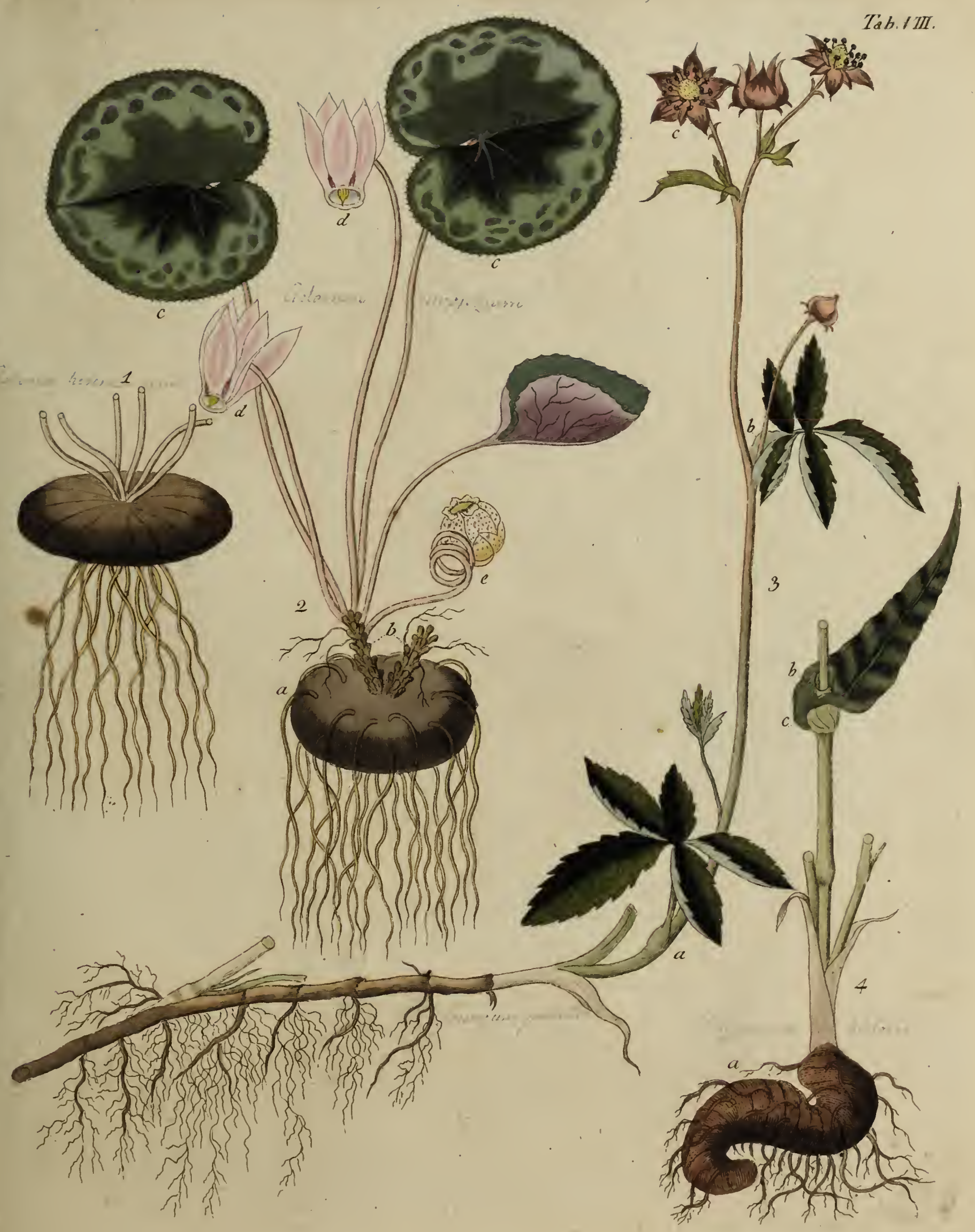



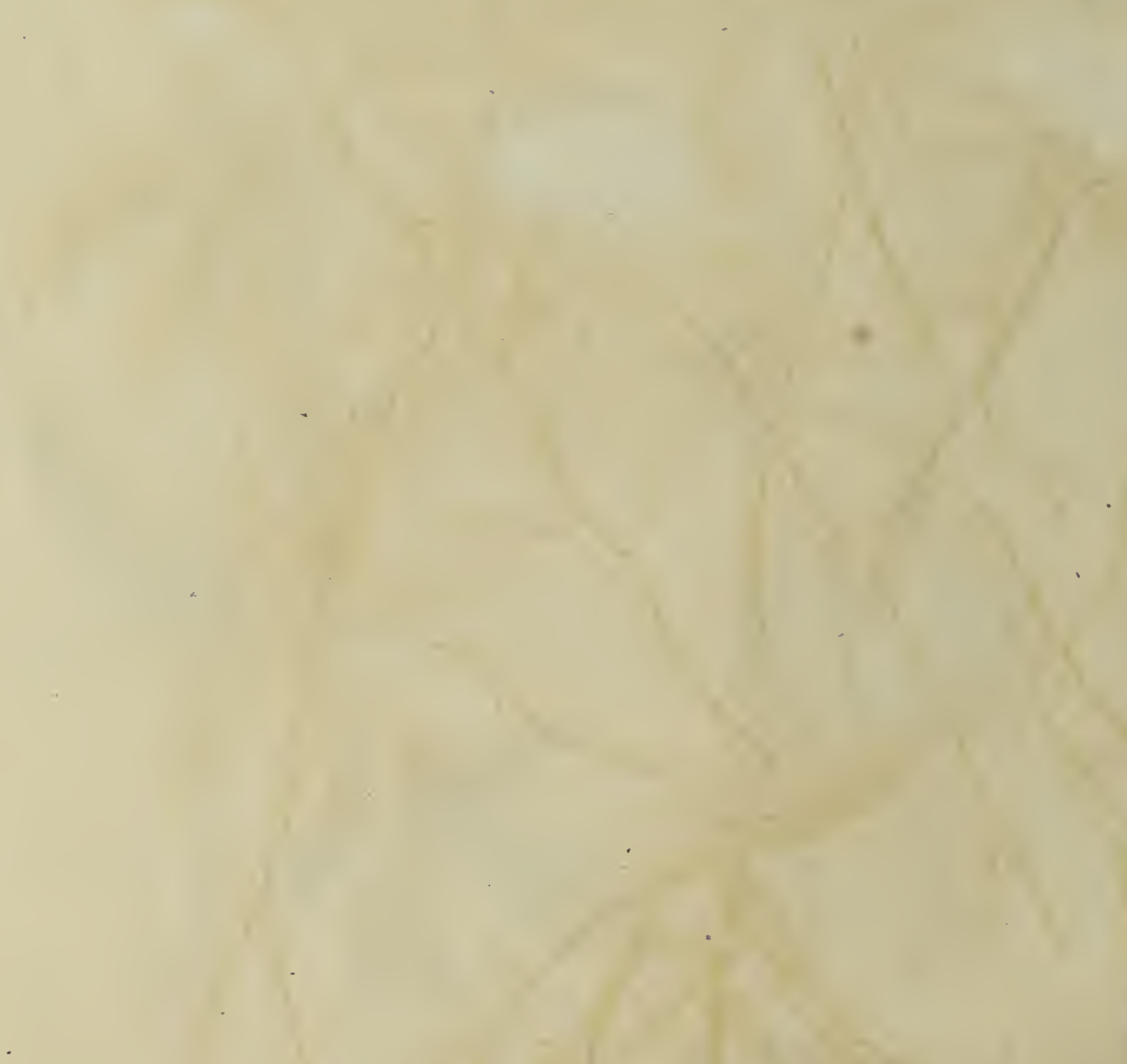



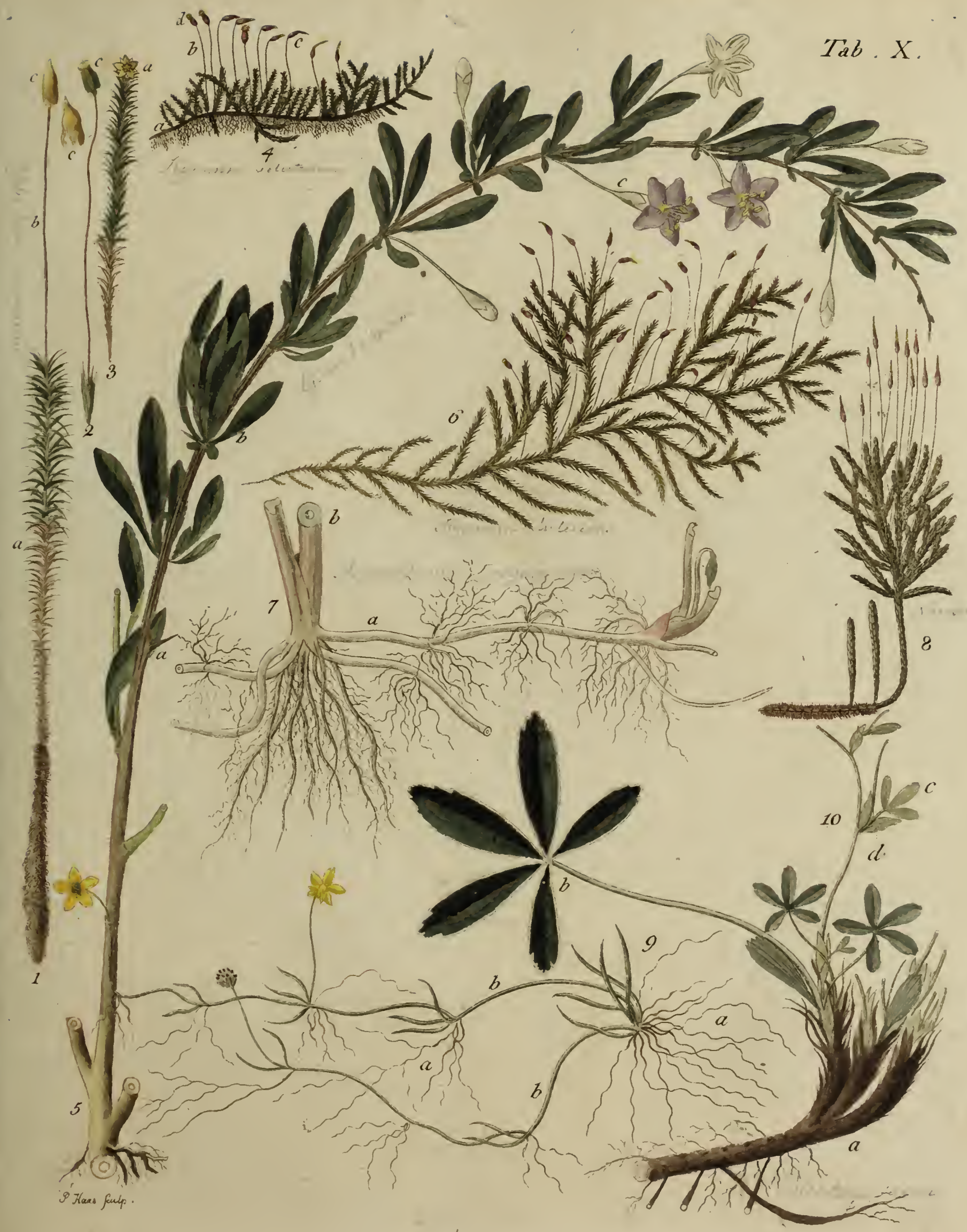



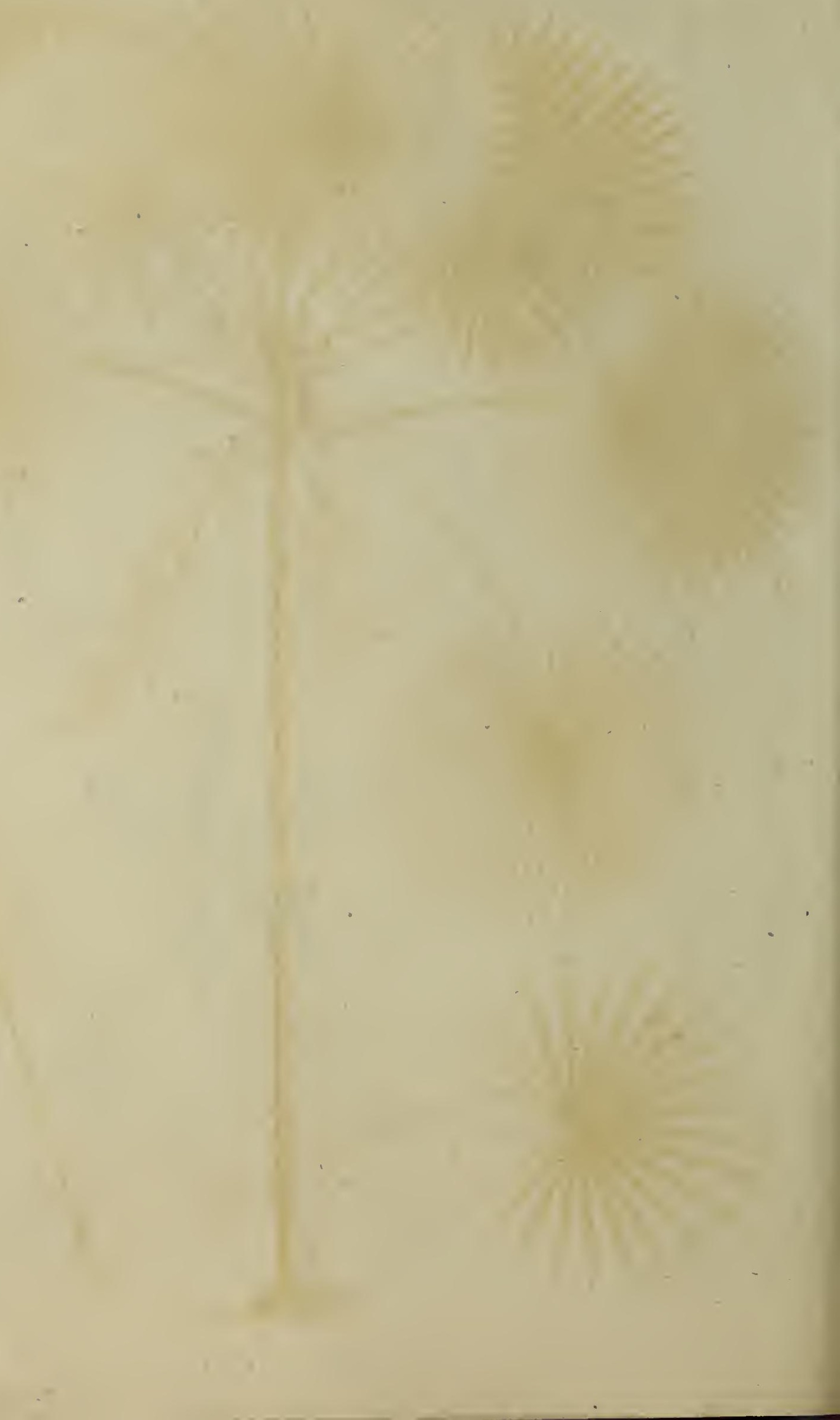


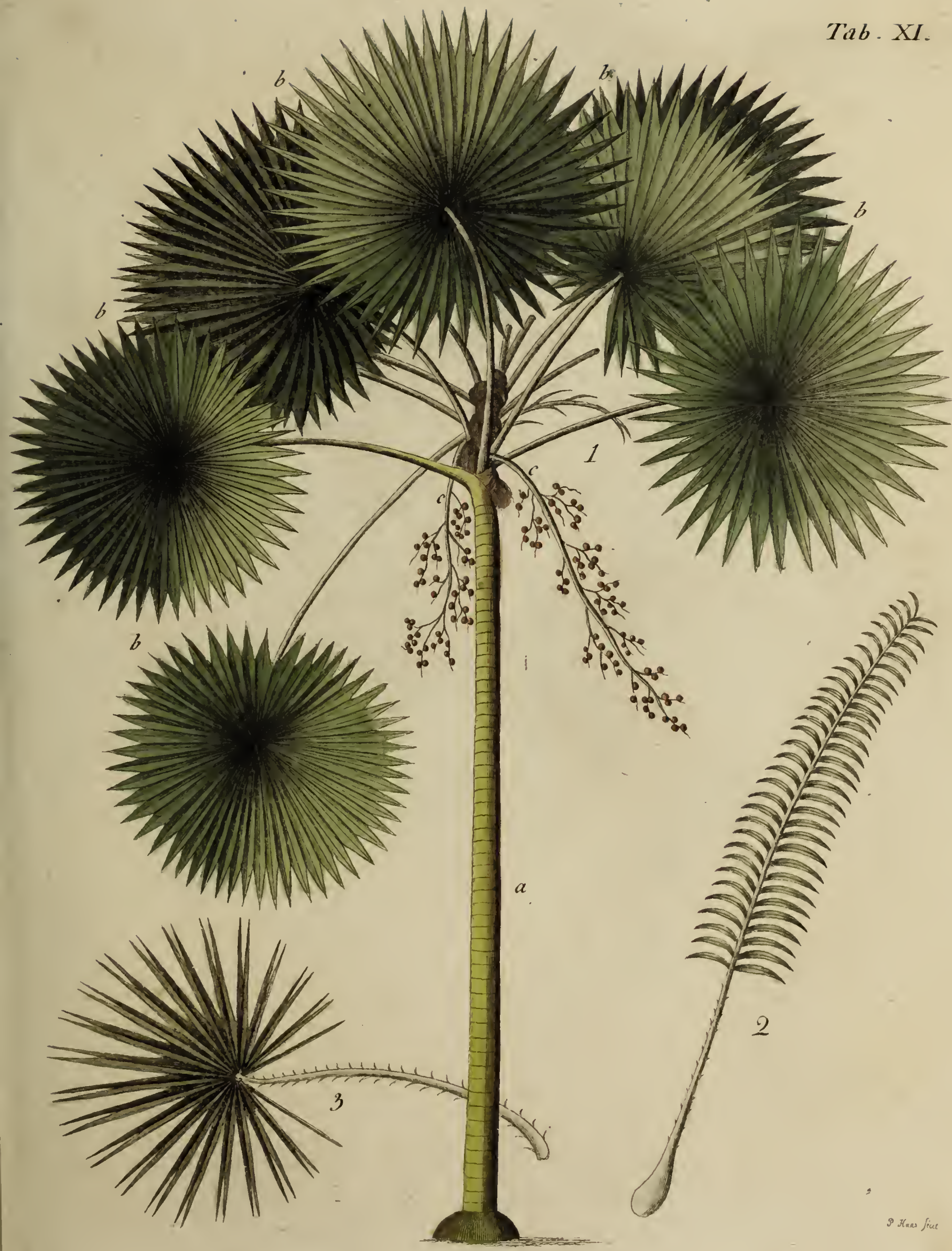




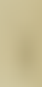

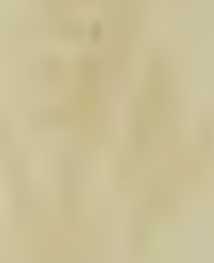




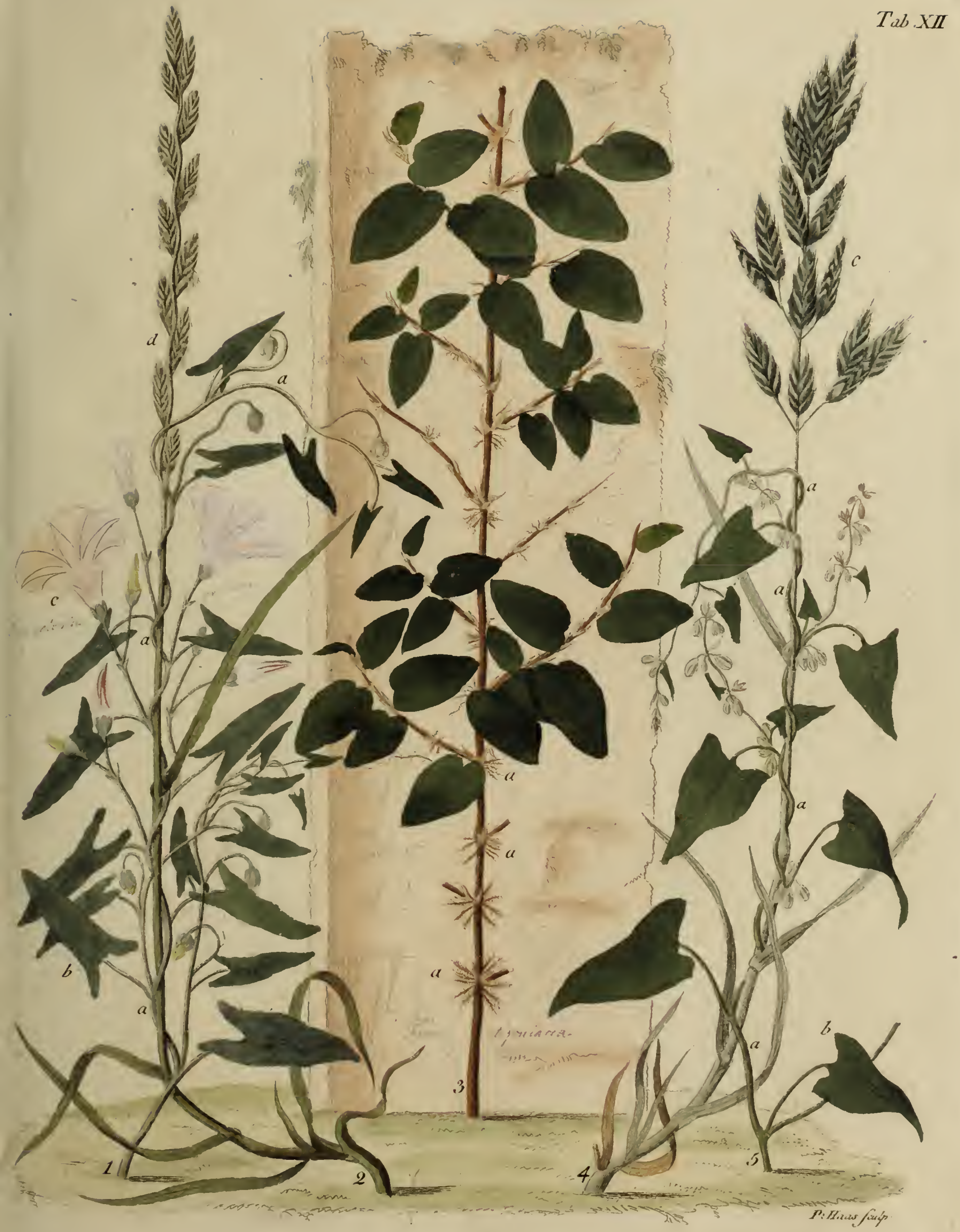




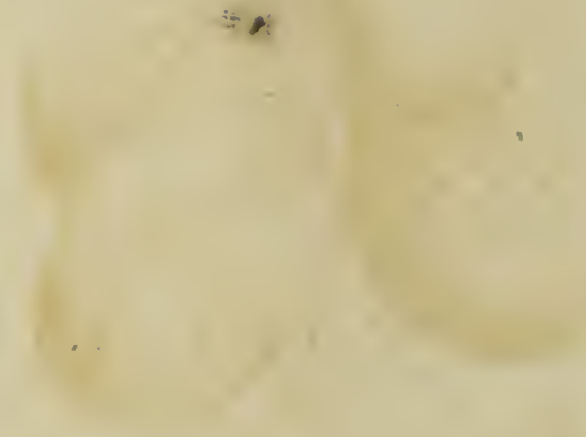



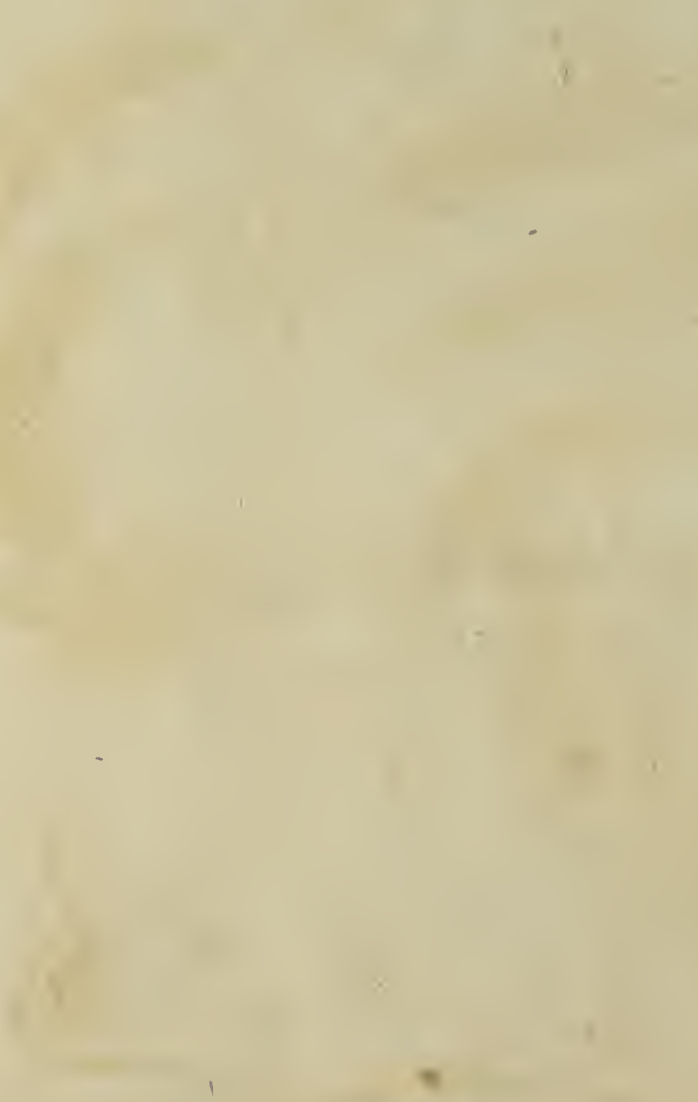

, 


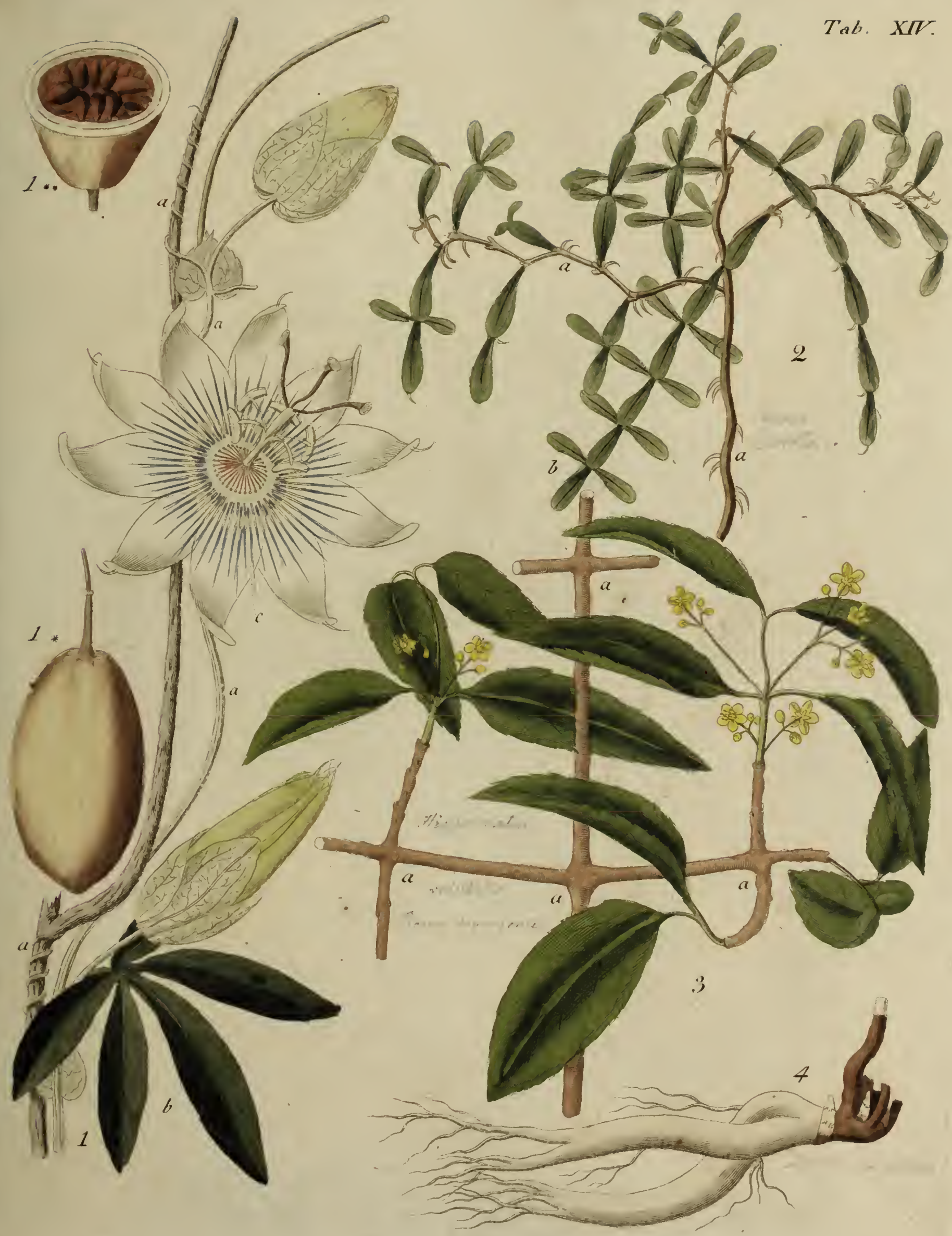





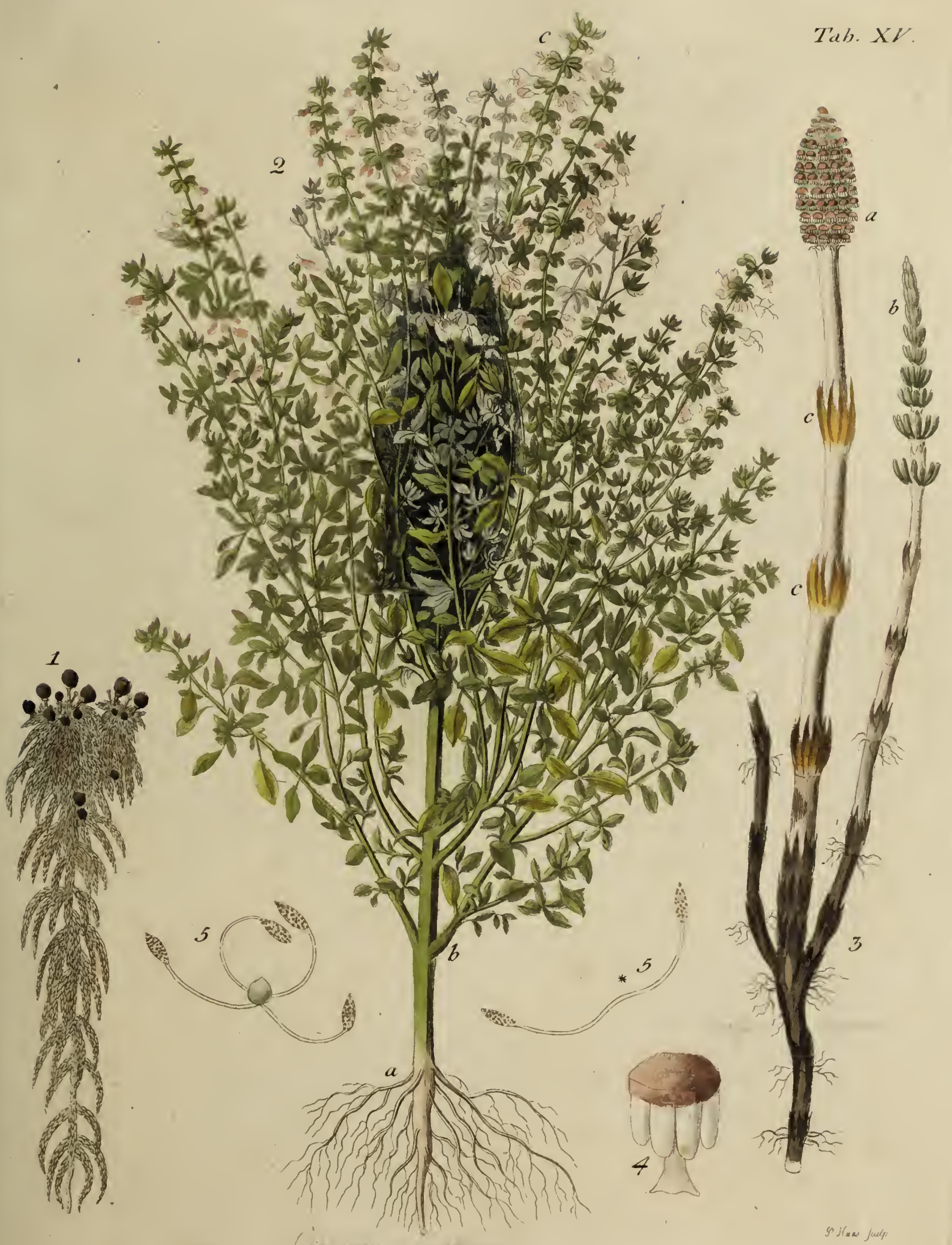





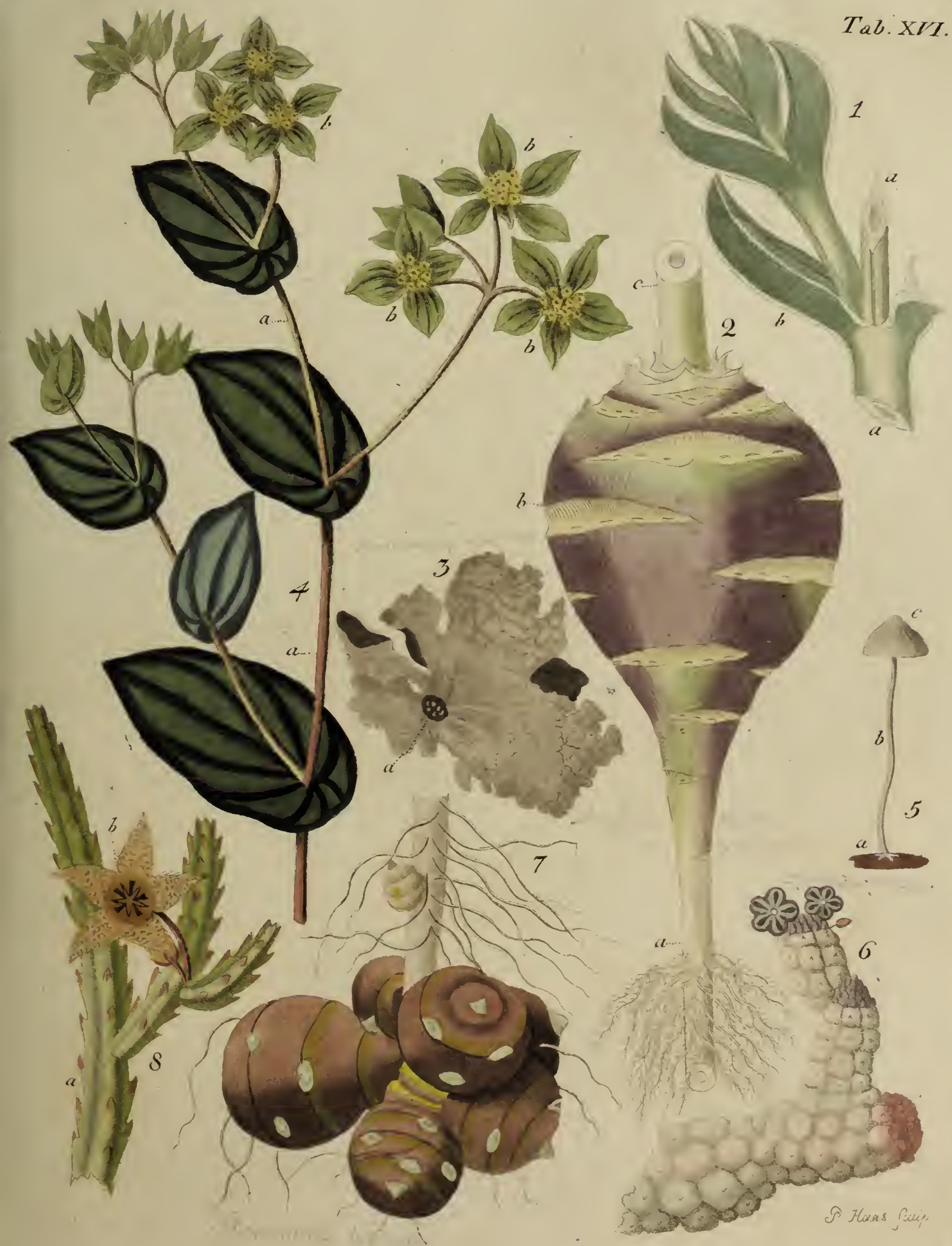






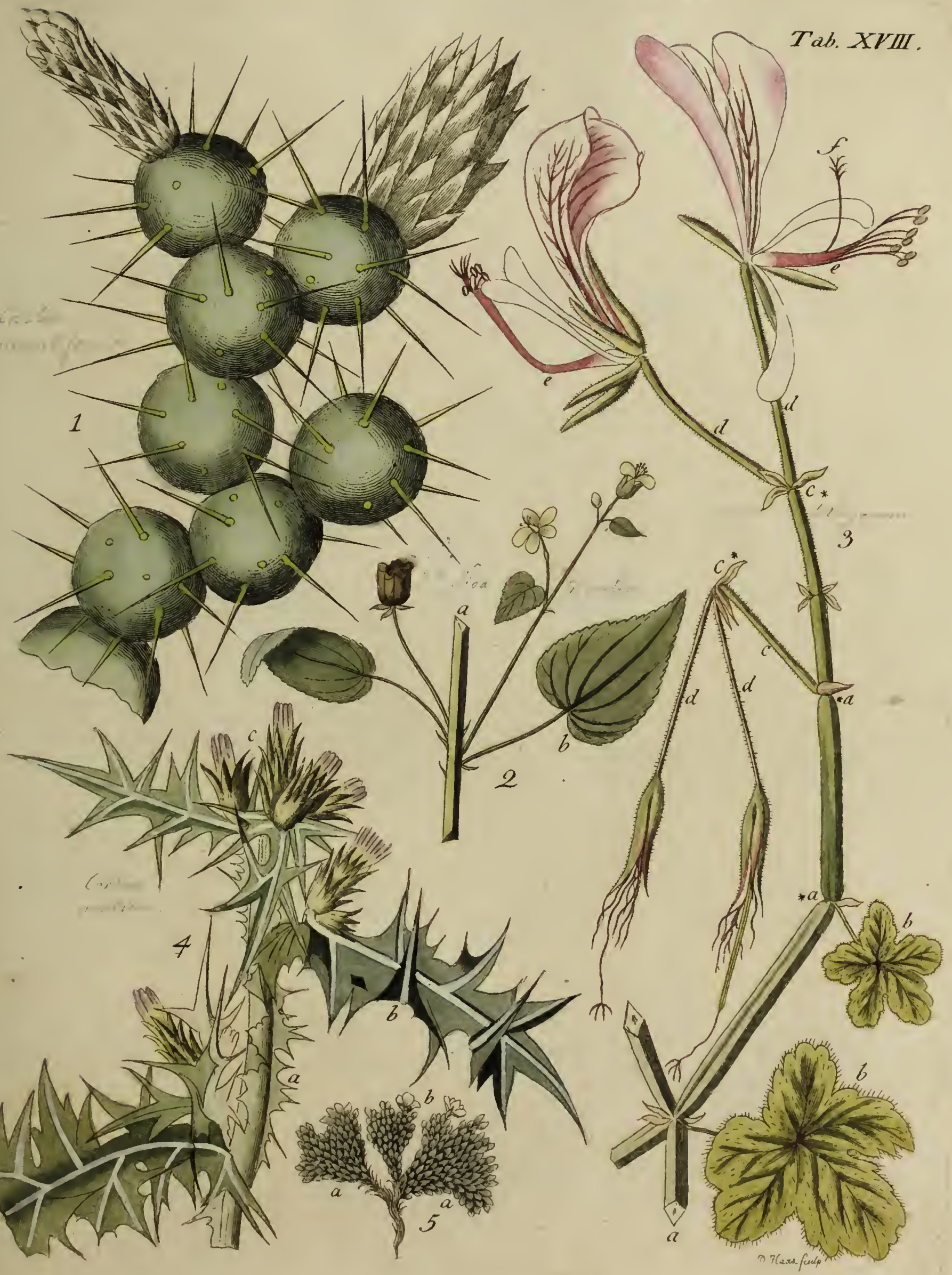





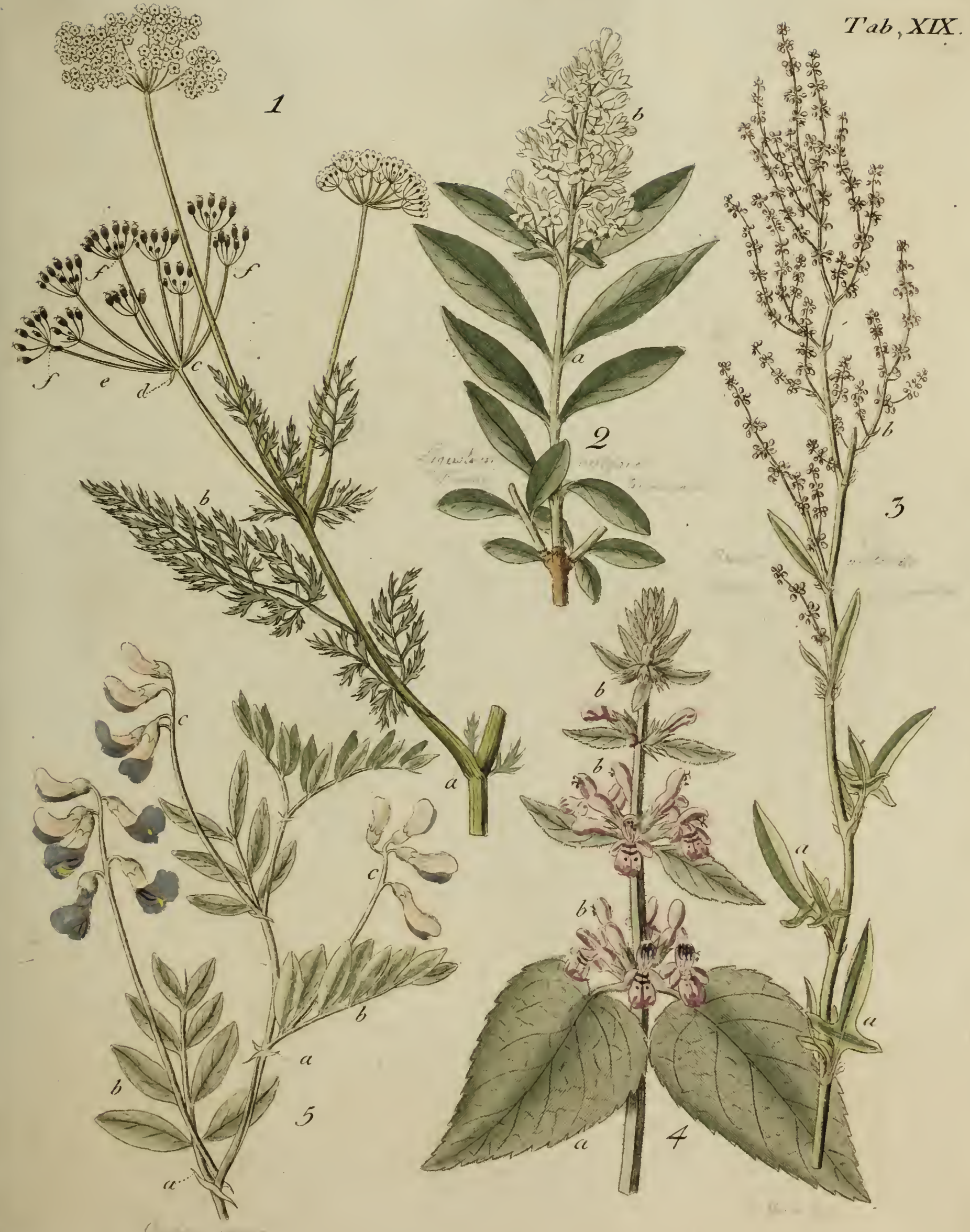





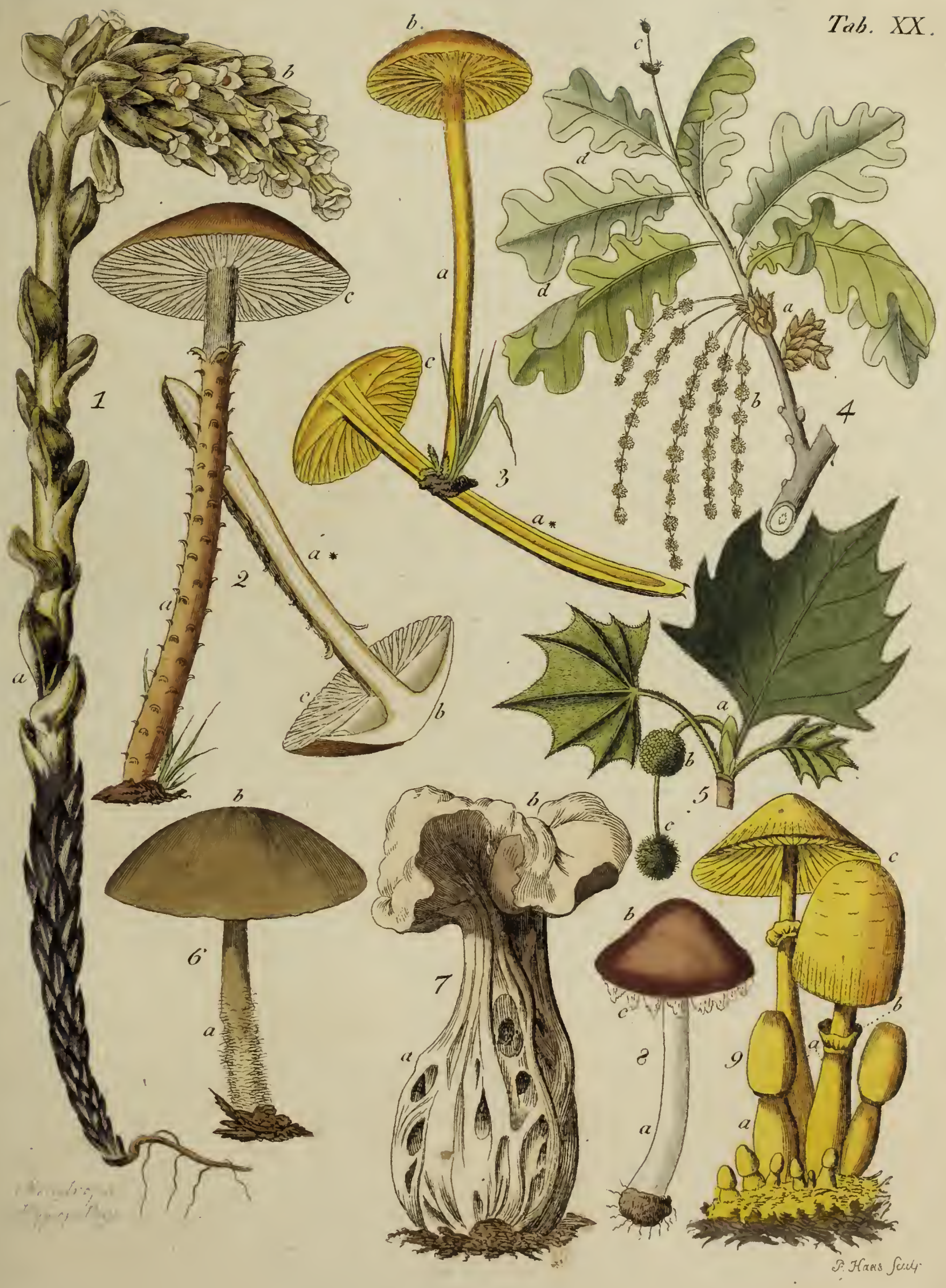





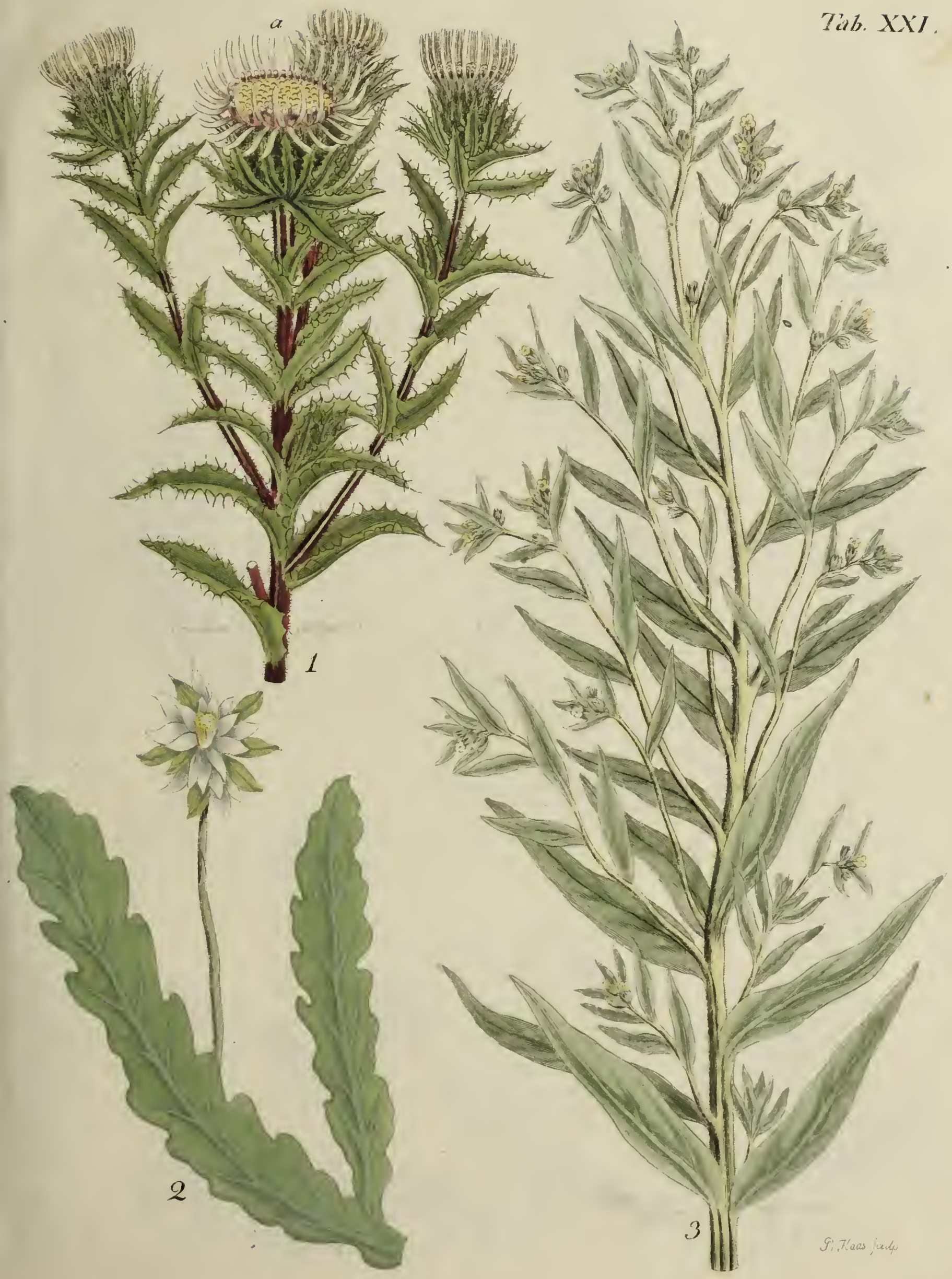





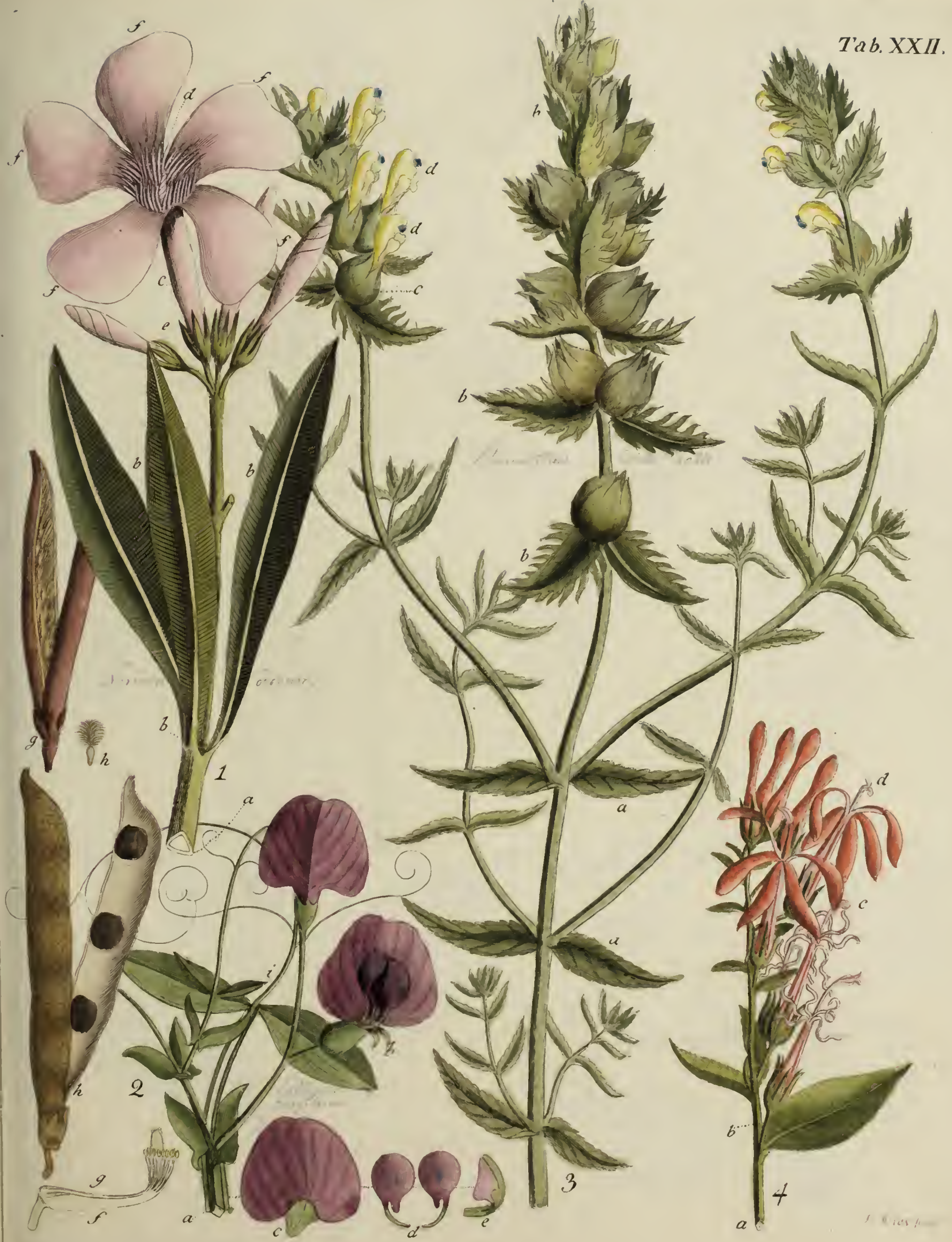





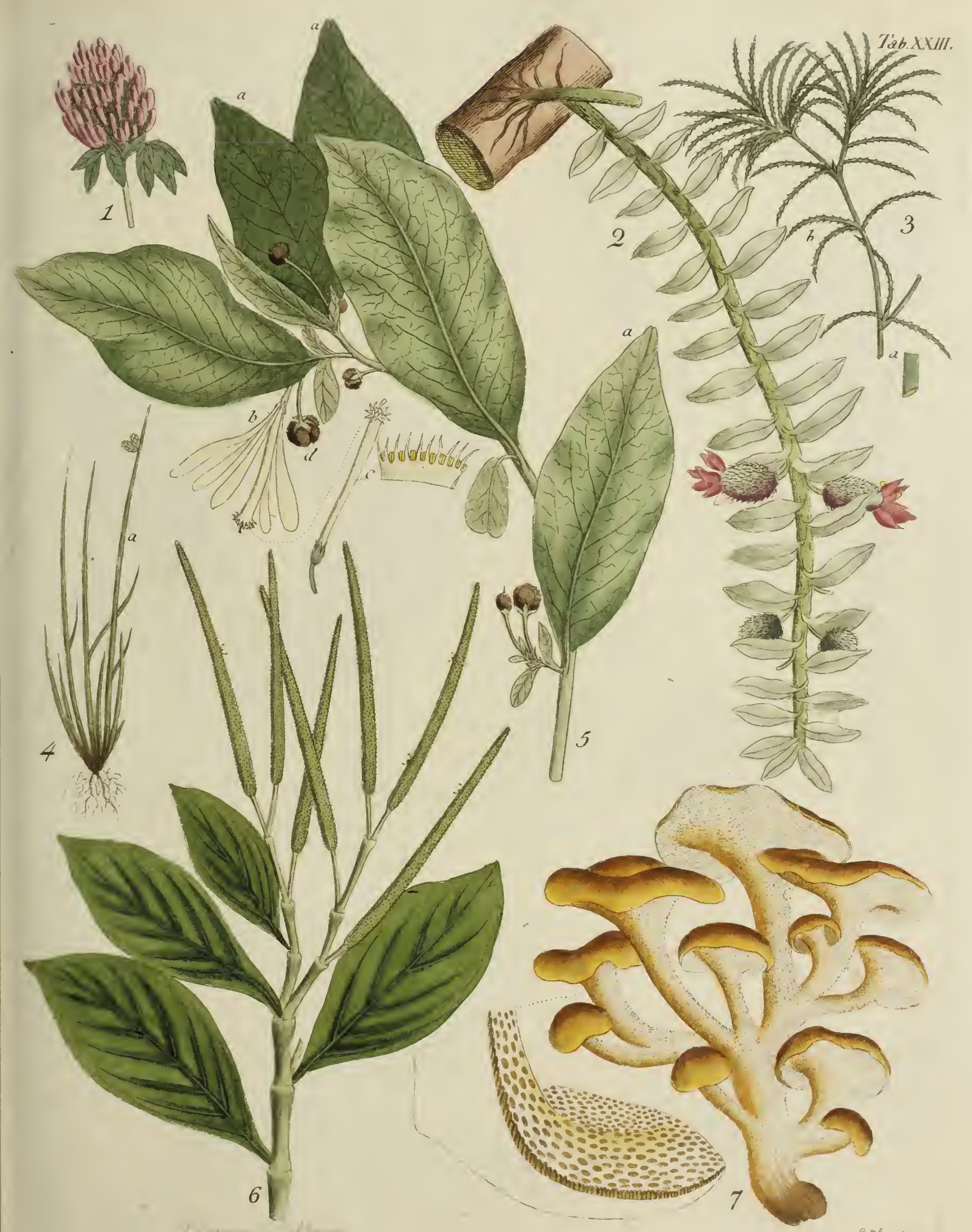

9. Haus fow. 



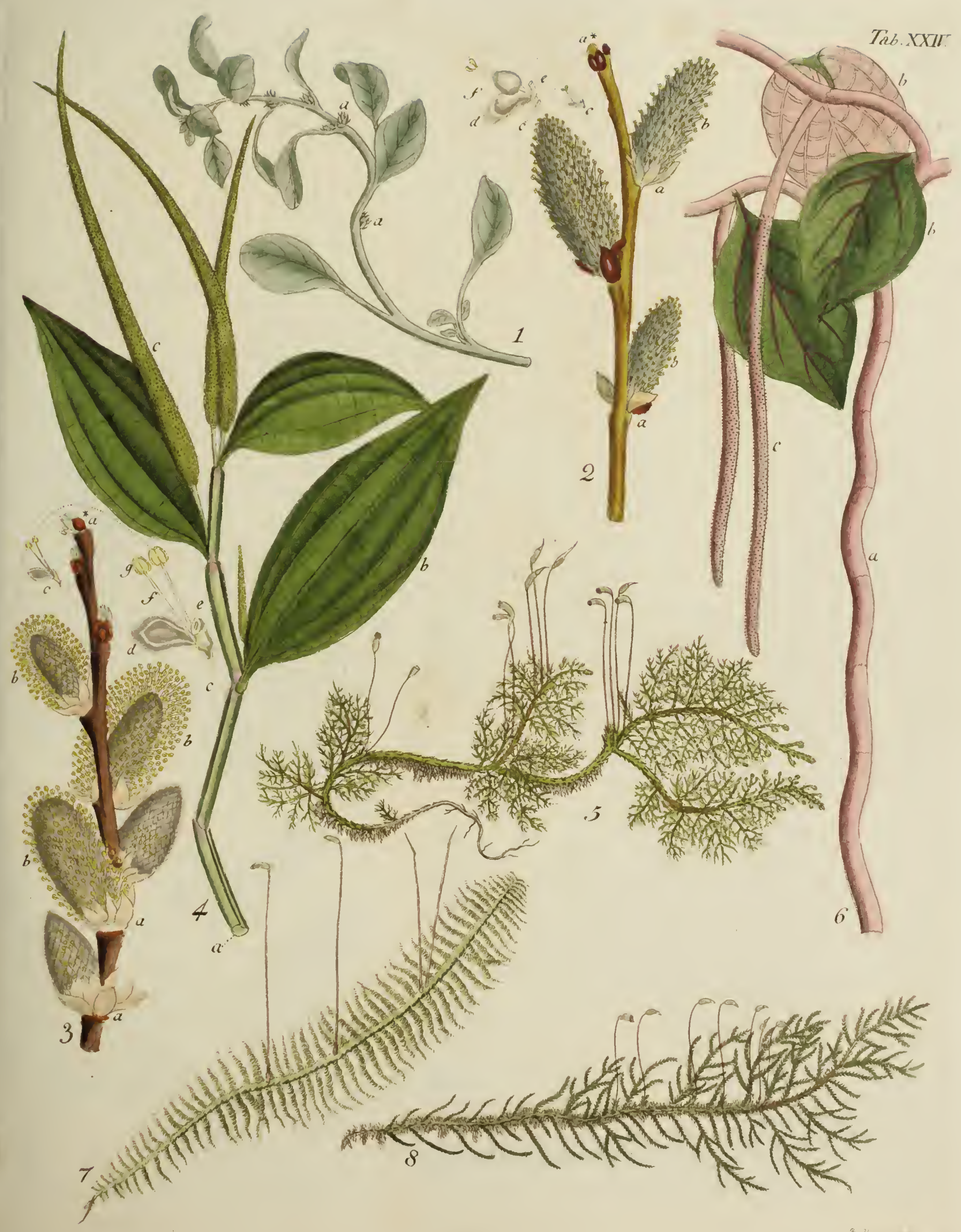





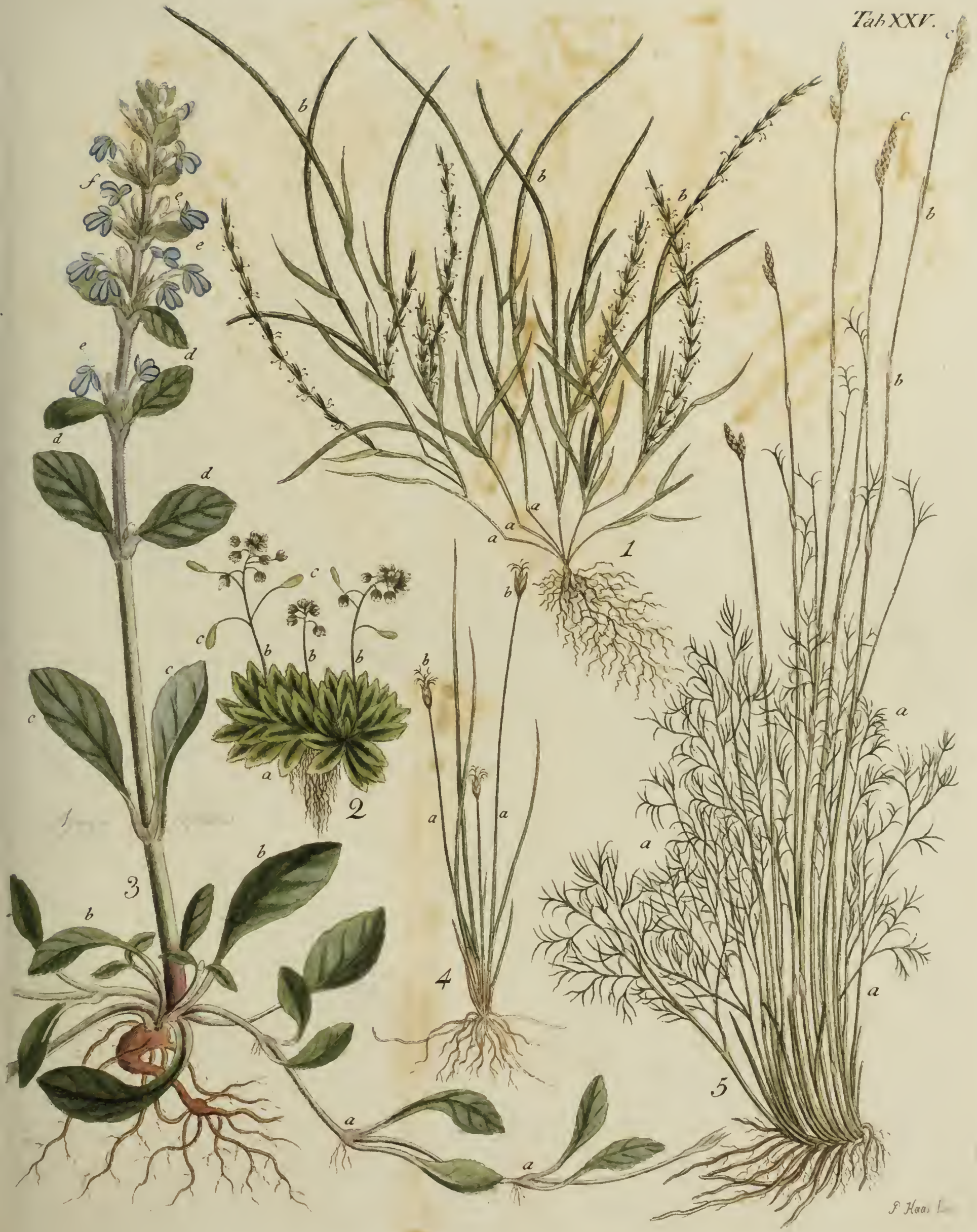




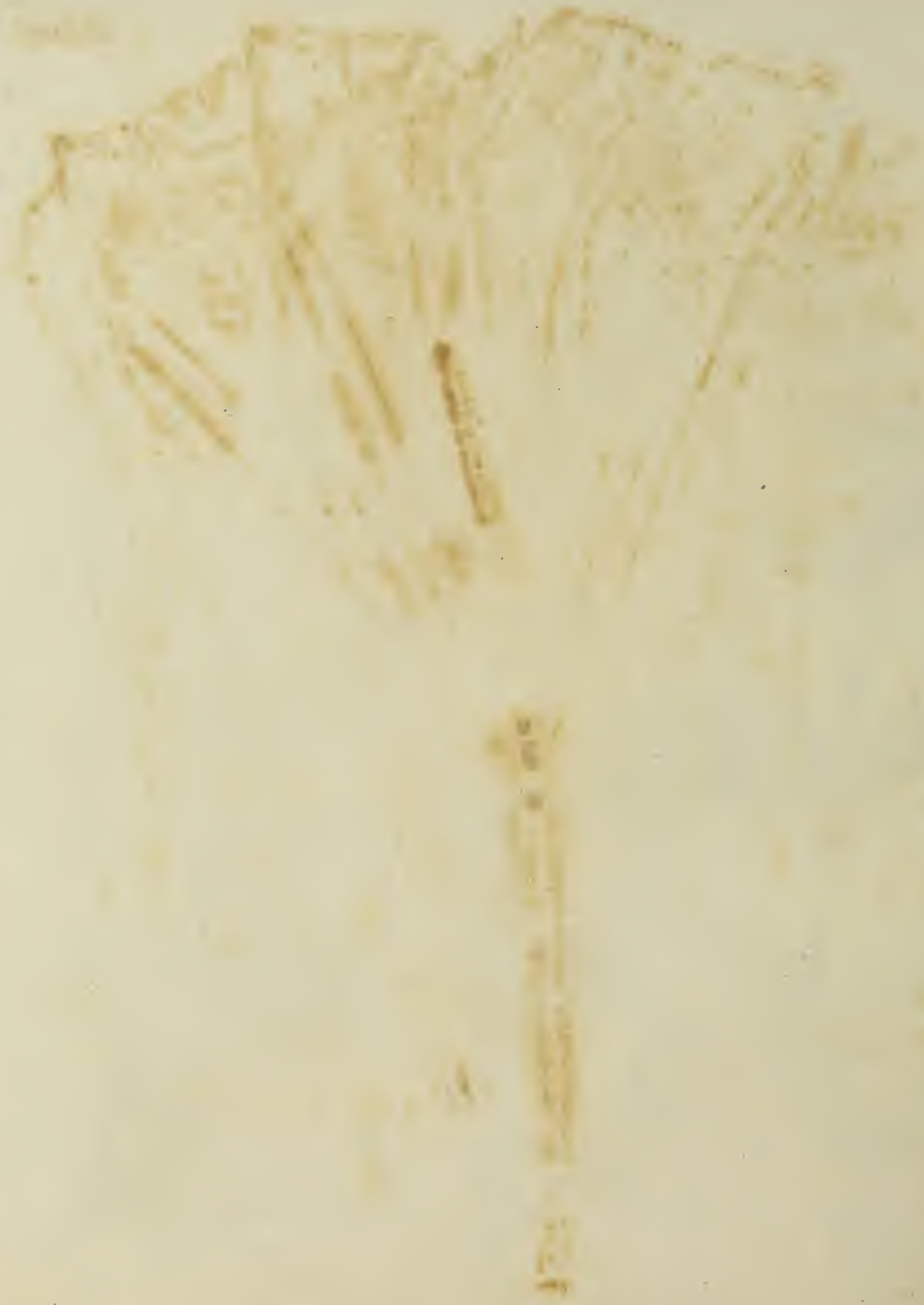




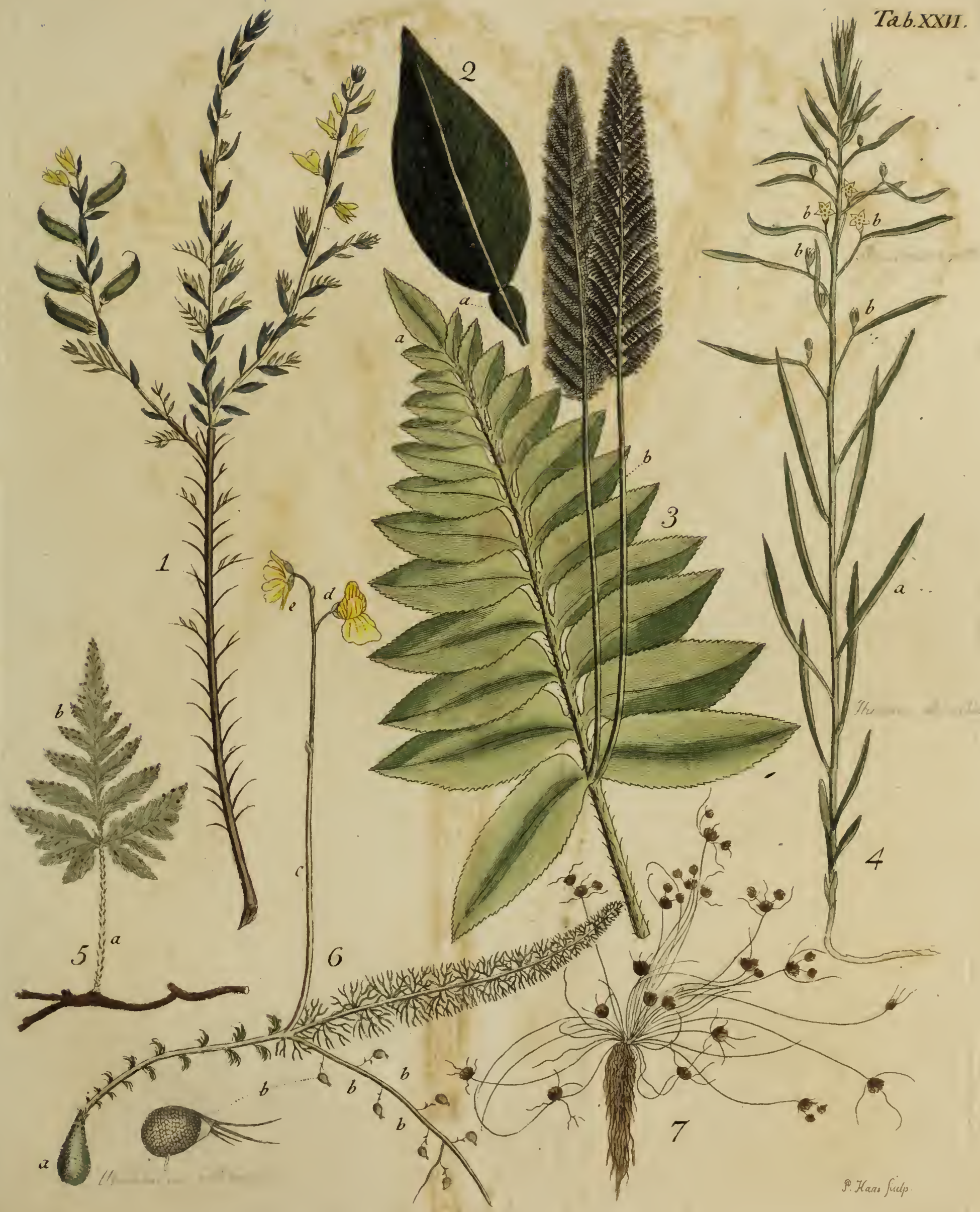






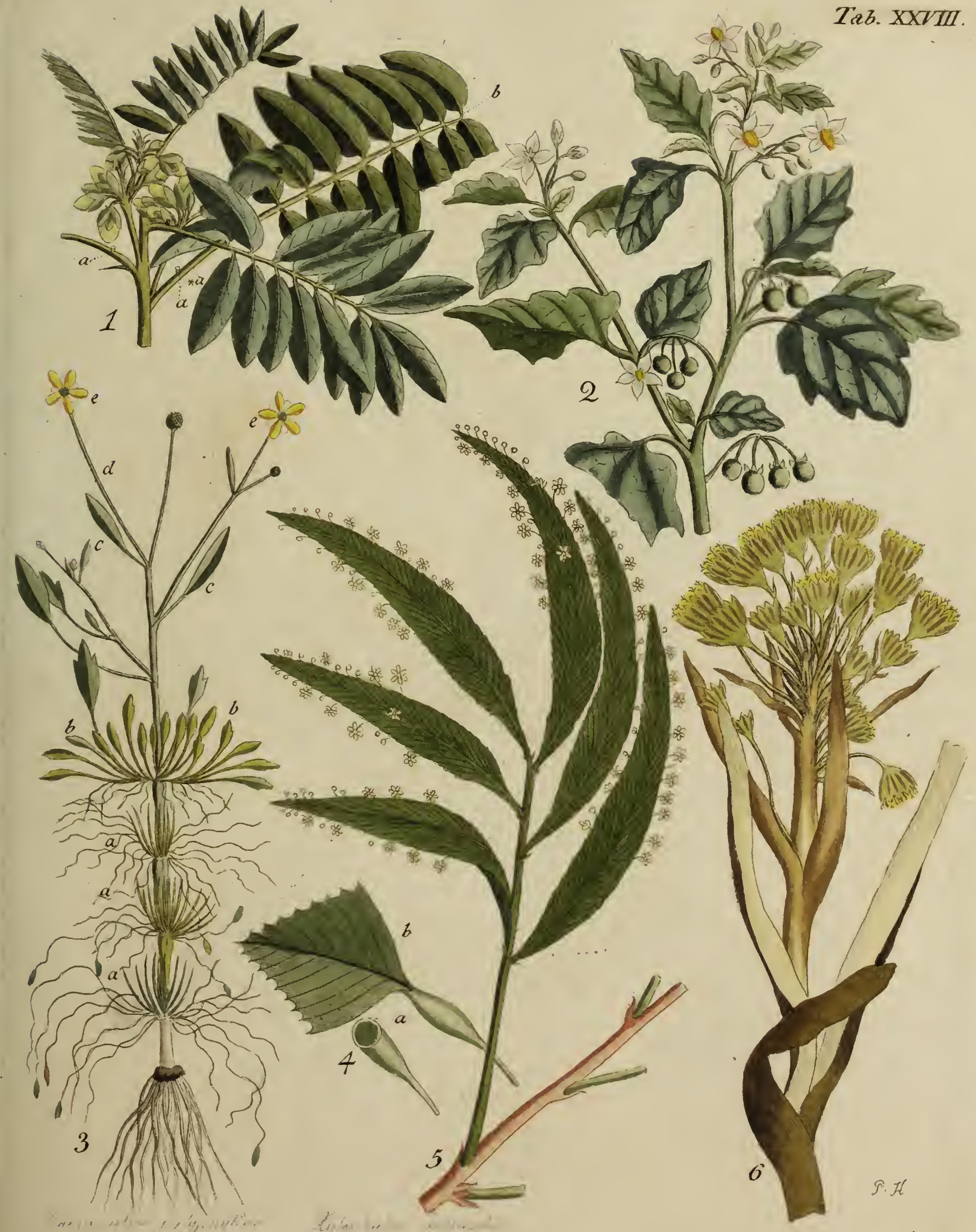





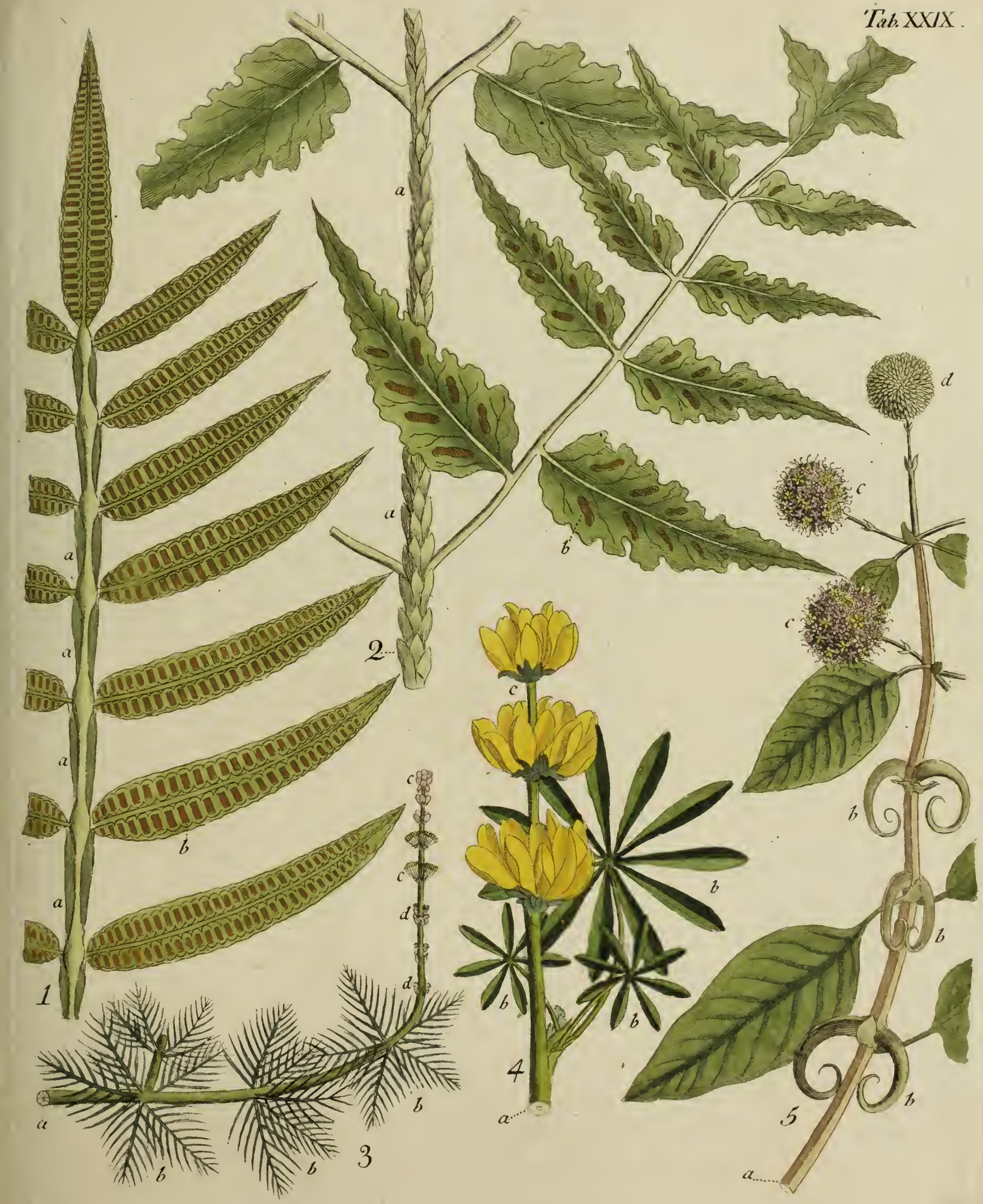





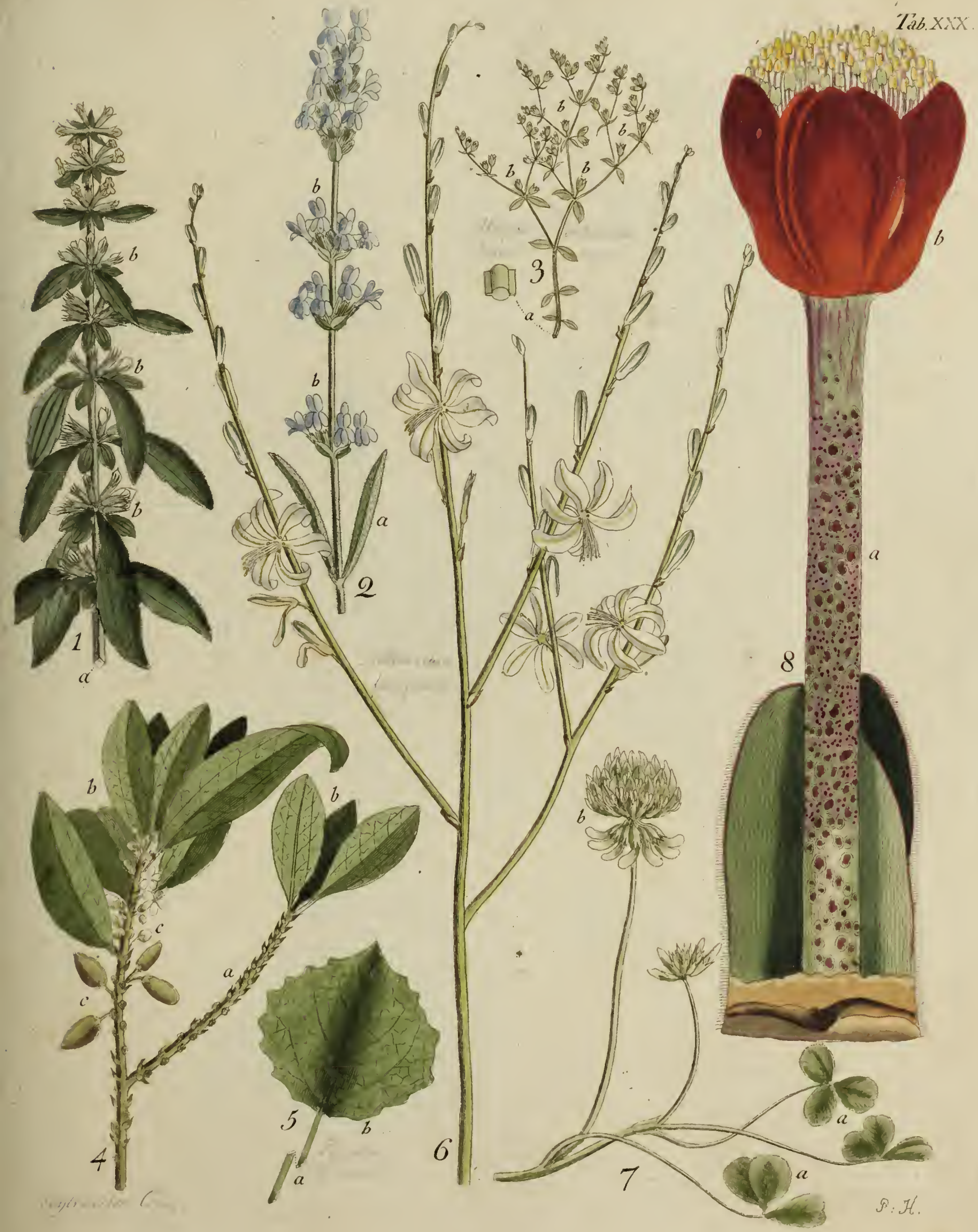





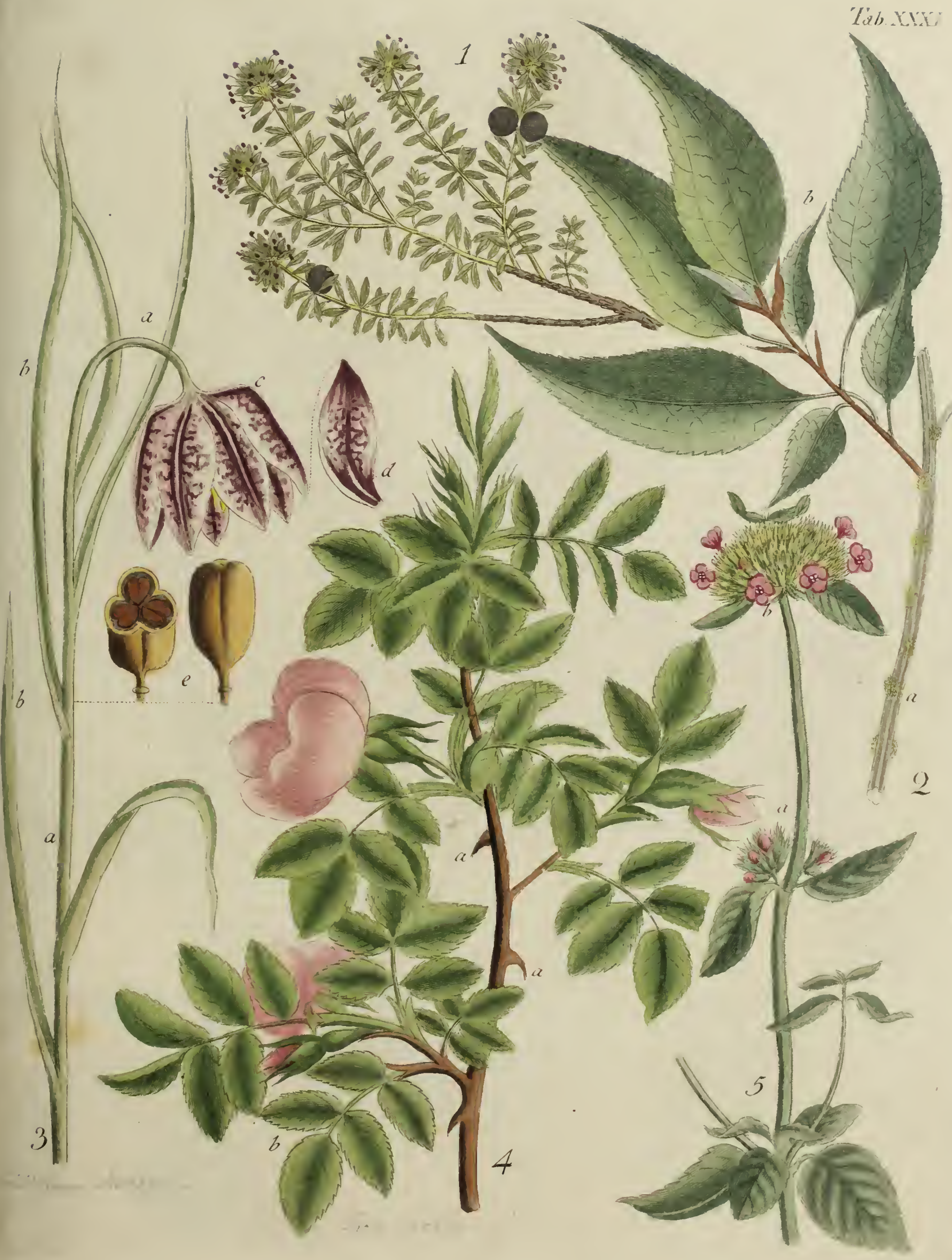




$$
\text { • }
$$




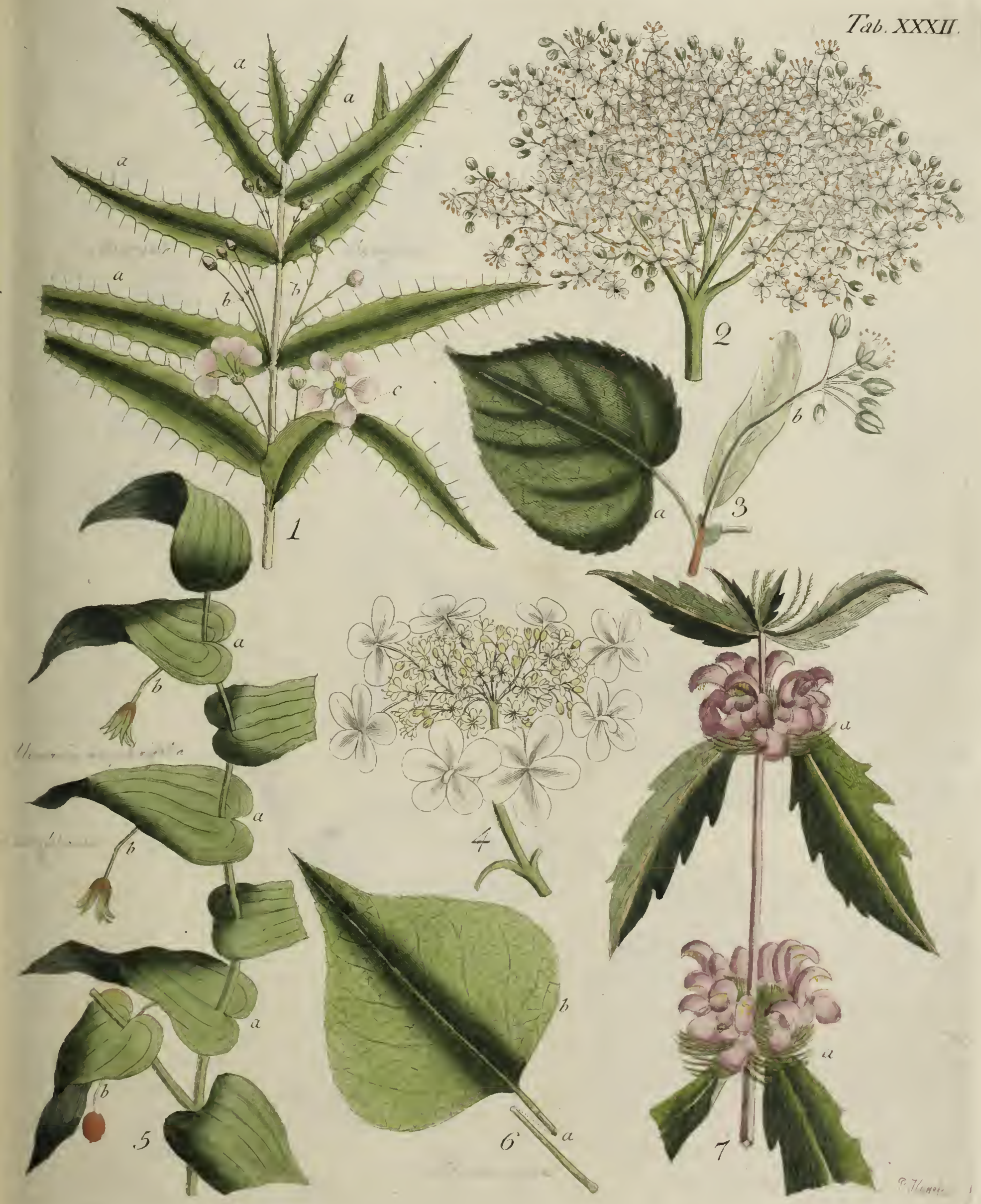





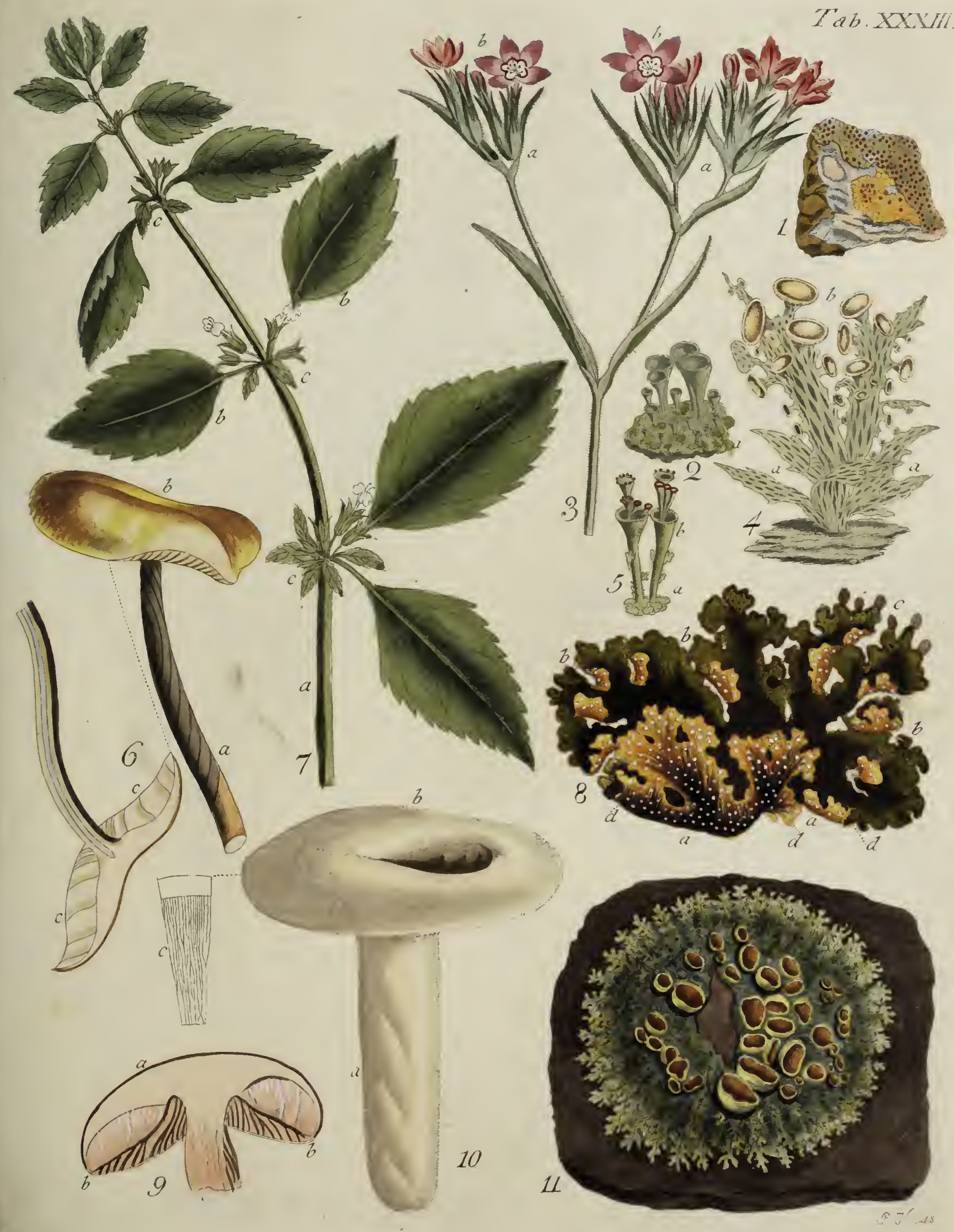




\section{,}

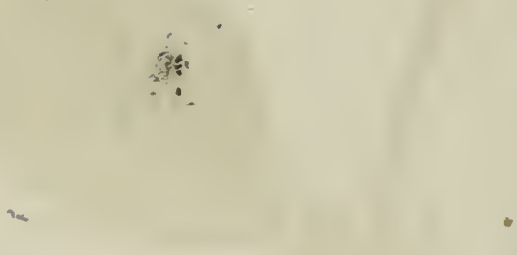

$-$

$-$ 


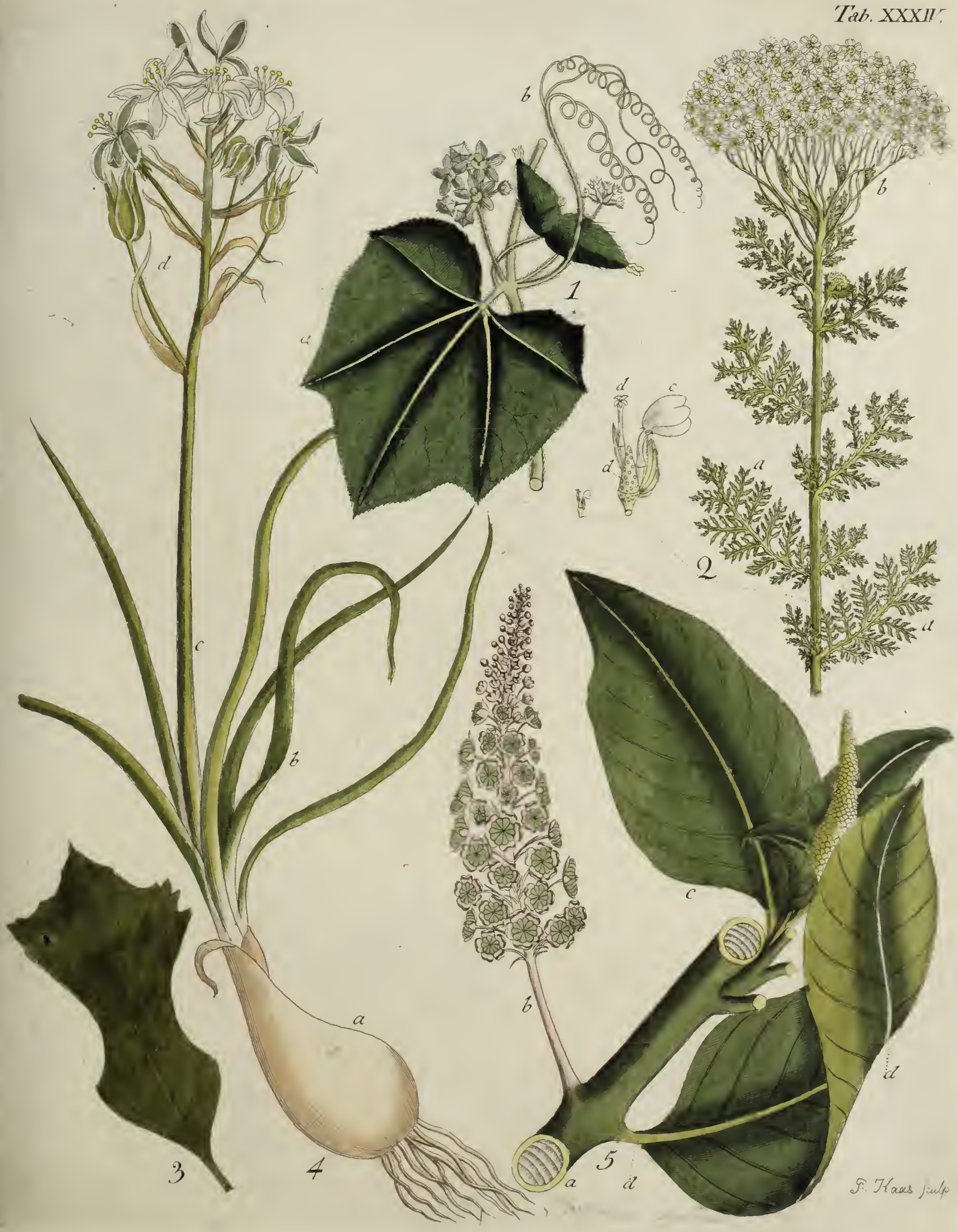





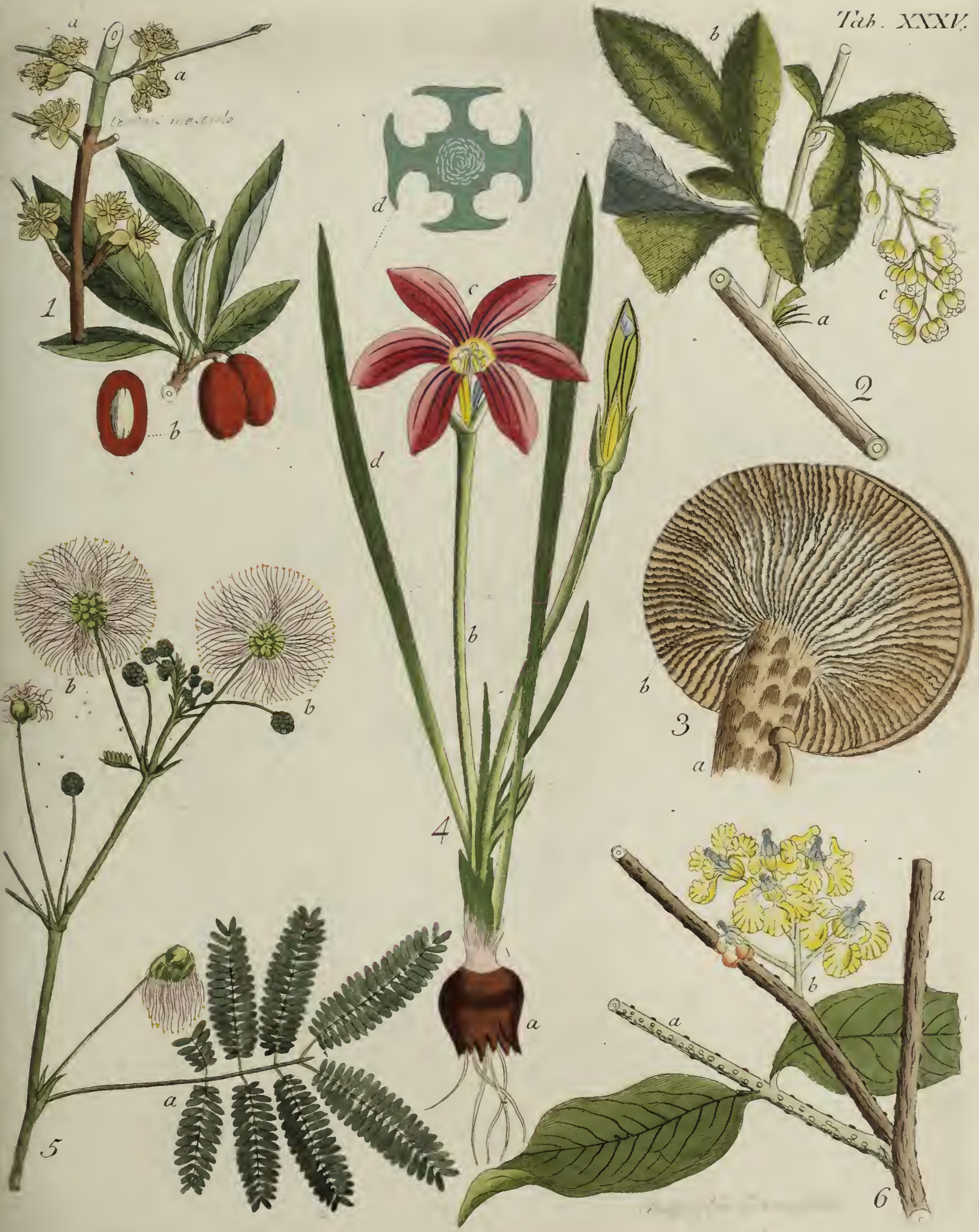




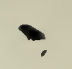




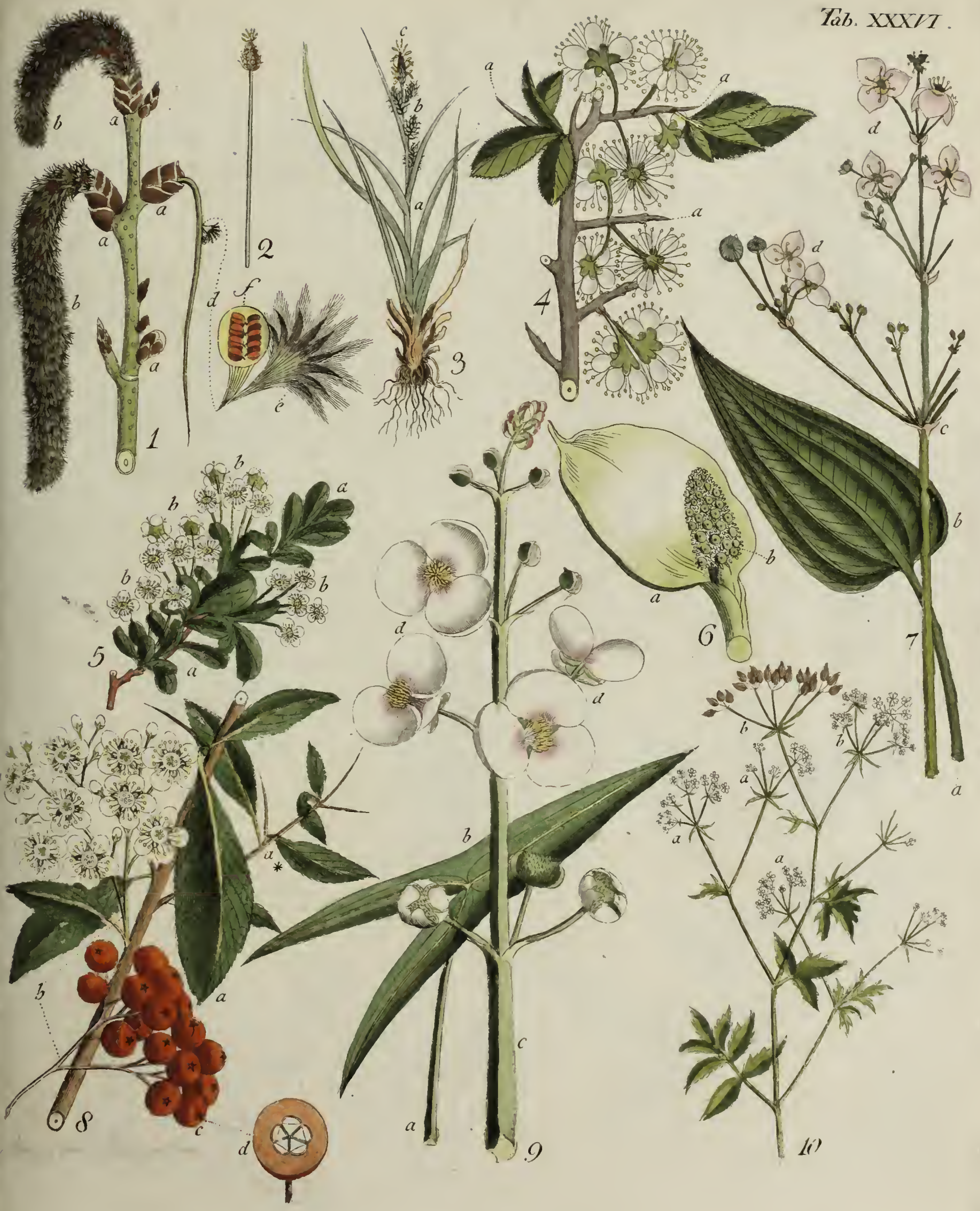





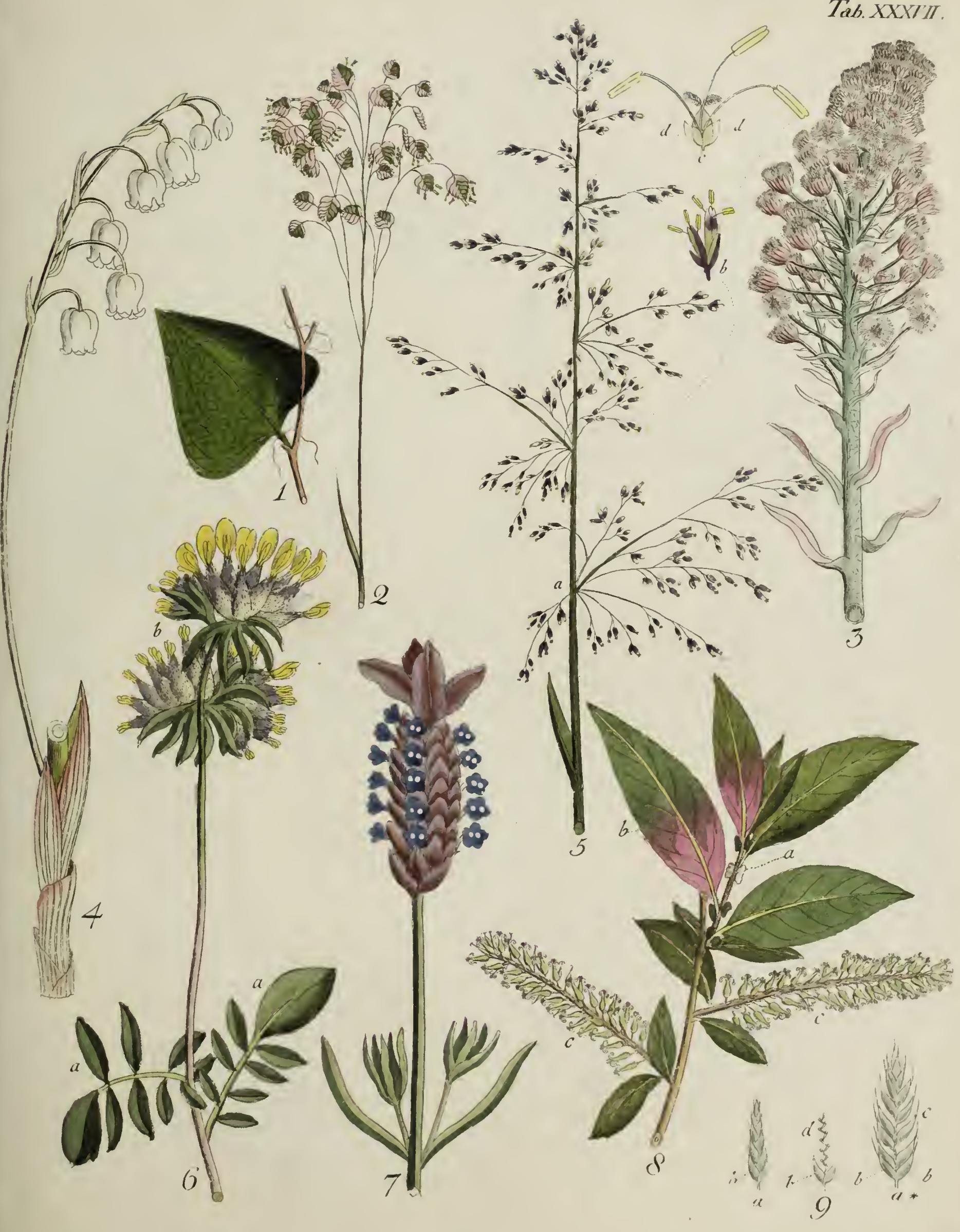





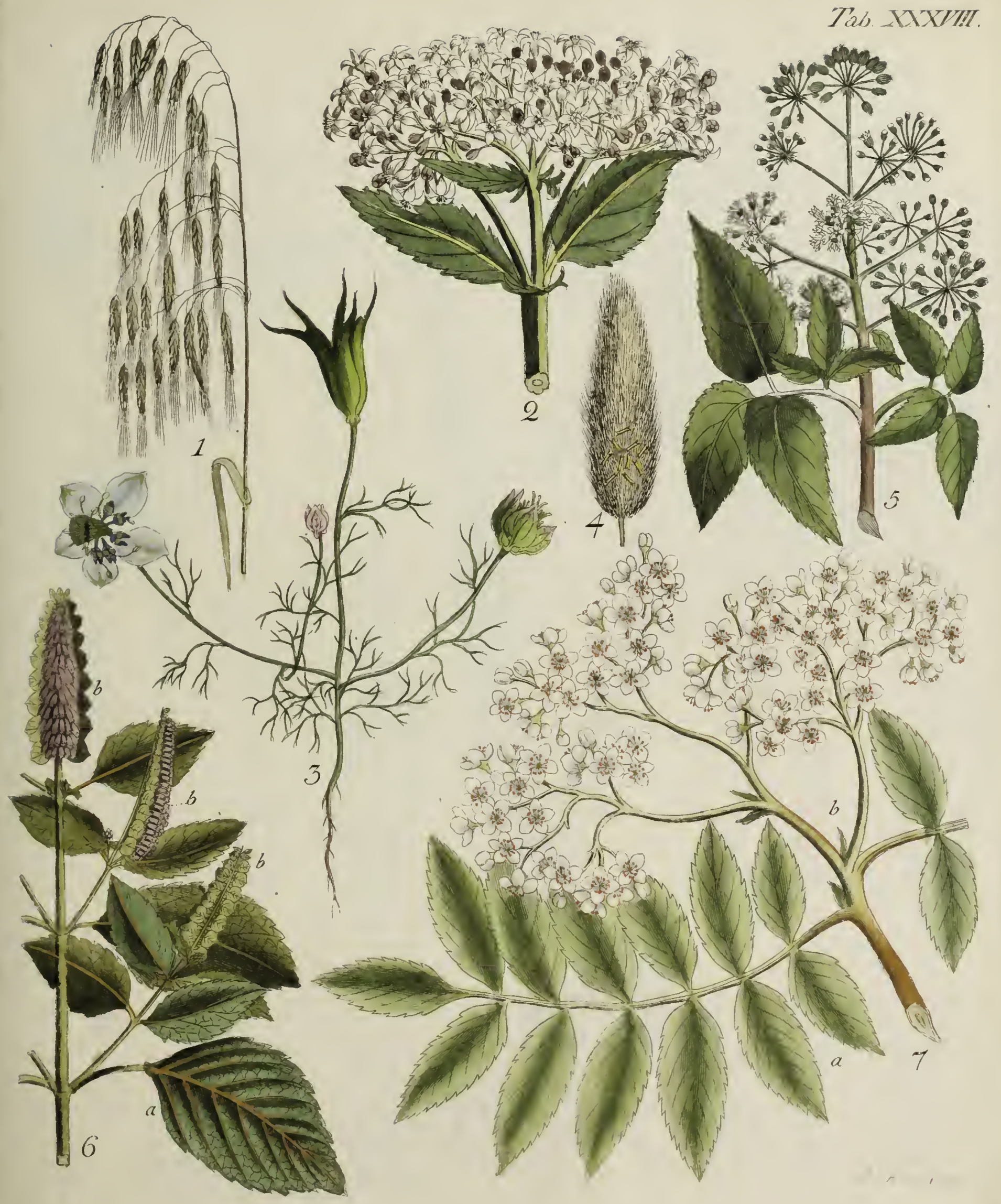




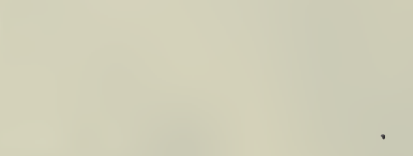




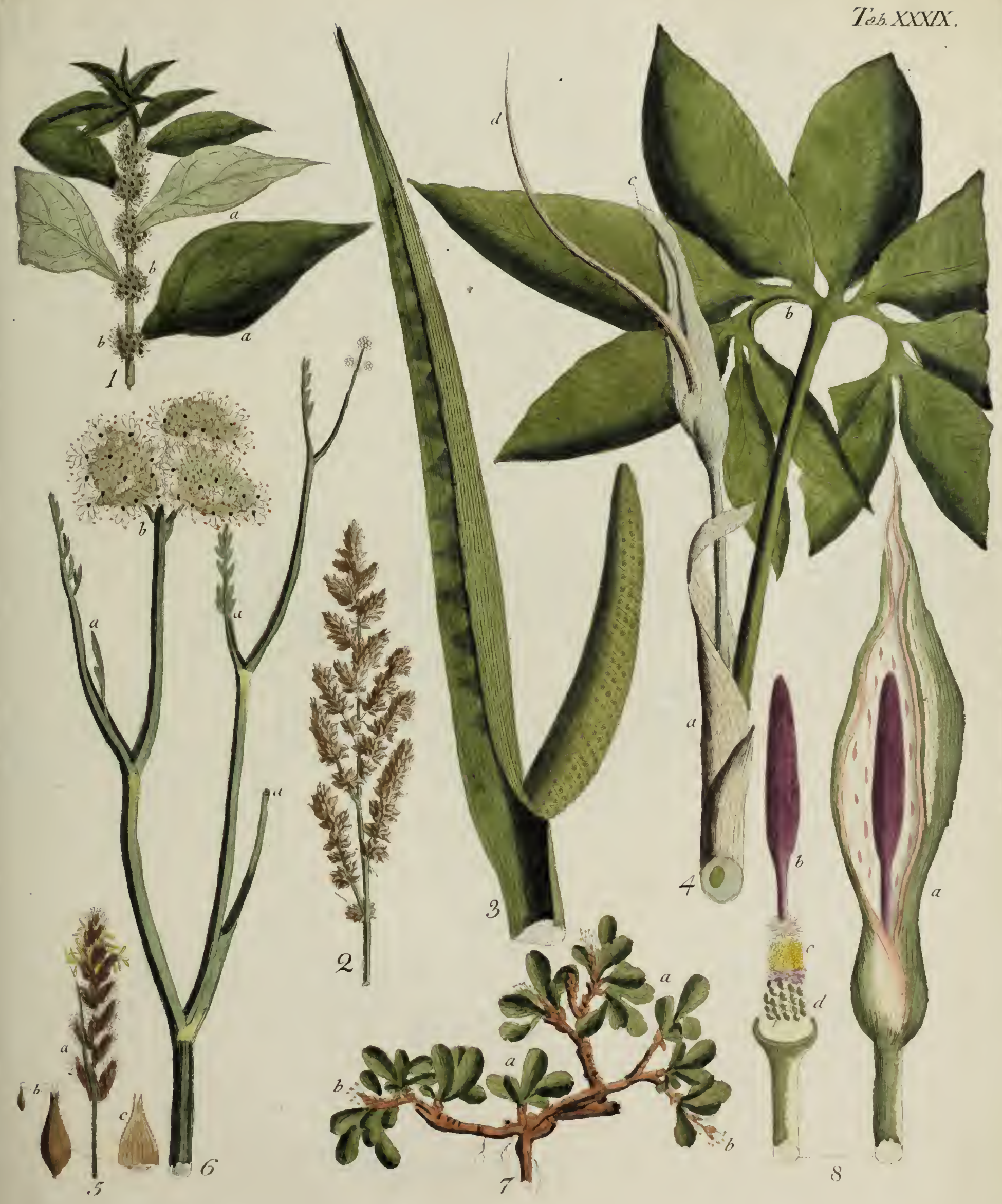





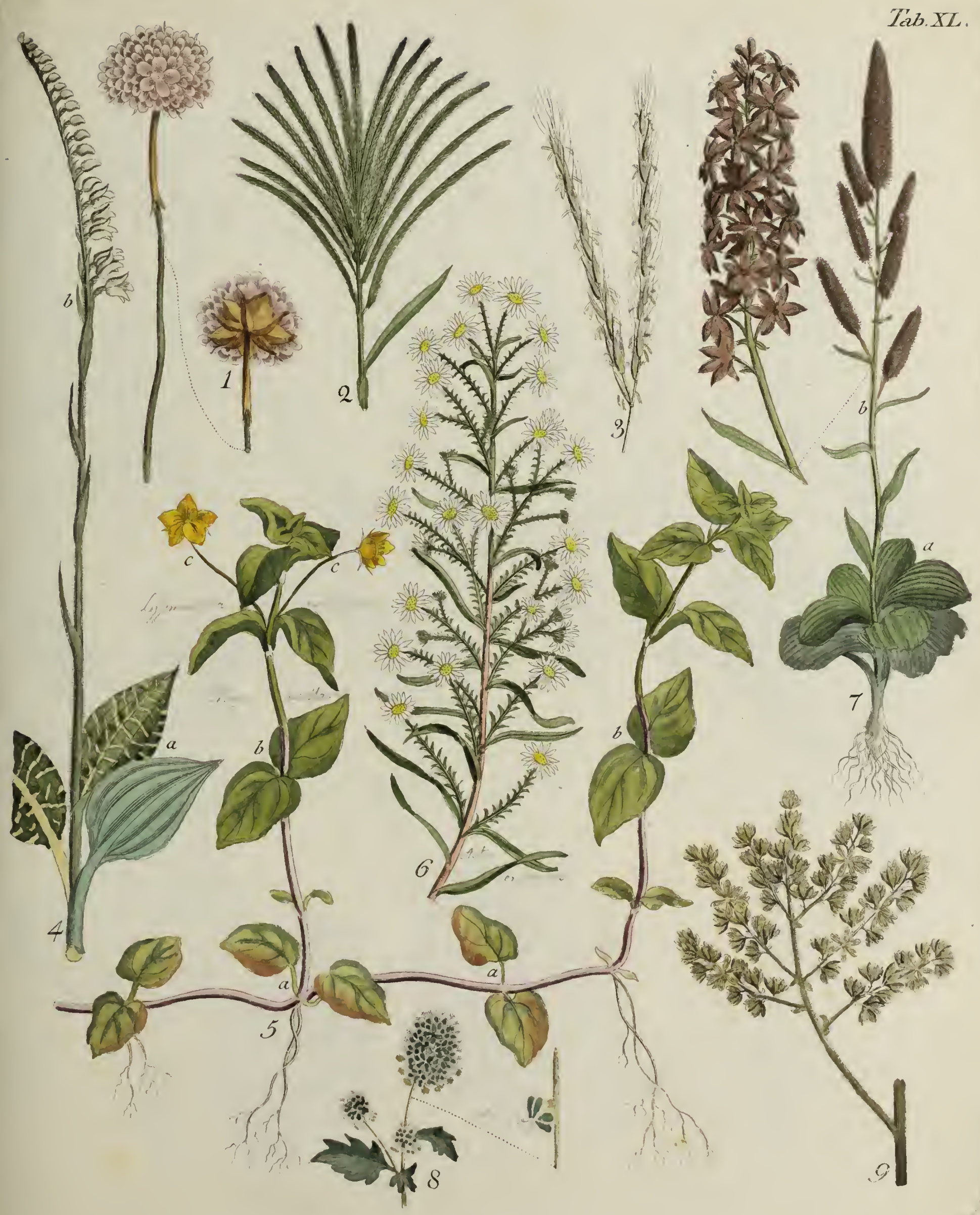





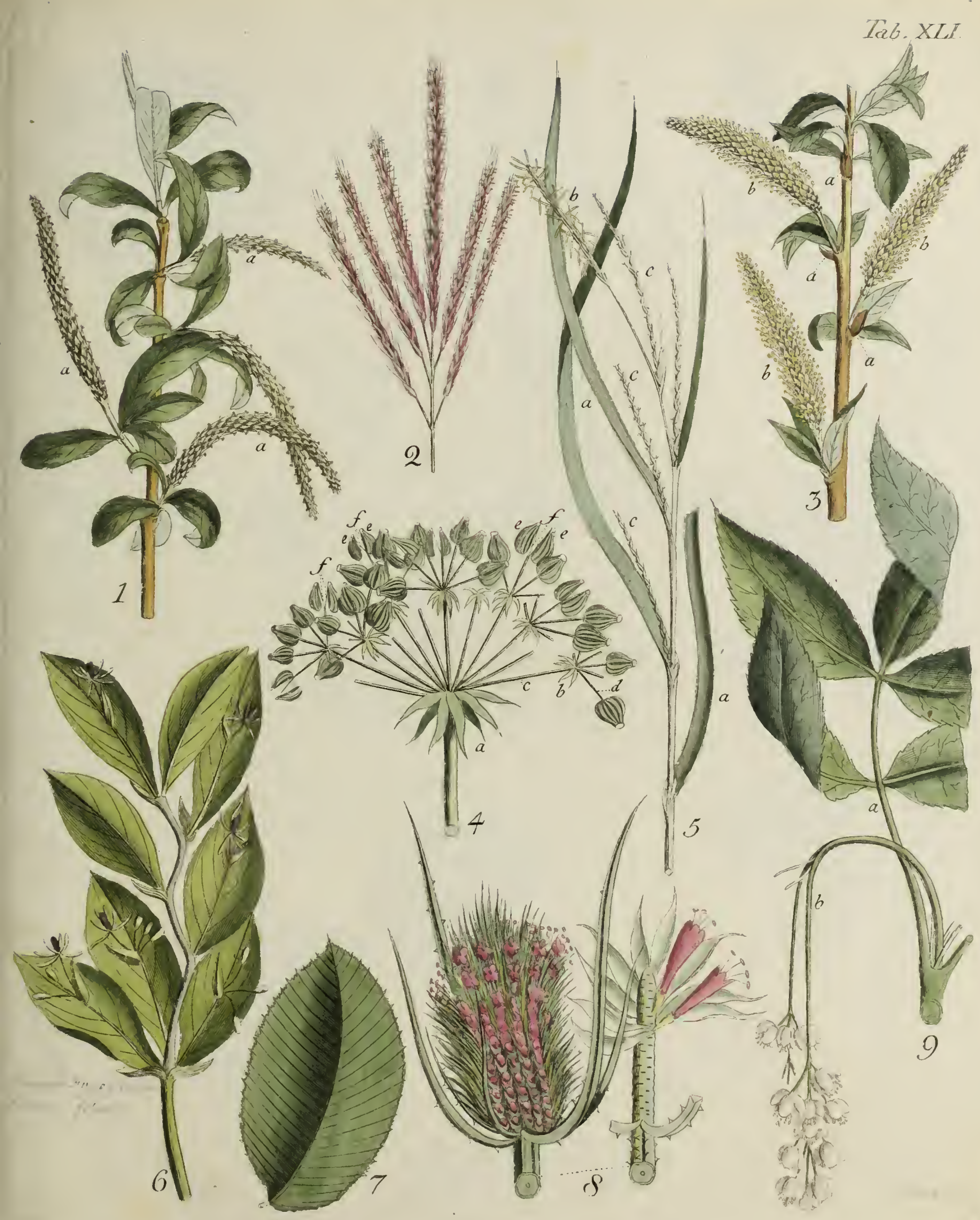





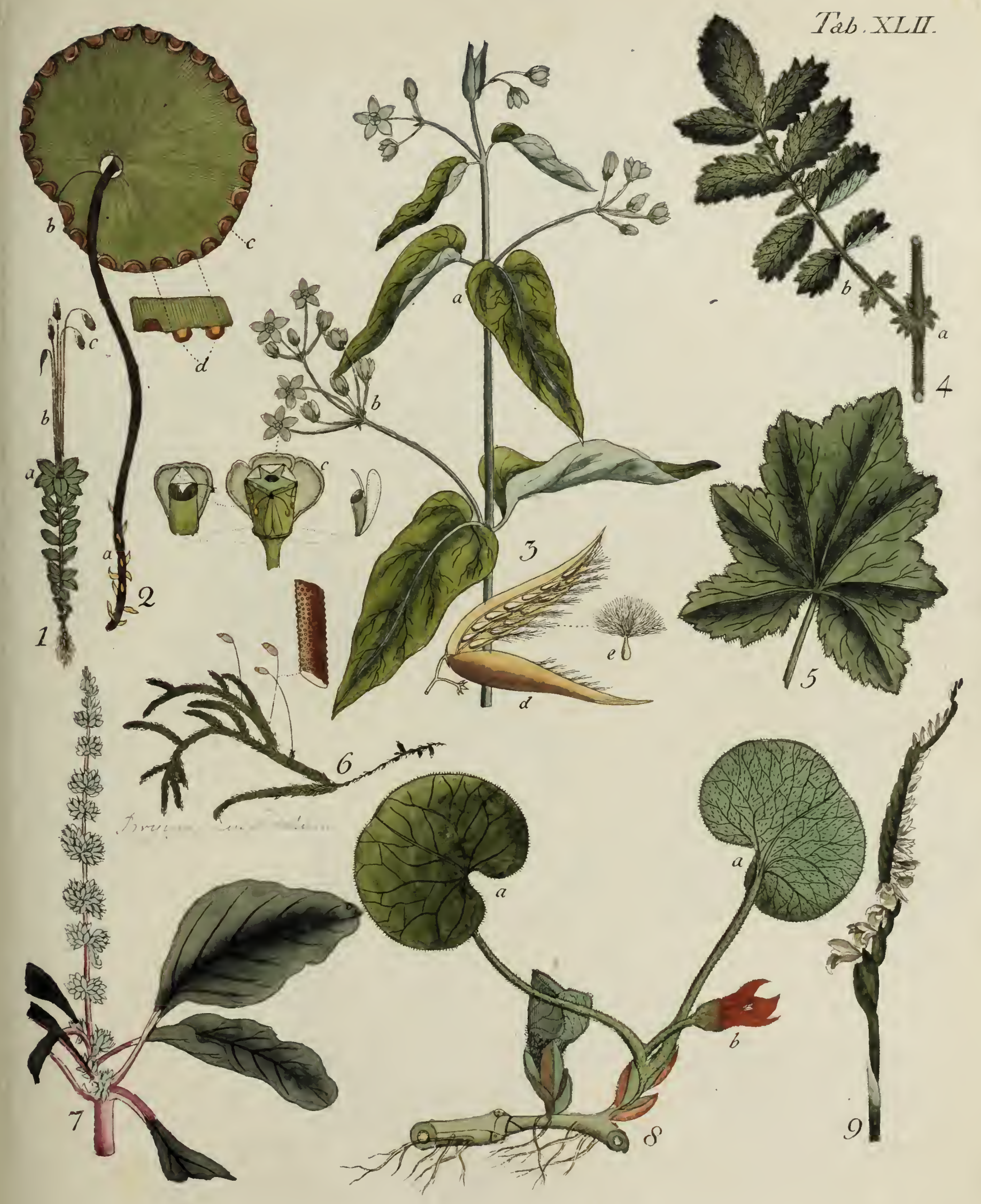





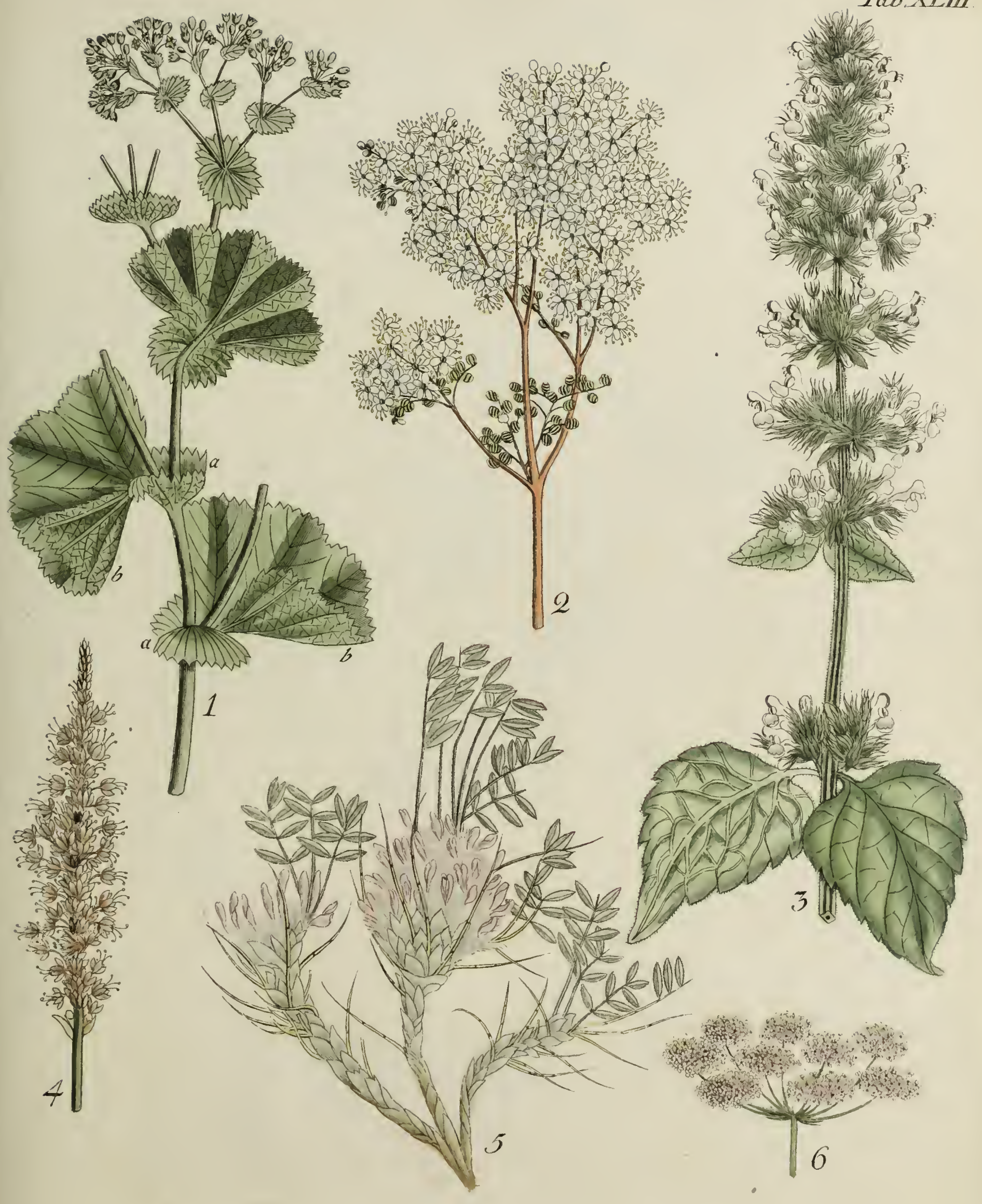





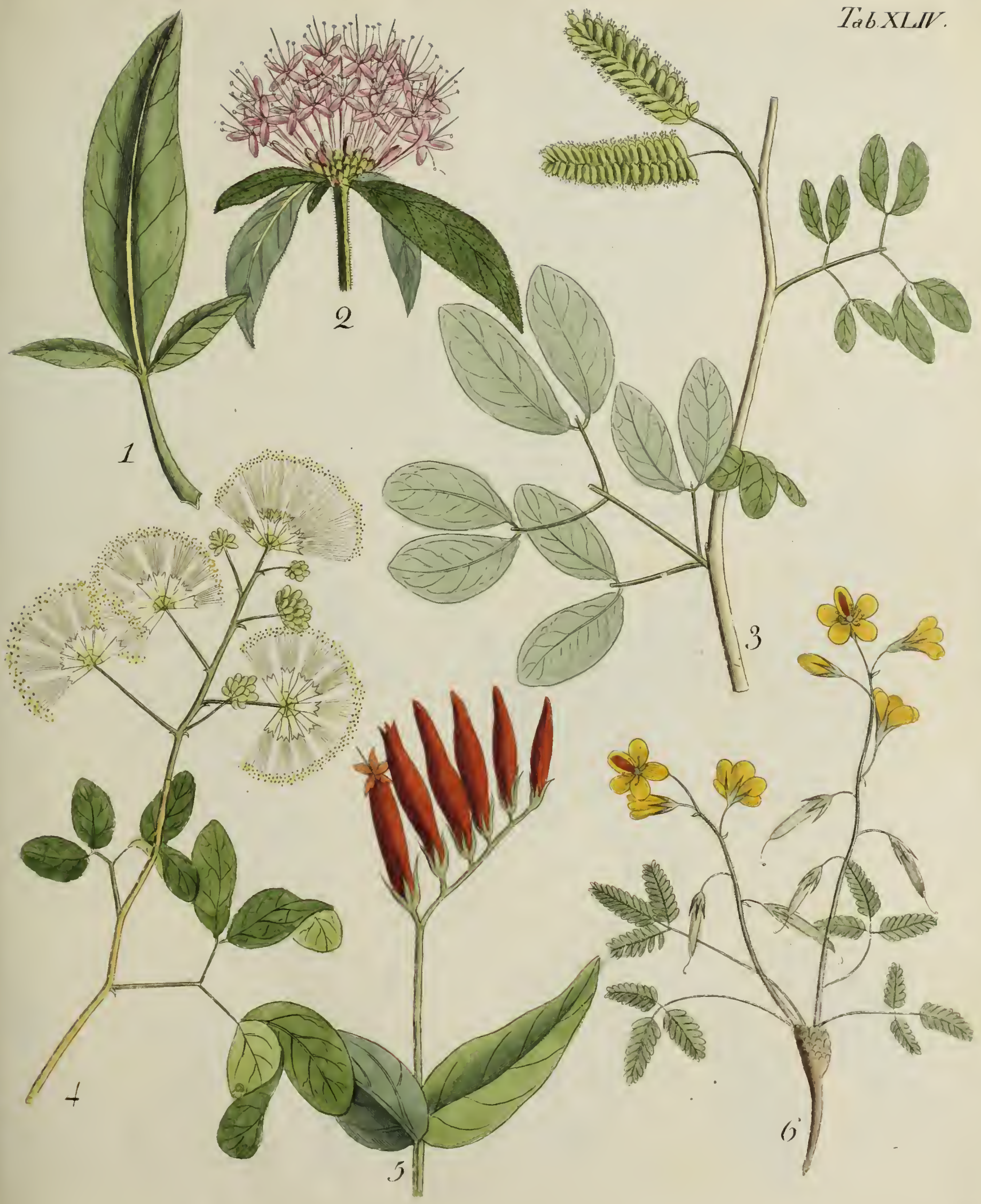





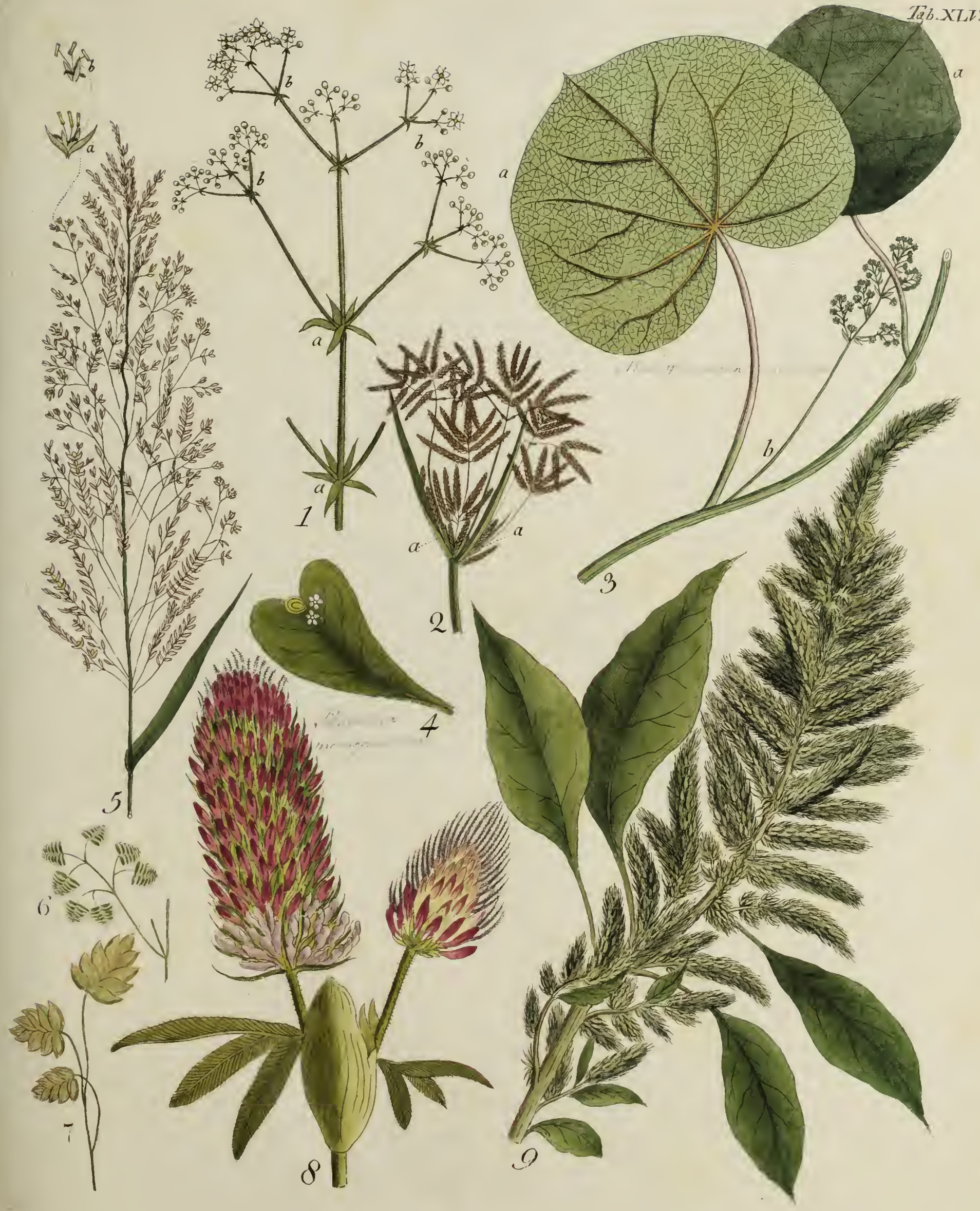





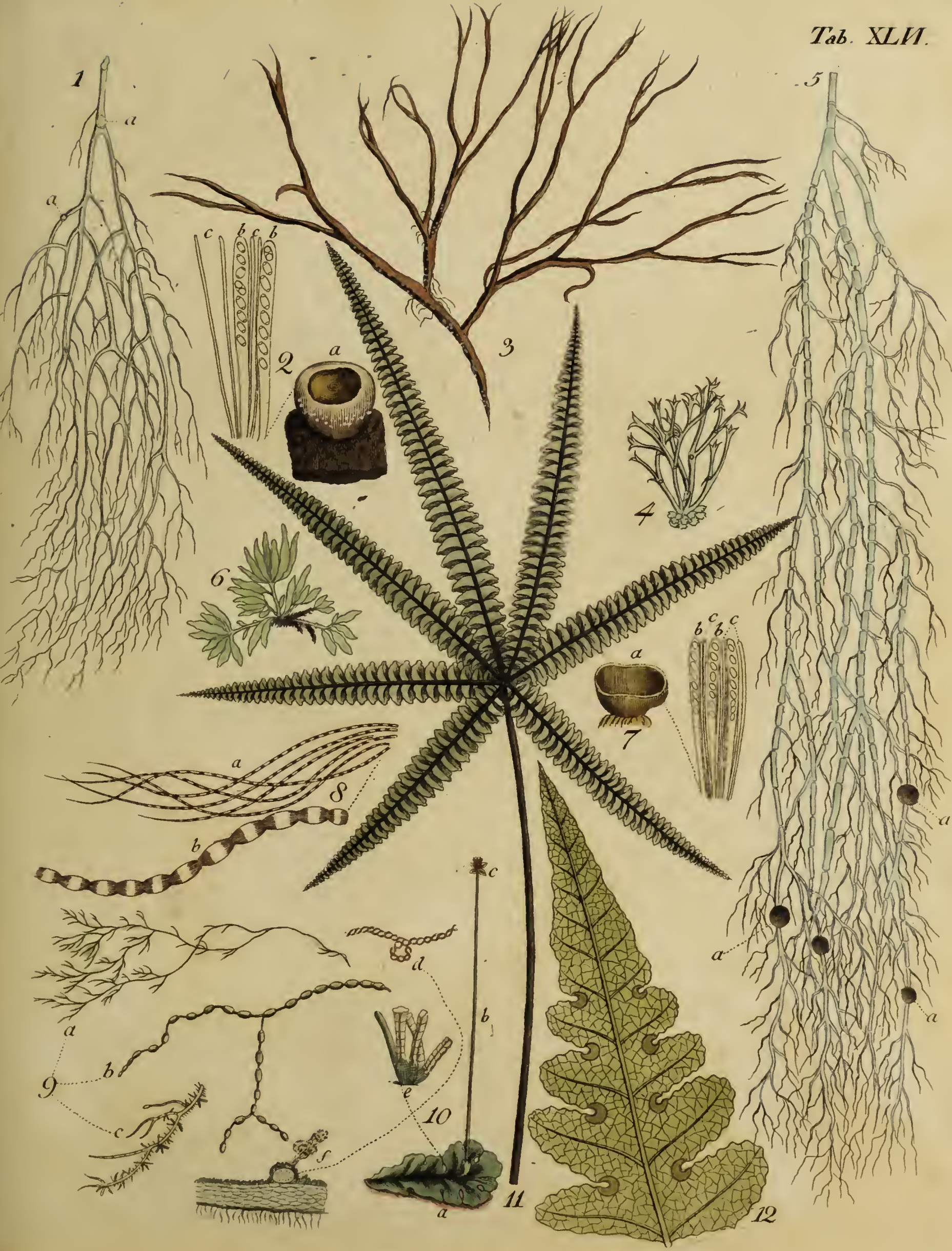





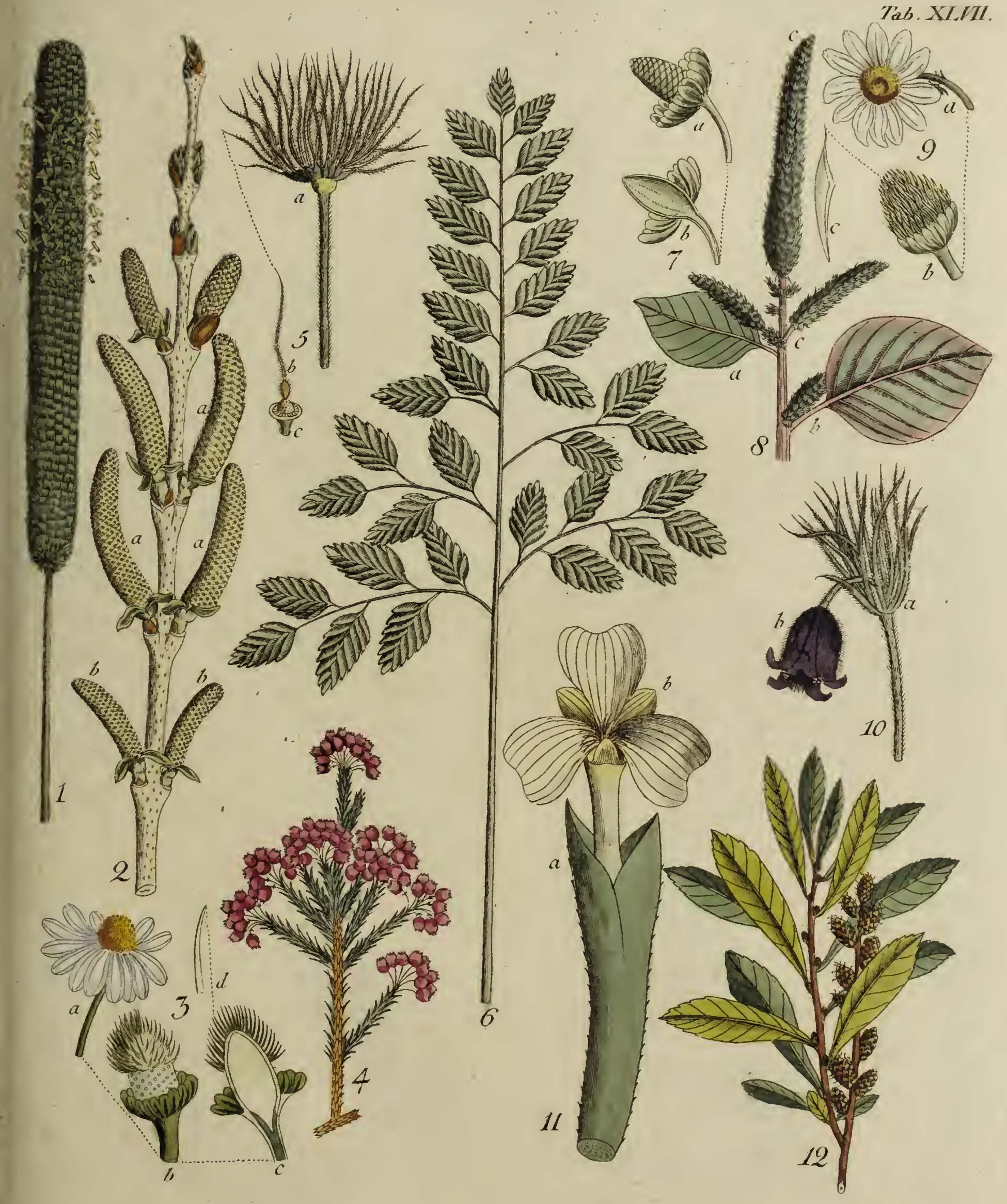





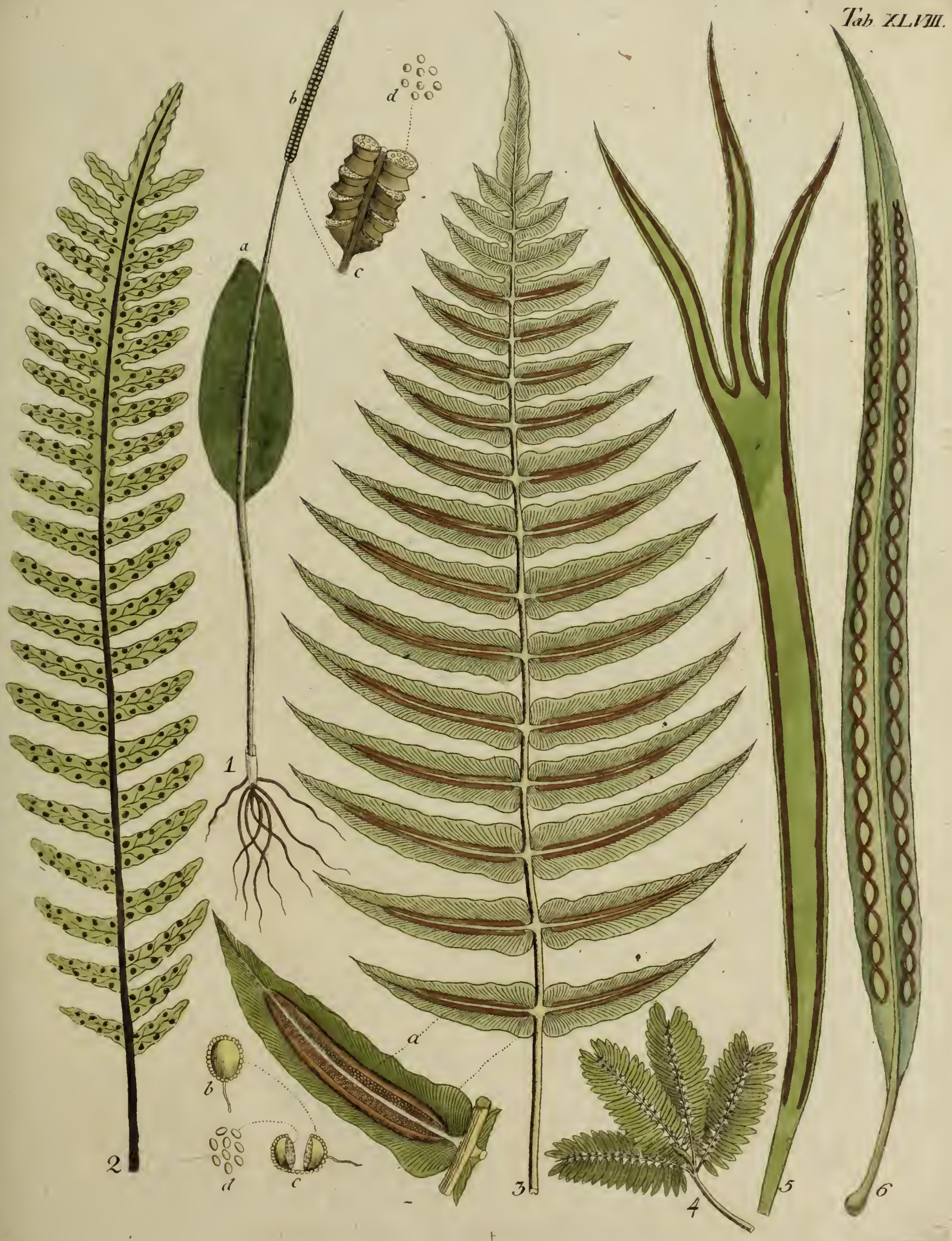





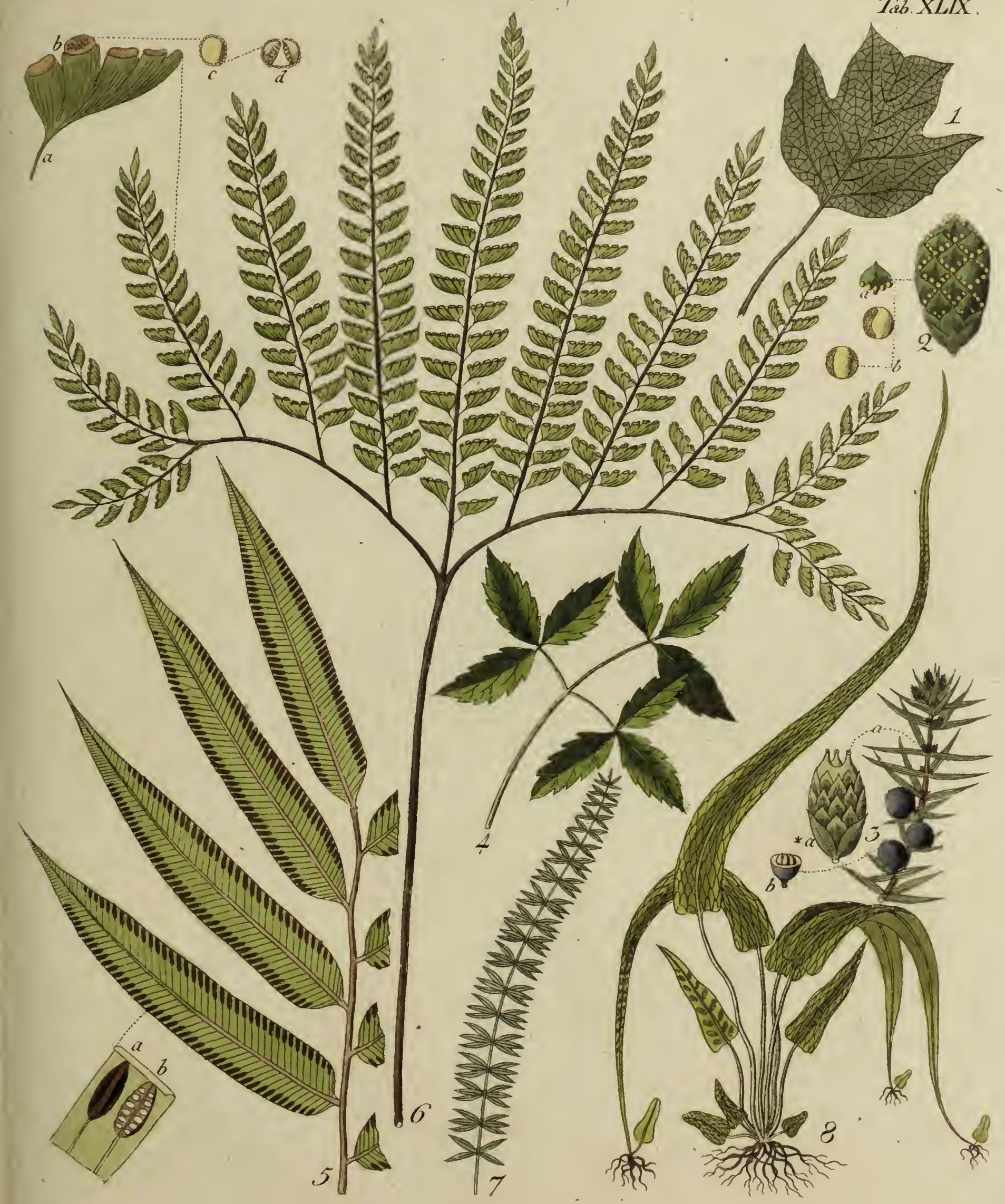



Tab. $L$

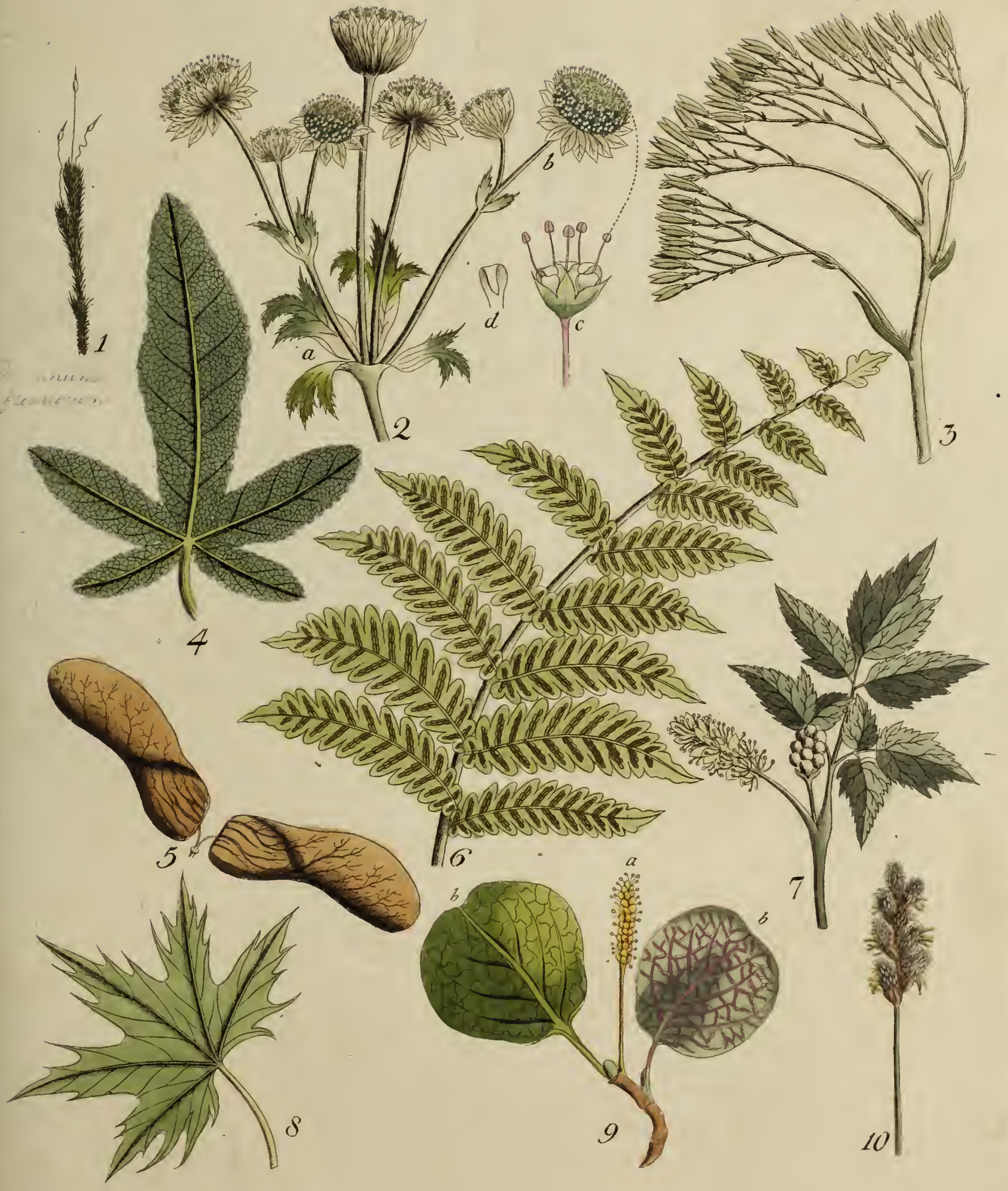




Tab. LII.

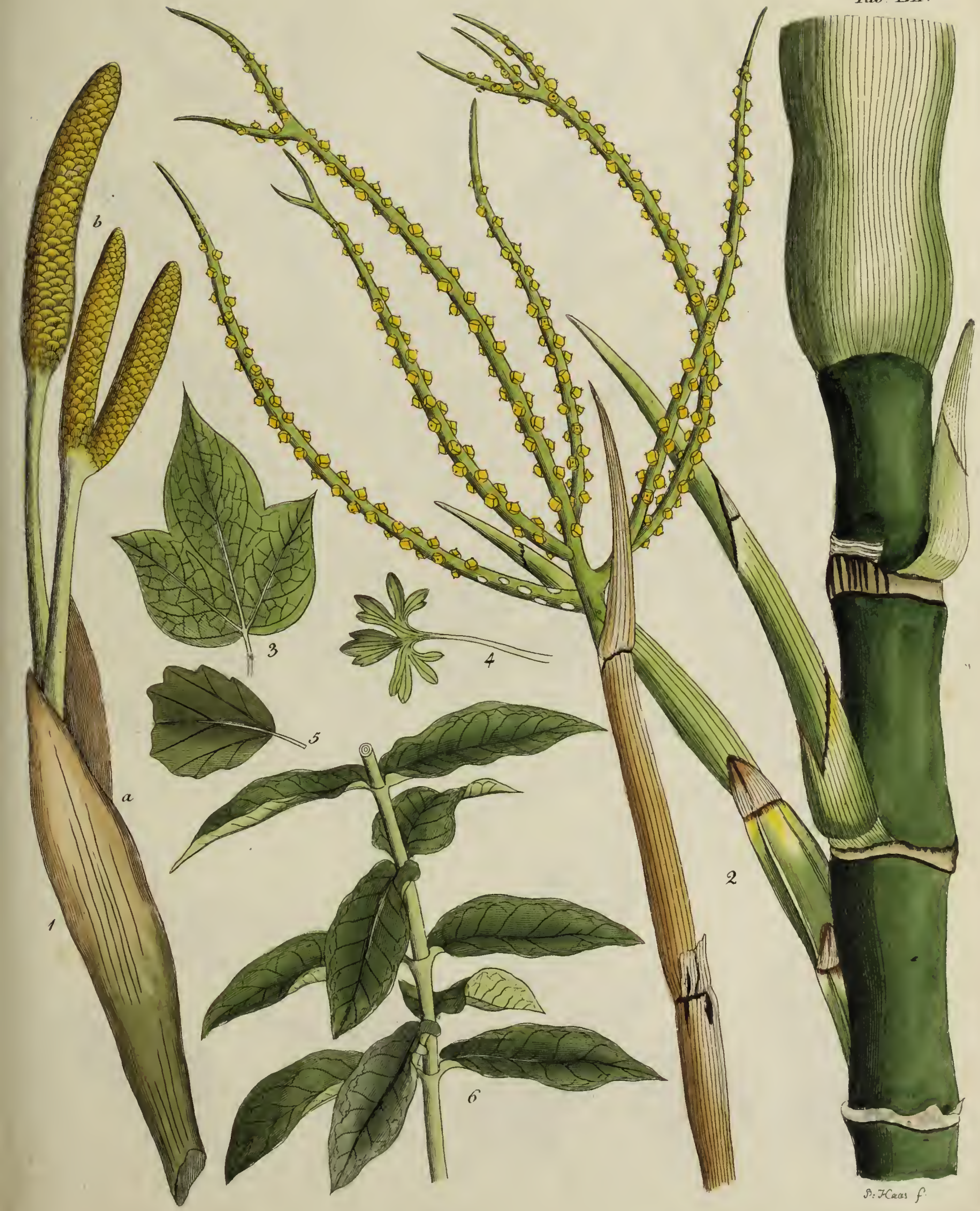




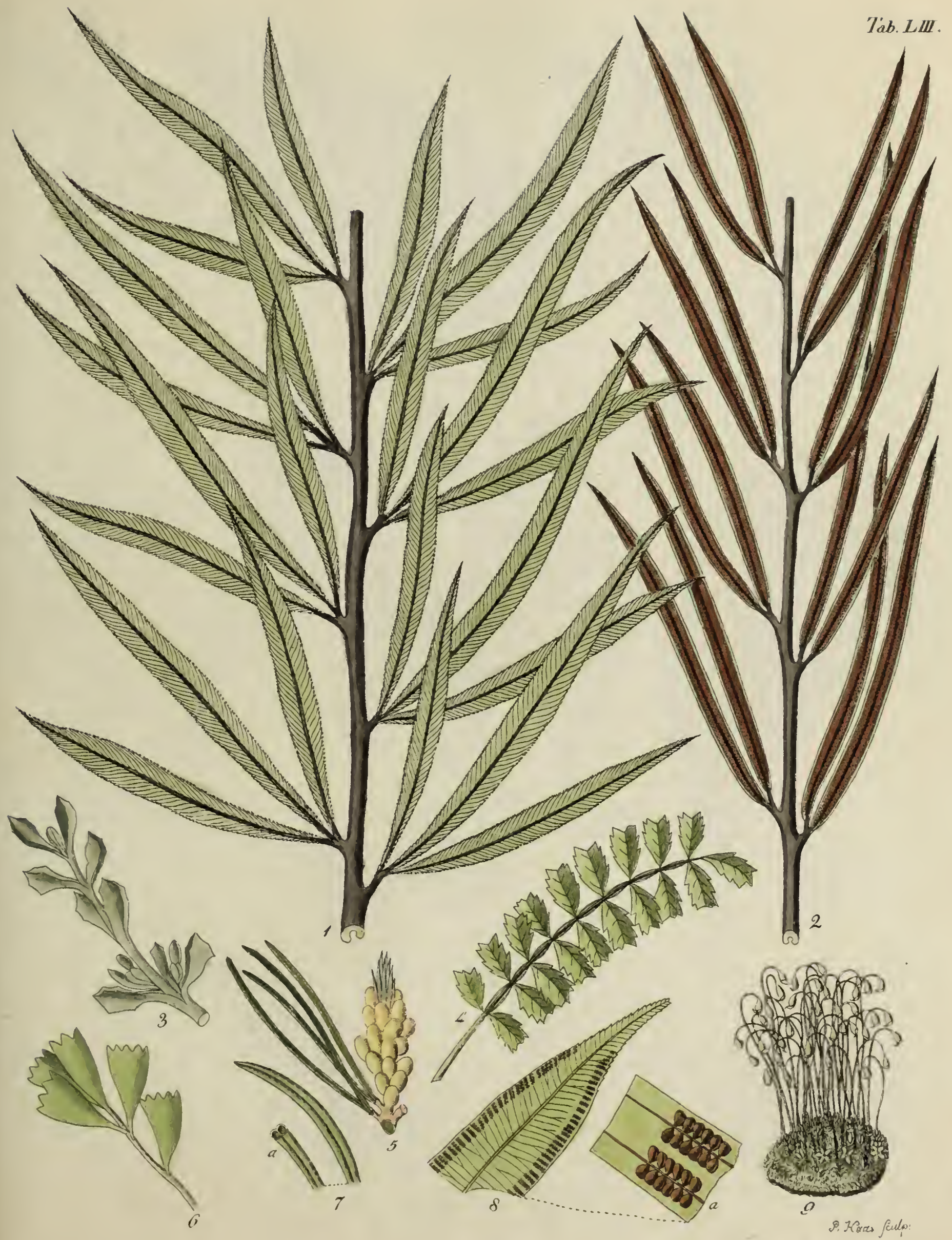





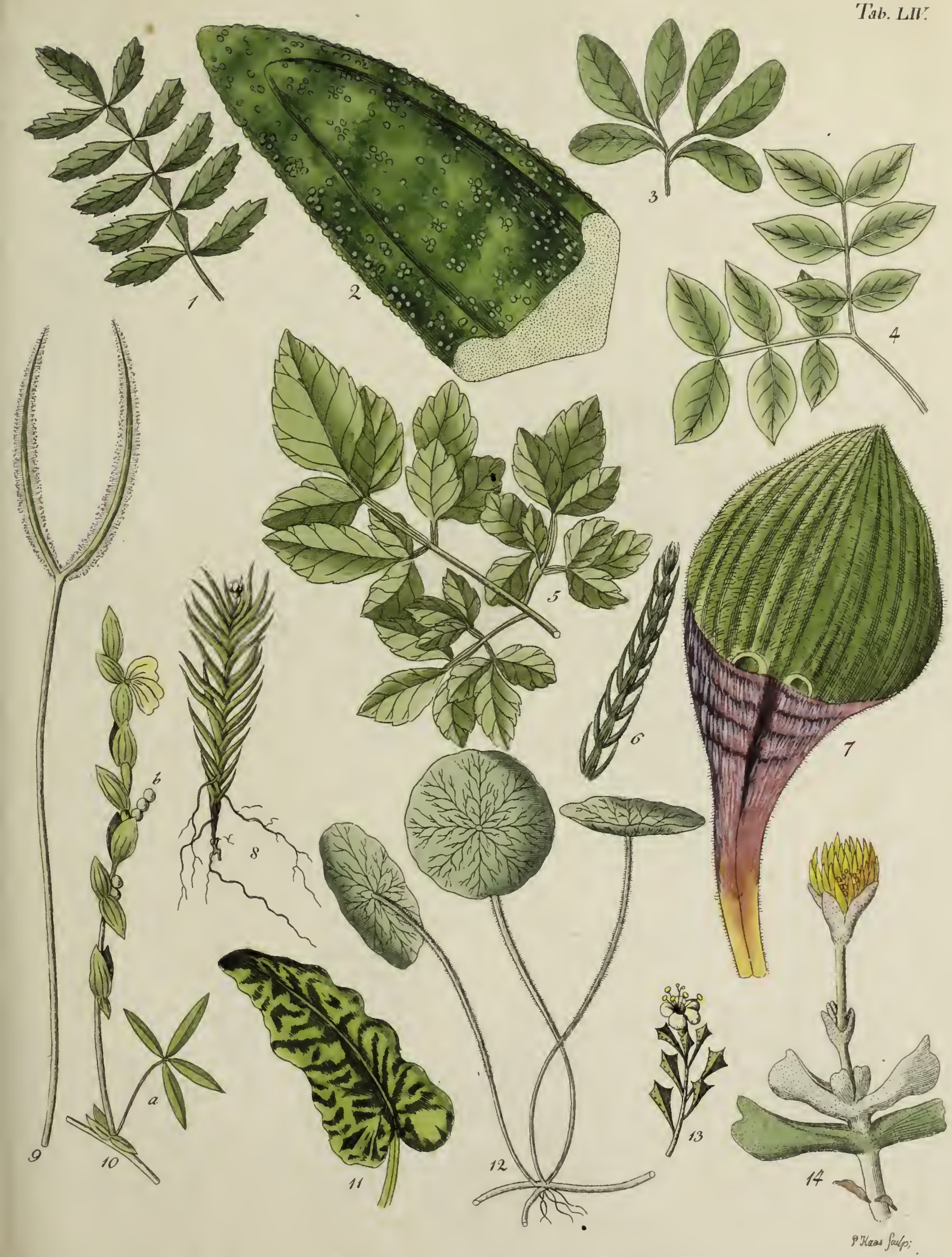



eminnmonmes

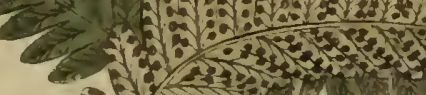

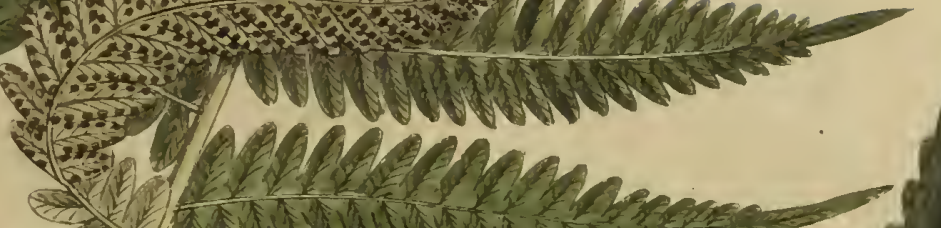
- $\int_{1}$
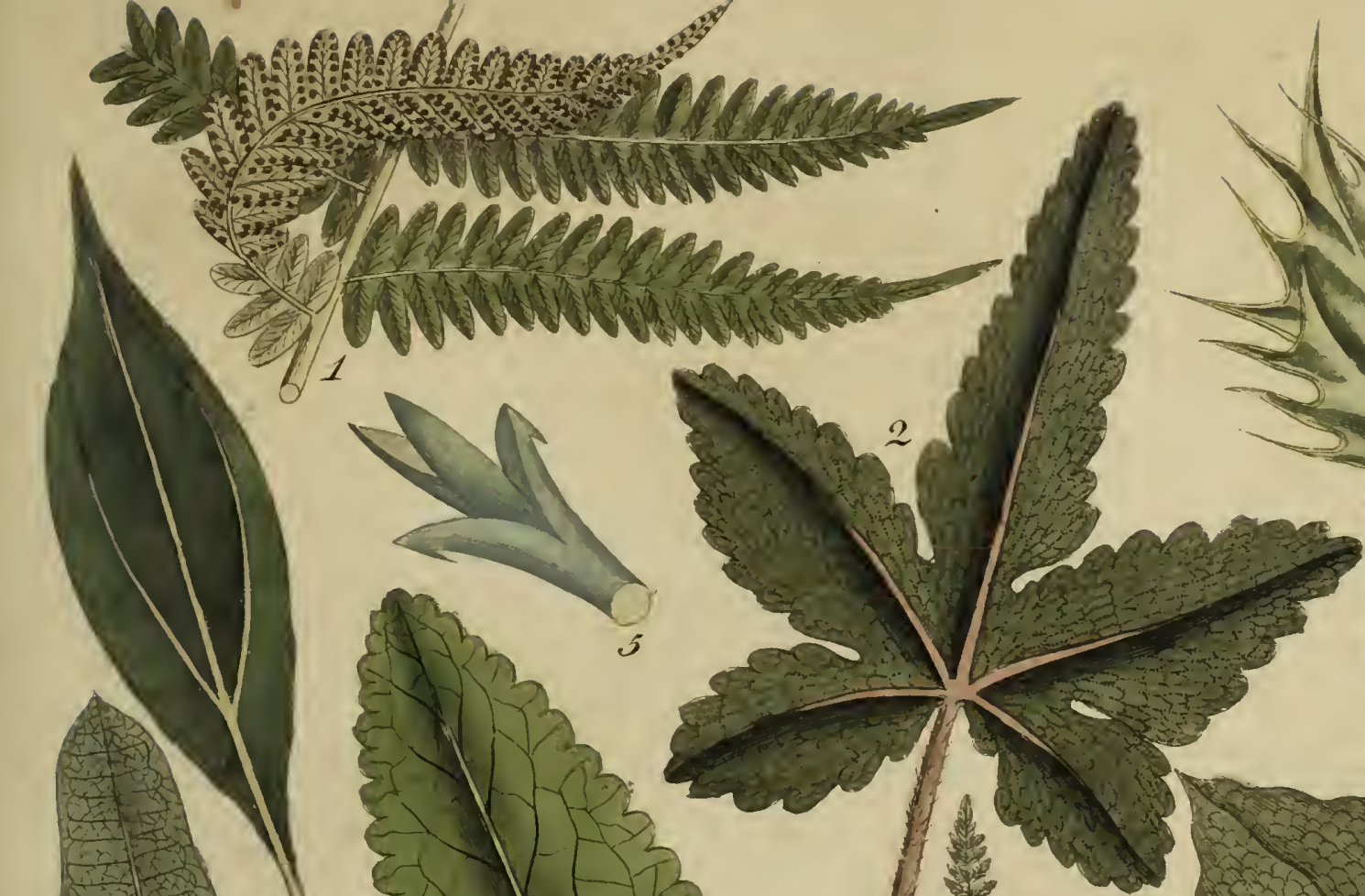

Tab.LIV
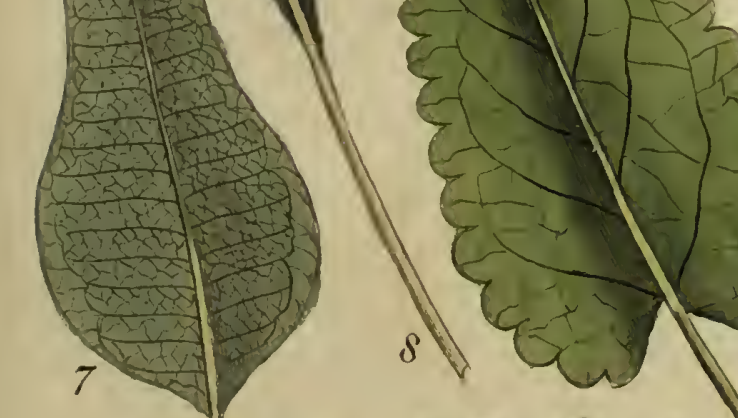


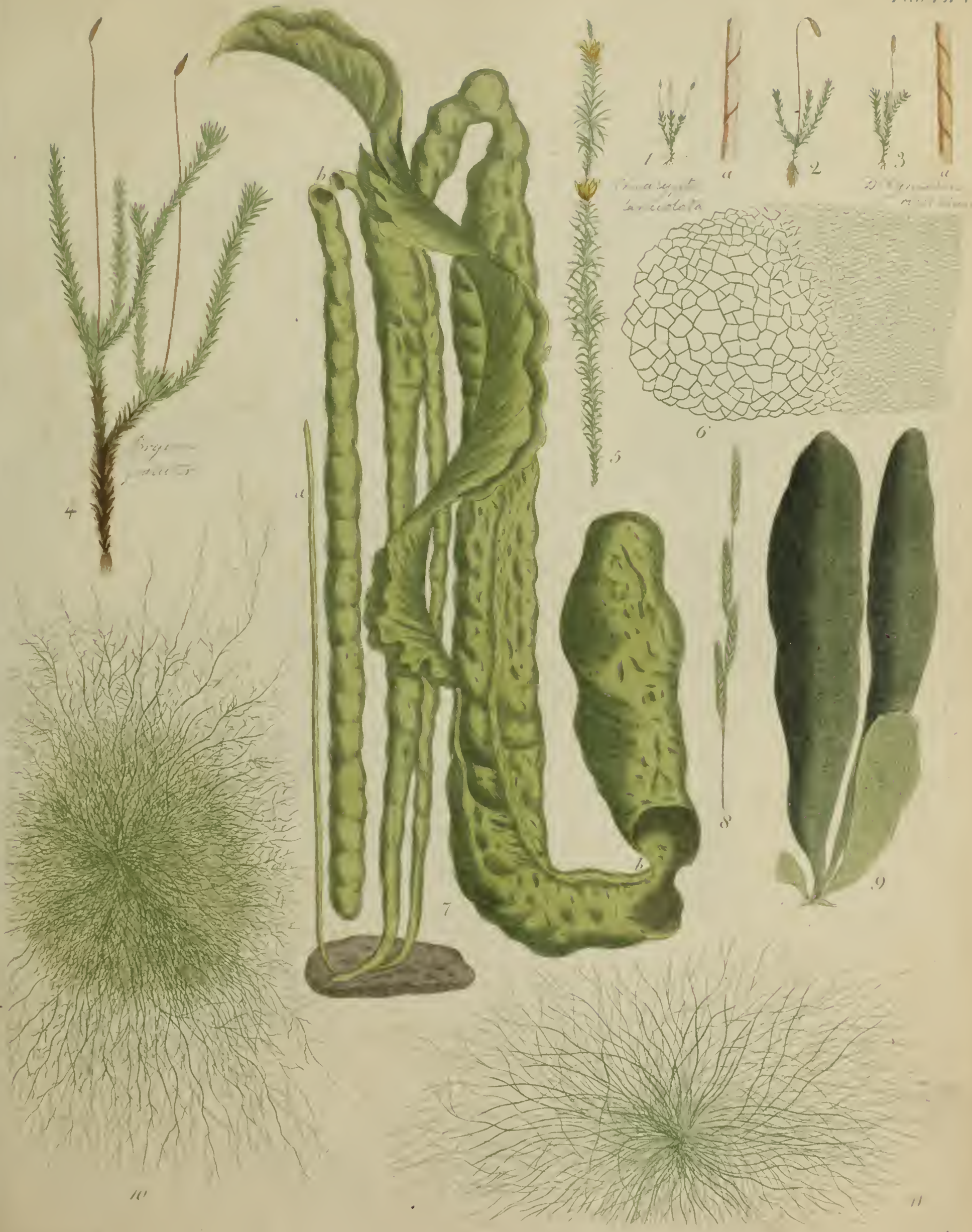





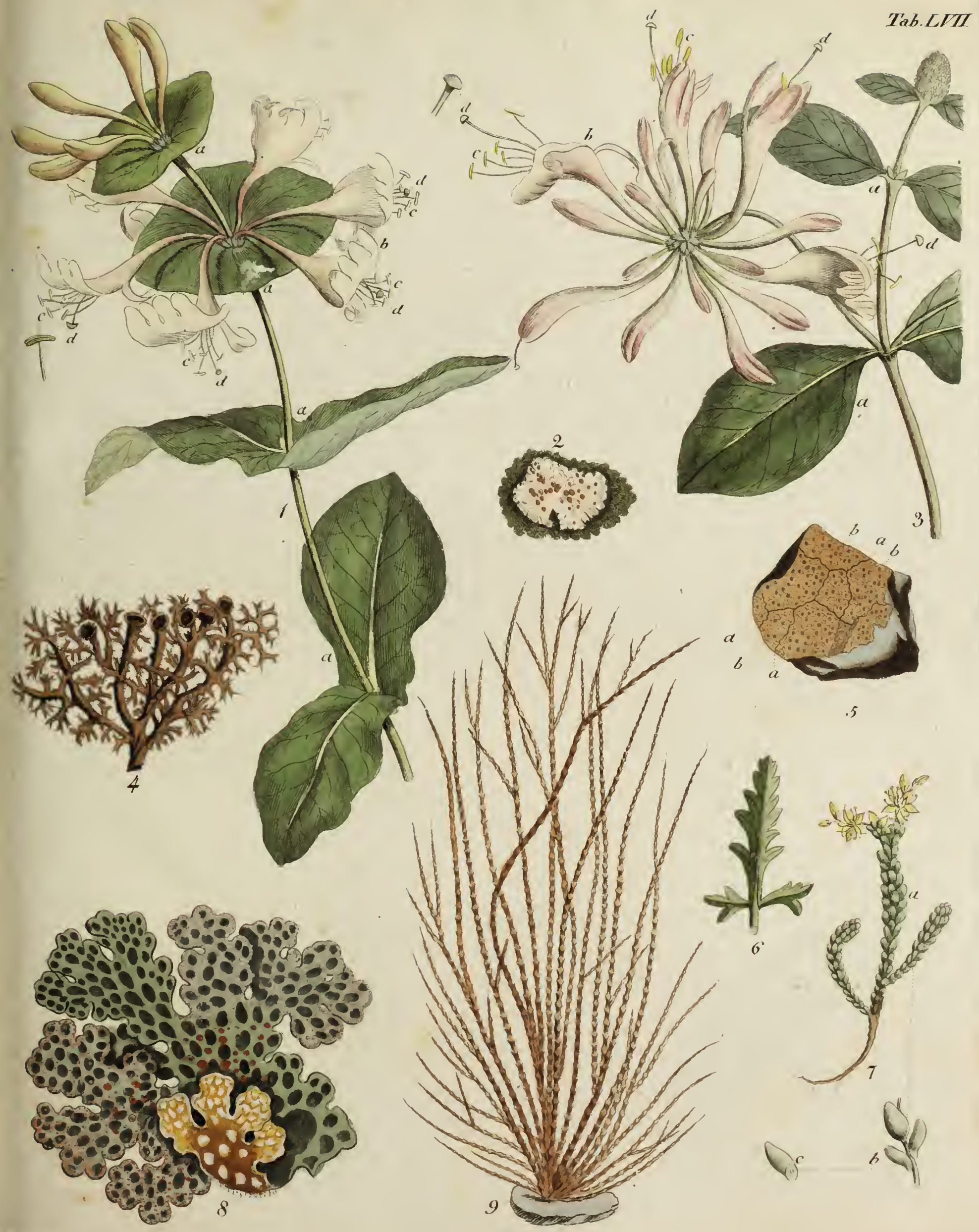





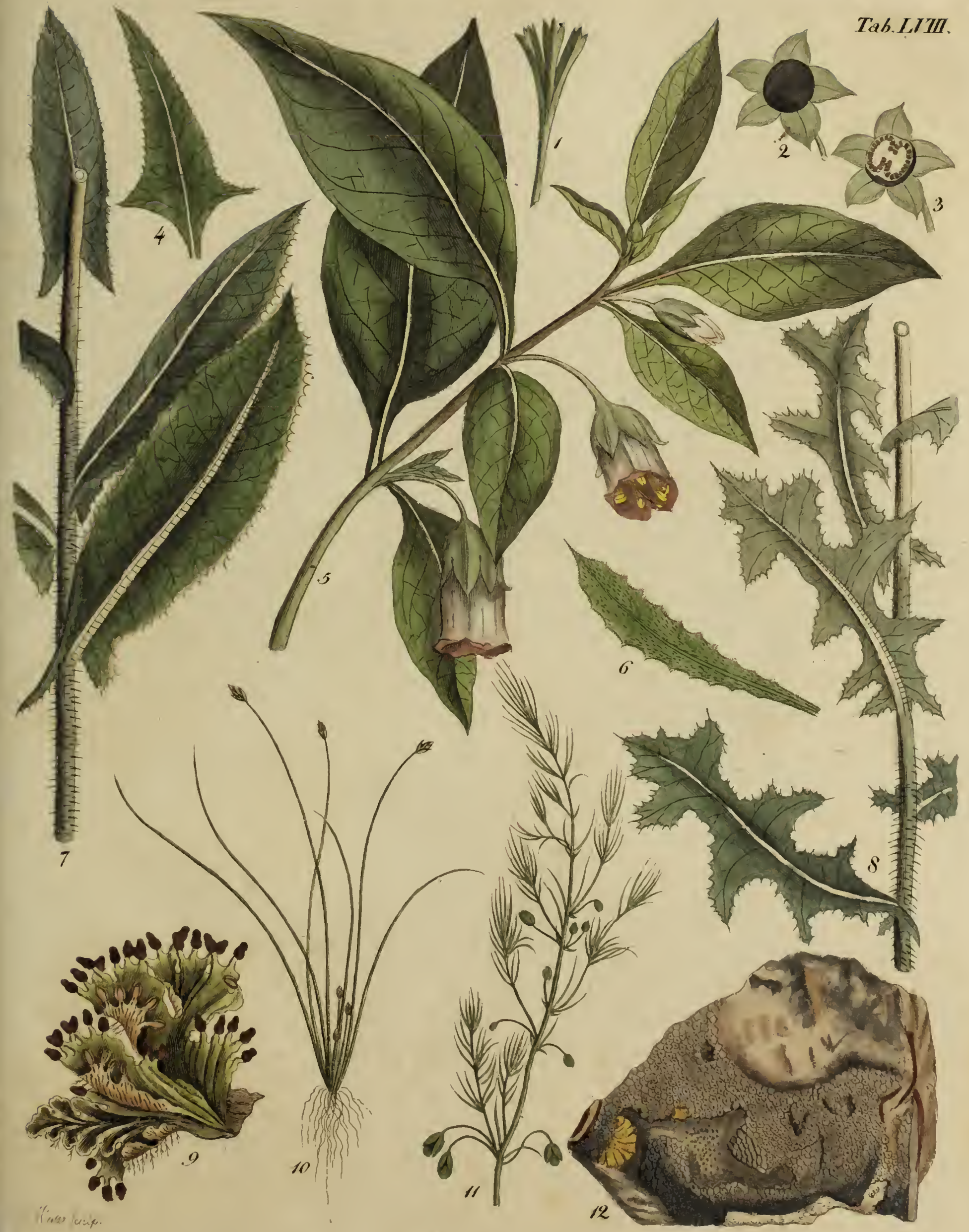





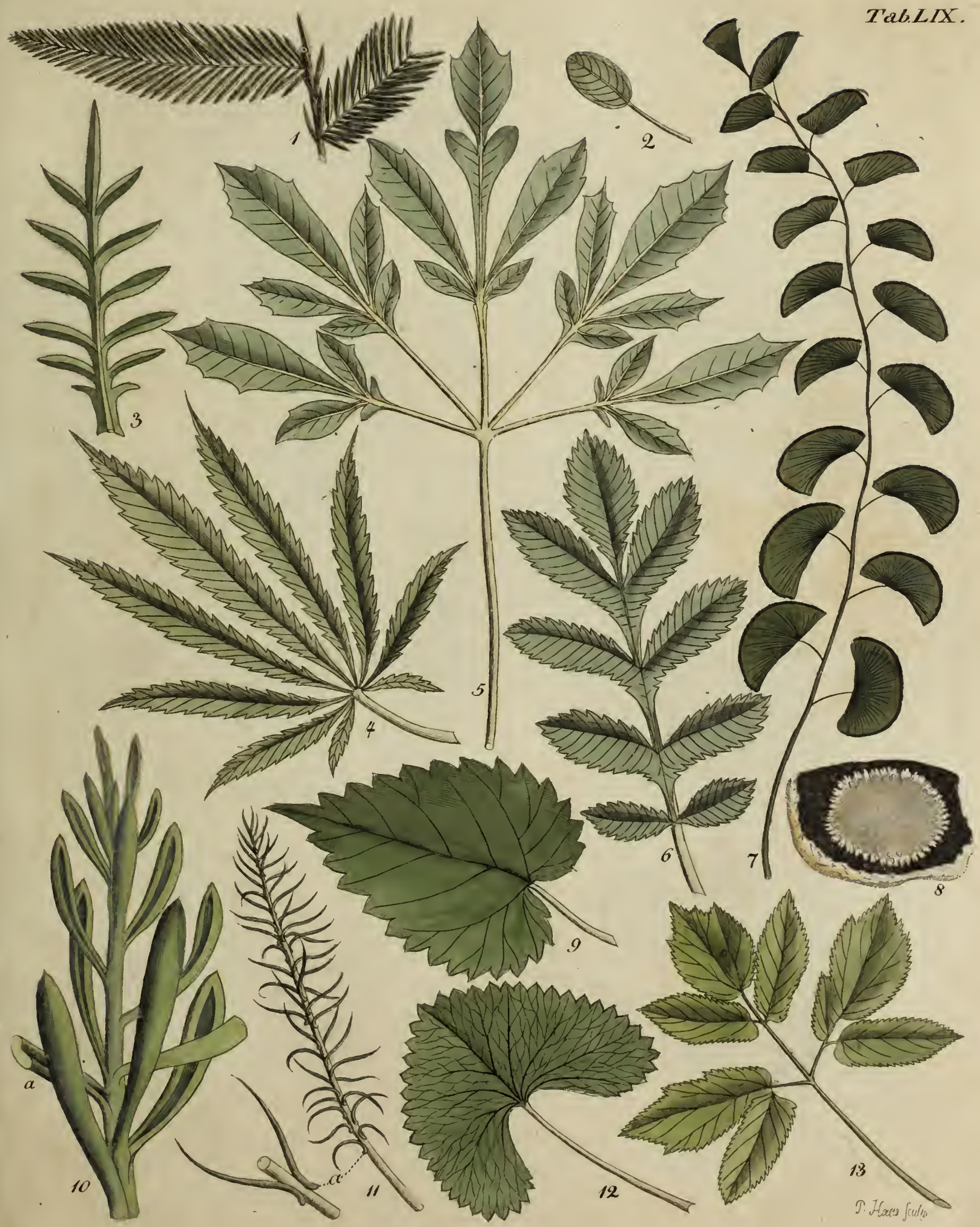





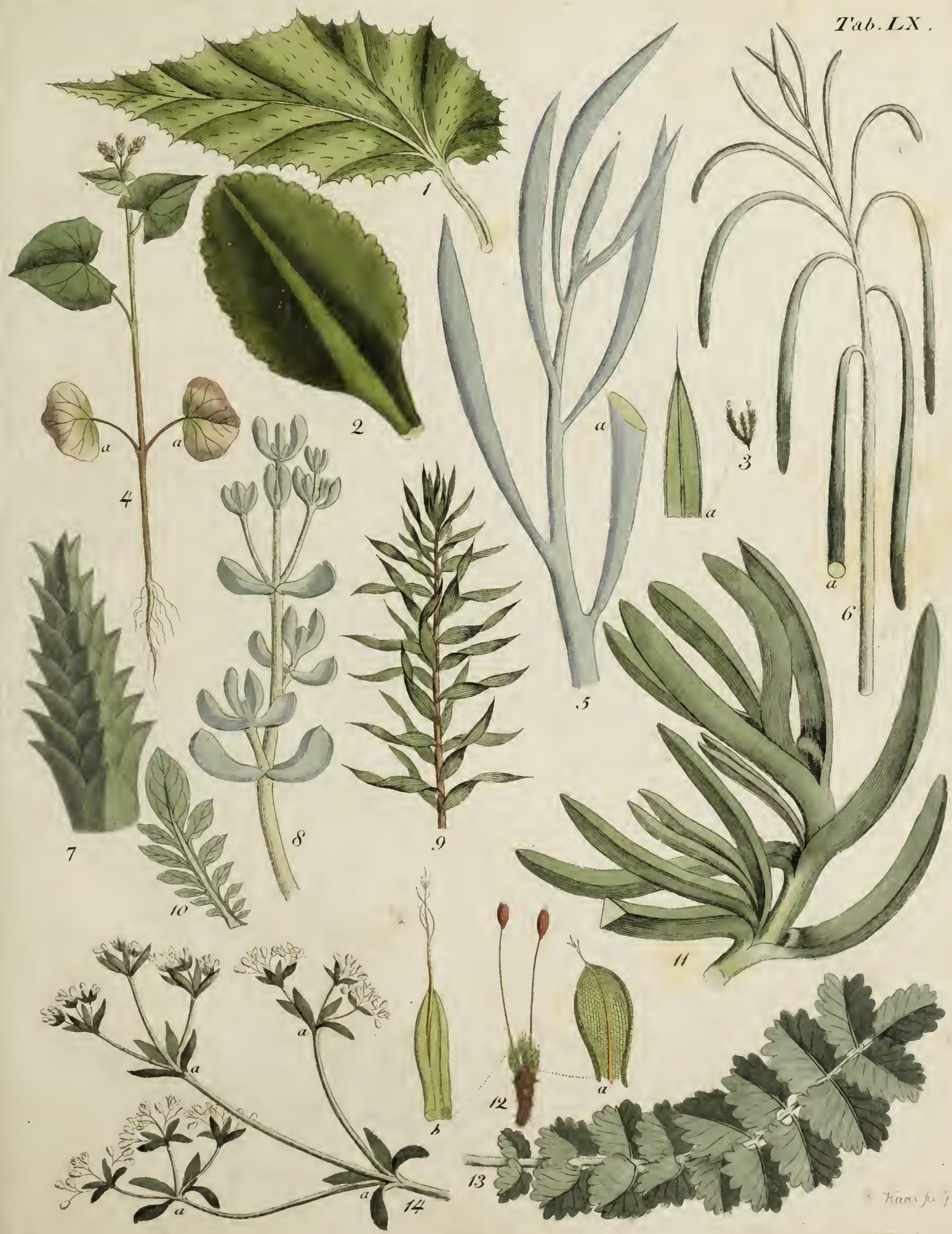





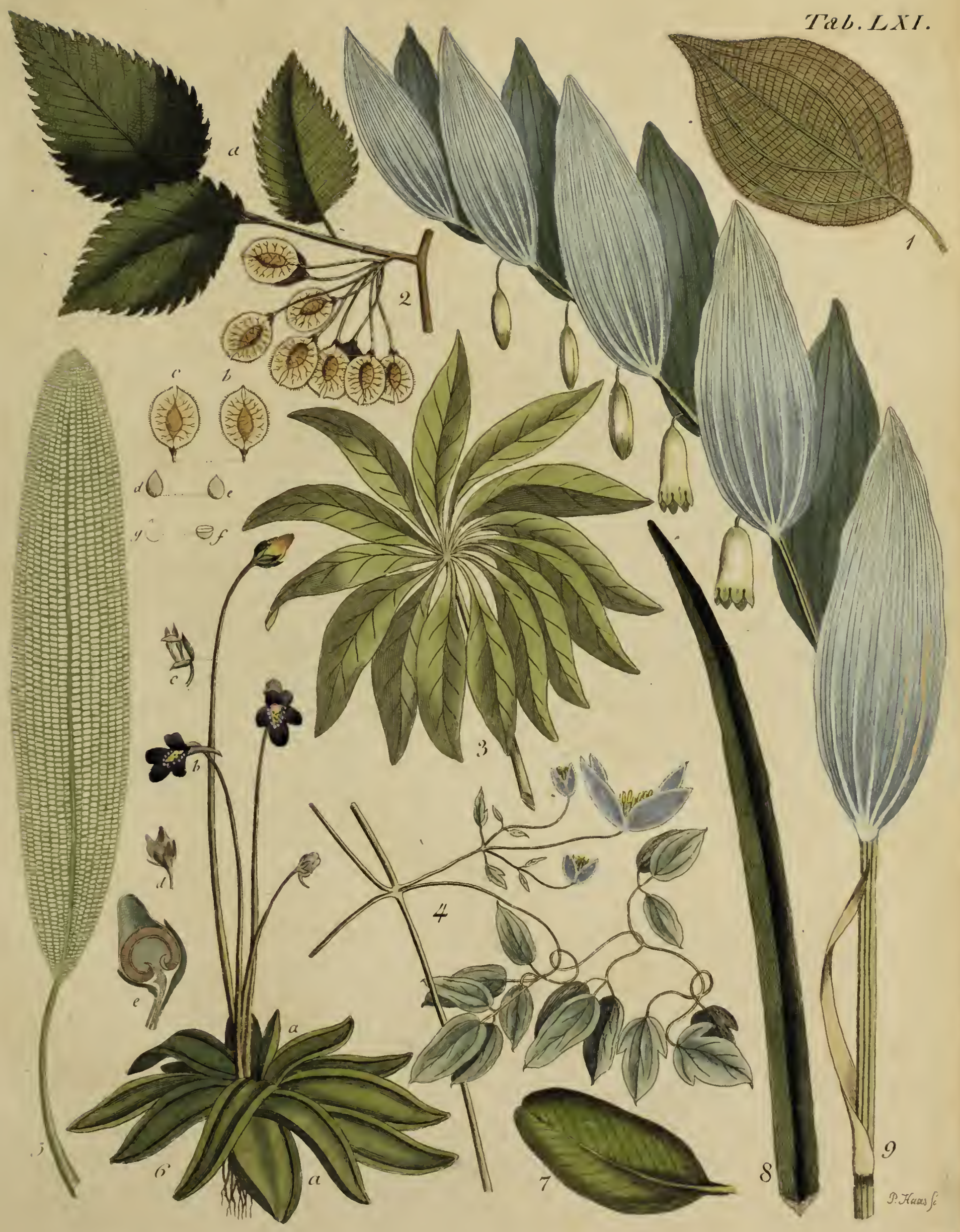





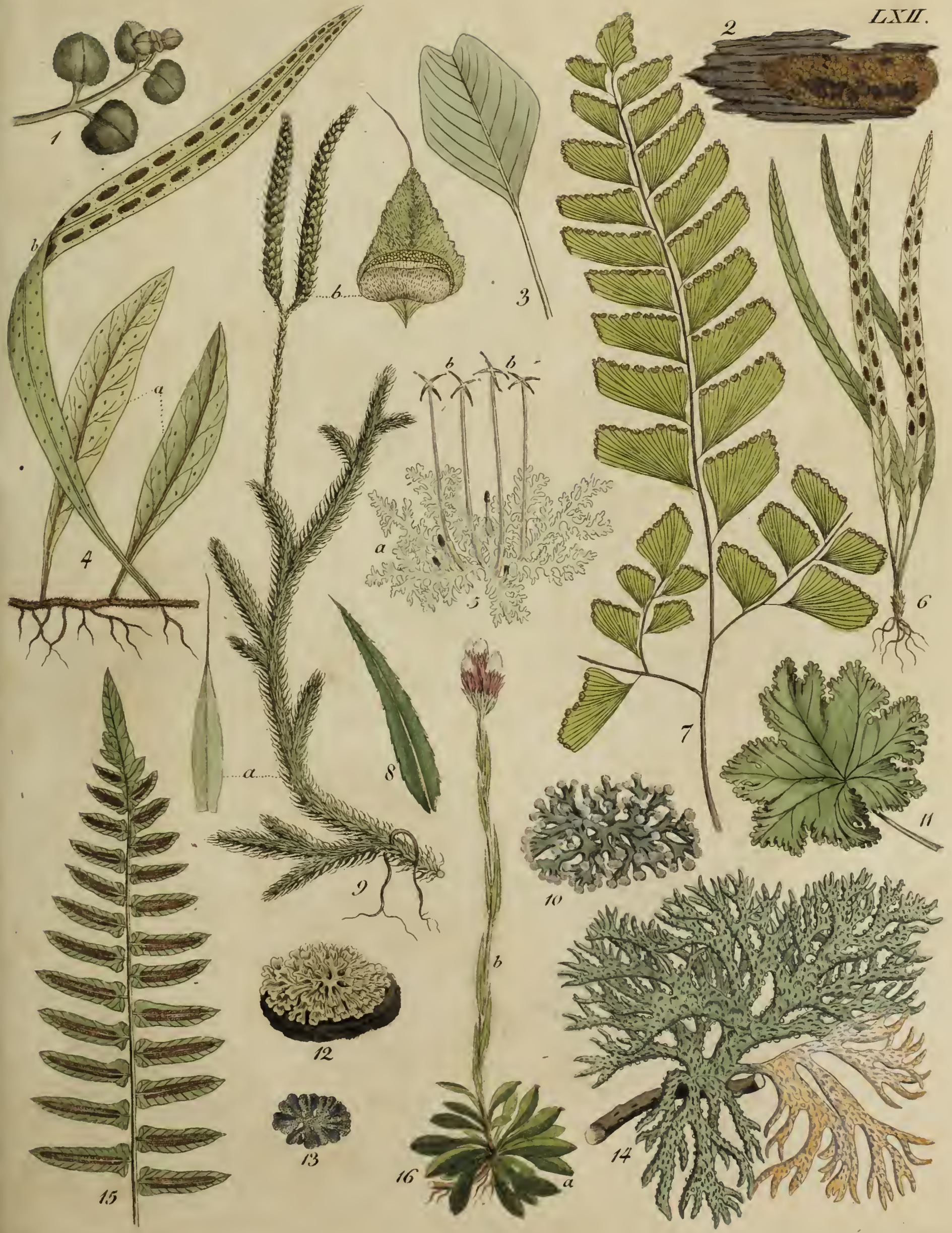





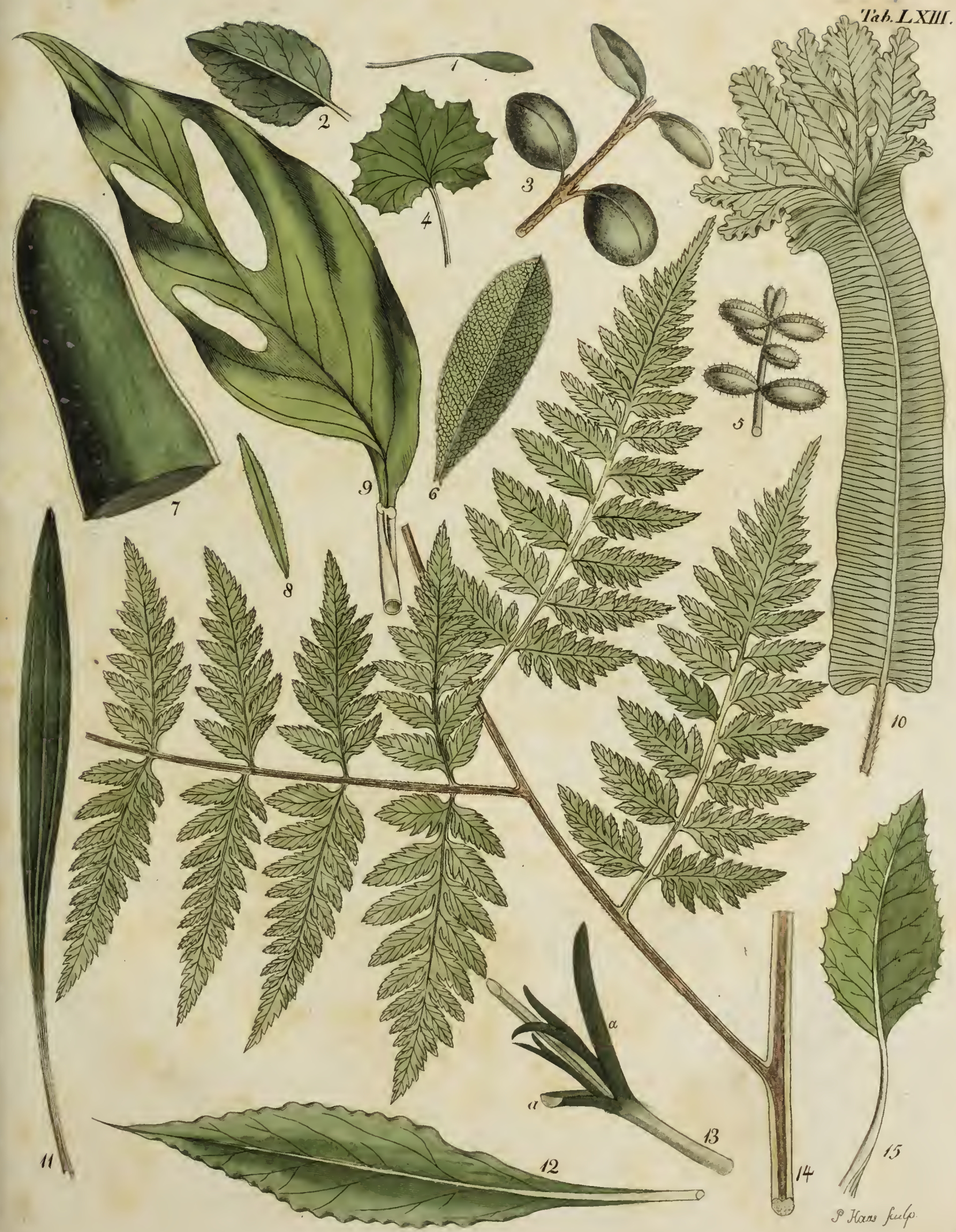





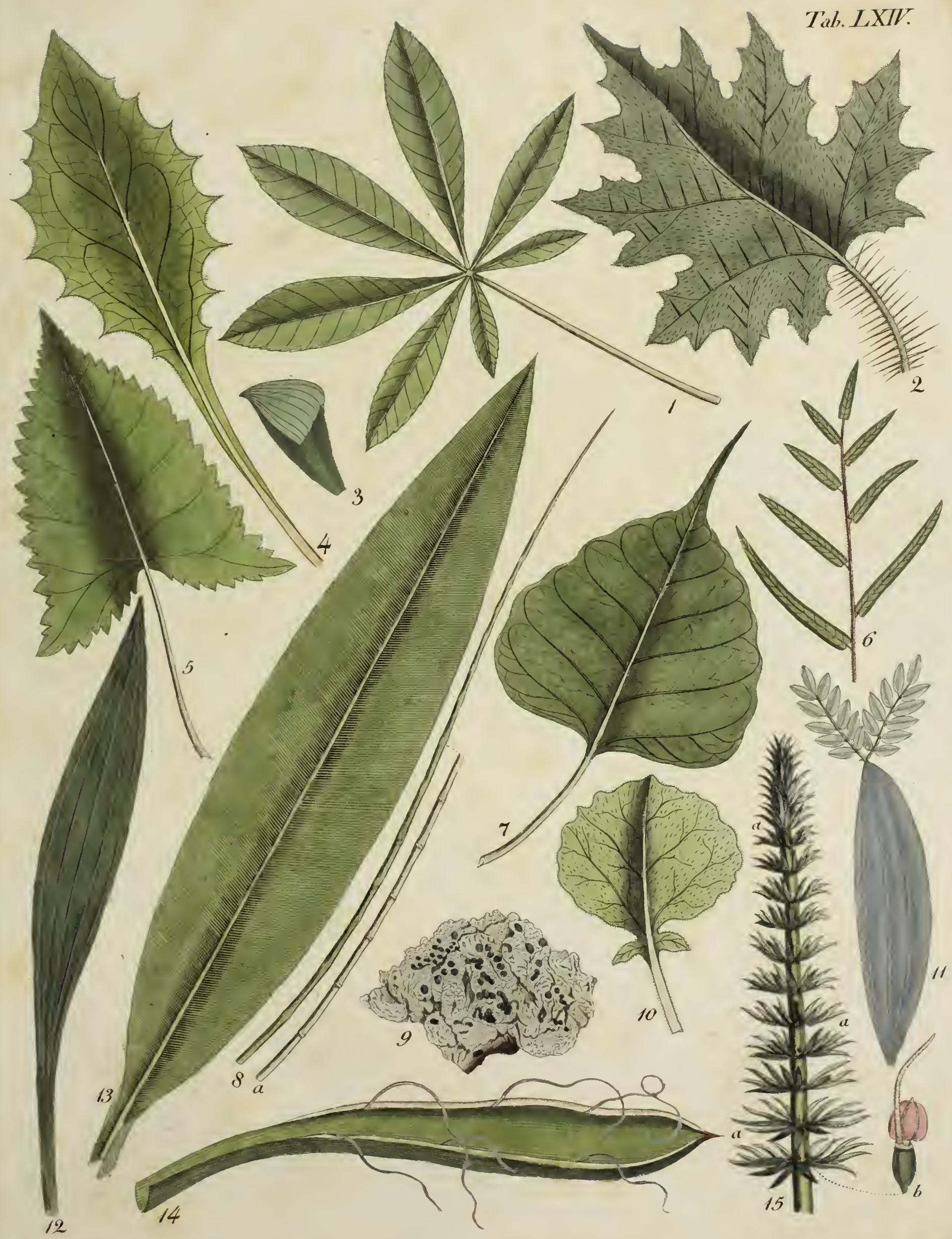





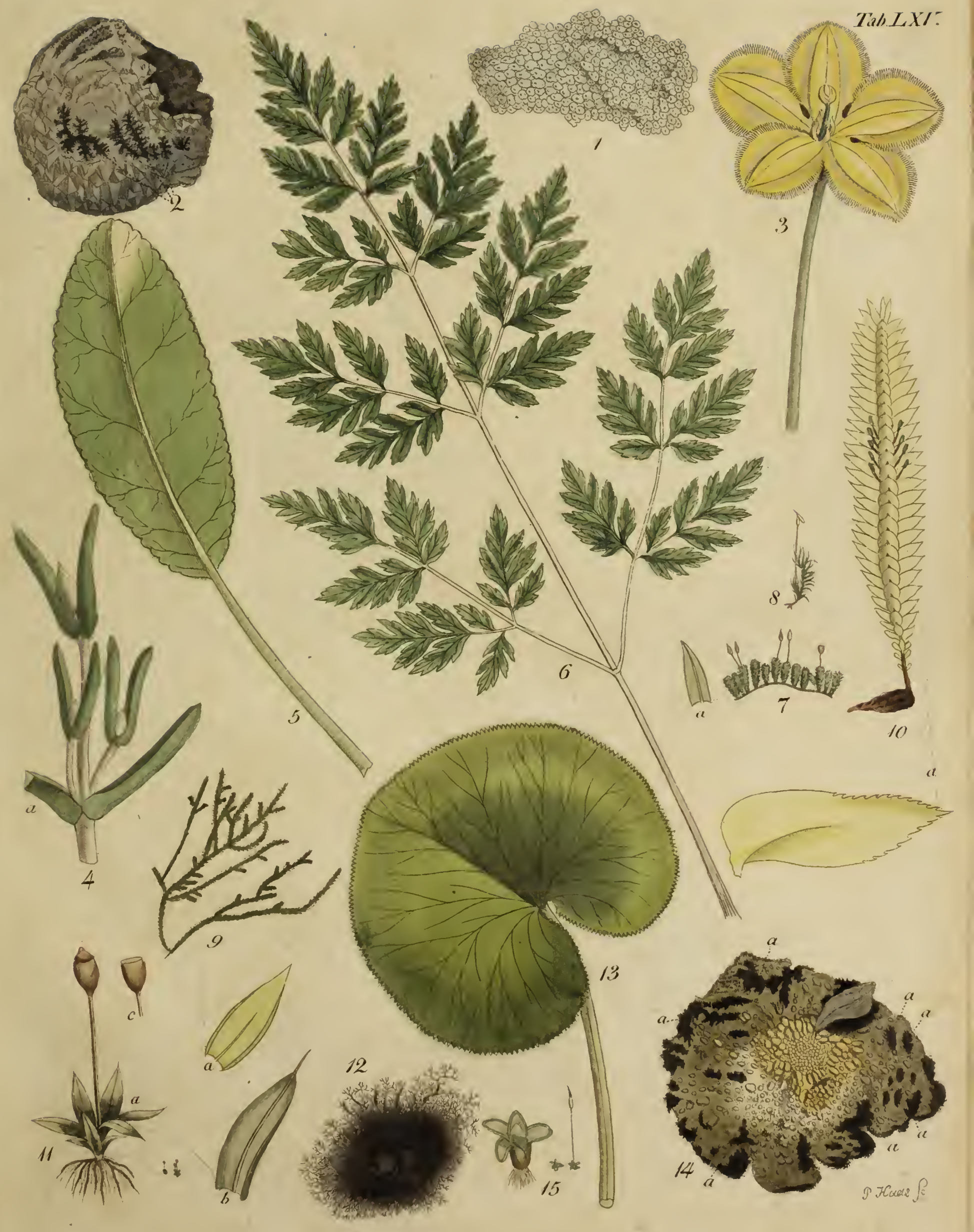





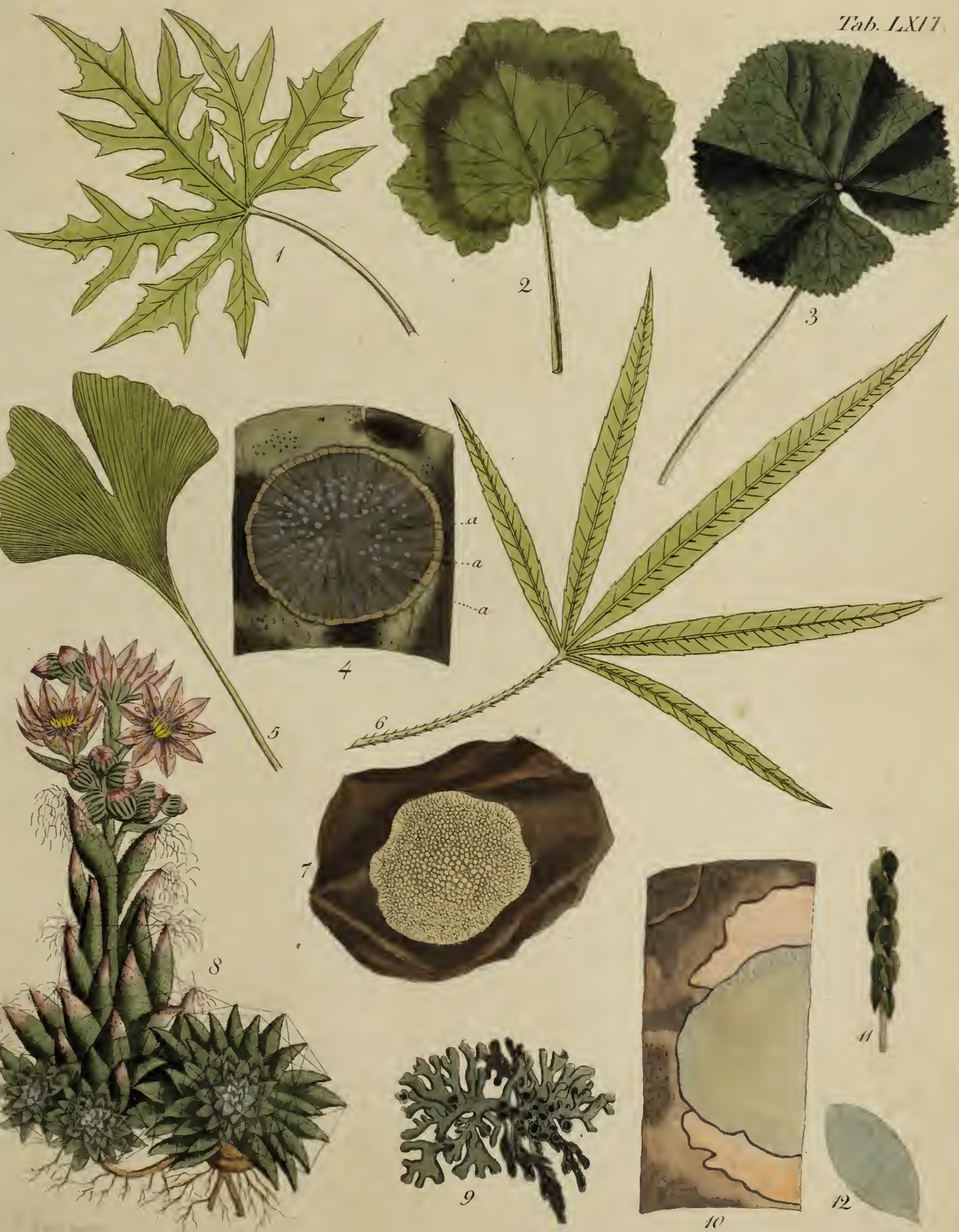





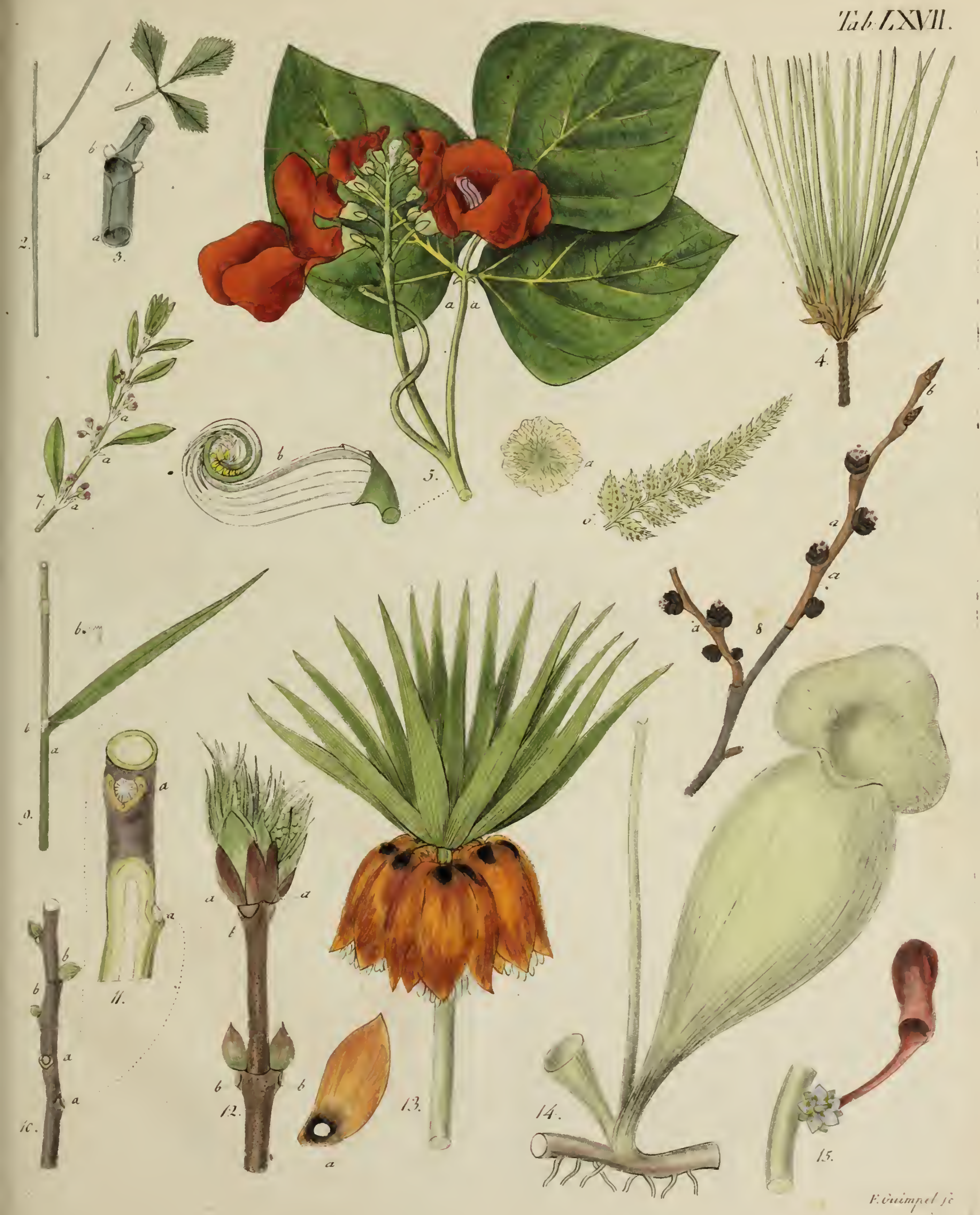





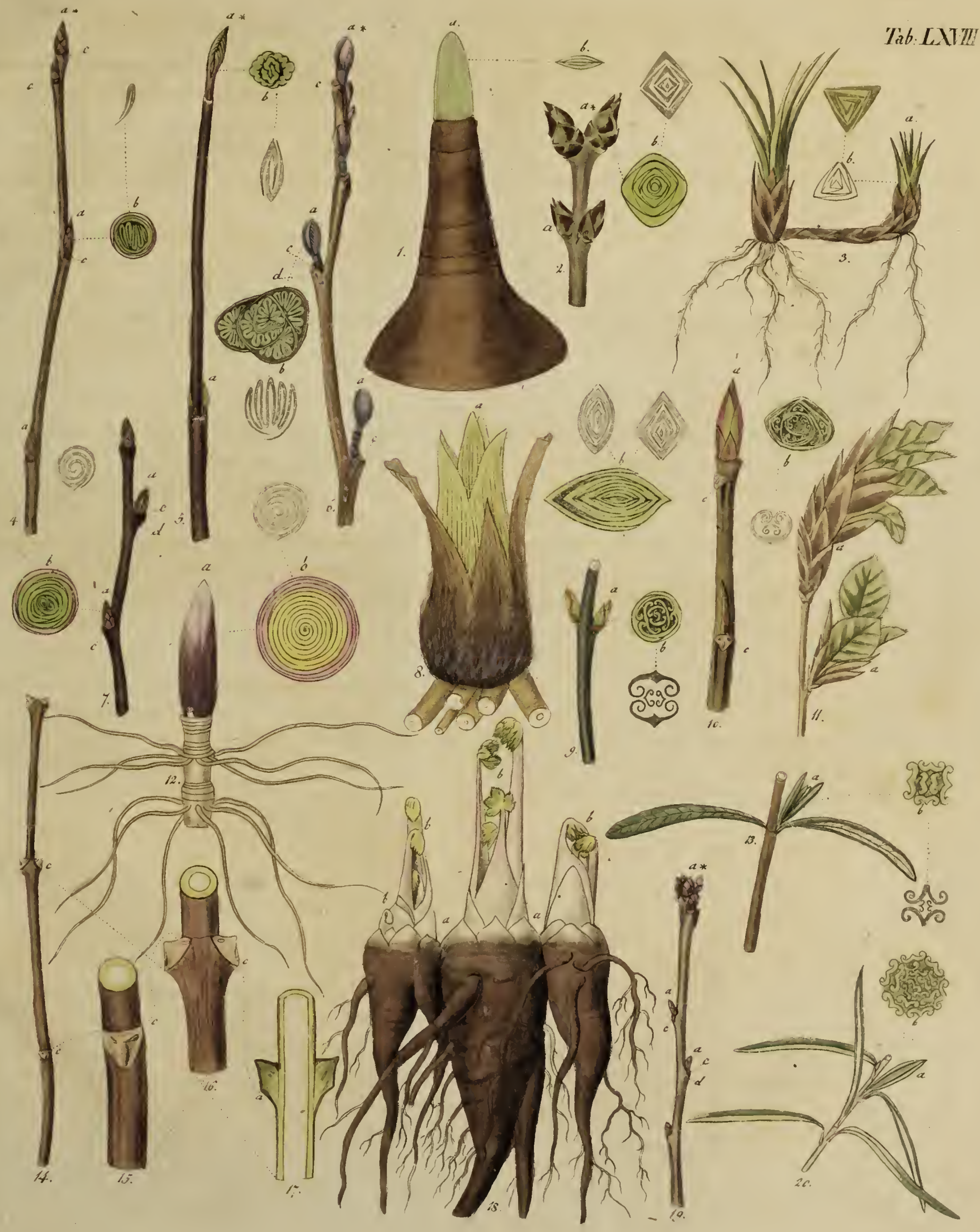





